Peter Batista Cheung

\title{
ANÁLISE DE REABILITAÇÃO DE REDES DE DISTRIBUIÇÃO DE ÁGUA PARA ABASTECIMENTO VIA ALGORITMOS GENÉTICOS MULTIOBJETIVO
}

Tese apresentada à Escola de Engenharia de São Carlos da Universidade de São Paulo, como parte dos requisitos para obtenção do Título de Doutor em Hidráulica e Saneamento

ORIENTADORA: Profa. Associada Luisa Fernanda Ribeiro Reis

São Carlos

2004 
Á Thelma Lucchese, mulher que tanto amo, admiro e me orgulho, exemplo de esposa... sentido de minha vida. 


\section{AGRADECIMENTOS}

A Deus pelo dom da vida.

À professora Luisa Fernanda Ribeiro Reis, pela orientação deste trabalho.

À Coordenadoria de Aperfeiçoamento de Pessoal de Nível Superior - CAPES, pela bolsa de estudo concedida.

À FINEP (Financiadora Nacional de Estudos e Projetos), na qualidade de agência financiadora do projeto integrado intitulado "Controle Operacional e Avaliação de Perdas em um Sub-Sistema Urbano de Distribuição de Água (subprojeto da sub-rede 2 da REHIDRO)", referência FINEP 3131/96, cuja infra-estrutura deu suporte ao desenvolvimento do presente trabalho.

Ao CNPq, pelo apoio financeiro concedido ao Projeto Temático (CT-HIDRO 01/2001) "Instrumentos do Uso Racional e Otimizado da Água em Meio Urbano", do qual este trabalho é parte integrante.

Aos professores Fazal Hussain Chaudhry, Robert Schiaveto de Souza e Rodrigo de Melo Porto, pela formação científica concedida.

Ao professor Dr. Kobus Van Zyl da Universidade Rand Afrikaans, Johannesburg (África do Sul), pelo auxílio na mudança do código do Epanet 2.

Ao professor Dr. Ezio Todini da Universidade de Bologna, Bologna (Itália), pelas constantes discussões sobre o método gradiente (Epanet 2).

A Andrés Arenas do Massachusetts Institute of Technology (MIT), por fornecer livremente o código da biblioteca de algoritmos genéticos (GAlib) desenvolvido para compilador Borland Builder C++ 5.0.

À Viktoria Neimane do Royal Institute of Technology, Stockholm, pela discussões sobre a biblioteca de algoritmos genéticos (GAlib).

À Companhia Águas Guariroba S.A., por propiciar o estudo de campo.

À Engenheira Civil Marilúcia P. Sandim, ao Técnico Nelson Motta Vieira e aos funcionários do Departamento de Projetos e Operação da Águas Guariroba S.A., pelo excelente auxílio no fornecimento dos dados e suporte durante a pesquisa de campo.

Aos meus pais, Hai Been e Lucynéa, pela formação e pelo incentivo.

Ao meu irmão, Andrés B. Cheung, meu grande amigo e companheiro.

Aos colegas do Laboratório de Simulação Numérica (LABSIN): Adelena, Alexandre, Andréa, Daniel, Fernando, Johannes, José Eduardo, Klebber, Leonardo, Liliane, Luciane, Tinil, Tosta.

A todos os professores, colegas e funcionários do Departamento de Hidráulica e Saneamento da EESC/USP. 


\section{RESUMO}

CHEUNG, P. B. (2003). Análise de reabilitação de redes de distribuição de distribuição de água para abastecimento via algoritmos genéticos multiobjetivo. São Carlos, 2004. 268p. Tese (Doutorado) - Escola de Engenharia de São Carlos, Universidade de São Paulo, São Carlos, 2003.

Reconhecendo-se a importância da água como recurso natural limitado e considerandose a perspectiva de crescimento do contingente populacional urbano, faz-se necessária uma investigação dos sistemas de distribuição de água para abastecimento, por trataremse de infra-estruturas básicas comuns aos núcleos populacionais do mundo todo. $\mathrm{O}$ planejamento da reabilitação das redes de distribuição de água torna-se de fundamental importância considerando os recursos financeiros limitados e o comportamento operacional desses sistemas que são alterados ao longo do tempo devido ao processo de deterioração de seus componentes. O presente trabalho representa um esforço no sentido de considerar objetivos mais promissores na análise de reabilitação de redes. Dessa maneira, foram considerados: custo, benefício, vazamentos e confiabilidade. Este trabalho apresenta contribuições às análises multiobjetivo via algoritmos genéticos, propriciando um aprimoramento do algoritmo Multiobjective Genetic Algorithm (MOGA) e realizando investigação dos operadores (recombinação e mutação) e dos métodos Non-dominated Sorting Genetic Algorithm (NSGA), Strength Pareto Evolutionary Algorithm (SPEA) e Elitist Non-Dominated Sorting Genetic Algorithm (NSGA II). Do ponto de vista hidráulico, este trabalho introduz tanto perdas por vazamentos como demanda variável com a pressão, proporcionando uma análise mais realística do problema. Os estudos desenvolvidos para redes hipotéticas e para um sistema real, possibilitaram que soluções satisfatórias fossem obtidas, chegando-se inclusive a uma proposição do conceito de programação dinâmica para o caso multiobjetivo.

Palavras-chave: Redes de distribuição de água, análise de reabilitação, otimização multiobjetivo, algoritmos genéticos. 


\section{ABSTRACT}

CHEUNG, P. B. (2003). Rehabilitation analyses of the water distribution networks by multiobjective genetic algorithms. São Carlos, 2004. 268p. Thesis (Doctorate) - São Carlos School of Engineering, University of São Paulo, São Carlos, 2003.

Recognizing the importance of water as a limited natural resource and considering the prospect of continued population growth, it is important to investigate water distribution systems which are common to all urban infrastructures. Planning of the water distribution network rehabilitation becomes additionally important given economic constraints and operational behavior these systems which modifies in time due to deterioration of water networks. The present work is an effort to consider the multiple objectives in the water network rehabilitation analyses. Four objectives were considered: cost minimization, benefit maximization, leakage minimization and reliability maximization. In addition, it presents some contributions to multiobjective optimization methodology by genetic algorithms, offering an improvement of Multiobjective Genetic Algorithm (MOGA). A detailed investigation is conducted on genetic operators (recombination and mutation) comparing some existing multiobjective optimization methods (Multiobjective Genetic Algorithm - MOGA, Non-dominated Sorting Genetic Algorithm - NSGA, Strength Pareto Evolutionary Algorithm - SPEA and Elitist Non-Dominated Sorting Genetic Algorithm - NSGA II). As regards the hydraulic analysis, this work introduces both leakages and pressure dependent demands in the simulations, providing a more realistic representation of actual field situations. The present study employs hypothetical networks and a real network obtaining satisfactory solutions. Further, dynamic programming concept is also incorporated into the multiobjective optimization framework.

Keywords: Water distribution networks, rehabilitation analyses, multiobjective optimization, genetic algorithms. 


\section{LISTA DE FIGURAS}

Figura 2.1 - Nós, ligações e alocação de demandas

Figura 2.2 - Perdas nos sistemas de abastecimento de água (adaptado de SILVA e CONEJO, 1998). 10

Figura 2.3 - Classificação dos modelos de avaliação de vazamentos ........................................ 14

Figura 2.4 - Ilustração hipotética reservatório - nó de consumo ................................................ 18

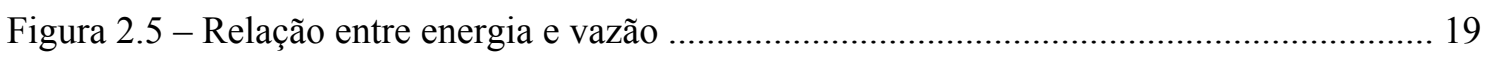

Figura 2.6 - Algoritmo iterativo de avaliação hidráulica (proposto por SOARES, 2003) ......... 26

Figura 2.7 - Algoritmo híbrido de calibração (proposto por SOARES, 2003)............................ 27

Figura 3.1 - Classificação dos modelos de reabilitação de redes hidráulicas (adaptado de

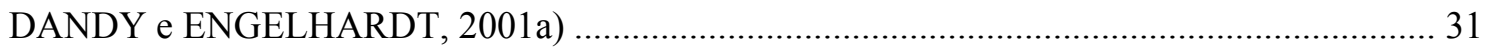

Figura 3.2 - Ciclo de vida de componentes (AGGARWAL, 1993) ......................................... 32

Figura 3.3 - Esquema geral do modelo proposto por DANDY e ENGELHARDT (2001a) ...... 49

Figura 3.4 - Curva diária de demanda (adapatado de WALTERS et al., 1999) .......................... 59

Figura 4.1 - Classificação dos modelos de otimização multiobjetivo convencionais ................. 65

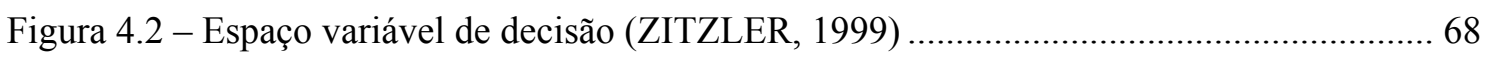

Figura 4.3 - Espaço função objetivo (ZITZLER, 1999) .......................................................... 69

Figura 4.4 - Ilustração dos conjuntos Pareto ótimo global e local (ZITZLER, 1999)

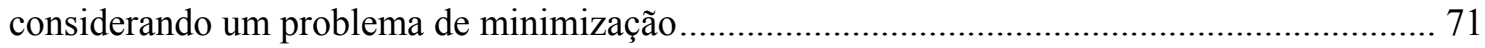

Figura 4.5 - Esquema geral de um procedimento multiobjetivo (DEB, 2001).......................... 72

Figura 4.6 - Esquema geral dos algoritmos genéticos convencionais ....................................... 74

Figura 4.7 - População inicial referente ao problema (4.9) ...................................................... 75

Figura 4.8 - População corrente dos AGs (iteração 30) referente ao problema (4.9).................. 76

Figura 4.9 - População final dos AGs (iteração 500) referente ao problema (4.9) ..................... 76

Figura 4.7 - Estrutura geral dos algoritmos genéticos multiobjetivo ....................................... 77

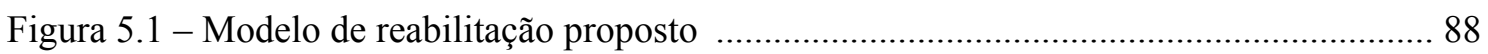

Figura 5.2 - Soluções referentes ao problema (5.9) (adaptado de DEB, 2001).......................... 98

Figura 5.3 - Procedimento geral do MOGA …….................................................................... 99

Figura 5.4 - Classificação realizada pelo MOGA no problema exemplo (5.9) ........................ 100

Figura 5.5 - Compartilhamento e nicho (adaptado de HORN e NAFPLIOTIS, 1993) ............ 102

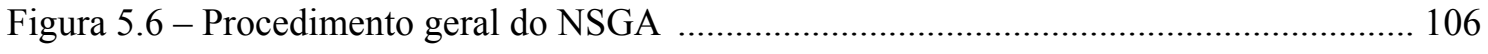


Figura 5.7 - Classificação realizada pelo NSGA para o problema exemplo (5.9) .................... 107

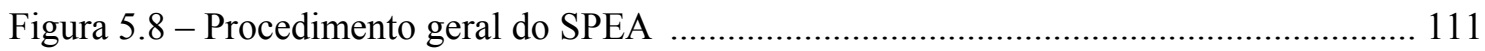

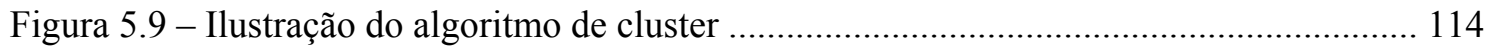

Figura 5.10 - Esquema do procedimento evolutivo do NSGA II (adaptado de DEB, 2001) ... 116

Figura 5.11 - Cálculo da distância de multidão do NSGA II .................................................... 117

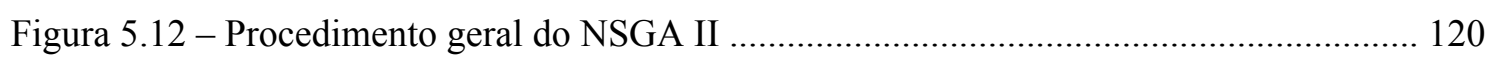

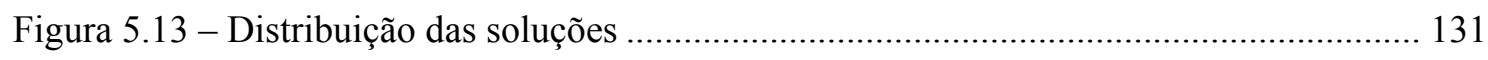

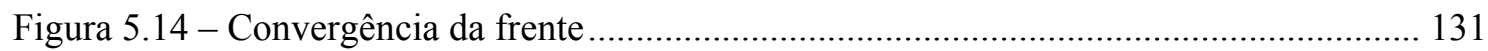

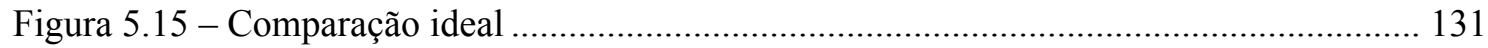

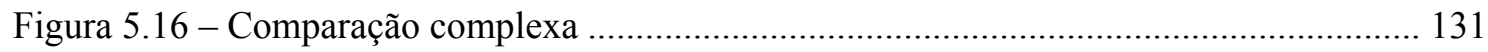

Figura 5.17 - Procedimento proposto para otimização multiobjetivo dinâmica........................ 140

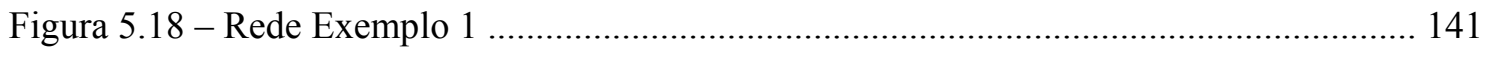

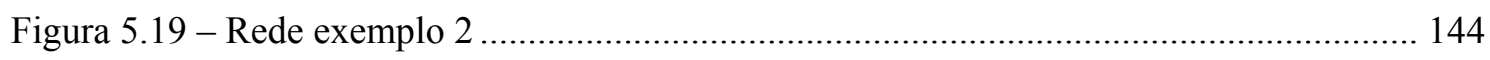

Figura 5.20 - Rede exemplo 3 (modelo simplificado do sistema RF-1)................................. 146

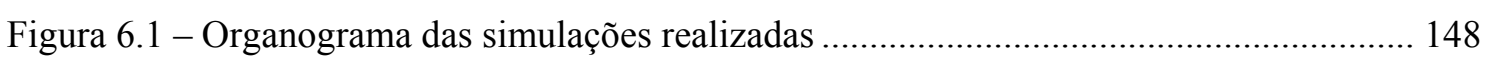

Figura 6.2 - Vetor solução referente ao problema de GESSLER (1985) ………..................... 150

Figura 6.3 - Simulações da rede exemplo 1 com diferentes pesos .......................................... 152

Figura 6.4 - Gráfico comparativo das pressões da rede para cenário 1 .................................... 155

Figura 6.5 - Gráfico comparativo das pressões da rede para cenário 2 ................................... 155

Figura 6.6 - Gráfico comparativo das pressões da rede para cenário 3 .................................... 155

Figura 6.7 - Soluções obtidas pelos AGs considerando diferentes pesos.................................. 156

Figura 6.8 - Soluções obtidas pelos AGs considerando diferentes pesos................................... 156

Figura 6.9 - Fluxograma do programa desenvolvido para reabilitação de redes considerando dois objetivos (custo e déficit de pressão) utilizando o MOGA como método de otimização

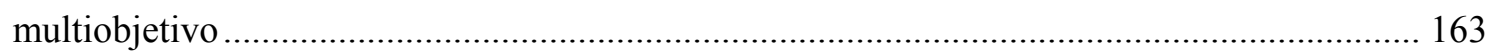

Figura 6.10 - Diferentes populações produzidas pelo MOGA …………….............................. 165

Figura 6.11 - Comparação de Frentes Pareto obtidas pelo MOGA............................................. 165

Figura 6.12 - Esquema explicativo de construção de um BOXPLOT ...................................... 167

Figura 6.13 - Valores da métrica C (A,B), descrita no item (5.6.1), para quatro métodos

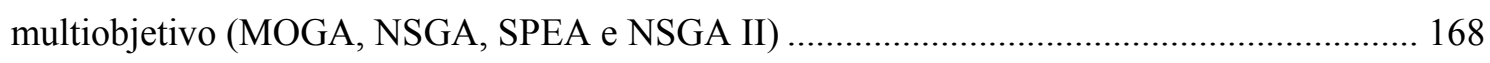

Figura 6.14 - Métrica de distribuição considerando a dimensão da população igual a 100 ..... 169

Figura 6.15 - Métrica de distribuição considerando a dimensão da população igual a 200 ..... 170

Figura 6.16 - Métrica de distribuição considerando a dimensão da população igual a 300 ..... 170

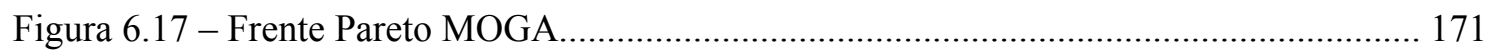

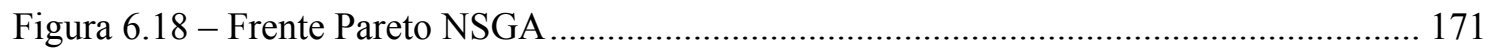

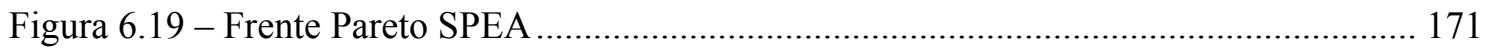

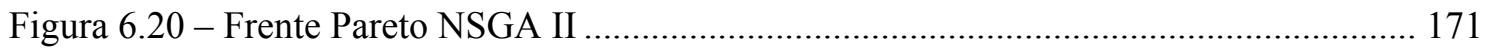


Figura 6.21 - Valores da métrica C (A,B) para SPEA considerando vários operadores genéticos

Figura 6.22 - Métrica de distribuição do SPEA considerando diferentes operadores genéticos (configurações de 1 a 9 )......

Figura 6.23 - Métrica de distribuição do SPEA considerando apenas configurações de 4 a 9172

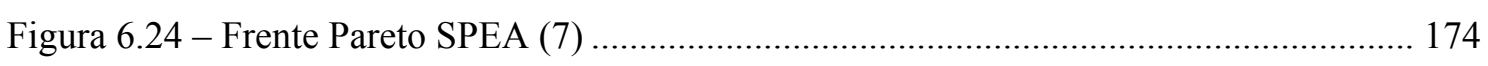

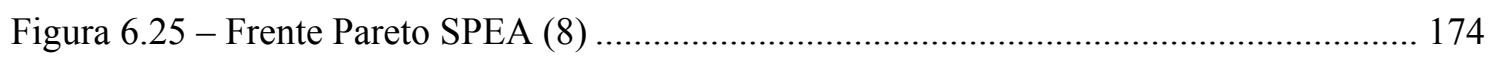

Figura 6.26 - Frente Pareto produzida pelo SPEA considerando um problema com três objetivos 174

Figura 6.27 - Demanda total (FUJIWARA e LI, 1998) e vazamentos (TUCCIARELLI, CRIMINISI e TERMINI, 1999) durante o processo iterativo 180

Figura 6.28 - Porcentagem de vazamentos e demandas para diferentes modelos de pressãodemanda...... 182

Figura 6.29 - Confiabilidade hidráulica para diferentes modelos de pressão-demanda 182 Figura 6.30 - Comparação das pressões nos nós da rede exemplo 2 considerando simulações hidráulicas convencional e com vazamentos

Figura 6.31 - Comparação das pressões nos nós da rede exemplo 2 considerando as simulações hidráulicas convencional e com modelo pressão-demanda de WAGNER, SHAMIR e MARKS (1988) 184

Figura 6.32 - Setores do modelo simplificado real 185

Figura 6.33 - Pontos de amostragem do modelo simplificado (rede exemplo 3).. 185

Figura 6.34 - Vazão abastecida da rede exemplo 3 187

Figura 6.36 - Frente Pareto obtida através da otimização multiobjetivo estática para estudo de caso real 203

Figura 6.37 - Autovalores contra número de fatores - otimização estática 206

Figura 6.38 - Gráfico de auxílio à tomada de decisão utilizando à Análise de Componentes Principais 206

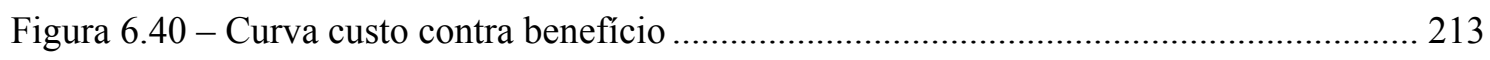

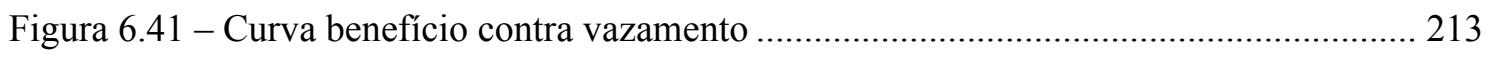

Figura 6.42 - Curva vazamento contra confiabilidade ….................................................... 213

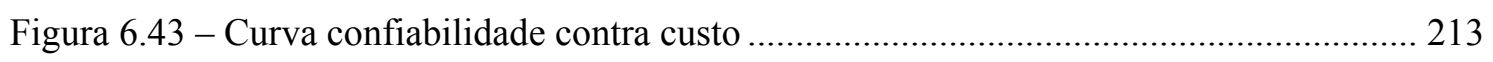

Figura 6.44 - Autovalores contra número de fatores - otimização dinâmica ........................... 214

Figura 6.45 - Gráfico de auxílio à tomada de decisão utilizando à Análise de Componentes

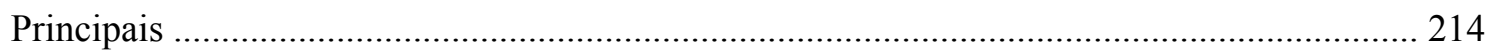

Figura 6.47 - Gráfico de decisão para cenário otimista - otimização dinâmica......................... 218

Figura 6.48 - Planos alternativos de reabilitação para rede real (rede exemplo 3)................... 220

Figura a.1 -Algoritmo de busca de soluções que dominam determinada solução i................... 242 
Figura a.2 - Algoritmo de busca de soluções não dominadas 2 243

Figura a.3 - Algoritmo de busca soluções não dominadas 3 ..................................................... 244

Figura a.4-Algoritmo de classificação de frentes não dominadas ............................................ 245

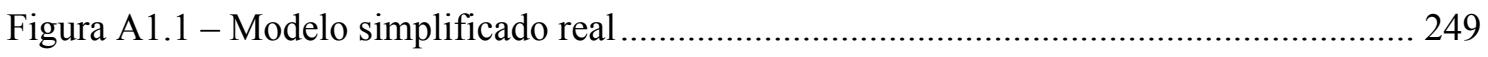

Figura A1.2 - Modelo simplificado real divido em setores de vazamento ............................... 250

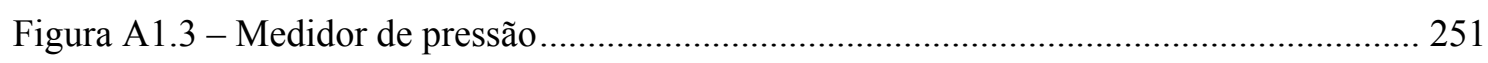

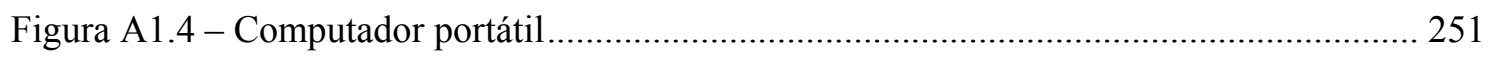

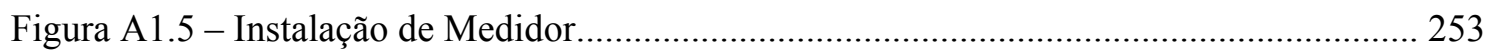

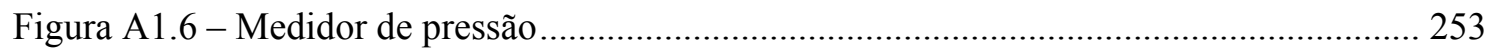

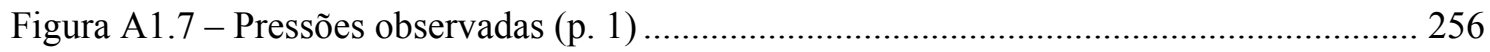

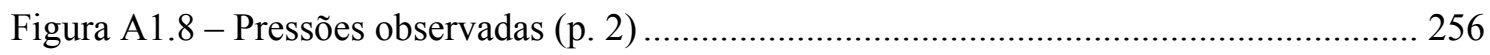

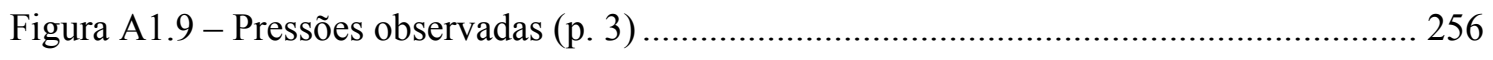

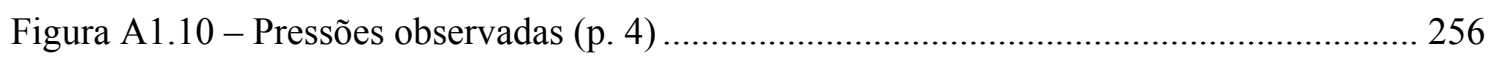

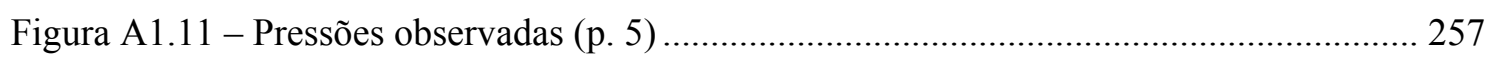

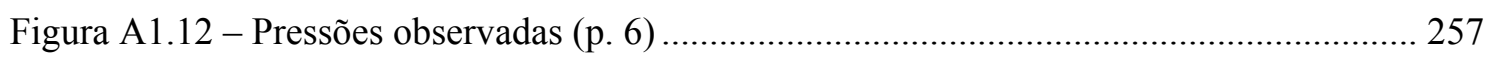

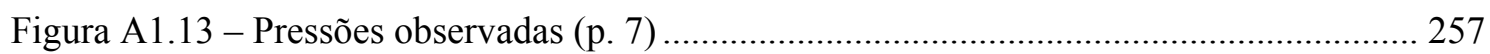

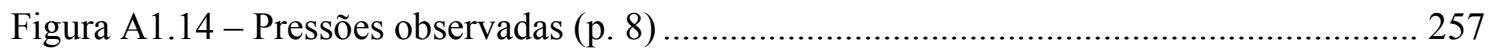

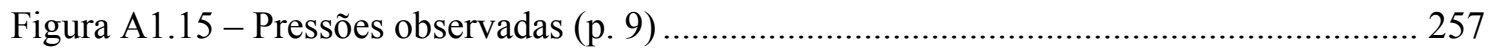

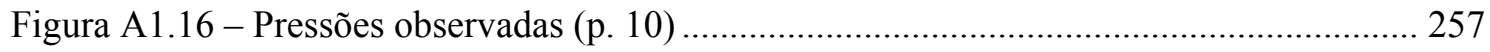

Figura A1.17 - Vazão abastecida pelo reservatório (19 04 2003)........................................... 258

Figura A1.18 - Vazão abastecida pelo reservatório (20 04 2003).......................................... 258

Figura A1.19 - Vazão abastecida pelo reservatório (21 04 2003) ............................................ 258

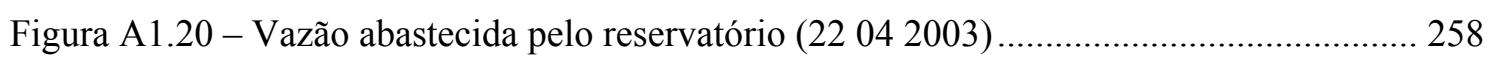

Figura A1.21 - Vazão abastecida pelo reservatório (23 04 2003) ........................................... 258

Figura A1.22 - Pressão Monitorada no ponto 1 (19 04 2003) .................................................. 260

Figura A1.23 - Pressão Monitorada no ponto 2 (19 04 2003)................................................. 260

Figura A1.24 - Pressão Monitorada no ponto 3 (19 04 2003).................................................. 260

Figura A1.25 - Pressão Monitorada no ponto 4 (19 04 2003)................................................... 260

Figura A1.26 - Pressão Monitorada no ponto 5 (19 04 2003).................................................. 260

Figura A1.27 - Pressão Monitorada no ponto 6 (19 04 2003).................................................. 260

Figura A1.28 - Pressão Monitorada no ponto 7 (19 04 2003).................................................. 260

Figura A1.29 - Pressão Monitorada no ponto 8 (19 04 2003) ................................................... 260

Figura A1.30 - Pressão Monitorada no ponto 9 (19 04 2003)................................................ 261

Figura A1.31 - Pressão Monitorada no ponto 10 (19 04 2003) ................................................. 261

Figura A1.32 - Pressão Monitorada no ponto 1 (20 04 2003).................................................. 261

Figura A1.33 - Pressão Monitorada no ponto 2 (20 04 2003)................................................ 261

Figura A1.34 - Pressão Monitorada no ponto 3 (20 04 2003)................................................ 261 
Figura A1.35 - Pressão Monitorada no ponto 4 (20 04 2003) .................................................... 261

Figura A1.36 - Pressão Monitorada no ponto 5 (20 04 2003)................................................. 261

Figura A1.37 - Pressão Monitorada no ponto 6 (20 04 2003)................................................. 261

Figura A1.38 - Pressão Monitorada no ponto 7 (20 04 2003) ................................................. 262

Figura A1.39 - Pressão Monitorada no ponto 8 (20 04 2003) ................................................. 262

Figura A1.40 - Pressão Monitorada no ponto 9 (20 04 2003)................................................. 262

Figura A1.41 - Pressão Monitorada no ponto 10 (20 04 2003)............................................... 262

Figura A1.42 - Pressão Monitorada no ponto 1 (21 04 2003)................................................ 262

Figura A1.43 - Pressão Monitorada no ponto 2 (21 04 2003)................................................. 262

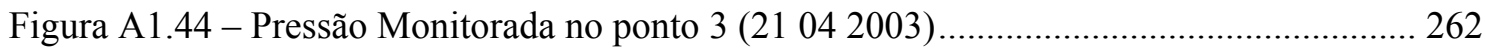

Figura A1.45 - Pressão Monitorada no ponto 4 (21 04 2003)................................................. 262

Figura A1.46 - Pressão Monitorada no ponto 5 (21 04 2003).................................................. 263

Figura A1.47 - Pressão Monitorada no ponto 6 (21 04 2003) ................................................. 263

Figura A1.48 - Pressão Monitorada no ponto 7 (21 04 2003)................................................ 263

Figura A1.49 - Pressão Monitorada no ponto 8 (21 04 2003)................................................. 263

Figura A1.50 - Pressão Monitorada no ponto 9 (21 04 2003)................................................. 263

Figura A1.51 - Pressão Monitorada no ponto 10 (21 04 2003)............................................... 263

Figura A1.52 - Pressão Monitorada no ponto 1 (22 04 2003)................................................ 263

Figura A1.53 - Pressão Monitorada no ponto 2 (22 04 2003)................................................ 263

Figura A1.54 - Pressão Monitorada no ponto 3 (22 04 2003).................................................. 264

Figura A1.55 - Pressão Monitorada no ponto 4 (22 04 2003)................................................. 264

Figura A1.56 - Pressão Monitorada no ponto 5 (22 04 2003)................................................. 264

Figura A1.57 - Pressão Monitorada no ponto 6 (22 04 2003).................................................. 264

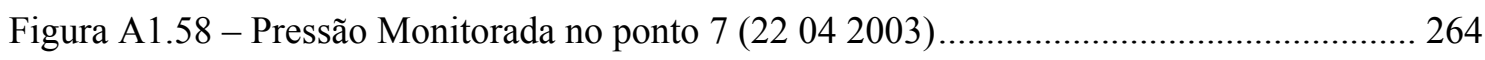

Figura A1.59 - Pressão Monitorada no ponto 8 (22 04 2003)................................................. 264

Figura A1.60 - Pressão Monitorada no ponto 9 (22 04 2003).................................................. 264

Figura A1.61 - Pressão Monitorada no ponto 10 (22 04 2003).................................................. 264

Figura A1.62 - Pressão Monitorada no ponto 1 (23 04 2003) .................................................. 265

Figura A1.63 - Pressão Monitorada no ponto 2 (23 04 2003)................................................. 265

Figura A1.64 - Pressão Monitorada no ponto 3 (23 04 2003) ................................................. 265

Figura A1.65 - Pressão Monitorada no ponto 4 (23 04 2003) ................................................. 265

Figura A1.66 - Pressão Monitorada no ponto 5 (23 04 2003)................................................ 265

Figura A1.67 - Pressão Monitorada no ponto 6 (23 04 2003)................................................ 265

Figura A1.68 - Pressão Monitorada no ponto 7 (23 04 2003) ................................................... 265

Figura A1.69 - Pressão Monitorada no ponto 8 (23 04 2003)................................................. 265

Figura A1.70 - Pressão Monitorada no ponto 9 (23 04 2003)................................................. 266

Figura A1.71 - Pressão Monitorada no ponto 10 (23 04 2003)................................................266 


\section{LISTA DE TABELAS}

Tabela 3.1 - Custos de reabilitação apresentados por HALHAL et al. (1997)............................ 57

Tabela 3.2 - Padrão de demanda utilizada por WALTERS et al. (1999) .................................... 58

Tabela 5.1 - Soluções geradas aleatoriamente para o problema (5.9) ....................................... 98

Tabela 5.2 - Notações utilizadas em um planejamento $3^{2}$ com $\mathrm{p}^{*}$ réplicas .............................. 134

Tabela 5.3 - Planejamento composto central para duas variáveis independentes ..................... 136

Tabela 5.4 - Planejamento composto central ortogonal para duas variáveis independentes .... 136

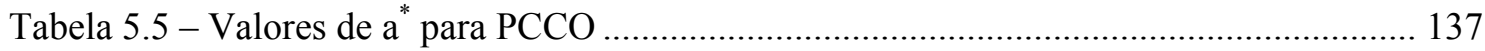

Tabela 5.6 - Características geométricas da rede exemplo 1.................................................. 142

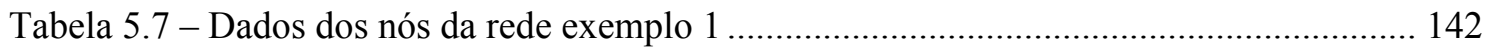

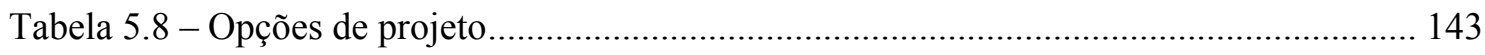

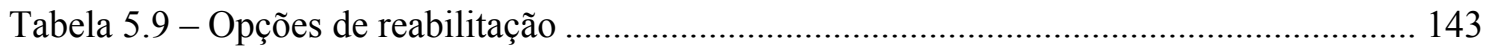

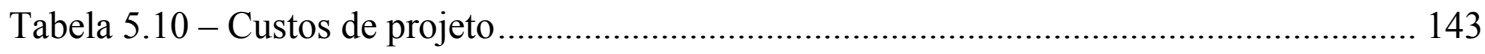

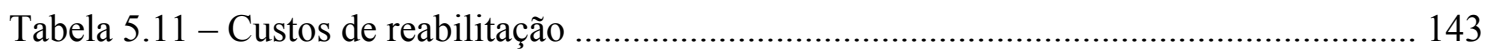

Tabela 5.12 - Características geométricas da rede exemplo 2 …............................................. 144

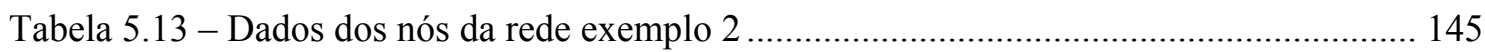

Tabela 5.14 - Decisões de reabilitação para rede exemplo 3.................................................... 146

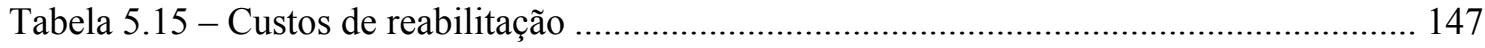

Tabela 6.1 - Soluções de mínimo custo (GAlib - Epanet 2).................................................... 153

Tabela 6.2 - Codificação dos fatores referente ao problema (eq. 6.2) ...................................... 159

Tabela 6.3 - Planejamento de simulações computacionais para rede exemplo 1 ....................... 160

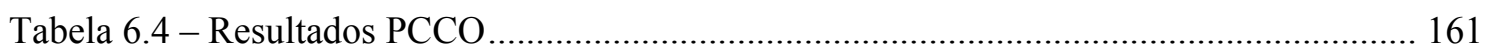

Tabela 6.5 -Pressões obtidas utilizando simulador hidráulico sem vazamentos e com

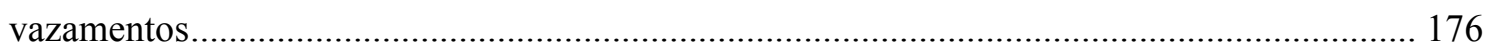

Tabela 6.6 - Pressões e vazamentos obtidos utilizando o modelo de Wagner et al. (1988) sem

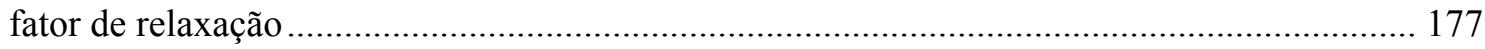

Tabela 6.7 - Pressões e vazamentos obtidos utilizando o modelo de Fujiwara e Li (1998) sem

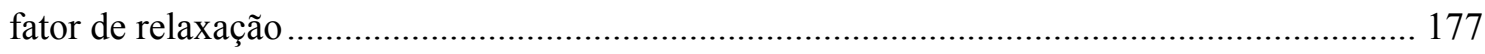

Tabela 6.8 - Pressões e vazamentos obtidos utilizando o modelo de Tucciarelli et.................. 178

Tabela 6.9 - Pressões e vazamentos obtidos utilizando o modelo de Wagner et ...................... 178 
Tabela 6.10 - Pressões e vazamentos obtidos utilizando o modelo de Fujiwara e Li. 179

Tabela 6.11 - Pressões e vazamentos obtidos utilizando o modelo de Tucciarelli et. 179

Tabela 6.12 - Desvio absoluto referentes às pressões nodais ................................................... 181

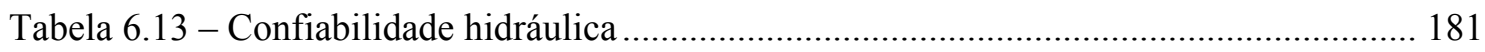

Tabela 6.14 - Demandas nodais da rede exemplo 3 .............................................................. 186

Tabela 6.15 - Pressões nos nós monitorados (simulada e observada) ..................................... 188

Tabela 6.16 - Parâmetros do modelo pressão-vazamento referente ao modelo simplificado real

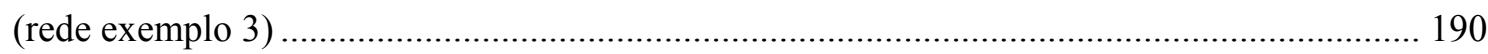

Tabela 6.17 - Pressões nos nós monitorados (observadas e calibradas) ................................... 190

Tabela 6.18 - Erro absoluto referente às pressões calibradas ................................................... 190

Tabela 6.19 - Parâmetros do modelo pressão-vazamento da rede exemplo 3 para diferentes cenários de consumo (valores médios de cinco populações iniciais).......................................... 192

Tabela 6.20 -Ajuste das manobras para os diferentes cenários de consumo ............................. 192

Tabela 6.21 - Pressões nos nós monitorados (observadas e calibradas considerando manobras e parâmetros de vazamento diferenciados para cada padrão de consumo) .................................... 192

Tabela 6.22 - Manobras calibradas considerando cenários de consumo distintos .................... 193

Tabela 6.23 - Parâmetros do modelo de vazamentos global .................................................... 194

Tabela 6.24 - Pressões calibradas considerando parâmetros de vazamentos globais................ 195

Tabela 6.25 - Pressões calibradas considerando parâmetros de vazamentos globais................ 196

Tabela 6.26 - Vazões abastecidas calibradas e observadas considerando parâmetros de

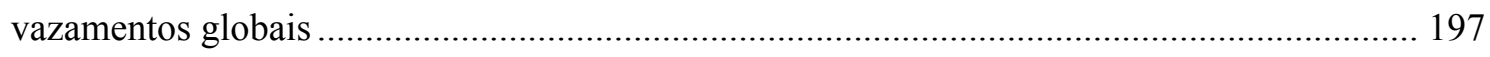

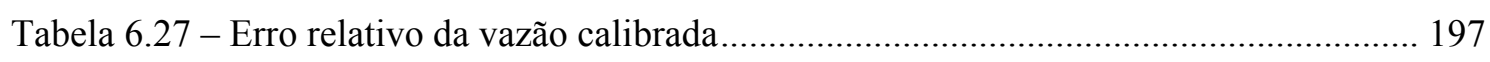

Tabela 6.28 - Análise detalhada da solução de menor desvio absoluto total (simulação 2)

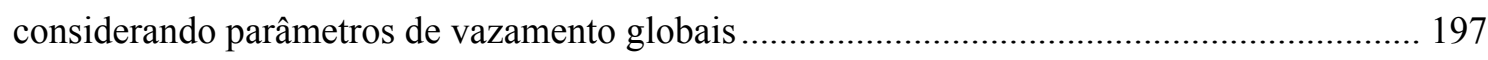

Tabela 6.29 - Parâmetros de vazamento utilizados nas análises de reabilitação ....................... 199

Tabela 6.30 - Estimativa das perdas físicas do setor RF-1 no período diurno ........................... 199

Tabela 6.31 - Estimativa das perdas físicas do setor RF-1 no período noturno.......................... 199

Tabela 6.32 - Demanda efetivamente atendida e confiabilidade hidráulica do setor RF-1 (modelo simplificado real - rede exemplo 3) .......................................................................... 200

Tabela 6.33 - Autovalores da matriz de dados referentes aos resultados da otimização estática

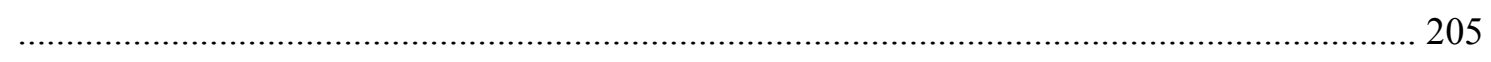

Tabela 6.34 - Funções objetivo de soluções da otimização estática......................................... 207

Tabela 6.35 - Decisões de reabilitação representativas dos três cenários obtidas na otimização

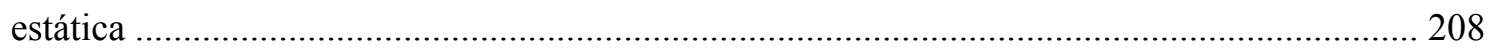

Tabela 6.36 - Autovalores da matriz de dados referentes a frente inicial da otimização dinâmica

Tabela 6.37 - Soluções escolhidas da frente Pareto inicial - otimização dinâmica 214 
Tabela 6.38 - Decisões de reabilitação para o primeiro período de planejamento em relação aos cenários da otimização dinâmica 215

Tabela 6.39 - Soluções da análise de reabilitação dinâmica .................................................... 216

Tabela 6.40 - Trechos a serem reabilitados no segundo período de planejamento ................... 216

Tabela 6.41 - Soluções da análise de reabilitação dinâmica ...................................................... 218

Tabela 6.42 - Decisões de reabilitação para o último período de planejamento em relação aos

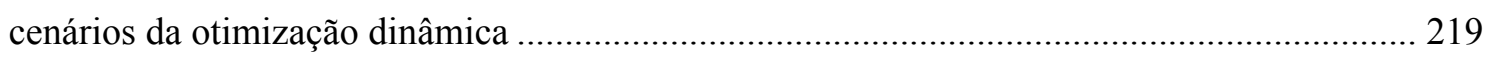

Tabela 7.1 - Modelos para análise de reabilitação de redes de distribuição de água e a

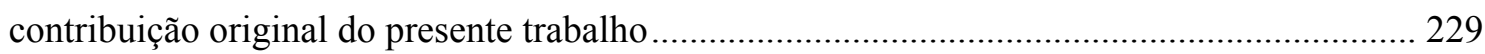

Tabela A1.1 - Demandas nos nós para modelo real simplificado ........................................... 252

Tabela A1.2 - Pontos de monitoramento de pressão …………………………….................... 254

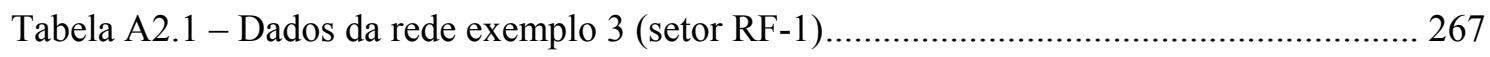




\section{LISTA DE SÍMBOLOS}

\author{
A \\ a \\ $\mathrm{a}_{0}$ \\ B \\ $\mathrm{b}_{0}$ \\ c \\ $\mathrm{c}_{0}$ \\ C \\ $\mathrm{C}_{\mathrm{d}}$ \\ $\mathrm{C}_{\mathrm{p}}$ \\ $\mathrm{C}_{\mathrm{r}}$ \\ $\mathrm{C}_{\mathrm{rf}}$ \\ $\mathrm{C}_{\mathrm{s}}$ \\ $\mathrm{C}_{\mathrm{T}}$ \\ $\mathrm{C}_{\mathrm{HW}}$ \\ $\mathrm{C}_{\text {duplicação }}$ \\ $\mathrm{C}_{\text {limpeza }}$ \\ $\mathrm{C}_{\text {projeto }}$ \\ $\mathrm{C}_{\text {substiuição }}$ \\ $\mathrm{C}_{1}$ \\ $\mathrm{C}_{2}$ \\ D \\ $\mathrm{DEF}_{\mathrm{o}}$ \\ $\mathrm{DEF}_{\mathrm{r}}$ \\ DR \\ $\mathrm{e}_{0}$ \\ F \\ FR \\ FT \\ $\mathrm{F}_{\mathrm{u}}$ \\ - Matriz de incidência dos nós interiores; Área \\ - $\quad$ Expoente de vazamentos; Expoente de regressão; Expoente de ajuste da evolução temporal; \\ Taxa de crescimento da rugosidade na tubulação \\ - Constante da curva característica de bombas \\ - Variável de decisão referente a capacidade de bombeamento; Benefício \\ - Constante da curva característica de bombas \\ - Constante nodal (análises dirigidas pela pressão) \\ - Constante da curva característica de bombas \\ - Custo; Conjuntos clusters; Métrica de cobertura da frente Pareto \\ - Coeficiente de descarga de orifícios \\ - Função penalidade \\ - Custo de reparo de uma quebra \\ - Custo de reparo de futuras quebras \\ - Custo de substituição de uma tubulação (\$) \\ - Custo total \\ - Coeficiente de Hazen-Williams \\ - Custo de implantação de tubulações em paralelo \\ - Custo de limpeza de tubulações \\ - Custo de implantação de novas tubulações \\ - Custo de substituição de tubulações \\ - $\quad$ Fator de correção (modelo proposto por WALSKI e PELLICCIA, 1982) \\ - $\quad$ Fator de correção (modelo proposto por WALSKI e PELLICCIA, 1982) \\ - Diâmetro de tubulação; Matriz diagonal \\ - Deficiência da rede original \\ - Deficiência da rede reabilitada \\ - Variável de decisão referente ao dimensionamento de reservatórios \\ - Expoente; Distância da função de compartilhamento; Distância euclidiana; Distância entre \\ soluções \\ - Exponencial \\ - $\quad$ Rugosidade interna de tubulação \\ - $\quad$ Função de aptidão \\ - $\quad$ Frentes não dominadas \\ - $\quad$ Fator temporal (modelo proposto por SOARES, 2003) \\ - $\quad$ Fator de quebra de tubulações em relação ao seu uso (residencial, comercial ou indsutrial)
}




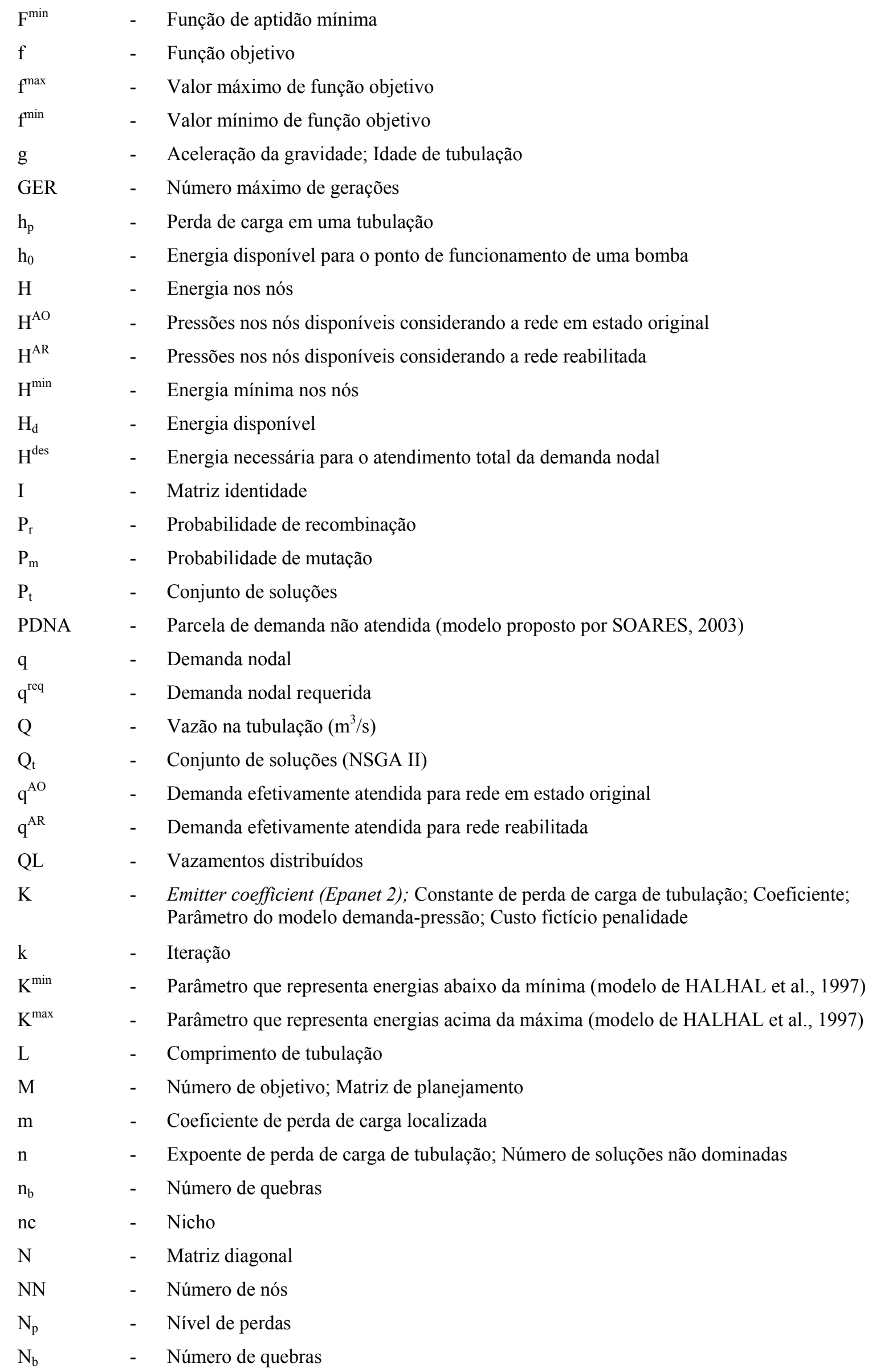




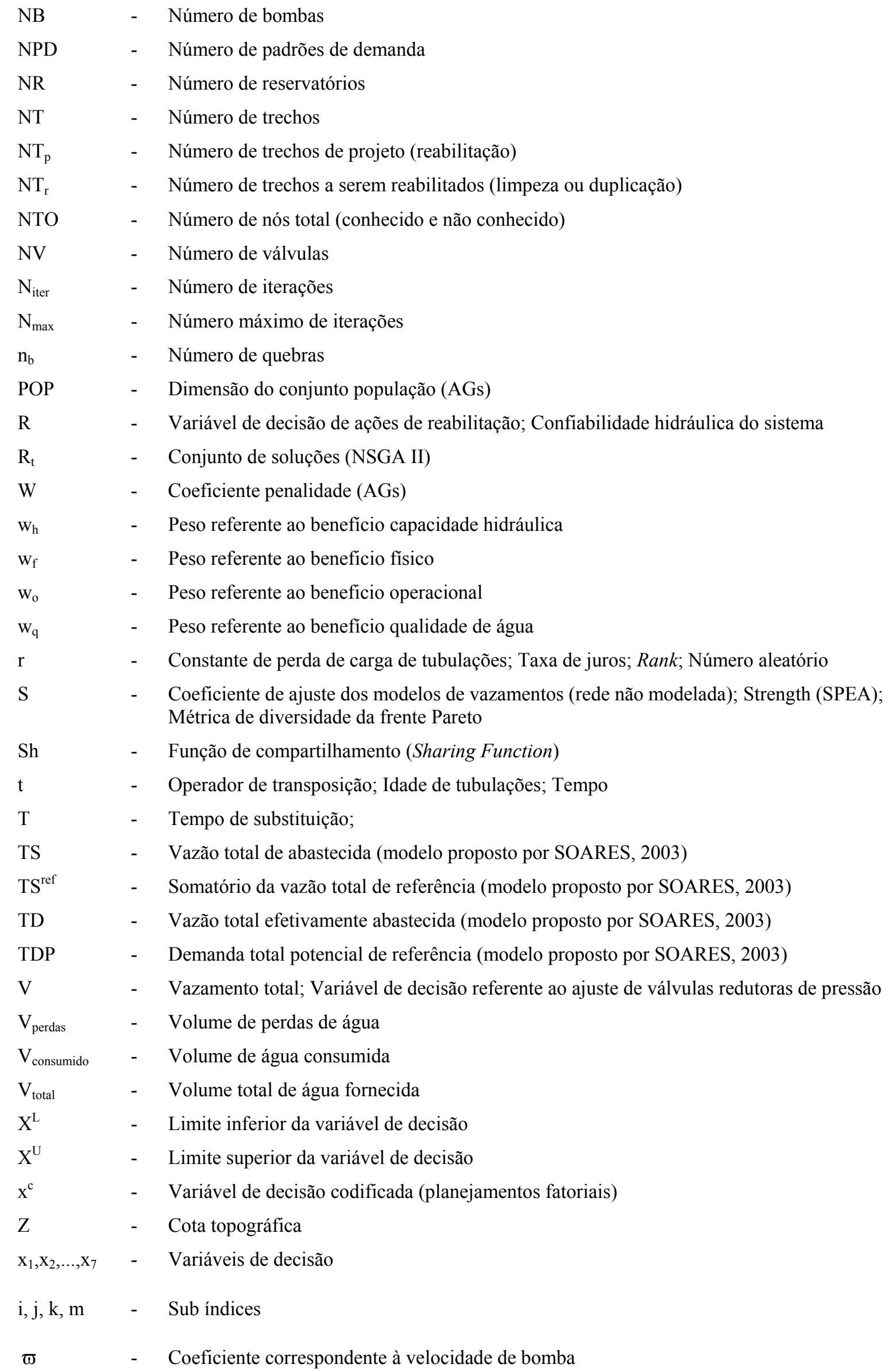




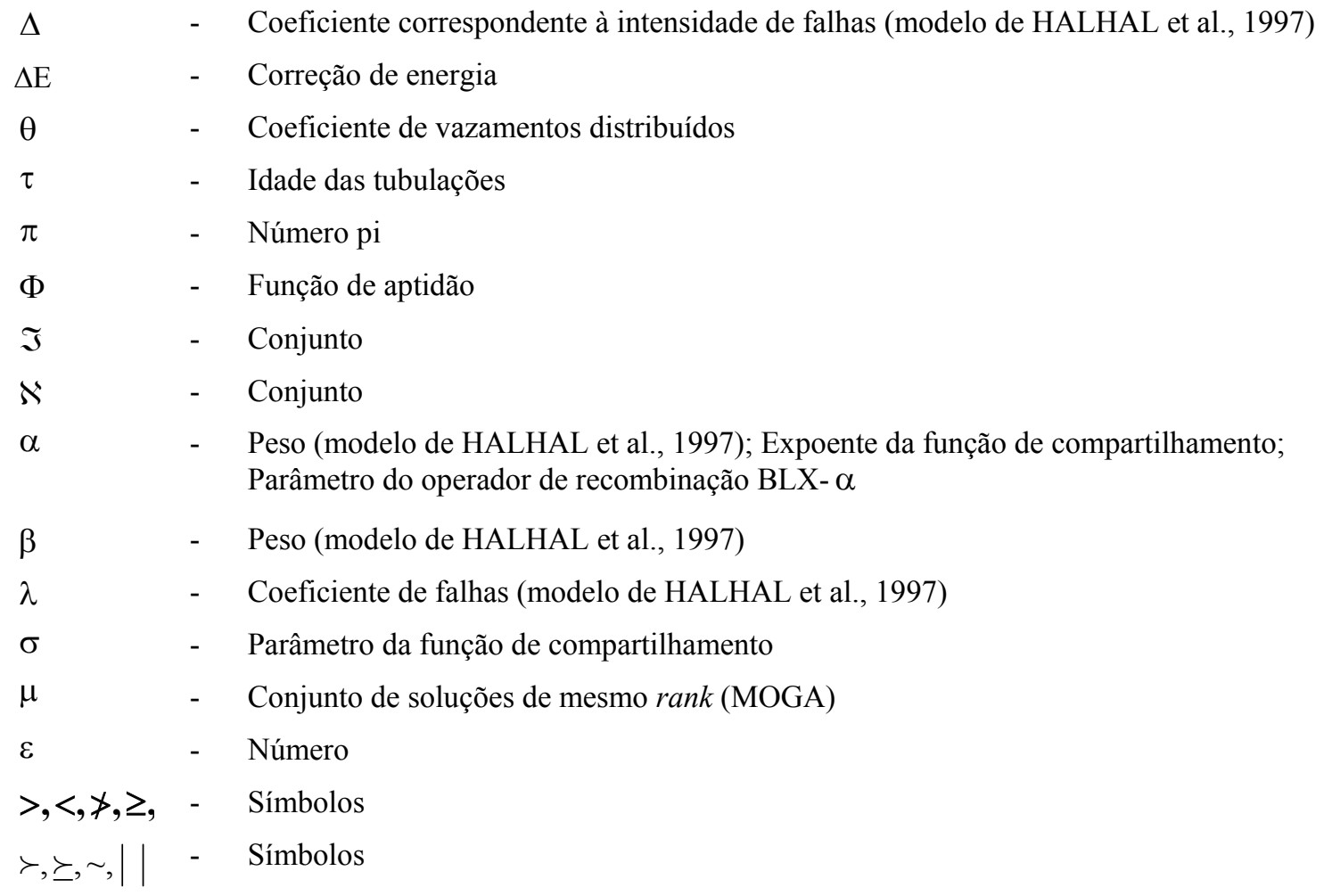




\section{SUMÁRIO}

AGRADECIMENTOS ...............................................................................ii

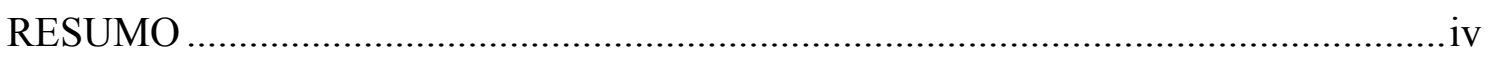

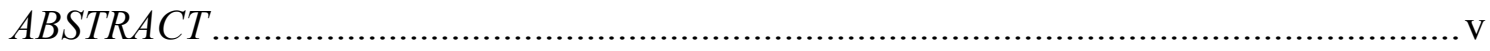

LISTA DE FIGURAS ……………………………….....................................

LISTA DE TABELAS …………………………………..................................

LISTA DE SÍMBOLOS .................................................................................

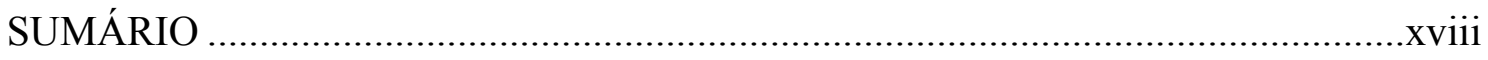

1 INTRODUÇÃO ...........................................................................................................

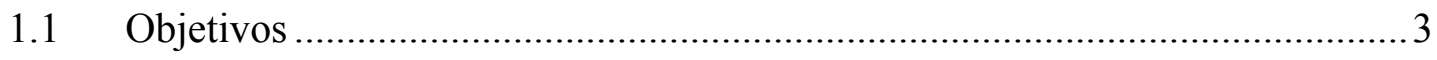

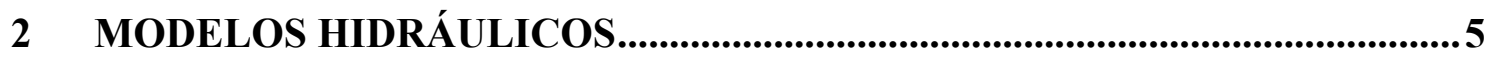

2.1 Análise de redes em regime permanente........................................................

2.1.1 Formulação do problema.................................................................................

2.2 Perdas em sistemas de abastecimento de água................................................. 10

2.2.1 Formulação matemática de vazamentos através de orifício...............................12

2.2.2 Modelação matemática de vazamentos através de seção variável ..................... 13

2.3 Demandas dependentes da pressão .............................................................. 17

3 MODELOS DE REABILITAÇÃO …………………….......................................28

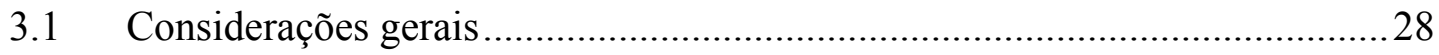

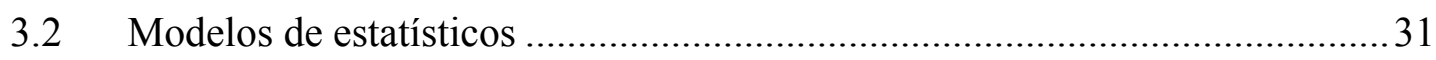

3.3 Modelos baseados nas técnicas de análise de sistemas......................................38

3.3.1 Algoritmos genéticos aplicados a sistemas de abastecimento ......................... 42

3.3.2 Modelos de otimização multiobjetivo ...........................................................52

4 MODELOS DE OTIMIZAÇÃO MULTIOBJETIVO ….....................................63

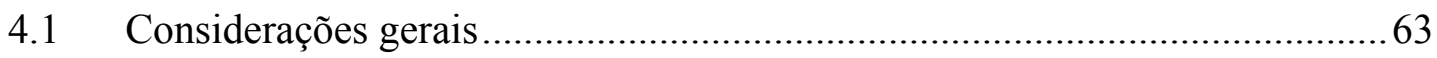

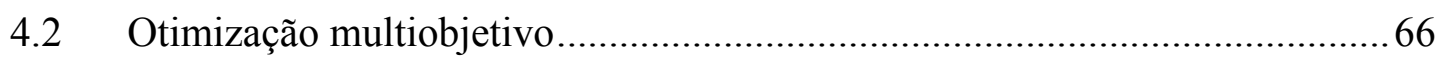

4.3 Algoritmos evolucionários ........................................................................

4.3.1 Exemplo de evolução dos algoritmos genéticos ..............................................75

4.3.2 Algoritmos evolucionários multiobjetivo ………………………………....... 77 
5 PROPOSIÇÃO DE MODELO COMPUTACIONAL .....................................86

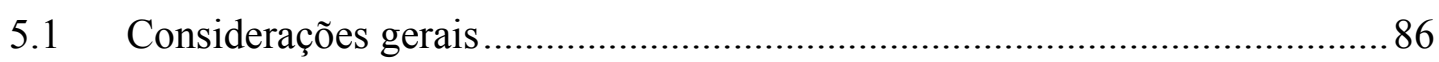

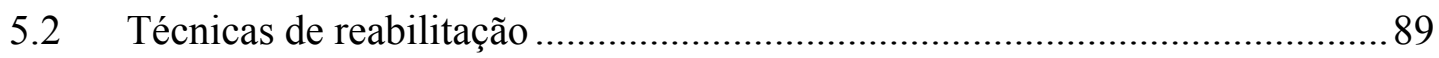

5.3 Formulação do problema de reabilitação de redes hidráulicas ........................90

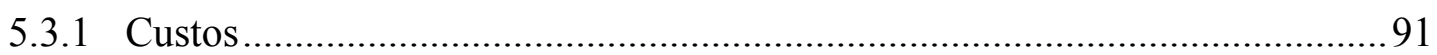

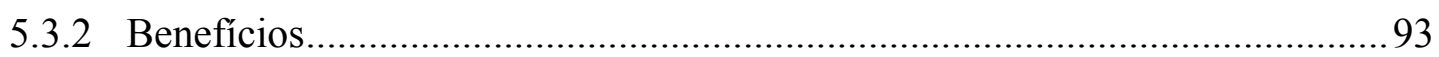

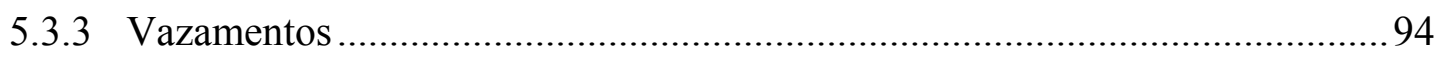

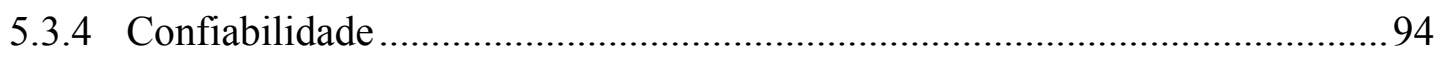

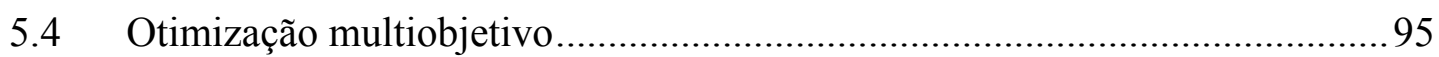

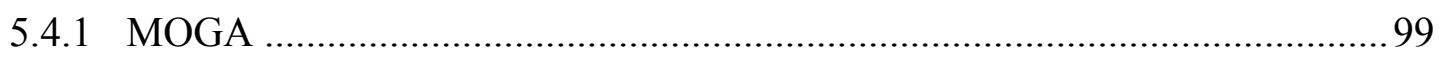

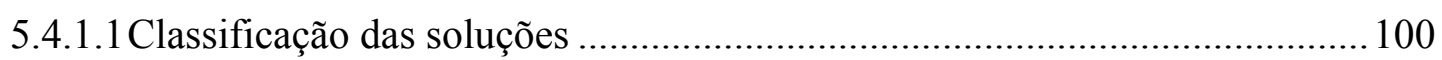

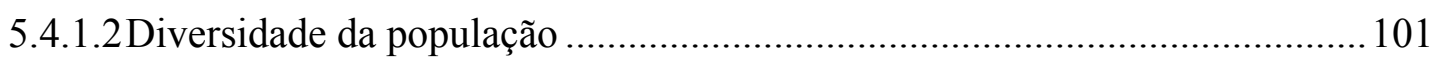

5.4.1.3 Etapas do procedimento iterativo do MOGA................................................ 103

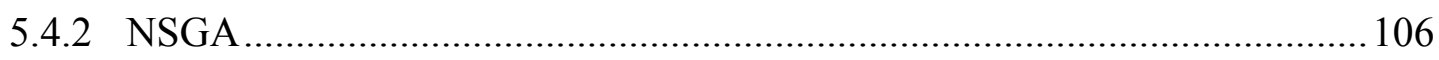

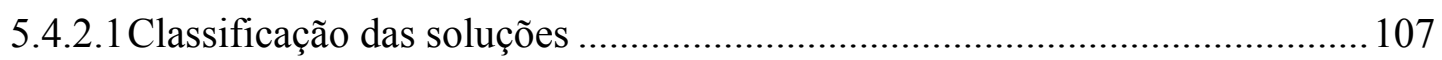

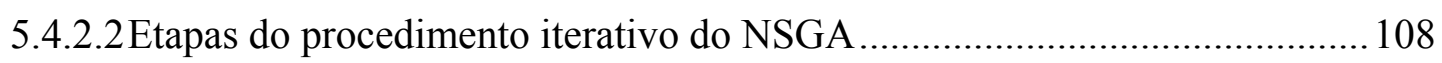

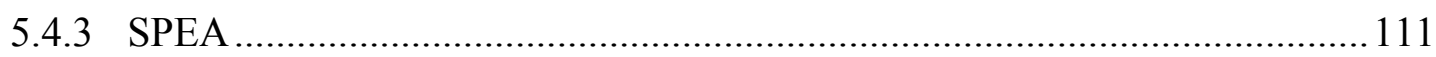

5.4.3.1 Etapas do procedimento iterativo do SPEA ...................................................... 112

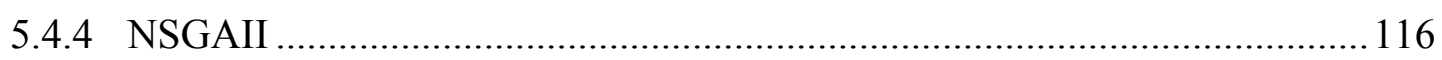

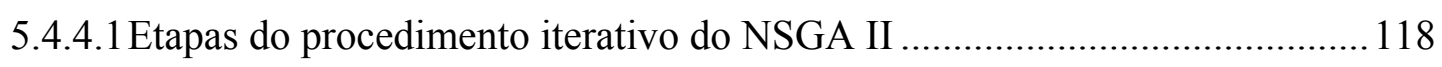

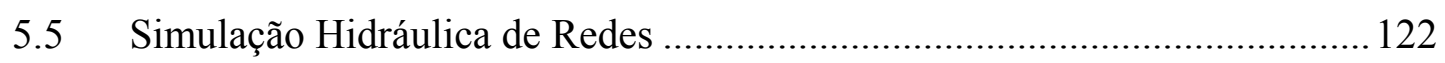

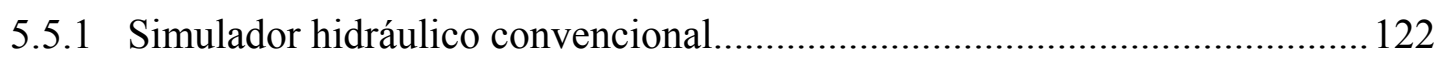

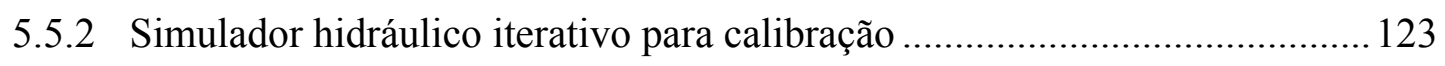

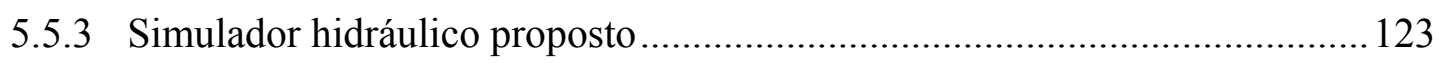

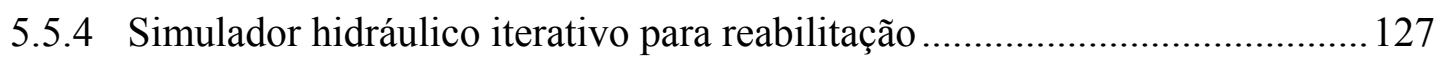

5.6 Implementação dos métodos evolucionários multiobjetivo ......................... 127

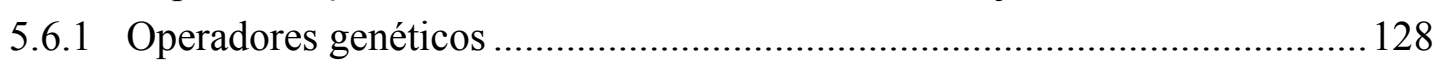

5.7 Medidas de desempenho para algoritmos evolucionários multiobjetivo ....... 130

5.7.1 Métrica para avaliar a convergência da frente Pareto .................................. 131

5.7.2 Métrica para avaliar a diversidade da frente Pareto ...................................... 132

5.8 Planejamento de experimentos computacionais.......................................... 132

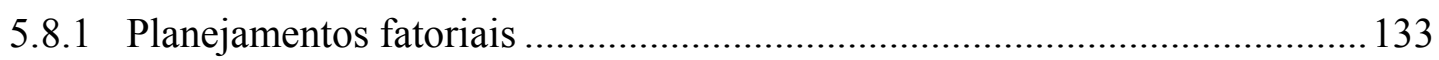

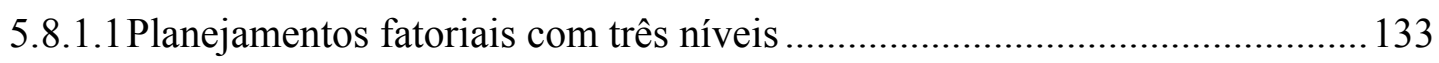

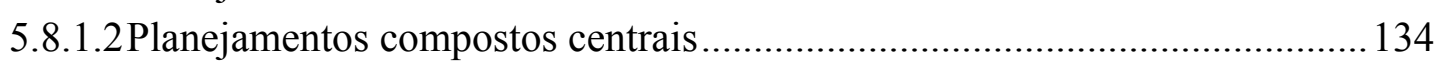

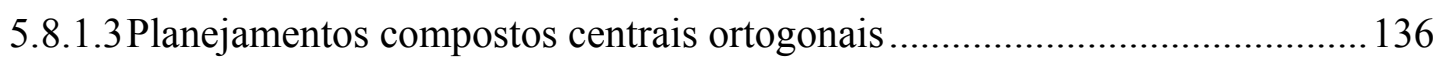

5.9 Análise de componentes principais - ferramenta de auxílio a tomada de

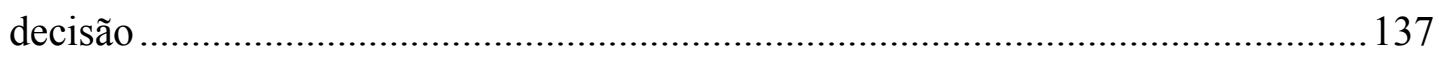

5.10 Análise de reabilitação através da otimização multiobjetivo de múltiplos

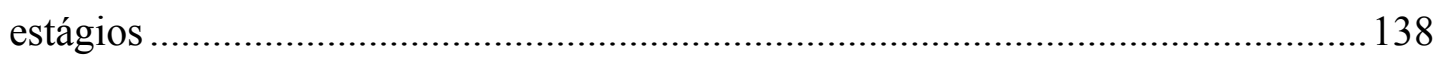

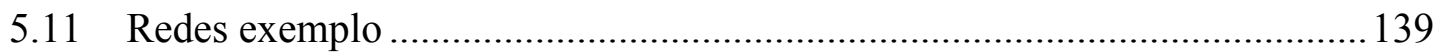

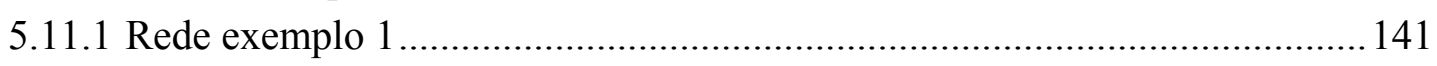

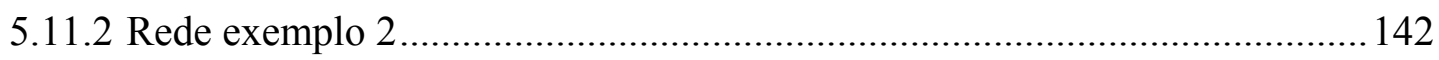




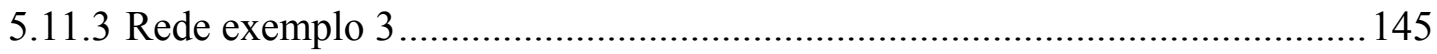

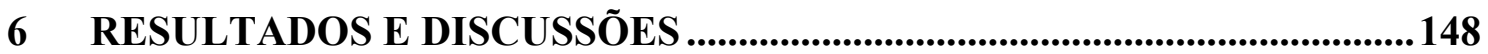

6.1 Análise de reabilitação através da otimização convencional - estudo

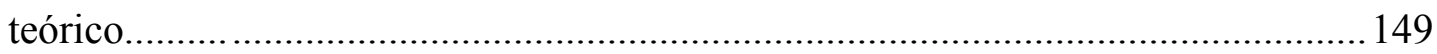

6.1.1 Análises estatísticas de experimentos computacionais com AGs ................ 157

6.2 Análise de reabilitação através da otimização multiobjetivo - estudo

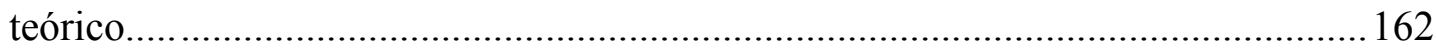

6.2.1 Comparações de métodos de otimização multiobjetivo................................. 166

6.3 Análise de redes através do simulador hidráulico proposto ......................... 175

6.4 Estimativa dos parâmetros do modelo de vazamentos - estudo de caso real 183

6.5 Análise de reabilitação através da otimização multiobjetivo estática - estudo

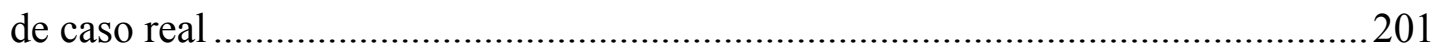

6.6 Análise de reabilitação através da otimização multiobjetivo dinâmica - estudo

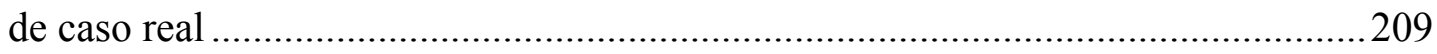

6.7 Comparação da análise de reabilitação estática e dinâmica..........................2220

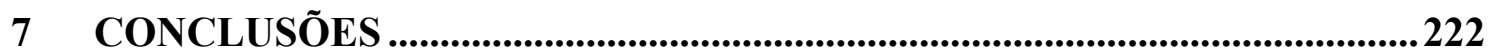

9 REFERÊNCIAS BIBLIOGRÁFICAS ..........................................................231

APÊEDICE A - Algoritmos de busca de soluções não dominadas.............................. 241

ANEXO A - Descrição da pesquisa de campo e preparação dos dados para determinação dos parâmetros do modelo de vazamentos para o sistema real (Setor RF 1) da cidade de Campo Grande, MS ..................................................................246

A1 MODELO SIMPLIFICADO REAL _.........................................................24

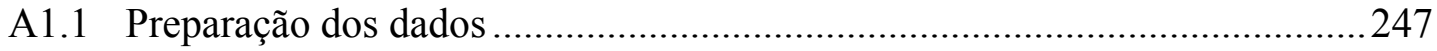

A1.2 Estudo de caso real: rede simplificada correspondente ao setor operacional

RF-1 da cidade de Campo Grande, MS................................................................ 249

A1.2.1 Simplificação da rede............................................................................. 250

A2 DADOS DA REDE EXEMPLO 3 (SETOR RF-1) .....................................267 


\section{INTRODUÇÃO}

A perspectiva de crescimento do contingente populacional urbano sugere que as fontes hídricas existentes sejam oneradas, acelerando o processo de exploração de novas fontes com o propósito de abastecimento. Dessa maneira, com base no reconhecimento de que a água constitui recurso natural limitado, a garantia de atendimento às necessidades das futuras gerações obriga a operação eficiente e eficaz dos sistemas de aproveitamento e de distribuição de águas em geral. Dentro desse contexto, os sistemas de distribuição de águas para abastecimento, componentes essenciais da infra-estrutura e desenvolvimento de áreas urbanizadas, merecem ser examinados.

As mudanças nas condições físicas dos elementos (tubulações, acessórios e componentes hidráulicos) que compõem as redes de distribuição alteram o comportamento econômico e operacional das mesmas, cuja deterioração provoca perda da capacidade de transporte, elevação nas pressões de bombeamento, aumento dos custos de operação e manutenção, além de pressões inadequadas. Esses problemas estão diretamente relacionados à idade das redes que, se elevada, pode gerar vazamentos e colapso das tubulações, resultando não apenas na perda de água, mas também em uma possível contaminação. Todavia, apesar dos custos elevados envolvidos nos trabalhos de reparo, em contraposição aos investimentos geralmente limitados que se dispõe, grande quantidade de capital tem sido investido na melhoria (reabilitação) de sistemas existentes, tendo em vista vantagens tais como, redução dos danos causados pelas pressões excessivas provenientes das variações de consumo nos nós da rede e minimização das perdas, dentre outras.

Maior confiabilidade e eficiência na distribuição de água podem ser obtidas através da reabilitação das redes. No entanto, esse é um problema complexo devido à necessidade de se prover soluções efetivas à tomada de decisão. A estratégia de decisão deve considerar as propriedades físicas, o prognóstico evolutivo do comportamento dinâmico do sistema e a satisfação do usuário, em substituição às análises do tipo custo/benefício convencionais. 
O projeto de abastecimento urbano através de redes hidráulicas constitui-se de uma técnica sistêmica antiga e comum. Muitos dos sistemas de distribuição existentes foram projetados utilizando o método de tentativa e erro, baseados também nas experiências anteriores bem sucedidas. Atualmente, alguns modelos computacionais vêm sendo desenvolvidos para estudar o problema de reabilitação de redes devido à reconhecida necessidade de se restabelecer e manter um nível de serviço adequado aos usuários.

Nas décadas passadas, os métodos matemáticos de otimização serviram como ferramentas facilitadoras para a busca de soluções que fornecessem menores custos para os projetos de redes hidráulicas. Esses métodos (programação linear, não-linear e dinâmica) obtiveram vantagens em relação aos procedimentos anteriores de tentativa e erro.

Recentemente, pesquisadores apontam desvantagens características dos métodos de otimização convencional, das quais estão relacionadas às dificuldades de obtenção do ótimo global, aplicações a problemas complexos, implementação de tais técnicas e, principalmente, no que se refere à necessidade enquadrar objetivos reais e múltiplos.

O modelo computacional para análise de reabilitação de redes de distribuição de água para abastecimento proposto no presente trabalho, é desenvolvido sob três fases distintas. A primeira fase, denominada etapa preliminar, contempla todos os estudos que envolvem a busca de informações do sistema. Essas informações são os dados cadastrais da rede, as estimativas de demandas nos nós, os registros de manutenção e operação e as observações em campo. Nessa etapa, é adotado um procedimento de calibração, cuja função é identificar os parâmetros característicos do modelo pressãovazamento, para que as perdas físicas possam ser consideradas nas análises hidráulicas. Alguns estudos na literatura demonstraram que os parâmetros de vazamento devem ser estimados antes de qualquer análise de redes de distribuição de água existentes, seja na operação e/ou na reabilitação. A calibração desses parâmetros possibilita que as simulações hidráulicas, realizadas posteriormente, reproduzam uma melhor aproximação do comportamento real do sistema. Esse procedimento faz-se necessário devido à análise de reabilitação de redes de distribuição de água tratar o problema como um sistema existente.

A segunda fase do modelo proposto, denominada etapa de avaliação, identifica soluções ótimas através de algoritmos de otimização que contemplam vários objetivos simultaneamente. Esses algoritmos, denominados algoritmos genéticos multiobjetivo, 
representam os métodos mais eficientes e versáteis encontrados na literatura até o momento. Quatro algoritmos genéticos multiobjetivo (Multiple Objective Genetic Algorithm - MOGA, Non-Dominated Sorting Genetic Algorithm - NSGA, Strength Pareto Evolutionary Algorithm - SPEA, Elitist Non-Dominated Sorting Genetic Algorithm - NSGA II) foram testados e comparados neste trabalho. Quatro funções objetivo (minimização de custo, maximização de benefícios, minimização de vazamentos e maximização da confiabilidade) são propostas para serem otimizadas simultaneamente.

Do ponto de vista hidráulico, o presente trabalho introduz tanto perdas por vazamentos como demanda variável com a pressão, possibilitando uma análise mais realística do problema. A literatura oferece duas possibilidades para incorporação dos modelos pressão-vazamento e pressão-demanda nas análises hidráulicas de redes, explícita (intervenção direta sobre o código) ou iterativa (sem intervenção direta sobre o código). Neste trabalho, as duas formas foram desenvolvidas e analisadas. A consideração explícita propiciou um aperfeiçoamento do método gradiente implementado no Epanet 2, originalmente proposto para análise dirigida pela demanda.

Finalmente, a terceira fase do modelo, denominada etapa de decisão, tem como objetivo apresentar as soluções ótimas, identificadas na etapa de avaliação e transformá-las em planos alternativos de reabilitação.

\subsection{Objetivos}

Face às necessidades prementes de ordem prática já enfatizada, definem-se como objetivos desta pesquisa:

- análise detalhada dos métodos de reabilitação de redes da literatura;

- identificação e formulação dos objetivos mais promissores a serem perseguidos no tratamento do problema de reabilitação de redes de distribuição de água para abastecimento;

- implementação de código computacional que utilize o ferramental básico de algoritmos genéticos (AGs), possibilitando análises multiobjetivo, através da inclusão de rotinas adicionais; e 
- realização de simulações computacionais que propiciem condições de comparação com resultados já reportados na literatura, bem como a sua aplicação uma rede existente. 


\section{MODELOS HIDRÁULICOS}

Neste capítulo são abordadas e discutidas algumas evoluções e tendências, referentes à consideração de perdas por vazamento e à relação de dependência da demanda com a pressão, nos modelos matemáticos para análise de redes de distribuição de água em regime permanente.

\subsection{Análise de redes em regime permanente}

Uma rede de distribuição de água é definida como sendo uma combinação de tubos, componentes hidráulicos (bombas e válvulas) e estruturas hidráulicas (reservatórios e estações de bombeamento) interconectados com propósito de transportar água potável para população, em quantidade e qualidade satisfatória. As redes são representadas por trechos de tubulações conectadas entre si em pontos bem definidos denominados nós. A análise do comportamento de tais sistemas é uma tarefa complexa tendo em vista a natureza não linear das leis físicas que regem o escoamento no interior de condutos forçados.

Com o advento dos computadores essas análises passaram a ser realizada com auxílio de técnicas numéricas, sendo os sistemas de distribuição de água representados através de modelos matemáticos ${ }^{1}$. SOUZA (1994) classifica os modelos matemáticos para análise de redes, também denominados simuladores hidráulicos, em dois principais grupos: modelos de ajuste simples (analogia elétrica, Hardy-Cross, comprimento equivalente, proporcionalidade das vazões) e modelos de ajuste simultâneo (teoria linear, Newton-Raphson e gradiente). Nos modelos de ajuste simples, as incógnitas (vazões e pressões) são obtidas independentemente, já nos métodos de ajuste simultâneo, essas incógnitas (variáveis de estado) são encontradas simultaneamente. Cabe destacar que grande parte dos pacotes computacionais existentes (WADISO, KYPIPE, H20NET, EPANET, WATERCAD, dentre outros) utiliza o ajuste simultâneo

\footnotetext{
${ }^{1}$ Segundo DENN apud GARCIA (1997), um modelo matemático é um sistema de equações cuja solução, dado um conjunto de dados de entrada, é representativa da resposta do processo.
} 
como metodologia de resolução, visando vantagens computacionais (convergência) frente aos métodos de ajuste simples.

A modelação matemática em sistemas de distribuição de água requer o uso de uma terminologia característica para descrever o problema físico, por exemplo, os termos nós e trechos. Os consumos ao longo dos trechos são concentrados nos nós, ou seja, atribui-se metade da demanda ao longo de um trecho ao nó de montante e a outra metade dessa demanda ao nó de jusante. A Figura 2.1 apresenta um exemplo da disposição de nós e trechos em um sistema, e como as demandas são consideradas para efeito da modelação.

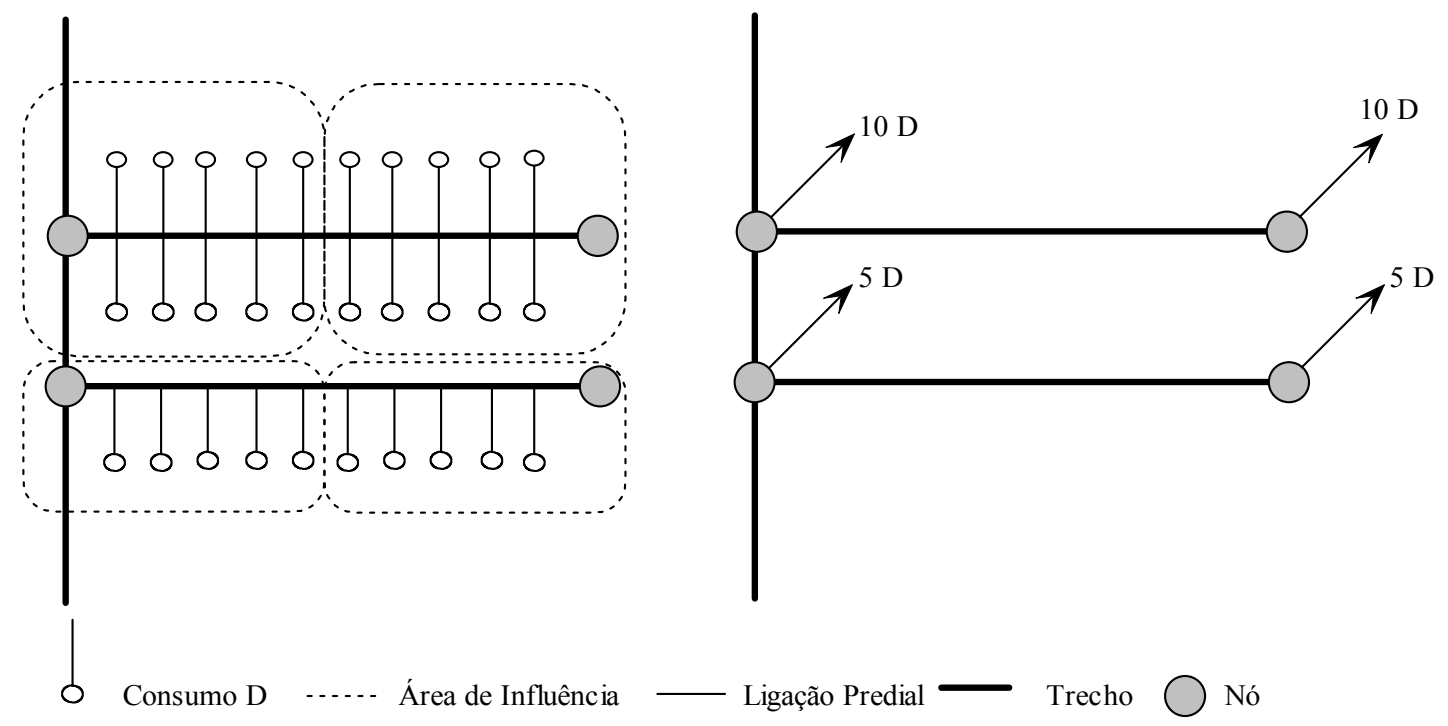

Figura 2.1 - Nós, ligações e alocação de demandas

As leis da física que governam o escoamento em condutos sob pressão são a conservação de massa e a conservação de energia. De acordo com a lei da conservação de massa, aplicada aos nós da rede, a demanda em um sistema representa a diferença entre a vazão aduzida (entrada) no sistema e a vazão requerida (saída) do sistema. É dessa forma que LANSEY e MAYS (2000) apresentam a equação da conservação de massa:

$$
\sum \mathrm{Q}_{\mathrm{i}}-\sum \mathrm{Q}_{\mathrm{j}}=\mathrm{q}
$$

sendo que $\mathrm{Q}_{\mathrm{i}}$ e $\mathrm{Q}_{\mathrm{j}}$ são as vazões das tubulações com fluxo direcionado ao nó (entrada) e para o fluxo em sentido oposto ao nó (saída), respectivamente, e q representa a demanda ou consumo no nó. 
$\mathrm{Na}$ lei da conservação de energia, a diferença de energia entre dois pontos é igual a soma de todas as perdas de carga (atrito e localizada) acrescidas às energias adicionais (bombas) nos trechos. Um balanço de energia pode ser descrito sob três formas: (1) entre dois pontos de um trecho, (2) entre dois nós de energia constante contendo uma série de tubulações, válvulas e bombas entre esses pontos, (3) um circuito que começa e termina no mesmo ponto. De maneira geral, LANSEY e MAYS (2000) apresentam essas afirmações conforme eq.(2.2).

$$
\sum_{\mathrm{i} \in \mathfrak{I}} \mathrm{h}_{\mathrm{p}_{\mathrm{i}}}+\sum_{\mathrm{i} \in \mathfrak{I}} \mathrm{h}_{\mathrm{bi}}=\Delta \mathrm{E}
$$

sendo $\mathfrak{I}$ um circuito (aberto ou fechado); $h_{p}$ a perda de carga do componente $\mathrm{i}$ pertencente ao circuito $\mathfrak{I} ; h_{b}$ a energia adicionada pela bomba no trecho i pertencente ao circuito $\mathfrak{I}$ e $\Delta \mathrm{E}$ a diferença de energia entre os pontos extremos do circuito.

A solução do problema hidráulico é obtida quando as equações hidráulicas (eqs. $2.1 \mathrm{e}$ 2.2) de balanço nos nós e nos circuitos ${ }^{2}$ são satisfeitas. Grande parte dos modelos (SHAMIR e HOWARD, 1968; EPP e FOWLER, 1970; WOOD e CHARLES, 1972; DONACHIE, 1974; CHANDRASHEKAR e STEWART, 1975; RIGHETTO, 1977; TODINI, 1979; TODINI e PILATI, 1988; NIELSEN, 1989; SOUZA, 1994) propostos na literatura baseiam-se nessas equações.

\subsubsection{Formulação do problema}

Embora existam vários métodos para análise de redes de distribuição de água (gradiente local, Newton-Raphson, linearização sucessiva e minimização numérica), neste item é apresentada apenas a formulação matricial proposta por TODINI e PILATI (1988), pois é o método de resolução implementado no Epanet 2 (ROSSMAN, 2000), simulador hidráulico utilizado neste trabalho.

A formulação proposta por TODINI e PILATI (1988) utiliza o método de NewtonRaphson para linearizar as equações não lineares e obter um sistema de equações lineares, a ser resolvido pela fatorização incompleta de Cholesky, em conjunto com o método do gradiente conjugado. Isso só é possível devido às características inerentes à matriz do sistema: esparsa, simétrica e definida positiva. Alguns trabalhos (TODINI,

\footnotetext{
${ }^{2}$ A definição de circuitos (abertos ou fechados) é apresentada por Walski (1992) em seu livro texto Analysis of Water Distribution Systems publicado pela Krieger Publishing Company.
} 
1979; SALGADO, TODINI e O’CONNELL, 1988) são referidos na literatura por apresentarem as provas de convergência desse método.

Em geral, a formulação matricial para um problema de análise de redes de distribuição de água é apresentada conforme eq.(2.3).

$$
\left[\begin{array}{ccc}
\mathrm{A}_{11} & \vdots & \mathrm{A}_{12} \\
\cdots & \cdots & \cdots \\
\mathrm{A}_{21} & \vdots & 0
\end{array}\right]\left[\begin{array}{l}
\mathrm{Q} \\
\cdots \\
\mathrm{H}
\end{array}\right]=\left[\begin{array}{c}
-\mathrm{A}_{10} \mathrm{H}_{0} \\
\cdots \\
-\mathrm{q}
\end{array}\right]
$$

Sendo $\mathrm{Q}^{\mathrm{t}}=\left[\mathrm{Q}_{1}, \mathrm{Q}_{2}, \cdots, \mathrm{Q}_{\mathrm{NT}}\right]$ o vetor de vazões não conhecidas; $\mathrm{H}^{\mathrm{t}}=\left[\mathrm{H}_{1}, \mathrm{H}_{2}, \cdots, \mathrm{H}_{\mathrm{NN}}\right]$ o vetor de energias não conhecidas; $\mathrm{H}_{0}^{\mathrm{t}}=\left[\mathrm{H}_{\mathrm{NN}+1}, \mathrm{H}_{\mathrm{NN}+2}, \cdots, \mathrm{H}_{\mathrm{NTO}}\right]$ o vetor das energias nodais conhecidas e $\mathrm{q}^{\mathrm{t}}=\left[\mathrm{q}_{1}, \mathrm{q}_{2}, \cdots, \mathrm{q}_{\mathrm{NN}}\right]$ o vetor de demandas nodais conhecidas. NT representa o número de tubulações, NN é o número de nós de energia desconhecida, NTO é o número total de nós da rede (energias conhecida e desconhecida), com isso, a subtração $(\mathrm{NTO}-\mathrm{NN})$ representa o número de nós com energia conhecida e $\mathrm{t}$ denota $\mathrm{o}$ operador de transposição. $\mathrm{A}_{11}, \mathrm{~A}_{12}, \mathrm{~A}_{21}, 0$ e $\mathrm{A}_{10}$ representam matrizes do sistema. $\mathrm{A}_{11}$ é definida conforme eq.(2.4) para $\mathrm{k} \in[1, \mathrm{NTO}], \mathrm{i} \in[1, \mathrm{NTO}] \mathrm{e} \mathrm{j} \in[1, \mathrm{NTO}]$.

$$
\mathrm{A}_{11}(\mathrm{k}, \mathrm{k})=\mathrm{r}\left|\mathrm{Q}_{\mathrm{ij}}\right|^{\mathrm{n}-1}+\mathrm{m}\left|\mathrm{Q}_{\mathrm{ij}}\right|
$$

sendo que r é a constante de perda de carga da tubulação e m é o coeficiente de perda de carga localizada. Para trechos dotados de bombas, os elemento da matriz $\mathrm{A}_{11}$ são definidos conforme eq.(2.5) ou eq.(2.6):

$$
\begin{aligned}
& A_{11}(k, k)=-\frac{\varpi^{2}\left(h_{0}-r\left(\frac{Q_{i j}}{\varpi}\right)^{n}\right)}{Q_{i j}} \\
& A_{11}(k, k)=-\left(\frac{a_{0} \varpi^{2}}{Q_{i j}}+b_{0} \varpi+c_{0} Q_{i j}\right)
\end{aligned}
$$

sendo $\varpi$ o coeficiente que está relacionado a velocidade de rotação da bomba; $r$ e $n$ são constantes da curva da bomba que também pode ser expressos em termos de $a_{0}, b_{0}$ e $c_{0} e$ $\mathrm{h}_{0}$ é a energia disponível para o ponto de funcionamento da bomba. Note que essa notação (eqs. 2.4, 2.5 e 2.6) é a mesma utilizada no Epanet 2 (ROSSMAN, 2000). 
A matriz $\mathrm{A}_{12}$, também denominada matriz de incidência, que descreve a topologia do sistema, é definida conforme eq.(2.7).

$\mathrm{A}_{12}(\mathrm{i}, \mathrm{j})=\left\{\begin{aligned}-1, & \text { se a vazão do tubo deixa o nó i } \\ 0, & \text { se o tubo j não está conectado ao nó i } \\ 1, & \text { se a vazão do tubo j entra no nó i }\end{aligned}\right.$

sendo que $A_{12}=A_{21}^{t}$.

Para resolver o sistema de equações não lineares (eq. 2.3) através da técnica de NewtonRaphson, diferenciam-se ambos os lados da eq.(2.3) em relação a Q e H, obtendo-se dessa forma a eq.(2.8).

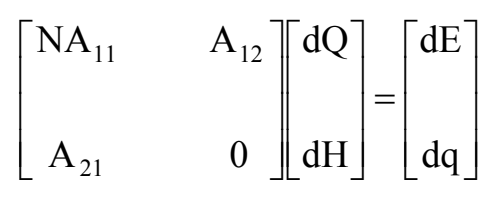

com $\mathrm{N}$ sendo uma matriz diagonal quadrada de ordem NT, cujos elementos representam os expoentes de perda de carga da respectivas tubulações. A solução do problema é, portanto, obtida iterativamente resolvendo o seguinte sistema de equações lineares a cada passo:

$\left[\begin{array}{l}\mathrm{dQ} \\ \mathrm{dH}\end{array}\right]=\left[\begin{array}{cc}\mathrm{NA}_{11} & \mathrm{~A}_{12} \\ \mathrm{~A}_{21} & 0\end{array}\right]^{-1}\left[\begin{array}{l}\mathrm{dE} \\ \mathrm{dq}\end{array}\right]$

sendo os diferenciais dQ, $\mathrm{dH}, \mathrm{dE}$ e dq substituídos pela forma discreta:

$\mathrm{dQ}=\mathrm{Q}^{\mathrm{k}}-\mathrm{Q}^{\mathrm{k}+1}$

$\mathrm{dH}=\mathrm{H}^{\mathrm{k}}-\mathrm{H}^{\mathrm{k}+1}$

$\mathrm{dE}=\mathrm{A}_{11} \mathrm{Q}^{\mathrm{k}}+\mathrm{A}_{12} \mathrm{H}^{\mathrm{k}+1}+\mathrm{A}_{10} \mathrm{H}_{0}$

$\mathrm{dq}=\mathrm{A}_{21} \mathrm{Q}^{\mathrm{k}}-\mathrm{q}$ 
Assim, após alguns procedimentos algébricos demonstrados por TODINI e PILATI (1988), obtém-se as formulações explícitas para o método de ajuste simultâneo utilizado no Epanet 2.

$$
\begin{aligned}
& \mathrm{H}_{\mathrm{k}+1}=-\left(\mathrm{A}_{21} \mathrm{~N}^{-1} \mathrm{~A}_{11}^{-1} \mathrm{~A}_{12}\right)^{-1}\left[\mathrm{~A}_{21} \mathrm{~N}^{-1}\left(\mathrm{Q}_{\mathrm{k}}+\mathrm{A}_{11}^{-1} \mathrm{~A}_{10} \mathrm{H}_{0}\right)+\left(\mathrm{q}-\mathrm{A}_{21} \mathrm{Q}_{\mathrm{k}}\right)\right] \\
& \mathrm{Q}_{\mathrm{k}+1}=\left(\mathrm{I}-\mathrm{N}^{-1}\right) \mathrm{Q}_{\mathrm{k}}-\mathrm{N}^{-1} \mathrm{~A}_{11}^{-1}\left(\mathrm{~A}_{12} \mathrm{H}_{\mathrm{k}+1}+\mathrm{A}_{10} \mathrm{H}_{0}\right)
\end{aligned}
$$

\subsection{Perdas em sistemas de abastecimento de água}

As perdas de água em sistemas públicos de abastecimento são calculadas como sendo a diferença do volume produzido pelo volume faturado. Segundo MARTíNEZ, CONEJOS e VERCHER (1999) as perdas de água nas redes de distribuição são de aproximadamente $50 \%$ do volume total aduzido. Tais perdas são classificadas em físicas e não físicas (Figura 2.2). A perdas físicas são referentes à parcela de água que não chega aos consumidores devido às falhas que ocorrem no sistema, já as perdas não físicas são referentes ao subfaturamento e estão relacionadas à parcela de água consumida, porém não contabilizada para efeito de tarifa.

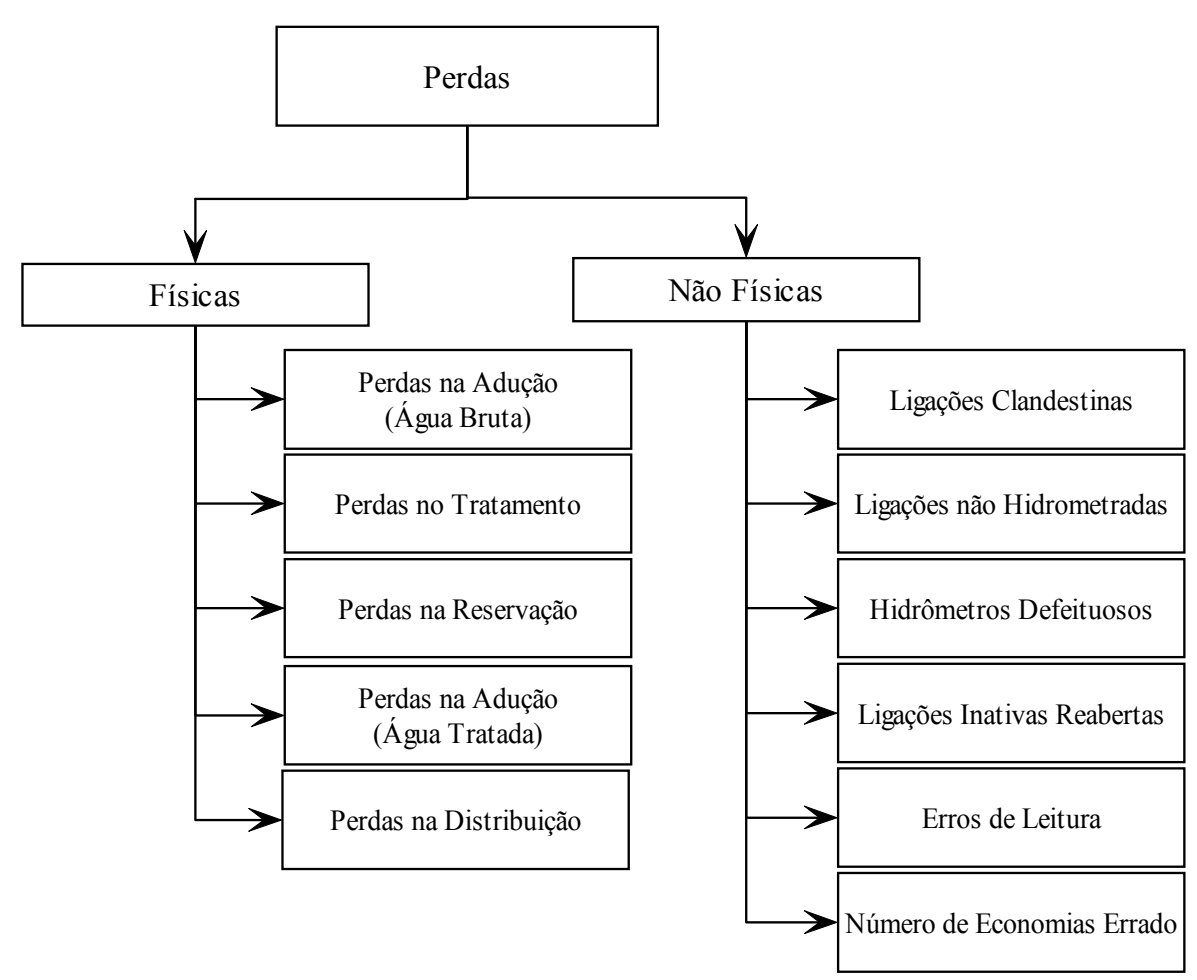

Figura 2.2 - Perdas nos sistemas de abastecimento de água (adaptado de SILVA e CONEJO, 1998)

As perdas físicas em redes de distribuição de água são classificadas em visíveis e inerentes. Segundo REIS et al. (2003) as perdas visíveis são aquelas detectáveis em 
campo, através de instrumentos apropriados, e podem ser facilmente reparadas. Já as perdas inerentes são aquelas que não podem ser detectadas e reparadas com a mesma facilidade, devido a fatores como a magnitude e a distribuições das mesmas ao longo das tubulações.

As perdas não físicas, segundo classificação apresentada por SILVA e CONEJO (1998), originam-se de ligações clandestinas ou não cadastradas, hidrômetros domiciliares defeituosos ou adulterados, falta de medição, fraudes nos hidrômetros e outras. Essas perdas são também conhecidas como perdas de faturamento, uma vez que seu principal indicador determina a relação entre o volume disponibilizado e o volume faturado.

Em geral, a estimativa das perdas de água (eq. 2.16) em um sistema de abastecimento é calculada através da diferença entre o volume de água transferido $\left(\mathrm{V}_{\text {total }}\right)$ de uma fonte de abastecimento e o volume de água consumido ( $\left.\mathrm{V}_{\text {consumido }}\right)$ nos pontos de demanda (situados na área de influência do ponto de transferência).

$\mathrm{V}_{\text {perdas }}=\mathrm{V}_{\text {total }}-\mathrm{V}_{\text {consumido }}$

Segundo LUVIZOTTO (1998) é usual exprimir as perdas em relação percentual ao volume total de água injetada (transferida) ao sistema. Esse índice (eq. 2.17) é denominado nível de perdas $\left(\mathrm{N}_{\mathrm{p}}\right)$.

$\mathrm{N}_{\mathrm{p}}=\frac{\mathrm{V}_{\text {perdas }}}{\mathrm{V}_{\text {total }}} \times 100 \%$

Um programa completo de detecção e controle de perdas envolve quatro etapas distintas: diagnóstico do sistema, identificação das perdas passíveis de serem encontradas através de operação de detecção, quantificação das perdas distribuídas, além das ações de reabilitação e prevenção. Entretanto, a etapa de detecção de perdas distribuídas representa um dos problemas mais complexos e um dos grandes desafios a serem perseguidos nos estudos de sistemas de distribuição de água existentes. Uma das formas que pesquisadores (CALIMAN, 2002; SOARES, 2003) encontraram para a resolução desse problema foi recorrer às técnicas computacionais.

LUVIZOTTO (1998) classifica os modelos matemáticos, para controle e detecção de perdas por vazamentos, em diretos e inversos. Os modelos diretos visam simular o comportamento dos sistemas de distribuição de água (pressões nos nós e vazões nos 
trechos), tendo conhecidas às características das tubulações e acessórios bem como os dados referentes aos vazamentos. Já os métodos inversos visam detectar a posição e o volume dos vazamentos, conhecendo-se algumas pressões e vazões no sistema (pontos monitorados), através do processo de calibração.

A seguir faz-se uma descrição detalhada das diferentes formulações de vazamentos existentes na literatura e da forma com que tais vazamentos são introduzidos nos modelos de análise hidráulica.

\subsubsection{Formulação matemática de vazamentos através de orifício}

A consideração de vazamentos nas análises de redes hidráulicas surgiu da necessidade de que em média 20 a 50\% (BROTHERS, 2001) de toda água produzida, para fins de abastecimento, é perdida ao longo da distribuição. Em consequência disso, surge também a dificuldade de como introduzi-los nas análises hidráulicas. Vários autores (PUDAR e LIGGETT, 1992; ROSSMAN, 2000; COLOMBO e KARNEY, 2002) ostentam a hipótese de que os vazamentos possam ser representados como orifícios de seção constante.

PORTO (1998) define orifício como sendo uma abertura de perímetro fechado, de forma geométrica definida (circular, retangular, triangular, etc.), realizada na parede ou fundo de um reservatório ou na parede de um canal ou conduto em pressão, pela qual o líquido em repouso ou movimento escoa em virtude da energia potencial e/ou cinética que possui. A expressão geral (lei dos orifícios) para a vazão descarregada através de um orifício de área $\mathrm{A}$, de pequenas dimensões e parede fina, sujeito a uma carga $\mathrm{H}$ é apresentada conforme eq.(2.19).

$$
\mathrm{Q}=\mathrm{C}_{\mathrm{d}} \mathrm{A} \sqrt{2 \mathrm{gH}}
$$

sendo $\mathrm{C}_{\mathrm{d}} \mathrm{o}$ coeficiente de descarga (adimensional); $\mathrm{A}$ à área do orifício (pequenas dimensões e parede fina em $\left.\mathrm{m}^{2}\right)$; g a aceleração da gravidade $\left(\mathrm{m} / \mathrm{s}^{2}\right)$ e $\mathrm{H}$ a carga hidráulica $(\mathrm{m})$.

$\mathrm{Na}$ prática é muito comum estimar porcentagens de vazamentos, considerando áreas de influências, e somá-las nas demandas de referência nos nós ${ }^{3}$. Segundo alguns pesquisadores (COLOMBO e KARNEY, 2002; TODINI, 2003) essa maneira é uma

\footnotetext{
${ }^{3}$ Essa informação foi obtida através de entrevistas realizadas com engenheiros de diversas companhias (SANESUL, ÀGUAS GUARIROBA, SAAE Piracicaba) de saneamento no Brasil.
} 
forma simplificada de considerar vazamentos nas análises hidráulicas. COLOMBO e KARNEY (2002) reportam que a formulação introduzida por ROSSMAN (2000), no Epanet 2, apresenta uma relação mais adequada para tal consideração.

ROSSMAN (2000) sugere que os vazamentos em redes de distribuição de água sejam modelados através da função de orifício (eq. 2.19). Segundo esse pesquisador, os parâmetros $C_{d}$, $A$ e $\sqrt{2 g}$ da eq.(2.19) podem ser agrupados em um único coeficiente $\left(\mathrm{C}_{\mathrm{e}}\right)$, denominado emitter coefficient no Epanet 2, para obter a eq.(2.20).

$\mathrm{QL}_{\mathrm{j}}=\theta_{\mathrm{i}} \mathrm{H}_{\mathrm{i}}^{\mathrm{a}}$

sendo QL o vazamento referente as tubulações i conectadas ao nó j; $\theta$ o coeficiente de vazamento implementado no Epanet $2\left(\mathrm{~m}^{3-\mathrm{a}} / \mathrm{s}\right), \mathrm{H}$ é a pressão média entre os nós extremos da tubulação i (m) e a é o expoente de vazamentos. Observa-se que se o expoente de vazamentos (a) for igual a 0,5, a eq.(2.20) representa a equação de orifícios e tem-se uma área de seção constante, caso contrário, o orifício tem dimensão variável (considera coeficiente de vazamento $(\theta)$ multiplicado pelo comprimento do trecho).

A função apresentada pela eq.(2.20) é definida por dois parâmetros ( $\begin{array}{lll}\theta & \text { e a). } O\end{array}$ coeficiente $\theta$ reflete a dimensão e a forma de um vazamento. O parâmetro a reflete a relação de elasticidade ente a área efetiva de vazamento e a pressão interna atuante na tubulação. Na literatura encontram-se muitas referências (PUDAR e LIGGETT, 1992; ROSSMAN, 2000; COLOMBO e KARNEY, 2002) sugerindo utilizar o valor de a igual a 0,5 , no entanto, essa é uma aproximação simples que admite uma área de seção constante para o orifício.

\subsubsection{Modelação matemática de vazamentos através de seção variável}

Vários modelos matemáticos vêm sendo propostos na literatura para avaliar os vazamentos em sistemas de distribuição de água. Tais modelos são classificados segundo SOARES (2003) em modelos de avaliação global e modelos de avaliações detalhadas e são ilustrados pela Figura 2.3.

A consideração de vazamentos em redes de distribuição de água está diretamente associada à pressão atuante nesses sistemas, sendo que, a taxa de vazamento aumenta proporcionalmente com a elevação de pressão. Assim, GERMANOPOULOS e 
JOWITT (1989) apresentam uma relação (não linear) entre vazamentos e pressão média de serviço conforme eq.(2.21).

$$
\mathrm{QL}_{\mathrm{ij}}=\theta \mathrm{L}_{\mathrm{ij}}\left[(\mathrm{H}-\mathrm{Z})_{\mathrm{i}}-(\mathrm{H}-\mathrm{Z})_{\mathrm{j}}\right]^{\mathrm{a}}
$$

sendo QL o vazamento ocorrendo no elemento de comprimento L entre os nós i e j; $\theta$ o coeficiente de vazamento que depende das características do sistema (idade e deterioração das tubulações e tipo de solo, dentre outras); $\mathrm{H}$ a energia no nó (i ou j); Z a cota topográfica do nó (i ou j) e a o expoente de vazamentos. GERMANOPOULOS e JOWITT (1989) reportaram que esse expoente foi baseado em investigações de campo e deveria ser igual a 1,18 .

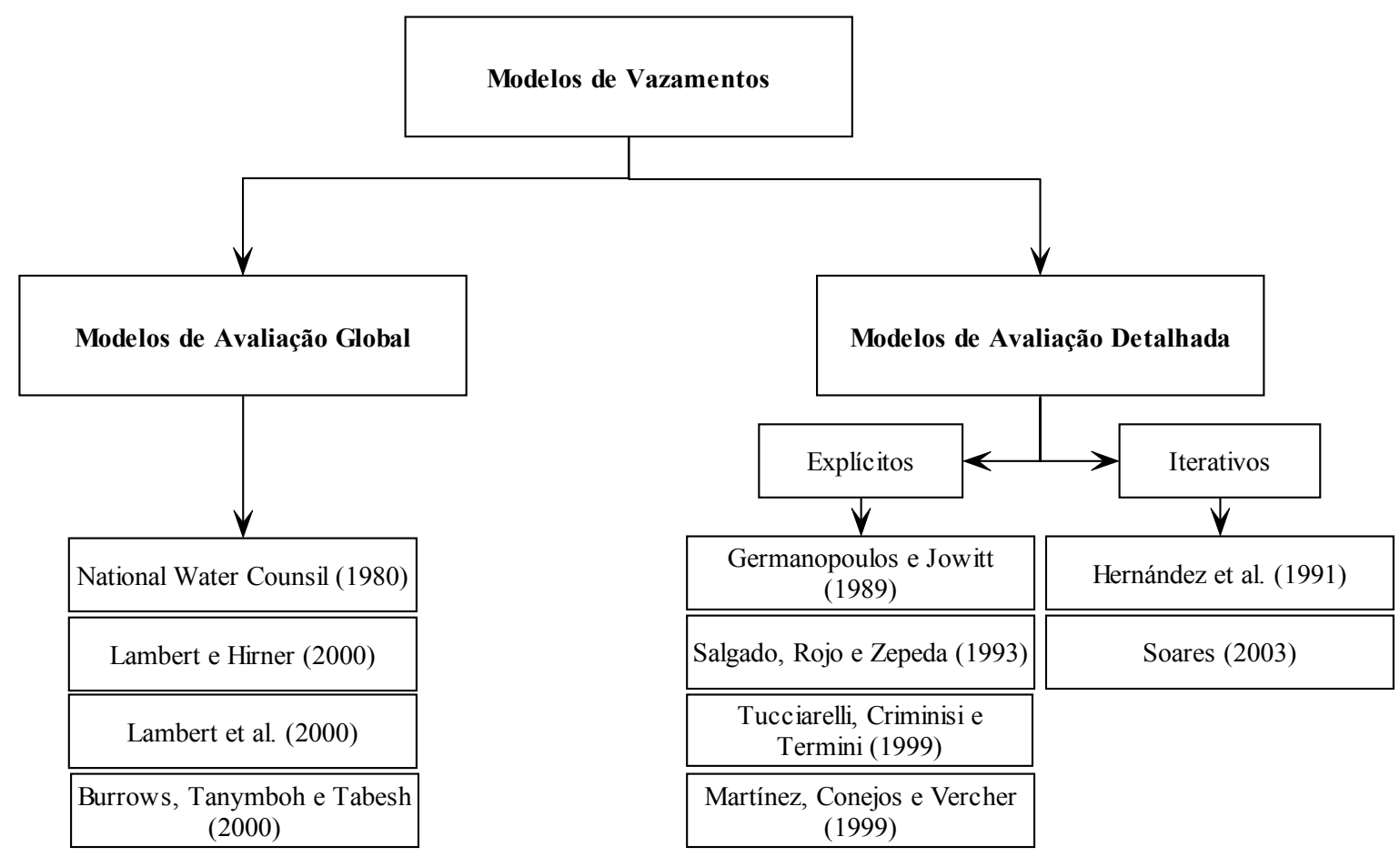

Figura 2.3 - Classificação dos modelos de avaliação de vazamentos

Depois de identificada a vazão referente à parcela de vazamentos em um elemento de rede (por exemplo, uma tubulação), pode-se apresentar então o balanço de massa nodal através da eq.(2.22). Para efeito de modelação matemática, representa-se um vazamento como uma ocorrência nodal, ou seja, o vazamento é dividido entre os nós de montante e jusante.

$$
\sum_{\mathrm{j} \in \mathfrak{\Im}_{\mathrm{i}}} \mathrm{Q}_{\mathrm{ij}}+\mathrm{q}_{\mathrm{i}}+\frac{1}{2} \sum_{\mathrm{j} \in \mathfrak{\Im}_{\mathrm{i}}} \mathrm{QL}_{\mathrm{ij}}=0 \quad \mathrm{i}=1,2, \ldots, \mathrm{NN}
$$


sendo Q a vazão entre os nós i e j; I o conjunto de nós conectado ao nó i; q a demanda no nó i; QL o vazamento na tubulação entre os nós i e j e NN é o número de nós na rede.

Redes de distribuição de água são projetadas e planejadas para atender as demandas atuais e futuras. Pressões excessivas podem ocorrer nos sistemas de distribuição de água, no entanto, para que um serviço seja considerado satisfatório essas pressões devem ser minimizadas, para consequentemente reduzir vazamentos. Foi dessa forma que JOWITT e XU (1990) propuseram uma metodologia para minimizar os vazamentos através do ajuste das válvulas controladoras de vazão na rede. As restrições referentes a esse problema foram o balanço de massa nos nós, os requisitos de energia mínima e o controle de válvulas. Como as equações desse problema são não lineares, o método da teoria linear foi empregado prioritariamente para linearizar as referidas equações, combinado com uma técnica de otimização (programação linear) que apresentava a cada passo aproximações das energias nos nós e das aberturas das válvulas. Vários trabalhos (REIS, PORTO e CHAUDHRY, 1997; VAIRAVAMOORTHY e LUMBERS, 1998) também se destacaram no ajuste de válvulas controladoras de forma a minimizar o vazamento total do sistema.

Estimar perdas por vazamentos em sistemas de distribuição de água é uma tarefa complexa. Os vazamentos referentes às tubulações conectadas em cada nó não são constantes e dependem de ambos os fatores: pressão e parâmetros característicos da rede. TUCCIARELLI, CRIMINISI e TERMINI (1999) propõem um procedimento inverso iterativo em dois passos, para obter uma estimativa dos parâmetros não conhecidos do sistema (coeficiente e expoente de vazamentos). Depois de determinado esses parâmetros característicos, as energias, as vazões e os vazamentos são então obtidos através da simulação hidráulica da rede. Esse procedimento estima as taxas de vazamentos para cada setor de rede (área de vazamentos). Isso pode ser útil na identificação de áreas prioritárias para substituição de tubulações, pois, em muitas situações reais os vazamentos estão diretamente relacionados à deterioração de componentes.

Esses mesmos pesquisadores supõem que as perdas por vazamentos em sistemas de distribuição de água são proporcionais aos fatores característicos (quebras, juntas mal vedadas, tipo de material e solo, qualidade de água, pressão de operação, idade do sistema, práticas incorretas de operação e manutenção) do setor que o nó pertence. Com 
isso, haverá valores característicos, referentes ao expoente de vazamentos (a) e ao coeficiente de vazamentos $(\theta)$, para cada setor de vazamentos da rede em estudo. Segundo esses pesquisadores quando o expoente tem valor mínimo de 0,5 (leis dos orifícios), corresponde a um valor constante de áreas de pequenos vazamentos em torno dos nós. Na formulação de GERMANOPOULOS e JOWITT (1989) esse expoente é maior que 1 (igual a 1,18), que fisicamente significa maiores vazamentos associados com um aumento de pressão. TUCCIARELLI, CRIMINISI e TERMINI (1999) defendem a hipótese de que cada sistema tem seus parâmetros característicos para o modelo de vazamentos, os quais devem ser calibrados para possibilitar uma estimativa razoável. Os vazamentos distribuídos ao longo da superfície das tubulações, propostos por esses autores, são formulados de acordo com a eq.(2.23).

$\mathrm{QL}_{\mathrm{i}}=\left(\mathrm{H}_{\mathrm{i}}-\mathrm{Z}_{\mathrm{i}}\right)^{\mathrm{a}} \sum_{\mathrm{j}=1}^{\Im_{\mathrm{i}}} \frac{\pi}{2} \mathrm{D}_{\mathrm{ij}} \theta_{\mathrm{ij}} \mathrm{L}_{\mathrm{ij}}$

sendo QL o vazamento quantificado do nó i; $\mathrm{H}$ a energia total disponível no nó i; $\mathrm{Z}$ cota topográfica referente ao nó i; a o expoente de perda referente ao setor de vazamentos que o nó i pertence; I é o conjunto de nós cujos trechos são interconectados ao nó i; D e L são o diâmetro e o comprimento, respectivamente dos trechos (j) ligados ao nó i e $\theta$ é a constante de vazamentos, por unidade de superfície de tubulação, do trecho j do nó i. Assumindo-se a variação espacial e temporal dos vazamentos, MARTÍNEZ, CONEJOS e VERCHER (1999) propuseram um modelo dinâmico para simular o comportamento da rede sob um período de 24 horas. Esse modelo incorporou tanto a dependência de pressão dos vazamentos quanto à dependência de pressão das demandas e foi construído utilizando o código do Epanet (ROSSMAN 1994). Em se tratando da modelação de vazamentos, tais pesquisadores consideraram formulações para a parte modelada (tubulações principais do sistema macro ou "esqueleto") e para a parte não modelada (tubulações com diâmetros pequenos, com consumos inferiores a parte modelada).

A formulação considerada por MARTÍNEZ, CONEJOS e VERCHER (1999) para parte modelada da rede é baseada na proposição de GERMANOPOULOS e JOWITT (1989) (eq. 2.21), que assume uma distribuição uniforme dos vazamentos ao longo das tubulações. Entretanto, MARTÍNEZ, CONEJOS e VERCHER (1999) aperfeiçoaram tal formulação pela introdução do conceito de falhas de tubulações. Essa formulação baseia-se no fato de que as perdas por vazamentos na parte modelada da rede podem ser 
consideradas proporcionais ao número de quebras de tubulações (eq. 2.24) durante certo intervalo de tempo.

$\mathrm{N}_{\mathrm{b}}=\mathrm{KLD}^{\mathrm{d}} \mathrm{e}^{\mathrm{a} \tau}$

sendo que $\mathrm{N}_{\mathrm{b}}$ é o número de quebras durante o intervalo $[0, \tau]$; $\mathrm{K}$ é um coeficiente dependente do material, do tipo e da qualidade da instalação; L é o comprimento da tubulação (m); D é o diâmetro da tubulação (m); d é um expoente que recebe o valor igual a 1 se forem tubos de diâmetros pequenos (abaixo de $125 \mathrm{~mm}$ ) e -1 para diâmetros maiores; a é um expoente de ajuste da evolução temporal das quebras e $\tau$ é a idade das tubulações (anos).

A eq.(2.21) pode ser reescrita (eq. 2.25) considerando um grupo de tubulações, de mesmo material e idade, e introduzindo o efeito estatístico do número de quebras na taxa de vazamentos do nó $i$.

$\mathrm{QL}_{\mathrm{i}}=\theta \mathrm{LD}^{\mathrm{d}} \mathrm{e}^{\mathrm{a} \tau}\left[(\mathrm{H}-\mathrm{Z})_{\mathrm{i}}\right]^{1,18}$

As perdas por vazamentos na parte não modelada da rede, segundo MARTÍNEZ, CONEJOS e VERCHER (1999), podem ser maiores que na parte modelada devido ao número elevado de quebras nas tubulações de diâmetros pequenos (rede secundária). A formulação apresentada (eq. 2.26) por esses pesquisadores admite vazamentos referentes à parte não modelada.

$\mathrm{QL}_{\mathrm{i}}=\mathrm{Kq}_{\mathrm{i}}\left[(\mathrm{H}-\mathrm{Z})_{\mathrm{i}}\right]^{\mathrm{a}}$

sendo $\mathrm{K}$ um coeficiente de ajuste global para um setor determinado $\left(\mathrm{m}^{-\mathrm{a}}\right)$; q a demanda no nó i $\left(\mathrm{m}^{3} / \mathrm{s}\right)$ pertencente ao mesmo setor; a o expoente de perda referente ao setor de vazamentos e $\mathrm{H}$ e $\mathrm{Z}$ são respectivamente a carga hidráulica $(\mathrm{m})$ e a cota topográfica do nó i (m).

\subsection{Demandas dependentes da pressão}

A modelação matemática permite que o projeto, a calibração, a reabilitação e a operação de redes hidráulicas possam ser investigados de maneira mais efetiva. A análise de redes realizada com tais propósitos deve satisfazer as equações de continuidade e energia. Trata-se de um problema complexo, face ao caráter não linear dessas equações. A 
técnica clássica para análise de redes é denominada análise dirigida pela demanda (ADD) desde a proposição de Hardy Cross, em 1930. As demandas nos nós são consideradas fixas, e cabe ao modelo determinar as vazões nas tubulações e pressões nos nós, hidraulicamente consistente com atendimento pleno dessas demandas, considerando que os sistemas são fechados e o escoamento ocorre sob pressão.

Em sistemas reais, orifícios e aberturas (vazamentos) estão presentes nos diversos componentes dessas redes (tubulações furadas ou quebradas, conexões com juntas mal vedadas, dentre outros) fazendo com que ocorram as perdas hídricas, denominadas vazamentos distribuídos ou latentes. Assim, se a pressão disponível no sistema for insuficiente, as referidas demandas não serão integralmente atendidas.

Dessa forma, alguns pesquisadores (SALGADO, ROJO e ZEPEDA, 1993; FUJIWARA e LI, 1998; MARTÍNEZ, CONEJOS e VERCHER, 1999; TUCCIARELLI, CRIMINISI e TERMINI, 1999; TABESH e KARIMZADEH, 2000; TANYIMBOH, TABESH e BURROWS, 2001; SOARES, 2003) vêm reexaminando os modelos existentes e afirmando que as demandas nos nós não devem ser fixas, mas variáveis com a pressão disponível na rede. Essas análises são denominadas análises dirigidas pela pressão (ADP).

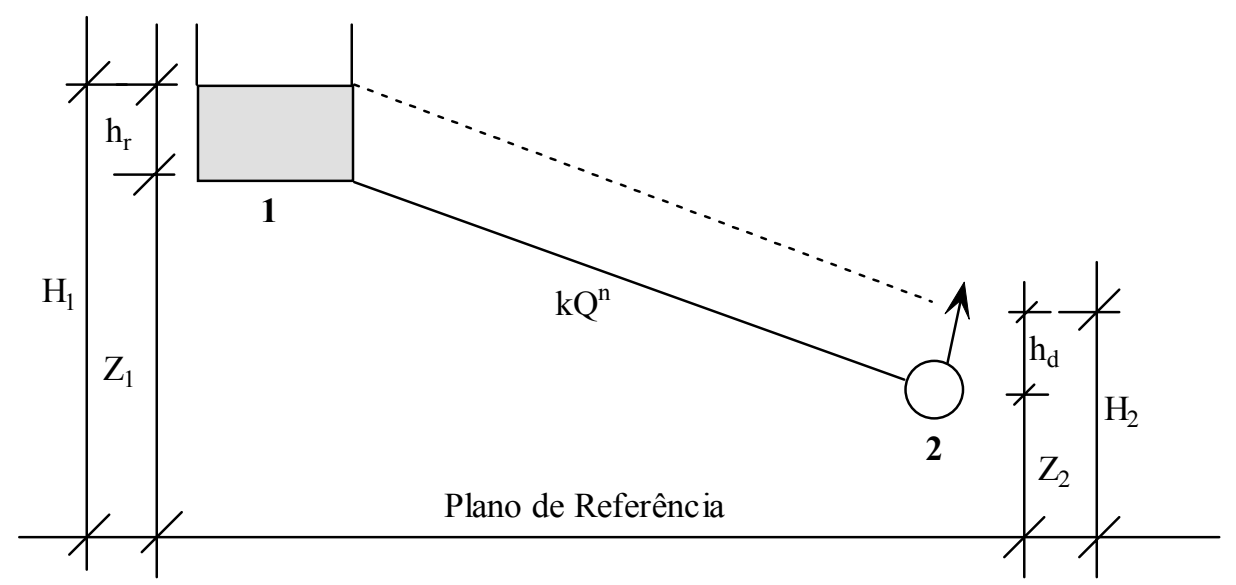

Figura 2.4 - Ilustração hipotética reservatório - nó de consumo

Investigando os diversos sistemas urbanos de distribuição na Índia e observando que a água abastecida à população era menor que a demanda real requerida, CHANDAPILLAI (1991) teceu várias críticas aos modelos de simulação vigentes, dizendo que tais modelos eram incapazes de reproduzir o comportamento do sistema devido à dependência de pressão das demandas nos nós. A Figura 2.4 apresenta a ilustração de tal procedimento através da consideração hipotética de um sistema 
reservatório-consumidor. Pode-se afirmar que a energia disponível no nó de consumo (ponto 2) é descrita conforme a eq.(2.27).

$\mathrm{H}_{2}=\mathrm{Z}_{2}+\mathrm{h}_{\mathrm{d}}$

sendo $\mathrm{H}_{2}$ a energia disponível no ponto $2 ; \mathrm{Z}_{2}$ a cota topográfica do nó no ponto 2 e $\mathrm{h}_{\mathrm{d}} \mathrm{a}$ pressão disponível no ponto 2 na qual pode variar dependendo das características da tubulação que liga os nós 1-2. Considerando a eq. (2.27), pode-se supor $\mathrm{H}_{2}$ em termos de duas condições conforme eq.(2.28).

$\mathrm{H}_{2}=\mathrm{H}^{\mathrm{min}}=\mathrm{Z}_{2}+\mathrm{P}^{\mathrm{min}}$
$\mathrm{H}_{2}=\mathrm{H}^{\text {des }}=\mathrm{Z}_{2}+\mathrm{P}^{\text {des }}$

sendo $\mathrm{H}^{\text {min }}$ e $\mathrm{H}^{\text {des }}$ as energias mínima e desejável, respectivamente; $\mathrm{P}^{\text {min }}$ a pressão mínima e $\mathrm{P}^{\mathrm{des}}$ a pressão desejável.

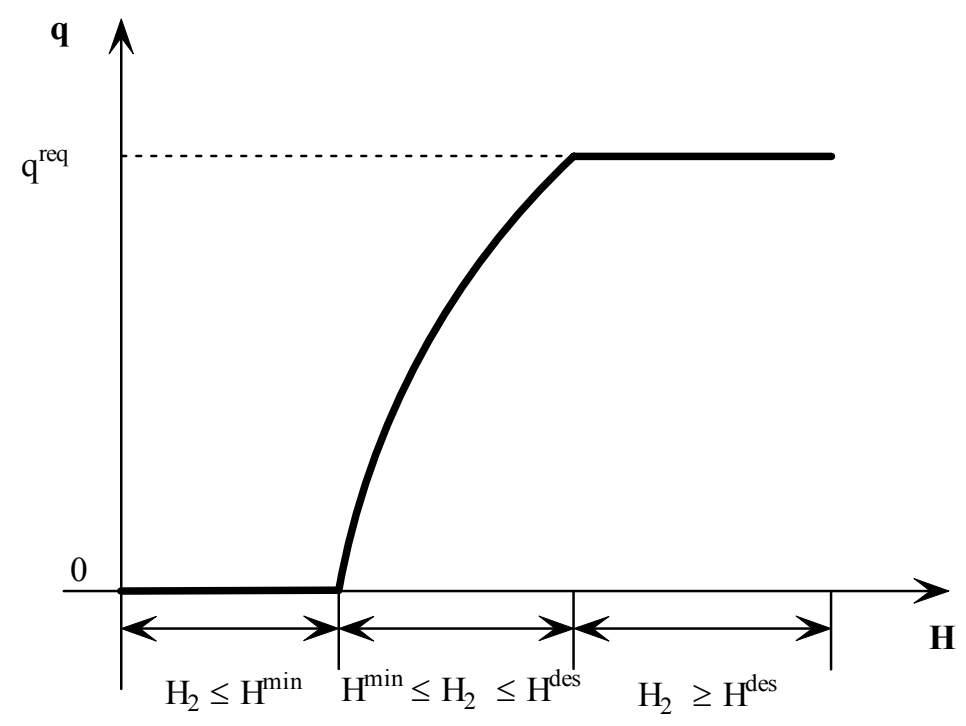

Figura 2.5 - Relação entre energia e vazão

Considerando a situação hipotética apresentada pela Figura 2.4, CHANDAPILLAI (1991) propõe uma relação parabólica (Figura 2.5) entre energia e demanda. Segundo esse autor, se no ponto de consumo (ponto 2) a pressão disponível ( $\mathrm{h}_{\mathrm{d}}$ ), para um dado instante, for menor que a pressão mínima necessária para que haja algum atendimento, a demanda requerida (estimada) para consumo naquele nó não é atendida. Se a pressão disponível estiver entre o valor de pressão mínimo e um valor de pressão desejável (pressão cessária para o atendimento da demanda integral), a demanda é parcialmente atendida. Caso essas duas situações anteriores não se verifiquem, a demanda é 
totalmente atendida. Para a situação onde a demanda (q) é parcialmente atendida, esse pesquisador apresenta uma relação conforme eq.(2.29).

$q_{j}=q_{j}^{r e q}\left(\frac{H_{j}-H_{j}^{\min }}{H_{j}^{\text {des }}-H_{j}^{\min }}\right)^{\frac{1}{n}}$

sendo q a demanda realmente atendida; $\mathrm{q}^{\text {req }}$ a demanda nodal (demanda de projeto, geralmente estimada); $\mathrm{H}$ é a energia do nó $\mathrm{j} ; \mathrm{H}^{\text {min }}$ é a energia mínima necessária para o atendimento parcial da demanda no nó $\mathrm{j}$ e $\mathrm{H}^{\mathrm{des}}$ é a energia desejável para que o atendimento a demanda nodal seja integral.

Uma outra situação a ser considerada é quando a demanda nodal torna-se excessiva em algum ponto da rede devido a uma condição extrema, por exemplo, demanda de incêndio ou quando uma bomba falha ou uma tubulação quebra. Assim, o sistema de distribuição de água torna-se deficiente por não satisfazer todas demandas nodais. Essa situação dificilmente pode ser simulada em modelos dirigidos pelas demandas onde todas as demandas são concentradas nos nós, presumindo que, as demandas nodais sempre sejam satisfeitas. Com base nessas discussões, GUPTA e BHAVE (1996) realizaram uma comparação dos métodos existentes que levam em consideração o não atendimento das demandas nodais devido a uma deficiência de pressão na rede. Segundo esses pesquisadores BHAVE (1981) apud GUPTA e BHAVE (1996) foi um dos pioneiros na introdução da demanda dependente da pressão simultaneamente nas análises hidráulicas. A relação proposta por esse pesquisador é apresentada conforme eq.(2.30).

$$
\begin{array}{lcc}
\mathrm{q}_{\mathrm{j}}=\mathrm{q}_{\mathrm{j}}^{\text {req }} & \text { se } & \mathrm{H}_{\mathrm{j}} \geq \mathrm{H}_{\mathrm{j}}^{\text {min }} \\
0<\mathrm{q}_{\mathrm{j}}<\mathrm{q}_{\mathrm{j}}^{\text {req }} & \text { se } & \mathrm{H}_{\mathrm{j}}=\mathrm{H}_{\mathrm{j}}^{\text {min }} \\
\mathrm{q}_{\mathrm{j}}=0 & \text { se } & \mathrm{H}_{\mathrm{j}} \leq \mathrm{H}_{\mathrm{j}}^{\text {min }}
\end{array}
$$

sendo q a demanda real; $\mathrm{q}^{\text {req }}$ é a demanda concentrada nos nós (demanda de projeto); $\mathrm{H}$ é a energia real disponível no nó $\mathrm{j}$ e $\mathrm{H}^{\mathrm{min}}$ é a energia mínima necessária para o atendimento parcial da demanda no nó j. Para o cálculo da demanda real q, pode ser utilizada a formulação de GERMANOPOULOS (1985) apud GUPTA e BHAVE (1996) 
que sugere uma relação pressão-demanda em função dos parâmetros já citados na eq.

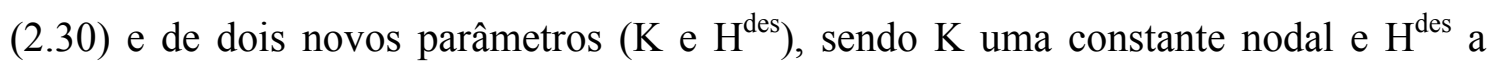
energia necessária para $\mathrm{o}$ atendimento integral da demanda requerida $\left(\mathrm{q}^{\mathrm{req}}\right)$. Essa formulação é apresentada através da eq.(2.31).

$$
\mathrm{q}_{\mathrm{j}}=\mathrm{q}_{\mathrm{j}}^{\text {req }}\left[1-10^{-\mathrm{K}_{\mathrm{j}}\left(\frac{\left(\mathrm{H}_{\mathrm{j}}-\mathrm{H}_{\mathrm{j}}^{\text {min }}\right)}{\left(\mathrm{H}_{\mathrm{j}}^{\text {des }}-\mathrm{H}_{\mathrm{j}}^{\text {min }}\right)}\right)}\right]
$$

A formulação apresentada por WAGNER, SHAMIR e MARKS (1988) e CHANDAPILLAI (1991) sugerem uma relação parabólica para a demanda parcialmente abastecida (q). Essa formulação é ilustrada pela Figura 2.5 e apresentada pela eq.(2.32).

$$
\begin{array}{lll}
\mathrm{q}_{\mathrm{j}}=\mathrm{q}_{\mathrm{j}}^{\text {req }} & \text { se } & \mathrm{H}_{\mathrm{j}} \geq \mathrm{H}_{\mathrm{j}}^{\text {des }} \\
\mathrm{q}_{\mathrm{j}}=\mathrm{q}_{\mathrm{j}}^{\text {req }}\left(\frac{\mathrm{H}_{\mathrm{j}}-\mathrm{H}_{\mathrm{j}}^{\text {min }}}{\mathrm{H}_{\mathrm{j}}^{\text {des }}-\mathrm{H}_{\mathrm{j}}^{\text {min }}}\right)^{\frac{1}{\mathrm{n}}} & \text { se } & \mathrm{H}_{\mathrm{j}}^{\text {min }}<\mathrm{H}_{\mathrm{j}}<\mathrm{H}_{\mathrm{j}}^{\text {des }} \\
\mathrm{q}_{\mathrm{j}}=0 & \text { se } & \mathrm{H}_{\mathrm{j}} \leq \mathrm{H}_{\mathrm{j}}^{\text {min }}
\end{array}
$$

sendo n um coeficiente geralmente igual a 2. Em linhas gerais, pode-se mencionar uma relação de dependência da vazão com a pressão.

Outra observação que deve ser ressaltada é a relação apresentada por BHAVE (1981) apud GUPTA e BHAVE (1996) que apresenta uma função em forma de degrau, ou seja, ou há atendimento integral ou não há atendimento. Já a formulação apresentada de WAGNER, SHAMIR e MARKS (1988) e de CHANDAPILLAI (1991) propõe uma função mais suave (relação parabólica) para as os nós com energias entre a mínima e a desejável (eq. 2.31). Essa proposição, fisicamente, é mais real, pois, se há energia no nó alguma parcela de demanda está sendo abastecida.

Um procedimento geral iterativo para analisar a relação demanda-pressão é apresentado por GUPTA e BHAVE (1996). Segundo esses pesquisadores essa análise pode ser dividida em quatro passos. 
Passo 1 - Inicialmente simula-se a condição em regime permanente considerando as demandas de entrada $\left(\mathrm{q}^{\mathrm{k}}\right)$ e obtêm-se as energias $\left(\mathrm{H}^{\mathrm{k}}\right)$ nodais referentes;

Passo 2 - Com os valores de $\mathrm{H}^{\mathrm{k}}$, corrige-se as demandas $\left(\mathrm{q}^{\mathrm{k}+1}\right)$ através da eq.(2.31) ou da eq. (2.32);

Passo 3 - Com os novos valores de demanda $\left(\mathrm{q}^{\mathrm{k}+1}\right)$, simula-se novamente a rede e obtêm-se os novos valores de $\mathrm{H}^{\mathrm{k}+1}$;

Passo 4 - Comparam-se os valores de $\mathrm{H}^{\mathrm{k}+1} \operatorname{com~} \mathrm{H}^{\mathrm{k}}$ e os valores de $\mathrm{q}^{\mathrm{k}+1} \operatorname{com} \mathrm{q}^{\mathrm{k}}$, e se não verificarem diferenças significativas, volta-se ao passo 1 calculando-se novos valores para q com as energias de $\mathrm{H}^{\mathrm{k}+1}$. Caso contrário a convergência é satisfeita.

Para investigar a eficiência e adequação dos métodos GUPTA e BHAVE (1996) compararam os métodos (eq. 2.30 e 2.32) em uma pequena rede em série de quatro trechos e um reservatório, e concluíram que, o método que utiliza a relação parabólica para a relação demanda-pressão foi o que apresentou os melhores resultados através de análises de regressão.

Um sistema de distribuição de água é considerado confiável quando, para cada nó, todas demandas impostas são atendidas com energia acima do limite de serviço. Se, porventura, alguma falha ocorrer no sistema (quebra de tubulações, parada de bombas, reparo na rede), e as demandas impostas não forem atendidas devido a alguma insuficiência de pressão, o sistema apresentará confiabilidade baixa.

Percebe-se, portanto, que modelos de simulação dirigidos pela demanda não são adequados para analisar a confiabilidade de redes em termos do atendimento nodal. Dessa forma, FUJIWARA e LI (1998) propuseram um método de programação de metas para analisar a confiabilidade de redes de distribuição de água considerando algumas situações de falhas. Tais pesquisadores reportam a necessidade de se incorporar demandas dependentes da pressão nos modelos de simulação hidráulica nas análises de confiabilidade. Uma das principais contribuições desse trabalho se refere à função demanda-pressão proposta, descrita pela eq. (2.33). Essa função (eq. 2.33) por ser diferenciável em seus pontos de inflexão, apresenta vantagens frente às outras funções descritas (eqs. 2.31 e 2.32), além de ser facilmente incorporada nos métodos de otimização que se baseiam no gradiente da função (matrizes jacobianas).

Incorporar demanda variável com a pressão nos modelos de simulação hidráulica para avaliar a confiabilidade hidráulica dos sistemas de distribuição de água tem sido uma 
tendência recente, pois estabelece uma situação mais real em termos das variáveis de estado (energias e vazões). Por exemplo, alguns pesquisadores (TUCCIARELLI, CRIMINISI e TERMINI, 1999; SOARES, 2003) vêm considerando tais análises na calibração de modelos de redes hidráulicas.

$$
\begin{array}{lll}
\mathrm{q}_{\mathrm{j}}=\mathrm{q}_{\mathrm{j}}^{\text {req }} & \text { se } & \mathrm{H}_{\mathrm{j}} \geq \mathrm{H}_{\mathrm{j}}^{\text {des }} \\
\mathrm{q}_{\mathrm{j}}=\mathrm{q}_{\mathrm{j}}^{\text {req }} \frac{\left(\mathrm{H}_{\mathrm{j}}-\mathrm{H}_{\mathrm{j}}^{\text {min }}\right)^{2}\left(3 \mathrm{H}_{\mathrm{j}}^{\text {des }}-2 \mathrm{H}_{\mathrm{j}}-\mathrm{H}_{\mathrm{j}}^{\text {min }}\right)}{\left(\mathrm{H}_{\mathrm{j}}^{\text {des }}-\mathrm{H}_{\mathrm{j}}^{\text {min }}\right)^{3}} & \text { se } & \mathrm{H}_{\mathrm{j}}^{\text {min }}<\mathrm{H}_{\mathrm{j}}<\mathrm{H}_{\mathrm{j}}^{\text {des }} \\
\mathrm{q}_{\mathrm{j}}=0 & \text { se } & \mathrm{H}_{\mathrm{j}} \leq \mathrm{H}_{\mathrm{j}}^{\text {min }}
\end{array}
$$

A formulação (eq. 2.34) proposta por TUCCIARELLI, CRIMINISI e TERMINI (1999) mostra-se adequada para efeito da modelação matemática, pois as funções são contínuas e finitas.

$$
\begin{array}{lll}
\mathrm{q}_{\mathrm{j}}=\mathrm{q}_{\mathrm{j}}^{\text {req }} & \text { se } & \mathrm{H}_{\mathrm{j}} \geq \mathrm{H}_{\mathrm{j}}^{\text {des }} \\
\mathrm{q}_{\mathrm{j}}=\mathrm{q}_{\mathrm{j}}^{\text {req }} \operatorname{sen}^{2}\left(\frac{\mathrm{H}_{\mathrm{j}}-\mathrm{Z}_{\mathrm{j}}}{\left.2 \mathrm{H}_{\mathrm{j}}^{\text {des }} \pi\right)}\right. & \text { se } & 0<\mathrm{H}_{\mathrm{j}} \leq \mathrm{H}_{\mathrm{j}}^{\text {des }} \\
\mathrm{q}_{\mathrm{j}}=0 & \text { se } & \mathrm{H}_{\mathrm{j}} \leq 0
\end{array}
$$

Diferentes níveis piezométricos (patamares de pressão) caracterizam o escoamento nas redes de distribuição de água durante as 24 horas de um dia típico. Por exemplo, em períodos diurnos as demandas são elevadas, e com isso, as pressões são baixas. Em períodos noturnos acontece o inverso, as demandas são menores (baixo consumo) e as pressões tornam-se elevadas (favorecendo vazamentos). Baseando-se nessas hipóteses, MARTÍNEZ, CONEJOS e VERCHER (1999) propuseram um modelo para descrever o comportamento dinâmico de redes de distribuição de água considerando a dependência de pressão (variável de estado) das demandas e dos vazamentos, para diferentes situações operacionais. Esse modelo matemático de vazamentos e de demandas foi incorporado de forma direta no código do Epanet (ROSSMAN, 1994). Esse pacote computacional é baseado no método convencional de análise de redes (ADD). A formulação de vazamentos utilizada por esses pesquisadores já foi discutida no sub item 
(2.2.2). A formulação que descreve a relação demanda-pressão é apresentada conforme eq.(2.35).

$\mathrm{q}_{\mathrm{i}}=\mathrm{K}_{\mathrm{i}}\left[\left(\mathrm{H}_{\mathrm{i}}-\mathrm{Z}_{\mathrm{i}}\right)-\left(\mathrm{H}_{\mathrm{i}}-\mathrm{H}_{\mathrm{i}}^{\mathrm{min}}\right)\right]^{\mathrm{n}}$

sendo K um coeficiente de ajuste global, por setor, para o nó i; q a demanda no nó i, H a energia disponível no nó $\mathrm{i} ; \mathrm{Z}$ a cota topográfica do nó $\mathrm{i}$ e $\mathrm{H}^{\mathrm{min}}$ a energia mínima necessária para o atendimento de uma determinada parcela de demanda e $\mathrm{n}$ um expoente que depende das características do setor. MARTÍNEZ, CONEJOS e VERCHER (1999) encontraram um valor para o expoente $n$ igual a 0,21 . A determinação desse expoente baseou-se em investigações de campo na cidade de Valência (Espanha), entretanto, não há descrições desse procedimento na literatura.

Uma das formas de identificar características (rugosidades absolutas das tubulações, demandas nos nós, acessórios presentes, mas que não se encontram nos dados cadastrais, diâmetros de tubulações, dentre outros) das redes de distribuição de água é utilizar procedimentos de calibração (WALSKI, 1983; BHAVE, 1988; ORMSBEE, 1989; BOULOS e WOOD, 1990; LANSEY e BASNET, 1991; DATTA e SRIDHARAN, 1994; DE SCHAETZEN et al., 2000; GAMBALE, 2000; CHEUNG, 2001; RIGHETTO, 2001; CALIMAN, 2002; KAPELAN, SAVIC e WALTERS, 2002; SILVA, 2003; SOARES, 2003). Tais procedimentos fornecem uma estimativa de parâmetros do sistema, não conhecidos ou alterados (idade avançada), para que em uma etapa posterior, o seu comportamento operacional possa ser avaliado de modo mais real. Grande parte desses modelos utilizou a análise convencional de redes (ADD) e não incorporou a dependência de pressão dos vazamentos e das demandas. No entanto, três trabalhos (CALIMAN, 2002; SILVA, 2003; SOARES, 2003), do conjunto ora citado, são exceções.

Por exemplo, CALIMAN (2002) propôs uma metodologia para calibração do modelo pressão-vazamento e aplicou essa metodologia em uma rede real da cidade de São Carlos, SP. SILVA (2003) propôs um modelo de calibração em dois passos cujo primeiro passo calibrava as rugosidades absolutas e o segundo passo calibrava os parâmetros de vazamentos, através da rotina computacional, proposta por CALIMAN (2002). 
Por fim, SOARES (2003) desenvolveu uma metodologia de calibração que incluía tanto a relação pressão-vazamento quanto à relação pressão-demanda. Os parâmetros calibrados nesse modelo foram: rugosidades absolutas, demandas, diâmetros, cotas topográficas e parâmetros do modelo de vazamentos além de localizar singularidades hidráulicas na rede.

Segundo HARRIS (1984), a calibração é uma técnica de determinação dos parâmetros do modelo (rugosidades, demandas, diâmetros, dentre outros) através de medições das variáveis de estado (energia ou vazão) em pontos estratégicos das redes de distribuição de água. A identificação desses parâmetros geralmente é realizada com auxílio de técnicas de otimização que minimizam a diferença entre os valores observados (reais) e os valores simulados. SOARES (2003) utilizou a técnicas dos algoritmos genéticos em conjunto com um algoritmo de busca baseado no método simplex.

A Figura 2.6 apresenta o algoritmo iterativo proposto por SOARES (2003) para as avaliações hidráulicas considerando demanda e vazamentos dependentes da pressão. Esse pesquisador investigou várias formulações da relação pressão-demanda e conclui que a formulação (eq. 2.34) apresentada por TUCCIARELLI, CRIMINISI e TERMINI (1999) consumiu menor tempo computacional e para efeito de modelação é a melhor. Em relação à formulação de vazamentos, a eq.(2.23) apresenta vantagens por considerar vazamentos por área de superfície de tubo, ao contrário de outras formulações (GERMANOPOULOS e JOWITT, 1989) que consideram perdas por comprimento.

A maior dificuldade na avaliação de vazamentos é distinguir a parcela de água (demanda) consumida e a parcela de vazamentos, dada uma vazão real conhecida (abastecida). O algoritmo proposto por SOARES (2003) faz essa distinção partindo do princípio que a vazão real abastecida é a soma das demandas mais a vazamentos (eq. 2.36).

$\mathrm{TS}=\mathrm{TD}+\mathrm{V}$

sendo que TS é a vazão total abastecida (conhecida); TD é o somatório da demanda total efetivamente abastecida e $\mathrm{V}$ é o vazamento total.

As demandas variam espacialmente e temporalmente, entretanto supondo-se que todos os nós possuam o mesmo padrão temporal (FT) para toda rede e que a demanda potencial de referência é definida como sendo a multiplicação desse fator temporal pelo 
somatório das demandas nos nós (demandas de referência), pode-se escrever a eq.(2.37).

$\mathrm{TDP}=\mathrm{FT} . \mathrm{TS}^{\mathrm{ref}}$

sendo TDP a demanda total potencial de referência; FT o fator temporal e $\operatorname{TS}^{\text {ref }}$ a demanda de referência nos nós (demanda concentrada). Assim, pode-se definir a demanda potencial total como sendo a soma demanda total potencial (2.38) menos a parcela (PDNA) de deixa que ser atendida devido às restrições de pressão (modelo pressão-demanda).

$\mathrm{TD}=\mathrm{TDP}-\mathrm{PDNA}$

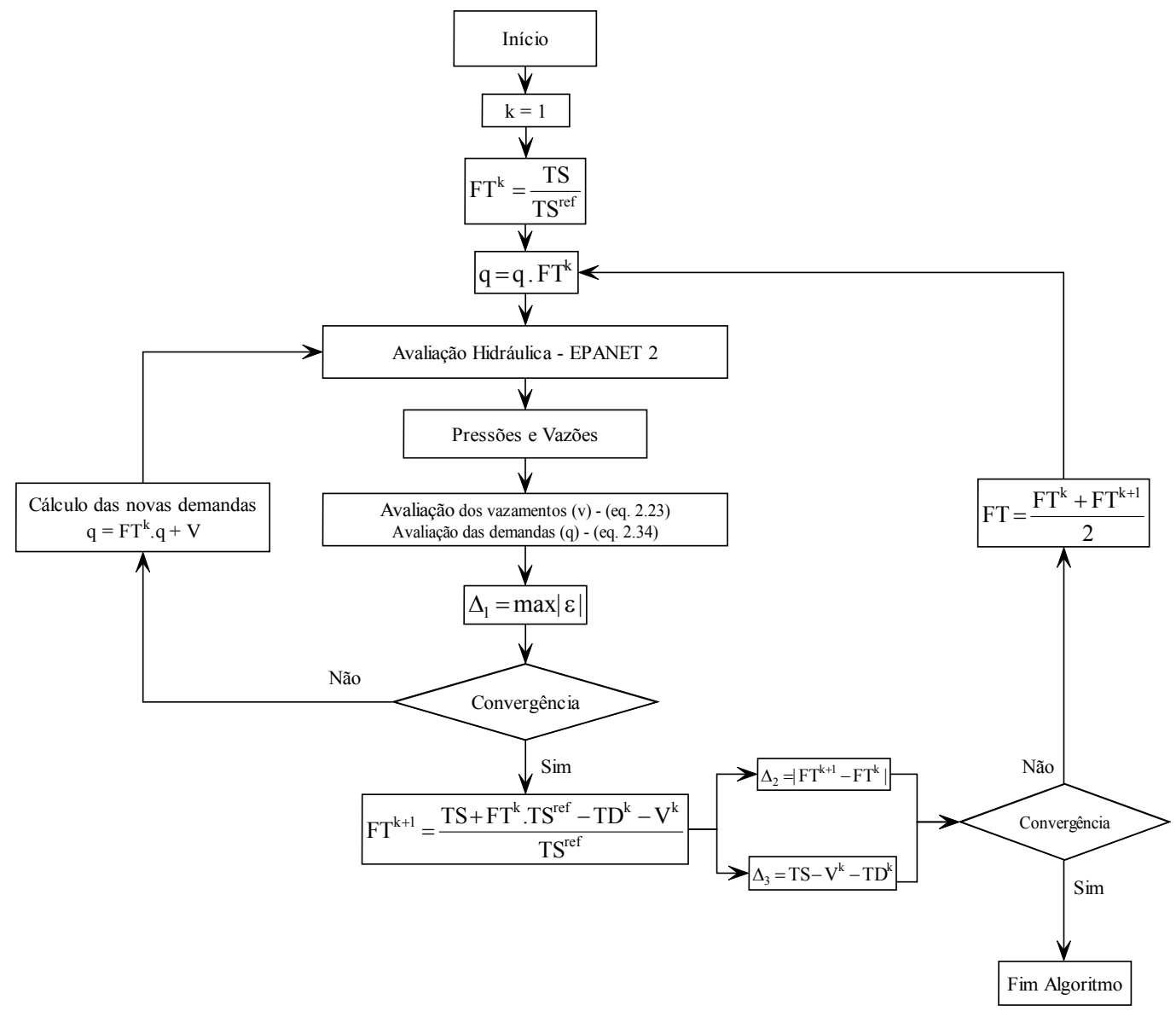

Figura 2.6 - Algoritmo iterativo de avaliação hidráulica (proposto por SOARES, 2003)

Substituindo as eqs.(2.37) e (2.38) na eq.(2.36), obtém-se a eq.(2.39).

$\mathrm{FT}=\frac{\mathrm{TS}+\mathrm{PDNA}-\mathrm{V}}{\mathrm{TS}^{\mathrm{ref}}}$ 
sendo que para o passo inicial $(\mathrm{k}=1) \mathrm{FT}$ é igual a TS/TS ${ }^{\text {ref }}$, ou seja, sem vazamentos. Para os passos posteriores $(\mathrm{k}+1)$ o fator multiplicador e calculado conforme eq.(2.40).

$\mathrm{FT}^{\mathrm{k}+1}=\frac{\mathrm{TS}+\mathrm{FT}^{\mathrm{k}} \cdot \mathrm{TS}^{\mathrm{ref}}-\mathrm{TD}^{\mathrm{k}}-\mathrm{V}^{\mathrm{k}}}{\mathrm{TS}^{\mathrm{ref}}}$

A Figura 2.7 apresenta o fluxograma do algoritmo de calibração proposto por SOARES (2003). Essa metodologia utiliza um procedimento híbrido entre um algoritmo de busca global (algoritmos genéticos) e um algoritmo de busca local baseado no método simplex. Segundo SOARES (2003), a hibridação além de poupar esforço computacional, permite um melhor refinamento da solução final.

O próximo item apresenta uma revisão bibliográfica dos modelos de reabilitação propostos na literatura. Esses modelos são classificados em modelos estatísticos e modelos baseados nas técnicas de análise de sistemas.

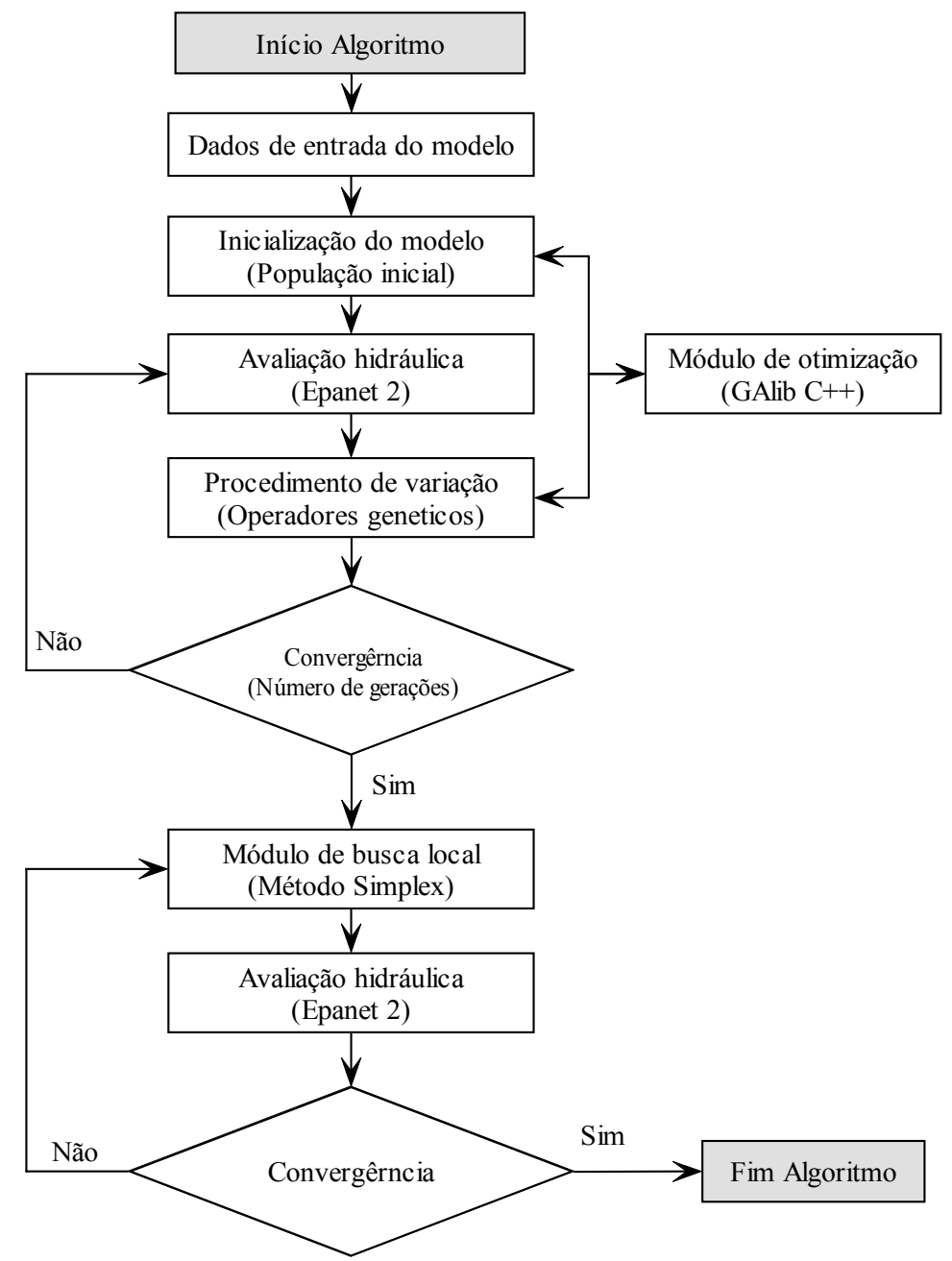

Figura 2.7 - Algoritmo híbrido de calibração (proposto por SOARES, 2003) 


\section{MODELOS DE REABILITAÇÃO}

Este capítulo enfoca os modelos de reabilitação de sistemas de distribuição de água para abastecimento existentes na literatura. Os mesmos podem ser classificados em dois grupos, o primeiro visa reabilitar componentes individuais da rede sem se preocupar com a análise hidráulica do sistema e são baseados em técnicas estatísticas. Já o segundo grupo identifica os componentes da rede que devem ser reabilitados, considerando a avaliação hidráulica do sistema e são baseados em técnicas de análise de sistemas. Os modelos pertencentes ao segundo grupo vêm sendo extensivamente investigados na literatura, ao longo dos anos, e utilizam técnicas de programação matemática como métodos de resolução. No entanto, as soluções apresentadas por esses métodos vêm sendo questionadas por não apresentarem flexibilidade de escolha da melhor alternativa, pois, geralmente são baseados na otimização de objetivo único, na qual gera apenas uma solução como reposta. Recentemente, pesquisadores têm apontado que o planejamento de sistemas urbanos não deve considerar um único objetivo no processo de decisão; objetivos múltiplos existem e devem ser incorporados nas análises. A seguir, apresenta-se uma breve revisão dos trabalhos encontrados na literatura relativos aos dois grupos, ora citados.

\subsection{Considerações gerais}

A reabilitação de sistemas de distribuição de água é uma prática antiga e comum que vem sendo desenvolvida desde a implantação dos primeiros núcleos urbanos servidos de redes de distribuição. Muitas reabilitações já foram realizadas na antiguidade, principalmente em civilizações que sofreram conflitos históricos (guerras), no entanto, a reabilitação só se consolidou como uma técnica científica com o surgimento das tubulações de ferro fundido.

A história retrata que as primeiras tubulações de ferro utilizadas para transportar água foram implantadas na Alemanha, especificamente, no castelo de Dillenburg em 1455; em Logensalya em 1562 e em Braunfels em 1661. Um fato histórico marcou o início do 
processo de reabilitação de sistemas de distribuição de água, quando em 1810, todas as tubulações de madeira, na cidade de Thames (Inglaterra), foram substituídas por tubulações de ferro fundido. Outra ocorrência marcante foi à substituição da tubulação principal que compunha o sistema de Braunfels, em 1932, por uma tubulação de maior diâmetro, após seus 271 anos de uso (SKEAT, 1961).

Após a revolução industrial, o crescimento populacional e a demanda por água elevaram-se no meio urbano, afetando os sistemas de distribuição de água existentes. Assim, as redes começaram a ser expandidas e modificadas com o propósito de transportar água aos consumidores de maneira eficiente. O desafio da época foi dimensionar sistemas redundantes, de forma possibilitar que parte da população continuasse recebendo água, caso ocorresse alguma falha no sistema. Isso foi conseguido com a proposição e construção de redes em circuitos fechados. Foi então nessa época que os primeiros modelos para análises de redes, também denominados simuladores hidráulicos, foram propostos (McLROY, 1950; SURYAPRAKASAN, REID e GEYER, 1950).

Durante muitos anos os sistemas de distribuição de água para abastecimento foram projetados sem auxílio de computador. Entretanto, recentemente, WALSKI et al. (2003) citam três vantagens dos modelos computacionais. Primeiro, os cálculos manuais de redes são extensos e tediosos e fazem com que os projetistas fixem previamente decisões a serem perseguidas. Segundo, os modelos computacionais podem incorporar com facilidade as complexidades do sistema real (bombas, válvulas, demanda variável com a pressão, vazamentos, dentre outros). Finalmente, a rapidez desses modelos fornece aos projetistas possibilidades de se avaliar várias alternativas sob várias condições, conferindo robustez aos projetos.

As aplicações dos modelos matemáticos para análise, operação e reabilitação de redes são dependentes da qualidade dos dados de entrada. O comportamento e as características de tais sistemas são dinâmicos, uma vez que mudam ao longo do tempo devido ao crescimento das demandas e a alteração nas rugosidades das tubulações que alteram a capacidade hidráulica da rede. Assim, tais análises só podem ser realizadas a contento se efetuadas para sistemas calibrados. Para que isso ocorra, a verdade de campo deve ser conhecida através de valores reais para os parâmetros de demandas, diâmetros, rugosidades, dentre outros. A etapa de calibração é imprescindível, geralmente é obtida através de métodos inversos, ou seja, minimização dos desvios 
entre os dados observados e os respectivos valores simulados. Vários modelos de calibração estão disponíveis na literatura (WALSKI, 1983; BHAVE, 1988; ORMSBEE, 1989; BOULOS e WOOD, 1990; LANSEY e BASNET, 1991; DATTA e SRIDHARAN, 1994; DE SCHAETZEN et al., 2000; GAMBALE, 2000; CHEUNG, 2001; RIGHETTO, 2001; CALIMAN, 2002; KAPELAN, SAVIC e WALTERS, 2002; SILVA, 2003; SOARES, 2003).

Recentemente, CHEUNG (2001) realizou uma comparação dos métodos clássicos de calibração de redes hidráulicas que ajustam simultaneamente os fatores de rugosidade e as demandas nos nós. $\mathrm{O}$ autor argumentou sobre a necessidade de utilização de algoritmos que determinem os melhores pontos de amostragem no sistema para obtenção de dados observados e apresentou uma generalização do algoritmo de calibração explícito proposto por BOULOS e WOOD (1990). Esse algoritmo foi baseado na técnica de Newton-Raphson, acoplado com o simulador hidráulico proposto por SOUZA (1994).

Depois que os dados são calibrados, os modelos computacionais podem ser utilizados para diversas finalidades, principalmente para auxiliar no dimensionamento ótimo de componentes da rede, seja no projeto de expansão, operação ou reabilitação. Tais dimensionamentos referem-se a novos diâmetros, ao ajuste das aberturas de válvulas, aos níveis de reservatórios, as decisões de reabilitação (limpeza, duplicação, substituição), dentre outros.

Vários modelos matemáticos já foram desenvolvidos para otimizar os sistemas de distribuição de água para abastecimento, cujos aperfeiçoamentos na busca de soluções mais elaboradas, são devidos aos esforços de diversos pesquisadores. As técnicas de simulação e programação matemática que foram empregadas no passado consideraram critérios pautados em análises do tipo custo/benefício. No princípio, essas técnicas visavam os projetos de abastecimento urbano e tinham como objetivo principal à minimização de custos. Com o decorrer do tempo e devido à idade avançada dos elementos que compõe as redes hidráulicas, as referidas técnicas começaram a ser desenvolvidas e aplicadas nos programas de reabilitação, pois os problemas de perdas de água e o colapso nas tubulações tornaram-se frequentes, reduzindo a qualidade do serviço e a água abastecida. Como consequências de tais fatos pode-se apontar a elevação dos custos de manutenção e operação, refletindo-se diretamente na insatisfação dos usuários. 
Os custos citados podem ser substanciais em uma análise de decisão, pois uma quantia de capital elevada é necessária para restabelecer e manter níveis adequados de serviços, em função dos fundos limitados de investimentos disponíveis no setor. As medidas adotadas para o problema geralmente são paliativas, tornando o processo de decisão uma área de grande interesse para reabilitação e/ou expansão dos sistemas. Nesse sentido, muitos pesquisadores têm estudado o estado das redes hidráulicas e as respectivas estratégias de manutenção e recuperação, visando alocação ótima de recursos financeiros limitados.

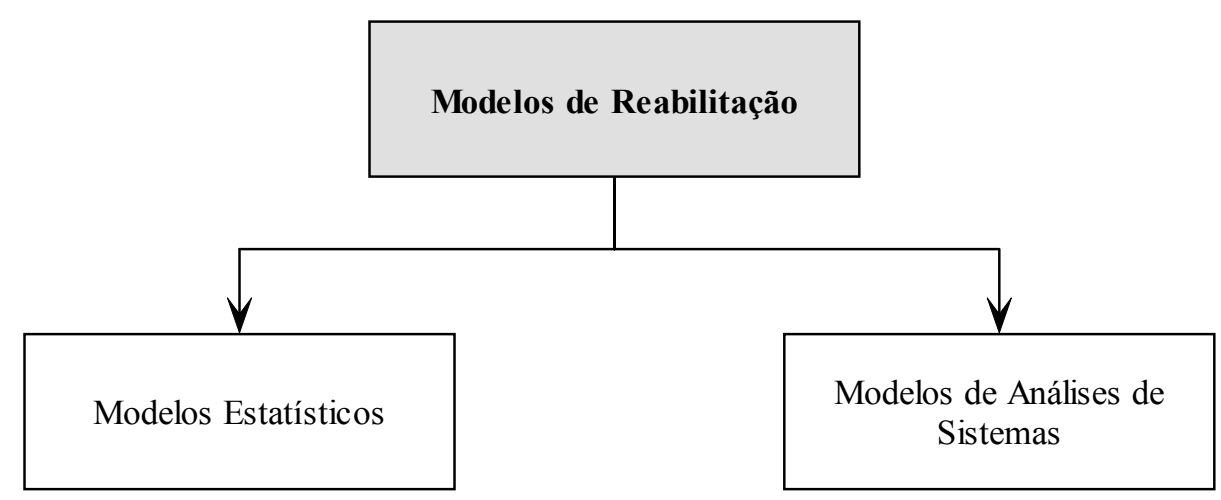

Figura 3.1 - Classificação dos modelos de reabilitação de redes hidráulicas (adaptado de DANDY e ENGELHARDT, 2001a)

A literatura reporta diversos modelos de decisão desenvolvidos para analisar o problema de reabilitação de redes. As complexidades que tais modelos variam de acordo com sua utilização. Esses modelos são classificados em modelos estatísticos e modelos de análises de sistemas (Figura 3.1), apresentados nos próximos itens deste trabalho.

\subsection{Modelos de estatísticos}

Os modelos de estatísticos identificam os componentes das redes hidráulicas que devem ser reabilitados individualmente, sem considerar os efeitos globais causados na rede decorrentes dessas mudanças. A maioria desses modelos baseia-se em estudos de caso isolados e específicos, utilizando como informações, o ciclo de vida dos componentes e os dados históricos disponíveis referentes aos reparos dos sistemas.

O ciclo de vida de componentes, descrito por AGGARWAL (1993), pode ser representado pelas diferentes etapas caracterizadas por taxas de falhas distintas, conforme é ilustrado na Figura 3.2. A fase prematura é o período em que os componentes exibem taxa de falhas elevada. Nessa fase, as mesmas ocorrem devido a erros de instalação e a defeitos de fabricação. Nas indústrias eletrônica e mecânica, por 
exemplo, essa fase é evitada através do funcionamento exaustivo desses componentes sob um certo período de tempo nos laboratórios de testes da própria indústria. Isto justifica o fato de vários modelos estatísticos considerarem apenas a fase final da curva do ciclo de vida, geralmente ajustado a um modelo exponencial, em suas análises. No entanto, para tubulações este procedimento não é possível. As falhas, nessa fase, ocorrem e não podem ser evitadas, pois estão relacionadas às instalações inadequadas, ao tipo de solo, as tensões de transporte, a falhas de fabricação, as condições transientes, dentre outras. As falhas em tubulações só podem ser identificadas a partir do instante em que estas se encontram no próprio local de operação.

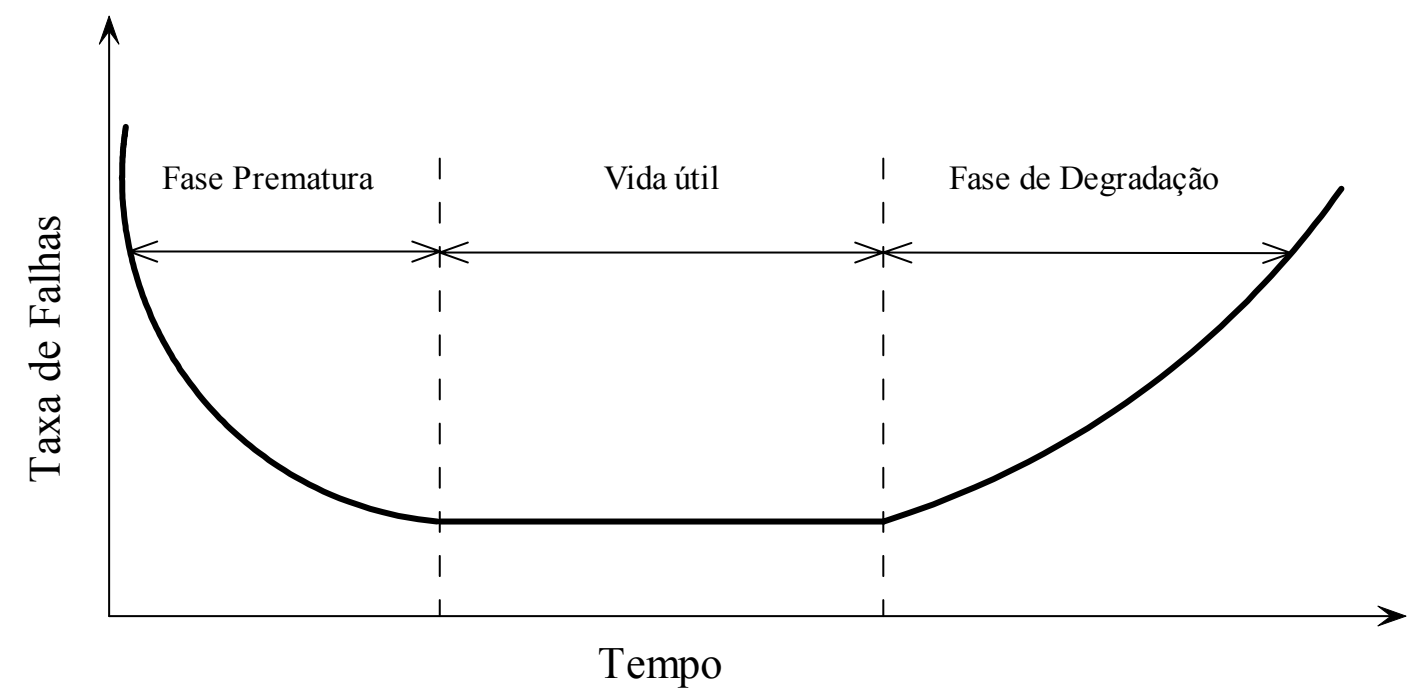

Figura 3.2 - Ciclo de vida de componentes (AGGARWAL, 1993)

O segundo período da curva do ciclo de vida, denominado vida útil, é caracterizado pela taxa constante. Nessa fase os componentes falham por efeitos aleatórios, denominados também efeitos catastróficos, ou pela interferência da terceira fase. Nesse período as falhas podem ser previstas através da geração de cenários sintéticos aleatórios seguindo uma distribuição estatística (AGGARWAL, 1993).

Finalmente, na fase de degradação, as falhas ocorrem principalmente devido à idade avançada das tubulações e demais componentes hidráulicos, em consequência das novas regras operacionais e da exposição ao meio em que se encontram. As falhas nesse período só podem ser evitadas através da manutenção do sistema, que envolve substituições, reparos e reforços de componentes deteriorados.

ASCHER e FEINGOLD (1984) classificaram a curva de ciclo de vida (curva representativa que relaciona a taxa de falhas de tubulações contra o tempo - a vida útil de operação de componentes) em unidades reparáveis ou não reparáveis. Se a unidade 
for não reparável, a curva descreve a probabilidade de falha instantânea (função de risco) em relação ao tempo, pois os modelos são dedicados à obtenção do período entre falhas. Se a unidade for reparável, a curva descreve a taxa de ocorrência de falha em relação ao tempo. Geralmente, os componentes de sistemas de distribuição de água são tratados como unidades reparáveis (MAYS et al., 1989), ou seja, podem ser colocados em serviço novamente, após reparos terem sido realizados.

Assim, antes de apresentar os modelos de reabilitação, é necessário definir falhas em sistemas de distribuição de água que, de modo geral, é qualquer fenômeno que ocasiona uma deficiência em termos de pressão e vazão nas redes hidráulicas. Segundo CULLINANE, LANSEY e MAYS (1992), essas falhas podem ser mecânicas ou hidráulicas. As falhas hidráulicas são decorrentes de diversos fatores, dentre os quais pode-se citar: o aumento de demandas nos nós (crescimento populacional), o aumento da rugosidade das tubulações (idade das redes), os vazamentos distribuídos (construção, tráfego, solo, dentre outros) e a falta de energia elétrica (desligamento de bombas). Já as falhas mecânicas são decorrentes de quebras dos componentes hidráulicos como bombas, válvulas e tubulações. Esses rompimentos são ocasionados por diversos fatores. Os mais comuns são: as pressões elevadas (interrupções da rede e transientes hidráulicos), os eventos catastróficos (movimentos sísmicos), os defeitos de fábrica desses componentes e as tensões elevadas (tráfego sob o sistema).

Devido às falhas hidráulicas ou mecânicas interferirem diretamente nos ciclos de vida dos componentes, alguns modelos apresentados posteriormente consideram as três fases da curva apresentada na Figura 3.2, enquanto outros, consideram apenas uma ou duas fases. PELLETIER, MAILHOT e VILLENEUVE (2003) classificam os modelos de falhas em três categorias: físicos, descritivos e de previsão.

Os modelos físicos consistem em analisar os fenômenos físicos que provocam falhas nas tubulações tais como: corrosão interna e externa, tensões de tráfego sobre a rede, tipo de solo, qualidade da água. RAJANI e KLEINER (2001) apresentam uma revisão completa desses modelos.

Os modelos descritivos têm objetivo de quantificar os parâmetros estatísticos que servem como indicador de padrões e tendências das quebras. Tais análises só podem ser desenvolvidas em sistemas que contém uma base de dados, com as características das tubulações e os registros históricos das quebras, completo. Por essa razão, existem 
poucos estudos de casos na literatura (CLARK e GOODRICH, 1989; MALE, WALSKI e SLUTSKY, 1990; GOULTER, DAVIDSON e JACOBS, 1993).

Os modelos de previsão têm objetivo de analisar o comportamento das quebras existentes e projetar esse comportamento para o futuro. Existem dois principais tipos de modelos: determinínisticos e probabilísticos. Os determinísticos são propostos (SHAMIR e HOWARD, 1979; WALSKI e PELLICCIA, 1982) através de relações lineares ou exponenciais entre o número de quebras e a idade das tubulações ou através de análises de regressão (CLARK, STAFFORD e GOODRICH, 1982) que tentam prever as quebras supondo fatores que influenciam a degradação das tubulações. Os probabilísticos (MARKS et al., 1985; HERZ, 1996; LEI, 1997; GAT e EISENBEIS, 2000; MAILHOT et al., 2000) utilizam a técnica de análise de sobrevivência para prever tal comportamento. A análise de sobrevivência é uma técnica estatística que quantifica o tempo em que uma tubulação possivelmente falhará.

\section{Modelos determinísticos}

O objetivo dos modelos determinísticos é investigar as falhas nas redes de distribuição de água utilizando parâmetros conhecidos, como idade e histórico de falhas, para então, priorizar os componentes hidráulicos a serem reabilitados. Uma das formas que alguns pesquisadores (SHAMIR e HOWARD, 1979; WALSKI e PELLICCIA, 1982) encontraram para implementar tais modelos foi dividir o sistema em setores de características semelhantes, de forma a manter a homogeneidade e uniformidade dos grupos de componentes pertencentes a cada setor.

SHAMIR e HOWARD (1979), estudando o histórico de quebras nos sistemas de distribuição de água reais, propuseram um modelo de previsão baseado em uma análise de regressão, para obter uma relação exponencial entre a taxa de quebra e a idade das tubulações. Segundo esses pesquisadores, as quebras são decorrentes da qualidade e idade das tubulações, do tipo de solo no qual a tubulação está assentada, do sistema construtivo e das condições operacionais do sistema. Para a determinação do tempo ótimo de substituição de tubulações, esses estudos incorporaram os custos totais convertidos para o valor presente, fornecendo dessa forma uma relação entre reabilitação e análise econômica. A função de quebras proposta por esses autores é:

$$
N_{b}(t)=N_{b}\left(t_{0}\right) e^{a\left(t-t_{0}\right)}
$$


sendo $\mathrm{t}$ o tempo em anos; $\mathrm{N}_{\mathrm{b}}$ representa o número de quebras por unidade de comprimento por ano (quebras $/ \mathrm{km} / \mathrm{ano}$ ) no ano $\mathrm{t}$ ou $\mathrm{t}_{0} ; \mathrm{t}_{0}$ refere-se ao ano de instalação da tubulação (tubulação nova) e a é o coeficiente de evolução (crescimento) da taxa de quebra $\left(\mathrm{ano}^{-1}\right)$. Esses pesquisadores não forneceram detalhes de onde foi realizado o estudo, da qualidade e quantidade dos dados disponíveis e dos métodos de análise. No entanto, recomendaram que análises de regressão fossem aplicadas para grupos de tubulações homogêneas, em relação aos fatores que influenciavam as quebras.

Nesse mesmo trabalho, SHAMIR e HOWARD (1979), investigando a relação entre reabilitação e vida útil econômica das tubulações, propuseram uma técnica analítica (eq. 3.2) para determinar o tempo ótimo de substituição de tubulações, baseada nos custos de uma tubulação em termos do valor presente de reparos de quebras e investimento de capital. Observa-se que o modelo exponencial (eq. 3.1) de quebras é incorporado na formulação, com objetivo de fornecer o tempo ótimo de substituição das tubulações. Tais análises (econômica) surgiram para substituir as técnicas subjetivas, baseadas na experiência dos analistas, utilizadas até então. Essa relação é dada pela função:

$C(T)=C_{s} e^{-r T}+\int_{0}^{T} L_{r} N_{b}\left(t_{0}\right) e^{a\left(t+t_{0}\right)} e^{-r t} d t$

sendo que $\mathrm{C}$ é o custo total; $\mathrm{C}_{\mathrm{s}}$ é o custo de substituição de uma tubulação $(\$ / \mathrm{km})$; $\mathrm{r}$ é a taxa de juros; T é o ano de substituição de uma tubulação; L é o comprimento da tubulação; $\mathrm{C}_{\mathrm{r}}$ é o custo de reparo de uma quebra (\$); $\mathrm{N}_{\mathrm{b}}$ é o número de quebras por unidade de comprimento por ano (quebras $/ \mathrm{km} / \mathrm{ano}$ ); $\mathrm{t}_{0}$ refere-se ao ano de instalação da tubulação (tubulação nova); a é o coeficiente de evolução (crescimento) da taxa de quebra $\left(\right.$ ano $\left.^{-1}\right)$ e $t$ é o tempo. O tempo de substituição ótimo é a primeira derivada de $\mathrm{C}(\mathrm{T})$ igualada a zero sendo resolvida para $\mathrm{T}$.

Críticas ao modelo proposto por SHAMIR e HOWARD (1979) foram tecidas por GOULTER, DAVIDSON e JACOBS (1993), demonstrando que o modelo proposto (eq 3.1) só poderia ser aplicado a grupos homogêneos de componentes da rede, pois assumia implicitamente uma distribuição uniforme de quebras em relação a esse grupo.

As falhas em tubulações representam uma fração significativa nos custos de manutenção dos sistemas de distribuição de água. Embora técnicas qualitativas forneçam as causas e o tempo de substituição dos componentes das redes, pouca atenção tem sido dada aos métodos quantitativos. Dessa forma, WALSKI e PELLICCIA (1982), 
realizando um estudo de caso e investigando os dados de quebras reais em conjunto com os custos envolvidos nos trabalhos de substituição e reparos, aperfeiçoaram a relação apresentada por SHAMIR e HOWARD (1979) propondo uma alteração no modelo exponencial. Esses pesquisadores (WALSKI e PELLICCIA, 1982) argumentaram sobre o valor utilizado no modelo proposto por SHAMIR e HOWARD (1979), o qual não indicava que a quebra elevava-se rapidamente com a idade das tubulações. Assim, dois fatores de correção $\left(\mathrm{C}_{1}, \mathrm{C}_{2}\right)$ foram incorporados ao modelo exponencial. O fator $\left(\mathrm{C}_{1}\right)$ é avaliado na quebra prévia conhecida dos tubos, já o outro fator $\left(\mathrm{C}_{2}\right)$ está relacionado aos diâmetros, por exemplo, diâmetros elevados ( $\geq 500)$ apresentaram taxa de rompimentos maior que diâmetros menores ( $<500)$. Essa relação é apresentada pela equação (3).

$\mathrm{N}_{\mathrm{b}}(\mathrm{t})=\mathrm{C}_{1} \mathrm{C}_{2} \mathrm{~N}_{\mathrm{b}}\left(\mathrm{t}_{0}\right) \mathrm{e}^{\mathrm{a}\left(\mathrm{t}-\mathrm{t}_{0}\right)}$

Críticas aos fatores de correção $\mathrm{C} 1$ e $\mathrm{C} 2$ foram realizadas por KLEINER e RAJANI (2001). Esses pesquisadores argumentaram sobre o quanto tais fatores melhorariam a qualidade da solução. Outra crítica recaiu sobre à arbitrariedade na incorporação desses fatores na formulação exponencial, sem consistência estatística. A justificativa de WALSKI e PELLICCIA (1982) para aperfeiçoamento do modelo exponencial foi de que o fator de crescimento de falhas era baixo no modelo proposto por SHAMIR e HOWARD (1979) e que os fatores C1 e C2 melhorariam a qualidade da solução, pois influenciavam apenas a taxa de quebra e não a taxa de crescimento anual.

A escolha da opção (limpar, revestir ou substituir) de reabilitação mais adequada para um dado sistema, atendendo às especificações de custo e capacidade de bombeamento, é um problema complexo. Por exemplo, em uma situação em que as opções disponíveis consistem na instalação de bombas adicionais, na limpeza ou no reforço de tubulações, o decisor pode optar por uma alternativa não desejada pelos consumidores. WALSKI (1982) ciente desses problemas apresentou um método para determinar a viabilidade econômica da substituição de tubulações, tendo em vista as reduções financeiras produzidas na energia e na capacidade de bombeamento do sistema. A identificação da decisão de reabilitar tubulações é baseada nos custos da energia consumida pelas bombas, na capacidade de adução, nas vazões dos tubos e no fator de atrito antes e depois da reabilitação. Análises de sensibilidade foram realizadas para demonstrar o efeito das diferentes variáveis, na decisão de reabilitação. O pesquisador demonstrou 
que para função custo de energia elétrica, o método pode descartar a possibilidade de reabilitar o sistema se o preço da energia for muito baixo.

\section{Modelos probabilísticos}

Os modelos probabilísticos são capazes de explicitar quantitativamente os fatores que causam falhas em sistemas de distribuição de água utilizando um breve histórico de quebras. Essas características fazem dos métodos probabilísticos, técnicas poderosas para a previsão de futuras quebras de componentes das redes hidráulicas. Entretanto, a aplicação desses métodos é complexa e exige certo grau de experiência do analista para concepção dos modelos. Algumas vantagens podem ser obtidas com tais métodos, dentre elas, a possibilidade de se trabalhar com um subconjunto dos dados históricos referentes ao sistema.

Vários modelos probabilísticos (MARKS et al., 1985; CONSTANTINE e DARROCH, 1993; HERZ, 1996; LEI, 1997; GAT e EISENBEIS, 2000; KLEINER e RAJANI, 2001) vêm sendo propostos na literatura. Os avanços desses estudos seguem para a determinação da distribuição de probabilidades que melhor se adapta às ocorrências de quebras em sistemas de distribuição de água. No entanto, esses métodos vêem sendo constantemente aperfeiçoados e revisados. Trabalhos como de CONSTANTINE e DARROCH (1993) propõem que a função que melhor se ajusta é a distribuição Poisson. Já BRÉMOND (1997) refere-se a distribuição Weibull como a função que melhor ajusta taxa de quebras baseados na função densidade de dados observados.

LOGANATHAN, PARK e SHERALI (2002) relacionaram a porcentagem de quebra de tubulações através de um modelo conjugado entre as distribuições Exponencial e Weibull. Parâmetros das distribuições de probabilidade são estimados e a porcentagem de quebras é retirada das funções estatísticas obtidas. Assim é possível derivar analiticamente o tempo de ótimo de substituição. Nesse trabalho, foi salientado que a distribuição Exponencial não apresentou bons resultados para a quantificação de falhas, ao contrário, a distribuição Weibull mostrou-se mais adequada ao problema além de requerer apenas um subconjunto do conjunto de dados considerados.

Portanto, pode-se dizer que o estado da arte continua avançando em relação aos modelos matemáticos e estatísticos de reabilitação de componentes dos sistemas de distribuição de água. Muitos algoritmos e técnicas são propostos, mas ainda não existe um modelo universal de falhas aplicado a redes hidráulicas. Uma atenção especial é 
dedicada aos modelos que utilizam análise de sobrevivência na literatura, devido à flexibilidade que esses modelos apresentam, pois permitem ajustar diferentes distribuições de probabilidade no decorrer da análise. Isto faz com que a modelação torne-se mais próxima da problemática real.

Uma complexidade inerente ao problema de reabilitação é a quantidade de fatores incertos que podem provocar as quebras nesses componentes. Esses fatores são locais e variam em relação à região de estudo. No entanto, alguns deles são comuns, como por exemplo, a idade avançada das tubulações, o tráfego sob o sistema, o material composto das tubulações e o tipo de solo que certamente afetam a taxa de quebras. A principal dificuldade em se aplicar tais modelos estatísticos está relacionada aos registros históricos das quebras, que nem sempre estão disponíveis.

No item seguinte são abordados os modelos de reabilitação encontrados na literatura que se baseiam em técnicas otimização para análise de reabilitação de sistemas de distribuição de água para abastecimento.

\subsection{Modelos baseados nas técnicas de análise de sistemas}

Com o surgimento de modelos eficientes para análise de redes, as técnicas de análise de sistemas começaram a ser aplicadas no planejamento de sistemas de distribuição de água, especificamente, no projeto ótimo dos mesmos. Os primeiros modelos foram propostos utilizando a programação linear (ALPEROVITS e SHAMIR, 1977; BHAVE, 1979) como ferramental para resolução do problema de dimensionamento de redes, atendendo-se às restrições de custo. No entanto, a simplificação (linearização) da função objetivo ocultam informações que deveriam ser consideradas em tais análises. No passado, essa simplificação tornou-se necessária devido às limitações computacionais.

Esforços e aperfeiçoamentos foram realizados (DEB e SAKAR, 1971; WATANATADA 1973; BHAVE, 1979; QUINDRY, BRILL LIEBMAN, 1981) para aprimoramento e refinamento das técnicas clássicas de otimização. Alguns estudos (KALLY, 1969; LIANG, 1971; YANG, LIANG e WU, 1975) adotaram a programação dinâmica como método de resolução. Como esta técnica requer elevado tempo computacional suas aplicações não se difundiram. As técnicas de programação não linear (JACOBY, 1968; MORGAN e GOULTER, 1985; FUJIWARA e GANESHARAJAH, 1993; FORMIGA, 1999) firmaram-se como ferramentas eficientes, por tratarem a não linearidade dos problemas, aproximando-se mais da problemática 
real. Alguns trabalhos destacaram-se também pela análise de todas as possíveis soluções para o problema de otimização através dos algoritmos de enumeração (GESSLER, 1985).

Enquanto esforço considerável foi empenhado durante as últimas décadas no desenvolvimento de projetos eficientes, a problemática da reabilitação de redes hidráulicas recebeu menor atenção. Pode-se afirmar que a reabilitação de sistemas de distribuição de água é um problema complexo, pois além de envolver muitas variáveis, considera várias opções (duplicação, substituição, limpeza, eliminação e reforços de componentes) que podem ser implementadas nos sistemas como alternativa de melhoria dos mesmos. Poucos modelos têm sido propostos para quantificar a melhor estratégia de reabilitação, comprometendo-se em manter o desempenho hidráulico do sistema em conformidade com os níveis de serviço adequados.

Ao contrário das técnicas descritas no item (3.2), os modelos baseados em técnicas de análise de sistemas avaliam as diversas alternativas (projeto, operação e reabilitação) através de simulações hidráulicas (avaliam o desempenho global). Esses modelos analisam tanto a eficiência como o custo do sistema reabilitado, simultaneamente, para gerar os planos de manutenção. Diversas aplicações, utilizando métodos clássicos de otimização, vêm sendo propostas na literatura (LI e HAIMES, 1992; LANSEY et al., 1992; KIM e MAYS, 1994; DE SCHAETZEN et al., 1998; KLEINER, ADAMS e ROGERS, 1998) para auxiliar na decisão de escolha das melhores opções de reabilitação a serem adotadas em um sistema.

Uma alternativa ideal seria a reabilitação de todos os componentes hidráulicos deteriorados de um sistema existente, entretanto, isso é inviável sob o ponto de vista econômico, pois os recursos financeiros disponíveis são limitados e insuficientes para contemplar todo sistema. Assim, a escolha da melhor alternativa de reabilitação não é uma tarefa simples, pois envolve decisões que consideram não só os aspectos econômicos e físicos das ações de reabilitação, mas também, o efeito das mesmas na confiabilidade do sistema.

A grande dimensão e o alto grau de não linearidade dos sistemas deteriorados fazem da reabilitação um problema de difícil resolução. LI e HAIMES (1992) propuseram um modelo, baseado na teoria de Markov, que maximiza a disponibilidade (medida de desempenho) do sistema considerando restrições de custos. As variáveis de decisão foram as tubulações. Esses pesquisadores consideraram também o modelo de falhas 
proposto por ANDREOU, MARKS e CLARK (1987). A metodologia foi aplicada à rede hipotética estudada por JACOBY (1968) e ALPEROVITS e SHAMIR (1977). Para reduzir a dimensão do problema, LI e HAIMES (1992) decompuseram o problema de otimização não linear em uma série de problemas lineares menores. A decomposição do problema não linear em problemas menores reduziu o custo computacional do modelo de otimização dinâmica e foi a principal contribuição do trabalho.

Um sistema devidamente reabilitado deve fornecer água em quantidade e qualidade satisfatórias aos consumidores. KIM e MAYS (1990), estudando as estratégias de decisão dos componentes de sistemas existentes, propuseram um método utilizando programação inteira em conjunto com a programação não-linear com restrições probabilísticas para elevar a capacidade de bombeamento, de tal forma que as demandas e as energias em todos os nós fossem atendidas, enquanto o custo total fosse minimizado. Variáveis inteiras ( 0 e 1 ) foram definidas como as opções a serem implementadas na rede. Quatro funções custo foram consideradas para enquadrar as diferentes opções de reabilitação (substituição, reparo, energia e aumento da capacidade de bombeamento). O algoritmo de solução utilizou a técnica de enumeração implícita acoplada ao algoritmo de gradiente generalizado reduzido, para resolver o subproblema não linear. Esses pesquisadores não garantiram a obtenção do ótimo global, mas admitiram a eficiência da técnica. As vantagens do modelo proposto foram incluir incertezas relativas a algumas variáveis de decisão, simular vários cenários de demanda e incorporar as diferentes funções de custo.

Segundo KLEINER, ADAMS e ROGERS (1998), a deterioração em uma rede de distribuição de água deve ser considerada sob dois aspectos, capacidade hidráulica (integridade estrutural devido à idade das tubulações) e critérios econômicos (custos de operação e manutenção, perdas por vazamento, redução na qualidade de serviço). $O$ método proposto utilizou a programação dinâmica em conjunto com a enumeração parcial e implícita para definir o projeto de reabilitação com base na minimização de todos os custos sobre um horizonte de planejamento sujeito às restrições do sistema, determinando o tempo final da próxima medida de reabilitação. A decisão de implementar uma ação de reabilitação em um certo período de tempo é determinada não apenas pelo estado corrente do sistema, mas também pelas ações futuras de reabilitação. A formulação da capacidade hidráulica foi derivada da equação de perda de carga em uma tubulação utilizando as equações de Hazen-Williams. 
Medidas de rugosidade interna das tubulações são importantes para todo tipo de análise em redes de distribuição de água. Fundamentalmente, existem três maneiras de obter as informações sobre esse parâmetro incerto. A primeira é utilizar valores típicos da literatura. A segunda maneira é determinar as rugosidades das tubulações existentes via modelos de calibração. Por último, pode-se medir a rugosidade das tubulações através de testes de perda de carga em campo. No entanto, nenhum desses métodos fornece a extrapolação desse parâmetro para o futuro.

Alguns trabalhos relacionam a taxa de deterioração com o tipo de tubulação, com a qualidade de abastecimento e com as práticas operacionais. COLEBROOK e WHITE (1937) e LAMONT (1981) apresentaram relações entre os coeficientes de rugosidade e o tempo através de dados históricos e estudos de caso, mas foi SHARP e WALSKI (1988) que propuseram uma metodologia consistente, baseada nos ajustes de Colebrook e White, segundo o qual o valor do coeficiente de rugosidade apresenta-se dependente do tempo e tem efeito na capacidade hidráulica. A formulação é apresentada em duas partes, uma para a tubulação antes da reabilitação e outra para a tubulação após a reabilitação. Para a tubulação antes da reabilitação é:

$$
\mathrm{C}_{H W}(\mathrm{t})=18,0-37,2 \log \left[\frac{\mathrm{e}_{0}+\mathrm{a}(\mathrm{t}+\mathrm{g})}{\mathrm{D}}\right]
$$

sendo $\mathrm{C}_{\mathrm{HW}}$ o coeficiente de rugosidade de Hazen-Williams na tubulação i e no tempo $\mathrm{t}$ (antes da reabilitação); $e_{0}$ é a rugosidade inicial na tubulação no tempo de instalação da tubulação (m), considerada nova; a é a taxa de crescimento da rugosidade na tubulação (m/ano); D é o diâmetro da tubulação (m); g é a idade da tubulação no tempo de análise (anos) e $\mathrm{t}$ é o tempo transcorrido do tempo presente aos períodos futuros $\left(\mathrm{t}<\mathrm{T}_{\mathrm{ij}}\right)$ em anos. Após a reabilitação da tubulação com a alternativa de reabilitação j o coeficiente de Hazen-Williams na tubulação no ano t é:

$$
\mathrm{C}_{\mathrm{HW}}(\mathrm{t})=18,0-37,2 \log \left[\frac{\mathrm{e}_{0}+\mathrm{a}\left(\mathrm{t}+\mathrm{T}_{\mathrm{j}}\right)}{\mathrm{D}}\right]
$$

onde $\mathrm{e}_{0}$ é a rugosidade inicial da tubulação na época de implementação da reabilitação (m); a é a taxa de crescimento da rugosidade da tubulação na época da reabilitação (m/ano); D é o diâmetro da tubulação após a reabilitação j (m); T é a época da 
reabilitação da tubulação (anos transcorridos até o tempo presente) e t é o tempo transcorrido desde a implementação da alternativa de reabilitação $\left(t>T_{i j}\right)$ em anos.

Uma estratégia de reabilitação deve garantir que um sistema de distribuição de água continue a operar eficientemente e economicamente de acordo com os requisitos operacionais, durante um extenso período de tempo. Essas análises devem ser baseadas no entendimento de como esses sistemas deterioram-se e suas diferentes características de desempenho. ENGELHARDT et al. (2000) afirmaram que vantagens podem ser obtidas quando a estratégia de reabilitação considera os custos associados em um planejamento de longo prazo. Os critérios econômicos, hidráulicos, de confiabilidade e de qualidade da água devem ser considerados na busca de uma estratégia efetiva. De acordo com os referidos autores, muitos modelos de decisão têm sido desenvolvidos, porém falhas resultantes da consideração meramente econômica tem representado inadequadamente os problemas reais. Poucos modelos consideram horizontes de planejamento de longo prazo e o ciclo de vida dos componentes do sistema.

Embora métodos de otimização convencionais incluindo programação linear, não linear e dinâmica possibilitam cálculos eficientes para a solução de mínimo custo ao longo dos anos, algumas desvantagens inerentes a esses métodos, devido à ineficiência na busca do ótimo global (solução ótima local), à falta de flexibilidade no trato de variáveis discretas e a complexidade na implementação, demandaram a busca por técnicas mais eficientes. Nos últimos anos, vem mudando o paradigma da pesquisa operacional com uso de métodos não convencionais. Várias técnicas de otimização recentes vêem sendo propostas e aperfeiçoadas de forma que o ótimo global possa ser obtido. Com as proposições de técnicas evolucionárias como os algoritmos genéticos, baseadas nos mecanismos da evolução natural das espécies, esses problemas começaram a ser revisto. A próxima seção aborda o estado da arte dessas técnicas, aplicadas a problemática dos sistemas de distribuição de água para abastecimento.

\subsubsection{Algoritmos genéticos aplicados a sistemas de abastecimento}

A complexidade inerente aos sistemas de abastecimento de água associada às suas propriedades não lineares tem limitado o uso de técnicas de otimização convencionais para analisar o desempenho global dos sistemas. Uma solução ótima para o problema de projeto redes hidráulicas é a combinação de diâmetros que fornece o custo mínimo para um conjunto de demandas projetadas satisfazendo simultaneamente às restrições de 
continuidade e energia. As vazões nas tubulações e pressões nos nós, correspondentes aos referidos diâmetros, são determinadas via análise hidráulica.

Geralmente na otimização, os diâmetros das tubulações são representados por variáveis discretas (diâmetros comerciais) e, dessa forma, a busca da solução ótima por métodos convencionais é dificultada, pois os mesmos trabalham com variáveis contínuas. Em se tratando de um sistema de abastecimento de água existente, analistas e decisores esbarram com uma variedade de opções que podem ser implementadas nesses sistemas de forma aumentar a eficiência tais como: limpeza, reforço, duplicação ou eliminação de tubulações existentes além de dimensionar novas tubulações. A questão é que ações de reabilitação são difíceis de serem aplicadas por procedimentos de otimização convencionais.

Diversos trabalhos (MURPHY e SIMPSON, 1992; SIMPSON, DANDY e MURPHY, 1994) foram propostos e são pioneiros na utilização dos algoritmos genéticos como ferramenta computacional para determinação do projeto ótimo, bem como de planos de reabilitação para sistemas hídricos em geral, mais especificamente os de abastecimento de água. Essas técnicas vêem se consolidando como técnicas adequadas e adaptáveis aos problemas em questão, devido à flexibilidade de incorporar problemas discretos, a ausência do uso de derivadas, a eficiência na exploração do espaço de busca, além das facilidades, na implementação e no tratamento de funções complexas e descontínuas.

Investigando os problemas relativos a sistemas de abastecimento de água, MURPHY e SIMPSON (1992) aplicaram algoritmos genéticos simples para projeto de expansão e reabilitação do sistema proposto por GESSLER (1985). As variáveis de decisão foram os diâmetros de tubulações novas e opções de reabilitação que incluía limpeza e construção de tubulações paralelas ao sistema existente. Para aplicação dos AGs foi utilizado um código binário onde cada variável do vetor de decisão foi representada por três bits. A justificativa de utilização desse código foi fundamentada nos conceitos básicos dos AGs (teorema do esquema) que GOLDBERG (1989) afirma ser eficiente, pois tende a manter os blocos de construção ${ }^{4}$ em cada iteração do modelo. A solução ótima global foi obtida por enumeração completa e comparada com as soluções produzidas pelos AGs. Como a solução ótima do problema tinha que obedecer às

\footnotetext{
${ }^{4}$ Holland em 1975 afirmou que a solução ótima será encontrada em uma região que contem alta proporção de boas soluções. Um conjunto de vetores (indivíduos) que representam boas soluções possui certas similaridades nos valores de suas variáveis de decisão. Um subvetor de similaridades, que pertence a esse conjunto citado, que contribui para elevar o valor de aptidão médio é denominado Bloco de Construção (WU e SIMPSON, 2001).
} 
restrições de pressões mínimas requeridas nos nós, sob três cenários de demandas, foi considerada uma função penalidade incorporada à função objetivo. A função penalidade considerada no trabalho foi:

$\mathrm{C}_{\mathrm{p}}=\max \left[\mathrm{K}\left(\mathrm{H}_{\mathrm{j}}^{\min }-\mathrm{H}_{\mathrm{j}}\right)\right] \quad \mathrm{j} \in \mathfrak{I}$

sendo que $\mathfrak{I}$ é o conjunto de todos os nós que apresentam déficit de pressão (abaixo da mínima requerida) para as diferentes curvas de demanda (mínima, média e máxima) de uma possível solução; K é o custo fictício unitário associado a penalidade $(\$ / \mathrm{m})$; H é a energia referente a combinação de variáveis produzidas pelos AGs no nó j (m) e $H^{\text {min }}$ é a energia mínima requerida no sistema para o nó j (m), sem considerar ações de melhorias do sistema.

Funções penalidade são aproximações que auxiliam a obtenção de soluções ótimas dentro da região factível do espaço de busca. O custo penalidade é somado ao custo total. Com isso, soluções boas tendem apresentar custo penalidade próximo de zero e soluções ruins tendem a manter custos penalidade elevados, provavelmente sendo descartadas pelos AGs durante o processo iterativo.

Para avaliação das soluções, recorre-se às denominadas funções aptidão, que relacionam as funções objetivo com as funções penalidade, para fornecer o índice de desempenho de cada vetor de decisão (mérito da solução). Considerando um problema de otimização qualquer, o valor da função objetivo corresponde ao custo total associado a um determinado conjunto de variáveis de decisão que representa completamente uma solução para o problema em questão. No trabalho de MURPHY e SIMPSON (1992), a função aptidão foi definida como sendo o inverso da função objetivo custo a ser minimizada, pois conceitualmente, os AGs foram propostos para maximização. Outro motivo para essa opção é o fato de que operadores de seleção foram desenvolvidos apenas para a maximização, por exemplo, o algoritmo de seleção através de roleta. A função de aptidão a ser maximizada considerada pelos referidos autores, no caso de minimização, foi:

$$
\Phi=\frac{1}{\sum_{j=1}^{N T} C_{T j}+C_{p}}
$$


sendo NT o número de tubulações no sistema; $\Phi$ representa a função de aptidão para uma dada solução; $\mathrm{C}_{\mathrm{T}}$ o custo total de todas as opções de reabilitação implementadas no sistema, através da combinação das variáveis de decisão e $C_{p}$ o custo fictício imposto para evitar soluções infatíveis (custo penalidade).

Devido ao aparecimento de técnicas de otimização não convencionais, os problemas de otimização de redes de distribuição de água para abastecimento começaram a ser revistos, sob a ótica da comparação com as técnicas já consolidadas na literatura. SIMPSON, DANDY e MURPHY (1994) compararam os algoritmos genéticos com a programação não-linear e a enumeração completa, para o problema proposto por GESSLER (1985). Na otimização não linear as variáveis de decisão foram consideradas contínuas, com a vantagem de consumir menos tempo computacional. Os autores reportaram que os resultados mantiveram-se próximos da solução global, mas não acurados, devido às variáveis serem contínuas. A técnica de enumeração completa consumiu 723 vezes mais tempo do que a otimização não linear. A aplicação de ambas as técnicas mencionadas anteriormente é inviável para sistemas de grande escala. Já os AGs mostram-se eficientes na busca da solução global, o tempo computacional gasto pelos AGs foi aproximadamente 7 vezes maior que a otimização não linear. Dificuldades foram encontradas na determinação do critério de parada. A maior vantagem apresentada por SIMPSON, DANDY e MURPHY (1994) foi que os AGs apresentaram bom desempenho para problemas de natureza discreta.

Diferentes valores para o expoente da função aptidão, código Gray ${ }^{5}$ e operador de mutação para código Gray são algumas da três maneiras que DANDY, SIMPSON e MURPHY (1996) encontraram para melhorar os AGs simples em termos de desempenho e acurácia. O operador de mutação específico (para código Gray) muda o valor do gene selecionado utilizando os valores de seus genes adjacentes. Esse operador pode ser aplicado com facilidade para codificação binária, mas não pode ser aplicado com eficiência para codificação real. Na codificação real, os genes adjacentes a outro, escolhido para sofrer mutação, podem ter limites de variáveis de decisão diferentes. $\mathrm{O}$ código Gray também considera dígitos binários ( 0 e 1), na representação de suas variáveis de decisão diferenciada da codificação convencional binária. O expoente na

\footnotetext{
${ }^{5}$ Essa codificação pode ser encontrada em textos especializados como GOLDBERG (1989) e MICHALEWICZ (1992). No entanto, de forma geral, esta codificação caracteriza-se pela diferenciação da codificação binária convencional. Na codificação Gray as subtrings adjacentes só tem um bit diferenciado. Por exemplo, considerando substrings adjacente: 0011,0010 e 0110 observa-se que apenas 1 bit mudou entre elas.
} 
função aptidão é uma forma de parametrização dos valores dessa função. Por exemplo, geração aleatória de indivíduos muito semelhantes, pode conduzir a valores de aptidão muito próximos, dificultando a diferenciação dos indivíduos mais aptos. A função de aptidão utilizada por esses pesquisadores foi:

$\Phi=\left(\frac{1}{\sum_{j=1}^{N T} C_{T j}+C_{p}}\right)^{d}$

sendo $\Phi$ a função aptidão modificada (parametrizada); NT é o número de tubulações no sistema; $\mathrm{C}_{\mathrm{Tj}}$ é o custo total para uma determinada solução; $\mathrm{C}_{\mathrm{p}}$ é o custo penalidade e $\mathrm{d}$ é um expoente, considerado unitário para AGs simples. A incorporação desse expoente na formulação aumentou a competitividade entre os indivíduos da população. Com baixo valor de d nas gerações iniciais, os AGs não detectam essas pequenas diferenças nos valores de aptidão, preservando dessa forma a diversidade da população na exploração global. Nas gerações posteriores, quando o valor de d torna-se maior, as diferenças no valor da aptidão das soluções são mais evidentes e os AGs passam a concentrar suas buscas em regiões mais promissoras do espaço de soluções. A mutação adotada nesse trabalho (DANDY, SIMPSON e MURPHY, 1996), destrói sutilmente as soluções, permitindo assim explorações locais do espaço de busca. O código Gray também foi considerado eficiente nas investigações realizadas. A principal desvantagem desse estudo foi o tempo computacional consumido, apesar da solução encontrada ser superior à solução de mínimo custo apresentada por FUJIWARA e KWANG (1990).

O desenvolvimento de modelos computacionais eficientes para identificação de projetos ótimos de sistemas de distribuição de água, atendendo as restrições não lineares inerentes ao problema, tornou-se um grande desafio para pesquisadores dessa área. SAVIC e WALTERS (1997) integraram algoritmos genéticos a um modelo para análise de redes (ROSSMAN 1994) e aplicaram tal técnica em projetos de custo mínimo para algumas redes exemplo propostas na literatura. O simulador hidráulico utilizado serviu como avaliador das energias nos nós e vazões nos trechos, fornecendo assim subsídios para o cálculo do custo total da solução que incorporava também uma parcela de penalidade, como realizado por outros pesquisadores (MURPHY e SIMPSON, 1992; 
DANDY, SIMPSON e MURPHY, 1996). Além disso, SAVIC e WALTERS (1997) consideraram o fator multiplicador de penalidade dinâmica expresso pela eq.(3.9):

$$
\Psi=\mathrm{K}\left(\frac{\mathrm{N}_{\text {iter }}}{\mathrm{N}_{\max }}\right)^{\mathrm{d}}
$$

sendo $\mathrm{K}$ um custo fictício (igual ao custo penalidade definido na eq. 3.6); $\mathrm{N}_{\text {iter }}$ é o número de iterações; $\mathrm{N}_{\max }$ é o número máximo de iterações e d é um parâmetro experimentalmente escolhido, geralmente igual a 0.8 (SAVIC e WALTERS, 1997). Esse fator penalidade age diretamente no processo, não deixando que a melhor solução infactível seja superior a alguma solução factível da população. Três problemas exemplos da literatura foram estudados, dentre os quais um de expansão. Os resultados mostraram que os AGs são adequados e não requerem hipóteses simplificadores (linearizações) em sua formulação. Sua principal desvantagem diz respeito ao esforço computacional requerido nas simulações.

A aplicação dos AGs a problemas de processamento de grande escala, impõe que o tempo computacional seja levado em consideração. Foi analisando o tempo de processamento dos AGs convencionais nos problemas de redes de distribuição de água que WU e SIMPSON (2001) propuseram a utilização dos algoritmos genéticos competentes $^{6}$ para projeto e reabilitação de sistemas de distribuição de água. $\mathrm{O}$ problema então foi determinar a combinação de mínimo custo, em termos de novos diâmetros, opções de reabilitação, capacidades de bombeamento, dimensionamento de reservatórios e ajuste de válvulas. Uma nova tubulação poderia representar a opção de expansão, substituição ou duplicação em um sistema existente. O custo total de uma solução de projeto e reabilitação foi então minimizado, satisfazendo um conjunto de objetivos do sistema. A função objetivo, referente ao custo total associado a todos os componentes a serem dimensionados e reabilitados, foi expresso pela eq.(3.10).

$$
\mathrm{C}_{\mathrm{T}}=\sum_{\mathrm{k}=1}^{\mathrm{NT} \mathrm{T}_{\mathrm{p}}} \mathrm{C}_{\mathrm{k}}\left(\mathrm{D}_{\mathrm{k}}\right) \mathrm{L}_{\mathrm{k}}+\sum_{\mathrm{k}=1}^{\mathrm{NT} \mathrm{T}_{\mathrm{r}}} \mathrm{C}_{\mathrm{k}}\left(\mathrm{D}_{\mathrm{k}}, \mathrm{R}_{\mathrm{k}}\right) \mathrm{L}_{\mathrm{k}}+\sum_{\mathrm{k}=1}^{\mathrm{NB}} \mathrm{C}_{\mathrm{k}}\left(\mathrm{B}_{\mathrm{k}}\right)+\sum_{\mathrm{k}=1}^{\mathrm{NR}} \mathrm{C}_{\mathrm{k}}\left(\mathrm{DR}_{\mathrm{k}}\right)+\sum_{\mathrm{k}=1}^{\mathrm{nv}} \mathrm{C}_{\mathrm{k}}\left(\mathrm{V}_{\mathrm{k}}\right)
$$

\footnotetext{
${ }^{6}$ Esses algoritmos também são denominados Algoritmos Genéticos Messy e foram inicialmente propostos por GOLDBERG et al. (1989), porém quem os desenvolveu foi um de seus orientados, DEB (1991), em sua tese de doutorado. O objetivo principal do desenvolvimento desses algoritmos foi focalizado na melhoria de identificação e mudança dos Blocos de Construção a qual é conseguida através dos comprimentos dos vetores solução variável. Esse algoritmo exige menor tempo computacional aos AGs convencionais.
} 
sendo $\mathrm{L}_{\mathrm{k}}$ o comprimento da tubulação $\mathrm{k} ; \mathrm{NT}_{\mathrm{p}}$ o número de tubulações de projeto; $\mathrm{NT}_{\mathrm{r}} \mathrm{o}$ número de tubulações a serem reabilitadas; NB o número de bombas; NR o número de reservatórios e NV o número de válvulas; $D_{k}, R_{k}, B_{k}, D R_{k}$ e $V_{k}$ são variáveis de decisão que representam diâmetro, opções de reabilitação (relacionada ao diâmetro), capacidade de bombeamento, dimensão do reservatório e ajuste da válvula reguladora e $C_{k}$ refere-se ao custo associado a cada variável de decisão. Para cada combinação de variáveis discretas, o simulador hidráulico é solicitado, para verificar as restrições de tal forma que a resposta seja factível. As restrições consideradas foram: pressões mínimas nos nós, velocidades e perda de carga máxima permitida, capacidade de bombeamento, ajustes de válvulas e volumes dos reservatórios.

Como forma de adaptar o problema de minimização através de uma formulação de maximização, WU e SIMPSON (2001) propuseram:

$\Phi=1-\frac{\mathrm{C}_{\mathrm{Ti}_{\mathrm{i}}}}{\max _{\mathrm{i}=1, \ldots, \mathrm{POP}} \mathrm{C}_{\mathrm{T}_{\mathrm{i}}}}$

sendo POP a dimensão do conjunto população e $\mathrm{C}_{\mathrm{Ti}}$ o custo total de uma solução de projeto e reabilitação da iteração corrente. $O$ valor da função aptidão varia $0 \leq \Phi \leq 1$. Para que uma função objetivo geral, por exemplo custo, seja minimizada o valor de $\Phi$ deve ser maximizado.

Muitos sistemas de distribuição de água existentes em operação, apresentam elevados níveis de deterioração, fazendo com que os custos de manutenção e operação sejam onerosos. Apesar dos investimentos disponíveis para recuperação das infraestruturas urbanas deterioradas, geralmente, apenas uma pequena parcela desse montante é destinada à reabilitação das redes hidráulicas. Assim, uma das complexidades do problema é como esses fundos devem ser alocados de maneira ótima. Partindo dessas premissas, DANDY e ENGELHARDT (2001a) desenvolveram um modelo de decisão para fornecer planos de substituição de tubulações para um período de planejamento de longo prazo. Para esses pesquisadores o desenvolvimento de uma estratégia de reabilitação eficiente deve envolver quatro estágios: investigação da problemática existente, estudo de caso, formulação do problema de reabilitação e compactação de resultados. Na fase de investigação da problemática é realizada uma revisão dos modelos de reabilitação propostos na literatura, bem como dos dados necessários à resolução do problema e a escolha do modelo a ser utilizado. Posteriormente é necessário realizar um estudo detalhado da aplicação do modelo e levantamento dos 
dados de entrada necessários, seguido de uma terceira fase, que é o estudo das formulações mais promissoras que descrevem o problema real. Finalmente, os analistas devem apresentar resultados do modelo implementado, de forma compacta e de fácil visualização aos decisores e gestores responsáveis.

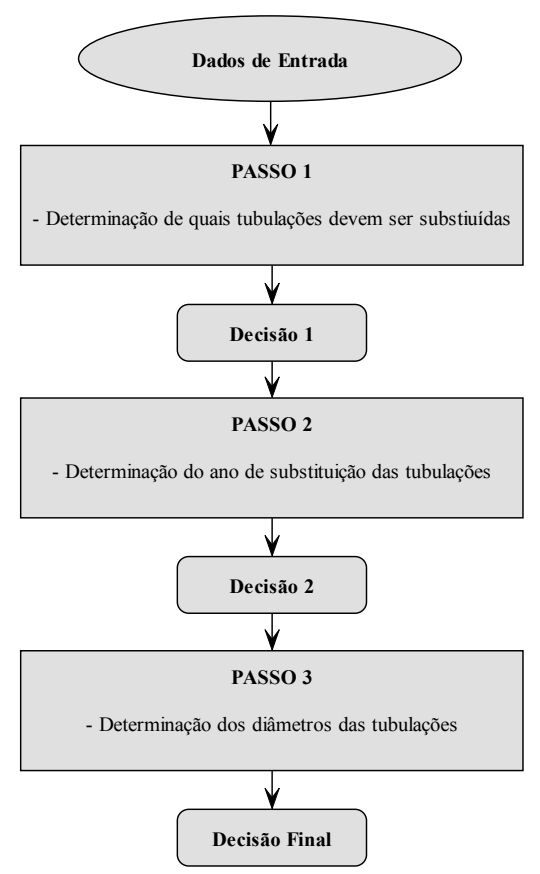

Figura 3.3 - Esquema geral do modelo proposto por DANDY e ENGELHARDT (2001a)

Antes que fosse desenvolvida uma estratégia de reabilitação efetiva, para apresentar os planos de substituição de tubulações em um sistema de distribuição real, DANDY e ENGELHARDT (2001a) realizaram uma ampla revisão dos modelos existentes na literatura e optaram por utilizar os AGs como técnica de otimização acoplada ao modelo de decisão que também incorporava um simulador hidráulico. A modelação compreendeu três fases. Na primeira fase, um modelo foi utilizado para decidir se as tubulações seriam substituídas imediatamente ou posteriormente. Na segundo fase, foi admitido um período de planejamento de vinte anos que incluía restrições de fundos disponíveis a cada cinco anos. Na terceira fase, o modelo determinava os diâmetros de novas tubulações do sistema. A Figura 3.3 ilustra tal procedimento. Os critérios econômicos considerados foram os valores presentes dos custos de reparos das tubulações existentes, dos custos de futuras reparações para novas tubulações e dos custos de substituição de tubulações. As formulações utilizadas foram:

$$
\mathrm{C}_{\mathrm{r}}\left(\mathrm{T}_{\mathrm{r}}\right)=\sum_{\mathrm{t}=0}^{\mathrm{T}_{\mathrm{s}}} \frac{\mathrm{k} \mathrm{N}_{\mathrm{b}}(\mathrm{D}, \mathrm{t}) \mathrm{C}_{\mathrm{r}}(\mathrm{D}) \mathrm{F}_{\mathrm{u}}(\mathrm{U}) \mathrm{L}}{(1+\mathrm{r})^{5 \mathrm{t}}}
$$


sendo $\mathrm{C}_{\mathrm{r}}$ o custo de reparos de quebras de tubulações; $T_{\mathrm{s}} \mathrm{o}$ tempo de substituição de tubulações; $k$ igual a 2,5 para $t=0$, caso contrário, $k$ igual a 5,0 para $t=T_{s} ; N_{b}$ a taxa de quebra esperada do diâmetro existente (D) no tempo $t$ para tubulações (quebras/km/ano); $\mathrm{C}_{\mathrm{r}}$ o custo de reparos de quebras para o diâmetro D; $\mathrm{F}_{\mathrm{u}} \mathrm{o}$ fator custo de quebra em relação ao seu uso (residencial, industrial, comercial, dentre outros); L o comprimento da tubulação $(\mathrm{km})$; t é o tempo (anos) e r é a taxa de juros. Observa-se que os referidos pesquisadores utilizaram a formulação (eq. 3.1) proposta por SHAMIR e HOWARD, (1979).

DANDY e ENGELHARDT (2001a) também apresentaram o custo de reparos de futuras quebras $\left(\mathrm{C}_{\mathrm{rf}}\right)$ de uma tubulação nova de diâmetro (D):

$$
\mathrm{C}_{\mathrm{rf}}\left(\mathrm{D}, \mathrm{T}_{\mathrm{r}}\right)=\sum_{\mathrm{t}=\mathrm{T}_{\mathrm{r}}}^{10} \frac{\mathrm{k} \mathrm{N}_{\mathrm{b}}(\mathrm{D}, \mathrm{t}) \mathrm{C}_{\mathrm{r}}(\mathrm{D}) \mathrm{F}_{\mathrm{u}}(\mathrm{U}) \mathrm{L}}{(1+\mathrm{r})^{5 \mathrm{t}}}
$$

sendo $\mathrm{D}$ o diâmetro da nova tubulação instalada no tempo $\mathrm{T}_{\mathrm{r}}$ e 10 menciona que as tubulações serão substituídas a cada 10 anos. $\mathrm{O}$ valor presente do custo de substituição de tubulação, com diâmetro (D) no tempo $\mathrm{T}_{\mathrm{r}}$, foi definido pela eq.(3.14)

$$
C\left(D, T_{r}\right)=\left(\frac{1000 C_{s}(D) L}{(1+r)^{5 T_{r}}}\right)
$$

sendo $\mathrm{C}_{\mathrm{s}} \mathrm{o}$ custo unitário (por metro de comprimento) de tubulação substituída de diâmetro $\mathrm{D}$.

O trabalho desenvolvido por DANDY e ENGELHARDT (2001a) proporcionou várias contribuições (incorporação do modelo de falhas, consideração de planejamento de longo prazo e reabilitações considerando as simulações hidráulicas) ao estudo da reabilitação de sistemas de distribuição de água, apesar de considerar apenas a substituição de tubulações como opção de reabilitação. A aplicação desse modelo foi realizada a um sistema de distribuição de água existente para o qual se podia contar com dados reais. O estudo de falhas (quebras) em tubulações foi aperfeiçoado de maneira a possibilitar a quantificação de custos de reparos. Até então, a literatura apenas reportava a utilização das equações propostas por SHAMIR e HOWARD (1968) e WALSKI e PELLICCIA (1982). Nesse trabalho, as falhas foram ajustadas aos dados históricos disponíveis pelo método dos mínimos quadrados, de maneira possibilitar o prognóstico das taxas de quebras futuras necessárias ao planejamento de longo prazo. Dez anos de 
registros de falhas foram utilizados, indicando a localização da quebra, o material (cimento amianto e ferro fundido) e o diâmetro da tubulação reparada. As equações obtidas e propostas para o prognóstico de falhas futuras foram as eqs.(3.15) e (3.16). A eq.(3.15) foi desenvolvida para tubulações de ferro. A eq.(3.16) foi desenvolvida para tubulações de cimento amianto.

$\mathrm{N}_{\mathrm{b}}=0,02214 \mathrm{e}^{\left(-8,64 \cdot 10^{-3} \mathrm{D}\right)} \mathrm{g}^{1,337}$

$\mathrm{N}_{\mathrm{b}}=1,974 \cdot 10^{-3} \mathrm{e}^{\left(-9,74 \cdot 10^{-3} \mathrm{D}\right)} \mathrm{g}^{1,808}$

sendo que g representa a idade da tubulação (anos). O trabalho apresentou desvantagens em relação ao tempo computacional requerido pelos AGs. Estudos futuros foram sugeridos, pautados na necessidade de incorporação de outros objetivos a serem considerados simultaneamente.

WALSKI (2001) criticou alguns modelos de otimização desenvolvidos nos últimos anos para os projetos de recursos hídricos e argumentou sobre a simplicidade da função objetivo (minimização de custos) geralmente empregada, razão pela qual, segundo o autor, os resultados obtidos não atendem às necessidades reais. $\mathrm{O}$ autor afirma que os sistemas de distribuição reais apresentam muitos outros objetivos que devem ser considerados nos modelos de decisão, como por exemplo, os benefícios não mensuráveis, e discute formas de quantificação desses objetivos através das melhorias nos sistemas, analisando as modificações realizadas na rede em comparação com o sistema existente. Foram discutidas também as incertezas quanto às demandas futuras e a sua influência na minimização dos custos e na capacidade do sistema, pois, quando as demandas elevam-se devido aos fatores sociais, os benefícios também crescem e, quando se minimiza apenas os custos, uma grande parcela do benefício é reduzida. $\mathrm{O}$ autor elogia e aponta o trabalho de WALTERS et al. (1999) como sendo uma das poucas publicações que trataram o problema dos sistemas de distribuição de água de forma multiobjetivo e propõe, como desafio, que os problemas reais de redes hidráulicas sejam investigados visando mudar o paradigma de não somente utilizar a minimização de custos, mas também a maximização de benefícios gerados. 


\subsubsection{Modelos de otimização multiobjetivo}

Infra-estruturas deterioradas em sistemas de distribuição de água podem provocar perdas por vazamentos, diminuição da capacidade de transporte de água, falhas nos componentes do sistema (tubulações, bombas, válvulas dentre outros), elevação nos custos de manutenção e operação, constantes interrupções do funcionamento dos sistemas e diminuição da sua confiabilidade. Esses fatores demonstram que a melhoria nessas infra-estruturas, apesar de necessária, não é uma tarefa fácil, pois os objetivos são múltiplos e conflitantes. Essa melhoria pode ser conseguida através de técnicas de reabilitação tais como substituição, duplicação, reparo de tubulações ou adição de componentes hidráulicos como bombas, válvulas e reservatórios. Dessa forma surge então o problema de quais componentes adicionar ou melhorar para maximizar os benefícios oriundos das mudanças no sistema, dado que os fundos disponíveis são limitados para atender todas as ações.

Quando benefícios de reabilitação de redes hidráulicas são maximizados através de algoritmos de otimização de objetivo único, a solução encontrada não atenderá os outros objetivos que estão implícitos no problema, por exemplo, custos, confiabilidade e vazamentos. Para um decisor é interessante que várias soluções estejam disponíveis de forma guiar uma escolha adequada, por exemplo, soluções com custos e benefícios diferenciados. Há uma tendência na literatura em substituir a otimização convencional, envolvendo apenas um objetivo, pela otimização multiobjetivo (HALHAL et al. 1997; WALTERS et al., 1999; DANDY e ENGELHARDT, 2001b; CHEUNG et al., 2003; FORMIGA et al., 2003) que se mostra mais adequada e próxima da realidade. Foi dessa forma que HALHAL et al. (1997) propuseram um método baseado em algoritmos genéticos para encontrar soluções ótimas de reabilitação dos sistemas de distribuição de água através de uma formulação multiobjetivo de minimização de custos e maximização de benefícios. A formulação proposta é reproduzida aqui neste trabalho, com a finalidade de introduzir a otimização multiobjetivo aos problemas de reabilitação de sistemas de distribuição de água.

O objetivo da otimização multiobjetivo aplicada ao problema em questão é encontrar a forma ótima de investimento que eleve a eficiência dos sistemas urbanos deteriorados através de modificações aplicadas às redes. Essas modificações visam à elevação da capacidade hidráulica da rede (limpeza, reforço, duplicação ou substituição das tubulações existentes), o aumento da integridade física através da substituição de 
tubulações propensas a falhas, o aumento da flexibilidade do sistema, adicionando tubulações em paralelo e a melhoria da qualidade da água, através da limpeza e do revestimento de tubulações antigas. Vários componentes de redes podem ser considerados, porém na formulação proposta por HALHAL et al. (1997) apenas as tubulações são objetos de estudo.

HALHAL et al. (1997) mencionam que de maneira geral os benefícios produzidos durante o período de planejamento devem ser maximizados e podem ser obtidos pelas melhorias realizadas no sistema. A soma dos valores presentes dos custos envolvidos deve ser minimizada com garantia de que esses custos devam se adequar ao orçamento disponível. Com isso, o problema pode ser colocado analiticamente como um problema de otimização multiobjetivo:

Maximizar Beneficios $=\sum \mathrm{B}(\mathrm{i})$

Minimizar Custos $=\sum \mathrm{C}(\mathrm{i})$

sujeito $a: \sum C(i) \leq I$

sendo que B (i) representa os benefícios relativos à implementação da solução i, C (i) são os custos de reabilitação da solução i e I é o investimento disponível total. A formulação de $\mathrm{B}(\mathrm{i})$ combina ainda quatro fatores através de pesos devidamente atribuídos. A soma dos benefícios (beneficio total) de uma solução i é expressa como a soma de quatro parcelas:

$B(i)=w_{h} B_{h}(i)+w_{p} B_{f}(i)+w_{f} B_{o}(i)+w_{q} B_{q}(i)$

sendo $\mathrm{B}_{\mathrm{h}} \mathrm{o}$ beneficio relativo à melhoria do desempenho hidráulico; $\mathrm{B}_{\mathrm{F}} \mathrm{o}$ beneficio de manutenção da melhor condição física das tubulações; $B_{0}$ é o beneficio operacional representado pela ação de reabilitação que possibilita melhor flexibilidade na distribuição de vazões na rede; $\mathrm{B}_{\mathrm{q}}$ é o beneficio de qualidade relativo à substituição de tubulações e $\mathrm{w}_{\mathrm{h}}, \mathrm{w}_{\mathrm{f}}, \mathrm{w}_{\mathrm{o}}, \mathrm{w}_{\mathrm{q}}$ são os pesos respectivos. A seguir é explicitado cada um desses componentes da formulação de benefícios. 
Benefício Hidráulico - O benefício hidráulico é o ganho de desempenho obtido decorrente de qualquer ação de melhoria implementada no sistema. Essa função pode ser quantificada como sendo a diferença entre as deficiências na rede original (sem melhoria), $\mathrm{DEF}_{\mathrm{o}}$, e as deficiências na rede reabilitada (com melhorias), $\mathrm{DEF}_{\mathrm{r}}$ :

$\mathrm{B}_{\mathrm{h}}=\mathrm{DEF}_{\mathrm{o}}-\mathrm{DEF}_{\mathrm{r}}$

sendo que $\mathrm{DEF}_{\mathrm{o}}$ refere-se à deficiência do sistema em termos das pressões nos nós da rede em seu estado original (sem modificações) e $D_{E F}$ é a deficiência da rede reabilitada (com modificações). $\mathrm{DEF}_{\mathrm{o}}$ e $\mathrm{DEF}_{\mathrm{r}}$ correspondem à soma de pressões nodais excessivas e deficitárias, respectivamente, representando dessa forma as duas situações críticas que devem ser evitadas no sistema. Tanto $\mathrm{DEF}_{\mathrm{o}}$ como $\mathrm{DEF}_{\mathrm{r}}$ podem ser calculadas através da eq.(3.22).

$\mathrm{DEF}_{\mathrm{o}} / \mathrm{DEF}_{\mathrm{p}}=\left(\alpha \mathrm{K}^{\mathrm{min}}+\beta \mathrm{K}^{\text {max }}\right)$

sendo que:

$\mathrm{K}^{\min }=\sum_{\mathrm{j} \in \mathfrak{I}} \Delta_{\mathrm{j}} \mathrm{Q}_{\mathrm{j}}$

$\mathrm{K}^{\max }=\sum_{\mathrm{j} \in \mathbb{N}} \Delta_{\mathrm{j}} \mathrm{Q}_{\mathrm{j}}$

sendo $\mathfrak{I}$ o conjunto de nós com pressões abaixo do nível mínimo considerado; conjunto de nós com pressões acima do nível máximo considerado; $\alpha$ e $\beta$ são pesos globais que podem ser ajustados enfatizando a elevação de pressões baixas ou o decréscimo de pressões altas e $\Delta$ correspondente a intensidade das falhas (pressões nodais acima da máxima ou pressões nodais abaixo da mínima) de pressões no sistema para o nó j e Q é a demanda no nó j. O acréscimo nas pressões mínimas ou decréscimo nas pressões máximas dos nós, gera melhorias na performance hidráulica e, portanto, apresenta reflexos sobre os respectivos benefícios. No entanto, quando a pressão é elevada, mas permanece abaixo de zero, a melhoria do sistema não tem efeito mensurável. Para contornar essa dificuldade, um coeficiente $(\lambda)$ foi introduzido na avaliação de pressão para considerar o impacto de falhas no sistema. Para um nó j tendo uma pressão $\mathrm{H}$ menor que a pressão mínima $\mathrm{H}^{\text {min }}$, podem ser consideradas as seguintes expressões: 
$\Delta_{\mathrm{j}}=\lambda\left[\mathrm{H}^{\min }-\mathrm{H}_{\mathrm{j}}\right] \quad$ se $\mathrm{H}_{\mathrm{j}}>0$

$\Delta_{\mathrm{j}}=\lambda \mathrm{H}^{\min }-\mathrm{H}_{\mathrm{j}} \quad$ se $\mathrm{H}_{\mathrm{j}}<0$

sendo que $\lambda$ representa um coeficiente geralmente maior que 1. Para a avaliação das pressões nos nós e da consequente deficiência de uma solução é necessária a utilização de um modelo para análise de redes, simulador hidráulico.

Benefício Físico - Esse benefício é calculado através do ganho obtido por qualquer ação de reabilitação implementada na rede, na qual melhora a condição estrutural das tubulações existentes, das quais estão suscetíveis a rompimentos e vazamentos. Quando as tubulações existentes são substituídas por tubulações novas, consideradas livres de quebras, gera um benefício que pode ser quantificado em função do valor presente dos custos de reparo relativos ao período em que essas tubulações foram substituídas:

$B_{f}=\sum_{j=1}^{\mathfrak{I}} C_{r j}$

sendo $\mathfrak{I}$ o conjunto que contém as tubulações a serem renovadas; $\mathrm{C}_{\mathrm{r}} \mathrm{o}$ custo de reparos de quebras da tubulação j. Segundo WALSKI (1986), os custos de reparos podem ser calculados pela eq.(3.28).

$C_{r}=\sum_{t=t_{p}}^{t=t_{r}} \frac{N_{b}(t) C_{r j}}{(1+r)^{t-t_{p}}}$

sendo que $\mathrm{C}_{\mathrm{r}}$ é igual ao custo de reparo de uma quebra na tubulação j; r é igual à taxa de juros; tp é igual ao ano presente; $\mathrm{t}_{\mathrm{r}}$ é igual ao ano $\mathrm{t}_{\mathrm{p}}$ mais 10 ; e $\mathrm{N}_{\mathrm{b}}$ corresponde a taxa de quebra no ano $t$ que pode ser aproximado pela eq.(3.29):

$\mathrm{N}_{\mathrm{b}}(\mathrm{t})=\mathrm{N}_{\mathrm{b}}\left(\mathrm{t}_{0}\right)(1+\mathrm{a})^{\mathrm{t}}$

sendo $\mathrm{N}_{\mathrm{b}}$ a taxa de quebra no ano 0 (quebra/km/ano); $\mathrm{b}$ a taxa de crescimento de quebra e té o tempo em anos.

Beneficio Operacional - O benefício operacional é calculado como sendo o ganho obtido por uma nova tubulação inserida em paralelo com uma tubulação velha (duplicação). Essa ação de reabilitação eleva o número de caminhos percorridos pela 
água e, portanto, aumenta a flexibilidade operacional do sistema. Esse benefício é expresso pela eq.(3.30).

$\mathrm{B}_{\mathrm{o}}=\sum_{\mathrm{j}=1}^{\mathfrak{I}} \mathrm{D}_{\mathrm{j}}$

sendo $\mathfrak{I}$ o conjunto que constituído pelo número de novas tubulações em paralelo e D o diâmetro da tubulação nova.

Beneficio de Qualidade - Um fator de rugosidade baixo em uma tubulação proporciona o surgimento de eventuais pontos de corrosão, de acumulação, no caso de tubulações de ferro, propiciando condições locais para o desenvolvimento de microorganismos e/ou mudança na cor da água. Portanto, a partir da limpeza ou substituição de tubulações, seu fator de atrito pode apresentar-se maior que um valor limite aceitável. Isso implica em um ganho na capacidade hidráulica da rede e nos respectivos benefícios gerados pela melhoria da qualidade da água, avaliado através da eq.(3.31).

$\mathrm{B}_{\mathrm{q}}=\sum_{\mathrm{j}=1}^{\mathfrak{I}} \mathrm{L}_{\mathrm{j}}$

sendo que $\mathfrak{I}$ é igual ao número de tubulações renovadas (limpas ou substituídas) e L (j) é o comprimento da tubulação renovada j.

Custo - O custo de uma tubulação nova corresponde à soma dos custos de aquisição e de implantação. Os custos de substituição de tubulações são mais elevados que os custos de implantação de novas tubulações, pois na substituição de tubulações estão envolvidos outros fatores que elevam o custo, por exemplo, a obstrução do pavimento e interrupções do sistema. Já os custos de limpeza e reforço estrutural são custos intermediários entre os citados. HALHAL et al. (1997) apresentaram os custos relativos a diferentes diâmetros (Tabela 3.1), mas não explicitaram a origem desses valores.

Como em muitos problemas de otimização, o projeto e a reabilitação de redes envolvem objetivos múltiplos, tais como a minimização de custos e maximização de benefícios. É possível, no entanto utilizar uma formulação de critério único para englobar esses objetivos no processo de decisão, considerando alguns deles como restrições do problema ou incorporando critérios múltiplos em uma única função objetivo, do tipo somatório, ponderados por pesos. HALHAL et al. (1997) afirmaram que nenhuma 
dessas abordagens é satisfatória e que na otimização multiobjetivo, os critérios devem ser tratados individualmente, sendo cada solução avaliada nesses termos. Não há uma solução ótima no procedimento multiobjetivo, mas um conjunto de soluções de compromisso em relação às funções objetivo consideradas. Esse conjunto de soluções é denominado Soluções Ótimas Pareto ${ }^{7}$. Cada combinação de variáveis pertencente a esse conjunto não é dominada por nenhuma outra combinação desse mesmo conjunto. Com isso, todas as soluções pertencentes ao conjunto são ótimas. A diferença entre as soluções é a relação de "troca" entre os objetivos, enquanto um objetivo apresenta bom desempenho os outros podem apresentar pior desempenho.

Tabela 3.1 - Custos de reabilitação apresentados por HALHAL et al. (1997)

\begin{tabular}{cccc}
\hline \hline & \multicolumn{3}{c}{ Custos Unitários $(\$ / \mathrm{m})$} \\
\hline Diâmetro $(\mathrm{mm})$ & Novas & Limpeza e Reforço & Substituição \\
80 & 100 & 85 & 110 \\
100 & 175 & 100 & 190 \\
150 & 220 & 150 & 240 \\
200 & 320 & 220 & 350 \\
300 & 550 & 300 & 600 \\
400 & 780 & 410 & 850 \\
500 & 980 & 500 & 1050 \\
600 & 1350 & 630 & 1500 \\
\hline \hline
\end{tabular}

HALHAL et al. (1997) utilizaram os algoritmos genéticos competentes (Messy Genetic Algorithms) com vetores soluções de comprimento variável em sua estrutura de dados e compararam esses algoritmos com as técnicas que utilizavam vetores soluções de comprimento fixo. Esse método foi aplicado a duas redes exemplo encontradas na literatura, uma considerada de pequeno porte, hipotética, e outra de médio porte, real. Concluiu-se que, os algoritmos genéticos competentes possibilitaram melhores resultados em relação para a rede exemplo de médio porte.

Em um outro trabalho, WALTERS et al. (1999) também utilizaram os AGs competentes para resolver problemas de projeto e reabilitação de sistemas de distribuição de água de maneira ótima. Adição de novas tubulações, reparos e substituição das existentes,

\footnotetext{
${ }^{7}$ O conceito Pareto ótimo foi formulado pelo pesquisador italiano Vilfredo Pareto no século XIX e constitui a base da otimização multiobjetivo. A obra original desse pesquisador é denominada Cours D' Ecomomie Politique, vol.I e II, F. Rouge, Lausanne em 1896.
} 
adição, ajuste e dimensionamento de novos reservatórios e previsão de novas bombas foram às opções de reabilitação adotadas por esses pesquisadores para aumentar a eficiência do sistema. As funções objetivo adotadas foram similares àquelas adotadas nos estudos de HALHAL et al. (1997), porém com algumas modificações. A presença de bombas requereu que o projeto e a operação da rede fossem considerados em conjunto no processo de otimização. O método permitiu a seleção do tipo e número de bombas a ser instalada para cada estação elevatória nova ou reabilitada. Os reservatórios foram adicionados ao sistema para simular o enchimento e o esvaziamento de sua capacidade. Por exemplo, durante os períodos de baixa demanda diária o reservatório deveria encher, já em períodos de demandas elevadas o reservatório deveria ser esvaziado, reduzindo assim os custos de reparo de tubulações e de bombeamento. Garantiu-se também um volume de reserva, para combate à incêndio e para o atendimento de consumo de emergência, para esses reservatórios.

Tabela 3.2 - Padrão de demanda utilizada por WALTERS et al. (1999)

\begin{tabular}{ccc}
\hline \hline Período & Tempo do Dia & Fator de Demanda Horária Média \\
\hline 1 & $00: 00-03: 00$ & 0,7 \\
2 & $03: 00-06: 00$ & 0,6 \\
3 & $06: 00-09: 00$ & 1,2 \\
4 & $09: 00-12: 00$ & 1,3 \\
5 & $12: 00-15: 00$ & 1,2 \\
6 & $15: 00-18: 00$ & 1,1 \\
7 & $18: 00-21: 00$ & 1,0 \\
8 & $21: 00-24: 00$ & 0,9 \\
\hline \hline
\end{tabular}

A inclusão dos reservatórios na otimização exige a simulação operacional do sistema (enchimento e esvaziamento) durante o ciclo diário de demandas, para garantir uma operação factível. Para isso, alguns autores (WALTERS et al., 1999) vêm considerando curvas de demanda diárias, conforme exemplo da Tabela 3.2, ilustrada através da Figura 3.4. Foram consideradas demandas fixas nos nós da rede para a situação atual ao longo do período de planejamento. Para a simulação das demandas horária nos nós, foram considerados esses padrões (Figura 3.4) multiplicados pela demanda fixa estabelecida nos nós.

A simulação da resposta do sistema para variações na demanda, utilizando simulação horária, consome muito tempo computacional, pois requer um grande número de 
avaliações. Com isso, WALTERS et al. (1999) realizaram uma simplificação na modelação. O período diário foi dividido em quatro níveis. Uma simulação de 24 horas na demanda máxima horária foi utilizada apenas para verificar a viabilidade dos projetos finais (solução final). O problema teste estudado por esses pesquisadores foi inicialmente proposto na literatura por WALSKI et al. (1987) para uma cidade fictícia denominada Anytown. Essa cidade possui as complexidades de um sistema real, principalmente, os problemas de expansão (projeto) e reabilitação de redes, tratados em conjunto.

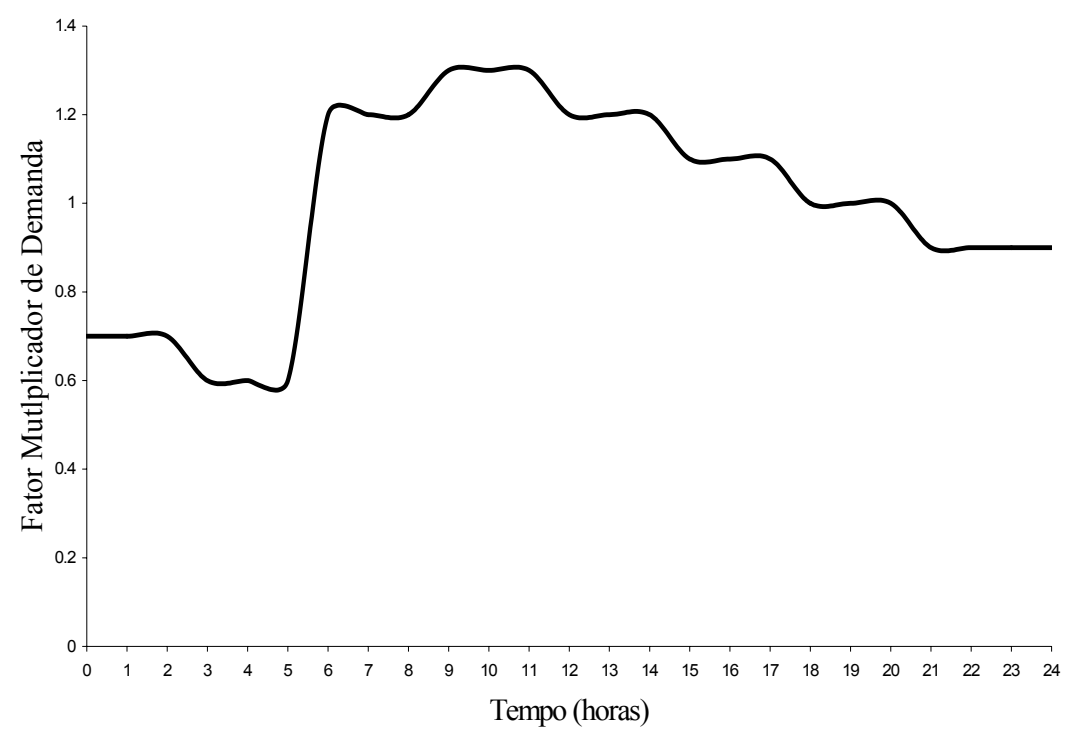

Figura 3.4 - Curva diária de demanda (adapatado de WALTERS et al., 1999)

O projeto de armazenamento dentro de uma rede pode ser definido adequadamente, pela localização de reservatórios e quantificação de seus níveis. Para cada reservatório, o volume e os níveis operacionais mínimos e máximos devem ser determinados. Além disso, todos os reservatórios devem esvaziar e encher sob as condições operacionais diárias, no dia de máxima demanda, deixando que os níveis armazenados para situações de emergência não sejam alterados. Dois tipos de investigação foram conduzidos no trabalho (WALTERS et al., 1999), para conseguir definir os reservatórios no processo de otimização. Na primeira, a localização e os volumes de novos reservatórios foram especificados como variáveis de projeto. Os níveis de operação máximo e mínimo foram tratados como variáveis dependentes. Os reservatórios foram tratados como nós de demandas conhecidas. As energias nos nós, correspondentes aos reservatórios, são determinadas pela simulação em regime permanente da rede para cada um dos quatro períodos de demanda. Para cada nó, onde foram localizados os reservatórios, a energia 
mínima e máxima identificada sobre os quatro períodos de demanda foi interpretada através dos níveis de operação máximo e mínimo para o reservatório correspondente. Como o volume dos reservatórios era conhecido, pode-se então determinar a área dos mesmos. Na segunda aplicação, a localização, o volume e os níveis de operação máximo e mínimo foram tratados como variáveis independentes para os reservatórios, definindo, dessa forma, o projeto das unidades de armazenamento. No entanto, a condição de armazenamento poderia não atender às restrições da rede. Para prevenir o transbordamento ou o esvaziamento dos reservatórios a níveis operacionais insatisfatórios, foi necessário utilizar um artifício de penalidade para dirigir os AGs para a região factível, balanceando assim as soluções.

Os resultados obtidos por WALTERS et al. (1999) representaram um grande avanço no planejamento das estratégias de reabilitação ótima em sistemas de distribuição de água. A consideração de bombas e simulações operacionais (reservatórios) para dar suporte ao processo de decisão proporcionou mais complexidade à modelação, porém possibilitou maior proximidade da problemática real. Alguns fatores podem ser destacados nesse trabalho como a formulação multiobjetivo que forneceu um aperfeiçoamento ao problema originalmente proposto por WALSKI et al. (1987) e a adequação dos AGs ao problema, demonstrando ser uma técnica poderosa, principalmente quando cresce a complexidade do sistema. A técnica de otimização proposta por esses pesquisadores utiliza dois conceitos propostos por GOLDBERG (1989) para o problema multiobjetivo, ordenação das soluções e o compartilhamento das mesmas com objetivo de manter soluções não dominadas na população corrente dos AGs.

O procedimento multiobjetivo proposto por WALTERS et al. (1999) pode ser apresentado de forma geral. Por exemplo, um conjunto de vetores solução (população) é gerado aleatoriamente, atendendo os limites de cada variável de decisão. Cada vetor pertencente a esse conjunto é ordenado e receberá um valor de ordenação (rank) de acordo com a classificação não dominada, cujos detalhes são abordados posteriormente nesse trabalho. Após classificar a solução, os valores de ordenação são utilizados para fornecer a medida de desempenho (aptidão) desses vetores, baseados na técnica de compartilhamento (sharing fitness) proposta por GOLDBERG (1989), de maneira a garantir a representatividade de soluções na frente Pareto. Nota-se que a medida de desempenho, utilizada para avaliar os vetores, é um valor fictício. Como os AGs mantém sempre um conjunto de vetores soluções a cada iteração, os vetores que se 
encontrarem na última geração, após o critério de convergência ser satisfeito, são as soluções ótimas Pareto. A principal contribuição da técnica foi a incorporação de períodos de planejamento de longo prazo na formulação proposta por HALHAL et al. (1997). Outro trabalho (WALTERS et al. 1999) utilizou essa mesma metodologia para projetar e planejar investimentos para reabilitação ótima de sistemas de distribuição água.

Recentemente, DANDY e ENGELHARDT (2001b) propuseram uma das maiores contribuições na otimização multiobjetivo aplicadas a problemas de reabilitação de redes de distribuição de água. Esses pesquisadores aplicaram e descreveram uma das técnicas mais avançadas encontradas na área de análise de sistemas, que trata os problemas com vários objetivos simultaneamente, sem ter que arbitrar pesos em suas formulações. Os algoritmos genéticos desenvolvidos para problemas multiobjetivo puderam identificar as soluções ótimas Pareto considerando os critérios custo e confiabilidade na substituição de tubulações a serem efetuadas no sistema. A confiabilidade foi definida em termos do número esperado de interrupções no sistema por ano. Um modelo de estimação das quebras de tubulações foi acoplado a um simulador hidráulico para definir o número esperado de interrupções. A identificação da frente Pareto ótima foi realizada através dos algoritmos genéticos multiobjetivo, com base na aproximação proposta por FONSECA e FLEMING (1993).

A revisão bibliográfica realizada demonstra que o estado da arte continua avançando e que vários modelos computacionais vem sendo desenvolvidos e aperfeiçoados para a análise dos problemas de sistemas de abastecimento de água. É certo, que esses sistemas não são conhecidos em sua totalidade e que várias incertezas estão presentes (demandas, parâmetros de rugosidade, material das tubulações, falhas, dentre outros), tornando o processo de planejamento complexo. No entanto, os modelos de otimização são as ferramentas mais poderosas e eficientes no tratamento dessa problemática, pois conseguem agregar não só as características físicas do sistema, mas fatores econômicos, operacionais, de confiabilidade e de qualidade de água, auxiliando os decisores e os analistas na tomada de decisão, de forma a satisfazer o consumidor e gerenciar os recursos hídricos eficientemente, preservando-os para futuras gerações.

Consideráveis esforços foram despendidos, ao longo da última década, no desenvolvimento de técnicas de otimização que tratam o problema de otimização de forma multiobjetivo. Consequentemente, várias simplificações e aproximações foram 
consideradas no processo de modelação. Com o surgimento das técnicas evolucionárias, como os algoritmos genéticos, a otimização passou por uma mudança de paradigma, conseguindo identificar os "ótimos globais" que até então não eram garantidos pelos métodos convencionais. Reconhecendo que os problemas de recursos hídricos possuem objetivos múltiplos e conflitantes, alguns pesquisadores (HALHAL et al. 1997; WALTERS et al., 1999; DANDY e ENGELHARDT, 2001b; CHEUNG et al., 2003; FORMIGA et al., 2003) consideraram tais aspectos em seus trabalhos. Porém, os AGs apesar de serem extremamente adaptados para buscas paralelas, sofreram também modificações para se adequarem ao problema de objetivos múltiplos. Mas só após a proposição de FONSECA e FLEMING (1993) que os algoritmos genéticos multiobjetivo se consolidaram como técnica de otimização multiobjetivo propriamente dita. A partir desse trabalho, vários métodos foram propostos na literatura (SRINIVAS e DEB, 1995; HORN e NAFPLIOTIS, 1994; ZITZLER, 1999; DEB, 2001), porém ainda não foram totalmente investigados e aplicados aos problemas de abastecimento de água. O próximo capítulo deste trabalho apresenta essa nova classe de métodos para os problemas de otimização multiobjetivo. 


\section{MODELOS DE OTIMIZAÇÃO MULTIOBJETIVO}

A existência de objetivos múltiplos e conflitantes na investigação de sistemas de naturezas diversas faz com que analistas busquem métodos mais confiáveis e eficientes para identificação de soluções. Em muitas aplicações apresentadas na literatura o problema multiobjetivo foi tratado como um problema de objetivo único e solucionado através de métodos de otimização convencionais. No entanto, com o aparecimento de técnicas de otimização não convencionais tais como os algoritmos evolucionários (AEs), flexíveis na busca paralela de solução, os problemas de otimização multiobjetivo vêm sendo revistos. Neste capítulo são apresentados os princípios e os conceitos básicos da otimização multiobjetivo, além de uma breve revisão das técnicas convencionais e das técnicas multiobjetivo não convencionais, baseadas na programação evolucionária.

\subsection{Considerações gerais}

Desde o advento da pesquisa operacional, durante a Segunda Guerra Mundial, técnicas de programação matemática vêm sendo desenvolvidas, aperfeiçoadas e aplicadas aos diversos problemas de engenharia existentes. Inicialmente essas técnicas não contemplavam abordagens científicas, apenas auxiliavam as decisões operacionais militares. Entretanto, o reconhecimento da importância da pesquisa operacional como ferramenta de resolução dos problemas complexos propiciou o seu emprego nas diversas áreas do conhecimento ${ }^{8}$. Diversas metodologias foram propostas ao longo do tempo com intuito de difundir procedimentos sistêmicos capazes de estruturar os processos reais através de modelos matemáticos, analisar interações entre alternativas de projeto e consequências futuras e desenvolver métodos para obtenção de alternativas de projeto que satisfaçam às necessidades da sociedade.

Programação linear, não linear e dinâmica são algumas dessas técnicas utilizadas com o objetivo maximizar ou minimizar uma função (função objetivo) sujeita a restrições. É conveniente destacar que tais técnicas possuem características distintas. A programação

\footnotetext{
${ }^{8}$ MAASS et. al. (1962) foram quem introduziram a pesquisa operacional no planejamento e gerenciamento de recursos hídricos.
} 
linear é distinta ao tratamento de problemas em que a função objetivo e as restrições podem ser expressas através de relações lineares das variáveis de decisão. A programação não linear é adequada aos problemas que envolvem função objetivo ou, no mínimo, uma restrição não linear. Já a programação dinâmica é uma técnica adequada para resolução de problemas sequenciais.

Nos últimos anos, vários pesquisadores (GOICOECHEA, HANSEN e DUCKSTEIN, 1982; LOUCKS, STEDINGER e HAITH 1981; COELLO, 1996; VELDHUIZEN, 1999; WALSKI, 2001) vêm tecendo críticas em relação ao desenvolvimento e aplicação das técnicas de programação matemática. O argumento principal levantado por esses autores é que essas técnicas são formuladas utilizando critério único, ao contrário dos problemas reais em engenharia, principalmente na área de recursos hídricos, nos quais os objetivos são múltiplos e conflitantes. Enquanto a otimização de objetivo único produz uma única solução, denominada solução ótima, o procedimento que envolve mais do que um objetivo é conhecido como otimização multiobjetivo e visa produzir um conjunto de soluções denominadas na literatura como soluções ótimas Pareto ou soluções Trade-offs. Essas soluções são ótimas porque não há outras soluções superiores a elas no espaço de busca, quando todos os objetivos são considerados.

Existem vários algoritmos propostos na literatura para tratar o problema multiobjetivo. COHON (1978) em seu livro texto classificou esses modelos em dois grupos, técnicas de geração de soluções não dominadas e técnicas baseadas na preferência do decisor, ilustrados através da Figura 4.1.

As técnicas de geração de soluções não dominadas têm apenas a função de produzir um conjunto de vetores solução para que o decisor possa escolher a solução que mais the convém. As técnicas baseadas na preferência do decisor (articulação prévia ou articulação posterior) utilizam informações de preferência de cada objetivo e iterativamente geram um conjunto de soluções ótimas. GOICOECHEA, HANSEN e DUCKSTEIN (1982) denominam essas técnicas (preferência) como métodos interativos, que são caracterizadas pelo conhecimento prévio necessário e pela interferência do decisor a cada iteração durante o processo. Nessa etapa do processo, o decisor influencia a direção do espaço de busca, o vetor peso e os pontos de referência. Isso justifica a interação do decisor com o processo de otimização, fornecendo dessa forma, suas informações implícitas ao problema. 


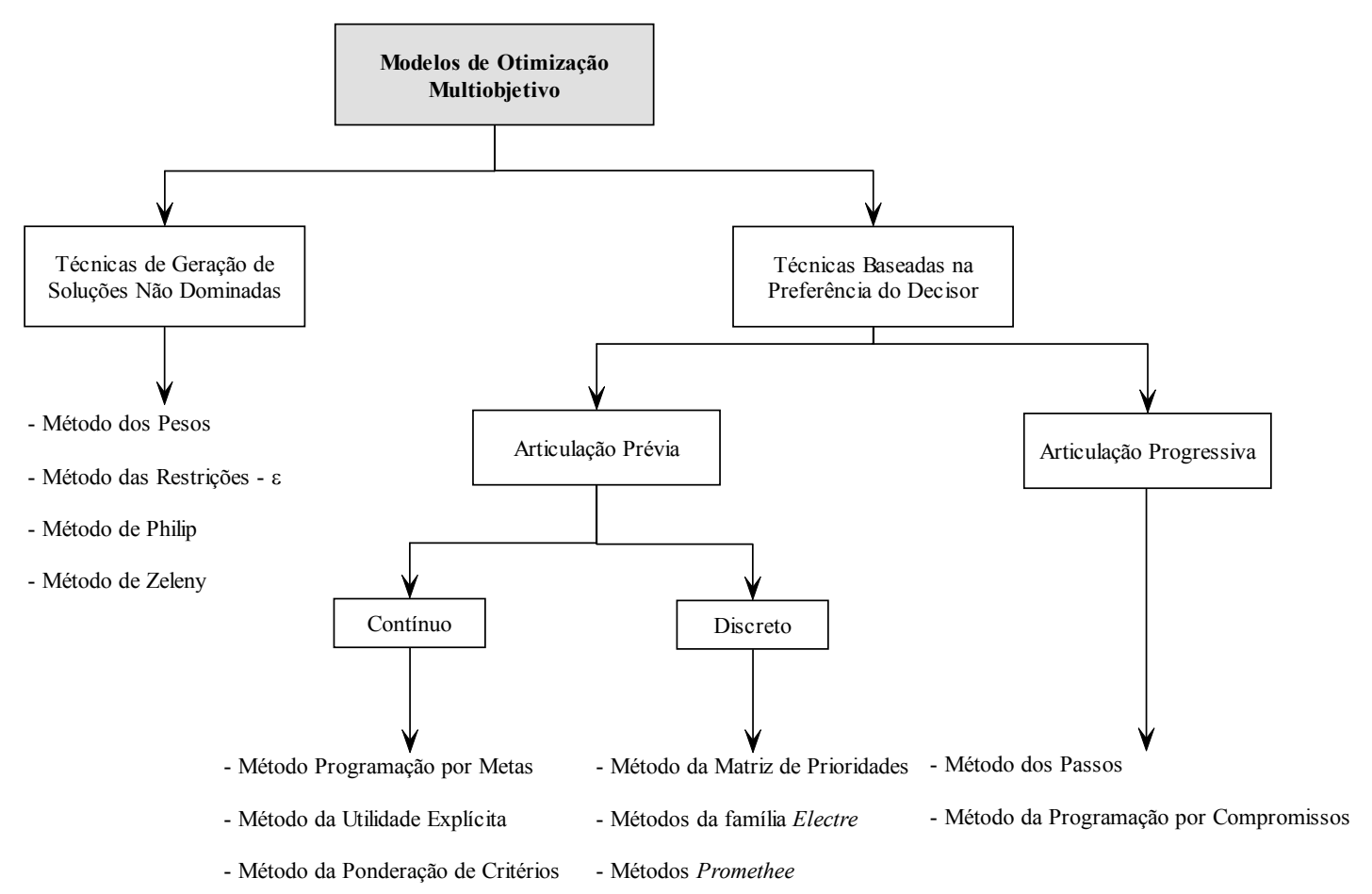

Figura 4.1 - Classificação dos modelos de otimização multiobjetivo convencionais

Quase todas as técnicas multiobjetivo convencionais apresentadas por COHON (1978) e GOICOECHEA, HANSEN e DUCKSTEIN (1982) transformam um problema de otimização de objetivos múltiplos em um problema de otimização de objetivo único. Por exemplo, o método de soma ponderada sugere minimizar uma soma (ponderada) de objetivos múltiplos; o método das restrições- $\varepsilon$ sugere otimizar uma função objetivo e utilizar todos os outros objetivo como restrições; o método de métricas ponderadas sugere minimizar um elemento métrico, que representa todos os objetivos; o método da programação de metas sugere minimizar uma soma ponderada dos desvios das metas. A formulação resultante permite que técnicas clássicas de otimização sejam utilizadas na solução do problema.

Embora muitos métodos de otimização desenvolvidos para o planejamento e o gerenciamento de recursos hídricos, tenham produzido soluções razoáveis à tomada de decisão, há um interesse por parte dos pesquisadores (GOICOECHEA, HANSEN e DUCKSTEIN, 1982; WALSKI, 2001; FRANCATO, 2002; CHEUNG et al. 2003; FORMIGA et al., 2003) em identificar e considerar simultaneamente vários objetivos na análise e solução desses problemas. As motivações principais que levam esses pesquisadores a analisar seus problemas sob a ótica da otimização multiobjetivo são: a definição explícita de objetivos múltiplos ao invés de tratar o problema como objetivo único, a geração de várias soluções (estratégias) simultaneamente com múltiplos valores 
(custo, benefício, vazamentos, confiabilidade, dentre outros) associados para cada solução, a avaliação de várias alternativas de projeto, operação e/ou reabilitação e a seleção da alternativa preferida pelo decisor, com conhecimento da compensação em relação a cada objetivo.

Dessa forma, um modelo de otimização multiobjetivo consistente deve contemplar os diversos objetivos envolvidos simultaneamente em suas análises, de forma a identificar soluções alternativas para o problema.

Técnicas de otimização convencionais, como métodos de busca direta ou métodos baseados no gradiente da função, são de difícil aplicação ao caso multiobjetivo, porque não trabalham com soluções múltiplas. Há, portanto, uma tendência em substituir os métodos de otimização convencionais por técnicas de otimização multiobjetivo não convencionais baseadas na programação evolucionária. Assim, o que se pretende nessa revisão é contemplar os conceitos básicos da otimização multiobjetivo e apresentar os modelos não convencionais propostos na literatura.

\subsection{Otimização multiobjetivo}

Um problema de otimização multiobjetivo consiste em um número de funções objetivo a serem minimizadas ou maximizadas simultaneamente. De maneira semelhante à otimização de objetivo único, a otimização multiobjetivo contém um número de restrições que devem ser satisfeitas. Neste item são apresentados os conceitos e terminologias da otimização multiobjetivo, de acordo com ZITZLER (1999). Sem perder generalidade, esse autor apresenta o conceito geral do problema multiobjetivo, para um problema de maximização e garante que para problemas de minimização ou mistos, maximização e minimização, as definições apresentadas são semelhantes. $\mathrm{O}$ problema pode então ser formulado, de maneira geral, segundo a Definição (1).

Definição 1: (Problema de Otimização Multiobjetivo) Um problema de otimização multiobjetivo inclui um conjunto de n parâmetros (variáveis de decisão), um conjunto de $k$ funções objetivo e $m$ restrições, funções das variáveis de decisão. O objetivo da otimização é:

$$
\begin{array}{ll}
\text { Maximizar } & \mathrm{y}=\mathrm{f}(\mathrm{x})=\left(\mathrm{f}_{1}(\mathrm{x}), \mathrm{f}_{2}(\mathrm{x}), \ldots, \mathrm{f}_{\mathrm{k}}(\mathrm{x})\right) \\
\text { sujeito à } & \mathrm{g}(\mathrm{x})=\left(\mathrm{g}_{1}(\mathrm{x}), \mathrm{g}_{2}(\mathrm{x}), \ldots, \mathrm{g}_{\mathrm{m}}(\mathrm{x})\right) \leq 0
\end{array}
$$


sendo

$$
\begin{aligned}
& x=\left(x_{1}, x_{2}, \ldots, x_{n}\right) \in X \\
& y=\left(y_{1}, y_{2}, \ldots, y_{k}\right) \in Y
\end{aligned}
$$

$e \mathrm{x}$ é o vetor de decisão, $\mathrm{y}$ é o vetor objetivo, $\mathrm{X}$ é denotado como o espaço de decisão e $\mathrm{Y}$ é denominado espaço objetivo. As restrições $\mathrm{g}(\mathrm{x}) \leq 0$ determinam o conjunto de soluções factíveis. Uma solução x que não satisfaz todas essas restrições (m) e todos os limites de cada variável de decisão é denominada solução infactível. Por outro lado, se alguma solução x satisfaz todas as restrições e todos os limites de cada variável de decisão, é denominada solução factível. O conjunto de todas soluções factíveis é denominado região factível ou $\mathrm{Y}$.

Definição 2: (Conjunto Factível) $O$ conjunto factível $\mathrm{X}_{\mathrm{f}}$ é definido como o conjunto de vetores de decisão $\mathrm{x}$ que satisfazem às restrições $\mathrm{g}(\mathrm{x})$ :

$$
X_{f}=\{x \in X \mid g(x) \leq 0\}
$$

A imagem de $\mathrm{X}_{\mathrm{f}}$, isto é, a região factível no espaço da superficie de resposta, é denotada como $\mathrm{Y}_{\mathrm{f}}=\mathrm{f}\left(\mathrm{X}_{\mathrm{f}}\right)=\mathrm{U}_{\mathrm{x} \in \mathrm{X}_{\mathrm{f}}}\{\mathrm{f}(\mathrm{x})\}$

A solução ótima global para um problema de objetivo único representa o valor mínimo ou máximo de determinada função atendendo todas as restrições. Entretanto, nos problemas multiobjetivo pode-se dizer que os ótimos globais são diferentes. O ideal seria que o valor ótimo de uma função (mínimo ou máximo) fosse ótimo para as outras funções também. Particularmente isso pode ocorrer, mas nem sempre acontece. Nos problemas de otimização multiobjetivo, geralmente, os objetivos são conflitantes, e consequentemente, uma solução que é ótima para uma dada função não é ótima para as outras funções. Portanto, os objetivos não podem ser otimizados simultaneamente, ao contrário, o que se pretende é buscar uma relação satisfatória, denominada também compensatória, compatibilizada ou de compromisso, entre as funções. Essa relação (trade-off) é contextualizada através da definição de otimalidade.

$\mathrm{Na}$ otimização de objetivo único, o conjunto factível é completamente ordenado de acordo com sua função objetivo (f). Por exemplo, para duas soluções a e b pertencentes ao conjunto $X_{f}$, o que pode ocorrer é $f(a) \geq f(b)$ ou $f(b) \geq f(a)$. A meta então é encontrar a solução que fornece um valor máximo ou mínimo de f. Entretanto, quando 
vários objetivos são envolvidos, a situação muda. Por exemplo, $\mathrm{X}_{\mathrm{f}}$, é, em geral não totalmente ordenado, mas parcialmente ordenado ${ }^{9}$, ilustrado pela Figura 4.2. Nessa ilustração considera-se que as funções $f_{1}$ e $f_{2}$ devam ser maximizadas. A solução representada pelo ponto $\mathrm{B}$ é melhor que a solução representada por $\mathrm{C}$, porque $\mathrm{B}$ apresenta maior valor que $\mathrm{C}$ para $\mathrm{f}_{1} \mathrm{e}_{2}$. Comparando $\mathrm{C}$ e $\mathrm{D}, \mathrm{C}$ é melhor que $\mathrm{D}$ porque o valor de $\mathrm{C}$ para $\mathrm{f}_{1}$ é maior e para $\mathrm{f}_{2}$ as soluções empatam. Para expressar essa situação matematicamente, as relações $=, \geq$ e $>$ são estendidos aos vetores objetivo por analogia ao caso de otimização de um único objetivo.

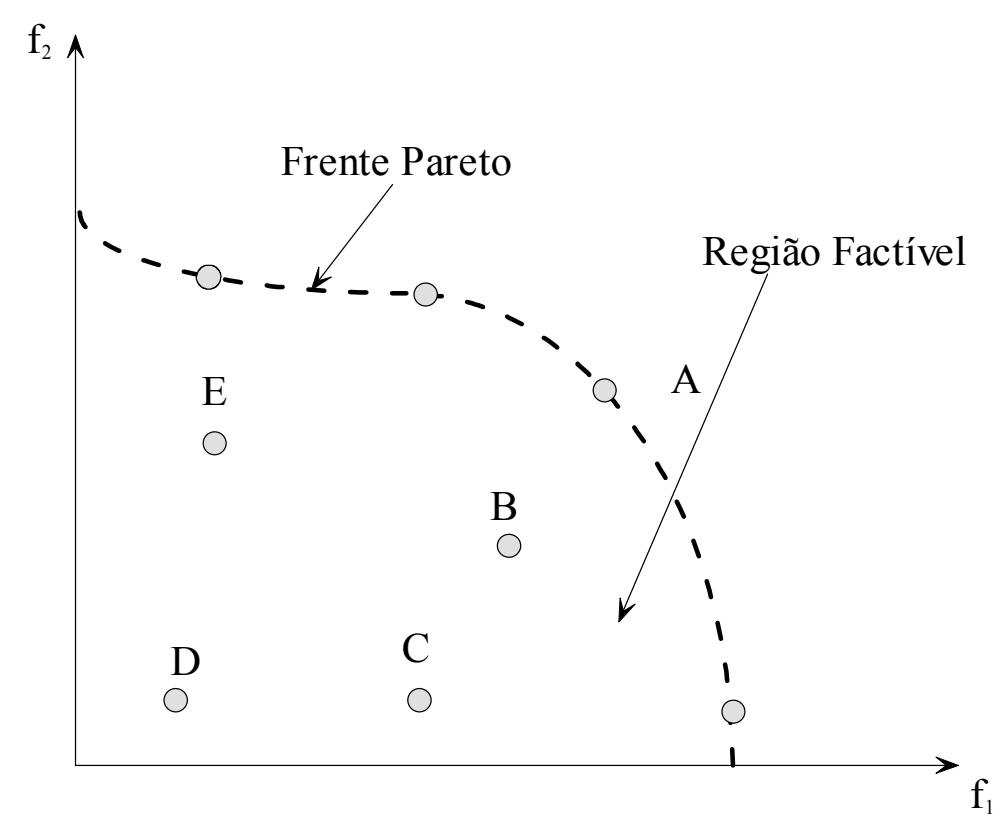

Figura 4.2 - Espaço variável de decisão (ZITZLER, 1999)

Definição 3: Considerando dois vetores $u$ e $v$,

$$
\begin{aligned}
& \mathrm{u}=\mathrm{v} \text { se e somente } \text { se } \forall \mathrm{i} \in\{1,2, \ldots, \mathrm{k}\}: \mathrm{u}_{\mathrm{i}}=\mathrm{v}_{\mathrm{i}} \\
& \mathrm{u} \geq \mathrm{v} \text { se e somente se } \forall \mathrm{i} \in\{1,2, \ldots, \mathrm{k}\}: \mathrm{u}_{\mathrm{i}} \geq \mathrm{v}_{\mathrm{i}} \\
& \mathrm{u}>\mathrm{v} \text { se e somente } \text { se } \mathrm{u} \geq \mathrm{v} \wedge \mathrm{u} \neq \mathrm{v}
\end{aligned}
$$

As relações $\leq e<$ são definidas similarmente.

Utilizando a notação da Definição (3), pode-se garantir na ilustração (Figura 4.2) que B $>$ C,$C>$ D implica que B $>$ D. Entretanto, quando B e E são comparados entre si, não se pode identificar qual solução é superior, desde que $\mathrm{B} \ngtr \mathrm{E}$ e $\mathrm{E} \ngtr \mathrm{B}$. Embora a

${ }^{9}$ PARETO, V. (1896) - Cours D' Ecomomie Politique, vol.I e II, F. Rouge, Lausanne. 
solução $E$ tenha maior valor de $f_{2}$ do que a solução $B$, quando observada a função $f_{1}$, a solução E tem menor valor que a solução B. Portanto, duas variáveis de decisão quaisquer $\mathrm{a}$ e $\mathrm{b}$ podem ter três possibilidades nos problemas multiobjetivo considerando o símbolo $\geq$ (em contraste aos problemas de objetivo único com duas soluções sendo comparadas): $f(a) \geq f(b), \quad f(b) \geq f(a)$, ou $f(a) \geq f(b) \wedge f(b) \geq f(a)$. Neste trabalho, essas terminologias são utilizadas para classificar e ordenar diferentes situações.

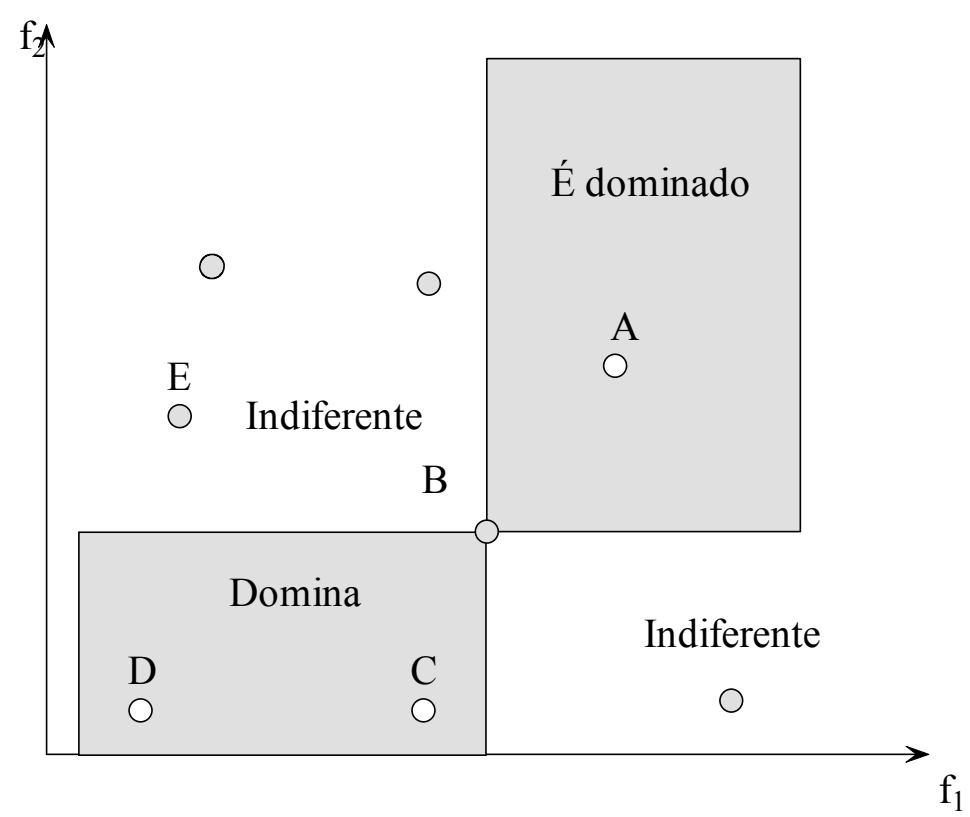

Figura 4.3 - Espaço função objetivo (ZITZLER, 1999)

Definição 4: (Dominância Pareto) Considerando conjunto dois vetores de decisão a $e$ b,

$$
\begin{array}{ll}
a \succ b(\text { a domina } b) & \text { se e somente se } f(a)>f(b) \\
a \succeq b(\text { a domina fracamente } b) & \text { se e somente se } f(a) \geq f(b) \\
a \sim b(\text { a é indiferente } a b) & \text { se e somente se } f(a) \ngtr f(b)
\end{array}
$$

As definições para os problemas de minimização $(\prec, \prec, \sim)$ são análogas.

Na Figura 4.3 no retângulo referenciado com o texto "Domina", significa que o vetor solução B domina todo espaço objetivo que contem as soluções C e D. O outro retângulo referenciado com o texto "É dominado", significa que o vetor solução A 
domina o vetor solução B. Todas as outras soluções pertencentes ao espaço objetivo são indiferentes em relação ao vetor solução B.

Assim, pode-se introduzir o critério da otimalidade baseado no conceito de dominância Pareto. O vetor solução A (Figura 4.2) é único dentre as outras soluções (C, D e E) não dominado por nenhum outro vetor no espaço objetivo. Tais soluções são denominadas Ótimas Pareto ou Não Inferiores (COHON, 1978).

Definição 5: (Otimalidade Pareto) $U m$ vetor de decisão $\mathrm{x} \in \mathrm{X}_{\mathrm{f}}$ é dito ser não dominado, ao considerar um conjunto $\mathrm{A} \subseteq \mathrm{X}_{\mathrm{f}}$, se e somente se

$$
\nexists \mathrm{a} \in \mathrm{A}: \mathrm{a} \succ \mathrm{x}
$$

Se estiver claro qual conjunto A é mencionado, essa relação simplesmente é omitida. Além disso, $\mathrm{x}$ é dito ser ótimo Pareto se e somente se $\mathrm{x}$ é não dominado considerando $\mathrm{X}_{\mathrm{f}}$.

Na Figura 4.2 todos os outros pontos pertencentes à linha pontilhada são soluções ótimas Pareto. Essas soluções são indiferentes umas das outras. Essa é a principal diferença dos problemas de otimização de objetivo único, não existe uma solução ótima, mas um conjunto de soluções compatibilizadas. Nenhuma dessas soluções pode ser dita melhor que as outras, a não ser que, alguma informação de preferência seja incluída. $\mathrm{O}$ conjunto de todas as soluções ótimas Pareto é denominado conjunto Pareto ótimo; os vetores (objetivo) correspondentes formam a frente ou a superficie Pareto ótima.

Definição 6: (Frentes e Conjuntos Não Dominados) Sendo $\mathrm{A} \subseteq \mathrm{X}_{\mathrm{f}}$. A função $\mathrm{p}(\mathrm{A})$ fornece o conjunto de vetores de decisão não dominado em $\mathrm{A}$ :

$$
\mathrm{p}(\mathrm{A})=\{\mathrm{a} \in \mathrm{A} \mid \mathrm{a} \text { é não dominado em } \mathrm{A}\}
$$

O conjunto $\mathrm{p}(\mathrm{A})$ é o conjunto não dominado em $\mathrm{A}$, o conjunto correspondente de vetores objetivo $\mathrm{f}(\mathrm{p}(\mathrm{A}))$ é a frente não dominada em A. Além disso, o conjunto $\mathrm{X}_{\mathrm{p}}=\mathrm{p}\left(\mathrm{X}_{\mathrm{f}}\right)$ é denominado conjunto Pareto ótimo e o conjunto $\mathrm{Y}_{\mathrm{p}}=\mathrm{f}\left(\mathrm{X}_{\mathrm{p}}\right)$ é denotado frente Pareto ótima.

O conjunto Pareto ótimo compreende as soluções de melhor compromisso. Entretanto, semelhante à otimização de objetivo único, na otimização multiobjetivo também existe os ótimos locais que constituem um conjunto não dominado dentro de uma certa 
vizinhança. Isso corresponde aos conceitos de conjunto ótimo local e global apresentado por DEB (1999).

Definição 7: Considerando um conjunto de vetores de decisão $A \subseteq X_{f}$.

1. O conjunto A é denotado como um conjunto ótimo Pareto se e somente se

$$
\forall \mathrm{a} \in \mathrm{A}: \nexists \mathrm{x} \in \mathrm{X}_{\mathrm{f}}: \mathrm{x} \succ \mathrm{a} \wedge\|\mathrm{x}-\mathrm{a}\|<\varepsilon \wedge\|\mathrm{f}(\mathrm{x})-\mathrm{f}(\mathrm{a})\|<\delta
$$

sendo que $\|$.$\| é uma métrica de distância correspondente e \varepsilon>0, \delta>0$.

2. O conjunto A é denominado um conjunto Pareto ótimo global se e somente se

$$
\forall \mathrm{a} \in \mathrm{A}: \nexists \mathrm{x} \in \mathrm{X}_{\mathrm{f}}: \mathrm{x} \succ \mathrm{a}
$$

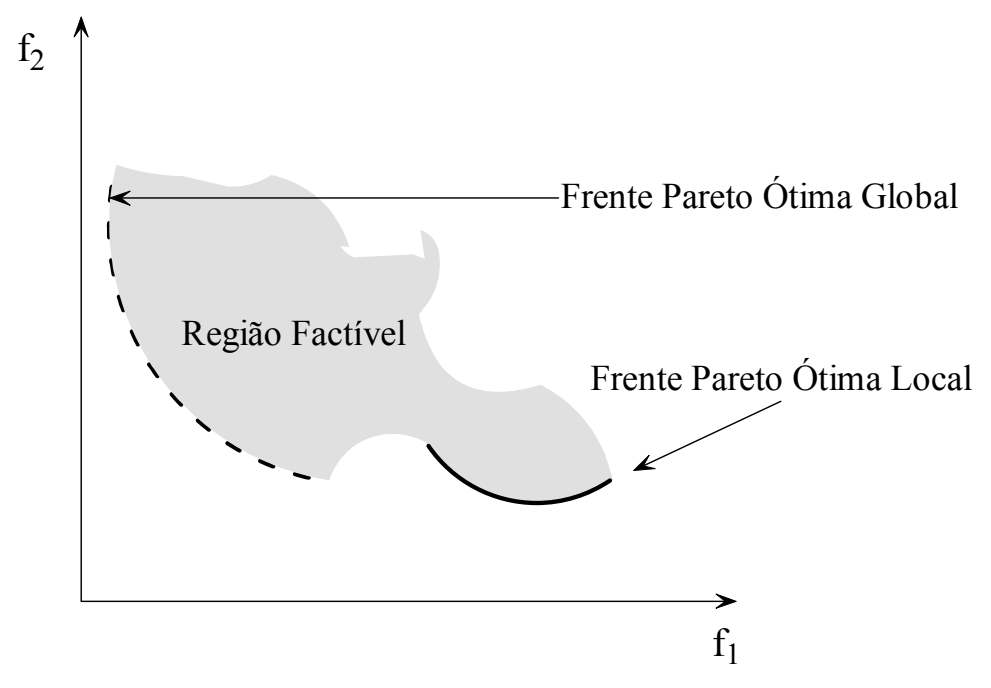

Figura 4.4 - Ilustração dos conjuntos Pareto ótimo global e local (ZITZLER, 1999) considerando um problema de minimização

A diferença entre os ótimos global e local é ilustrada pela Figura 4.4. A linha pontilhada constitui a frente Pareto ótima global enquanto a linha continua uma frente Pareto ótima local. Pode-se notar que a um conjunto Pareto ótimo não necessariamente contem todas soluções ótimas Pareto e que o conjunto ótimo global é um conjunto ótimo local.

DEB (2001) apresenta uma relação ideal para o procedimento multiobjetivo, o qual é dividido em duas etapas. A primeira etapa tem como objetivo gerar as soluções ótimas aplicando-se algum modelo de otimização e a segunda etapa refere-se à escolha dessas soluções. Existem modelos que também podem ser aplicados nessa segunda etapa, como forma de classificar as soluções seguindo uma ordem de preferência fornecida por decisores. De forma geral, a Figura 4.5 apresenta tal procedimento. 
Cada solução na frente Pareto corresponde a uma ordem específica de importância dos objetivos. Assim, se fatores de preferência entre os objetivos forem conhecidos para um problema específico, não há necessidade de seguir o princípio mostrado na Figura 4.5 para um problema multiobjetivo.

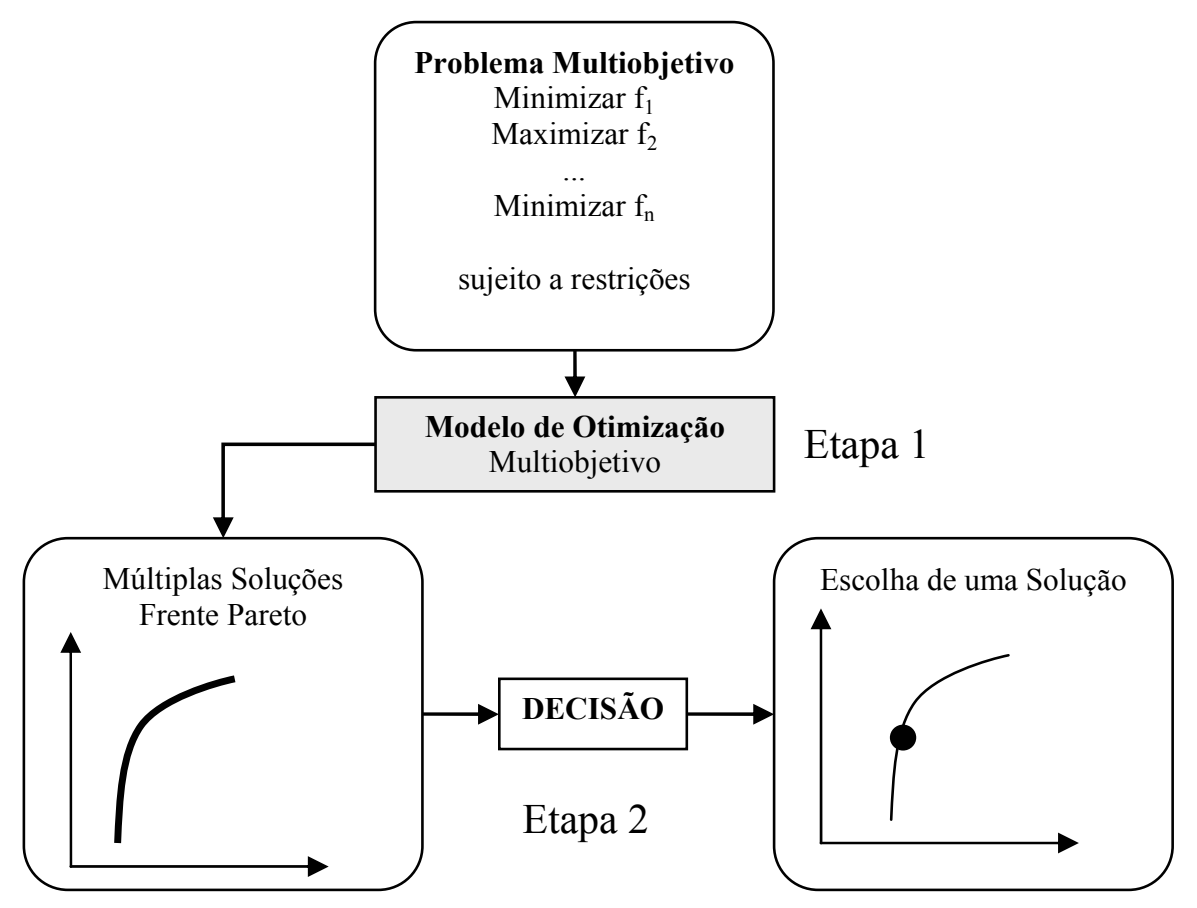

Figura 4.5 - Esquema geral de um procedimento multiobjetivo (DEB, 2001)

Um método simples seria compor uma função através da soma dos pesos dos objetivos, onde um peso para um objetivo é proporcional ao fator de preferência garantido para um objetivo, em particular. O procedimento de escalonar um vetor objetivo em uma única função converte o problema multiobjetivo em um problema de objetivo único. Quando uma função é composta dessa forma, a solução obtida, geralmente, representa uma solução aproximada de uma solução de compromisso particular.

\subsection{Algoritmos evolucionários}

A pesquisa operacional tem mudado nos últimos anos pela introdução de algoritmos de otimização não convencionais denominados Algoritmos Evolucionários (AEs). Segundo ZITZLER (1999) o termo evolucionário vem de uma classe de métodos de otimização estocásticos que compartilham a mesma base conceitual, com intuito de simular o processo de evolução de qualquer sistema. Os AEs são classificados em: Algoritmos Genéticos (AGs), Estratégias de Evolução (EE), Programação Evolucionária (PE), Programação Genética (PG) e Sistemas Classificatórios (SCs). 
ZITZLER (1999) menciona ainda que os AEs tiveram sua origem marcada por volta de 1950, e que a partir de 1970 várias metodologias foram propostas. Todas essas técnicas operam um conjunto de soluções simultaneamente (algoritmos populacionais). Esse conjunto evolui por dois princípios básicos: seleção e variação. A seleção é baseada no princípio da seleção natural de Darwin e representa a competição entre indivíduos de mesma espécie, sendo caracterizada pela escolha de soluções candidatas dentro desse conjunto de possíveis soluções e simulada por um processo de seleção estocástica. Cada solução recebe a chance de se reproduzir um certo número de vezes, dependendo da sua qualidade enquanto solução. A qualidade da solução é denominada valor aptidão ou fitness na literatura especializada (GOLDBERG, 1989; MICHALEWICZ, 1992; GEN e CHENG, 1996). O outro princípio, a variação, imita a capacidade natural das espécies de criar "novos" indivíduos, no caso dos AGs, esse princípio é analogamente associado ao processo de recombinação e mutação.

SRINIVAS e DEB (1995) afirmaram que os AEs são robustos por buscarem pontos de inflexão em funções descontínuas, multimodais e perturbadas em espaços complexos. Adicionalmente, ZITZLER (1999) garantiu que esses algoritmos são extremamente adaptados ao problema de otimização multiobjetivo pela habilidade de manter múltiplas soluções em uma única simulação e pela facilidade em se explorar regiões do espaço através do principio da variação (recombinação e mutação).

Nos trabalhos aplicados a sistemas de distribuição de água para abastecimento maior atenção foi dada aos algoritmos genéticos (AGs) convencionais. A literatura reporta diversas e recentes aplicações (SIMPSON, DANDY e MURPHY, 1994; REIS, PORTO e CHAUDHRY, 1997; HALHAL et al., 1997, WALTERS et al., 1999; SILVA, 2003; SOARES, 2003) desses algoritmos. A seguir apresenta-se uma descrição sucinta dos AGs convencionais cujos conceitos podem ser aprofundados com o auxílio de textos especializados, tais como GOLDBERG (1989), MICHALEWICZ (1992), GEN e CHENG (1996) e DEB(2001).

Os AGs são métodos de busca estocástica que imitam matematicamente os mecanismos de evolução natural das espécies, compreendendo processos da genética das populações, sobrevivência e adaptação dos indivíduos. Foram inicialmente desenvolvidos por John Holland, em 1975, porém quem os popularizou foi um dos seus alunos (GOLDBERG, 1989). Os objetivos desses pesquisadores, inicialmente, foram investigar e projetar sistemas artificiais, análogos aos mecanismos naturais considerados perfeitos. Em 
termos biológicos, a evolução natural é o processo que ocorre nos cromossomos (elementos microscópicos das células nucleares) dos quais as informações hereditárias são transmitidas para seus descendentes, através dos genes.

Os AGs diferem das técnicas de busca convencionais, pois iniciam o processo gerando aleatoriamente um conjunto inicial de soluções possíveis denominadas população. Cada indivíduo dessa população, denominado cromossomo, constitui uma possível representação completa de solução para o problema. O cromossomo é representado por um vetor, cujos elementos são denominados analogamente genes, que representam as características de uma solução e podem ser codificados através de números binários ou reais. Os cromossomos tendem a evoluir gradativamente através de sucessivas iterações, produzindo novas gerações de indivíduos mais aptos ou capazes em termos da função de aptidão.

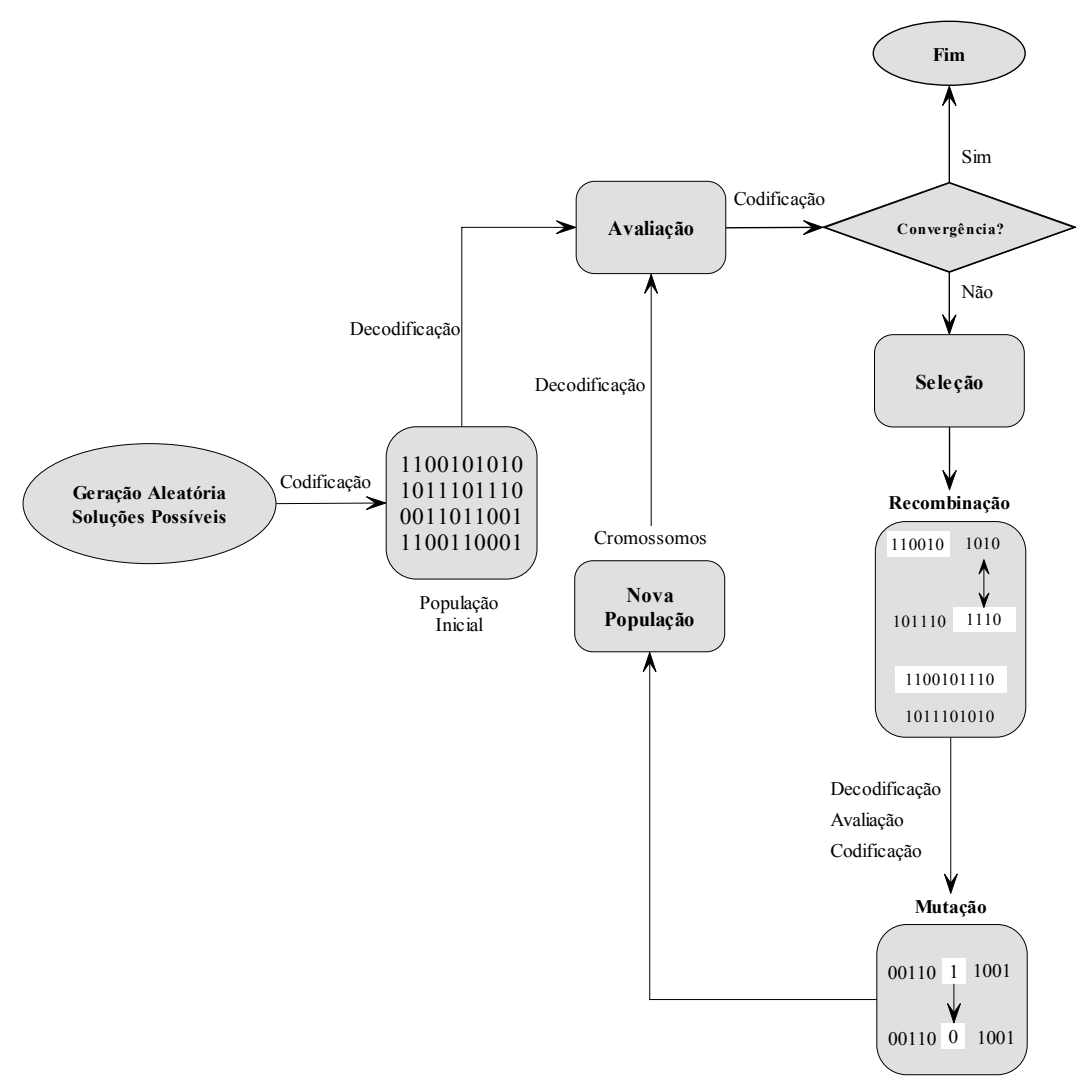

Figura 4.6 - Esquema geral dos algoritmos genéticos convencionais

Durante cada iteração (geração), as soluções (cromossomos) são avaliadas através da função objetivo ou através de uma função modificada (aptidão), que permite sua classificação e ordenação enquanto solução. Uma nova geração é formada através dos processos de seleção, recombinação e mutação, cujas soluções com valor elevado da função objetivo têm maior probabilidade de serem preservadas para a próxima geração. 
Para se criar uma nova geração, novos cromossomos denominados filhos ou descendentes são produzidos pela combinação de dois indivíduos pais (cromossomos) da geração corrente, utilizando os operadores genéticos de recombinação e mutação (modificação eventual dos genes). Após várias iterações o algoritmo converge para uma solução ótima ou quase ótima do problema.

Apesar de seguirem uma estrutura geral, conforme apresentada no esquema da Figura 4.6, onde as soluções são representadas em código binário, diversas são as possibilidades de implementação dos AGs em termos da sistemática de representação das soluções, dos operadores genéticos e dos parâmetros a serem adotados como as probabilidades de recombinação e mutação, o número de indivíduos da população de soluções e o critério de convergência.

\subsubsection{Exemplo de evolução dos algoritmos genéticos}

Para exemplificar e ilustrar as etapas de evolução dos AGs, foi aplicado pelo autor do presente trabalho os AGs em um problema simples de maximização (eq. 4.9).

$$
\operatorname{Maximizar} \mathrm{f}\left(\mathrm{x}_{1}, \mathrm{x}_{2}\right)=\mathrm{x}_{1}+\mathrm{e}^{\left(-\mathrm{x}_{1}^{2}-\mathrm{x}_{2}^{2}\right)}
$$

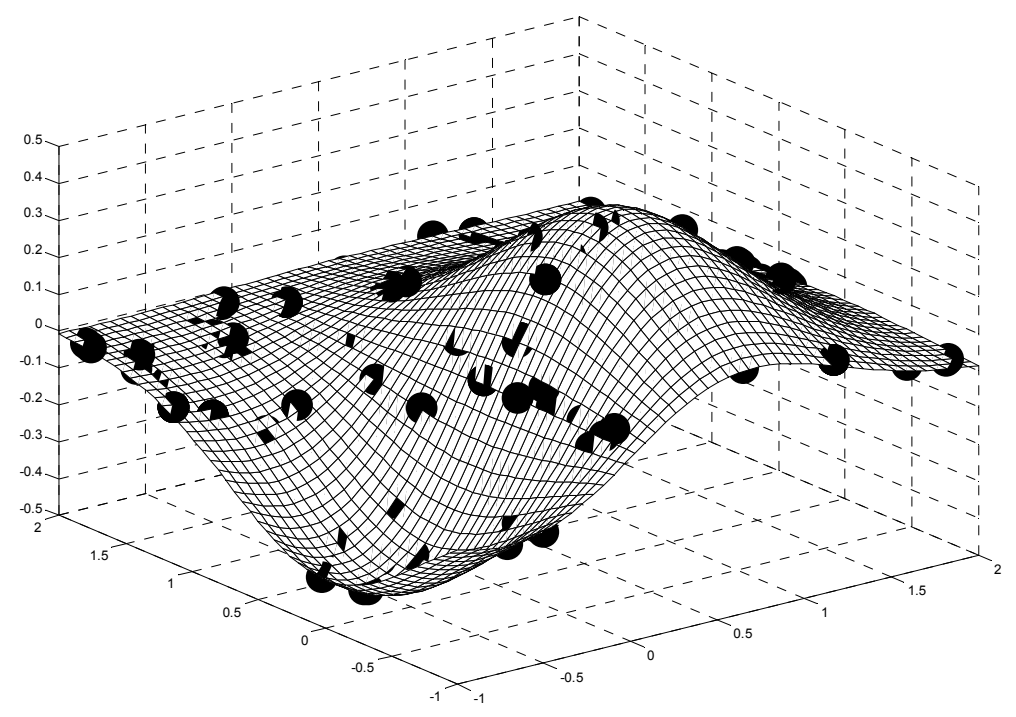

Figura 4.7 - População inicial referente ao problema (4.9)

Um pacote computacional (GAlib) escrito em C++ por WALL (1996) e desenvolvido especificamente para AGs, foi utilizado para demonstração de tal procedimento. O número de vetores soluções contidos no conjunto inicial foi 100 , o número de iterações 
foi 500, as probabilidades de recombinação e mutação foram 0,9 e 0,01 , respectivamente.

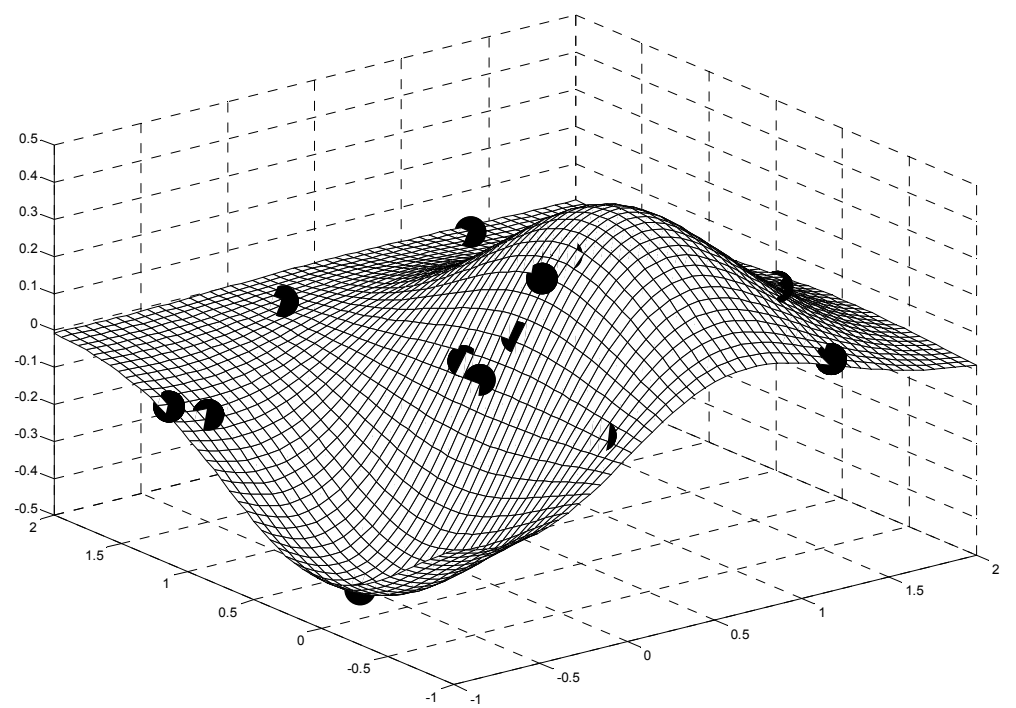

Figura 4.8 - População corrente dos AGs (iteração 30) referente ao problema (4.9)

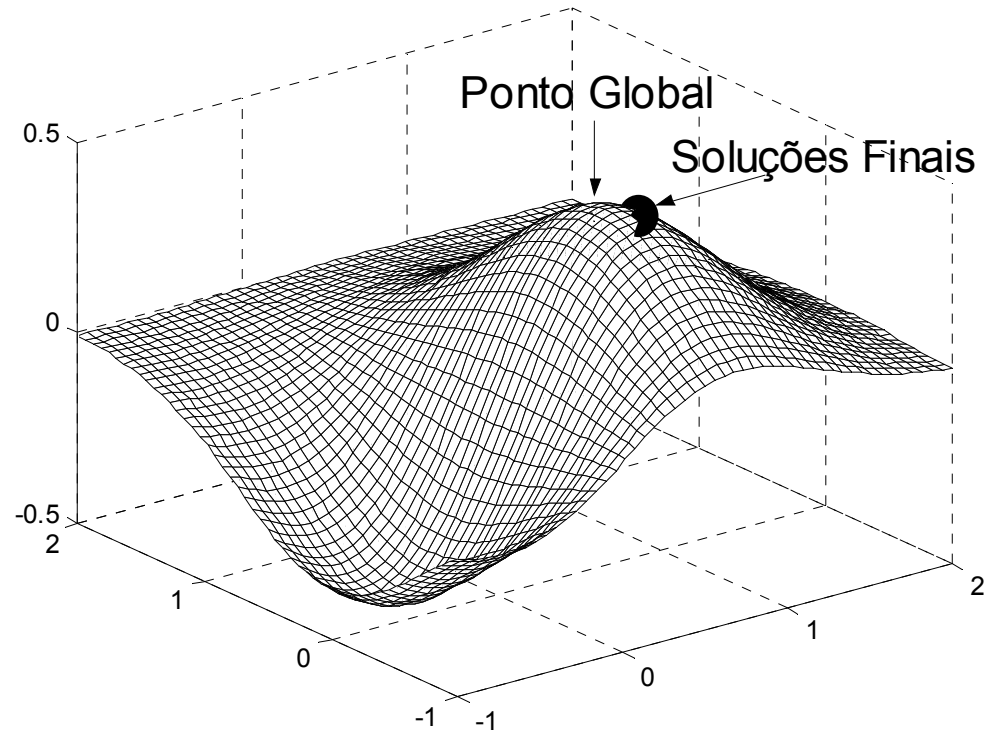

Figura 4.9 - População final dos AGs (iteração 500) referente ao problema (4.9)

A Figura 4.7 tem objetivo de ilustrar o conjunto inicial de soluções no espaço de objetivos gerado aleatoriamente pelos AGs e a maneira com que esses vetores solução são distribuídos na superfície da função. Essa é uma das diferenças dos AGs em relação aos métodos convencionais de otimização, que ao contrário, partem de uma única solução inicial (estimativa inicial). As Figuras 4.8 e 4.9 apresentam o conjunto de soluções (população) na iteração 30 e 500 (geração final), respectivamente. 
Nos últimos anos os AGs têm demonstrado eficiência frente aos problemas de otimização e em diversas áreas da ciência. A grande força da técnica (teoria do esquema) é o processo de aprendizado que os AGs desenvolvem através de seus operadores genéticos para garantir melhores soluções para as próximas gerações.

\subsubsection{Algoritmos evolucionários multiobjetivo}

Devido à dificuldade de obtenção de soluções ótimas Pareto pelos métodos convencionais de otimização, os AEs são as técnicas mais modernas e eficientes para a otimização multiobjetivo (FONSECA e FLEMING, 1995; VELDHUIZEN, 1999; ZITZLER, 1999; DEB, 2001). O paralelismo implícito, possibilidade de se trabalhar com várias soluções simultaneamente, fazem dos AEs ferramentais poderosos na identificação de múltiplas soluções ótimas em uma única simulação.

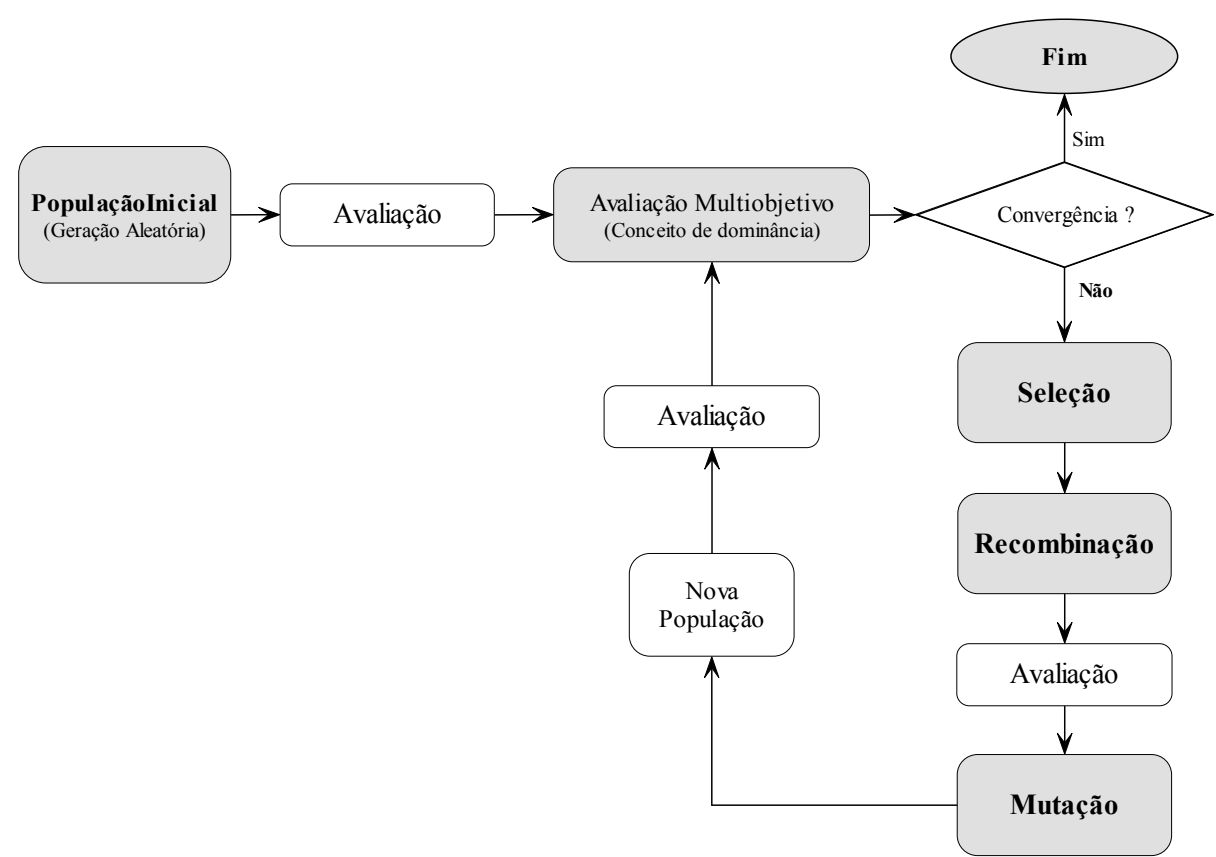

Figura 4.7 - Estrutura geral dos algoritmos genéticos multiobjetivo

Os métodos de otimização multiobjetivo têm três principais objetivos que devem ser perseguidos para melhorar a acurácia das soluções. Esses objetivos referem-se à minimização da distância entre a frente não dominada e a frente ótima Pareto e a produção de soluções bem distribuídas ao longo da frente. No entanto, observa-se que dois problemas vem sendo enfrentados para que os AEs possam atingir esses objetivos. O primeiro está relacionado aos procedimentos de avaliação e seleção dos AEs de forma a garantir uma busca eficiente para o conjunto ótimo Pareto. O segundo problema refere-se em como manter uma diversidade da população de forma a evitar a convergência prematura. 
O procedimento de busca de soluções ótimas Pareto através de algoritmos evolucionários multiobjetivo (Figura 4.10) é similar aos AGs convencionais (Figura 4.6). Pequenas modificações na estrutura dos AGs convencionais são realizadas, no estágio de avaliação, para que os algoritmos evolucionários multiobjetivo busquem ao invés de uma solução, um conjunto de soluções ótimas. Por exemplo, segundo os algoritmos genéticos convencionais os melhores indivíduos (valor de aptidão alto) têm alta probabilidade de pertencer ao conjunto solução na próxima geração, a solução ótima representa a combinação de variáveis (vetor de decisão) que tem o maior valor de aptidão, no caso de maximização, na última iteração (geração). Nos algoritmos genéticos multiobjetivo, primeiro, a população inicial é classificada segundo os conceitos de dominância (4.7), e dessa forma, obtêm-se os vetores de decisão que são não dominados. Esses vetores são as melhores combinações da iteração corrente e têm alta probabilidade de se encontrarem na próxima iteração (geração). A solução final compreenderá todos vetores de decisão não dominados da última iteração.

FONSECA e FLEMING (1995) apresentaram uma revisão dos vários algoritmos evolucionários aplicados à otimização multiobjetivo presentes na literatura. De modo particular, esses autores classificaram os métodos multiobjetivo em: (1) técnicas de funções agregadas, (2) técnicas baseados em um conjunto de soluções (população) sem considerar o conceito Pareto e (3) técnicas baseadas em um conjunto de soluções considerando o conceito Pareto. A primeira possibilidade incorpora os objetivos através de uma combinação ponderada por pesos em uma função única. Assim, as soluções não dominadas serão geradas por várias combinações de pesos e representam as retas tangentes à frente Pareto. A segunda possibilidade considera os objetivos definidos individualmente e tratados simultaneamente. Nesse caso, os operadores genéticos devem ser alterados de forma a adequar o problema segundo os princípios de busca das soluções ótimas Pareto. A terceira possibilidade consiste na combinação das duas possibilidades anteriores.

\section{Técnicas de funções agregadas}

As técnicas de funções agregadas representam esforços de pesquisadores em tentar reproduzir a frente Pareto. Pode ser considerada como uma evolução da otimização clássica multiobjetivo. Essas técnicas têm a característica de combinar várias funções em uma única função através do escalonamento de valores das funções objetivo. Com 
isso, o decisor propõe as metas que devem ser alcançadas e, então, o algoritmo é aplicado várias vezes para gerar a solução compatibilizada.

A vantagem de se otimizar uma única função é atribuída à simplicidade de implementação que visa encontrar apenas uma solução para o problema. Porém, essa aproximação apresenta sérios problemas em relação à determinação de pesos, que geralmente é subjetiva. Outro problema encontrado é que soluções alternativas fundamentais à tomada de decisão não são necessariamente obtidas como resposta. Várias aplicações têm sido reportadas na literatura, considerando os problemas de objetivos múltiplos agregados em uma única função objetivo. O trabalho de RICHARDSON et al. (1989) pode ser considerado um esforço no sentido de dar suporte para o enquadramento de pesos relativos às restrições inseridas como penalidades na função objetivo.

HAJELA e LIN (1992) desenvolveram um método de busca no qual inclui pesos no vetor de decisão e promove a diversidade na população com técnicas de compartilhamento. Como conseqüência, um conjunto de indivíduos é obtido para cada combinação de pesos. Portanto, para cada objetivo considerou-se um peso $\left.\mathrm{w}_{\mathrm{i}} \in\right] 0,1[$, de tal forma que, $\sum \mathrm{w}_{\mathrm{i}}=1$. O valor da avaliação é calculado como sendo a soma dos valores objetivos ponderados, $\mathrm{w}_{\mathrm{i}} \mathrm{f}_{\mathrm{i}}(\mathrm{x})$. Para se buscar soluções múltiplas em paralelo, esses pesquisadores adotaram pesos variáveis. A diversidade da combinação de pesos é promovida pelas técnicas de compartilhamento. O algoritmo evolui através da combinação de pesos simultaneamente.

Todos esses métodos citados utilizaram funções agregadas ponderadas em sua formulação. No entanto, nenhum incorporou a definição do conceito Pareto (dominância). O interesse principal desses métodos era gerar soluções não dominadas, sem a preocupação de manter a diversidade da população na frente Pareto.

Técnicas populacionais que não consideram o conceito Pareto

As técnicas populacionais que não consideram o conceito Pareto têm a característica de trabalhar com soluções múltiplas em uma única simulação. O critério de seleção é diferente dos AGs convencionais, pois a busca é realizada em várias direções ao mesmo tempo. Esses algoritmos utilizam várias combinações lineares dos objetivos. $\mathrm{O}$ trabalho pioneiro nessa direção foi o trabalho de SCHAFFER (1984), que desenvolveu uma extensão dos algoritmos genéticos simples para acomodar valores das funções aptidão 
ou avaliação em um vetor que foi denominado VEGA (Vector Evaluated Genetic Algorithm).

Esse algoritmo (SCHAFFER, 1984) executa a seleção para cada objetivo separadamente. $\mathrm{O}$ algoritmo considera um conjunto (mating pool) dividido em n partes de dimensões iguais. Uma parte desse conjunto é preenchida com indivíduos escolhidos aleatoriamente na população corrente de acordo com um dos seus objetivos. Posteriormente, a outra parte é preenchida por novos indivíduos criados a partir de indivíduos que já se encontram nesse conjunto. Os novos vetores solução (indivíduos) são obtidos através da aplicação dos operadores genéticos (recombinação e mutação) convencionais. Depois desse procedimentos, aplica-se o operador de seleção proporcional.

Um dos problemas encontrados nas soluções produzidas pelo algoritmo VEGA foi à tendência da população em dividir-se, em diferentes espécies fortes em relação aos objetivos considerados. A esse fenômeno é dado o nome de especiação (FONSECA e FLEMING, 1995; SRINIVAS e DEB, 1995).

FONSECA e FLEMING (1995) afirmaram que o procedimento desenvolvido por SCHAFFER (1984) é implicitamente um combinação linear e explica o porquê da população dividir-se em espécies fortes em relação a cada um dos objetivos, no caso de regiões côncavas. Os autores referidos argumentaram que pontos em regiões côncavas são de difícil localização quando se tem uma combinação linear dos objetivos, para um conjunto de pesos.

SCHAFFER (1984) tentou minimizar a ocorrência desse fenômeno (especiação) desenvolvendo duas heurísticas: a heurística de seleção não dominada e a heurística de seleção de pares. Na primeira, indivíduos dominados são penalizados através da subtração de um valor fixo (penalidade) pequeno no número esperado de suas cópias durante a seleção. A penalidade total para as soluções dominadas é calculada proporcionalmente as soluções não dominadas, que têm o seu número de cópias esperado elevado durante a seleção. Entretanto, o algoritmo falha quando a população apresenta poucos indivíduos não dominados, resultando em um elevado valor de aptidão e, eventualmente, atribuindo-lhes uma alta probabilidade de seleção. A segunda heurística realiza uma espécie de junção de pares, promovendo a recombinação entre os cromossomos. O método é implementado selecionando pares de indivíduos aleatoriamente, cuja sua distância (um em relação ao outro) no espaço euclidiano deve 
ser máxima. A técnica também falha por impedir que indivíduos com baixos valores de aptidão participem da seleção, dada a possibilidade de grandes distâncias euclidianas entre indivíduos "campeões" e "medíocres".

GOLDBERG (1989) também propôs uma técnica para minimizar a ocorrência do fenômeno da especiação, realizando a classificação não dominada em conjunto com uma técnica de compartilhamento. $\mathrm{O}$ autor afirma que a probabilidade de reprodução de todos os indivíduos não dominados em uma população pode ser estabelecida através de níveis de dominância (frentes não dominadas). Dessa forma, se uma frente não dominada é determinada, os indivíduos pertencentes a esta frente são removidos da concatenação. Segue-se então o processo para determinar a nova frente não dominada com os indivíduos remanescentes da população. No final, toda população é classificada de acordo com seu grau de dominação (frentes).

KURSAWE (1991) propôs um algoritmo que consiste em várias etapas. Para cada etapa, um objetivo é selecionado aleatoriamente de acordo com um vetor probabilidade, e utilizado para determinar a anulação de indivíduos da população corrente. Esta implementação se assemelha aos algoritmos desenvolvidos por SCHAFFER (1984).

Técnicas populacionais que consideram o conceito Pareto

As técnicas populacionais que consideram o conceito Pareto são baseadas nas proposições de GOLDBERG (1989), que sugeriu incorporar o conceito de dominância nos algoritmos genéticos. Vários pesquisadores (FONSECA e FLEMING, 1993; HORN e NAFPLIOTIS, 1993; SRINIVAS e DEB 1995) concentraram seus esforços na incorporação e implementação desse conceito nos AGs. A partir dessas contribuições, esses algoritmos tornaram-se capazes de buscar soluções não dominadas independentemente e simultaneamente (paralelamente) em uma única iteração, possibilitando assim, que a subjetividade referente à atribuição de pesos na função objetivo fosse evitada.

FONSECA e FLEMING (1993) foram os primeiros a introduzir técnicas de otimização multiobjetivo, utilizando o conceito de dominação (soluções não dominadas), em algoritmos genéticos. Esse algoritmo foi denominado MOGA (Multi Objective Genetic Algorithms) pelos autores. No MOGA, as soluções não dominadas e a diversidade da população são tratadas simultaneamente durante o processo iterativo. 
A classificação da população baseada no conceito de dominância garante que todos os indivíduos não dominados tenham o mesmo valor de ordenação, mas não garante uniformidade de soluções na frente. De forma a evitar a tendência da população em dividir-se em pequenas sub populações e convergirem individualmente para cada um dos objetivos considerados, algumas técnicas preventivas foram desenvolvidas. Essas técnicas possibilitam a representatividade das soluções não dominadas de maneira distribuída ao longo da superfície Pareto. Essas aplicações são denominadas técnicas de compartilhamento (fitness sharing).

HORN, NAFPLIOTIS e GOLDBERG (1994) propuseram uma combinação da seleção torneio com o conceito de dominância Pareto. Esta técnica toma dois indivíduos que estão competindo e um conjunto formado por indivíduos selecionados aleatoriamente da população. Se um dos indivíduos competidores é dominado por algum membro do conjunto comparação, e o outro não é, então esse último é escolhido como sendo vencedor do torneio. Se ambos os indivíduos são dominados (ou não dominados), o resultado do torneio é decidido por pela técnica de compartilhamento: o competidor que obtiver menor número de indivíduos em seu nicho (definido pelo $\sigma_{\text {share }}$ ) é selecionado para reprodução. Esse algoritmo é reportado na literatura internacional como NPGA (Niched Pareto Genetic Algorithm). O nicho, na biologia, é definido por um grupo de indivíduos de mesma espécie com características comuns. Na otimização evolucionária faz-se uma analogia a esse processo. Vetores solução com valores de aptidão altos (indivíduos fortes) podem produzir várias cópias de seus vetores na próxima geração, fazendo com que a população perca diversidade através da eliminação dos outros vetores solução pelo processo estocástico. Com isso, diz-se que toda população é aglomerada em um nicho de indivíduos ou converge para uma única solução.

SRINIVAS e DEB (1995) desenvolveram uma aplicação baseada nos conceitos de otimização multiobjetivo sugeridas por GOLDBERG (1989). Esse algoritmo é denominado NSGA (Nondominated Sorting Genetic Algorithm). Nesse algoritmo o operador de seleção é aplicado em várias etapas. Em cada etapa, as soluções não dominadas constituem uma frente não dominada às quais, são atribuídos valores fictícios de aptidão a essas soluções pertencentes a cada frente. Esta avaliação fictícia é ajustada utilizando valores da técnica de compartilhamento (Sharing Fitness) nas frentes não dominadas. A classificação das soluções acontece por frentes, e para cada frente são calculados os respectivos compartilhamentos. Depois de atribuído o valor de aptidão 
fictício de cada solução pertencente a uma frente, passa-se para próxima frente não dominada e o processo se repete até que toda população seja classificada. Nos primeiros estudos de SRINIVAS e DEB (1995) foi desenvolvido um método de seleção combinado com operador de seleção estocástica convencional.

Percebe-se, no algoritmo proposto por SRINIVAS e DEB (1995), que as soluções pertencentes à primeira frente não dominada recebem valores fictícios maiores do que as soluções que pertencem às frentes não dominadas posteriores. Com isso, a probabilidade desses indivíduos passarem para a próxima geração também é maior.

Autores como FONSECA e FLEMING (1993), HORN e NAFPLOTIS (1993) e SRINIVAS e DEB (1995) contribuíram também na evolução das técnicas de compartilhamento. Essas técnicas tendem a manter diversidade da população, ao longo da superfície Pareto, e são baseadas no processo natural das espécies, onde indivíduos tendem a se aglomerar em pequenas comunidades denominados nichos. A partir das diferentes formas de compartilhamento e estabelecimento de nichos, as implementações dos AGs para problemas multiobjetivo apresentam diferentes aproximações, cujo objetivo principal é encontrar e manter uma amostra representativa de soluções da frente Pareto.

Como reportado, a literatura conta com três implementações clássicas: FONSECA e FLEMING (1993), HORN e NAFPLIOTIS (1993) e SRINIVAS e DEB (1995). Esses autores desenvolveram e testaram seus algoritmos evolucionários para vários problemas reais e provaram que os algoritmos evolucionários multiobjetivo baseados no conceito de dominância Pareto são confiáveis. Esses algoritmos apresentam duas características comuns nos seus operadores de evolução. A primeira característica refere-se à maneira de avaliar as soluções considerando o conceito de dominância. Já a segunda refere-se à forma com que esses algoritmos preservaram a diversidade das soluções na fronteira não dominada.

Apesar dessas implementações terem demonstrado eficiência na identificação de soluções ótimas Pareto para diversos problemas testes e de engenharia, autores como ZITZLER e THIELE (1998), KNOWLES e CORNE (2000) e DEB et al. (2002) identificaram a necessidade de introduzir um operador de desempenho comprovado nos AGs convencionais. Particularmente, o interesse foi introduzir a sistemática do 
elitismo ${ }^{10}$ nos algoritmos evolucionários multiobjetivo, de forma a garantir propriedades de convergência.

ZITZLER e THIELE (1998) sugeriram um algoritmo evolucionário multiobjetivo elitista. Esse algoritmo é denominado SPEA (Strength Pareto Evolutionary Algorithm) e tem como característica fundamental a manutenção de uma população externa ao longo das iterações de forma a armazenar todas as soluções não dominadas encontradas desde a população inicial. Essa população participa de todas as operações evolutivas. Em cada iteração uma população combinada, entre as populações externa e corrente, é construída. Todas as soluções não dominadas da população combinada são avaliadas e recebem um valor de aptidão baseado no número de soluções que essas soluções dominam. Já as soluções dominadas recebem um valor de aptidão pior que o pior valor de aptidão das soluções classificadas como não dominadas. Esse procedimento garante que a busca seja direcionada para espaço das soluções não dominadas. Para manter a diversidade das soluções não dominadas é aplicada uma técnica de agrupamento.

Com um procedimento simples de comparação de soluções não dominadas entres dois vetores solução KNOWLES e CORNE (2000) propuseram um algoritmo evolucionário multiobjetivo elitista, denominado PAES (Pareto-Archived Evolution Strategy). Esse algoritmo utiliza a codificação binária ao invés da codificação real para criar um novo vetor solução (filho) através da mutação. O processo resume-se na seguinte análise, se o vetor solução filho domina o vetor solução pai, o filho é aceito como próximo pai e as iterações continuam. Por outro lado, se o pai domina o filho, o filho é descartado e uma nova mutação é realizada para gerar um novo vetor solução (filho). No entanto, se o vetor solução pai e o vetor solução filho não apresentam relação de dominância, a escolha é realizada comparando os dois com uma lista de soluções boas armazenadas ao longo das gerações.

Baseando-se no ordenamento elitista por não dominância e aperfeiçoando o algoritmo não elitista NSGA, DEB et al. (2002) propuseram o algoritmo NSGA II (Elitist NonDominated Sorting Genetic Algorithm). O NSGA II trabalha com dois conjuntos simultâneos em cada iteração, denominados população pai e população filha. Na primeira iteração gera-se um conjunto inicial como nos AGs convencionais e ordena-se esse conjunto considerando o níveis de não dominância, por exemplo, soluções com

\footnotetext{
${ }^{10}$ O elitismo foi introduzido por DEJONG apud ZITZLER (1999) nos algoritmos evolucionários convencionais. Este operador sugere que as melhores soluções da população correntes sejam preservadas sem modificações e incorporadas na população posterior. Segundo o autor, esse operador evita a convergência prematura dos AEs.
} 
nível 1 são as melhores soluções do conjunto, soluções com nível 2 correspondem ao segundo melhor grupo, e assim por diante. Cada solução recebe um valor de aptidão igual a seu nível de dominação (frentes). São aplicados então os operadores de seleção (torneio), recombinação e mutação, sucessivamente, para se obter a população filha. As duas populações têm a mesma dimensão. Após isso, ambas as populações são unidas em um único conjunto temporário (dimensão $2 \mathrm{~N}$ ). Realiza-se um ordenamento por não dominância desse conjunto temporário de forma a identificar os novos níveis de dominação. Dado que apenas N soluções podem estar contidas no próximo conjunto, então as $\mathrm{N}$ piores soluções são descartadas, de acordo com um critério de seleção que considera uma técnica de compartilhamento para garantir a diversidade da próxima população.

Finalmente, pode-se concluir, através da revisão bibliográfica realizada, que o problema de otimização multiobjetivo recebeu um grande avanço com o surgimento das técnicas de otimização não convencionais como os AEs, mais especificamente os AGs. Comprovadamente, a literatura vem reportando as desvantagens dos modelos de otimização multiobjetivo convencionais em relação aos métodos não convencionais, principalmente pela dificuldade na atribuição de pesos inerentes às técnicas convencionais. Cabe destacar que os algoritmos evolucionários de otimização multiobjetivo também vêm recebendo aperfeiçoamentos de forma a garantir a identificação e distribuição de soluções não dominadas na frente Pareto. No entanto, atualmente são as técnicas mais modernas e eficientes na abordagem multiobjetivo.

O próximo capítulo é destinado à proposição do modelo computacional para reabilitação de sistemas de distribuição de água que considera o caráter multiobjetivo do problema. Quatro algoritmos (MOGA, NSGA, SPEA e NSGA II) são investigados na resolução do problema em questão, como forma de identificar o modelo mais adequado. Assim, o detalhamento de cada uma dessas técnicas e os métodos (métricas) de comparação desses algoritmos são descritos no próximo capítulo. 


\section{PROPOSIÇÃO DE MODELO COMPUTACIONAL}

Este capítulo descreve a proposição de um modelo computacional para análise de reabilitação de redes de distribuição de água para abastecimento considerando o aspecto multiobjetivo do problema (objetivos múltiplos e conflitantes). Para tal finalidade, o modelo proposto é concebido em três etapas. A primeira etapa compreende os programas necessários para a calibração dos dados de entrada do modelo. A segunda etapa refere-se ao módulo de avaliação e compreende o algoritmo de otimização multiobjetivo e o simulador hidráulico que auxilia avaliações das funções objetivo. A terceira etapa representa a resposta final do modelo, ou seja, os planos ótimos de reabilitação (soluções alternativas). Minimização de custos e vazamentos e maximização da confiabilidade e benefícios são os critérios que o módulo de otimização considera simultaneamente, para gerar os planos ótimos de reabilitação. Tais planos refletem a relação de compromisso entre a satisfação dos consumidores (maximização de benefício e confiabilidade), a proteção dos recursos naturais (minimização de vazamentos) e as metas de investimento a serem cumpridas pelas companhias de saneamento (minimização de custo). Neste capítulo também são encontradas as descrições das funções objetivo (critérios) propostas, dos algoritmos de otimização multiobjetivo e das técnicas de análise dos resultados.

\subsection{Considerações gerais}

A modelação matemática, como alvo de pesquisa, tem por objetivo caracterizar um problema físico qualquer através de equações matemáticas, para gerar um modelo representativo. Segundo SEBORG, EDGAR e MELLICHAMP (1989), um modelo nada mais é que uma abstração matemática de um processo real. Essas equações depois de formuladas e resolvidas fornecem o comportamento do sistema para diversas condições de projeto e/ou de operação. Entretanto, um modelo bem desenvolvido deve considerar as características mais importantes do sistema real, de forma que os critérios a serem analisados sejam expressos numericamente. Em se tratando da tomada de 
decisão, o modelo deve propiciar uma avaliação, dos efeitos causados pelas decisões sobre os objetivos estabelecidos para um determinado sistema, com objetivo de identificar as melhores alternativas de projeto e operação.

Nos últimos anos a modelação matemática de sistemas de distribuição de água tem se tornado uma área de grande interesse por parte dos pesquisadores e profissionais, devido principalmente às complexidades inerentes de tais sistemas. Existem várias razões que levam a essa procura. A primeira está relacionada à necessidade de fornecer às empresas tecnologias eficientes que auxiliem na investigação dos sistemas e seus processos. A segunda razão se refere à possibilidade de identificar planos de melhorias para promover a adequação eficiente dos sistemas existentes aos novos padrões de consumo, evitando assim, o desperdício de água e as possíveis falhas decorrentes de componentes deteriorados. Finalmente, WALSKI et al. (2003) afirmam que a disponibilidade dos recursos computacionais possibilita o desenvolvimento de tais ferramentas para o planejamento (projeto e reabilitação) e operação (calibração, controle e operação) de tais sistemas.

Confiabilidade, custos, benefícios e vazamentos são alguns dos aspectos que devem ser incorporados nas análises de reabilitação dos sistemas de distribuição de água. Entretanto, observa-se que esses critérios, quando tratados como funções objetivo, além de serem múltiplos são conflitantes. Por exemplo, considere um problema de dimensionamento ótimo de uma rede (mínimo custo). Se apenas a função objetivo custo for utilizada, a solução obtida tende apresentar soluções com os menores diâmetros disponíveis e consequentemente menores pressões. Se para essa mesma situação fosse considerada simultaneamente, a maximização da capacidade hidráulica como outro objetivo, essa situação mudaria, pois a consideração de capacidade hidráulica exige do algoritmo de otimização maiores diâmetros e oferece maiores pressões. Demonstra-se então, o conflito de objetivos para uma simples situação hipotética. Isso caracteriza uma das complexidades do planejamento (projeto e/ou reabilitação) de sistemas de distribuição de água. Uma das formas que analistas e decisores encontram para solucionar tais problemas é recorrer às técnicas de programação matemática para auxiliarem-nos nesse processo.

Como já mencionado em capítulos anteriores, os métodos de otimização multiobjetivo convencionais apresentam desvantagens frente aos métodos não convencionais. Por isso, o modelo aqui proposto foi concebido sob a ótica dos algoritmos evolucionários 
multiobjetivo que são técnicas mais recentes encontradas na literatura para tratar o problema em questão. Tais algoritmos, além de considerarem objetivos múltiplos simultaneamente, através da busca paralela, exploram as similaridades das soluções através do processo de variação (recombinação e mutação). Não obstante a técnica empregada, o que deve ser levado em consideração na análise de reabilitação de redes de distribuição de água, é a identificação das soluções ótimas Pareto. Quatro implementações desses algoritmos são detalhadas e investigadas neste trabalho, com objetivo de estudar seu comportamento frente ao problema ora proposto.

ETAPA PRELIMINAR

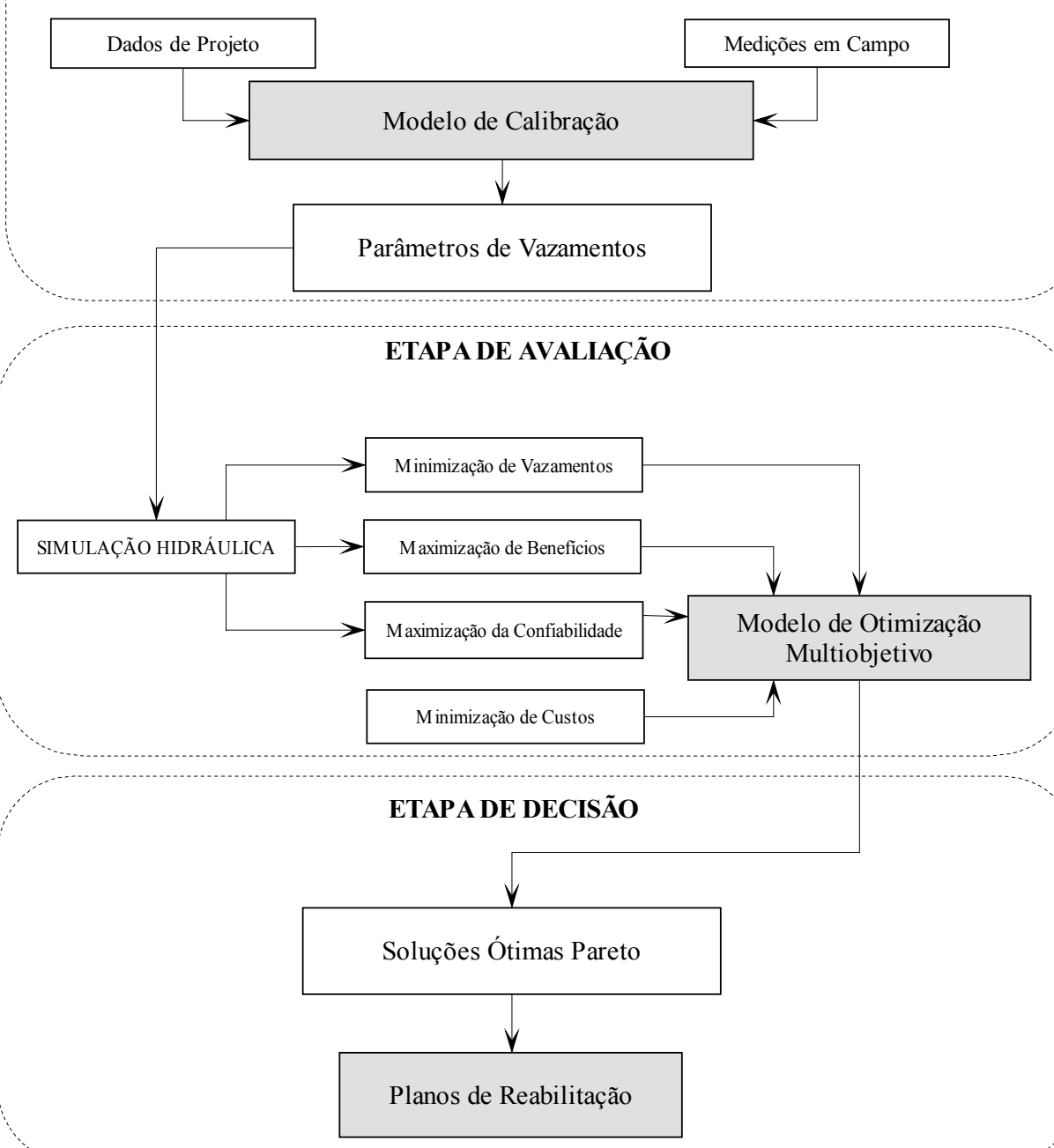

Figura 5.1 - Modelo de reabilitação proposto

Em geral, a análise de reabilitação de redes de distribuição de água consiste em identificar e formular os objetivos promissores, avaliar tais objetivos através de técnicas de otimização, e assim, gerar planos ótimos de reabilitação e selecionar as intervenções (planos) a serem implementadas nos sistemas de forma a melhorar o desempenho dos 
mesmos. A Figura 5.1 ilustra o modelo de reabilitação proposto neste trabalho. Observa-se que este modelo considera três etapas bem distintas. A etapa preliminar (primeira etapa) compreende todos os procedimentos necessários para ajustar os dados de entrada que irão alimentar o módulo de avaliação (otimização multiobjetivo). Como a reabilitação de redes visa melhorar o desempenho de um sistema existente, é extremamente necessário o comportamento real do mesmo seja conhecido, por isso a etapa preliminar torna-se imprescindível. Tais dados se dividem em dados cadastrais e dados experimentais. Os dados cadastrais envolveram todo tipo de estudos referentes: à simplificação do sistema, aos estudos de consumo (para estimar as demandas nodais), aos dados cadastrais da rede (características geométricas, posição de componentes hidráulicos, dentre outros), aos relatórios de manutenção (vazamentos e pequenos reparos), aos relatórios operacionais (manobras na rede), dentre outros. Os dados experimentais foram caracterizados pelos dados obtidos em campo através de instrumentação (medidores de pressão e medidores de vazão). O módulo referente à segunda etapa visa avaliar o sistema em estudo através de um procedimento de otimização multiobjetivo auxiliado por um simulador hidráulico. A terceira etapa do modelo proposto, também denominado módulo de decisão, apresenta os resultados da modelação, ou seja, os planos ótimos de reabilitação (soluções alternativas).

Nas próximas seções são abordados e descritos os objetivos considerados no modelo proposto, os métodos de otimização multiobjetivo investigados, os índices de comparação desses métodos, os simuladores hidráulicos e as redes exemplos, objeto de estudo deste trabalho.

\subsection{Técnicas de reabilitação}

Existem inúmeras técnicas para a reabilitação de redes de distribuição de água. ENGELHARDT et al. (2000) classifica essas técnicas em quatro principais categorias: substituição, revestimento estrutural, limpeza e outras técnicas.

Substituição - A substituição de tubulações consiste em trocar as tubulações existentes por tubulações novas. Essa técnica de reabilitação tem efeitos negativos e diretos na satisfação dos usuários. Barulho, poluição visual, conserto das vias de transporte e obstrução do tráfego são alguns dos fatores que propiciam desconforto à população que reside próximo ao local do reparo. 
Revestimento estrutural - Esta técnica visa revestir as paredes internas e externas das tubulações protegendo contra possíveis corrosões, no caso de tubulações de ferro. Geralmente, esse revestimento é aplicado após a limpeza das tubulações e não possui impacto estrutural direto na tubulação. Os materiais para revestimento mais utilizados são cimento e resina epóxi.

Limpeza - A limpeza de tubulações é uma técnica de reabilitação muito comum. Tal técnica tem como objetivo remover depósitos de sedimentos incrustados no interior das tubulações. Atualmente, existem procedimentos mais avançados que removem tais incrustações sem causar danos as tubulações. No entanto, essa técnica deve ser aplicada criteriosamente, pois incrustações podem estar localizadas em pontos onde possivelmente ocorreram vazamentos, considerando regiões que a água tem alto índice de carbonato de cálcio. Portanto, é conveniente aplicar algum revestimento estrutural nas paredes externas das tubulações após a aplicação desta técnica.

Outras técnicas - A detecção prévia de vazamentos nos redes de distribuição é uma das técnicas que podem ser aplicadas nos sistemas de forma a retardar a deterioração dos mesmos. No caso de tubulações de ferro fundido, o mais recomendável é controlar a qualidade da água nas estações de tratamento. Outra técnica muito utilizada nas redes de distribuição de água é o reforço de tubulações em paralelo ao sistema macro (rede principal) de forma a garantir abastecimento a toda população através do aumento da capacidade hidráulica do sistema.

\subsection{Formulação do problema de reabilitação de redes hidráulicas}

Enquanto as demandas crescem com o tempo, o desempenho dos sistemas decresce devido a fatores internos ou externos. Fatores internos estão vinculados à deterioração das superfícies internas das tubulações, resultando em uma diminuição da capacidade hidráulica, degradação da qualidade da água e redução da confiabilidade do sistema. Os fatores externos são provenientes da deterioração estrutural das tubulações relacionadas às tensões impostas sobre o sistema. Esses fatores propiciam o surgimento de vazamentos, queda da pressão, deterioração da qualidade de água, não atendimento de pressões requeridas nos sistemas, dentre outros. KLEINER e RAJANI (2001) enfatizam que uma melhoria tardia em um sistema degradado pode propiciar grandes gastos nos reparos emergenciais de quebras, detecções de vazamentos, investigação das reclamações durante os anos, além de causar descontentamento e redução do bem estar da população. 
De acordo com HALHAL et al. (1997) o aumento da performance hidráulica das redes de distribuição de água depende de algumas melhorias realizadas nas mesmas, que apresentam reflexos diretos, sobre sua capacidade hidráulica. Essas melhorias são obtidas através da recuperação da integridade física da rede por meio da substituição de tubulações danificadas, da incorporação de tubulações adicionais e das remoções e/ou limpezas das tubulações antigas. Esses objetivos, no entanto, variam de um sistema para outro de acordo com sua utilidade.

A modelação matemática desenvolvida sob a ótica da análise de sistemas exige que critérios ou objetivos sejam expressos numericamente. Para isso, é necessária a investigação dos objetivos mais promissores do problema, de forma que exista uma relação entre o problema físico e a sua formulação. As funções objetivo para análise de reabilitação de redes baseiam-se em critérios como capacidade hidráulica, integridade física das tubulações, recursos financeiros, desempenho e flexibilidade dos sistemas. Essas funções são detalhadas nas próximas seções.

\subsubsection{Custos}

Os custos representam os investimentos financeiros calculados pela soma dos valores presentes referentes às ações a serem implementadas no sistema ao longo do período de planejamento, representado pela eq.(5.1).

$\mathrm{C}_{\mathrm{T}}=\mathrm{C}_{\text {projeto }}+\mathrm{C}_{\text {lim peza }}+\mathrm{C}_{\text {duplicação }}+\mathrm{C}_{\text {substituição }}$

Em algumas situações é possível identificar e quantificar benefícios, em termos monetários, decorrentes da implementação de melhorias realizadas nos sistemas. Dessa forma, tais parcelas (benefícios) podem ser consideradas na formulação de custo total através de uma subtração no valor do custo total.

Projeto - Em algumas situações, a reabilitação de redes está associada à expansão do sistema (dimensionamento ótimo). Quantifica-se o custo de implantação de novas tubulações conforme a eq.(5.2).

$$
\mathrm{C}_{\text {projeto }}=\sum_{\mathrm{j} \in \mathfrak{I}_{1}} \mathrm{C}_{\mathrm{j}} \mathrm{L}_{\mathrm{j}}
$$


sendo $\mathfrak{I}_{1}$ o conjunto de trechos que receberão novas tubulações; $\mathrm{j}$ representa o trecho de tubulação de projeto; c é o custo unitário de novas tubulações e L é o comprimento do trecho.

Duplicação - O custo de implantação de tubulações em paralelo é expresso pela eq.(5.3). Esse custo é um caso particular do custo de projeto, entretanto, em algumas situações reais seu valor pode ser diferenciado do custo de projeto. A duplicação de tubulações está diretamente relacionada a um sistema existente, e dessa forma implica em um desconforto da população ${ }^{11}$ nas proximidades do local da reabilitação, e consequentemente tende a ter custos mais elevados. No caso de projeto, muitas vezes o que se pretende obter é uma medida preventiva para minimizar problemas futuros, havendo ou não interferências de residências próximas, assim os custos são menos elevados quando comparados com as da duplicação.

$$
\mathrm{C}_{\text {duplicą̧ão }}=\sum_{\mathrm{j} \in \mathfrak{\Im}_{2}} \mathrm{C}_{\mathrm{j}} \mathrm{L}_{\mathrm{j}}
$$

sendo $\mathfrak{I}_{2}$ o conjunto de trechos que irão ser duplicados; $\mathrm{j}$ representa o trecho tubulações que será duplicado; c é o custo unitário de novas tubulações e L é o comprimento do trecho da tubulação que receberá duplicação.

Limpeza - O custo de limpeza de tubulações é expresso pela eq.(5.4).

$$
\mathrm{C}_{\text {limpeza }}=\sum_{\mathrm{j} \in \mathfrak{I}_{3}} \mathrm{C}_{\mathrm{j}} \mathrm{L}_{\mathrm{j}}
$$

sendo $\mathfrak{I}_{3}$ o conjunto de tubulações que irão ser limpas; j representa as tubulações que serão limpas; c é o custo unitário da limpeza das tubulações e L é o comprimento da tubulação a ser limpa.

Substituição - O custo de substituição de tubulações é expresso pela eq.(5.5). Essa técnica é uma das mais onerosas, tendo em vista que para substituir tubulações é necessário realizar obstruções do tráfego e interrupções no abastecimento. Em muitas situações reais, essa técnica não é utilizada.

\footnotetext{
${ }^{11}$ A rede de abastecimento de água do centro da cidade de Piracicaba (SP) em 1998 foi reabilitada utilizando essa técnica de reabilitação. A duplicação da rede foi feita no passeio (calçada) tendo em vista a não obstrução do tráfego local (área comercial). Essa comunicação foi fornecida pelo diretor do SAAE de Piracicaba Eng. Civil Renato Takami.
} 
$\mathrm{C}_{\text {substituição }}=\sum_{\mathrm{j} \in \mathfrak{I}_{4}} \mathrm{C}_{\mathrm{j}} \mathrm{L}_{\mathrm{j}}$

sendo $\mathfrak{I}_{4}$ o conjunto de tubulações que irão ser substituídas; j representa a tubulação que será substituída; c é o custo unitário da substituição de tubulações e L é o comprimento da tubulação.

WALSKI (2001) argumentou sobre a utilização das técnicas de otimização aplicadas aos recursos hídricos e sobre a necessidade de incorporar não só custos nas análises, mas também os benefícios gerados pela implementação de técnicas de reabilitação. $O$ autor reconhece a dificuldade de se quantificar tais objetivos e ressalta que alguns pesquisadores como HALHAL et. al. (1997) e WALTERS et al. (1999) iniciaram esforços para formulação desses benefícios baseando-se na quantificação da capacidade hidráulica do sistema sem e com reabilitação.

Entretanto, algumas críticas podem ser tecidas em relação a essas formulações (HALHAL et. al., 1997; WALTERS et al. 1999). A questão que se remete é como os benefícios podem ser somados na formulação proposta (eq. 3.20), se os mesmos não apresentam as mesmas unidades e são desprovidos de significado físico. No presente trabalho, essas formulações foram aperfeiçoadas através de um procedimento simples. Análises adimensionais foram aplicadas para conceder não só um significado físico as tais formulações, mas também uma conversão de unidades de maneira que as parcelas dos benefícios possam ser somadas. Essas formulações são apresentadas a seguir.

\subsubsection{Benefícios}

Em geral, os benefícios referem-se à melhoria do nível de serviço prestado aos consumidores, combinados com uma medida de decréscimo dos custos associados à operação e manutenção dos sistemas de distribuição de água. O benefício no presente trabalho é descrito pela eq.(5.6) e representa o ganho de capacidade hidráulica alcançado pelo sistema a partir de melhorias realizadas nas redes.

$\mathrm{B}=\gamma \sum_{\mathrm{i}=1}^{\mathrm{NPD}}\left(\sum_{\mathrm{j}=1}^{\mathrm{NN}} \mathrm{q}_{\mathrm{j}}^{\mathrm{AR}} \mathrm{H}_{\mathrm{j}}^{\mathrm{AR}}-\sum_{\mathrm{j}=1}^{\mathrm{NN}} \mathrm{q}_{\mathrm{j}}^{\mathrm{AO}} \mathrm{H}_{\mathrm{j}}^{\mathrm{AO}}\right)_{\mathrm{i}}$

sendo B o benefício $(\mathrm{kW}) ; \gamma$ o peso específico da água $\left(9,8 \mathrm{kN} / \mathrm{m}^{3}\right) ; \mathrm{q}^{\mathrm{AR}}$ a demanda efetivamente atendida no nó $\mathrm{j}$ considerando a rede reabilitada $\left(\mathrm{m}^{3} / \mathrm{s}\right) ; \mathrm{q}^{\mathrm{AO}}$ a demanda efetivamente atendida no nó j considerando a rede em seu estado original $\left(\mathrm{m}^{3} / \mathrm{s}\right) ; \mathrm{H}^{\mathrm{AR}} \mathrm{a}$ 
pressão disponível no nó $\mathrm{j}$ para a rede reabilitada $(\mathrm{m}) ; \mathrm{H}^{\mathrm{AO}}$ a pressão disponível no nó $\mathrm{j}$ para rede em seu estado original e NPD é o número de padrões de consumo considerados (geralmente, mínimo, médio e máximo). Observe que para se quantificar (podendo ser utilizada as eqs. 2.32, 2.33 e 2.34) tanto $\mathrm{q}^{\mathrm{AR}}$ como $\mathrm{q}^{\mathrm{AO}}$, é necessário utilizar um simulador hidráulico dirigido pela pressão (descrito posteriormente).

\subsubsection{Vazamentos}

A quantificação das perdas físicas em sistemas de distribuição de água é calculada através da pressuposta relação entre vazamento e pressão de serviço na rede. No presente trabalho utiliza-se a formulação proposta por TUCCIARELLI, CRIMINISI e TERMINI (1999) assumindo que os vazamentos são distribuídos ao longo da superfície de área das tubulações. Essa função objetivo é definida pela eq.(5.7).

$\mathrm{V}=\sum_{\mathrm{i}=1}^{\mathrm{NN}} \mathrm{QL}_{\mathrm{i}}$

sendo $\mathrm{V}$ o vazamento total na rede e QL o vazamento no nó i considerando o sistema reabilitado.

\subsubsection{Confiabilidade}

Embora não exista uma definição universal para os índices de confiabilidade nos estudos de redes de distribuição de água, segundo TODINI (2000) a técnica heurística baseada no conceito de resiliência ${ }^{12}$ é um índice muito apropriado para medir a confiabilidade das redes de distribuição de água, principalmente pela facilidade computacional que a mesma oferece. O índice proposto por esse autor mede a capacidade hidráulica do sistema atender as demandas nodais da rede em situações de falhas. Considera-se que, a falha hidráulica é resultante das mudanças nos padrões de consumo, deterioração de tubulações, perdas físicas, dentre outras. A eq.(5.8) descreve o índice mencionado.

$$
\mathrm{R}=\frac{\sum_{\mathrm{i}=1}^{\mathrm{NN}} \mathrm{q}_{\mathrm{i}}^{*}\left(\mathrm{~h}_{\mathrm{i}}-\mathrm{h}_{\mathrm{i}}^{*}\right)}{\sum_{\mathrm{k}=1}^{\mathrm{NR}} \mathrm{Q}_{\mathrm{k}} \mathrm{H}_{\mathrm{k}}-\sum_{\mathrm{i}=1}^{\mathrm{NN}} \mathrm{q}_{\mathrm{i}}^{*} \mathrm{~h}_{\mathrm{i}}^{*}}
$$

\footnotetext{
${ }^{12}$ A resiliência é definida como sendo a capacidade do sistema se recuperar dado que ocorreu alguma falha (mecânica ou hidráulica).
} 
sendo R o índice de confiabilidade hidráulica; NN o número total de nós; NR o número total de reservatórios; $\mathrm{q}^{*}$ a demanda efetivamente abastecida no nó i; h a energia do nó i; $\mathrm{h}^{*}$ a energia desejável para que a demanda seja totalmente atendida; $\mathrm{Q}$ a vazão abastecida correspondente ao reservatório $\mathrm{k}$ e $\mathrm{H}$ a energia total do reservatório $\mathrm{k}$.

\subsection{Otimização multiobjetivo}

Analistas estão sempre tentando encontrar formas para solucionar e flexibilizar a complexidade de seus problemas (complexos) através do emprego de técnicas avançadas de programação matemática. A maioria desses analistas visa propor modelos eficientes e bem calibrados para produzir projetos seguros e, assim, promover economias financeiras.

A maioria dos problemas na engenharia de recursos hídricos envolve decisões complexas devido à existência dos objetivos múltiplos e conflitantes, por exemplo, encontrar uma alternativa de projeto de redes de distribuição de água que contemple, máxima confiabilidade, mínimo custo, máximo benefício gerado e mínimo vazamento. A maximização de benefícios tende apresentar soluções de projeto com maiores diâmetros, e consequentemente pressões elevadas no sistema. Observa-se que essa maximização é conflitante com a minimização de vazamentos, que prioriza soluções de projeto com pressões mais baixas.

Como já mencionado nos capítulos prévios, a otimização de objetivo único visa encontrar a melhor solução, que corresponde o valor mínimo ou máximo de uma determinada função. Esse tipo de otimização é útil no sentido de fornecer aos decisores, informações preliminares sobre a natureza do problema, mas não fornece soluções alternativas que relacionam os objetivos. Ao contrário, na otimização multiobjetivo não existe uma única solução ótima, mas sim várias soluções que correspondem a atribuição de prioridades diferentes aos objetivos do problema, fornecendo assim um conjunto de soluções de compromisso, denominadas trade-off, soluções não dominadas, soluções não inferiores ou soluções ótimas Pareto (SAVIC, 2002).

A consideração de vários objetivos em um projeto ou plano garante três melhorias ao processo de tomada de decisão. Segundo COHON (1978) essa três melhorias são: um conjunto de soluções ótimas é identificado quando uma metodologia multiobjetivo é empregada; a consideração de objetivos múltiplos promove regras próprias aos participantes do processo de planejamento e tomada de decisão, por exemplo, o analista 
ou o modelador tem a função de gerar soluções alternativas e apresentar ao tomador de decisão que utiliza essas soluções geradas para escolha; se objetivos múltiplos forem considerados o modelo torna-se mais real.

As tubulações são os componentes mais comuns para transporte de água, gases e óleos necessários aos complexos urbanos. O projeto de sistemas de distribuição de água foi sempre visto como um problema de minimização de custos (objetivo único) considerando diâmetros como variáveis de decisão. O problema do dimensionamento de tubulações visando custo mínimo é um problema não linear e combinatorial discreto. Seria ideal que todas as possíveis soluções do problema fossem analisadas, entretanto, esses problemas tornam-se intratáveis por técnicas de enumeração quando o sistema a ser otimizado possui dimensão elevada (situações reais).

A otimização de sistemas de distribuição de água é uma das áreas de pesquisa mais complexas e promissoras. Vários artigos relatam o estado da arte dos modelos de otimização de sistemas de distribuição de água (GOULTER, 1992; LANSEY, 2000) nas últimas décadas. No entanto, WALSKI (2001) critica tais aplicações e discute porque essas técnicas não são utilizadas por usuários nas companhias de saneamento. Segundo esse autor há dificuldades em se definir objetivos e restrições devido: as demandas nos nós variam e os modelos disponíveis consideram demandas fixas; o sistema é construído aos poucos, e se for considerar as soluções resultantes da otimização, o sistema deveria ser construído em uma única etapa; há uma tendência da otimização reduzir diâmetros e até mesmo eliminar tubulações através da minimização de custos, deixando o sistema vulnerável, ou seja, com capacidade insuficiente para responder as quebras ou demandas que excedem os valores de projeto. Dessa forma, o problema ora proposto foi formulado como um problema de otimização multiobjetivo sendo solucionado através dos algoritmos evolucionários.

Os Algoritmos Evolucionários (AEs), como já citados no item (4.3), são técnicas que imitam matematicamente os processos encontrados na natureza, como por exemplo, a evolução natural das espécies. Esses algoritmos mostram-se adequados à otimização multiobjetivo, em particular, pela flexibilidade de se explorar a similaridade das soluções através da busca paralela (conjunto de soluções simultaneamente) e, dessa forma, identificar um conjunto de soluções ótimas em uma única simulação. Um dos algoritmos mais conhecidos pertencentes à classe dos AEs são os algoritmos genéticos 
(AGs). Entretanto, os AGs convencionais foram desenvolvidos para otimização de objetivo único.

Para adequar os AEs à otimização multiobjetivo foram necessárias modificações no módulo de avaliação desses algoritmos, pois ao invés de selecionar uma única solução, os AEs deveria incorporar o critério de dominância (4.4) para selecionar várias soluções (solução não dominadas) a cada iteração. Após essas modificações surgiu uma nova classe de algoritmos voltados ao problema multiobjetivo, tais algoritmos são denominados Algoritmos Evolucionários Multiobjetivo (AEMO). Existe também uma classe específica dos AEMO denominada Algoritmos Genéticos Multiobjetivo (AGMO), considerados como evolução dos AGs aos problemas multiobjetivo.

Os algoritmos evolucionários multiobjetivo são classificados em dois grupos segundo DEB (2001). O primeiro grupo não possui nenhum tipo de operador de elitismo (operador que garante a presença dos melhores vetores solução nas próximas iterações) sendo denominado algoritmos evolucionários multiobjetivo não elitistas. $\mathrm{O}$ segundo grupo refere-se aos modelos que de alguma forma garantem que os melhores vetores solução do conjunto (população) corrente se encontrem nas próximas iterações, esses algoritmos recebem a denominação de algoritmos evolucionários multiobjetivo elitistas.

No presente trabalho, optou-se por utilizar quatro dos mais conhecidos $\mathrm{AEMO}$, dois não elitistas (FONSECA e FLEMING, 1993; SRINIVAS e DEB, 1995) e dois elitistas (ZITZLER e THIELE, 1998; DEB et al., 2002), como forma de verificar a eficiência e a adequação desses algoritmos no problema de análise de reabilitação de sistemas de distribuição de água.

As denominações referentes aos AEMO são distintas e diversas. Assim, visando adequar este trabalho a literatura internacional, preservou-se as denominações sugeridas pelos próprios autores. A aproximação proposta por FONSECA e FLEMING (1993) é denominada Multiobjective Genetic Algorithm (MOGA), a aproximação proposta por SRINIVAS e DEB (1995) é denominada Non-Dominated Sorting Genetic Algorithm (NSGA). ZITZLER e THIELE (1998) denominam seu algoritmo como Strength Pareto Evolutionary Algorithm (SPEA) e, recentemente DEB et al. (2002) propôs o Elitist NonDominated Sorting Genetic Algorithm (NSGA II), considerado como um aperfeiçoamento do algoritmo não elitista NSGA. 
Para descrição e demonstração dos quatro algoritmos utilizados (MOGA, NSGA, SPEA e NSGA II) neste trabalho, um problema exemplo apresentado por DEB (2001) é reproduzido. Esse problema contém duas variáveis de decisão e duas funções objetivo nas quais ambas devem ser minimizadas. A eq.(5.9) descreve tal problema.

$\operatorname{Minimizar} F 1(X)=x_{1}$
$\operatorname{Minimizar~F2(X)}=\frac{1+x_{2}}{x_{1}}$

sujeito à : $\quad 0,1 \leq \mathrm{x}_{1} \leq 1$

$$
0 \leq \mathrm{x}_{2} \leq 5
$$

Tabela 5.1 - Soluções geradas aleatoriamente para o problema (5.9)

\begin{tabular}{ccccc}
\hline \hline Solução & $\mathrm{x}_{1}$ & $\mathrm{x}_{2}$ & $\mathrm{~F} 1$ & $\mathrm{~F} 2$ \\
\hline 1 & 0,31 & 0,89 & 0,31 & 6,10 \\
2 & 0,43 & 1,92 & 0,43 & 6,79 \\
3 & 0,22 & 0,56 & 0,22 & 7,09 \\
4 & 0,59 & 3,63 & 0,59 & 7,85 \\
5 & 0,66 & 1,41 & 0,66 & 3,65 \\
6 & 0,83 & 2,51 & 0,83 & 4,23 \\
\hline \hline
\end{tabular}

Fonte: DEB (2001)

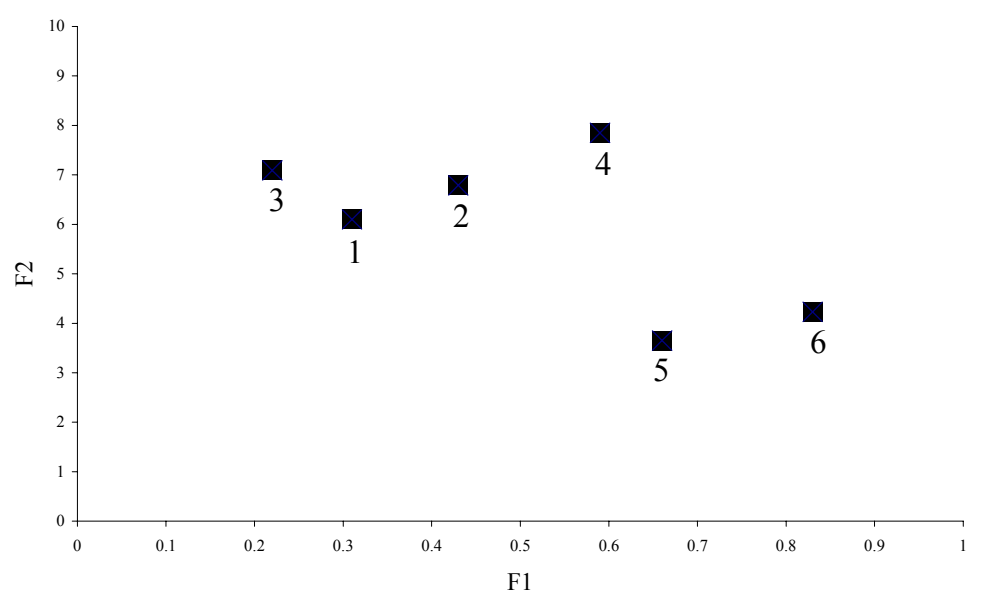

Figura 5.2 - Soluções referentes ao problema (5.9) (adaptado de DEB, 2001)

A Tabela 5.1 apresenta seis soluções geradas aleatoriamente e calculadas conforme a eq.(5.9). Essas soluções são utilizadas como referência para a demonstração do desenvolvimento dos quatro algoritmos. A Figura 5.2 ilustra os valores das funções objetivo (F1 e F2) correspondente ao conjunto aleatório apresentado na Tabela 5.1. 


\subsubsection{MOGA}

O MOGA (Multiobjective Genetic Algorithm) é referenciado na literatura como sendo a primeira técnica de otimização multiobjetivo que considera simultaneamente o conceito de dominância e a diversidade das soluções não dominadas. Esse algoritmo foi proposto por FONSECA e FLEMING (1993) e difere-se dos algoritmos genéticos convencionais (AGs) na maneira com que a avaliação é conduzida, pois a cada iteração o algoritmo deve buscar não uma solução mas um conjunto de soluções não dominadas. Os operadores de variação (recombinação e mutação) são aplicados de forma idêntica aos AGs convencionais. A Figura 5.3 ilustra o procedimento iterativo geral do MOGA.

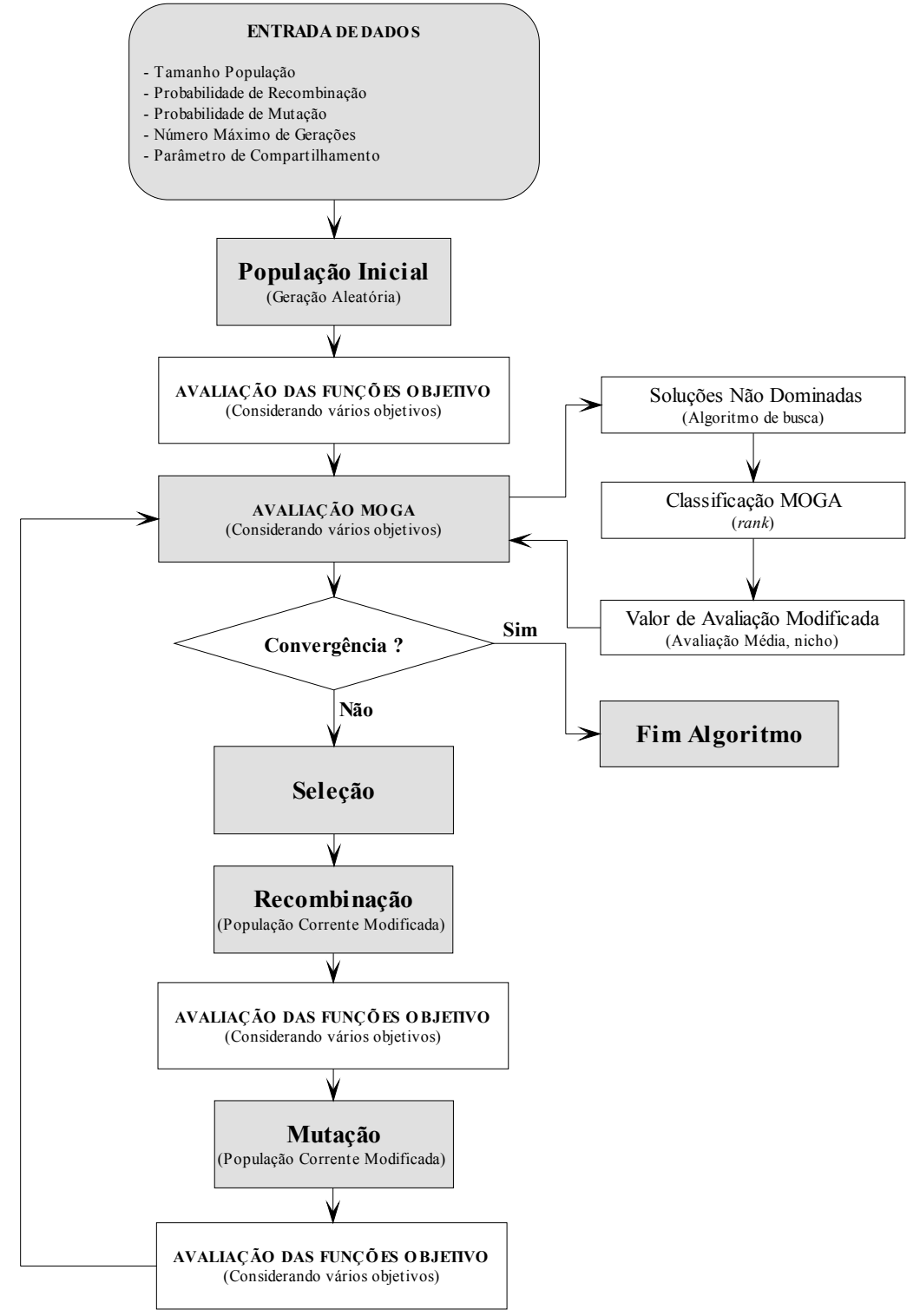

Figura 5.3 - Procedimento geral do MOGA 


\subsubsection{Classificação das soluções}

A cada vetor solução pertencente ao conjunto corrente (população), na otimização de objetivo único, é associado um valor (aptidão) que representa seu desempenho. Esse valor, em muitos casos, é o próprio valor da função objetivo. Com isso, o melhor indivíduo recebe o maior valor de aptidão e possivelmente pertencerá ao conjunto referente à próxima iteração.

Como a otimização multiobjetivo trabalha com soluções ótimas Pareto a cada iteração, não é possível identificar um único vetor solução melhor desse conjunto. Os melhores valores de aptidão são dados ao conjunto de soluções não dominadas da iteração corrente, que são melhores em relação aos outros vetores solução. Considerando tais aspectos, GOLDBERG (1989) propôs que a função aptidão para o conjunto de soluções não dominadas deveria basear-se em um procedimento de ordenação (rank).

FONSECA e FLEMING (1993) propuseram um operador de classificação (rank) para o MOGA, similar as sugestões de GOLDBERG (1989). O rank é baseado no número de soluções que dominam determinada solução i, dada pela eq.(5.10).

$$
\mathrm{r}_{\mathrm{i}}=1+\mathrm{n}_{\mathrm{i}}
$$

sendo que $\mathrm{r}$ representa o rank da solução i e $\mathrm{n}$ representa o número de soluções que dominam a solução i. Para o cálculo dessas soluções há um algoritmo descrito no APÊNDICE A (Algoritmo1) deste trabalho.

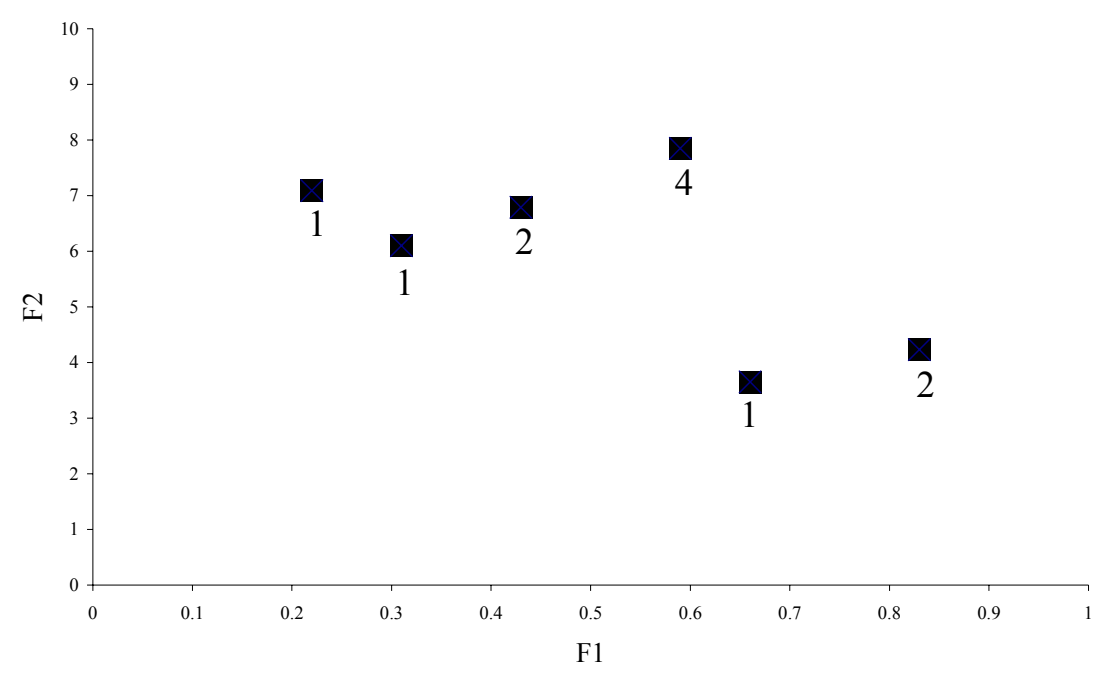

Figura 5.4 - Classificação realizada pelo MOGA no problema exemplo (5.9) 
Considerando o problema exemplo (eq. 5.9), pode-se mostrar (Figura 5.4) a classificação que o MOGA realiza utilizando eq.(5.10). Se na Figura 5.2 os números representam as soluções, na Figura 5.4 são apresentados os ranks dessas soluções (observe que nem sempre a ordenação garante o uso de todos os possíveis valores, 1-6). Essas informações são necessárias durante processo de avaliação das soluções.

\subsubsection{Diversidade da população}

Algoritmos evolucionários são métodos de otimização que partem inicialmente de diversos vetores solução simultaneamente, ou seja, trabalham com várias soluções (população) a cada iteração (geração). Isso faz com que esses métodos contemplem características de busca global. Esse conjunto de soluções possui informações distintas referentes à solução ótima global. Entretanto, tais informações estão distribuídas entre os vetores pertencentes a esse conjunto. Essa distribuição de informações, entre os vetores solução, é denominada diversidade da população.

Manter a diversidade da população durante todo processo iterativo é a principal dificuldade dos AEs. Isso se deve ao fato de que vetores "fortes" (alto valor de aptidão) podem estar presentes na população e podem dominar o processo de otimização. A dominação que esses vetores solução impõem no processo só acontece porque a seleção dos melhores indivíduos da população está relacionada ao valor de aptidão. Como esses indivíduos (fortes) têm elevado valores de aptidão, há uma tendência dos mesmos produzirem diversas cópias para a próxima geração, fazendo com que informações sobre o ótimo sejam perdidas e, consequentemente, provocar uma convergência prematura (ótimos locais) do algoritmo.

Segundo ZITZLER (1999) existem três fatores que fazem com que a população perca diversidade: pressão de seleção, perturbação na seleção e operadores de variação. A pressão de seleção é definida como sendo o fator que determina o número de cópias de vetores solução na próxima geração. Por exemplo, uma alta pressão de solução indica que muitas cópias da melhor solução estarão presentes na próxima geração, fazendo com que a população perca diversidade e que o algoritmo recaia em ótimos locais. A perturbação de seleção está relacionada aos diferentes métodos de seleção existentes e às diferentes formas de tais métodos trabalharem. Já os operadores de variação fazem com que a população perca diversidade devido os efeitos destrutivos que tais operadores (recombinação e mutação) podem causar nas soluções. 
Em se tratando do problema multiobjetivo, semelhante à otimização de objetivo único, os AEMO também têm dificuldades de evolução em decorrência da perda de diversidade da população. Entretanto, nesse caso (otimização multiobjetivo) o algoritmo pode convergir não para um ponto local, mas sim para um conjunto de pontos locais (Figura 4.4), não identificando dessa forma a frente Pareto.

GOLDBERG e RICHARDSON (1987) propuseram uma técnica para manter múltiplas soluções na população em cada geração. Esta técnica é denominada função de compartilhamento cujo objetivo é distribuir proporcionalmente na população diferentes soluções contendo informações do espaço de busca. Para isso, o valor da função de aptidão é dividido pela dimensão do nicho associado a essa solução, obtendo dessa forma a função partilhada. A dimensão do nicho é uma estimativa do quão densa é a região do espaço à qual essa solução pertence, em outras palavras, a dimensão do nicho representa o número de elementos candidatos a representante desse local na superfície da função.

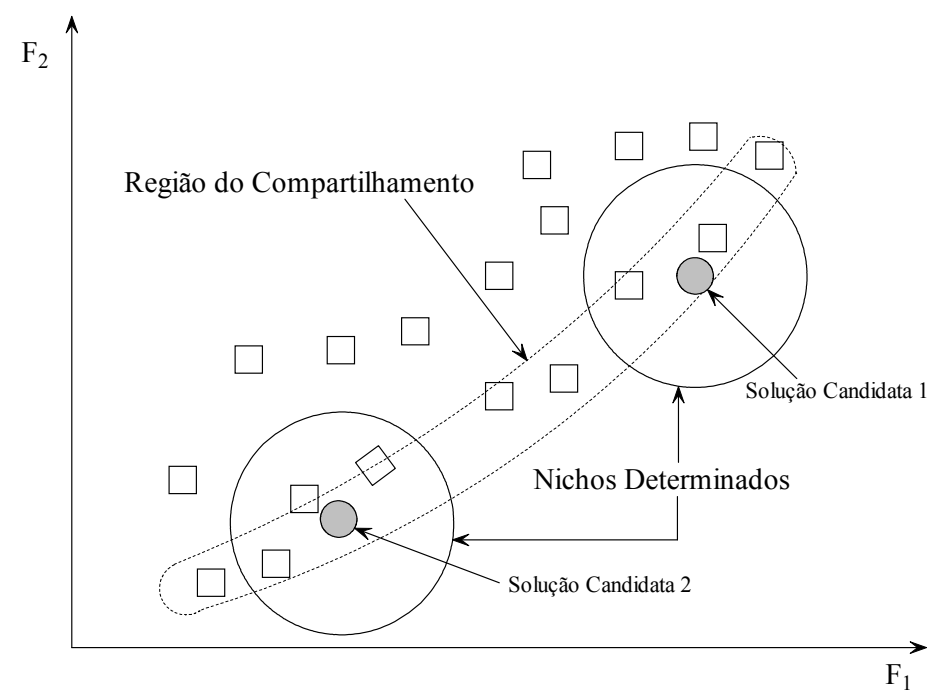

Figura 5.5 - Compartilhamento e nicho (adaptado de HORN e NAFPLIOTIS, 1993)

A Figura 5.5 ilustra essas definições e a eq.(5.11) apresenta a formulação matemática.

$\operatorname{Sh}(d)=\left\{\begin{array}{cl}1-\left(\frac{d}{\sigma}\right)^{\alpha} & \text { se } d \leq \sigma \\ 0 & \text { caso contrário }\end{array}\right.$

o parâmetro d é conhecido como sendo a distância normalizada (eq. 5.12) entre duas soluções (i e j) na população com mesma ordem; $\alpha$ é um expoente que caracteriza a função e o parâmetro $\sigma$ é denominado parâmetro de compartilhamento das soluções. 
Existem valores na literatura para os parâmetros $\alpha$ e $\sigma$. SIRINIVAS e DEB (1995) propõe, $\sigma=0,5$ e $\alpha=1$.

$$
\mathrm{d}_{\mathrm{ij}}=\sqrt{\sum_{\mathrm{k}=1}^{\mathrm{M}}\left(\frac{\mathrm{f}_{\mathrm{k}}^{(\mathrm{i})}-\mathrm{f}_{\mathrm{k}}^{(\mathrm{j})}}{\mathrm{f}_{\mathrm{k}}^{\max }-\mathrm{f}_{\mathrm{k}}^{\min }}\right)^{2}}
$$

sendo que $\mathrm{f}_{\mathrm{k}}^{\max } \mathrm{e}_{\mathrm{k}}^{\min }$ são os valores máximo e mínimo das funções objetivo. Para uma solução i, $d_{i j}$ é calculada para cada solução j (incluindo i), sendo que, i e j possuem mesma ordem; $M$ são os objetivos considerados e $f_{k}$ são os valores das funções objetivo correspondentes a cada solução. Considerando, $\alpha=1$ na eq.(5.11), calcula-se o nicho conforme a eq.(5.13).

$$
\mathrm{nc}_{\mathrm{i}}=\sum_{\mathrm{j}=1}^{\mu\left(\mathrm{r}_{\mathrm{i}}\right)} \operatorname{Sh}\left(\mathrm{d}_{\mathrm{ij}}\right)
$$

sendo $\mu\left(\mathrm{r}_{\mathrm{i}}\right)$ é o número de soluções com ordem $\left(\mathrm{r}_{\mathrm{i}}\right)$ e $\mathrm{j}$ são as soluções que estão contidas na mesma ordem de $\mathrm{i}$.

\subsubsection{Etapas do procedimento iterativo do MOGA}

Diversas são as possibilidades de implementação dos algoritmos evolucionários multiobjetivo em termos da sistemática de obtenção da frente Pareto ótima, dos operadores genéticos e dos parâmetros adotados, das técnicas de distribuição de soluções nas frentes não dominadas, das probabilidades de recombinação e mutação e do critério de convergência. Nesta seção segue a descrição e implementação do algoritmo MOGA de acordo com fluxograma apresentado na Figura 5.3.

\section{Dados de Entrada}

- Dimensão da população: POP

- Probabilidade de recombinação: $P_{r}$

- Probabilidade de mutação: $\mathrm{P}_{\mathrm{m}}$

- Parâmetro de compartilhamento (5.11): $\sigma$

- Número máximo de gerações: GER 


\section{Etapa 1 - População inicial}

- Geração da população inicial aleatória $P_{t}$ considerando o parâmetro de entrada POP.

Etapa 2 - Avaliação das funções objetivo

- Cada vetor solução pertencente à população inicial $\mathrm{P}_{\mathrm{t}}$ é avaliado de acordo com as funções objetivo consideradas. Esta etapa é denominada avaliação das funções de avaliação ou aptidão.

\section{Etapa 3 - Avaliação MOGA}

- Para cada vetor solução i pertencente ao conjunto $P_{t}$ é calculado o número de soluções que dominam (n) esse vetor (Algoritmo 1 - APÊNDICE A).

- O próximo passo é classificar as soluções ( $\left.r_{i}\right)$ conforme eq.(5.10).

- Após ter determinado o rank de cada vetor pertencente à população $\mathrm{P}_{\mathrm{t}}$, calculase a função avaliação média para todos os vetores solução POP através da eq.(5.14):

$$
\mathrm{F}_{\mathrm{i}}=\mathrm{n}_{\text {população }}-\left(\sum_{\mathrm{k}=1}^{\mathrm{r}_{\mathrm{i}}-1} \mathrm{u}(\mathrm{k})\right)-0,5\left(\mathrm{u}\left(\mathrm{r}_{\mathrm{i}}\right)-1\right)
$$

sendo que $\mathrm{u}(\mathrm{k})$ representa o conjunto de vetores solução de rank $\mathrm{k}$. Por exemplo, $\mathrm{u}(1)$ refere-se ao número de vetores solução com rank 1 .

- Após calcular a avaliação média é necessário dimensionar o nicho (5.13) para cada solução i de mesmo rank e assim calcular a avaliação compartilhada conforme eq.(5.14). A avaliação compartilhada $\left(F_{i}^{\prime}\right)$ é uma das formas de garantir diversidade na população.

$$
\mathrm{F}_{\mathrm{i}}^{\prime}=\frac{\mathrm{F}_{\mathrm{i}}}{\mathrm{nc}_{\mathrm{i}}}
$$

- Finalmente, como forma de preservar a escala da avaliação média, a avaliação compartilhada (avaliação modificada) é recalculada conforme eq.(5.16):

$$
\mathrm{F}_{\mathrm{i}}^{\prime}=\frac{\mathrm{F}_{\mathrm{i}} \mathrm{u}\left(\mathrm{r}_{\mathrm{i}}\right)}{\sum_{\mathrm{k}=1}^{\mathrm{u}\left(\mathrm{r}_{\mathrm{i}}\right)} \mathrm{F}_{\mathrm{k}}^{\prime}} \mathrm{F}_{\mathrm{i}}^{\prime}
$$




\section{Etapa 5 - Convergência}

- Nessa etapa o algoritmo verificará seu critério de convergência. Em geral, adotase o número máximo de iterações (GER) para essa verificação. Se tal critério for satisfeito o algoritmo segue para a etapa 10 e o processo é finalizado, caso contrário, o algoritmo segue para a etapa 6 (procedimento de variação).

Etapa 6 - Seleção

- Utilizando os valores de aptidão modificado $\left(F_{i}^{\prime}\right)$, mecanismos de compartilhamento e nichos, calculados para cada vetor da população, nessa etapa acontece a seleção das soluções candidatas que irão compor a próxima população. No MOGA a técnica de seleção utilizada é a amostragem estocástica universal.

\section{Etapa 7 - Recombinação}

- Nessa etapa os AEMO se assemelham aos AEs. A recombinação é também denominado operador de variação. É nessa etapa que o algoritmo evolui sua busca, analogamente essa etapa pode ser comparada ao processo de mudanças de direções e coordenadas realizadas pelos algoritmos convencionais de busca. Esse operador é aplicado como na estrutura geral dos AGs convencionais simples (Figura 4.6).

\section{Etapa 8-Mutação}

- O operador de mutação também faz parte do processo de variação e é responsável pela introdução de diversidade na população, que muitas vezes é perdida ao longo das iterações, em outras palavras pode-se dizer que esse operador é responsável pela introdução de material genético na população. Em geral, esse operador é aplicado como na estrutura dos AGs convencionais apresentada pela Figura 4.6.

Etapa 9 - Nova População

- Uma nova população é formada devido à aplicação dos operadores de recombinação e mutação. Assim é necessário que uma nova avaliação seja realizada para cada vetor solução pertencente a essa nova população, retornando o processo a etapa 2 .

\section{Etapa 10 - Resultados}

- Nessa etapa o algoritmo apresenta as soluções ótimas Pareto. 


\subsubsection{NSGA}

O NSGA (Non Dominated Sorting Genetic Algorithm) foi proposto por SRINIVAS e DEB (1995) com objetivo de se trabalhar o conceito de dominância e a manutenção da diversidade da população simultaneamente seguindo a idéia inicial de GOLDBERG (1989). Esse método é muito semelhante ao algoritmo MOGA, entretanto o NSGA difere da aproximação proposta por FONSECA e FLEMING (1993) na maneira como classifica os vetores solução não dominados (frentes) e na forma com que o método de compartilhamento é considerado (espaço dos parâmetros) para garantir a diversidade da população. Os operadores de recombinação e mutação são aplicados como nos AGs convencionais (Figura 4.6). A Figura 5.6 ilustra o procedimento geral do NSGA.

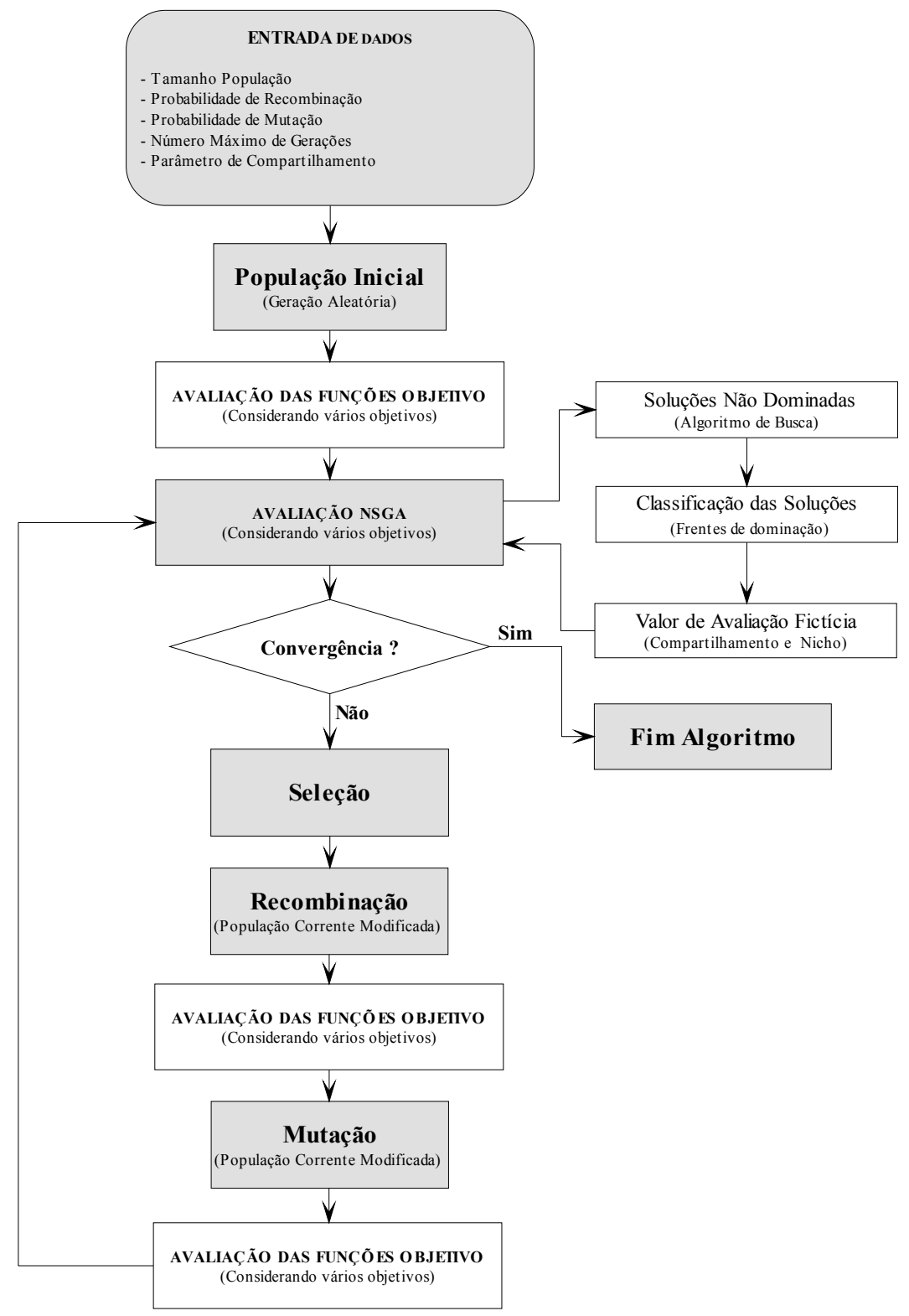

Figura 5.6 - Procedimento geral do NSGA 


\subsubsection{Classificação das soluções}

Antes que a seleção seja desenvolvida, é necessário classificar as soluções conforme o conceito de dominância apresentado no item (eq. 4.4) deste trabalho. Entretanto, o NSGA desenvolve a classificação através de frentes de dominação sendo que todos os indivíduos pertencentes a essas frentes recebem um mesmo valor de aptidão o qual é utilizado posteriormente para o cálculo da função compartilhada.

SRINIVAS e DEB (1995) propuseram o operador de classificação de soluções do NSGA baseado em frentes não dominadas. Encontrar o conjunto de soluções não dominadas para uma dada população é similar ao princípio de encontrar o mínimo ou máximo de um conjunto de números. Existem vários algoritmos para determinação desse conjunto de soluções, no entanto esses algoritmos diferem entre si em complexidade computacional. Alguns trabalhos (KUNG, LUCCIO e PREPARATA, 1975; DEB, 2001) discutem a complexidade desses algoritmos. Nesse trabalho são apresentados dois algoritmos de busca de soluções não dominadas que podem ser encontrados no Anexo A. O primeiro algoritmo (Algoritmo 2 - APÊNDICE A) tem um custo computacional mais elevado do que o segundo (Algoritmo 3 - APÊNDICE A), porém é mais simples de ser implementado.

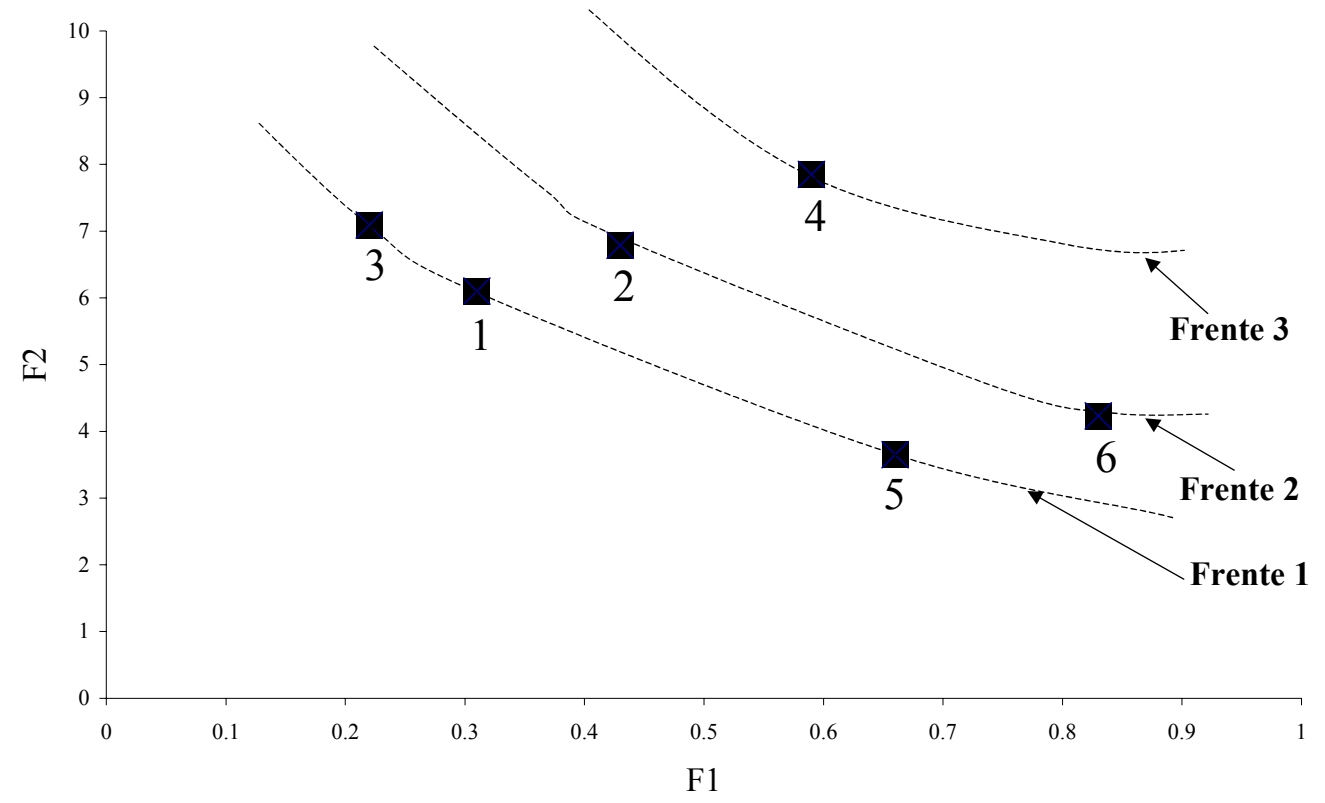

Figura 5.7 - Classificação realizada pelo NSGA para o problema exemplo (5.9)

No algoritmo NSGA a população é ordenada de acordo com um procedimento de classificação baseado em frentes de dominação (Algoritmo 4 - APÊNDICE A). Esse 
procedimento é ilustrado pela Figura 5.7, considerando o problema exemplo (5.9). Observa-se que as soluções 1,3 e 5 pertencem a primeira frente de dominância e são candidatas a evoluir para frente Pareto.

\subsubsection{Etapas do procedimento iterativo do NSGA}

Nesta seção apresentam-se a descrição e implementação do algoritmo NSGA de acordo com fluxograma apresentado na Figura 5.6.

\section{Dados de Entrada}

- $\quad$ Dimensão da população: POP

- $\quad$ Probabilidade de recombinação: $P_{\mathrm{r}}$

- $\quad$ Probabilidade de mutação: $\mathrm{P}_{\mathrm{m}}$

- $\quad$ Parâmetro de compartilhamento (4.19): $\sigma$

- $\quad$ Número máximo de gerações: GER

\section{Etapa 1 - População inicial}

- Geração da população inicial aleatória $P_{t}$ considerando o parâmetro de entrada POP

Etapa 2 - Avaliação das funções objetivo

- Cada vetor solução pertencente à população inicial $P_{t}$ é avaliado de acordo com as funções objetivo consideradas. Esta etapa é denominada avaliação das funções de avaliação ou aptidão considerando objetivos múltiplos.

\section{Etapa 3 - Avaliação NSGA}

- Ajuste um número pequeno positivo $(\varepsilon)$ e um contador j que representa a frente não dominada $\left(F R_{j}\right)$, e inicialize um valor de aptidão mínimo $\left(F^{m i n}\right)$ conforme eq. (5.17):

$$
\mathrm{F}^{\mathrm{min}}=\mathrm{POP}+\varepsilon
$$

- Para cada vetor solução i pertencente ao conjunto $P_{t}$ é identificado a frente não dominada à qual esse vetor pertence (Algoritmo 4 - APÊNDICE A), com isso existirão $\rho$ frentes não dominadas $\left(\mathrm{FR}_{1}, \mathrm{FR}_{2}, \ldots, \mathrm{FR}_{\rho}\right)$. $\mathrm{O}$ número de frentes não dominadas $\rho$ depende do problema e da população. 
- Para cada vetor i pertencente a cada frente não dominada $\left(\operatorname{FR}_{j} \quad j=1,2, \ldots, \rho\right)$ de índice j é calculada sua avaliação fictícia $\mathrm{F}_{\mathrm{j}}^{\mathrm{i}}$ (eq. 5.26), o seu nicho $\mathrm{nc}_{\mathrm{i}}$ (eq. 5.19) considerando a distância euclidiana $d_{i k}$ (eq. 5.19) no espaço das variáveis de decisão e sua avaliação compartilhada $F_{i}^{\prime}$ (eq. 5.23) correspondente.

$F_{j}^{i}=F^{\min }-\varepsilon$

sendo que $\mathrm{i}$ representa todos os vetores pertencentes a frente $\mathrm{F}_{\mathrm{j}}$. A distância euclidiana no espaço das variáveis de decisão é:

$\mathrm{d}_{\mathrm{ik}}=\sqrt{\sum_{\mathrm{p}=1}^{\left|\mathrm{P}_{\mathrm{t}}\right|}\left(\frac{\mathrm{x}_{\mathrm{p}}^{\mathrm{i}}-\mathrm{x}_{\mathrm{p}}^{\mathrm{k}}}{\mathrm{x}_{\mathrm{p}}^{\max }-\mathrm{x}_{\mathrm{p}}^{\min }}\right)^{2}}$

sendo que $\left|\mathrm{P}_{\mathrm{t}}\right|$ refere-se à dimensão do espaço da conjunto $\mathrm{P}_{\mathrm{t}}$. Por exemplo, para o problema (5.9) $\left|\mathrm{P}_{\mathrm{t}}\right|$ é igual a 2. A distância entre duas soluções i e k $\left(\mathrm{d}_{\mathrm{ik}}\right)$ é calculada considerando que essas soluções pertencem à mesma frente não dominada.

- Após terem sido calculadas todas as distâncias $d_{i k}$ referentes às soluções pertencentes à frente não dominada $\mathrm{j}$, é possível dimensionar os nichos correspondentes dessas soluções através da eq. (5.11).

- O próximo passo é calcular a avaliação compartilhada para cada solução i pertencente à frente não dominada $\mathrm{j}$ através da eq. (5.20).

$$
\mathrm{F}_{\mathrm{j}}^{\prime(\mathrm{i})}=\frac{\mathrm{F}_{\mathrm{j}}^{\mathrm{i}}}{\mathrm{nc}_{\mathrm{i}}}
$$

- A partir do cálculo das avaliações compartilhada, um novo valor de $F^{\text {min }}$ é identificado através da eq.(5.21), um incremento de j é ajustado (p. ex. frente não dominada $2-\mathrm{FR}_{2}$ ) e volta-se o início desse módulo de avaliação até que todas as frentes $(\rho)$ sejam consideradas.

$$
F^{\min }=\min \left(F_{j}^{\prime(i)} \mid j \in F_{j}\right)
$$




\section{Etapa 5 - Convergência}

- Nessa etapa o algoritmo verificará se o critério de convergência foi atendido. Em geral, adota-se o número máximo de iterações para essa verificação. Se tal critério for satisfeito o algoritmo segue para a etapa 10 e o processo é finalizado, caso contrário, o algoritmo segue para a etapa 6 (procedimento de variação).

Etapa 6 - Seleção

- Utilizando os valores de aptidão modificado $\left(\mathrm{F}_{\mathrm{j}}^{(\mathrm{i})}\right)$ para cada solução $\mathrm{j}$ pertencente a frente $\mathrm{i}$, calcula-se para cada vetor da população o número de cópias que cada vetor solução irá ter na próxima população. Nos estudos iniciais do NSGA, a técnica de seleção utilizada foi seleção estocástica proposta por GOLDBERG (1989).

\section{Etapa 7 - Recombinação}

- Nessa etapa os AEMO se assemelham aos AEs. A recombinação é também denominado operador de variação. É nessa etapa que o algoritmo evolui sua busca, analogamente essa etapa pode ser comparada ao processo de mudanças de direções e coordenadas realizadas pelos algoritmos convencionais de busca. Esse operador é aplicado como na estrutura geral dos AGs convencionais simples (Figura 4.6).

\section{Etapa 8-Mutação}

- O operador de mutação também faz parte do processo de variação e é responsável pela introdução de diversidade na população, que muitas vezes é perdida ao longo das iterações. Em outras palavras pode-se dizer que esse operador é responsável pela introdução de novo material genético na população. Em geral, esse operador é aplicado como na estrutura dos AGs convencionais apresentada pela Figura (4.6).

\section{Etapa 9 - Nova População}

- Uma nova população é formada devido à aplicação dos operadores de recombinação e mutação. Assim é necessário que uma nova avaliação seja realizada para cada vetor solução pertencente a essa nova população, por isso volta-se a etapa 2 .

Etapa 10 - Resultados

- Nessa etapa o algoritmo apresenta as soluções ótimas Pareto. 


\subsubsection{SPEA}

O SPEA (Strength Pareto Evolutionary Algorithm) foi proposto por ZITZLER e THIELE (1998) com objetivo de introduzir o elitismo nos algoritmos evolucionários multiobjetivo. As melhores soluções (soluções não dominadas) de cada iteração, denominadas elite, são armazenadas em um conjunto externo (temporário). Em cada iteração do algoritmo, as soluções externas são comparadas com as soluções pertencentes ao conjunto corrente de forma que as melhores soluções são preservadas.

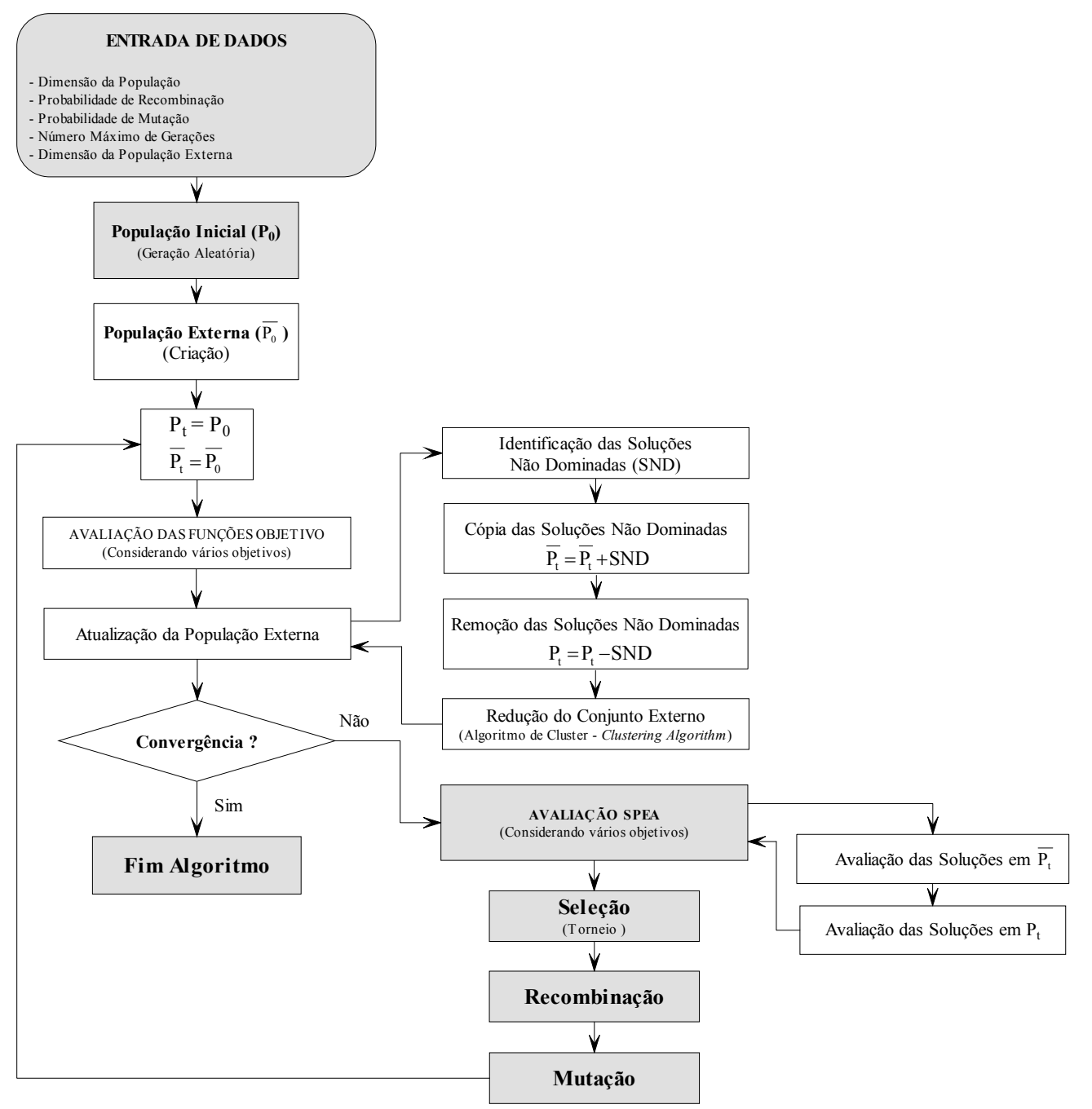

Figura 5.8 - Procedimento geral do SPEA

Existem várias similaridades entre o SPEA e os outros algoritmos evolucionários multiobjetivo (SCHAFFER, 1984; FONSECA e FLEMING, 1993; HORN e NAFPLIOTIS, 1993; SRINIVAS e DEB, 1995). Dentre as principais pode-se citar a garantia de vetores solução representantes da frente não dominada entre as soluções consideradas e a utilização do conceito de dominância Pareto para atribuir valores de aptidão baseados nesse conceito. Entretanto, o SPEA difere dos demais métodos em 
relação alguns aspectos: atribuição do valor aptidão de um vetor solução é determinado entre os conjuntos externo e corrente, e não entre vetores pertencentes à mesma população, todos os vetores solução no conjunto externo participam da seleção e a utilização de um novo método de manutenção da diversidade da população.

\subsubsection{Etapas do procedimento iterativo do SPEA}

Nesta seção descreve-se a implementação do algoritmo SPEA de acordo com fluxograma apresentado na Figura (5.8). Em geral, pode-se dizer que o SPEA cria um conjunto inicial aleatório $\mathrm{P}_{0}$ de dimensão POP e um conjunto externo vazio $\overline{\mathrm{P}}_{0}$ com uma dimensão máxima $\overline{\mathrm{POP}}$. Na iteração $t$, as soluções não dominadas da população $\mathrm{P}_{\mathrm{t}}$ são copiadas para a população externa $\overline{\mathrm{P}}_{\mathrm{t}}$. Com isso, acontece a união entre as soluções não dominadas (população elite) da iteração corrente e da iteração prévia, e em seguida, identificam-se e excluem-se as soluções dominadas desse conjunto unificado. O que permanece nesse conjunto externo são as melhores soluções elite encontradas durante o processo iterativo. Entretanto, à medida que o processo evolui, em alguns problemas, o número de soluções contidas nesse conjunto é considerado elevado.

Como forma de restringir o aumento exagerado de soluções não dominadas no conjunto externo, uma dimensão ( $\overline{\mathrm{POP}})$ é fixada. Assim, quando a dimensão da população externa é menor que $\overline{\mathrm{POP}}$, toda a população elite é encontrada no conjunto. No entanto, quando a dimensão excede $\overline{\mathrm{POP}}$, nem toda população elite pode estar na população externa. Dessa forma, os autores (ZITZLER e THIELE, 1998) do SPEA propuseram uma técnica para reduzir as soluções da população externa denominada. Essa técnica é denominada na literatura internacional como clustering algorithm, aqui denominado algoritmo de agrupamento (cluster).

\section{Dados de Entrada}

- Dimensão da população: POP

- Probabilidade de recombinação: $\mathrm{P}_{\mathrm{r}}$

- Probabilidade de mutação: $\mathrm{P}_{\mathrm{m}}$

- Dimensão da população externa: $\overline{\mathrm{POP}}$

- Número máximo de gerações: GER 


\section{Etapa 1 - População inicial}

- Geração da população inicial aleatória $P_{t}$ considerando o parâmetro de entrada POP.

Etapa 2 - População externa

- Criação da população externa $\overline{\mathrm{P}}_{\mathrm{t}}$ vazia de dimensão $\overline{\mathrm{POP}}$ (parâmetro de entrada).

Etapa 3 - Avaliação das funções objetivo

- Cada vetor solução pertencente à população inicial $\mathrm{P}_{\mathrm{t}}$ é avaliado de acordo com as funções objetivo consideradas. Esta etapa é denominada avaliação das funções de avaliação ou aptidão considerando objetivos múltiplos.

Etapa 4 - Atualização da população externa

- Identificação das soluções não dominadas da população $\mathrm{P}_{\mathrm{t}}$.

- Cópia das soluções não dominadas encontradas em $\mathrm{P}_{t}$ para a população $\overline{\mathrm{P}}_{\mathrm{t}}$.

- Remoção das soluções não dominadas de $P_{t}$.

- Adequação do conjunto externo, conforme dimensão da população externa $\overline{\mathrm{POP}}$, através do algoritmo de cluster. Esse algoritmo reduz a dimensão da população externa corrente $\left(\overline{\mathrm{POP}}_{\text {corrente }}\right)$ para a dimensão limite $(\overline{\mathrm{POP}})$, fornecida nos dados de entrada (sendo $\overline{\mathrm{POP}}_{\text {corrente }}>\overline{\mathrm{POP}}$ ). Assume-se inicialmente que cada solução $i$ $\left(\mathrm{i} \in \overline{\mathrm{P}}_{\mathrm{t}}\right)$ pertence a um cluster individual, portanto, existem $\overline{\mathrm{POP}}_{\text {corrente }}$ clusters. Por exemplo, se o conjunto externo possui 20 soluções, inicialmente para o algoritmo de corte, considera-se a existência de 20 clusters. Assim, as distâncias entre pares de clusters são calculadas. Em geral, a distância $\left(\mathrm{d}_{\mathrm{kp}}\right)$ entre dois clusters $\left(\mathrm{C}_{\mathrm{k}}\right.$ e $\left.\mathrm{C}_{\mathrm{p}}\right)$ é definida como sendo a distância euclidiana de todos pares de soluções ( $i \in \mathrm{C}_{\mathrm{k}}$ e $\mathrm{j} \in \mathrm{C}_{\mathrm{p}}$ ) ou matematicamente conforme eq.(5.22):

$$
d_{k p}=\frac{1}{\left|C_{k}\right|\left|C_{p}\right|} \sum_{i \in C_{k}, j \in C_{p}} d(i, j)
$$

sendo que a distância d(i,j) pode ser calculada no espaço de variáveis de decisão ou no espaço objetivo. No SPEA, os autores preferiram trabalhar no espaço objetivo. Uma vez que todas as distâncias de clusters são calculadas, os dois clusters com distância mínima são combinados para formarem um cluster maior. 
Assim, as distâncias de cluster são recalculadas para todos os pares de clusters, para posteriormente dois clusters serem unidos novamente. O processo continua até que o número de clusters na população externa é reduzida à dimensão desejada $\overline{\mathrm{POP}}$. Consequentemente, em cada cluster, a solução de distância mínima média das outras soluções no cluster é retida e as outras são excluídas. A Figura 5.9 ilustra o procedimento geral do algoritmo de cluster.

\section{Etapa 5 - Convergência}

Nessa etapa o algoritmo verificará seu critério de convergência. Em geral, adotase o número máximo de iterações para essa verificação. Se tal critério for satisfeito o algoritmo segue para a etapa 11 e o processo é finalizado, caso contrário, o algoritmo segue para a etapa 6 .
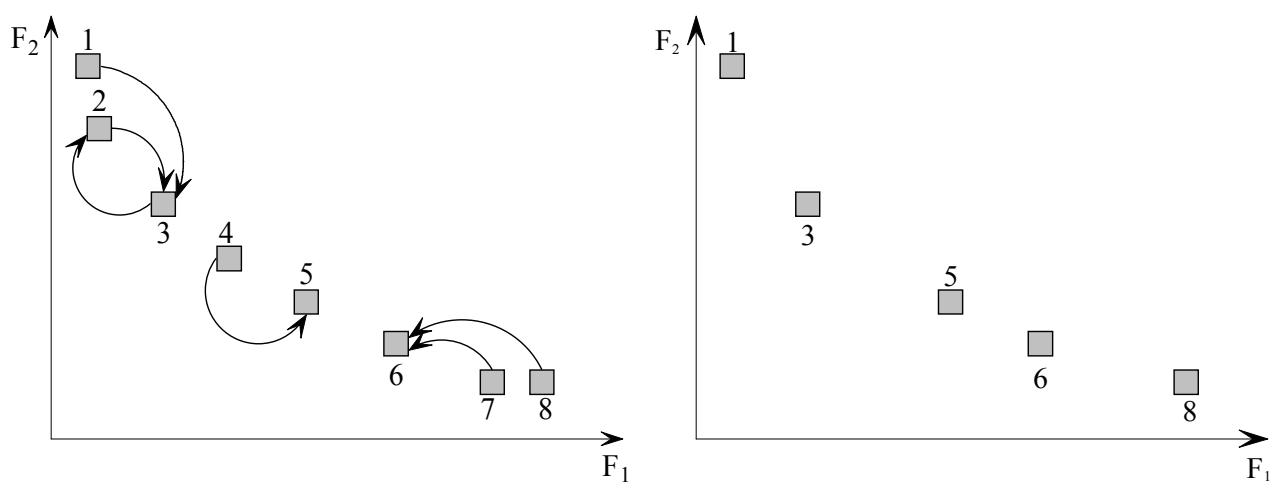

Figura 5.9 - Ilustração do algoritmo de cluster

\section{Etapa 6-Avaliação SPEA}

- O módulo de avaliação tem objetivo de atribuir valores de aptidão as soluções como forma de preparar para ao operador seleção. No SPEA, esse procedimento é realizado sob duas etapas. Primeiro todos vetores solução i pertencentes à população externa $\left(\overline{\mathrm{P}}_{\mathrm{t}}\right)$ são classificados e recebem um valor de aptidão $\mathrm{S}_{\mathrm{i}}$ denominado na literatura internacional como strength. Esse valor de aptidão, para um dado vetor de solução i, é proporcional ao número de soluções dominadas pela solução i na população corrente. Matematicamente, esse valor é definido pela eq.(5.23):

$$
\mathrm{S}_{\mathrm{i}}=\frac{\mathrm{n}_{\mathrm{i}}}{\mathrm{n}_{\text {população }}+1}
$$


sendo que $\mathrm{n}$ representa o número de vetores pertencentes a população corrente que uma solução i domina. Após todos os valores de $\mathrm{S}_{\mathrm{i}}$ terem sido calculados, atribui-se a $F_{i}$ tais valores.

- Posteriormente, calcula-se os valores de aptidão $\left(F_{j}\right)$ de todas as soluções j pertencentes à população corrente $\left(\mathrm{P}_{\mathrm{t}}\right)$. Esse valor de aptidão é calculado (eq. 5.24) como sendo a soma de todos os valores de aptidão $S_{i}$ das soluções externas i que dominam vetores $\mathrm{j}$ da população corrente:

$$
\mathrm{F}_{\mathrm{i}}=1+\sum_{\mathrm{i} \in \overline{\mathrm{P}}_{\mathrm{t}}, \mathrm{i} \prec \mathrm{j}} \mathrm{S}(\mathrm{i})
$$

- O valor 1 presente na eq.(5.24) garante que soluções de $\overline{\mathrm{P}}_{\mathrm{t}}$ tenham valores de aptidão melhor que soluções de $\mathrm{P}_{\mathrm{t}}$ (note que o valor de aptidão deve ser minimizado, isto é, menores valores de aptidão correspondem a altas probabilidades de cópias (reprodução), na próxima população).

\section{Etapa 7 - Seleção}

- Nessa etapa o SPEA se difere de ambos os métodos, MOGA e NSGA. Pois, a técnica de seleção utilizada no SPEA é a seleção por torneio. Após todas as soluções, pertencentes aos conjuntos externo e corrente, terem recebido seus respectivos valores de aptidão $(\mathrm{F})$, os conjuntos $\mathrm{P}_{t}$ e $\overline{\mathrm{P}}_{\mathrm{t}}$ são unidos para ser aplicado o operador de seleção.

- A seleção por torneio no SPEA é desenvolvida da seguinte forma: cria-se um conjunto temporário $\left(\mathrm{P}_{\text {temp }}\right)$ de dimensão $\mathrm{n}_{\text {população }}$; seleciona-se aleatoriamente duas soluções (i e j) pertencentes a conjunto unificado $\left(P_{t} \cup \bar{P}_{t}\right)$; se $F(i)<F(j)$ então i é incluso em $\mathrm{P}_{\text {temp }}$ caso contrário j é incluso em $\mathrm{P}_{\text {temp }}$ (note que a melhor solução é a que apresenta menor valor de aptidão F).

\section{Etapa 8 - Recombinação}

- Nessa etapa o SPEA se assemelham aos AEs simples. A recombinação é denominada operador de variação. Esse operador é aplicado como na estrutura geral dos AGs convencionais simples (Figura 4.6). 


\section{Etapa 9 - Mutação}

- O operador de mutação também faz parte do processo de variação e é responsável pela introdução de diversidade na população, que muitas vezes é perdida ao longo das iterações, em outras palavras pode-se dizer que esse operador é responsável pela introdução de material genético na população. Em geral, esse operador é aplicado como na estrutura dos AGs convencionais apresentada pela Figura (4.6).

\section{Etapa 10 - Nova População}

- Uma nova população é formada devido à aplicação dos operadores de recombinação e mutação. Assim é necessário que uma nova avaliação seja realizada para cada vetor solução pertencente a essa nova população, portanto volta-se a etapa 3 .

Etapa 11 - Resultados

- Nessa etapa o algoritmo apresenta as soluções ótimas Pareto.

\subsubsection{NSGAII}

Considerando a necessidade de diminuir a complexidade computacional na classificação não dominada, introduzir o elitismo e eliminar a subjetividade na atribuição do parâmetro de compartilhamento, DEB et al. (2002) propuseram o NSGA II (Elitist Nondominated Sorting Genetic Algorithm).

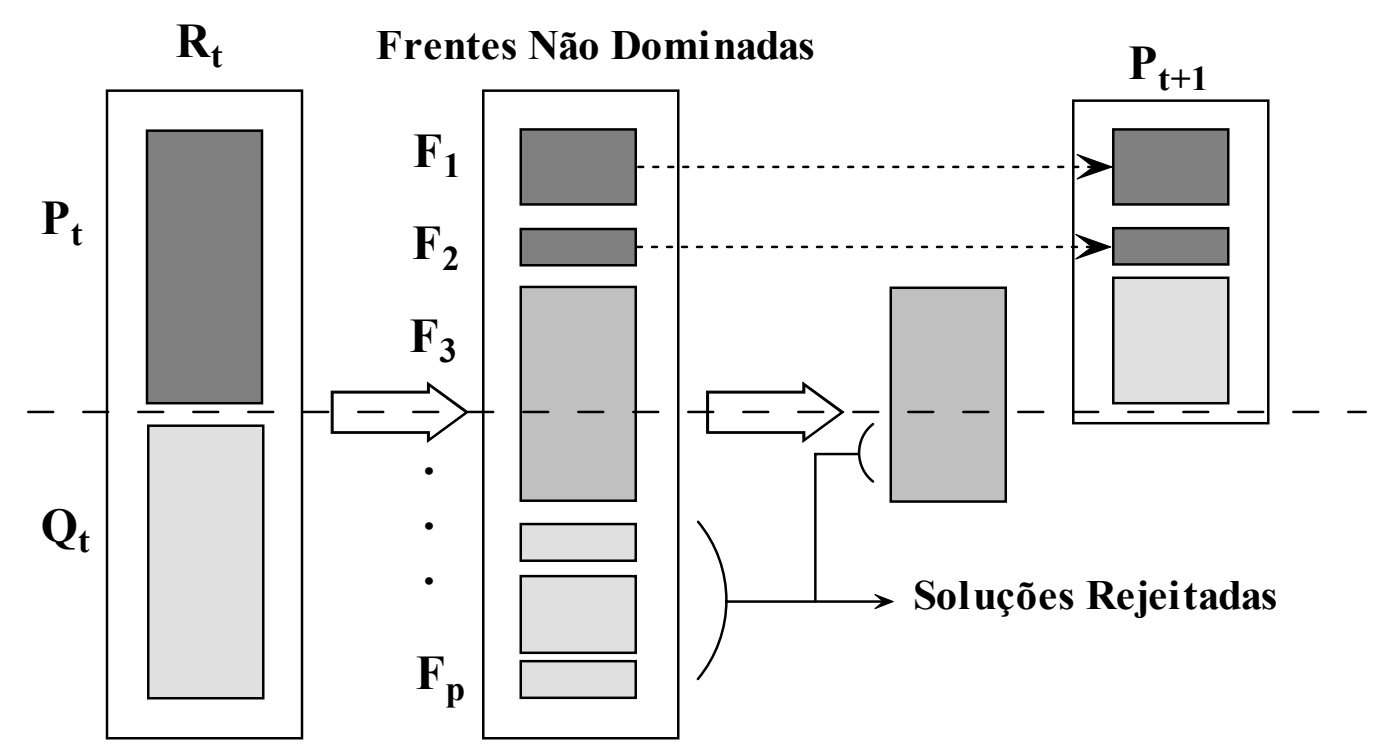

Figura 5.10 - Esquema do procedimento evolutivo do NSGA II (adaptado de DEB, 2001) 
Em se tratando da complexidade computacional, o NSGA II contém um algoritmo de classificação não dominada com menor complexidade computacional (ordem $\mathrm{MN}^{2}$ ) frente aos outros AEMO (MOGA, NSGA e SPEA), que apresentam uma complexidade aproximada na ordem de $\mathrm{MN}^{3}$, sendo $\mathrm{M}$ o número de objetivos e $\mathrm{N}$ a dimensão da população. Já o elitismo, no NSGA II, é garantido através de preservação das melhores soluções (frentes não dominadas) na população posterior. Em geral, o procedimento desenvolve-se da seguinte forma, uma população derivada (filha) da população corrente (pai) é criada utilizando a seleção por torneio de multidão seguida da recombinação e mutação. Após isso, esses dois conjuntos de mesma dimensão (pai e filha) são unidos em uma única população e aplica-se a classificação não dominada (Algoritmo 4 APÊNDICE A) em frentes de dominância. Inicia-se então o processo de preenchimento de uma nova população colocando as melhores frentes não dominadas nesse novo conjunto, garantindo dessa forma o elitismo. A Figura 5.10 ilustra esse procedimento.

Observa-se na Figura (5.10) que nem todas as frentes podem ser incluídas na nova população $\left(\mathrm{P}_{\mathrm{t}+1}\right)$, por exemplo a frente $3\left(\mathrm{~F}_{3}\right)$. Assim, os autores do NSGA II (DEB et al., 2002) propuseram um método, que combina as frentes não incluídas no conjunto, para compor os últimos espaços da população $\mathrm{P}_{\mathrm{t}+1}$. Esse método é denominado distância de multidão, ilustrado pela Figura 5.11. Com a utilização dessa técnica para alocação de soluções na população $\mathrm{P}_{\mathrm{t}+1}$ é garantida a diversidade da população (estimação de densidade das soluções) e eliminação da subjetividade de introdução do parâmetro de compartilhamento utilizado nos métodos não elitistas, pois diferentes soluções podem tem chances de pertencer à nova população.

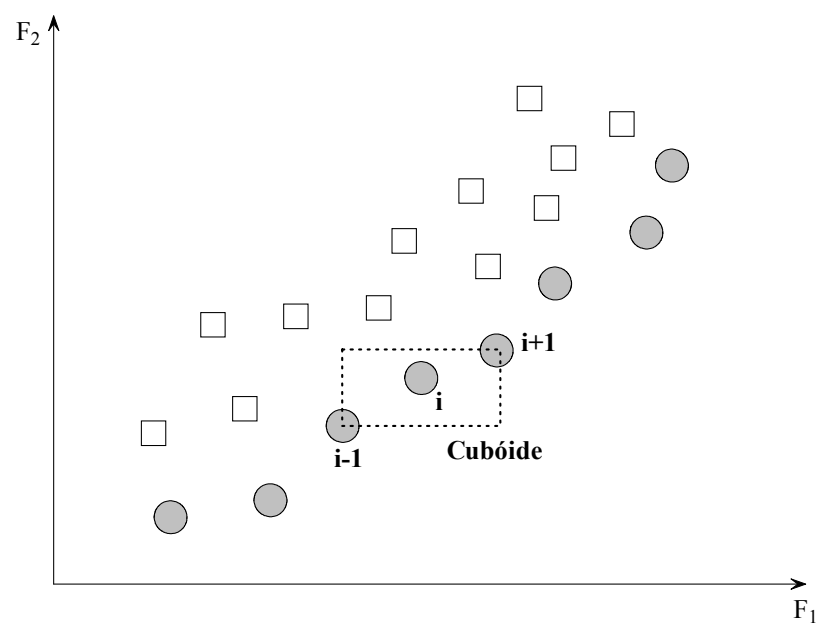

Figura 5.11 - Cálculo da distância de multidão do NSGA II 


\subsubsection{Etapas do procedimento iterativo do NSGA II}

Nesta seção é apresentada a descrição e a implementação do algoritmo NSGA II de acordo com fluxograma apresentado na Figura 5.12. Em geral, pode-se dizer que o NSGA II inicia seu processo através de um conjunto inicial aleatório $\mathrm{P}_{0}$ de dimensão POP. Através desse conjunto inicial obtém-se uma população derivada $\mathrm{Q}_{0}$ de dimensão POP denominada população filha, utilizando operadores de seleção, recombinação e mutação. Esses dois conjuntos são unidos e formam um conjunto $\mathrm{R}_{0}$ de dimensão 2POP. A partir desse passo, inicia-se o processo de classificação não dominada e formação da nova população $P_{t}$. Essa nova população é preenchida com soluções de diversas frentes não dominadas, que garante a diversidade da população.

\section{Dados de Entrada}

- Dimensão da população: POP

- Probabilidade de recombinação: $P_{\mathrm{r}}$

- Probabilidade de mutação: $\mathrm{P}_{\mathrm{m}}$

- Número máximo de gerações: GER

Etapa 1 - População inicial

- Geração da população inicial aleatória $\mathrm{P}_{0}$ considerando o parâmetro de entrada POP.

Etapa 2 - Classificação da população inicial

- Cada vetor solução da população inicial é classificado em frentes de dominância (Algoritmo 4 - APÊNDICE A).

- Para cada solução é atribuído um valor de aptidão igual ao seu nível de dominação (1 o melhor nível, 2 o segundo melhor nível e assim por diante).

Etapa 3 - Seleção para criação da população $Q_{0}$

- Nessa etapa o NSGA II se assemelha ao operador de seleção utilizado pelo SPEA. Entretanto, no NSGA II o operador $\left(<_{c}\right)$ compara duas soluções e retorna o vencedor do torneio. Assume-se que toda solução i tem dois atributos:

a) um rank $\left(\mathrm{r}_{\mathrm{i}}\right)$ de solução não dominada, ou seja, o nível de dominação (frente no qual a solução pertence) na população. 
b) uma distância de multidão local $\left(\mathrm{d}_{\mathrm{i}}\right)$ na população.

c) sendo que a distância de multidão $d_{i}$ de uma solução i é uma medida do espaço de busca em torno da solução i a qual não é ocupado por nenhuma outra solução na população. $\mathrm{O}$ valor de $\mathrm{d}_{\mathrm{i}}$ serve como estimativa do perímetro do cubóide (Figura 5.11) formado pelos vizinhos mais próximos com vértices calculado para cada frente não dominada. Quando maior o cubóide de i, mais afastada essa solução se encontra de seus vizinhos. As soluções extremas em cada objetivo terão um cubóide infinito. O procedimento para encontrar a distância de multidão é descrito a seguir.

- Considerando $F^{j}$ como sendo o conjunto de soluções na fronteira j e L o número de soluções em $\mathrm{F}^{\mathrm{j}}$, faça para cada i pertencente ao conjunto $\mathrm{F}^{\mathrm{j}} \mathrm{d}_{\mathrm{i}}=0$

- Para cada função objetivo $\left(f_{m}, m=1,2, \ldots, M\right)$ classifique o conjunto em ordem decrescente de $\mathrm{f}_{\mathrm{m}}$ e coloque o índice dessas soluções em uma lista $\mathrm{I}^{\mathrm{m}}$, por exemplo $I_{0}^{1}=3$ representa que a solução 3 possui o menor valor de função objetivo 1 encontrado na população.

- Para cada $\mathrm{m}=1,2, \ldots, \mathrm{M}$ atribua um valor infinito para as soluções extremas (máximo e mínima), ou seja, $\mathrm{d}_{\mathrm{I}_{0}^{\mathrm{m}}}=\mathrm{d}_{\mathrm{I}_{\mathrm{L}}^{\mathrm{m}}}=\infty$, e calcule $\mathrm{d}_{\mathrm{I}_{\mathrm{i}}^{\mathrm{m}}}$ para as outras soluções i $(i=1, \ldots, L-1$, lembrando que o primeiro elemento representa o índice $0)$ :

$$
\mathrm{d}_{\mathrm{I}_{\mathrm{i}}^{\mathrm{m}}}=\mathrm{d}_{\mathrm{I}_{\mathrm{i}}^{\mathrm{m}}}+\frac{\mathrm{f}_{\mathrm{m}}^{\left(\mathrm{I}_{\mathrm{i}+1}^{\mathrm{m}}\right)}-\mathrm{f}_{\mathrm{m}}^{\left(\mathrm{I}_{\mathrm{i}-1}^{\mathrm{m}}\right)}}{\mathrm{f}_{\mathrm{m}}^{\max }-\mathrm{f}_{\mathrm{m}}^{\min }}
$$

Baseado nos dois atributos citados (rank e distância de multidão) DEB (2001) define a seleção por torneio de multidão através da definição 8.

Definição 8: Uma solução $i$ vence um torneio com outra solução $j$ se alguma das condições são verdadeiras:

Se a solução i tem um rank (frente não dominada) melhor, então, $\mathrm{r}_{\mathrm{i}}<\mathrm{r}_{\mathrm{j}}$;

Se ambas as soluções tem um mesmo rank, mas a solução i tem uma distância de multidão melhor que a solução $j$, então, $\mathrm{r}_{\mathrm{i}}=\mathrm{r}_{\mathrm{j}}$ e $\mathrm{d}_{\mathrm{i}}>\mathrm{d}_{\mathrm{j}}$. 


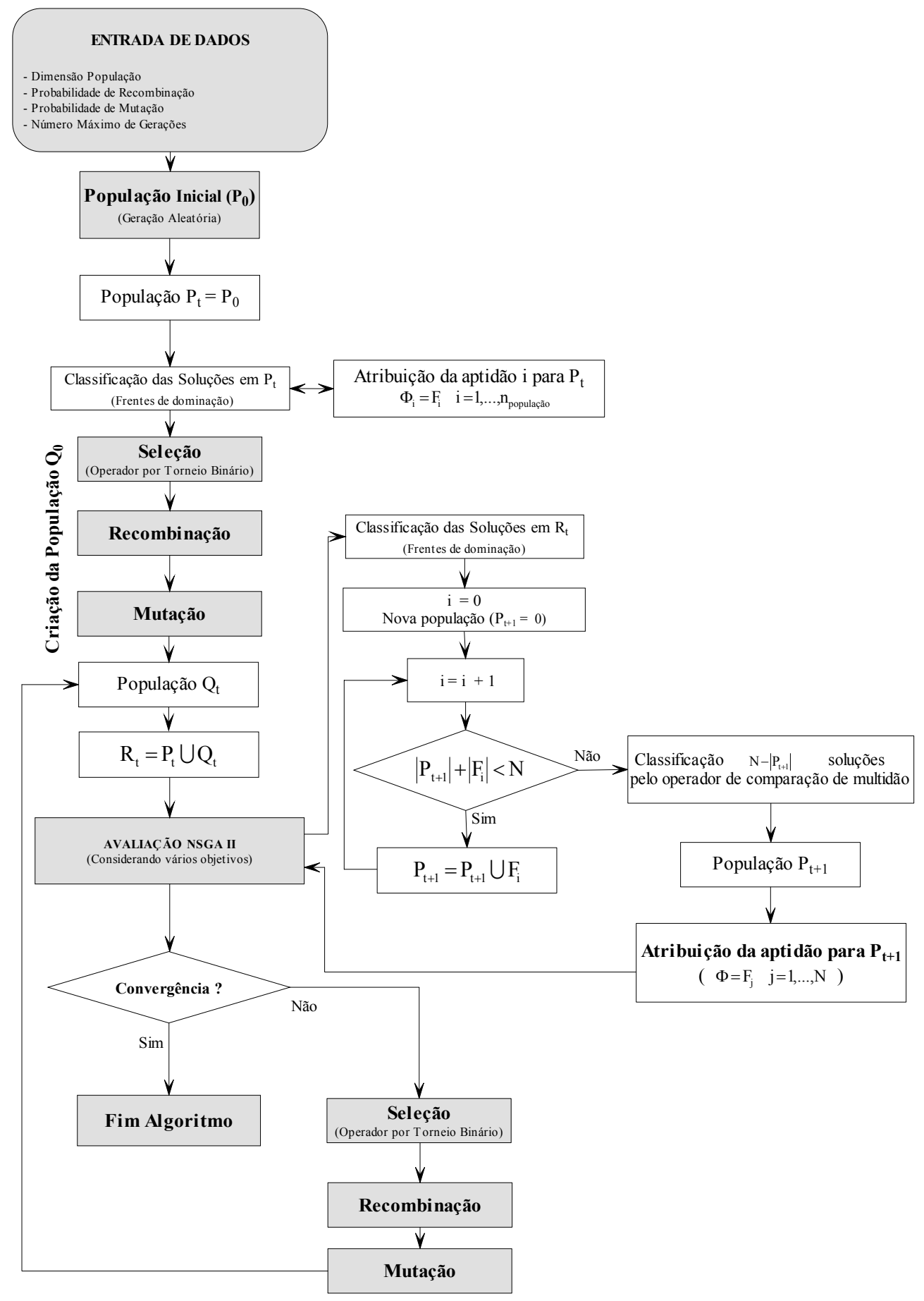

Figura 5.12 - Procedimento geral do NSGA II

\section{Etapa 4 - Recombinação}

- Esse operador é aplicado como na estrutura geral dos AGs convencionais simples.

\section{Etapa 5 - Mutação}

- Esse operador é aplicado como na estrutura geral dos AGs convencionais simples. 
Etapa 6 - População $Q_{0}$

- Obtenção da população derivada da população inicial $\mathrm{P}_{0}$. Essa população derivada é denominada população filha.

Etapa 7 - Criação da população $R_{t}$

- Nessa etapa uma população combinada $R_{t}\left(R_{t}=P_{0} \cup Q_{0}\right)$ é formada pela união das populações pai e filha. A população $\mathrm{R}_{\mathrm{t}}$ tem dimensão $2 \mathrm{POP}$.

Etapa 8 - Avaliação NSGA II

- O módulo de avaliação tem objetivo de atribuir valores de aptidão das soluções não dominadas identificado no conjunto $R_{t}$ através do algoritmo que classifica solução não dominadas em frentes.

- Crie uma nova população $P_{t}$ e coloque todas as soluções pertencentes as frentes não dominadas $\mathrm{F}^{\mathrm{j}}$ nesse conjunto enquanto $\left|\mathrm{P}_{\mathrm{t}}\right|+\left|\mathrm{F}^{\mathrm{j}}\right|<\mathrm{n}_{\text {populacão }}$. Se houver violação dessa condição (Figura 5.10), é aplicado o cálculo da distância de multidão (eq. 5.25) da última frente candidata que não entrou no conjunto $P_{t} e$ as outras frentes como forma de escolher quais soluções serão alocadas nessa nova população.

- Após todas as soluções serem acomodadas no conjunto $P_{t}$, atribui-se o valor de aptidão para essas soluções conforme seu nível de dominação (frente não dominada). Por exemplo, uma determinada solução pertence a frente 2, portanto seu valor de aptidão é 2 .

Etapa 9 - Convergência

- Nessa etapa o NSGA II verificará seu critério de convergência. Em geral, adotase o número máximo de iterações para essa verificação. Se tal critério for satisfeito o algoritmo segue para a etapa 10 e o processo é finalizado, caso contrário, o algoritmo segue para a etapa 3 considerando a população $P_{t}$ semelhante o que aconteceu com a população $\mathrm{P}_{0}$.

Etapa 10 - Resultados

- Nessa etapa o algoritmo apresenta as soluções ótimas Pareto. 


\subsection{Simulação Hidráulica de Redes}

As avaliações hidráulicas constituem parte essencial no cômputo dos valores das funções objetivo. Há, portanto, necessidade de incorporar um simulador hidráulico à rotina computacional que quantifica os objetivos estabelecidos. O simulador deve desempenhar o papel de avaliador das variáveis de estado (pressões e vazões) do sistema. Neste trabalho, três simuladores hidráulicos são utilizados e todos se baseiam no código original do Epanet 2 (ROSSMAN 2000) acoplado a um compilador C++ (Borland Builder $C++5.0$ ).

\subsubsection{Simulador hidráulico convencional}

A técnica clássica para análise de redes é denominada análise dirigida pela demanda (ADD) desde a proposição de Hardy Cross, em 1930. As demandas são consideradas fixas e seus valores representativos são concentrados nos nós, cabendo ao modelo determinar as vazões nas tubulações e pressões nos nós consistentes com atendimento pleno das mesmas, além de considerar os sistemas como sendo fechados (sem vazamentos) e o escoamento sob pressão.

O Epanet 2 (ROSSMAN, 2000) é um programa de domínio público desenvolvido pela Environmental Protection Agency (EPA) para analisar redes de distribuição de água em regime permanente. Esse pacote computacional é distribuído gratuitamente sob duas formas: executável e código fonte (Toolkit). A forma executável é recomendável para estudos que envolvem apenas as simulações hidráulicas. A forma de código fonte é recomendável para estudos que envolvem o acoplamento de outros modelos (calibração, vazamentos, demanda variável, dentre outros) com o Epanet 2.

A Toolkit é uma biblioteca de vínculo dinâmico (DLL) que contém funções que permitem aos programadores o desenvolvimento de aplicações específicas. Essas funções podem ser incorporadas em aplicações Windows escritas em: $\mathrm{C} / \mathrm{C}++$, Pascal (Delphi), Visual Basic ou outras linguagens de programação que possibilitam chamar funções através de DLLs. Além disso, essa biblioteca permite abrir e fechar um arquivo que descreve a rede (.INP), ler e modificar os vários parâmetros de projeto e operação, simular períodos extensivos acessando resultados a cada passo e escrever os resultados das simulações nos arquivos de saída (.RPT). Além de possibilitar o desenvolvimento de modelos específicos (calibração, projeto e operação), a Toolkit também oferece uma 
certa flexibilidade para acoplar e integrar plataformas CAD e GIS, que auxiliam na modelação de redes de distribuição de água.

Para acoplar o Epanet 2 com o compilador $\mathrm{C}++$ (Borland Builder $C++5.0$ ), primeiramente, é necessário realizar o download dos arquivos fonte (Toolkit) na página $^{13}$ da Environmental Protection Agency (EPA). A Toolkit inclui diferentes arquivos de cabeçalho (.h), diferentes arquivos de funções e arquivos .lib que simplificam a tarefa de interface da biblioteca com o compilador $(\mathrm{C} / \mathrm{C}++$, Pascal (Delphi, Visual Basic). Essa biblioteca contém também um arquivo de ajuda para orientar a utilização adequada das várias funções existentes através de alguns programas exemplo.

\subsubsection{Simulador hidráulico iterativo para calibração}

Com objetivo de aplicar a metodologia proposta em uma rede existente e incorporar vazamentos nas análises de reabilitação de redes de distribuição de água, é necessária a utilização de um simulador hidráulico que considere ambas as relações pressãovazamento e pressão-demanda.

A metodologia proposta neste trabalho sugere à utilização de um procedimento de calibração, na etapa preliminar (Figura 5.1), para ajustar os parâmetros do modelo pressão-vazamento (coeficiente e expoente). Adotou-se o modelo desenvolvido por SOARES (2003), ilustrado pela Figura 2.7, que ajusta tais parâmetros através de um modelo inverso baseado em um procedimento híbrido (AGs-SIMPLEX). O simulador hidráulico do referido autor é baseado em um procedimento iterativo (Figura 2.6) para considerar as relações de dependência de pressão tanto para vazamento como para as demandas. Cabe ressaltar que esse simulador hidráulico foi construído sem interferência direta no código do Epanet 2.

\subsubsection{Simulador hidráulico proposto}

A análise de redes de distribuição de água é realizada de maneira a satisfazer os princípios da continuidade e da conservação de energia. A consideração de vazamentos e demanda variável com a pressão nos modelos para análise de redes requer algumas mudanças na formulação clássica (eq. 2.3). Tais mudanças referem-se às demandas nos nós que não serão mais fixas, mas dependentes da pressão disponível no sistema (o vetor $\mathrm{Q}$ dependerá do vetor $\mathrm{h}$ ), e da existência da parcela referente aos vazamentos

\footnotetext{
${ }^{13}$ http://www.epa.gov/ORD/NRMRL/wswrd/epanet.html\#Downloads
} 
distribuídos. No presente item, propõe-se um simulador hidráulico que considera ambas as relações. Na verdade, este simulador é uma modificação do Epanet 2 e representa uma contribuição deste trabalho no sentido de se produzir resultados mais realísticos para análise de redes em regime permanente.

Até então, apenas MARTÍNEZ et al. (1999) tinham introduzido as relações pressãovazamento e pressão-demanda diretamente no código da versão original do Epanet (ROSSMAN, 1994). O objetivo principal desses pesquisadores era minimizar o elevado tempo computacional consumido pelas análises dirigidas pela pressão através de procedimentos iterativos (sem interferir no código). Isso foi evidenciado por SOARES (2003) nos estudos de calibração de modelos de redes de distribuição de água considerando vazamentos e demanda variável com a pressão.

Várias soluções têm sido propostas na literatura (SALGADO, ROJO e ZEPEDA, 1993; FUJIWARA e LI, 1998; MARTÍNEZ, CONEJOS e VERCHER, 1999; TUCCIARELLI, CRIMINISI e TERMINI, 1999; TABESH e KARIMZADEH, 2000; TANYIMBOH, TABESH e BURROWS, 2001) com objetivo de converter o modelo matemático, baseado nas análises dirigidas pela demanda, para análises dirigidas pela pressão. TODINI (2003) mostra como essas relações podem ser introduzidas no Epanet 2. Inicialmente, esse pesquisador remete a formulação clássica (eq. 2.3) incorporando um termo adicional $\left(\mathrm{A}_{22}\right)$ conforme demonstrado pela eq.(5.26).

$\left[\begin{array}{ccc}\mathrm{A}_{11} & \vdots & \mathrm{A}_{12} \\ \cdots & \cdots & \cdots \\ \mathrm{A}_{21} & \vdots & \mathrm{A}_{22}\end{array}\right]\left[\begin{array}{l}\mathrm{Q} \\ \cdots \\ \mathrm{H}\end{array}\right]=\left[\begin{array}{c}-\mathrm{A}_{10} \mathrm{H}_{0} \\ \cdots \\ -\mathrm{q}^{*}\end{array}\right]$

sendo $\mathrm{A}_{22}$ uma matriz diagonal de ordem $(\mathrm{NT} \times \mathrm{NT})$ com os elementos fora da diagonal iguais a zero. As outras matrizes $\left(\mathrm{A}_{11}, \mathrm{~A}_{12}\right.$ e $\left.\mathrm{A}_{21}\right)$ são definidas conforme formulação matricial apresentada no item (2.1.1) deste trabalho. O termo q é um vetor de ordem $(1 \times \mathrm{NN})$ com seus elementos sendo igual a demanda atribuída ao nó se a demanda não é dirigida pela energia ou sendo igual a zero no caso da demanda dirigida pela energia. Seguindo a formulação de WAGNER, SHAMIR e MARKS (1988), a matriz A 22 pode ser definida, segundo o presente trabalho, conforme eq.(5.27). 


$$
\mathrm{A}_{22}(\mathrm{i}, \mathrm{i})=\left\{\begin{array}{cc}
0 & \mathrm{H}_{\mathrm{i}}<\mathrm{H}_{\mathrm{i}}^{\text {min }} \\
\mathrm{q}_{\mathrm{i}}^{\text {req }}\left(\frac{\mathrm{H}_{\mathrm{i}}-\mathrm{H}_{\mathrm{i}}^{\text {min }}}{\mathrm{H}_{\mathrm{i}}^{\text {des }}-\mathrm{H}_{\mathrm{i}}^{\text {min }}}\right)^{\frac{1}{\mathrm{n}}} & \mathrm{H}_{\mathrm{i}}^{\text {min }}<\mathrm{H}_{\mathrm{i}}<\mathrm{H}_{\mathrm{i}}^{\text {des }} \\
\mathrm{q}_{\mathrm{i}}^{\text {req }} & \mathrm{H}_{\mathrm{i}} \geq \mathrm{H}_{\mathrm{i}}^{\text {des }}
\end{array}\right.
$$

sendo $\mathrm{H}^{\text {des }}$ a energia nodal requerida para o atendimento pleno da demanda e $\mathrm{n}$ um coeficiente geralmente igual a 2 .

Para resolver o sistema de equações não lineares (eq. 5.26), a técnica de NewtonRaphson é utilizada, diferenciando ambos os lados da eq.(5.26) em relação a Q e H para obter:

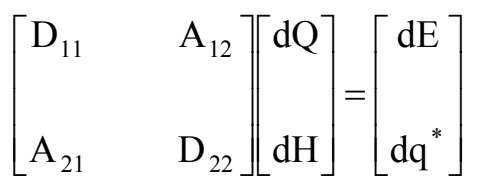

sendo $\mathrm{D}_{11}$ uma matriz diagonal com elementos definidos para $\mathrm{k} \in 1, \mathrm{NT} ; \mathrm{i} \in 1, \mathrm{NTO} ; \mathrm{j} \in 1$, NTO definida conforme eq.(5.37) para tubos e eq.(5.38) para bombas. NT representa o número de tubulações e NTO é o número total de nós na rede.

$$
\begin{aligned}
& \mathrm{D}_{11}(\mathrm{k}, \mathrm{k})=\mathrm{nr}\left|\mathrm{Q}_{\mathrm{ij}}\right|^{\mathrm{n}-1}+2 \mathrm{~m}\left|\mathrm{Q}_{\mathrm{ij}}\right| \\
& \mathrm{D}_{11}(\mathrm{k}, \mathrm{k})=\mathrm{nr} \omega^{2-\mathrm{n}}\left|\mathrm{Q}_{\mathrm{ij}}\right|^{\mathrm{n}-1} \quad \text { ou } \quad \mathrm{D}_{11}(\mathrm{k}, \mathrm{k})=-\left(\mathrm{b}_{0} \omega+2 \mathrm{c}_{0} \mathrm{Q}_{\mathrm{ij}}\right)
\end{aligned}
$$

Para incluir a demanda dirigida pela pressão, um nova matriz $\left(\mathrm{D}_{22}\right)$ de dimensão $(\mathrm{NN} \times \mathrm{NN})$ é introduzida, sendo $\mathrm{NN}$ o número de nós na rede. Os elementos da matriz $\mathrm{D}_{22}$ são zeros se a demanda não é dirigida pela energia, caso contrário, define-se a matriz $\mathrm{D}_{22}$ conforme eq.(5.31), que corresponde à derivação da eq.(5.27).

$$
\mathrm{D}_{22}(\mathrm{i}, \mathrm{i})= \begin{cases}0 & \mathrm{H}_{\mathrm{i}}<\mathrm{H}_{\mathrm{i}}^{\text {min }} \\ \frac{\mathrm{q}_{\mathrm{i}}^{\text {req }}}{\mathrm{n}\left(\mathrm{H}_{\mathrm{i}}^{\text {des }}-\mathrm{H}_{\mathrm{i}}^{\min }\right)^{\frac{1}{\mathrm{n}}}}\left(\mathrm{H}_{\mathrm{i}}-\mathrm{H}_{\mathrm{i}}^{\min }\right)^{\frac{1-\mathrm{n}}{\mathrm{n}}} & \mathrm{H}_{\mathrm{i}}^{\text {min }}<\mathrm{H}_{\mathrm{i}}<\mathrm{H}_{\mathrm{i}}^{\text {des }} \\ 0 & \mathrm{H}_{\mathrm{i}} \geq \mathrm{H}_{\mathrm{i}}^{\text {des }}\end{cases}
$$


Considerando linearização local entre a solução da iteração k e a solução da iteração $\mathrm{k}+1$, pode-se reescrever a eq.(5.28) através de seus respectivos diferenciais $\mathrm{dQ}, \mathrm{dH}, \mathrm{dE}$ e dq.

$\mathrm{dQ}=\mathrm{Q}^{\mathrm{k}}-\mathrm{Q}^{\mathrm{k}+1}$

$\mathrm{dH}=\mathrm{H}^{\mathrm{k}}-\mathrm{H}^{\mathrm{k}+1}$

$\mathrm{dE}=\mathrm{A}_{11} \mathrm{Q}^{\mathrm{k}}+\mathrm{A}_{12} \mathrm{H}^{\mathrm{k}+1}+\mathrm{A}_{10} \mathrm{H}_{0}$

$\mathrm{dq}^{*}=\mathrm{A}_{21} \mathrm{Q}^{\mathrm{k}}+\mathrm{A}_{22} \mathrm{H}^{\mathrm{k}}+\mathrm{q}^{*}$

Substituindo as eqs.(5.32, 5.33, 5.34 e 5.35) na eq.(5.28) e resolvendo analiticamente o sistema de equações, obtém-se a formulação iterativa para análise de redes considerando demanda variável com a energia.

$$
\left\{\begin{array}{l}
\mathrm{H}^{\mathrm{k}+1}=\mathrm{A}^{-1} \mathrm{~F} \\
\mathrm{Q}^{\mathrm{k}+1}=\mathrm{Q}^{\mathrm{k}}-\mathrm{D}_{11}^{-1}\left(\mathrm{~A}_{11} \mathrm{Q}^{\mathrm{k}}+\mathrm{A}_{12} \mathrm{H}^{\mathrm{k}+1}+\mathrm{A}_{10} \mathrm{H}_{0}\right)
\end{array}\right.
$$

sendo que

$$
\begin{aligned}
& \mathrm{A}=\mathrm{A}_{21} \mathrm{D}_{11}^{-1} \mathrm{~A}_{12}-\mathrm{D}_{22} \\
& \mathrm{~F}=\mathrm{A}_{21} \mathrm{Q}^{\mathrm{k}}+\mathrm{q}^{*}-\mathrm{A}_{21} \mathrm{D}_{11}^{-1} \mathrm{~A}_{11} \mathrm{Q}^{\mathrm{k}}-\mathrm{A}_{21} \mathrm{D}_{11}^{-1} \mathrm{~A}_{10} \mathrm{H}_{0}
\end{aligned}
$$

Considerando $\mathrm{D}_{11}^{-1} \mathrm{~A}_{11}=\mathrm{N}^{-1}$ e multiplicando ambos os lados dessa expressão por $\mathrm{A}_{11}^{-1}$ obtém-se $\mathrm{D}_{11}^{-1}=\mathrm{A}_{11}^{-1} \mathrm{~N}^{-1}$. Substituindo essa última expressão nas eqs.(5.37) e (5.38) e comparado-as com as eqs.(2.14) e (2.15), percebe-se que os termos adicionais são a matriz diagonal $\mathrm{D}_{22}$ e o vetor $\mathrm{q}^{*}$.

Apesar de TODINI (2003) apresentar como incorporar a demanda variável com a energia no Epanet 2, esse pesquisador não implementa tais considerações no código desse programa e nem demonstra a incorporação de vazamentos.

As sugestões apresentadas por TODINI (2003) serviram de guias para que os modelos pressão-demanda e pressão-vazamento fossem incluídos no código do Epanet 2. O modelo pressão-vazamento (eq. 2.23) adotado foi proposto por TUCCIARELLI, 
CRIMINISI e TERMINI (1999). Dessa forma, foi possível redefinir as matrizes $\mathrm{A}_{22} \mathrm{e}$ $\mathrm{D}_{22}$ (eqs. 5.27 e 5.31) descritas por TODINI (2003).

$A_{22}(i, i)=q(H)+Q L$

$\mathrm{D}_{22}(\mathrm{i}, \mathrm{i})=\frac{\partial \mathrm{q}(\mathrm{H})}{\partial \mathrm{H}}+\frac{\partial \mathrm{QL}}{\partial \mathrm{H}}$

sendo $\mathrm{q}(\mathrm{H})$ definido pela eq.(5.27) e QL definido pela eq.(2.23).

Quando a biblioteca Toolkit é utilizada, nos casos dos itens (5.5.1) e (5.5.2), o acesso direto ao código do Epanet 2 fica impossibilitado, pois o modelo é acoplado por meio de arquivos DLL (Epanet2.DLL) e LIB (Epanet2bc.lib). Por isso, para incorporar as relações pressão-demanda e pressão-vazamento (mudança do código do Epanet 2) conforme descrito neste item, foi utilizada uma biblioteca do Epanet 2 orientada a objetos (OOTEN - Object Oriented Toolkit for Epanet), em C++, desenvolvida por ZYL et al. (2003) na Universidade Rand Afrikaans (África do Sul).

\subsubsection{Simulador hidráulico iterativo para reabilitação}

Com objetivo de aplicar a metodologia proposta considerando vazamentos e demandas variável nas análises de reabilitação de redes de distribuição de água, um simulador hidráulico iterativo (sem intervenção direta sobre o código) foi desenvolvido utilizando a biblioteca do Epanet 2 orientada a objetos (OOTEN - Object Oriented Toolkit for Epanet). O modelo pressão-vazamento (eq. 2.23) implementado nesse simulador foi o proposto por TUCCIARELLI, CRIMINISI e TERMINI (1999) e o modelo de demanda variável foi o proposto por WAGNER, SHAMIR e MARKS (1988).

\subsection{Implementação dos métodos evolucionários multiobjetivo}

Quatro métodos evolucionários de otimização multiobjetivo (MOGA, NSGA, SPEA e NSGA II) são investigados neste trabalho. O MOGA foi implementado em C++ suportado pela biblioteca de algoritmos genéticos $\left(\mathrm{GAlib}^{14}\right)$, de domínio público, escrita por Matthew Wall em 1996, do Instituto de Tecnologia de Massachusetts (MIT). A GAlib conta com quatro tipos de algoritmos genéticos implementados (Simple, SteadyState, Incremental e Deme), cuja descrição detalhada de cada qual pode ser encontrada no próprio manual da biblioteca (WALL, 1996).

${ }^{14} \mathrm{http}: / /$ lancet.mit.edu/ga 
Os algoritmos NSGA, SPEA e NSGA II foram avaliados através da biblioteca de metasheurísticas multiobjetivo MOMHLib++ ${ }^{15}$ (JASKIEWICZ, 1999), de domínio público, escrita em C++ por Andrzej Jaskiewicz em 1999 da Universidade de Tecnologia de Poznan (Polônia). A MOMHLib++ não tem implementada em seu código, operadores genéticos (recombinação e mutação) gerais, esses por sua vez devem ser construídos pelo próprio usuário em conformidade com o problema que está sendo tratado. $\mathrm{O}$ próximo item apresenta a descrição dos operadores genéticos implementados na MOMHLIb++ e investigados no presente trabalho.

\subsubsection{Operadores genéticos}

O principal objetivo dos operadores genéticos é gerar novas soluções dentro do espaço de busca, com intuito de explorar novas regiões desse espaço. O operador de recombinação tem a função de criar novas soluções (filhos) através da recombinação de soluções correntes (pais). Para imitar a natureza estocástica da evolução natural, uma probabilidade de recombinação é associada com esse operador. Ao contrário, o operador de mutação desempenha um papel importante no processo de evolução dos AEs, pois é através desse operador que novo "material genético" é introduzido a uma população durante o processo iterativo. O operador de mutação modifica as soluções correntes através de uma mudança gradual nas variáveis de decisão (genes) do vetor associado (cromossomo) obedecendo a um critério probabilítisco (probabilidade de mutação).

Recombinação linear: WRIGHT (1991) propôs uma das primeiras implementações de recombinação. Segundo esse autor novas soluções (filhos ou descendentes) podem ser geradas através de combinações lineares entre as soluções pais $\left(\mathrm{x}_{\mathrm{i}}^{(1, t)}, \mathrm{x}_{\mathrm{i}}^{(2, \mathrm{t})}\right)$ da geração $\mathrm{t}$. As eqs. (5.41-5.43) descrevem tal proposição.

$$
\begin{aligned}
& x_{i}^{(1, t+1)}=0,5 x_{i}^{(1, t)}+0,5 x_{i}^{(2, t)} \\
& x_{i}^{(1, t+1)}=1,5 x_{i}^{(1, t)}-0,5 x_{i}^{(2, t)} \\
& x_{i}^{(1, t+1)}=-0,5 x_{i}^{(1, t)}+1,5 x_{i}^{(2, t)}
\end{aligned}
$$

sendo x a variável de decisão; i o índice da variável de decisão; t o índice da geração; 1 e 2 são os índices dos vetores pais. Observa-se que três novas soluções são geradas.

\footnotetext{
${ }^{15} \mathrm{http}$ //www-idss.cs.put.poznan.pl/ jaskiewicz/MOMHLib
} 
Entretanto, no presente trabalho, a melhor solução é escolhida para próxima geração através do conceito de dominância.

Recombinação BLX (Blend Crossover): ESHELMAN e SCHAFFER (1993) sugeriram o operador BLX para AGs com parâmetros reais. Partindo das soluções pais $x_{i}^{(1, t)}$ and $\mathrm{x}_{\mathrm{i}}^{(2, \mathrm{t})}$ e assumindo que $\mathrm{x}_{\mathrm{i}}^{(1, \mathrm{t})}$ é menor que $\mathrm{x}_{\mathrm{i}}^{(2, \mathrm{t})}$, o operador BLX aleatoriamente seleciona uma solução no intervalo $\left[\mathrm{x}_{\mathrm{i}}^{(1, \mathrm{t})}-\alpha\left(\mathrm{x}_{\mathrm{i}}^{(2, \mathrm{t})}-\mathrm{x}_{\mathrm{i}}^{(1, \mathrm{t})}\right), \mathrm{x}_{\mathrm{i}}^{(2, \mathrm{t})}+\alpha\left(\mathrm{x}_{\mathrm{i}}^{(2, \mathrm{t})}-\mathrm{x}_{\mathrm{i}}^{(1, \mathrm{t})}\right)\right]$. Assim, considerando $\mathrm{u}_{\mathrm{i}}$ como sendo um número aleatório entre 0 e 1 , tal operador é descrito pela eq.(5.44).

$\mathrm{x}_{\mathrm{i}}^{(1, \mathrm{t}+1)}=\left(1-\gamma_{\mathrm{i}}\right) \mathrm{x}_{\mathrm{i}}^{(1, \mathrm{t})}+\gamma_{\mathrm{i}} \mathrm{x}_{\mathrm{i}}^{(2, \mathrm{t})}$

sendo $\gamma_{\mathrm{i}}=(1+2 \alpha) \mathrm{u}_{\mathrm{i}}-\alpha$. DEB (2001) garante que $\alpha$ igual a 0,5 desenvolve um bom desempenho.

Recombinação uniforme: MICHALEWICZ (1992) descreveram o método de recombinação uniforme como um operador que modifica as variáveis de decisão individuais de um vetor solução. Tal autor sugere esse operador para a representação binária. Entretanto, como neste trabalho a codificação utilizada é a real, tal operador foi modificado. Inicialmente, gera-se aleatoriamente um vetor temporário $\left(\mathrm{m}_{\mathrm{i}}\right)$, com valores variando entre 0 e 1, de mesmo tamanho do vetor solução em cada operação de recombinação. O próximo passo é determinar as novas soluções através da formulação descrita pela eq.(5.45).

$x_{i}^{(1, t+1)}=\left\{\begin{array}{lll}x_{i}^{(1, t)} & \text { if } & m_{i}=0 \\ x_{i}^{(2, t)} & \text { if } & m_{i}=1\end{array}\right.$

Mutação limite: MICHALEWICZ (1992) descreve que esse operador (5.46) substitui o valor de uma variável de decisão, selecionada aleatoriamente, por outro cujo valor é obtido aleatoriamente $\left(\mathrm{x}_{\mathrm{i}}^{(\mathrm{L})}\right.$ ou $\left.\mathrm{x}_{\mathrm{i}}^{(\mathrm{U})}\right)$, sendo $\mathrm{x}_{\mathrm{i}}^{(\mathrm{L})} \mathrm{e} \quad \mathrm{x}_{\mathrm{i}}^{(\mathrm{U})}$ os limites inferiores $\mathrm{e}$ superiores das variáveis de decisão, respectivamente.

$x_{i}^{(t+1)}=\left\{\begin{array}{lll}x_{i}^{L} & \text { if } & r<0,5 \\ x_{i}^{u} & \text { if } & r>0,5\end{array}\right.$ 
sendo $\mathrm{x}_{\mathrm{i}}^{\mathrm{t}+1}$ a variável de decisão obtida e $\mathrm{r}$ um número aleatório pertencente ao intervalo $[0,1]$.

Mutação aleatória: DEB (2001) descreve esse operador como sendo uma das implementações mais simples. Esse procedimento cria uma solução aleatoriamente dentro do espaço de busca através da eq.(5.47).

$x_{i}^{(t+1)}=r_{i}\left(x_{i}^{U}-x_{i}^{L}\right)$

Mutação dinâmica: Esse operador utiliza os valores da geração corrente e o número máximo de gerações concedidas para criar uma nova solução (DEB, 2001). A eq.(5.48) descreve tal operador.

$\mathrm{x}_{\mathrm{i}}^{(\mathrm{t}+1)}=\mathrm{x}_{\mathrm{i}}^{(1, \mathrm{t}+1)}+\tau\left(\mathrm{x}_{\mathrm{i}}^{\mathrm{U}}-\mathrm{x}_{\mathrm{i}}^{\mathrm{L}}\right)\left(1-\mathrm{r}_{\mathrm{i}}^{\left(1-\frac{\mathrm{t}}{\mathrm{GER}}\right)^{\mathrm{b}}}\right)$

sendo $\tau$ um valor aleatório que assume -1 ou 1 , gerado com um probabilidade de 0,5 ; GER denota o número máximo de iterações concedidas; $r$ um número aleatório pertencente ao intervalo [0,1] e b é um parâmetro definido pelo usuário. No presente trabalho o valor de $\mathrm{b}$ foi considerado igual a 6 , seguindo a sugestão de MICHALEWICZ (1992).

\subsection{Medidas de desempenho para algoritmos evolucionários multiobjetivo}

Quando uma nova metodologia torna-se popular, diversas implementações surgem devido aos aperfeiçoamentos realizados e propostos. Torna-se então necessário, investigar os métodos propostos sob o ponto de vista de desempenho computacional. Em se tratando dos métodos de otimização multiobjetivo, DEB et al. (2002) afirma que para compará-los é necessário que no mínimo duas métricas de performance sejam avaliadas. No presente trabalho, os algoritmos evolucionários multiobjetivo são comparados e avaliados sob a ótica de duas métricas de desempenho, conforme alguns autores (ZITZLER, 1999; DEB, 2001) propõem. Essas métricas foram propostas para avaliar a convergência da frente Pareto e a diversidade das soluções ao longo da frente Pareto. Um algoritmo evolucionário multiobjetivo será considerado eficiente se ambas as métricas são adequadamente satisfatórias. As Figuras 5.13 a 5.14 mostram uma exemplificação do porquê da necessidade de comparar métodos através dessas medidas de performance. 


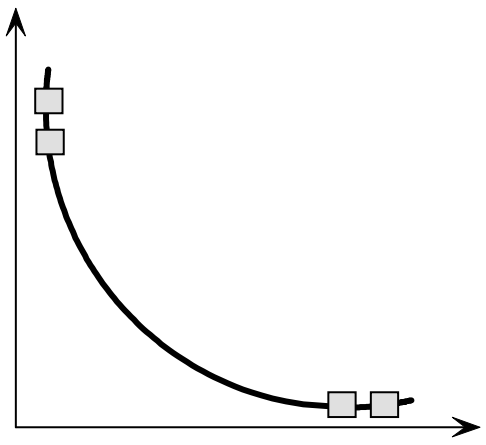

Figura 5.13 - Distribuição das soluções

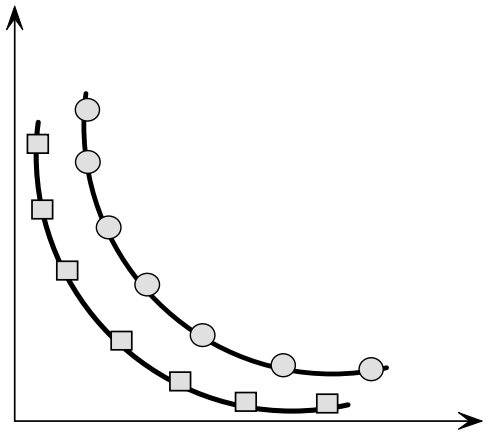

Figura 5.15 - Comparação ideal

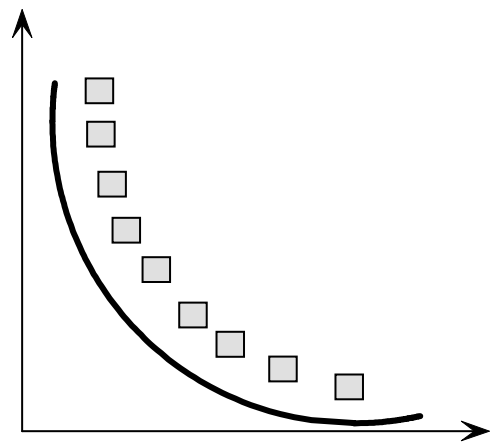

Figura 5.14 - Convergência da frente

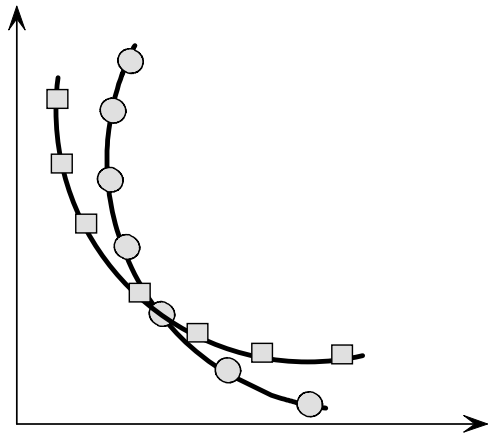

Figura 5.16 - Comparação complexa

Supõe-se nas Figuras 5.13 e 5.14 um problema hipotético de minimização de ambas as funções objetivo. Observa-se na Figura 5.13 que, apesar das soluções apresentarem convergência para suposta "Frente Pareto" verdadeira, tais soluções não apresentam diversidade. Ao contrário pode ser verificado na Figura 5.14, onde as soluções apresentam boa diversidade, mas há convergência prematura. Uma outra discussão refere-se à forma com que as frentes produzidas por diferentes métodos são comparadas. Seria ideal que quando frentes Pareto distintas fossem construídas juntas, as mesmas pudessem apresentar uma relação como na Figura 5.15, que possibilita a identificação do melhor método visualmente. Isso não acontece no exemplo da Figura 5.16, onde as frentes se sobrepõem.

\subsubsection{Métrica para avaliar a convergência da frente Pareto}

Dados dois conjuntos A e B, a métrica de cobertura (Set Coverage Metric) calcula a proporção de soluções de B que são dominadas pelas soluções de A, conforme avaliação realizada pela eq.(5.41).

$\mathrm{C}(\mathrm{A}, \mathrm{B})=\frac{|\mathrm{b} \in \mathrm{B}| \exists \mathrm{a} \in \mathrm{A}: \mathrm{a} \preceq \mathrm{b} \mid}{|\mathrm{B}|}$ 
sendo que $C(A, B)=1$ significa que todas as soluções em B são dominadas por soluções de $\mathrm{A}$. Se $\mathrm{C}(\mathrm{A}, \mathrm{B})=0$ então nenhuma solução de B é dominada pelas soluções de $\mathrm{A}$. Dado que o operador de dominância não é simétrico, $\mathrm{C}(\mathrm{A}, \mathrm{B})$ não é necessariamente igual a $\mathrm{C}(\mathrm{B}, \mathrm{A})$. Então, devem-se calcular ambos os valores, tanto para as soluções de A que dominam B, quanto para as soluções de B que dominam A.

\subsubsection{Métrica para avaliar a diversidade da frente Pareto}

A métrica de diversidade (Spacing) calcula o desvio padrão entre distâncias de soluções consecutivas, matematicamente:

$\mathrm{S}=\sqrt{\frac{1}{|\mathrm{Q}|} \sum_{\mathrm{i}=1}^{|\mathrm{Q}|}\left(\mathrm{d}_{\mathrm{i}}-\overline{\mathrm{d}}\right)^{2}}$

sendo que:

$$
\begin{aligned}
& \mathrm{d}_{\mathrm{i}}=\min _{\mathrm{k} \in \mathrm{Q} \mathrm{e} \neq \mathrm{i}} \sum_{\mathrm{m}=1}^{\mathrm{M}}\left|\mathrm{f}_{\mathrm{m}}^{\mathrm{i}}-\mathrm{f}_{\mathrm{m}}^{\mathrm{k}}\right| \\
& \overline{\mathrm{d}}=\frac{\sum_{\mathrm{i}=1}^{|\mathrm{Q}|} \mathrm{d}_{\mathrm{i}}}{|\mathrm{Q}|}
\end{aligned}
$$

sendo $\mathrm{Q}$ o conjunto que contém as soluções não dominadas, $\mathrm{d}_{\mathrm{i}}$ a variável que representa o mínimo do somatório do valor absoluto da diferença dos valores das funções objetivo entre a solução i e qualquer outra solução q e M representa o número

de funções objetivo consideradas. Por outro lado, $\overline{\mathrm{d}}$ representa a média do valores de $\mathrm{d}_{\mathrm{i}}$. Quanto menor o desvio de $\mathrm{S}$, melhor distribuída estará a frente Pareto.

\subsection{Planejamento de experimentos computacionais}

Uma das principais preocupações dos pesquisadores que utilizam algoritmos evolucionários como ferramenta computacional é conhecer a combinação de parâmetros "ideal" para garantir uma boa solução ao problema tratado. Na engenharia de recursos hídricos tais respostas geralmente são obtidas através da simulação extensiva de diversas combinações de parâmetros (números de soluções iniciais, número de iterações, probabilidade de recombinação e probabilidade de mutação) de tal forma que essas questões possam ser solucionadas. 
Entretanto, na literatura existem trabalhos (LIN e RARDIN, 1980; PETROVSKI, WILSON e McCALL, 1998) que fornecem diretrizes para analisar essas questões. Por exemplo, LIN e RARDIN (1980) afirmam que quando os algoritmos de otimização possuem entradas aleatórias, as técnicas de planejamento estatístico fornecem uma base para analisar os diversos efeitos nos experimentos computacionais.

Segundo BOX (1978), o planejamento fatorial de experimento computacional é uma metodologia adequada para identificar valores referentes aos fatores mais significativos da performance de um algoritmo e para encontrar os níveis de sensibilidade desses fatores quando dados de entrada aleatórios são simulados.

Existem vários livros textos (BOX, 1978; MONTGOMERY, 1991; MENDENHALL, 1992) que abordam esse tema com profundidade. No presente trabalho, optou-se pela linha metodológica proposta por PETROVSKI, WILSON e McCALL (1998) para investigar os efeitos significativos dos parâmetros de entrada dos algoritmos genéticos sobre a variável resposta (ótimo). O planejamento fatorial utilizado aqui não será em dois níveis $\left(2^{\mathrm{k}}\right)$ como proposto por PETROVSKI, WILSON e McCALL (1998), mas em três níveis $\left(3^{\mathrm{k}}\right)$ seguindo a metodologia de MARTÍNEZ (2001), que propôs um planejamento composto central ortogonal (PCCO).

\subsubsection{Planejamentos fatoriais}

Em muitas situações experimentais, aqui aplicadas a experimentos computacionais, diferentes fatores de entrada produzem respostas distintas. Uma situação particular é o estudo de algoritmos evolucionários, segundo os quais diferentes parâmetros de entrada (dimensão da população, número máximo de gerações, probabilidade de recombinação e probabilidade de mutação) produzem diferentes respostas. Segundo MONTGOMERY (1991) um planejamento fatorial é a técnica que investiga todas as combinações, referentes aos níveis dos fatores, para cada ensaio.

\subsubsection{Planejamentos fatoriais com três níveis}

Segundo MARTÍNEZ (2001) os planejamentos fatoriais com três níveis são formados por $\mathrm{k}$ fatores, cada um com três níveis. Em um planejamento $3^{\mathrm{k}}$ ou em qualquer planejamento fatorial não é conveniente trabalhar com os valores reais das variáveis $\mathrm{x}_{\mathrm{i}}^{*}$, mas utilizar variáveis codificadas $\left(\mathrm{x}_{\mathrm{i}}^{\mathrm{c}}\right)$ através de seus níveis. 
A codificação dos níveis dos fatores de um planejamento $3^{\mathrm{k}}$ mais utilizada é $-1,0$ e 1 para denotar os níveis baixo, intermediário e alto do fator, como ilustrado pela Tabela 5.2. As $\mathrm{p}^{*}$ réplicas correspondem, neste trabalho, às sementes aleatórias distintas para cada simulação. Os fatores A e B podem ser, por exemplo, as probabilidades de recombinação e mutação.

Tabela 5.2 - Notações utilizadas em um planejamento $3^{2}$ com $\mathrm{p}^{*}$ réplicas

\begin{tabular}{cccc}
\hline \hline Simulação & Resposta & \multicolumn{2}{c}{ Fatores } \\
$\mathrm{i}$ & $\mathrm{Y}$ & $\mathrm{A}$ & $\mathrm{B}$ \\
\hline 1 & $\mathrm{y}_{11} \cdots \mathrm{y}_{1 \mathrm{p}^{*}}$ & -1 & -1 \\
2 & $\mathrm{y}_{21} \cdots \mathrm{y}_{2 \mathrm{p}^{*}}$ & 0 & -1 \\
3 & $\mathrm{y}_{31} \cdots \mathrm{y}_{3 \mathrm{p}^{*}}$ & 1 & -1 \\
4 & $\mathrm{y}_{41} \cdots \mathrm{y}_{4 \mathrm{p}^{*}}$ & -1 & 0 \\
5 & $\mathrm{y}_{51} \cdots \mathrm{y}_{5 \mathrm{p}^{*}}$ & 0 & 0 \\
6 & $\mathrm{y}_{61} \cdots \mathrm{y}_{6 \mathrm{p}^{*}}$ & 1 & 0 \\
7 & $\mathrm{y}_{71} \cdots \mathrm{y}_{7 \mathrm{p}^{*}}$ & -1 & 1 \\
8 & $\mathrm{y}_{81} \cdots \mathrm{y}_{8 \mathrm{p}^{*}}$ & 0 & 1 \\
9 & $\mathrm{y}_{91} \cdots \mathrm{y}_{9 \mathrm{p}^{*}}$ & 1 & 1 \\
\hline \hline
\end{tabular}

\subsubsection{Planejamentos compostos centrais}

Se o número de fatores aumenta (variáveis a serem analisadas) nos planejamentos fatoriais $3^{\mathrm{k}}$, consequentemente, o número de simulações também aumentará. Portanto, uma alternativa proposta por MARTÍNEZ (2001) para reduzir o número de ensaios é utilizar planejamentos compostos centrais (PCC).

Segundo KHURI (1996) um planejamento composto central é formado por um planejamento fatorial $2^{\mathrm{k}}$ completo, sendo os níveis dos fatores codificados pelos valores -1 e 1 , representados pela matriz $\mathrm{M}$ (eq. 5.45), e por dois pontos axiais em cada eixo das variáveis do planejamento, a uma distância a ${ }^{*}$ do centro do planejamento, sendo a uma constante que deve ser escolhida pelo pesquisador. Esses pontos podem ser representados pela matriz $\mathrm{M}^{*}$ (eq. 5.46).

Segundo MARTÍNEZ (1999) o número total de pontos experimentais em um planejamento composto central é igual: $\mathrm{n}=2^{\mathrm{k}}+2 \mathrm{k}+\mathrm{n}_{0}$, sendo $\mathrm{n}_{0} \quad\left(\mathrm{n}_{0} \geq 1\right)$ as observações no centro do planejamento $(0,0, \cdots, 0)$. Uma escolha adequada de $a^{*}$ pode 
ser feita conforme eq.(5.47). Isso converte o PCC em rotativo. Em outras palavras, a variância da resposta estimada é constante para todos os pontos, as quais são eqüidistantes a partir do centro do planejamento. A Tabela 5.3 apresenta um exemplo de um planejamento composto central com duas variáveis independentes $\mathrm{x}_{1}^{\mathrm{c}} \mathrm{e} \mathrm{x}_{2}^{\mathrm{c}}$, isto é, com dois fatores $(\mathrm{k}=2)$ com $\mathrm{n}_{0}$ igual a $1 \mathrm{e} \mathrm{a}^{*}=\left(2^{2}\right)^{\frac{1}{4}}=\sqrt{2}$.

$$
\begin{aligned}
& M=\left[\begin{array}{ccccc}
-1 & -1 & -1 & \cdots & -1 \\
1 & -1 & -1 & \cdots & -1 \\
-1 & 1 & -1 & \cdots & -1 \\
1 & 1 & -1 & \cdots & -1 \\
& & \vdots & & \\
-1 & 1 & -1 & \cdots & 1 \\
1 & 1 & -1 & \cdots & 1 \\
-1 & -1 & 1 & \cdots & 1 \\
1 & -1 & 1 & \cdots & 1 \\
-1 & 1 & 1 & \cdots & 1 \\
1 & 1 & 1 & \cdots & 1
\end{array}\right] \\
& \mathrm{M}^{*}=\left[\begin{array}{cccccc}
-\mathrm{a}^{*} & 0 & 0 & \cdots & 0 & 0 \\
\mathrm{a}^{*} & 0 & 0 & \cdots & 0 & 0 \\
0 & -\mathrm{a}^{*} & 0 & \cdots & 0 & 0 \\
0 & \mathrm{a}^{*} & 0 & \cdots & 0 & 0 \\
& & \vdots & & & \\
0 & 0 & \cdots & 0 & -\mathrm{a}^{*} & 0 \\
0 & 0 & \cdots & 0 & \mathrm{a}^{*} & 0 \\
0 & 0 & \cdots & 0 & 0 & -\mathrm{a}^{*} \\
0 & 0 & \cdots & 0 & 0 & \mathrm{a}^{*}
\end{array}\right] \\
& a^{*}=\left(2^{k}\right)^{\frac{1}{4}}
\end{aligned}
$$

$\mathrm{Na}$ Tabela 5.3, as simulações correspondentes de 1 a 4, correspondem ao planejamento fatorial $2^{2}$ completo, a simulação 5 é o centro do planejamento e as simulações 6 a 9 são os dois pontos axiais em cada eixo das variáveis de planejamento, a uma distância igual a $\sqrt{2}$ do centro do planejamento. 
Tabela 5.3 - Planejamento composto central para duas variáveis independentes

\begin{tabular}{cccc}
\hline \hline Simulação & Fatores & Fatores & Resposta \\
$\mathrm{i}$ & $\mathrm{x}_{1}^{\mathrm{c}}$ & $\mathrm{x}_{2}^{\mathrm{c}}$ & $\mathrm{Y}$ \\
\hline 1 & -1 & -1 & $\mathrm{y}_{11} \cdots \mathrm{y}_{1 \mathrm{p}^{*}}$ \\
2 & 1 & -1 & $\mathrm{y}_{21} \cdots \mathrm{y}_{2 \mathrm{p}^{*}}$ \\
3 & -1 & 1 & $\mathrm{y}_{31} \cdots \mathrm{y}_{3 \mathrm{p}^{*}}$ \\
4 & 1 & 1 & $\mathrm{y}_{41} \cdots \mathrm{y}_{4 \mathrm{p}^{*}}$ \\
5 & 0 & 0 & $\mathrm{y}_{51} \cdots \mathrm{y}_{5 \mathrm{p}^{*}}$ \\
6 & $-\sqrt{2}$ & 0 & $\mathrm{y}_{61} \cdots \mathrm{y}_{6 \mathrm{p}^{*}}$ \\
7 & $\sqrt{2}$ & 0 & $\mathrm{y}_{71} \cdots \mathrm{y}_{7 \mathrm{p}^{*}}$ \\
8 & 0 & $-\sqrt{2}$ & $\mathrm{y}_{81} \cdots \mathrm{y}_{8 \mathrm{p}^{*}}$ \\
9 & 0 & $\sqrt{2}$ & $\mathrm{y}_{91} \cdots \mathrm{y}_{9 \mathrm{p}^{*}}$ \\
\hline \hline
\end{tabular}

Tabela 5.4 - Planejamento composto central ortogonal para duas variáveis independentes

\begin{tabular}{cccc}
\hline \hline $\begin{array}{c}\text { Simulação } \\
\mathrm{i}\end{array}$ & Fatores & Fatores & Resposta \\
\hline 1 & $\mathrm{x}_{1}^{\mathrm{c}}$ & $\mathrm{x}_{2}^{\mathrm{c}}$ & $\mathrm{Y}$ \\
2 & -1 & -1 & $\mathrm{y}_{11} \cdots \mathrm{y}_{1 \mathrm{p}^{*}}$ \\
3 & 1 & -1 & $\mathrm{y}_{21} \cdots \mathrm{y}_{2 \mathrm{p}^{*}}$ \\
4 & -1 & 1 & $\mathrm{y}_{31} \cdots \mathrm{y}_{3 \mathrm{p}^{*}}$ \\
5 & 1 & 1 & $\mathrm{y}_{41} \cdots \mathrm{y}_{4 \mathrm{p}^{*}}$ \\
6 & 0 & 0 & $\mathrm{y}_{51} \cdots \mathrm{y}_{5 \mathrm{p}^{*}}$ \\
7 & -1 & 0 & $\mathrm{y}_{61} \cdots \mathrm{y}_{6 \mathrm{p}^{*}}$ \\
8 & 1 & 0 & $\mathrm{y}_{71} \cdots \mathrm{y}_{7 \mathrm{p}^{*}}$ \\
9 & 0 & -1 & $\mathrm{y}_{81} \cdots \mathrm{y}_{8 \mathrm{p}}{ }^{*}$ \\
\hline \hline
\end{tabular}

\subsubsection{Planejamentos compostos centrais ortogonais}

Os planejamentos compostos centrais ortogonais (PCCO) são alternativas aos planejamentos $3^{\mathrm{k}}$, propiciando flexibilidade ao pesquisador (MARTÍNEZ, 2001), pois permitem várias escolhas de $\mathrm{a}^{*}$. Uma outra escolha possível para $\mathrm{a}^{*}$ é através dos planejamentos compostos centrais ortogonais conforme descrito pela eq.(5.48). A Tabela 5.4 apresenta um exemplo de um planejamento composto central ortogonal com 
duas variáveis independentes $x_{1}^{c}$ e $x_{2}^{c}$, isto é, com dois fatores $(k=2)$ com $n_{0}$ igual a 1 e a* igual a 1 obtido pela eq.(5.48).

$$
\mathrm{a}^{*}=\left(\frac{\left(2^{\mathrm{k}}\right)^{\frac{1}{2}}\left(2^{\mathrm{k}}+2 \mathrm{k}+\mathrm{n}_{0}\right)-2^{\mathrm{k}}}{2}\right)^{\frac{1}{2}}
$$

$\underline{\underline{T} \text { Tabela } 5.5 \text { - Valores de }} \mathrm{a}^{*}$ para PCCO

\begin{tabular}{cc}
\hline \hline $\mathrm{K}$ & $\mathrm{a}^{*}$ \\
\hline 2 & 1,000 \\
3 & 1,216 \\
4 & 1,414 \\
\hline
\end{tabular}

Observa-se que para $a^{*}$ igual a 1 o PCCO torna-se um planejamento fatorial $3^{3}$. A Tabela (5.5) apresenta alguns valores de $\mathrm{a}^{*}$ para diversos valores de $\mathrm{k}$.

\subsection{Análise de componentes principais - ferramenta de auxílio a tomada de decisão}

A análise de componentes principais (ACP) faz parte de um conjunto de técnicas estatísticas, denominadas técnicas de análise multivariada. Os objetivos principais da ACP são descrever as relações entre as variáveis e reduzir a dimensionalidade do problema formando um novo conjunto de variáveis (fatores) de forma eliminar a variáveis redundantes do conjunto de dados iniciais.

Teoricamente, a ACP é definida através de uma matriz X com m vetores, dos quais no presente estudo representam valores das funções objetivo relativos às diversas soluções do problema de reabilitação resultante da frente Pareto. O primeiro componente principal é expresso por uma combinação linear das colunas da matriz $\mathrm{X}$, isto é variáveis (nesse estudo, objetivos), que apresentam a maior variabilidade em $\mathrm{X}$, $\mathrm{t}_{1}=\mathrm{X} \cdot \mathrm{p}_{1}$, dado que $\left|\mathrm{p}_{1}\right|=1$. No espaço $\mathrm{m}$-dimensional (no caso $\mathrm{m}$ é igual 4), $\mathrm{p}_{1}$ é definido como a direção de maior variabilidade (autovetor) e $t_{1}$ representa a projeção de cada variável em $\mathrm{p}_{1}$. O segundo componente principal é a combinação linear definida por $\mathrm{t}_{2}=\mathrm{E}_{1} \cdot \mathrm{p}_{2}$, sendo que a variância desse segundo componente está sujeito à condição de ser ortogonal ao primeiro componente principal $t_{1}$. Portanto pode-se escrever a eq. 5.49: 
$\mathrm{E}_{1}=\left(\mathrm{X}-\mathrm{t}_{1} \cdot \mathrm{p}_{1}^{\mathrm{t}}\right)$

sendo $\mathrm{p}_{\mathrm{i}}$ um autovetor da matriz de covariância de $\mathrm{X}, \mathrm{t}_{1}$ o primeiro componente principal, t o operador de transposição e p o vetor que descreve a direção da maior variabilidade dos dados. O procedimento (5.49) é repetido até que m componentes principais possam ser calculados. Dessa forma, a ACP decompõe o conjunto inicial X conforme eq. 5.50 :

$\mathrm{X}=\mathrm{TP}^{\mathrm{t}}=\sum_{\mathrm{i}=1}^{\mathrm{m}} \mathrm{t}_{\mathrm{i}} \mathrm{p}_{\mathrm{i}}^{\mathrm{t}}$

sendo $\mathrm{p}_{\mathrm{i}} \mathrm{o}$ autovetor da matriz $\mathrm{X}, \mathrm{P}$ a matriz de componentes principais e $\mathrm{T}$ a matriz de coeficientes dos componentes principais. A matriz $\mathrm{T}$ fornece a informação do impacto de cada variável sobre componente principal.

A proposta de aplicação dessa metodologia (ACP) como ferramenta de auxílio à escolha de soluções representativas das frentes Pareto, foi inspirada no trabalho de NEIMANE (2001), que utilizou o referido método (ACP) na análise de reabilitação de redes de distribuição de energia elétrica. Para isso, foi utilizado um pacote computacional de análise estatística MINITAB (versão demonstrativa).

\subsection{Análise de reabilitação através da otimização multiobjetivo de múltiplos estágios}

Um plano de reabilitação deve estabelecer a seqüência de ações a serem implementadas na rede ao longo do horizonte de planejamento, em conformidade com o Plano Diretor de Abastecimento da cidade, subdividido em intervalos de tempo menores. Considerando que o problema de reabilitação além de ser multicriterial é dinâmico, propôs-se, como sistemática de resolução, uma extensão do conceito da otimalidade de Bellman (BELLMAN e KALABA, 1965) para o caso multiobjetivo, de maneira que os planos de reabilitação possam ser identificados. O problema a ser resolvido num estágio j, qualquer, pode ser expresso através da equação recursiva forward conforme eq.(5.51):

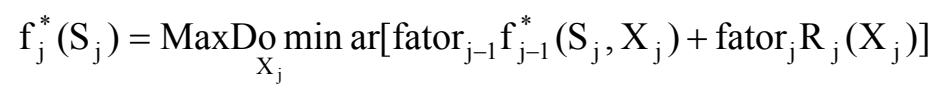

sendo que $\mathrm{f}_{\mathrm{j}}^{*}\left(\mathrm{~S}_{\mathrm{j}}\right)$ é o vetor dos objetivos acumulados do primeiro ao estágio $\mathrm{j}$, representativo das soluções pertencentes à frente Pareto resultante no estágio j; 
$\mathrm{f}_{\mathrm{j}-1}^{*}\left(\mathrm{~S}_{\mathrm{j}}, \mathrm{X}_{\mathrm{j}}\right)$ é o vetor dos objetivos acumulados do primeiro ao estágio j-1 (“sub-ótimo”), representativo das soluções pertencentes à frente Pareto resultante no estágio j-1; $\mathrm{R}_{\mathrm{j}}\left(\mathrm{X}_{\mathrm{j}}\right)$ é a contribuição do estágio $\mathrm{j}$ em termos dos objetivos; $\mathrm{X}_{\mathrm{j}}$ é o vetor de decisões relativas ao estágio $\mathrm{j} ; \mathrm{S}_{\mathrm{j}}$ é vetor de variáveis determinantes do estado do sistema relativas ao início do estágio $\mathrm{j}$ ou final do estágio $\mathrm{j}-1$; fator $_{\mathrm{j}-1}$ e fator $\mathrm{f}_{\mathrm{j}}$ representam os fatores de ponderação dessas duas parcelas, cujos valores dependem do objetivo considerado, no caso do custo, expresso em unidades monetárias, o objetivo acumulado corresponde à soma dos valores presentes dos custos de cada estágio. Nesse caso, fator $\mathrm{j}_{\mathrm{j}}$ corresponde à unidade e fator ${ }_{j-1}$ ao fator de recuperação do capital $\left[\mathrm{frc}=\frac{1}{(1+\mathrm{r})^{5 .(\mathrm{j}-1)}}\right]$,sendo $\mathrm{r}$ a taxa de juros anual, fixada em $5 \%$ ]. No caso do benefício, expresso em unidades de potência, o objetivo acumulado corresponde à soma dos

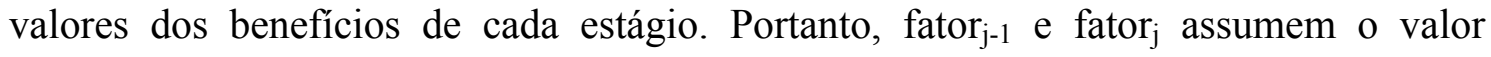
unitário. Já no caso dos vazamentos e da confiabilidade, os respectivos objetivos acumulados correspondem à média dos três estágios. Assim, os valores dos fatores devem ser adequados de maneira a avaliar vazamento médio e confiabilidade média dos três estágios.

Para viabilizar o processamento computacional, algumas simplificações foram ainda necessárias, para que somente algumas soluções representativas da frente Pareto resultante de um estágio fossem consideradas no estágio seguinte, de acordo com a metodologia descrita no item 5.9 (Análise de Componentes Principais). A Figura 5.17 apresenta o procedimento geral da otimização multiobjetivo dinâmica.

\subsection{Redes exemplo}

Nesse item apresentam-se as redes utilizadas neste trabalho. Duas dessas redes (Figuras 5.18 e 5.19) são proposições da literatura e servem de referência para testes e avaliações dos algoritmos propostos e utilizados. A terceira rede (Figura 5.20) é um modelo representativo, sistema macro (tubulações principais, desprezando-se tubulações secundárias, menores que $100 \mathrm{~mm}$ ), de um sistema real. 


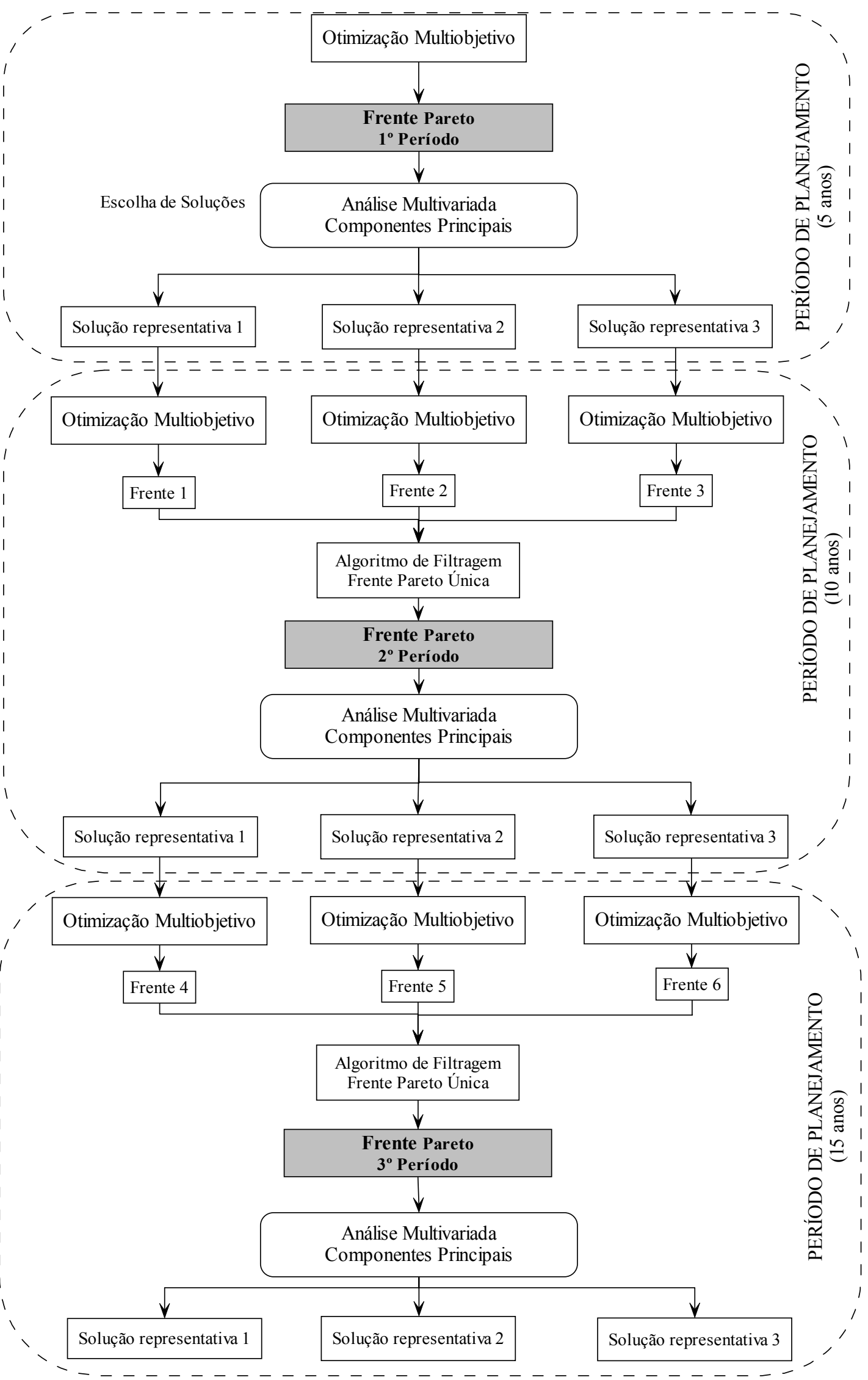

Figura 5.17 - Procedimento proposto para otimização multiobjetivo dinâmica 


\subsubsection{Rede exemplo 1}

O estudo de reabilitação da rede exemplo 1 (Figura 5.18) foi inicialmente proposto por GESSLER (1985). Essa rede possui 14 tubulações, 2 reservatórios de nível constante (nós 1 e 5) e 9 nós de demanda $(2,3,6,7,8,9,10,11$ e 12). As linhas sólidas representam o sistema existente e linhas pontilhadas as novas tubulações.

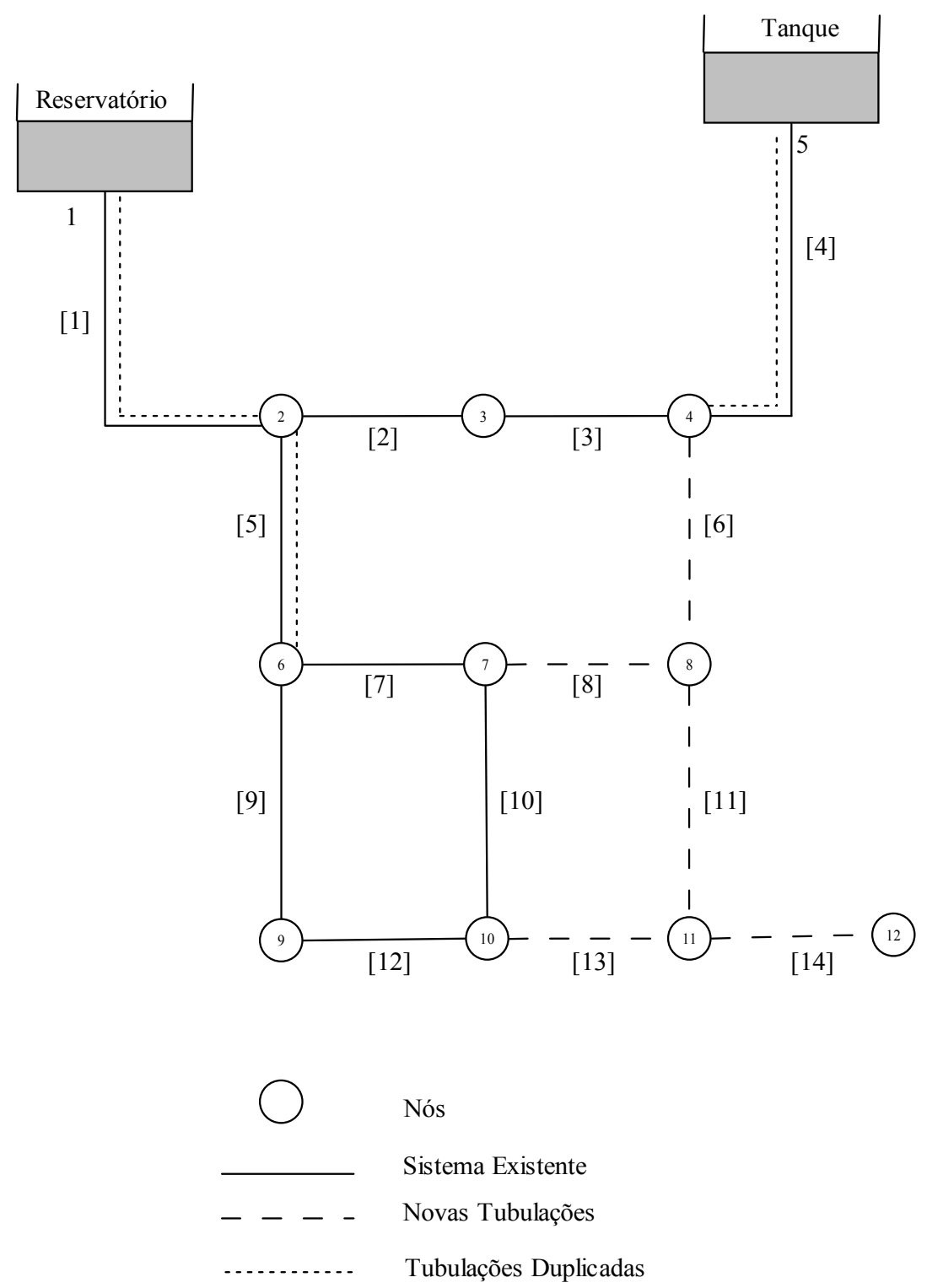

Figura 5.18 - Rede Exemplo 1

Os dados dos trechos e dos nós da rede exemplo 1 são apresentados nas Tabelas 5.6 e 5.7, respectivamente. A complexidade desse problema é determinada pelas diversas combinações possíveis (variáveis de decisão) que o sistema pode admitir. Por exemplo, existem cinco tubulações de projeto $(6,8,11,13$ e 14) dos quais seus diâmetros devem ser escolhidos entre 8 possibilidades (Tabela 5.8). Três tubulações existentes (1, 4 e 5) 
podem sofrer reabilitação, oito são as possibilidades (Tabela 5.9). Os custos associados com essas variáveis de decisão são apresentados nas Tabelas 5.10 e 5.11.

Tabela 5.6 - Características geométricas da rede exemplo 1

\begin{tabular}{cccc}
\hline \hline Tubulação & $\begin{array}{c}\text { Diâmetro } \\
\mathrm{mm}\end{array}$ & $\begin{array}{c}\text { Comprimento } \\
\mathrm{m}\end{array}$ & $\begin{array}{c}\text { Coeficiente } \\
\text { HW }\end{array}$ \\
\hline 1 & 356 & 4828 & 75 \\
2 & 254 & 1609 & 80 \\
3 & 254 & 1609 & 80 \\
4 & 254 & 6437 & 80 \\
5 & 254 & 1609 & 80 \\
6 & Projeto & 1609 & 120 \\
7 & 203 & 1609 & 100 \\
8 & Projeto & 1609 & 120 \\
9 & 254 & 1609 & 80 \\
10 & 102 & 1609 & 100 \\
11 & Projeto & 1609 & 120 \\
12 & 203 & 1609 & 100 \\
13 & Projeto & 1609 & 120 \\
14 & Projeto & 1609 & 120 \\
\hline \hline
\end{tabular}

Tabela 5.7 - Dados dos nós da rede exemplo 1

\begin{tabular}{cccccccc}
\hline \hline \multirow{2}{*}{ Nó } & \multirow{2}{*}{ Elevação } & \multicolumn{2}{c}{ Cenário 1 } & \multicolumn{2}{c}{ Cenário 2 } & \multicolumn{2}{c}{ Cenário 3 } \\
& & $\mathrm{q}$ & $\mathrm{P}_{\min }$ & $\mathrm{q}$ & $\mathrm{P}_{\min }$ & $\mathrm{q}$ & $\mathrm{P}_{\min }$ \\
& $\mathrm{m}$ & $\mathrm{L} / \mathrm{s}$ & $\mathrm{m}$ & $\mathrm{L} / \mathrm{s}$ & $\mathrm{M}$ & $\mathrm{L} / \mathrm{s}$ & $\mathrm{m}$ \\
\hline 1 & 365,76 & - & - & - & - & - & - \\
2 & 320,40 & 12,62 & 28,18 & 12,62 & 14,09 & 12,62 & 14,09 \\
3 & 326,14 & 12,62 & 17,61 & 12,62 & 14,09 & 12,62 & 14,09 \\
4 & 323,23 & 0 & 17,61 & 0 & 14,09 & 0 & 14,09 \\
5 & 371,86 & - & - & - & - & - & - \\
6 & 298,70 & 18,93 & 35,22 & 18,93 & 14,09 & 18,93 & 14,09 \\
7 & 295,66 & 18,93 & 35,22 & 82,03 & 10,57 & 18,93 & 14,09 \\
8 & 292,61 & 18,93 & 35,22 & 18,93 & 14,09 & 18,93 & 14,09 \\
9 & 289,56 & 12,62 & 35,22 & 12,62 & 14,09 & 12,62 & 14,09 \\
10 & 289,56 & 18,93 & 35,22 & 18,93 & 14,09 & 18,93 & 14,09 \\
11 & 292,61 & 18,93 & 35,22 & 18,93 & 14,09 & 18,93 & 14,09 \\
12 & 289,56 & 12,62 & 35,22 & 12,62 & 14,09 & 50,48 & 10,57 \\
\hline \hline
\end{tabular}

\subsubsection{Rede exemplo 2}

A rede exemplo 2 (Figura 5.19) foi proposta por TUCCIARELLI, CRIMINISI e TERMINI (1999) para estudar as perdas por vazamento (estimativa). Para isso, essa 
rede foi dividida em três setores de vazamentos $(\theta)$ e um expoente de vazamento $(\varepsilon)$ comum a esses três setores. Essa rede conta com 25 trechos de tubulações, 15 nós e três reservatórios. As Tabelas 5.12 e 5.13 apresentam os dados relativos aos trechos (comprimentos, diâmetros, coeficiente de vazamentos e expoente de vazamentos) e aos nós (elevação e demanda), respectivamente.

Tabela 5.8 - Opções de projeto

\begin{tabular}{cc}
\hline \hline $\begin{array}{c}\text { Diâmetro } \\
\mathrm{mm}\end{array}$ & Código \\
\hline 152 & 0 \\
203 & 1 \\
254 & 2 \\
305 & 3 \\
356 & 4 \\
407 & 5 \\
458 & 6 \\
509 & 7 \\
\hline \hline
\end{tabular}

Tabela 5.9 - Opções de reabilitação

\begin{tabular}{cc}
\hline \hline Ação & Código \\
\hline Deixar como está & 0 \\
Limpar Tubulação & 1 \\
Duplicar com 152 & 2 \\
Duplicar com 203 & 3 \\
Duplicar com 254 & 4 \\
Duplicar com 305 & 5 \\
Duplicar com 356 & 6 \\
Duplicar com 407 & 7 \\
\hline \hline
\end{tabular}

Tabela 5.10 - Custos de projeto

\begin{tabular}{cc}
\hline \hline $\begin{array}{c}\text { Diâmetro } \\
\mathrm{mm}\end{array}$ & $\begin{array}{c}\text { Custo de tubos } \\
\$ / \mathrm{m}\end{array}$ \\
\hline 152 & 49,54 \\
203 & 63,32 \\
254 & 94,82 \\
305 & 132,87 \\
356 & 170,93 \\
407 & 194,88 \\
458 & 232,94 \\
509 & 264,10 \\
\hline \hline
\end{tabular}

Tabela 5.11 - Custos de reabilitação

\begin{tabular}{cc}
\hline \hline $\begin{array}{c}\text { Diâmetro } \\
\mathrm{mm}\end{array}$ & $\begin{array}{c}\text { Custo de limpeza } \\
\$ / \mathrm{m}\end{array}$ \\
\hline 152 & 47,57 \\
203 & 51,51 \\
254 & 55,12 \\
305 & 58,07 \\
356 & 60,70 \\
407 & 63,00 \\
458 & - \\
509 & - \\
\hline \hline
\end{tabular}




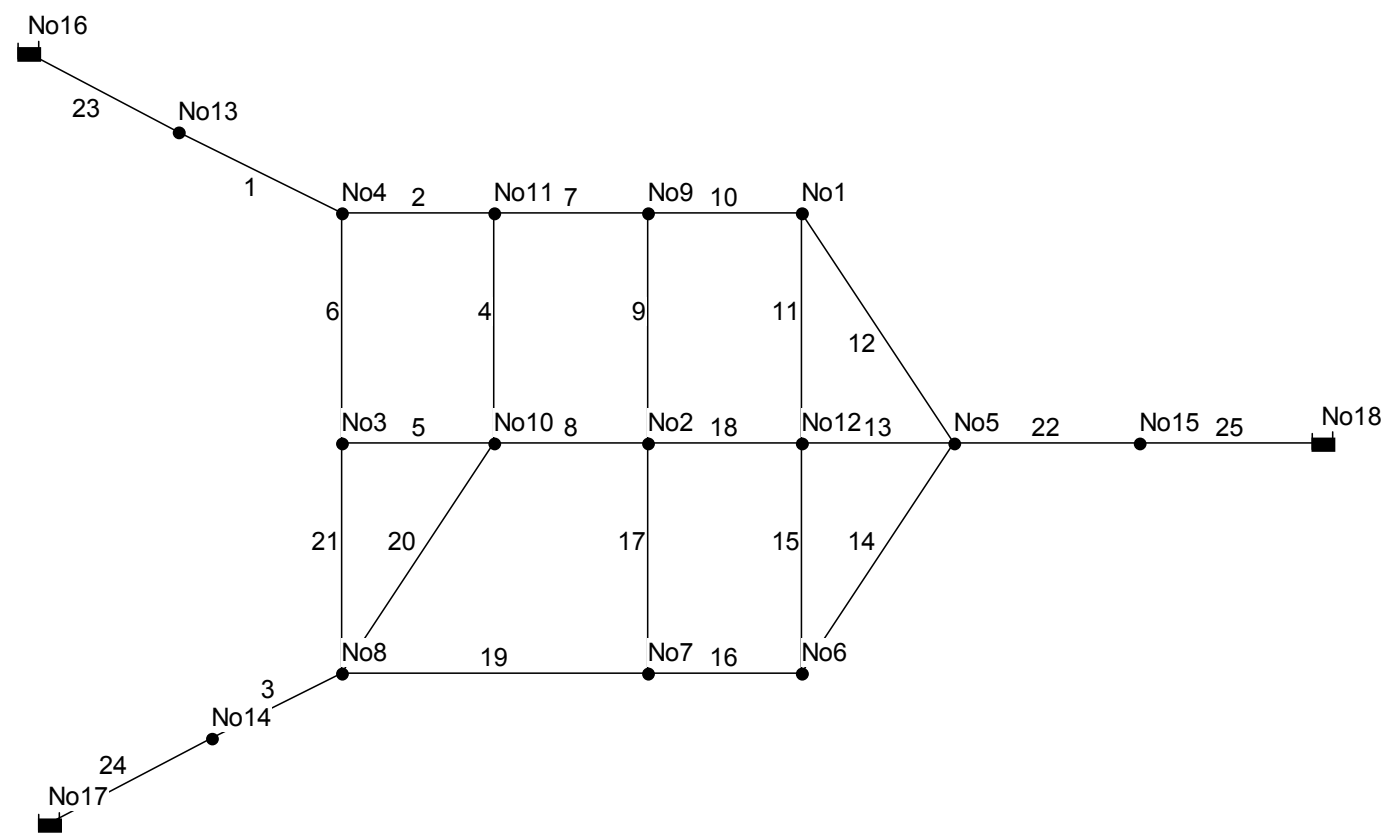

Figura 5.19 - Rede exemplo 2

Tabela 5.12-Características geométricas da rede exemplo 2

\begin{tabular}{ccccc}
\hline \hline Tubulação & $\begin{array}{c}\text { Diâmetro } \\
\mathrm{mm}\end{array}$ & $\begin{array}{c}\text { Comprimento } \\
\mathrm{m}\end{array}$ & $\begin{array}{c}\text { Rugosidade } \\
\mathrm{mm}\end{array}$ & $\begin{array}{c}\text { Vazamento } \\
\text { setor }\end{array}$ \\
\hline 1 & 500 & 1000 & 3,474 & 1 \\
2 & 250 & 500 & 3,474 & 2 \\
3 & 500 & 1000 & 3,474 & 1 \\
4 & 150 & 500 & 3,474 & 2 \\
5 & 150 & 500 & 3,474 & 2 \\
6 & 250 & 500 & 3,474 & 2 \\
7 & 250 & 500 & 3,474 & 2 \\
8 & 150 & 500 & 3,474 & 2 \\
9 & 150 & 500 & 3,474 & 3 \\
10 & 250 & 500 & 3,474 & 3 \\
11 & 150 & 500 & 3,474 & 3 \\
12 & 250 & 560 & 3,474 & 3 \\
13 & 250 & 250 & 3,474 & 3 \\
14 & 250 & 560 & 3,474 & 3 \\
15 & 150 & 500 & 3,474 & 3 \\
16 & 250 & 500 & 3,474 & 3 \\
17 & 150 & 500 & 3,474 & 3 \\
18 & 150 & 500 & 3,474 & 3 \\
19 & 250 & 500 & 3,474 & 3 \\
20 & 150 & 700 & 3,474 & 3 \\
21 & 250 & 500 & 3,474 & 3 \\
22 & 500 & 500 & 3,474 & 1 \\
23 & 500 & 1 & 3,474 & 1 \\
24 & 500 & 1 & 3,474 & 1 \\
25 & 500 & 1 & 3,474 & 1 \\
\hline \hline
\end{tabular}


Tabela 5.13 - Dados dos nós da rede exemplo 2

\begin{tabular}{ccc}
\hline \hline Nó & $\begin{array}{c}\text { Elevação } \\
\mathrm{m}\end{array}$ & $\begin{array}{c}\mathrm{Q} \\
\mathrm{L} / \mathrm{s}\end{array}$ \\
\hline 1 & 25 & 30,4 \\
2 & 20 & 30,4 \\
3 & 22 & 30,4 \\
4 & 27 & 0,0 \\
5 & 30 & 0,0 \\
6 & 27 & 30,4 \\
7 & 22 & 0,0 \\
8 & 25 & 0,0 \\
9 & 25 & 0,0 \\
10 & 20 & 0,0 \\
11 & 22 & 30,4 \\
12 & 27 & 0,0 \\
13 & 25 & 0,0 \\
14 & 25 & 0,0 \\
15 & 30 & 0,0 \\
16 & 70 & 0,0 \\
17 & 70 & 0,0 \\
18 & 70 & 0,0 \\
\hline \hline
\end{tabular}

\subsubsection{Rede exemplo 3}

O sistema de abastecimento de água da cidade de Campo Grande - MS é divido em 20 setores operacionais, responsáveis pelo atendimento de 706.442 mil habitantes (SANDIM et al., 2002). Especificamente, o sistema de distribuição RF-1/TH é o setor operacional que apresenta mais perda de água, em média $48 \%$, e por isso, está sendo objeto de estudo neste trabalho. Esse setor está localizado na região norte do município de Campo Grande, sendo totalmente abastecido pelo sistema integrado (compreende as regiões da cidade cujo abastecimento tem como fontes de suprimento principais as captações superficiais). Esse setor é divido em: parte alta (TH) e parte baixa (RF-1), e neste trabalho, apenas o setor RF-1 está sendo investigado.

Foi constatado ${ }^{16}$ que, em se tratando da análise de reabilitação de redes de distribuição de água, as companhias de saneamento tem interesse em avaliar a reabilitação apenas do sistema macro (tubulações principais) e não de redes secundárias (tubos com diâmetros menores que $100 \mathrm{~mm}$ ). Por isso, no presente estudo tubulações com diâmetros inferiores a $100 \mathrm{~mm}$ foram desprezadas, gerando dessa forma, um modelo simplificado ilustrado pela Figura 5.20.

\footnotetext{
${ }^{16}$ Entrevista realizada com a gerente de projetos Eng ${ }^{\mathrm{a}}$ Civil Marilúcia Sandim Pereira da Companhia de Saneamento Água Guariroba S. A., Campo Grande -MS, em Abril de 2003.
} 


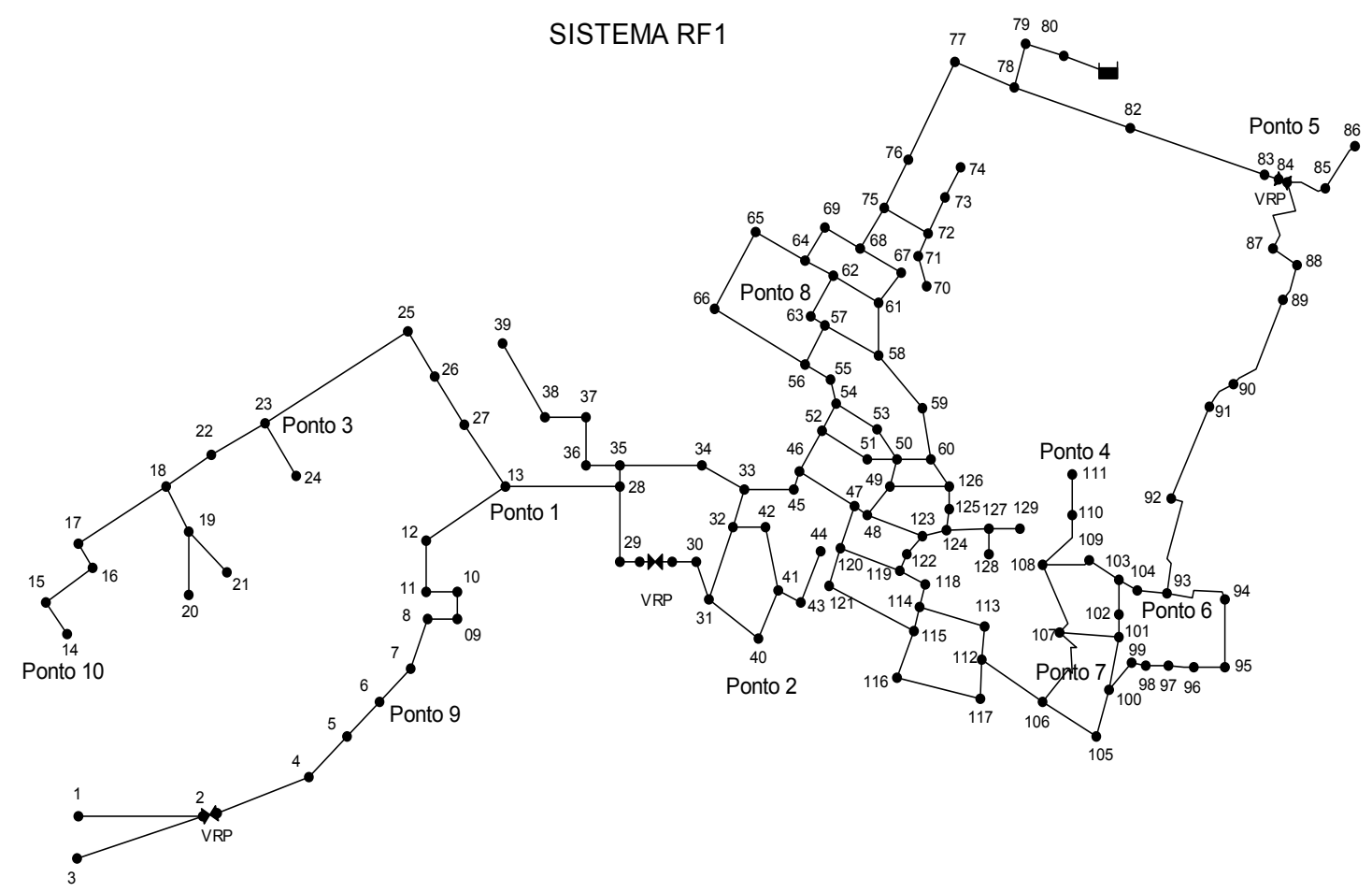

Figura 5.20 - Rede exemplo 3 (modelo simplificado do sistema RF-1)

Tabela 5.14 - Decisões de reabilitação para rede exemplo 3

\begin{tabular}{ccc}
\hline \hline Código & Ação de Reabilitação & Diâmetro $(\mathrm{mm}) / \mathrm{C}_{\mathrm{HW}}$ \\
\hline 0 & Substituição & 150 \\
1 & Substituição & 200 \\
2 & Substituição & 300 \\
3 & Substituição & 500 \\
4 & Substituição & 600 \\
5 & Substituição & 700 \\
6 & Substituição & 800 \\
7 & Substituição & 900 \\
8 & Deixar como está & - \\
9 & Duplicação & 150 \\
10 & Duplicação & 200 \\
11 & Duplicação & 500 \\
12 & Duplicação & 600 \\
13 & Duplicação & 700 \\
14 & Duplicação & 800 \\
15 & Duplicação & 900 \\
16 & Limpeza & $120^{*}$ \\
\hline Coeficiente de Hazen Williams após limpeza do tubo \\
\hline \hline
\end{tabular}

O suprimento de água do setor de distribuição RF1 ocorre por meio de dois reservatórios semi-enterrados, cada qual com um volume de armazenamento de 6000 
$\mathrm{m}^{3}$. Esse setor é responsável por atender a demanda de aproximadamente 100.000 habitantes (SANDIM et al., 2002) sendo a sua rede composta de PVC e cimento amianto com 432.509,27 metros de tubulações. Os dados dessa rede encontram-se no ANEXO A. A complexidade desse problema é determinada pelas diversas combinações possíveis (variáveis de decisão) que o sistema pode admitir. Por exemplo, existem 148 trechos possíveis de serem reabilitadas e 17 ações que podem ser implementadas (Tabela 5.14). Os custos associados com essas variáveis de decisão são apresentados na Tabelas 5.15.

Tabela 5.15 - Custos de reabilitação

\begin{tabular}{cccc}
\hline \hline & \multicolumn{3}{c}{ Custos $(\$ / \mathrm{m})$} \\
Diâmetro $(\mathrm{mm})$ & Substituição & Duplicação & Limpeza \\
\hline 150 & 42 & 47 & 39 \\
200 & 58 & 65 & 39 \\
250 & 74 & 82 & 39 \\
300 & 96 & 106 & 43 \\
350 & 119 & 132 & 47 \\
400 & 143 & 159 & 51 \\
450 & 169 & 188 & 56 \\
500 & 197 & 219 & 66 \\
600 & 253 & 281 & 76 \\
700 & 346 & 381 & 82 \\
800 & 374 & 402 & 90 \\
900 & 401 & 452 & 110 \\
\hline \hline
\end{tabular}




\section{RESULTADOS E DISCUSSÕES}

Nesse capítulo são apresentados e discutidos os resultados obtidos da análise de reabilitação de redes de distribuição de água para abastecimento aplicada a problemas exemplos da literatura e a um estudo de caso real, utilizando a metodologia proposta no presente trabalho. Um organograma é apresentado através da Figura 6.1 com objetivo de enfatizar as etapas desenvolvidas na pesquisa e facilitar ao leitor o acompanhamento das investigações e das conclusões obtidas.

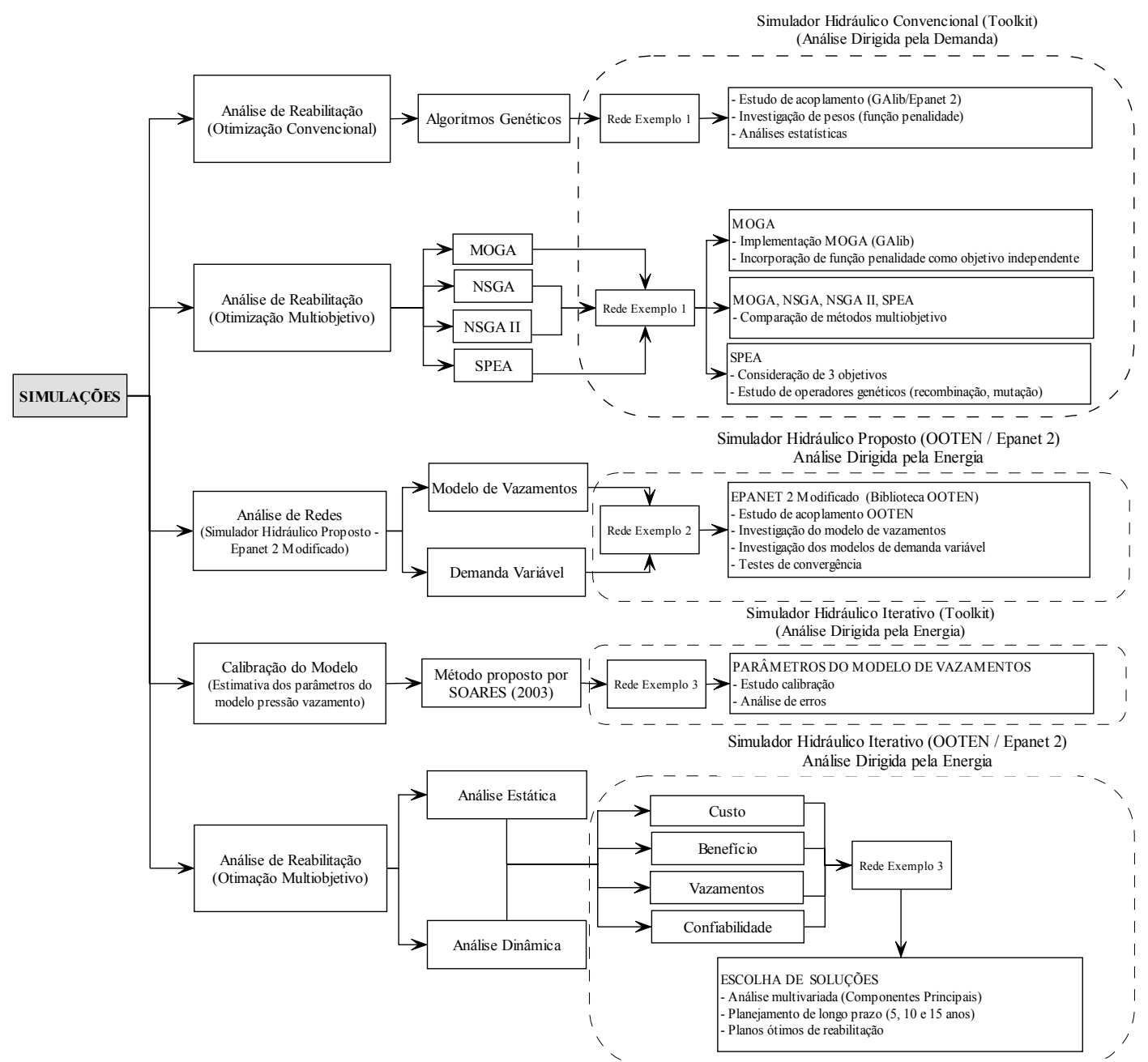

Figura 6.1 - Organograma das simulações realizadas 
Qualquer estudo de sistemas de distribuição de água que utilize a modelação matemática como ferramenta, deve tomar por base um modelo de simulação hidráulica confiável que possibilite analisar o comportamento dos sistemas sob diversas condições operacionais. No presente trabalho, quatro simuladores hidráulicos foram utilizados e testados, conforme descrito no item 5.5. Todos esses simuladores são baseados no código fonte do Epanet 2 (ROSSMAN, 2000) e acoplados a um compilador $\mathrm{C}++$ (Borland Builder $C++5.0$ ).

O Epanet 2 é um programa computacional de domínio público, escrito em linguagem de programação $\mathrm{C}$, de desempenho comprovado e bem aceito pela comunidade científica. Sua principal vantagem é a possibilidade de incorporar diversos dispositivos hidráulicos (bombas, válvulas, reservatórios com níveis variáveis) associada as simulações em período extensivo. Esse programa está disponível na sua forma executável (visual) ou através de suas bibliotecas (rotinas de funções). A utilização de códigos (sub-rotinas), ao invés do programa executável, flexibiliza o acoplamento de rotinas adicionais.

Os resultados apresentados nesse capítulo são divididos em: estudos das análises de reabilitação através da otimização convencional (algoritmos genéticos) e da otimização multiobjetivo (algoritmos evolucionários) em problemas da literatura, análise do comportamento numérico do simulador hidráulico proposto (Epanet 2 modificado) em relação aos modelos dirigidos pela pressão (vazamento e demanda) nele implementados e suas respectivas convergências, estimativa dos parâmetros do modelo de pressão vazamento (calibração do modelo) e análises de reabilitação (estática e dinâmica) de uma rede real considerando objetivos múltiplos (custo, benefício, vazamentos e confiabilidade).

\subsection{Análise de reabilitação através da otimização convencional - estudo teórico}

Essa seção aborda os resultados da análise de reabilitação através da otimização convencional (Algoritmos Genéticos - objetivo único) e síntese dos procedimentos desenvolvidos. Vários testes foram realizados utilizando o simulador hidráulico convencional (5.5.1) com objetivo de verificar a sua adequação diante do problema de reabilitação de redes. Esses testes envolveram estudos preliminares de acoplamento desse simulador com o compilador Borland Builder C++ 5.0, de chamadas de funções, de entrada e saída de dados, além de investigações de como se modificava as características geométricas de um dado arquivo de rede, por exemplo, a mudança de 
diâmetros e coeficientes de rugosidade, de como considerar os vários padrões de demanda, dentre outros.

Após ter exaurido as investigações sobre a utilização do simulador, iniciou-se a fase de integração do modelo hidráulico com o modelo de otimização. Partiu-se da hipótese de que como o código fonte do simulador hidráulico (Epanet 2) está escrito em linguagem C, o módulo de otimização deveria estar ou na mesma linguagem ou em uma linguagem compatível com a linguagem C. Adotou-se, portanto, a biblioteca de otimização GAlib $\mathrm{C}++{ }^{17}$ (WALL, 1996), baseada na técnica de algoritmos genéticos, de domínio público e de desempenho científico comprovado, escrita por Matthew Wall em 1996 no Instituto de Tecnologia de Massachusetts (MIT). A GAlib conta com quatro tipos de algoritmos genéticos implementados (Simple, Steady-State, Incremental e Deme), cuja descrição detalhada consta no manual da biblioteca (WALL, 1996).

Três etapas iniciais devem ser rigorosamente cumpridas antes de resolver qualquer problema de otimização através de AGs. Essas etapas são: representação adequada das possíveis soluções para o problema, escolha dos parâmetros de entrada dos operadores genéticos (probabilidades de recombinação e de mutação) e formulação da função objetivo (função que descreve o mérito de um determinado vetor solução) do problema em estudo.

\section{Tubulações}

\begin{tabular}{|c|c|c|c|c|c|c|c|}
\hline 1 & 4 & 5 & 6 & 8 & 11 & 13 & 14 \\
\hline $0-7$ & $0-7$ & $0-7$ & $0-7$ & $0-7$ & $0-7$ & $0-7$ & $0-7$ \\
\hline
\end{tabular}

Figura 6.2 - Vetor solução referente ao problema de GESSLER (1985)

Para representação das possíveis soluções do problema, geralmente, utiliza-se um vetor que contém combinações de códigos (binários ou reais) que representa as variáveis de decisão do problema (solução completa). A literatura apresenta várias formas de representar essa combinação (GOLDBERG, 1989; MICHALEWICZ, 1992). Cada qual possui vantagens e desvantagens. Por exemplo, uma desvantagem da codificação binária é o tempo computacional exigido durante a fase de decodificação (converter números

\footnotetext{
${ }^{17}$ Essa biblioteca está disponível na página http:// lancet.mit.Edu/ga/ e pode ser utilizada, sem custo, para fins educacionais e pesquisa.
} 
binários em reais). Para problemas de grande escala a decodificação torna-se inviável devido seu elevado tempo computacional. Como os problemas de redes de distribuição de água (projeto, calibração, operação e reabilitação) envolvem uma grande quantidade de variáveis de decisão, neste trabalho optou-se por utilizar a codificação real visando economia de tempo computacional.

GESSLER (1985) propôs um problema teste (Figura 5.18) para otimização de redes de distribuição de água que envolve decisões de reabilitação e de projeto simultaneamente. Esse problema vem sendo estudado por diversos pesquisadores (SIMPSON, DANDY e MURPHY, 1994; WU e SIMPSON, 1996; WU e SIMPSON, 2001; CHEUNG et al., 2003; CHEUNG, REIS e CARRIJO, 2003) ao longo dos anos. O objetivo principal desse problema é determinar a combinação ótima de mínimo custo das ações de reabilitação (Tabela 5.9) a serem implementadas em três tubulações existentes (1, 4 e 5) e das ações de projeto (Tabela 5.8) de expansão em cinco tubulações novas (determinação de diâmetros), de tal forma que as restrições de pressão mínima (Tabela 5.7) para três padrões de demanda sejam atendidas. A Figura 6.2 representa o vetor solução para o problema, cuja função de avaliação do mérito (função objetivo) de cada vetor solução é apresentada pela eq.(6.1).

Minimizar custo total, $\mathrm{F}_{1}=\sum_{\mathrm{i} \in \mathfrak{I}} \mathrm{c}_{\mathrm{i}} \mathrm{L}_{\mathrm{i}}+\sum_{\mathrm{k} \in \pi} \mathrm{c}_{\mathrm{k}} \mathrm{L}_{\mathrm{k}}$

sendo i o índice das tubulações a serem reabilitadas (limpeza ou inalteradas); $\mathrm{k}$ o índice de novas tubulações (substituídas ou duplicadas); $\mathfrak{I}$ o conjunto de alternativas relativas às tubulações que requerem reabilitação; $\pi$ o conjunto de novas tubulações; L o comprimento das tubulações e $c_{i}$ e $c_{k}$ são os custos unitários (Tabelas 5.11 e 5.10) de reabilitação de tubulações e de novas tubulações, respectivamente.

Como há dificuldades em se trabalhar com restrições nos AGs, SIMPSON, DANDY e MURPHY (1994) propuseram, para esse problema (eq. 6.1), que o atendimento de pressões mínimas (restrições) fossem introduzidas na função objetivo na forma de função penalidade. A formulação proposta por esses pesquisadores é apresentada pela eq.(6.2).

Minimizar custo total, $\mathrm{F}_{1}=\sum_{\mathrm{i} \in \mathfrak{J}} \mathrm{c}_{\mathrm{i}} \mathrm{L}_{\mathrm{i}}+\sum_{\mathrm{k} \in \pi} \mathrm{c}_{\mathrm{k}} \mathrm{L}_{\mathrm{k}}+\mathrm{W} \sum_{\mathrm{i}=1}^{\mathrm{NPD}} \max \left(\sum_{\mathrm{j} \in \mathbb{N}}\left(\mathrm{H}_{\mathrm{j}}^{\min }-\mathrm{H}_{\mathrm{j}}\right)\right)_{\mathrm{i}}$ 
sendo W um coeficiente penalidade; i o índice que varia de acordo com o número de cenários de demanda; NPD denota o número de padrões de demanda; $\aleph$ o conjunto de nós que apresentam energias abaixo da mínima; $\mathrm{H}$ representa a energia no nó $\mathrm{j}$ e $\mathrm{H}^{\text {min }}$ representa a energia mínima requerida no nó j (Tabela 5.7).

Para investigação do problema (eq. 6.2), um programa computacional foi desenvolvido integrando o Epanet 2 (simulador hidráulico convencional) e a GAlib (módulo de otimização) em uma única rotina. As soluções obtidas através desse programa permitiram que comparações, com o trabalho de SIMPSON, DANDY e MURPHY (1994), fossem realizadas, com intuito de avaliar a performance do modelo integrado (otimização - GAlib e simulação hidráulica - Epanet 2). Além disso, esse programa permitiu o estudo das possibilidades de uso da GAlib (em termos de seus operadores), para que posteriormente fosse desenvolvida uma rotina de otimização multiobjetivo utilizando operadores convencionais dessa biblioteca.

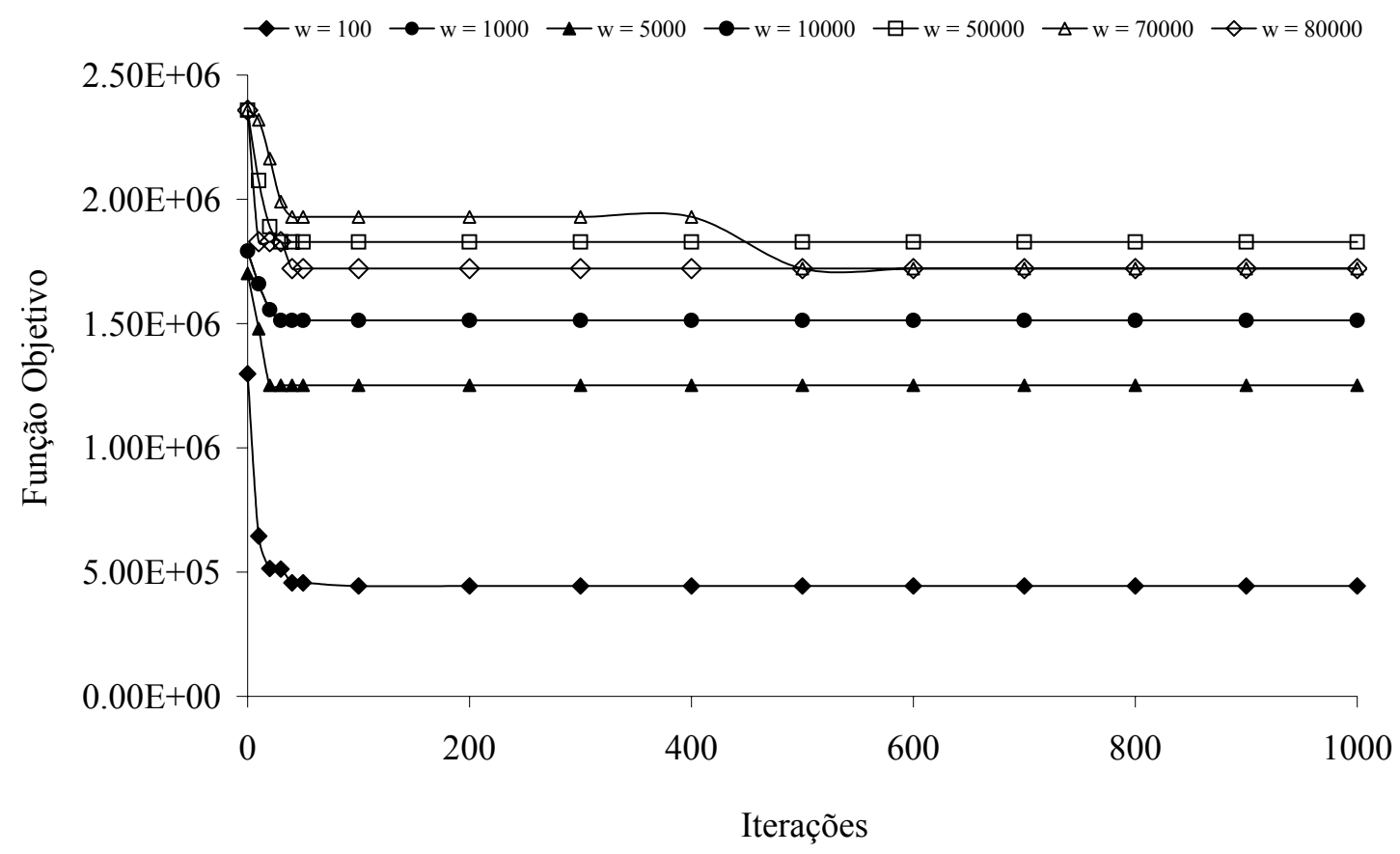

Figura 6.3 - Simulações da rede exemplo 1 com diferentes pesos

A Figura 6.3 apresenta os resultados de algumas simulações realizadas com o programa GAlib - Epanet 2, para rede exemplo 1, considerando o problema mencionado na eq.(6.2). O objetivo dessa ilustração foi demonstrar a dificuldade em se encontrar fatores penalidade adequados de forma que a solução ótima pudesse ser obtida. GESSLER (1985) foi quem propôs esse problema e o resolveu utilizando técnicas de 
enumeração parcial. A solução de mínimo custo encontrada por esse pesquisador foi \$1.833.744. SIMPSON, DANDY e MURPHY (1994) construíram dois programas para resolução desse problema. No primeiro programa, foi implementada a técnica de enumeração completa para obter a solução ótima global do problema. Cada vetor solução foi avaliado por uma rotina de análise hidráulica, construída pelos próprios autores, baseada na técnica de Newton-Raphson. SIMPSON, DANDY e MURPHY (1994) também construíram um programa baseado na técnica dos AGs. A solução de mínimo custo, encontrada por esses pesquisadores, utilizando ambos os programas (enumeração completa e algoritmos genéticos) foi \$1.750.300 ("mínimo global"). Para esse último caso (algoritmos genéticos) a solução de mínimo custo foi encontrada considerando um valor penalidade de $\mathrm{W}$ (eq. 6.2) igual a 70.000 .

Tabela 6.1 - Soluções de mínimo custo (GAlib - Epanet 2)

\begin{tabular}{cccc}
\hline \hline \multirow{2}{*}{ Simulação } & Pesos & \multicolumn{2}{c}{ Solução encontrada } \\
& W & \$ & Restrição \\
\hline 1 & 100 & $4.44 \mathrm{E}+05$ & 457 \\
2 & 1000 & $1.51 \mathrm{E}+06$ & 361 \\
3 & 2000 & $8.98 \mathrm{E}+05$ & 179 \\
4 & 3000 & $1.07 \mathrm{E}+06$ & 143 \\
5 & 4000 & $1.20 \mathrm{E}+06$ & 60 \\
6 & 5000 & $1.25 \mathrm{E}+06$ & 58 \\
7 & 6000 & $1.29 \mathrm{E}+06$ & 42 \\
8 & 7000 & $1.38 \mathrm{E}+06$ & 60 \\
9 & 8000 & $1.44 \mathrm{E}+06$ & 60 \\
10 & 9000 & $1.42 \mathrm{E}+06$ & 45 \\
11 & 10000 & $1.51 \mathrm{E}+06$ & 34 \\
12 & 20000 & $1.61 \mathrm{E}+06$ & 6 \\
13 & 30000 & $1.71 \mathrm{E}+06$ & 4 \\
14 & 40000 & $1.70 \mathrm{E}+06$ & 0 \\
15 & 50000 & $1.83 \mathrm{E}+06$ & 0 \\
16 & 60000 & $1.80 \mathrm{E}+06$ & 0 \\
17 & 70000 & $1.72 \mathrm{E}+06$ & 0 \\
18 & 80000 & $1.72 \mathrm{E}+06$ & 0 \\
19 & 90000 & $1.81 \mathrm{E}+06$ & 0 \\
\hline \hline
\end{tabular}

No presente trabalho (Tabela 6.1), a melhor solução obtida (mínimo custo) foi igual a $\$ 1.700 .000$, considerando $\mathrm{W}$ igual a 40.000 . Utilizando $\mathrm{W}$ igual a 70.000 , o valor de mínimo custo encontrado foi $\$ 1.720 .000$. As simulações realizadas para os pesos 40.000 e 70.000 satisfizeram à restrição de pressão mínima. Percebe-se que essas soluções estão abaixo da solução "ótima global" apontada por SIMPSON, DANDY e MURPHY (1994). Atribui-se a diferença entre a "solução global", obtida anteriormente pelos autores, e a solução de mínimo custo apresentada aqui, aos diferentes simuladores 
hidráulicos utilizados. A Tabela 6.1 apresenta os valores das soluções de mínimo custo, os pesos que foram atribuídos e os valores das restrições (atendida ou não), encontrados pelo programa desenvolvido (GAlib-Epanet 2).

Quando algoritmos genéticos são utilizados, no mínimo quatro parâmetros de entrada são necessários para o processo iterativo: dimensão da população, número máximo de gerações, probabilidade de recombinação e probabilidade de mutação. Para as simulações apresentadas na Tabela 6.1 esses parâmetros foram: 100, 1000, 0,9 e 0,02, respectivamente. Para todas as simulações, a população inicial foi gerada a partir da mesma semente aleatória $(7000)^{18}$.

A reabilitação de redes justifica-se quantitativamente através de análises comparativas entre as energias nos nós da rede para condição anterior à reabilitação e as energias nos nós da rede para condição posterior à reabilitação. Tais análises são apresentadas através das Figuras 6.4, 6.5 e 6.6. Esses gráficos apresentam as pressões nos nós da rede, referentes à solução de mínimo custo obtida pela simulação 14 (Tabela 6.1), as pressões nos nós da rede sem considerar reabilitação e as pressões mínimas requeridas para os cenários 1, 2 e 3 (Tabela 5.7), respectivamente. Para realizar a simulação hidráulica da rede exemplo 1 (Figura 5.18) foi necessário adotar diâmetros médios disponíveis (356 mm) para os trechos 6, 8, 11, 13 e 14 (trechos inexistentes - projeto) para representar uma situação similar à existente.

A Tabela 6.1 mostra diversas soluções alcançadas pelos algoritmos genéticos para diversos pesos. Todas essas soluções representam intervenções que podem ser implementadas na rede, possibilitando ao decisor do sistema escolher a solução que melhor lhe satisfaça. Por exemplo, se o órgão gestor do sistema decidir que o investimento na rede deva ser inferior a $\$ 1.700 .000$, existem alternativas (soluções) que podem satisfazer tal restrição, entretanto, o déficit de pressão aceitável pode ser violado em algum período do dia.

\footnotetext{
${ }^{18}$ A biblioteca GAlib oferece a possibilidade de influenciar o processo de evolução (atribuir um valor para a semente aleatória), possibilitando assim reproduzir as mesmas simulações. Isso não acontece quando o "relógio" do computador é utilizado como semente aleatória.
} 


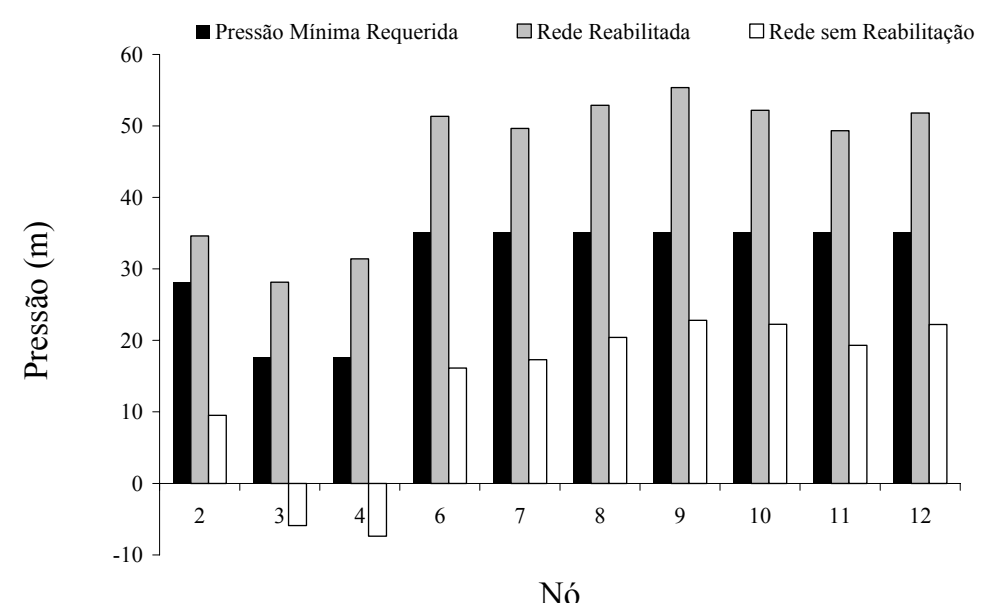

Figura 6.4 - Gráfico comparativo das pressões da rede para cenário 1

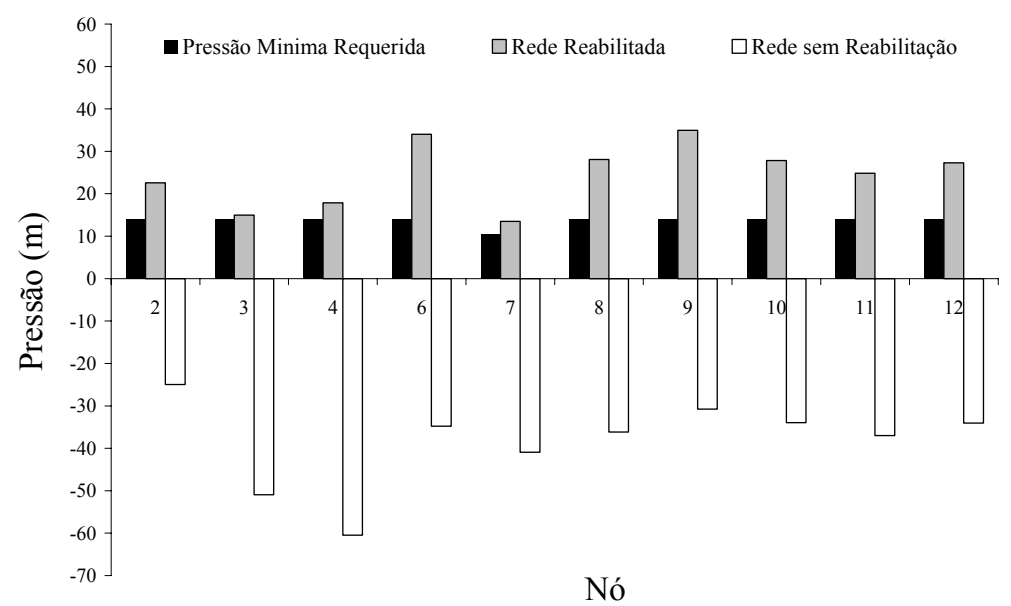

Figura 6.5 - Gráfico comparativo das pressões da rede para cenário 2

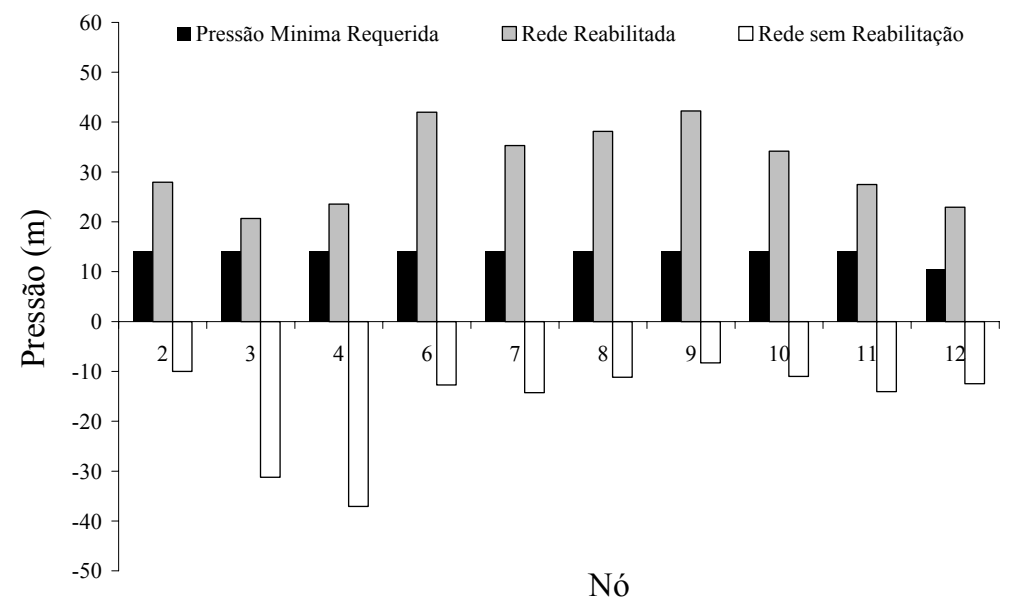

Figura 6.6 - Gráfico comparativo das pressões da rede para cenário 3 
Uma boa solução, para essa situação hipotética, seria a solução gerada pela simulação 12 que, além de satisfazer a restrição de investimento (menor que \$1.700.000), apresenta um déficit de pressão em torno de $6 \mathrm{~m}$ (aceitável para sistemas reais) em um determinado período do dia. Observe que para todos os cenários considerados (1, 2 e 3$)$ as energias da rede reabilitada representam valores acima da pressão mínima requerida e, portanto, déficit de pressão zero.

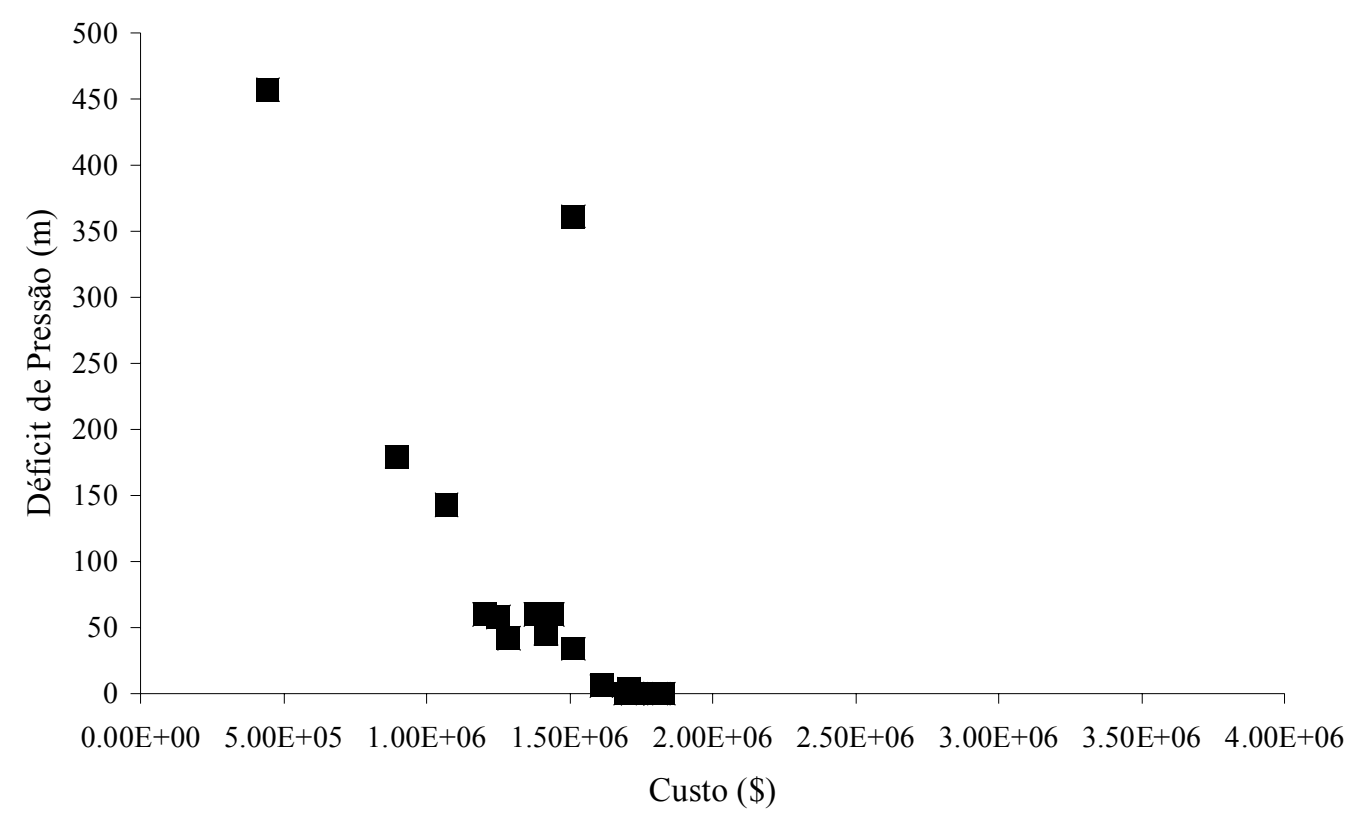

Figura 6.7 - Soluções obtidas pelos AGs considerando diferentes pesos

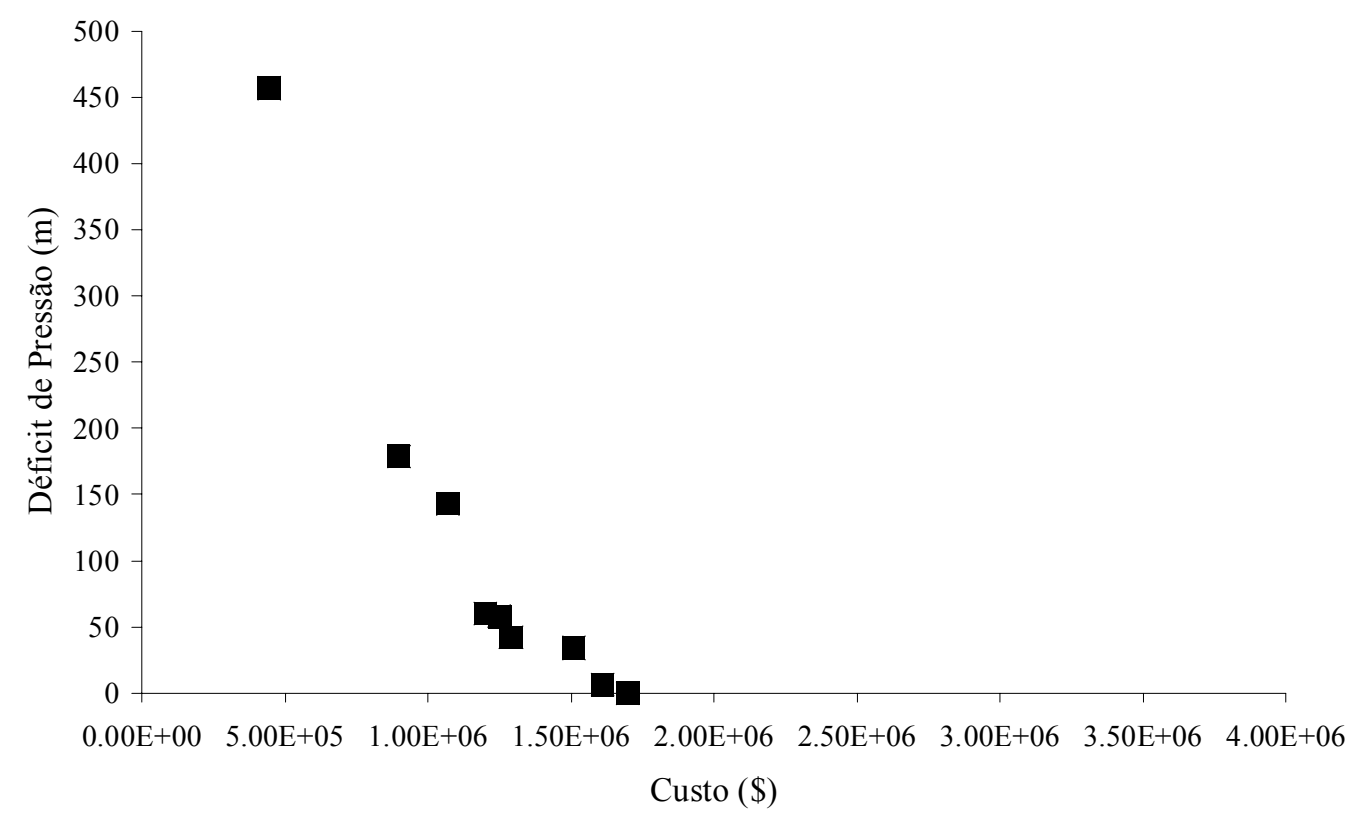

Figura 6.8 - Soluções obtidas pelos AGs considerando diferentes pesos 
Através dos dados da Tabela 6.1, considerando custo e déficit de pressão, foi possível construir uma curva de troca (Tradeoff) de todas as soluções encontradas nas 19 simulações. Essa curva (Figura 6.7) auxilia o decisor na tomada de decisão. Observa-se na Figura 6.7 uma tendência de esboço da frente Pareto. Entretanto, essa curva não pode ser considerada Pareto ótimo pois inclui soluções dominadas em seu conjunto. Uma frente Pareto ótimo, de acordo com conceito apresentado no capítulo 4 (eq. 4.4), deve apresentar apenas soluções não dominadas conforme ilustrada pela Figura 6.8, onde as soluções dominadas foram incluídas.

\subsubsection{Análises estatísticas de experimentos computacionais com AGs}

Uma das principais dificuldades na utilização dos AGs é determinar parâmetros de entrada adequados (dimensão da população, número máximo de gerações, probabilidade de recombinação e probabilidade de mutação) de forma a garantir que a solução obtida seja obtida. Em geral, pesquisadores realizam análises de sensibilidades como procedimento inicial de forma a identificar tais parâmetros.

Neste trabalho, uma metodologia científica foi buscada de forma a dar suporte à investigação dos fatores que mais interferem nesse processo (LIN e RARDIN, 1980; PETROVSKI, WILSON e McCALL, 1998), para que, posteriormente, apenas esses parâmetros possam ser avaliados criteriosamente.

As características estocásticas dos AGs estão presentes no processo de variação do método (busca por regiões do espaço inexploradas) através dos seus operadores genéticos (recombinação e mutação). Esses operadores desenvolvem um papel importante na eficiência do método. Infelizmente, não existe expressão analítica ou um modelo teórico que descreva a performance dos AGs em termos dos seus fatores (dimensão da população, número de gerações, probabilidade de recombinação e probabilidade de mutação). Uma maneira de estimar os efeitos que esses fatores promovem sobre a solução final é utilizar análises estatísticas (planejamentos fatoriais).

Neste trabalho, foi utilizado o planejamento composto central ortogonal (baseado nos planejamento $3^{\mathrm{k}}$ ), descrito no item (5.7.1.3), ao invés dos planejamentos fatoriais $2^{\mathrm{k}}$. Essa escolha se deve ao fato de que os planejamentos $2^{\mathrm{k}}$ permitem que se investiguem apenas dois níveis (alto e baixo) para um determinado fator k. Por exemplo, considere uma situação hipotética onde se quer conhecer a influência de um determinado fator $\mathrm{k}$ (por exemplo, probabilidade de recombinação) na solução final. Se for utilizado um 
planejamento fatorial $2^{\mathrm{k}}$, as análises ficariam restritas ao estudo de um nível alto (probabilidade de recombinação igual a 0,9) e de um nível baixo (probabilidade igual a $0,1)$. Observe que analisar apenas dois níveis seria injusto, uma vez que existem outros valores intermediários nesse intervalo importantes e que devem influenciar a resposta. Por isso, optou-se por utilizar planejamentos compostos centrais ortogonais (PCCO) que levam em consideração níveis intermediários entre o limite superior e o limite inferior.

Para se utilizar essa metodologia estatística (planejamento fatoriais) na análise dos fatores que mais interferem na solução ótima produzida pelo algoritmo de otimização, deve-se em primeiro lugar, escolher quais os fatores $\left(\mathrm{x}_{\mathrm{n}}\right)$ a serem analisados. Para $\mathrm{o}$ problema (eq. 6.2) proposto por GESSLER (1985), quatro fatores $(\mathrm{k}=4)$ foram escolhidos: o número máximo de gerações, a dimensão da população, a probabilidade de recombinação e a probabilidade de mutação. O próximo passo foi determinar, de acordo com os trabalhos da literatura que apresentam à aplicação de AGs nos problemas relacionados a sistemas de distribuição de água (SIMPSON, DANDY e MURPHY, 1994; REIS, PORTO e CHAUDHRY, 1997; HALHAL et al., 1997, WALTERS et al., 1999; SILVA, 2003; SOARES, 2003), os intervalos numéricos de cada fator k, descrito pelas eqs.(6.3), (6.4), (6.5) e (6.6).

Número máximo de gerações: $\quad \mathrm{x}_{1}^{\mathrm{c}} \rightarrow(100, \cdots, 5000)$

Dimensão da população: $\quad x_{2}^{c} \rightarrow(30, \cdots, 500)$

Probabilidade de recombinação: $\quad \mathrm{x}_{3}^{\mathrm{c}} \rightarrow(0,1, \cdots, 0,9)$

Probabilidade de mutação: $\quad \mathrm{x}_{4}^{\mathrm{c}} \rightarrow(0,01, \cdots, 0,2)$

Depois de determinados os fatores e os intervalos respectivos necessita-se codificar os níveis dos fatores para o planejamento. A codificação mais utilizada é $-1,0$ e 1 , considerando um planejamento $3^{\mathrm{k}}$, conforme descrito no item (5.7.1). Como neste trabalho foi utilizado o PCCO, além dos níveis intermediários $(-1,0$ e 1$)$ mais dois níveis $\left(-\mathrm{a}^{*}, \mathrm{a}^{*}\right)$ são determinados conforme descrito no item (5.7.1.3). A Tabela 6.2 apresenta os valores numéricos para os respectivos níveis.

Para construção da Tabela 6.3 é necessário atribuir para o nível zero (centro do planejamento) o valor numérico médio aproximado referente ao intervalo de cada fator 
(eqs. 6.3, 6.4, 6.5 e 6.6). O mesmo é feito para os níveis -1 e 1 , atribuindo valores equidistantes do centro do planejamento. Observe que para o primeiro fator $\left(\mathrm{x}_{1}^{\mathrm{c}}\right)$ a distância entre o nível -1 e 0 é 1800, o mesmo acontece entre o intervalo 0 e 1 (distância igual a 1800). Segundo MARTÍNEZ (2001) a codificação de um planejamento $3^{\mathrm{k}}$ é descrita pela eq.(6.7).

$$
x_{i}^{c}=\frac{x_{i}^{*}-\overline{x_{i}^{*}}}{s_{i}^{*}}
$$

sendo $\overline{\mathrm{x}}_{\mathrm{i}}^{*} \mathrm{o}$ valor médio entre os níveis $0,1 \mathrm{e}-1 ; \mathrm{s}_{\mathrm{i}}^{*}$ a distância equidistantes entres os níveis e $\mathrm{x}_{\mathrm{i}}^{*}$ os valores numéricos correspondentes ao intervalo da variável i. Por exemplo para i igual a 1 , com valor de $\mathrm{x}_{1}^{*}$ sendo $1200, \mathrm{x}_{1}^{*}$ sendo 3000 e $\mathrm{s}_{1}^{*}$ sendo 1800 tem-se $\mathrm{x}_{1}^{\mathrm{c}}$ igual -1 .

Tabela 6.2 - Codificação dos fatores referente ao problema (eq. 6.2)

\begin{tabular}{rccccc}
\hline \hline Fatores & $-\mathrm{a}^{*}$ & -1 & 0 & 1 & $\mathrm{a}^{*}$ \\
\hline $\mathrm{x}_{1}^{\mathrm{c}}$ & 480 & 1200 & 3000 & 4800 & 5520 \\
$\mathrm{x}_{2}^{\mathrm{c}}$ & 40 & 100 & 250 & 400 & 460 \\
$\mathrm{x}_{3}^{\mathrm{c}}$ & 0,08 & 0,2 & 0,5 & 0,8 & 0,92 \\
$\mathrm{x}_{4}^{\mathrm{c}}$ & 0,03 & 0,05 & 0,10 & 0,15 & 0,17 \\
\hline \hline
\end{tabular}

Para o cálculo dos outros níveis $\left(-\mathrm{a}^{*}, \mathrm{a}^{*}\right)$ do PCCO, a variável $\mathrm{x}_{\mathrm{i}}^{\mathrm{c}}$ assume um a valor conhecido (Tabela 5.13). Como para esse estudo assumiu-se uma análise de quatro fatores, os valores de -a ${ }^{*}$ e a ${ }^{*}$ são -1,4 e 1,4, respectivamente. Assim, pode-se determinar os valores correspondentes de $x_{i}^{*}$ na Tabela 6.2 .

Observe na Tabela 6.3 que da configuração 1 até a configuração 16 os dados se referem ao planejamento fatorial $2^{\mathrm{k}}$ completo, com $\mathrm{k}$ igual a 4 , na configuração 17 encontra-se o centro do planejamento e da configuração 18 até a configuração 25, essa parcela completa todo planejamento composto central ortogonal. Essa metodologia fornece o número exato das simulações a serem realizadas com suas respectivas combinações de parâmetros. 
Para cada combinação de fatores (mesmos parâmetros de entrada) pode-se repetir o experimento várias vezes (réplicas). $\mathrm{O}$ número necessário de réplicas não é determinado por essa metodologia. PETROVSKI, WILSON e McCALL (1998) utilizaram 50 réplicas para cada configuração (simulação). SRINIVAS e DEB (1995), comparando dois métodos evolucionários de otimização multiobjetivo, afirmaram que para uma comparação justa a população inicial dos dois algoritmos deveria ser igual (mesma semente aleatória).

Tabela 6.3 - Planejamento de simulações computacionais para rede exemplo 1

\begin{tabular}{|c|c|c|c|c|c|c|c|c|c|}
\hline $\begin{array}{l}\text { Configuração } \\
\text { (Simulação) }\end{array}$ & $\mathrm{x}_{1}^{\mathrm{c}}$ & $x_{2}^{c}$ & $x_{3}^{c}$ & $\mathrm{x}_{4}^{\mathrm{c}}$ & $\mathrm{x}_{1}^{*}$ & $x_{2}^{*}$ & $\mathrm{x}_{3}^{*}$ & $\mathrm{x}_{4}^{*}$ & $\begin{array}{l}\text { Variável Resposta } \\
\text { (Mínimo Custo) }\end{array}$ \\
\hline 1 & -1 & -1 & -1 & -1 & 1200 & 100 & 0,2 & 0,05 & $1.87 \mathrm{E}+06$ \\
\hline 2 & 1 & -1 & -1 & -1 & 4800 & 100 & 0,2 & 0,05 & $1.84 \mathrm{E}+06$ \\
\hline 3 & -1 & 1 & -1 & -1 & 1200 & 400 & 0,2 & 0,05 & $1.81 \mathrm{E}+06$ \\
\hline 4 & 1 & 1 & -1 & -1 & 4800 & 400 & 0,2 & 0,05 & $1.78 \mathrm{E}+06$ \\
\hline 5 & -1 & -1 & 1 & -1 & 1200 & 100 & 0,8 & 0,05 & $1.90 \mathrm{E}+06$ \\
\hline 6 & 1 & -1 & 1 & -1 & 4800 & 100 & 0,8 & 0,05 & $1.72 \mathrm{E}+06$ \\
\hline 7 & -1 & 1 & 1 & -1 & 1200 & 400 & 0,8 & 0,05 & $1.78 \mathrm{E}+06$ \\
\hline 8 & 1 & 1 & 1 & -1 & 4800 & 400 & 0,8 & 0,05 & $1.80 \mathrm{E}+06$ \\
\hline 9 & -1 & -1 & -1 & 1 & 1200 & 100 & 0,2 & 0,15 & $1.86 \mathrm{E}+06$ \\
\hline 10 & 1 & -1 & -1 & 1 & 4800 & 100 & 0,2 & 0,15 & $1.75 \mathrm{E}+06$ \\
\hline 11 & -1 & 1 & -1 & 1 & 1200 & 400 & 0,2 & 0,15 & $1.78 \mathrm{E}+06$ \\
\hline 12 & 1 & 1 & -1 & 1 & 4800 & 400 & 0,2 & 0,15 & $1.75 \mathrm{E}+06$ \\
\hline 13 & -1 & -1 & 1 & 1 & 1200 & 100 & 0,8 & 0,15 & $1.80 \mathrm{E}+06$ \\
\hline 14 & 1 & -1 & 1 & 1 & 4800 & 100 & 0,8 & 0,15 & $1.80 \mathrm{E}+06$ \\
\hline 15 & -1 & 1 & 1 & 1 & 1200 & 400 & 0,8 & 0,15 & $1.75 \mathrm{E}+06$ \\
\hline 16 & 1 & 1 & 1 & 1 & 4800 & 400 & 0,8 & 0,15 & $1.80 \mathrm{E}+06$ \\
\hline 17 & 0 & 0 & 0 & 0 & 3000 & 250 & 0,5 & 0,10 & $1.81 \mathrm{E}+06$ \\
\hline 18 & $-a^{*}$ & 0 & 0 & 0 & 480 & 250 & 0,5 & 0,10 & $1.81 \mathrm{E}+06$ \\
\hline 19 & $a^{*}$ & 0 & 0 & 0 & 5520 & 250 & 0,5 & 0,10 & $1.85 \mathrm{E}+06$ \\
\hline 20 & 0 & $-a^{*}$ & 0 & 0 & 3000 & 40 & 0,5 & 0,10 & $1.86 \mathrm{E}+06$ \\
\hline 21 & 0 & $\mathrm{a}^{*}$ & 0 & 0 & 3000 & 460 & 0,5 & 0,10 & $1.72 \mathrm{E}+06$ \\
\hline 22 & 0 & 0 & $-a^{*}$ & 0 & 3000 & 250 & 0,08 & 0,10 & $1.75 \mathrm{E}+06$ \\
\hline 23 & 0 & 0 & $\mathrm{a}^{*}$ & 0 & 3000 & 250 & 0,92 & 0,10 & $1.75 \mathrm{E}+06$ \\
\hline 24 & 0 & 0 & 0 & $-a^{*}$ & 3000 & 250 & 0,5 & 0,03 & $1.75 \mathrm{E}+06$ \\
\hline 25 & 0 & 0 & 0 & $\mathrm{a}^{*}$ & 3000 & 250 & 0,5 & 0,17 & $1.72 \mathrm{E}+06$ \\
\hline
\end{tabular}


No caso da Tabela 6.3, para cada combinação de parâmetros (número máximo de gerações, dimensão da população, probabilidade de recombinação e probabilidade de mutação) cinco réplicas foram realizadas. Cada réplica partiu de cinco sementes aleatórias distintas. Assim, a variável resposta (solução mínimo custo) foi definida como sendo a média das cinco soluções de mínimo custo produzidas pelo programa (GAlib - Epanet 2).

Tabela 6.4 - Resultados PCCO

\begin{tabular}{|c|c|c|c|c|}
\hline Fator & Efeito & Coeficiente & Valor $\mathrm{t}$ & Valor $p$ \\
\hline Constante & 1773616 & 26290 & 67,463 & 0 \\
\hline $\mathrm{x}_{1}^{\mathrm{c}}$ & -17851 & 13941 & $-1,281$ & 0,229 \\
\hline$x_{?}^{c}$ & -34157 & 13941 & $-2,45$ & 0,034 \\
\hline$x_{3}^{c}$ & -6325 & 13941 & $-0,454$ & 0,660 \\
\hline $\mathrm{X}_{4}^{\mathrm{c}}$ & -17711 & 13941 & $-1,27$ & 0,233 \\
\hline $\mathrm{x}_{1}^{\mathrm{c}} * \mathrm{x}_{1}^{\mathrm{c}}$ & 65301 & 31180 & 2,094 & 0,063 \\
\hline$x_{2}^{c} * x_{2}^{c}$ & 25301 & 31180 & 0,811 & 0,436 \\
\hline$x_{3}^{c} * x_{3}^{c}$ & -14699 & 31180 & $-0,471$ & 0,647 \\
\hline $\mathrm{x}_{4}^{\mathrm{c}} * \mathrm{x}_{4}^{\mathrm{c}}$ & -29699 & 31180 & $-0,952$ & 0,363 \\
\hline$x_{1}^{c} * x_{2}^{c}$ & 40425 & 21777 & 1,856 & 0,093 \\
\hline$x_{1}^{c} * x_{3}^{c}$ & 11025 & 21777 & 0,506 & 0,624 \\
\hline $\mathrm{x}_{1}^{\mathrm{c}} * \mathrm{x}_{4}^{\mathrm{c}}$ & 15925 & 21777 & 0,731 & 0,481 \\
\hline $\mathrm{x}_{2}^{\mathrm{c}} * \mathrm{x}_{3}^{\mathrm{c}}$ & 13475 & 21777 & 0,619 & 0,550 \\
\hline $\mathrm{x}_{2}^{\mathrm{c}} * \mathrm{x}_{4}^{\mathrm{c}}$ & 3675 & 21777 & 0,169 & 0,869 \\
\hline $\mathrm{x}_{3}^{\mathrm{c}} * \mathrm{x}_{4}^{\mathrm{c}}$ & 13475 & 21777 & 0,619 & 0,550 \\
\hline
\end{tabular}

Analisando os resultados obtidos (soluções de mínimo custo) correspondentes às diferentes combinações de fatores consideradas na Tabela 6.3 através do software de análise estatística MINITAB (versão demonstrativa) foi possível construir a Tabela 6.4, através do planejamento composto central ortogonal (item 5.8.1).

Através dessa metodologia (PETROVSKI, WILSON e McCALL, 1998) foi possível analisar os fatores e os efeitos das variáveis dependentes sobre a variável independente utilizando análise de variância, considerando termos lineares, termos quadráticos e iterações entre os termos. 
A Tabela 6.4 apresenta o resultado do MINITAB. O valor de $\mathrm{p}$ representa a significância da variável dependente ou da combinação de variáveis (no caso de efeito quadrático) na solução final. Segundo HAIR (1998) valores de p pequenos, por exemplo, p igual a $0,034\left(x_{2}^{c}\right)$ e p igual a $0,063\left(x_{1}^{c} * x_{1}^{c}\right)$, indicam efeito significativo na solução final. $\mathrm{O}$ valor de t é um teste estatístico que avalia a significância das variáveis sobre o modelo estatístico inferido. Por exemplo, avaliar o quanto o(s) coeficiente(s) de regressão (Tabela 6.4) interfere no processo. O efeito é uma medida que exerce a mesma função do valor de t, no entanto, tal valor é parametrizado como forma de visualizar os valores em outras escalas.

Pode-se então afirmar que, para o problema estudado, a dimensão da população ( $\mathrm{p}=$ 0,034) e o número máximo de gerações $(\mathrm{p}=0,063)$ são os fatores mais interferem na resposta e devem ser investigados criteriosamente. Vale ressaltar que o efeito significativo referente ao número de gerações, apresentado pelas análises, foi o efeito quadrático $\left(\mathrm{x}_{1}^{\mathrm{c} *} \mathrm{x}_{1}^{\mathrm{c}}\right)$.

\subsection{Análise de reabilitação através da otimização multiobjetivo - estudo teórico}

Uma das formas de considerar restrições nos AGs é incorporá-las à função objetivo na forma de penalidades. Em muitos problemas de engenharia, essa aproximação tem possibilitado bons resultados, embora (funções penalidade) possua limitações bem conhecidas, como a necessidade de adequação dos pesos (discutidos na Figura 6.3) e o custo computacional envolvido. Geralmente, esse ajuste é feito por tentativa e erro, conforme resultados apresentados na Tabela 6.1.

O problema de reabilitação da rede exemplo 1 (eq. 6.1), inicialmente equacionado como sendo de objetivo único, foi reformulado como um problema de otimização multiobjetivo, passando então a ter dois objetivos a serem alcançados simultaneamente: minimização de custos, descrito pela eq. (6.1), e minimização do déficit de pressão, descrito pela eq.(6.8).

Minimizar déficit de pressão, $F_{2}=\sum_{i=1}^{N P D} \max \left(\sum_{j=1}^{\pi} H_{j}^{\min }-H_{j}\right)_{i}$

sendo i o índice que varia de acordo com o número de padrões de demanda; NPD denota o número total de padrões de demanda considerado; $\pi$ o conjunto de nós que 
apresentam pressões abaixo da mínima; $\mathrm{H}$ representa a energia no nó $\mathrm{j}$ e $\mathrm{H}^{\mathrm{min}}$ representa a energia mínima requerida no nó j (Tabela 5.7).

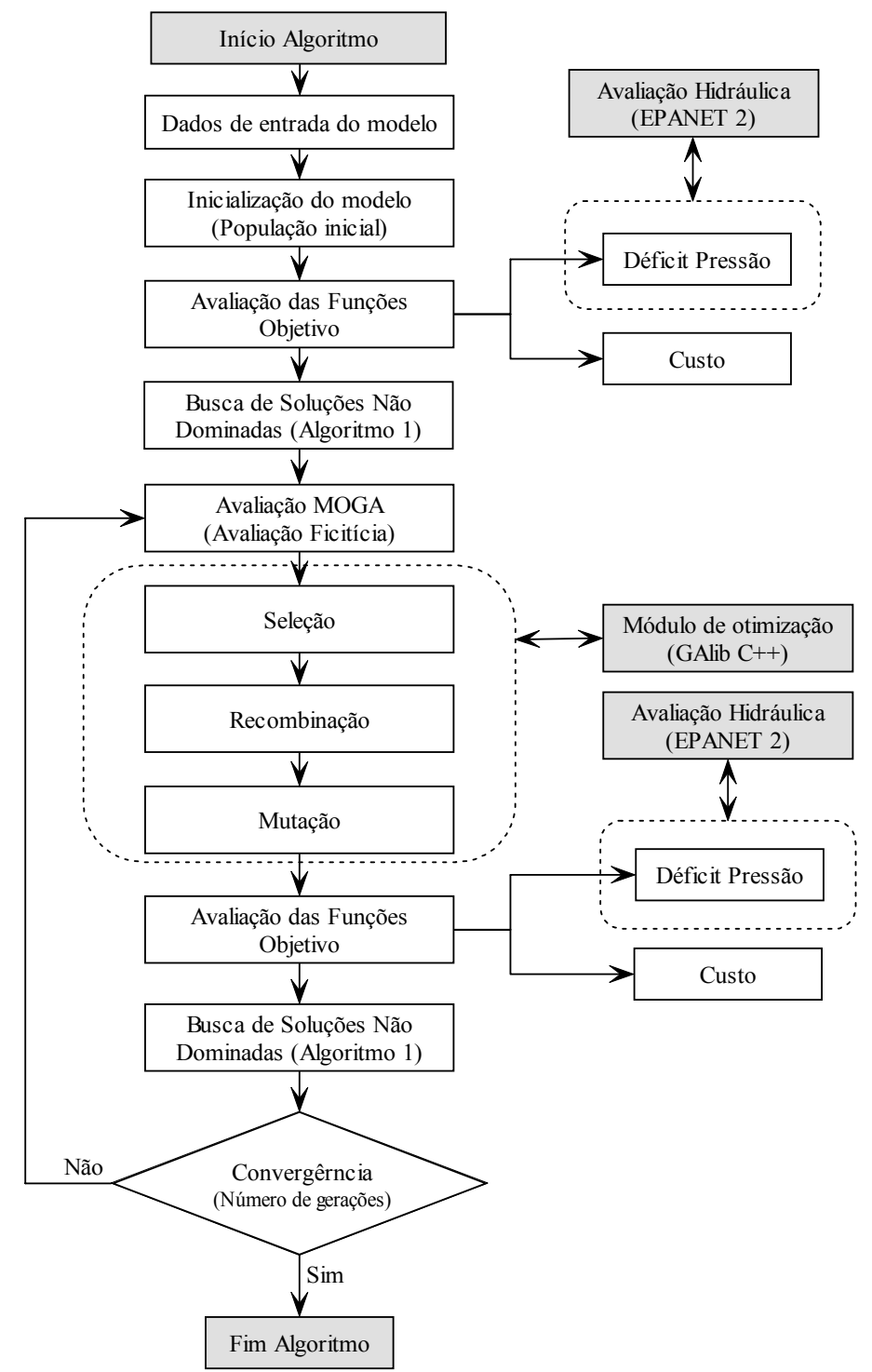

Figura 6.9 - Fluxograma do programa desenvolvido para reabilitação de redes considerando dois objetivos (custo e déficit de pressão) utilizando o MOGA como método de otimização multiobjetivo

Apesar de muitos objetivos poderem ser incorporados na análise de reabilitação de redes, nesse item, optou-se por formular o problema considerando dois objetivos (incorporando a restrição como objetivo), como forma de comparar os resultados obtidos pela otimização de objetivo único, que utilizou uma combinação de pesos (Figura 6.8). Através dessa formulação foi possível também investigar os métodos de otimização multiobjetivo e os operadores de recombinação e mutação apropriados ao problema. 
Para avaliação simultânea das funções objetivo (eq. 6.1 e eq. 6.8), referentes ao problema da rede exemplo 1, foi implementado um programa computacional em $\mathrm{C}++$ baseado no método de otimização multiobjetivo MOGA descrito no item (5.41). Esse programa foi construído com suporte das rotinas da biblioteca GAlib (operadores de seleção, recombinação e mutação) e do simulador hidráulico convencional (Epanet 2).

Na otimização multiobjetivo através de algoritmos evolucionários, a etapa de avaliação difere dos algoritmos genéticos convencionais. Assim, foi necessário também implementar um algoritmo de busca de soluções não dominadas. Esse algoritmo é encontrado no APÊNDICE A (Algoritmo 1) deste trabalho. A Figura 6.9 apresenta o fluxograma do programa desenvolvido, mostrando os módulos que cada rotina executa. É importante ressaltar que só foi possível construir esse modelo integrado, pois tanto a GAlib como o Epanet 2 estão em linguagens $\mathrm{C}++$ e $\mathrm{C}$, respectivamente.

A Figura 6.10 apresenta os resultados de uma simulação do programa MOGA - Epanet 2 considerando uma população de 100 soluções, um número de gerações igual a 500, probabilidade de recombinação igual a 0,9 e probabilidade de mutação igual 0,1 . Através dessa ilustração, demonstra-se a evolução das populações da geração inicial até a geração final. Nessa mesma ilustração (Figura 6.10), é possível identificar uma convergência prematura caso o número de gerações adotado fosse 250 . Outro fato evidenciado foi a perda de soluções pertencentes à geração 250 quando comparada com as soluções referentes à geração 500. Nesse caso, a perda de soluções é decorrente da aplicação dos operadores genéticos (recombinação e mutação) sobre o conjunto referente à última geração.

Uma forma alternativa de evitar a perda dessas soluções e melhorar a distribuição de soluções na frente Pareto é criar um conjunto externo que armazene todas as soluções não dominadas encontradas durante o processo iterativo, sendo que, no final, apenas as soluções não dominadas estejam contidas nesse conjunto (algoritmo de busca de soluções não dominadas). Essa proposição foi implementada no programa MOGA Epanet 2 e representou uma melhoria (Figura 6.11) quando comparada com as frentes produzidas pela Figura 6.10, que não considera o conjunto externo. Observe que a frente Pareto obtida através do conjunto externo apresentou soluções correspondentes a pontos da curva que a frente obtida sem o conjunto (Figura 6.10) externo não conseguiu explorar. Pode-se concluir que a frente Pareto obtida através do conjunto externo 
apresenta maior diversidade de soluções que aquela obtida sem considerar esse conjunto.

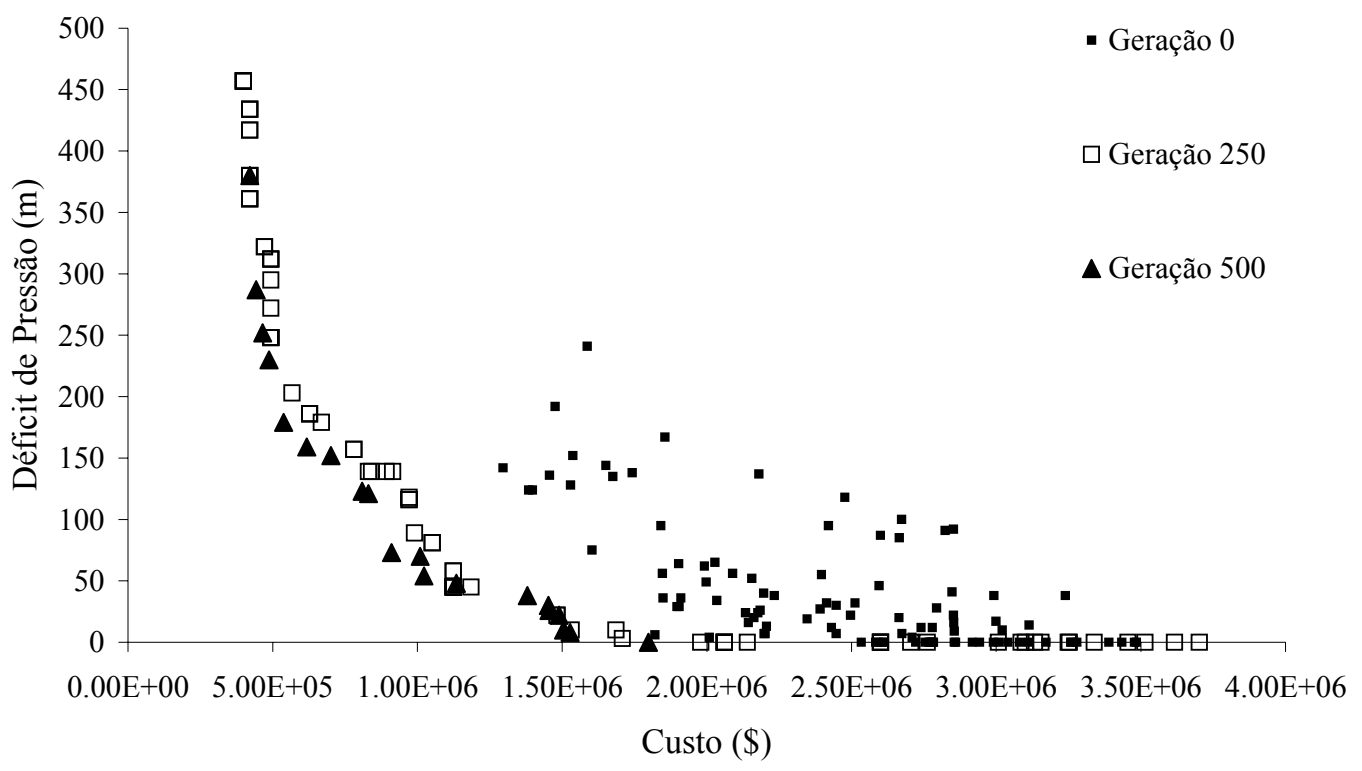

Figura 6.10 - Diferentes populações produzidas pelo MOGA

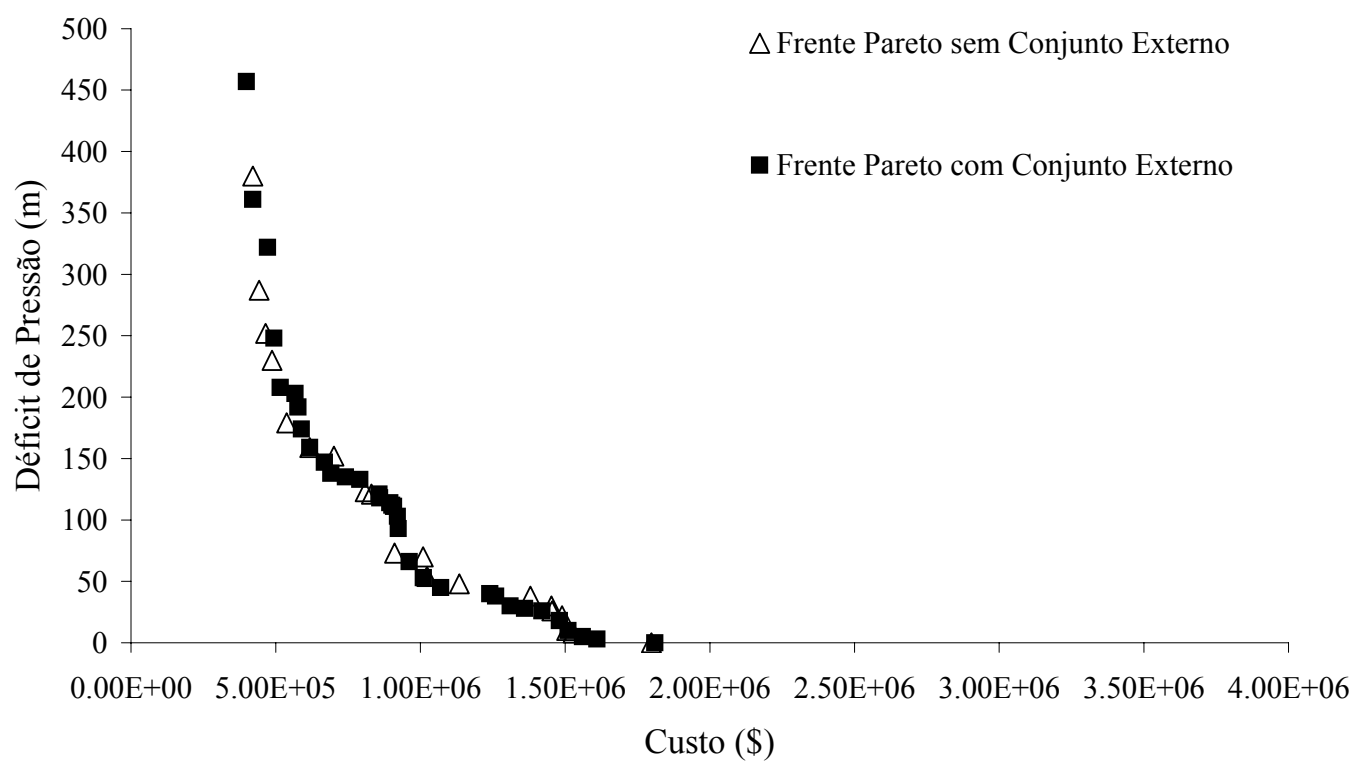

Figura 6.11 - Comparação de Frentes Pareto obtidas pelo MOGA

Uma comparação foi realizada entre a frente Pareto produzida através da otimização multiobjetivo (Figura 6.11) e a frente produzida através da otimização de objetivo único (Figura 6.8). Nota-se, portanto, uma vantagem significativa (distribuição de soluções na frente) em se utilizar à otimização multiobjetivo ao invés da otimização de objetivo 
único. A otimização multiobjetivo fornece maior flexibilidade ao decisor, uma vez que uma diversidade maior de alternativas é produzida. A otimização multiobjetivo considerando dois objetivos consumiu tempo de processamento bem inferior ao da otimização de objetivo único. Na situação de objetivo único, 19 simulações foram necessárias para gerar a frente ilustrada pela Figura 6.8. Na otimização multiobjetivo apenas uma simulação foi necessária para obter as frentes ilustradas na Figura 6.11.

\subsubsection{Comparações de métodos de otimização multiobjetivo}

Como já mencionado anteriormente, existe uma tendência em utilizar algoritmos evolucionários para problemas de otimização envolvendo objetivos múltiplos. A literatura reporta a existência de diversos métodos capazes de buscar em uma única simulação as soluções ótimas Pareto. Entretanto, a escolha do método mais eficiente não é uma tarefa fácil. Na Ciência da Computação, área na qual tais métodos vêm sendo difundidos, ainda existem poucos estudos comparativos (SRINIVAS e DEB, 1995; ZITZLER e THIELE, 1998; TAN, LEE e KHOR, 2001; DEB et al., 2002; CHEUNG et al., 2003).

Neste trabalho, quatro métodos evolucionários de otimização multiobjetivo (MOGA, NSGA, SPEA e NSGA II) foram investigados. DEB et al. (2002) reportam que para se comparar tais métodos é necessário que no mínimo duas métricas de performance (convergência e distribuição) sejam avaliadas. Visando à avaliação dos algoritmos, várias simulações foram desenvolvidas empregando MOGA, NSGA, SPEA e NSGA II, partindo das mesmas cinco populações iniciais distintas e considerando o problema de reabilitação da rede exemplo 1 (Figura 5.18) com dois objetivos (eqs. 6.1 e 6.8). Segundo SRINIVAS e DEB (1995) cinco populações iniciais distintas são consideradas satisfatórias para se comparar métodos, lembrando que os mesmos devem partir das mesmas populações iniciais.

Os resultados do MOGA foram produzidos através do programa descrito no item anterior (Figura 6.9). Os resultados do NSGA, SPEA e NSGA II foram obtidos utilizando a biblioteca MOMHLib++ (descrita no item 5.6) acoplada ao simulador hidráulico convencional (Epanet 2). Três operadores de recombinação (Linear, BLX- $\alpha$ e Uniforme) e três operadores de mutação (Limite, Aleatória e Dinâmica) foram implementados e investigados aqui, conforme descrito no item 5.6.1. Os resultados das 
simulações, referentes à métrica que avalia a convergência das frentes Pareto (Set Coverage Metric), são apresentadas através de gráficos Boxplot ${ }^{19}$.

A Figura 6.12 apresenta o esquema de construção de um Boxplot. As letras A e B denotam os métodos que estão sendo comparados (p.ex. MOGA e NSGA). Como cada método parte de cinco populações distintas, para cada configuração adotada (dimensão de população, número de gerações, probabilidade de recombinação e probabilidade de mutação), cinco frentes Pareto são obtidas (FR). Assim, é possível obter 25 medidas de $\mathrm{C}$ e construir os gráficos Boxplot. Esses gráficos medem a variabilidade dos valores de C.

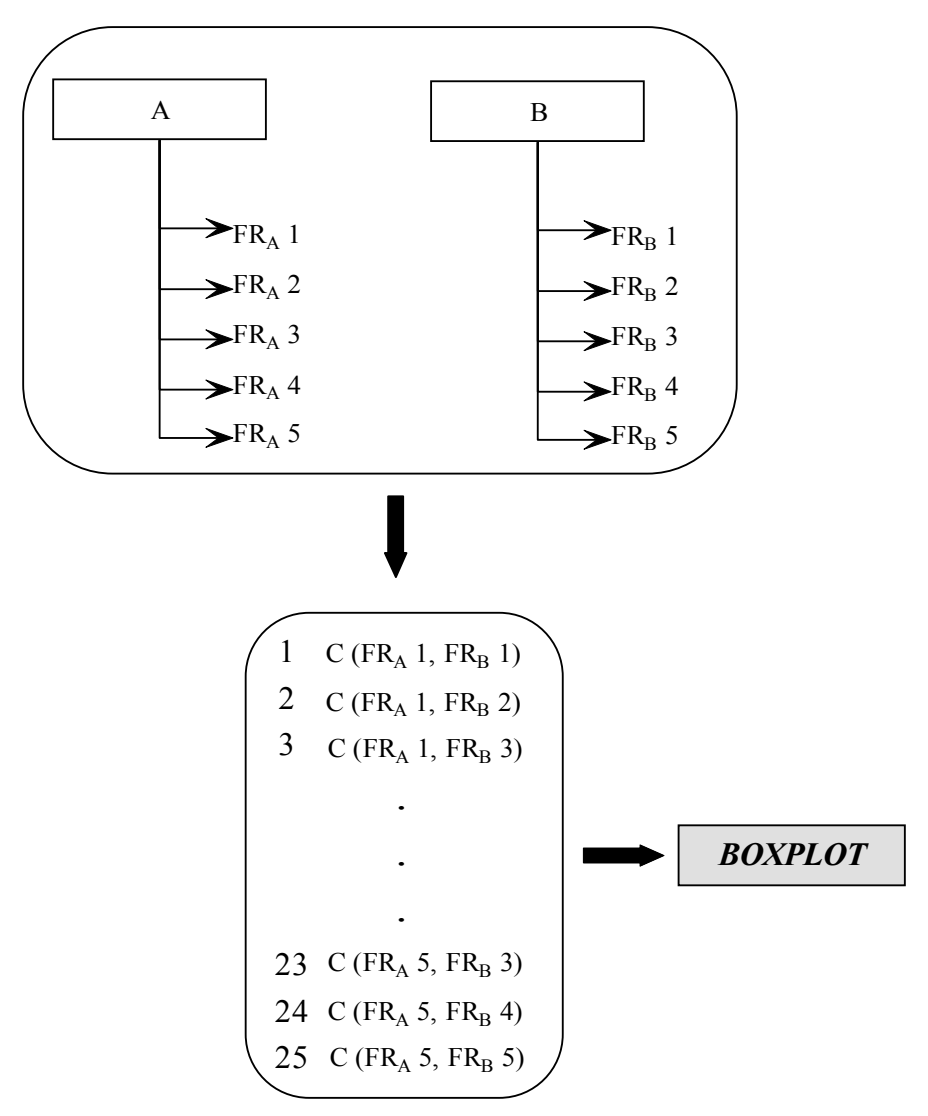

Figura 6.12 - Esquema explicativo de construção de um BOXPLOT

Partindo do pressuposto que os parâmetros que mais afetam os algoritmos evolucionários (item 6.1.1) são a dimensão da população e o número de gerações, análises de sensibilidades foram realizadas com objetivo de identificar os parâmetros mais adequados ao problema. O estudo do número máximo de gerações foi desenvolvido por CHEUNG et al. (2003) para esse mesmo estudo de caso (rede

\footnotetext{
${ }^{19}$ Os gráficos Boxplot são ilustrações gráficas que representam os valores do quartil inferior, da mediana e do quartil superior de uma amostra de dados (Manual do MATLAB 6.0).
} 
exemplo 1 - dois objetivos) e os resultados obtidos demonstraram que um número máximo de gerações igual a 200, produz frentes Pareto eficientes para o problema em questão.

A Figura 6.13 apresenta os resultados da métrica $C$ (item 5.6.1), para os diferentes métodos considerados (MOGA, NSGA, SPEA e NSGA II), através de Boxplot. Para tais simulações foram adotados os seguintes parâmetros de entrada: dimensão de população variável igual a 100, 200 e 300, número máximo de gerações igual a 500, probabilidade de recombinação igual a 0,9 , probabilidade de mutação igual a 0,1 . Uma vez que cinco simulações foram realizadas, para cada configuração considerada (MOGA 100, MOGA 200, MOGA 300, NSGA 100, NSGA 200, NSGA 300, SPEA 100, SPEA 200, SPEA 300, NSGA II 100, NSGA II 200, NSGA II 300), e que cada algoritmo partiu das mesmas cinco populações iniciais, as comparações em termos da métrica $C$, foram obtidas (Figura 6.12) considerando todos as combinações possíveis de frentes.

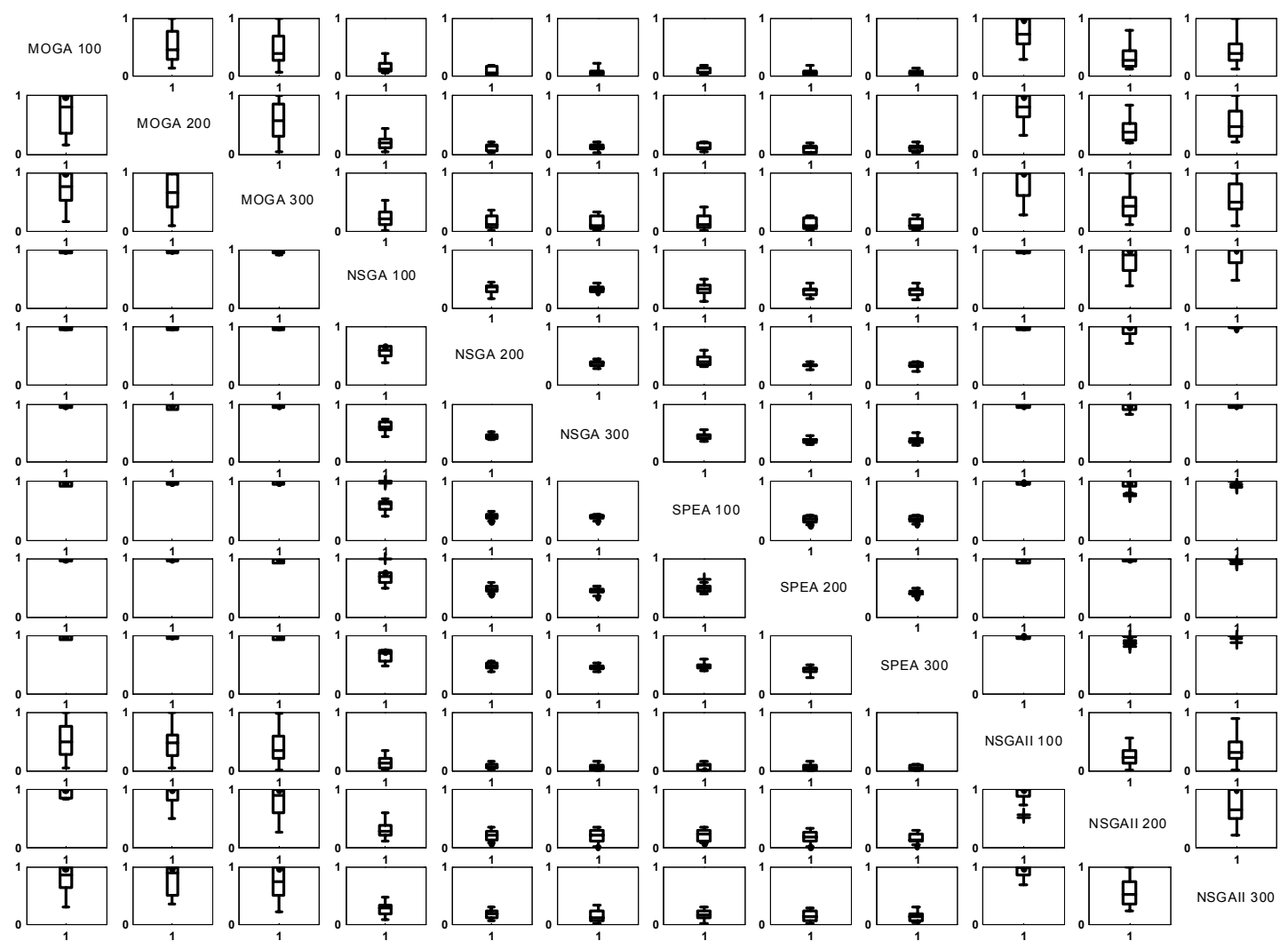

Figura 6.13 - Valores da métrica C (A,B), descrita no item (5.6.1), para quatro métodos multiobjetivo (MOGA, NSGA, SPEA e NSGA II)

Conforme apresentado na eq.(5.41), a métrica $\mathrm{C}(\mathrm{A}, \mathrm{B})$ apresenta valor igual a 1 quando toda população de B é dominada pela população de A. Observando a Figura 6.13 e comparando o MOGA (Método A) em relação aos demais métodos (Métodos B), 
sempre avaliando linha em relação a coluna, percebe-se que tanto o NSGA quanto o SPEA dominam as soluções do MOGA, pois o MOGA apresenta valores de C próximos de zero, enfatizando que suas soluções não dominam as soluções do NSGA e do SPEA. O mesmo não acontece quando se compara o MOGA em relação ao NSGA II.

Comparando-se o NSGA e o SPEA com o NSGA II, constata-se que ambos os métodos produzem soluções que dominam as soluções do NSGA II. Portanto, tanto o NSGA como o SPEA apresentou boa eficiência quanto à convergência da frente. Entretanto, nada se pode afirmar enquanto não for avaliada a métrica de distribuição da frente. As Figuras 6.14, 6.15 e 6.16 apresentam os resultados da métrica $S$ (item 5.7.2) que avalia a distribuição das soluções na frente Pareto. Quanto menor o valor de S, melhor distribuída estarão as soluções ao longo da frente (DEB, 2001). Os valores de S também são apresentadas em termos de gráficos Boxplots e demonstram a variabilidade das medidas. Os valores (1, 2, 3 e 4) no eixo horizontal das Figuras 6.14, 6.15 e 6.16, referem-se respectivamente aos métodos (MOGA, NSGA, SPEA, NSGA II) avaliados.

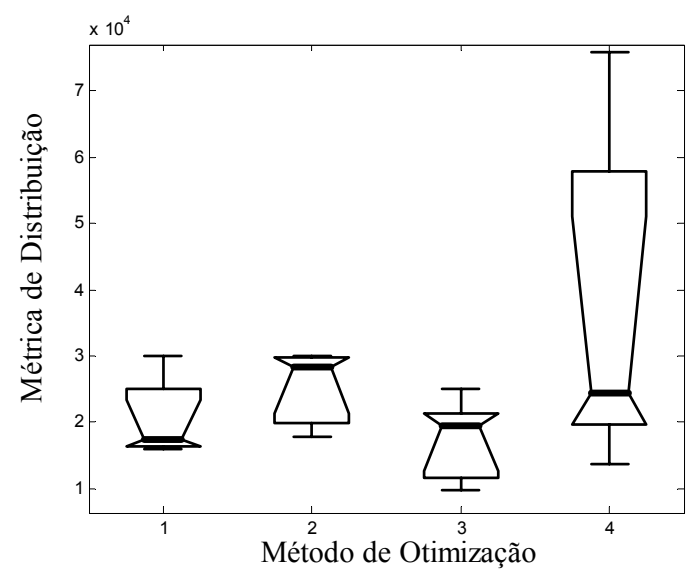

Figura 6.14 - Métrica de distribuição considerando a dimensão da população igual a 100

Através das Figuras 6.14, 6.15 e 6.16 pode-se afirmar que o NSGA II apresentou maiores desvios em termos da métrica S. O MOGA também apresentou grandes desvios quando comparados com o NSGA e o SPEA. Já o SPEA, apresentou os menores desvios e demonstrou ser um método eficiente em relação à convergência (Métrica $\mathrm{C}$ ) e a distribuição das soluções na frente Pareto (Métrica S).

Como forma de ilustrar os resultados das simulações, os gráficos das frentes Pareto, referente aos quatro métodos (MOGA, NSGA, SPEA e NSGA II) avaliados, foram construídos (Figuras 6.17-6.20). Todas essas frentes correspondem o caso em que a 
dimensão da população foi igual 200 e com a mesma semente aleatória. Observa-se que tanto o NSGA como o SPEA, apresentaram soluções melhores distribuídas do que o MOGA e o NSGA II. Na realidade essa inspeção visual reforça os resultados obtidos pela métrica $\mathrm{S}$ (Figura 6.15).

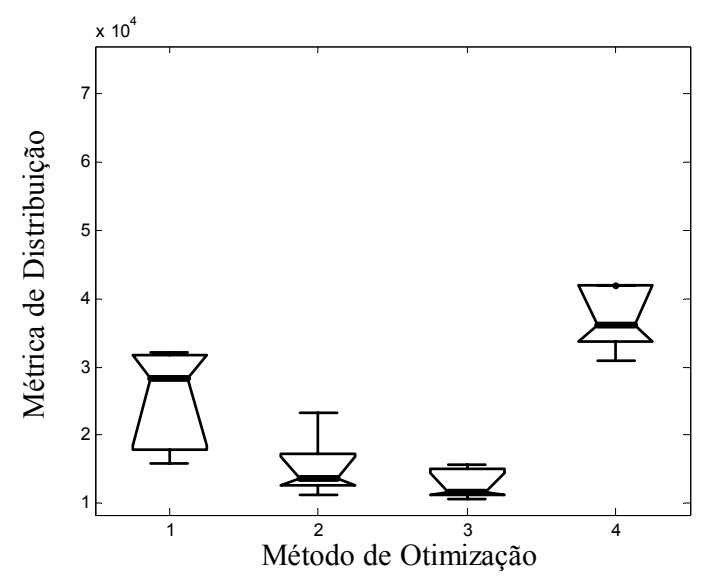

Figura 6.15 - Métrica de distribuição considerando a dimensão da população igual a 200

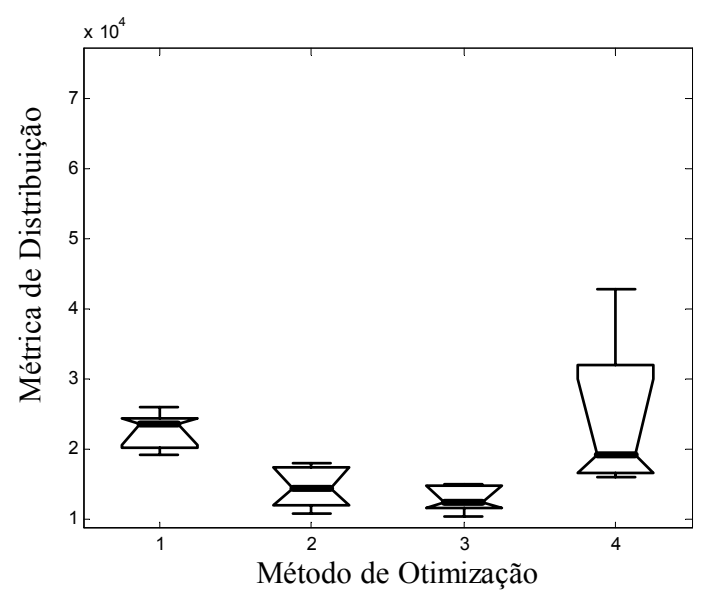

Figura 6.16 - Métrica de distribuição considerando a dimensão da população igual a 300

Depois de identificado o método mais eficiente (SPEA) para o problema de análise de reabilitação de redes de distribuição de água considerando objetivos múltiplos, foram realizados estudos em relação aos operadores genéticos, de recombinação e de mutação, com intuito de identificar os mais adequados ao problema. Para isso, três operadores de recombinação e três operadores de mutação foram considerados. Esses operadores foram descritos no item 5.6.1 do presente trabalho. 


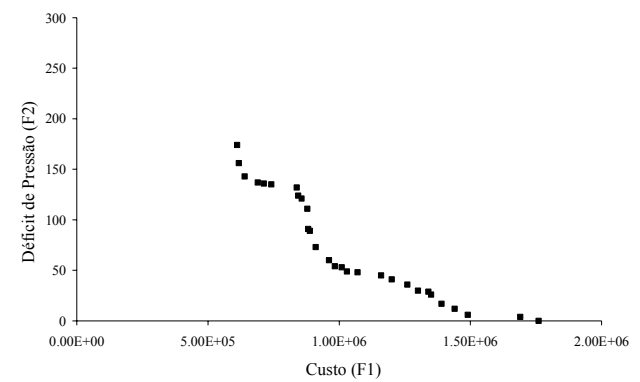

Figura 6.17 - Frente Pareto MOGA

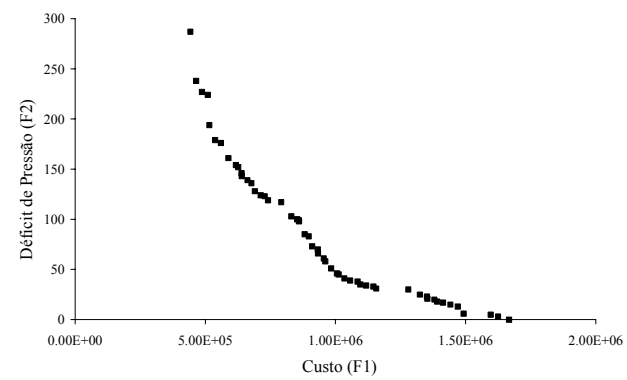

Figura 6.19 - Frente Pareto SPEA

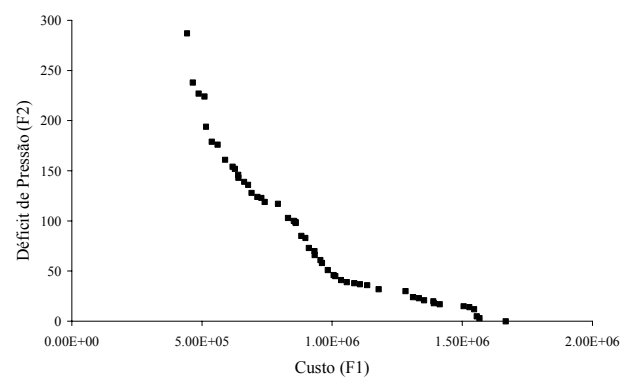

Figura 6.18 - Frente Pareto NSGA

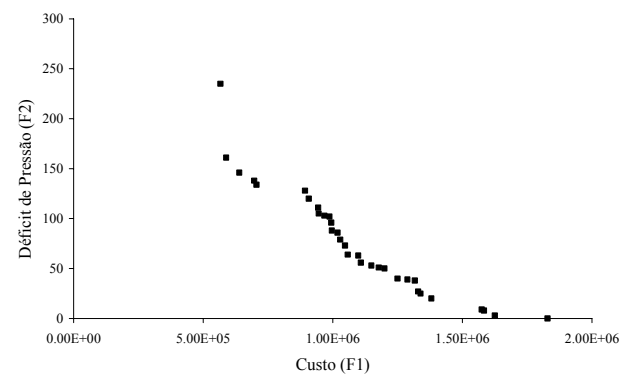

Figura 6.20 - Frente Pareto NSGA II

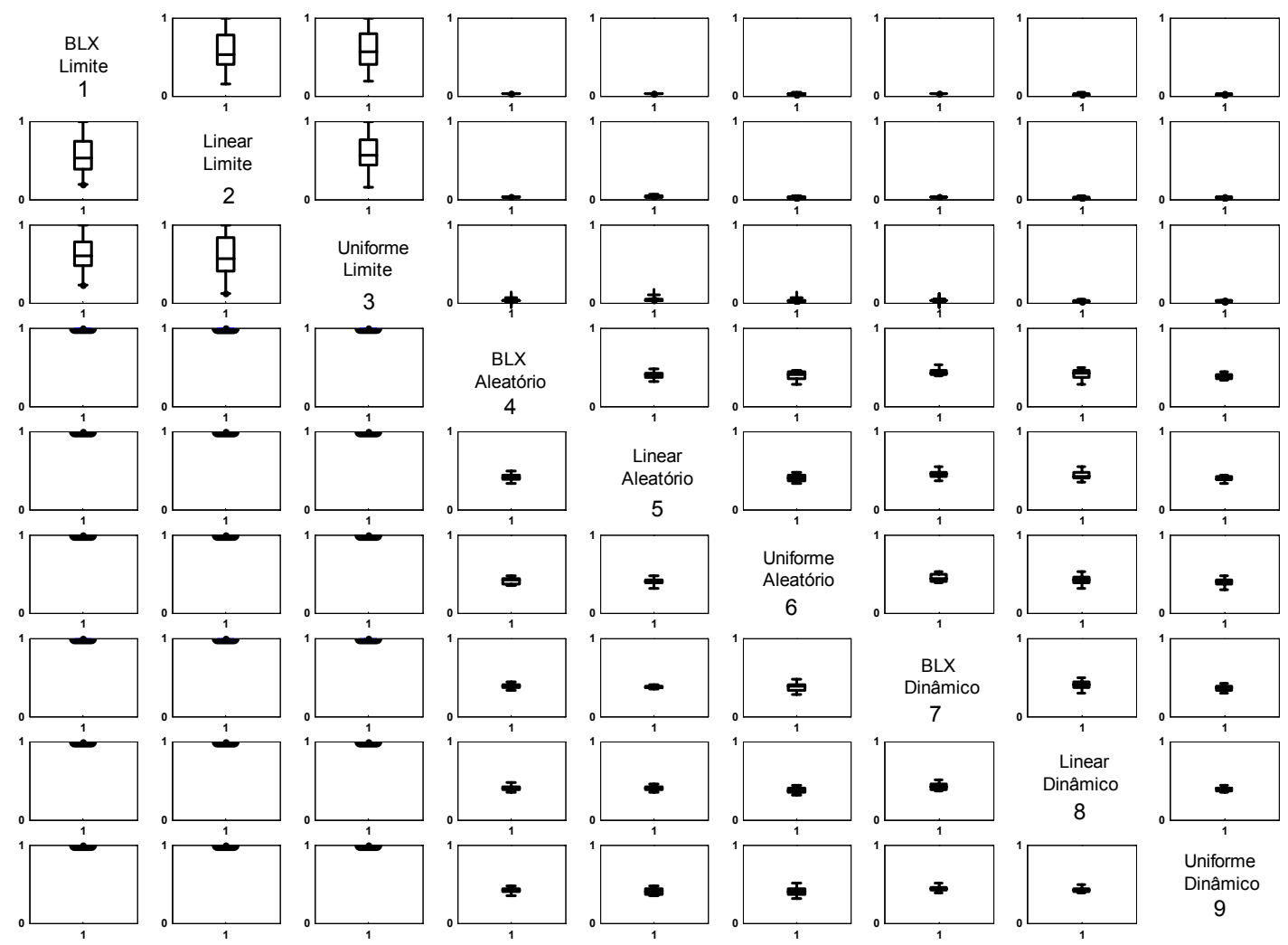

Figura 6.21 - Valores da métrica C (A,B) para SPEA considerando vários operadores genéticos A Figura 6.21 apresenta os valores da métrica $C$ para as nove combinações de operadores consideradas. Esses valores foram obtidos seguindo o mesmo procedimento mostrado na Figura 6.12. Para esse estudo, o método utilizado foi o SPEA com 
configurações de operadores (recombinação e mutação) distintos. Por exemplo, a configuração 1 representa a aplicação do algoritmo SPEA simulado com operador de recombinação BLX e operador de mutação Limite. Os parâmetros de entrada para todos os nove casos foram: dimensão da população igual a 200, número de gerações igual a 500, probabilidade de recombinação 0,9 e probabilidade de mutação 0,1 .

A inspeção da Figura 6.21 permite que se conclua que se todas as soluções Pareto produzidas pelas configurações 1, 2 e 3 (mutação Limite) foram dominadas pelas demais $(4,5,6,7,8$ e 9). Entretanto, não se constata nenhuma combinação ideal entre as configurações $4,5,6,7,8$ e 9, pois todas essas configurações são competitivas.

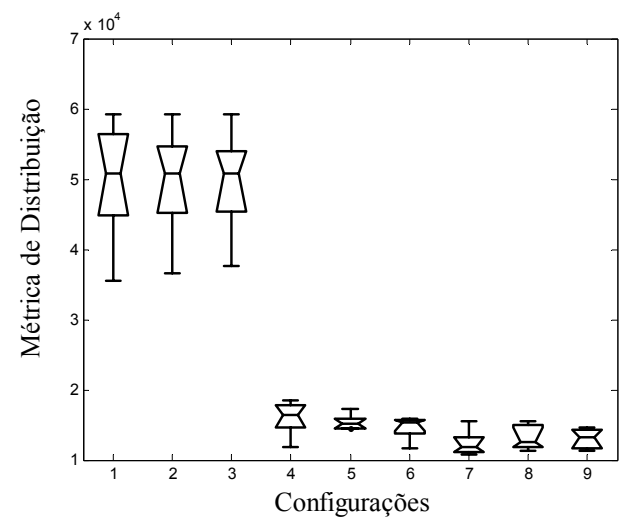

Figura 6.22 - Métrica de distribuição do SPEA considerando diferentes operadores genéticos (configurações de 1 a 9)

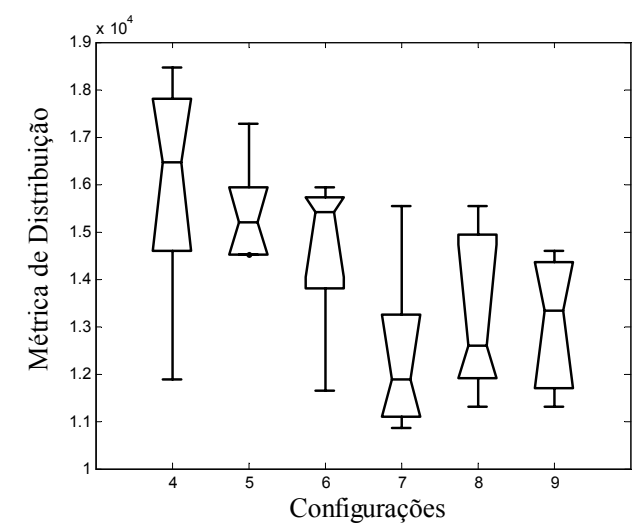

Figura 6.23 - Métrica de distribuição do SPEA considerando apenas configurações de 4 a 9

A Figura 6.22 apresenta os resultados da métrica $S$ (item 5.7.2) para as simulações realizadas com o SPEA considerando diferentes operadores genéticos. Observa-se que os resultados referentes às configurações que contém o operador de mutação Limite apresentaram os maiores desvios. Assim, pode-se admitir que esse operador não é eficiente, pois de acordo com as métricas (C e S) seus resultados são ruins. As outras combinações de operadores (4-9) apresentaram os valores de S de mesma ordem de grandeza, no entanto, uma ligeira vantagem pode ser observada na configuração 7 (operador de recombinação BLX e operador de mutação Dinâmico) através da Figura 6.22. Como a Figura 6.22 apresenta todos os resultados da métrica $S$, e as combinações que apresentam resultados da mutação Limite produziram valores muito elevados, fica difícil avaliar quais configurações de 4 à 9 são mais eficientes (menor desvio). Assim, foi construída a Figura 6.23, na qual considerou apenas as configurações de interesse (49). Observando-se à Figura 6.23, constata-se que os valores medianos das combinações 
de operadores 4, 5 e 6, que utilizaram a mutação dinâmica, apresentaram os melhores valores em termos da métrica $\mathrm{S}$.

As configurações 1, 2 e 3 apresentaram valores medianos semelhantes. O mesmo acontece com 4, 5 e 6 e com o grupo formado pelas configurações 7, 8 e 9. Buscou-se então uma explicação para esse fato. A principal diferença encontrada nesses grupos está relacionada ao operador de mutação. Com isso, pode-se afirmar que o operador de mutação tem mais influência no processo iterativo do que o operador de recombinação. As Figuras 6.24 e 6.25 apresentam as frentes Pareto do SPEA referentes às configurações 7 e 8, respectivamente. Observa-se que a comparação visual torna-se difícil. Um círculo localizado na Figura 6.25 mostra a região da superfície Pareto que o SPEA, com operador de recombinação BLX e mutação dinâmica, explorou melhor.

Depois de identificados o algoritmo SPEA e os operadores genéticos mais eficientes para o problema de reabilitação de redes, iniciaram-se estudos referentes às funções objetivo mais promissoras. HALHAL et al. (1997) sugerem que se alguma ação de melhoria for implementada no sistema há um ganho direto de desempenho decorrente dessa intervenção sobre o sistema. Esse ganho foi denominado benefício hidráulico. Para quantificar esse benefício, HALHAL et al. (1997) propõem o uso de uma formulação (eq. 3.21) que calcula as deficiências (DEF) da rede sem reabilitação e com reabilitação, respectivamente. Uma crítica que se faz a essa formulação é a unidade, $\mathrm{m}^{4} / \mathrm{s}$, obtida do benefício hidráulico, a qual não tem nenhum significado físico. Como forma de aperfeiçoar tal formulação, no presente trabalho foi proposta a eq.(6.9) para cálculo desse benefício.

Maximizar benefício hidráulico, $\mathrm{F}_{3}=\mathrm{DEF}_{\mathrm{o}}-\mathrm{DEF}_{\mathrm{p}}$

sendo que $\mathrm{DEF}_{\mathrm{o}}$ refere-se a deficiência da rede, em termos de pressões não atendidas, em seu estado original (sem reabilitação) e $\mathrm{DEF}_{\mathrm{p}}$ corresponde a deficiência da rede reabilitada. Tanto $\mathrm{DEF}_{\mathrm{o}}$ como $\mathrm{DEF}_{\mathrm{p}}$ podem ser calculadas através da eq.(6.10).

$$
\mathrm{DEF}_{\mathrm{o}} / \mathrm{DEF}_{\mathrm{p}}=\gamma \sum_{\mathrm{j} \in \mathfrak{I}}\left(\mathrm{H}_{\mathrm{j}}^{\mathrm{min}}-\mathrm{H}_{\mathrm{j}}\right) \mathrm{Q}_{\mathrm{j}}
$$

sendo $\gamma$ o peso específico da água $\left(9,8 \mathrm{kN} / \mathrm{m}^{3}\right)$; $\mathfrak{I}$ o conjunto de nós que não atendem as pressões mínimas; $\mathrm{H}^{\mathrm{min}}$ a energia mínima requerida para o nó $\mathrm{j}(\mathrm{m}) ; \mathrm{H}$ a energia 
simulada para o nó j (m) e Q a demanda requerida para o nó j $\left(\mathrm{m}^{3} / \mathrm{s}\right)$. Nota-se que os valores obtidos pelo benefício hidráulico serão apresentados em termos de potência $(\mathrm{kW})$.

Simulações foram realizadas com o SPEA para o problema de reabilitação da rede exemplo 1 (Figura 5.18) considerando três objetivos (eqs. 6.1, 6.8 e 6.9). O operador de recombinação (probabilidade igual a 0,9) BLX e a mutação dinâmica, com probabilidade igual a 0,1 , foram utilizados. A dimensão de população considerada foi igual a 200 e o número máximo de gerações igual a 500. A Figura 6.20 apresenta a frente Pareto obtida através dessa simulação.

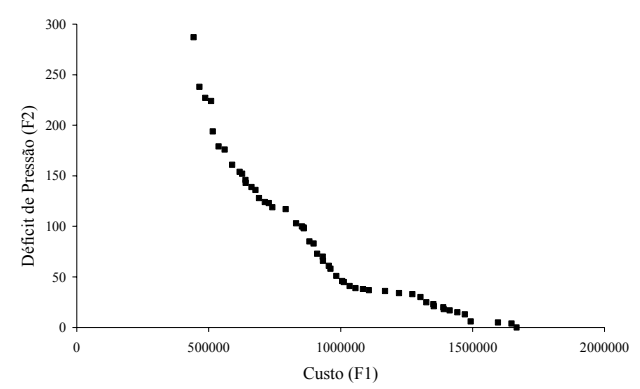

Figura 6.24 - Frente Pareto SPEA (7)

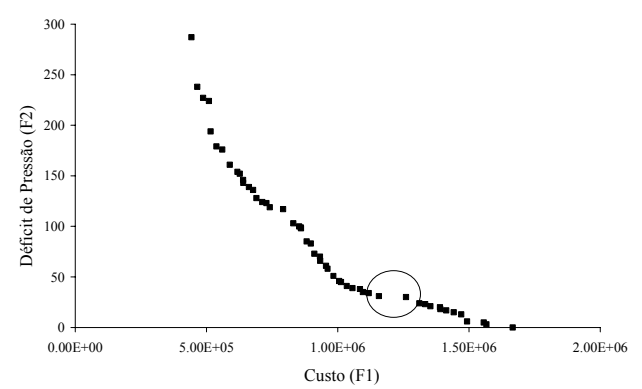

Figura 6.25 - Frente Pareto SPEA (8)

\section{$\mathrm{F}_{1}$}
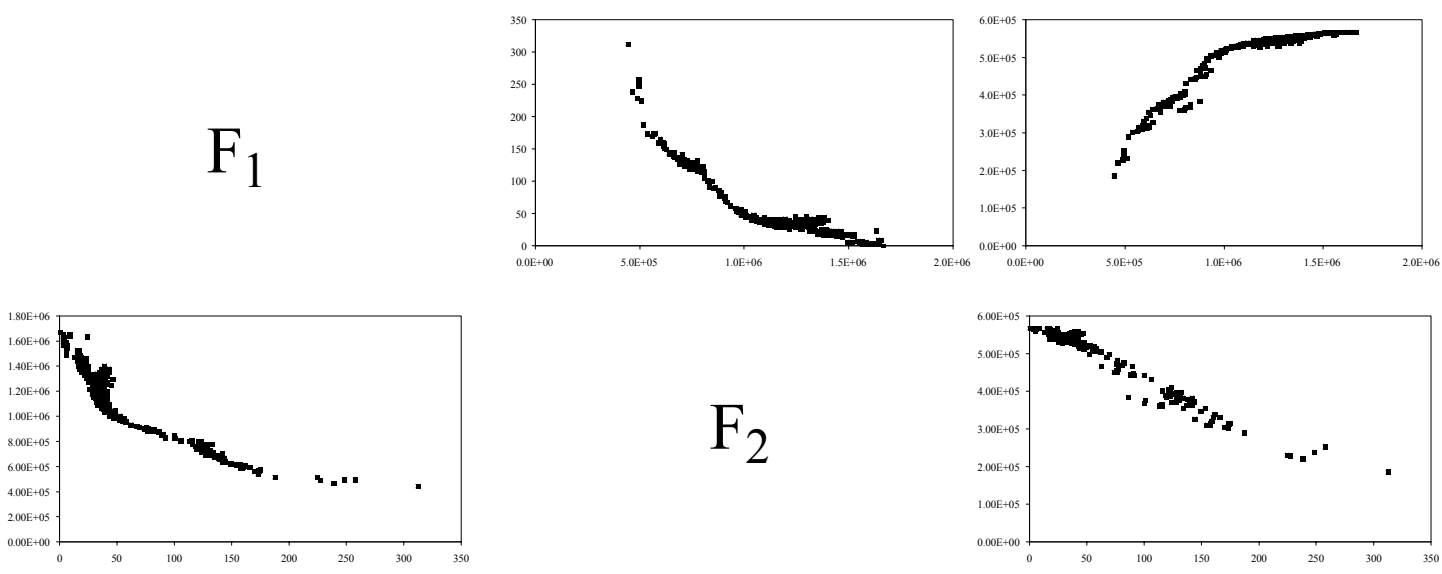

$\mathrm{F}_{2}$
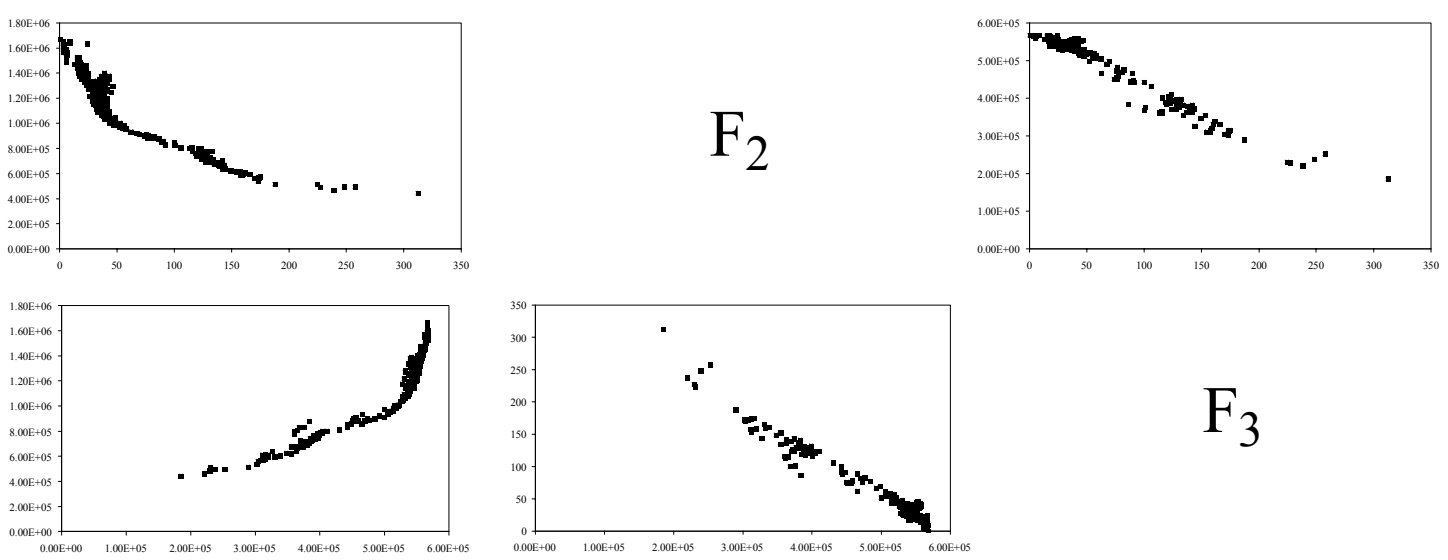

$\mathrm{F}_{3}$

Figura 6.26 - Frente Pareto produzida pelo SPEA considerando um problema com três objetivos As soluções da Figura 6.26 evidenciam o efeito causado pela escolha de uma alternativa de reabilitação (solução) sobre os objetivos considerados. Por exemplo, considerando $\mathrm{F}_{1}$ 
em relação a $F_{2}$ (gráfico a direita de $F_{1}$ ), se o decisor escolher uma solução de mais baixo custo $\left(F_{1}\right)$, o déficit de pressão $\left(F_{2}\right)$ tem a ser mais elevado, da mesma forma que se for analisado $F_{1}$ em relação a $F_{3}$, uma solução de baixo custo produziria um benefício hidráulico menor.

\subsection{Análise de redes através do simulador hidráulico proposto}

A incorporação de modelos pressão-demanda e pressão-vazamento nas análises de redes em regime permanente é uma tendência da literatura, com objetivo de produzir resultados mais realísticos. Tais modelos, quando incorporados na formulação clássica de redes, fazem com que as demandas trabalhem dinamicamente (e não fixas como nas proposições clássicas), ou seja, variem em função da carga hidráulica atuante nos nós da rede.

Nesse item são apresentadas algumas investigações referentes ao simulador hidráulico modificado proposto (item 5.5.1). Esse simulador representa uma intervenção direta sobre o método de TODINI e PILATI (1988), implementado no Epanet 2, e constitui uma das contribuições originais deste trabalho. Cabe ressaltar que essa modificação foi realizada utilizando uma biblioteca do Epanet 2 orientada a objetos, denominada OOTEN (ZY1 et al., 2003). A principal vantagem da OOTEN é o acesso ao código fonte do Epanet 2, o que não é conseguido quando se utiliza a biblioteca do Epanet 2 (Toolkit) disponível. Na Toolkit, o acesso direto ao código do Epanet 2 fica impossibilitado devido a presença de arquivos DLL (epanet2.DLL) e LIB (epanet2bc.lib). Assim, a incorporação da relação pressão-demanda e da relação pressão-vazamento através da Toolkit não é possível, a não ser que sejam construídos novos arquivos (DLL e LIB) para qualquer modificação realizada no código fonte do Epanet 2.

Vários testes foram conduzidos com o simulador hidráulico proposto com intuito de verificar sua adequação aos diferentes modelos de pressão-demanda existentes (eqs. 2.32, 2.33 e 2.34). Considerando a rede exemplo 2 (TUCCIARELLI, CRIMINISI e TERMINI, 1999), com os dados geométricos apresentados nas Tabelas 5.12 e 5.13 e considerando uma altura igual a 40 m.c.a. (condição operacional em que as demandas requeridas nos nós são elevadas e as pressões mais baixas) para os três reservatórios, diversas análises foram realizadas.

Um primeiro estudo (Tabela 6.5) foi desenvolvido visando comparar a superfície piezométrica de uma simulação convencional, considerando demandas fixas sem 
vazamentos, com uma simulação considerando vazamentos (eq. 2.23). Observe na Figura 5.18 que existem diferentes setores de vazamentos (Tabela 5.12) para a rede em estudo (rede exemplo 2). Para o setor 1 foi considerado um valor para o coeficiente de vazamentos $\left(\theta_{1}\right)$ igual a 0 . Para o setor 2 foi considerado um coeficiente de vazamentos igual a $205,4 \cdot 10^{-7}\left(\mathrm{~m}^{3-\mathrm{a}} / \mathrm{s}\right)$ e para o setor 3 foi considerado um coeficiente de vazamentos igual a $104,6 \cdot 10^{-7}\left(\mathrm{~m}^{3-a} / \mathrm{s}\right)$. O expoente (a) da formulação de vazamentos (eq. 2.23) foi considerado igual a 0,1 . Tanto os coeficientes adotados quanto o expoente são baseados em um caso investigado por TUCCIARELLI, CRIMINISI e TERMINI (1999) para a obtenção dos resultados da Tabela 6.5 considerando a situação em que se admite vazamentos.

Tabela 6.5 -Pressões obtidas utilizando simulador hidráulico sem vazamentos e com vazamentos

\begin{tabular}{cccccc}
\hline \hline & Demanda & Sem vazamentos & \multicolumn{2}{c}{ Com vazamentos } & \\
Nó & $\mathrm{q}$ & Pressão & Pressão & QL & Erro Absoluto \\
& $\mathrm{L} / \mathrm{s}$ & m.c.a & m.c.a & L/s & \\
\hline 1 & 30,4 & 13,26 & 12,27 & 14,1 & 0,99 \\
2 & 30,4 & 17,22 & 15,64 & 11,2 & 1,58 \\
3 & 30,4 & 17,26 & 16,84 & 9,7 & 0,42 \\
4 & 0,0 & 12,80 & 12,67 & 5,3 & 0,13 \\
5 & 0,0 & 9,81 & 9,66 & 13,9 & 0,15 \\
6 & 30,4 & 12,14 & 11,52 & 14,0 & 0,62 \\
7 & 0,0 & 17,29 & 16,61 & 13,9 & 0,68 \\
8 & 0,0 & 14,85 & 14,68 & 14,9 & 0,17 \\
9 & 0,0 & 13,24 & 12,19 & 10,9 & 1,05 \\
10 & 0,0 & 18,59 & 17,35 & 9,4 & 1,24 \\
11 & 30,4 & 16,25 & 15,23 & 7,0 & 1,02 \\
12 & 0,0 & 12,48 & 12,01 & 11,9 & 0,47 \\
13 & 0,0 & 15,00 & 15,00 & 0,00 & 0,00 \\
14 & 0,0 & 15,00 & 15,00 & 0,00 & 0,00 \\
15 & 0,0 & 10,00 & 10,00 & 0,00 & 0,00 \\
Soma & 152,0 & & & 136,3 & 8,52 \\
\hline \hline
\end{tabular}

$\mathrm{Na}$ Tabela 6.5 foi desenvolvida uma comparação simples das pressões simuladas considerando e não considerando vazamentos através do cálculo do erro absoluto. Observa-se que as pressões obtidas sem considerar os vazamentos são mais elevadas quando comparadas com a simulação convencional. Somando-se as parcelas referentes aos vazamentos e as demandas (Tabela 6.5) obtém-se uma demanda total requerida pelo sistema igual a $288,3 \mathrm{~L} / \mathrm{s}$. Observe que se não fossem incorporados os vazamentos nas análises hidráulicas a demanda total requerida pelo sistema estaria em torno de $152 \mathrm{~L} / \mathrm{s}$, 
o que representa uma situação irreal, considerando que parcela expressiva de vazamentos são apresentados no sistema em análise.

Um segundo estudo (Tabelas 6.6 - 6.11) foi realizado com objetivo de comparar as diferentes formulações do modelo pressão-demanda sobre a mesma rede exemplo. Três modelos pressão-demanda foram investigados: WAGNER, SHAMIR e MARKS (1988) (Modelo A), FUJIWARA e LI (1998) (Modelo B) e TUCCIARELLI, CRIMINISI e TERMINI (1999) (Modelo C).

Tabela 6.6 - Pressões e vazamentos obtidos Tabela 6.7 - Pressões e vazamentos obtidos utilizando o modelo de Wagner et al. (1988) utilizando o modelo de Fujiwara e Li (1998) sem fator de relaxação

\begin{tabular}{cccc}
\hline \hline & & \multicolumn{2}{c}{ WAGNER et al,(1988) } \\
Nó & Pressão & Vazamentos & Demanda Variável \\
& M & L/s & L/s \\
\hline 1 & 8,91 & 13,65 & 18,9 \\
2 & 10,07 & 10,69 & 21,6 \\
3 & 14,73 & 9,58 & 30,0 \\
4 & 12,20 & 5,28 & 0,0 \\
5 & 9,28 & 13,81 & 0,0 \\
6 & 9,77 & 13,78 & 20,9 \\
7 & 15,06 & 13,75 & 0,0 \\
8 & 14,27 & 14,94 & 0,0 \\
9 & 8,67 & 10,56 & 0,0 \\
10 & 14,18 & 9,23 & 0,0 \\
11 & 11,67 & 6,83 & 24,8 \\
12 & 10,95 & 11,78 & 0,0 \\
13 & 15,00 & 0,00 & 0,0 \\
14 & 15,00 & 0,00 & 0,0 \\
15 & 10,00 & 0,00 & 0,0 \\
SOMA & & 133,88 & 116,3 \\
\hline \hline
\end{tabular}
sem fator de relaxação

\begin{tabular}{cccc}
\hline \hline & \multicolumn{3}{c}{ FUJIWARA e LI (1998) } \\
Nó & Pressão & Vazamentos & $\begin{array}{c}\text { Demanda Variável } \\
\end{array}$ \\
M & L/s & L/s \\
\hline 1 & 13,27 & 13,4 & 4,7 \\
2 & 17,58 & 10,5 & 7,0 \\
3 & 15,31 & 9,6 & 30,0 \\
4 & 12,54 & 5,3 & 0,0 \\
5 & 9,71 & 13,8 & 0,0 \\
6 & 11,23 & 13,7 & 12,7 \\
7 & 16,42 & 13,7 & 0,0 \\
8 & 14,51 & 14,9 & 0,0 \\
9 & 13,02 & 10,4 & 0,0 \\
10 & 17,80 & 9,2 & 0,0 \\
11 & 15,81 & 6,7 & 17,0 \\
12 & 12,23 & 11,7 & 0,0 \\
13 & 15,00 & 0,0 & 0,0 \\
14 & 15,00 & 0,0 & 0,0 \\
15 & 10,00 & 0,0 & 0,0 \\
SOMA & & 132,88 & 71,37 \\
\hline \hline
\end{tabular}

Os valores de energia obtidos considerando uma pressão mínima de 5 m.c.a. e pressão desejada de suprimento da demanda de 15 m.c.a. para todos os nós da rede, são mostrados nas Tabelas 6.6-6.11. Para os casos analisados nas Tabelas (6.6-6.8) não foi considerado um fator de relaxação. Esse fator é um procedimento numérico que auxilia a convergência do método, pois quando os modelos pressão-demanda e pressãovazamento são integrados nas simulações hidráulicas, observa-se a presença de oscilações. Essas oscilações surgem devido ao cálculo dos gradientes das funções que compõem a matriz Jacobiana. Em alguns casos (Tabela 6.7), as oscilações produzem respostas ruins, quando observada a soma total da demanda variável. Considerando o 
modelo pressão demanda de FUJIWARA E LI (1998) no domínio entre $\mathrm{H}^{\text {min }}$ e $\mathrm{H}^{\text {des }}$ (eq. 6.11), o fator de relaxação (FS) dessa formulação nada mais é que o termo que envolve as energias. Para a iteração atual o fator de relaxação é calculado através da eq.(6.12) utilizando os valores das iterações $(\mathrm{k})$ anteriores.

$$
\begin{aligned}
& \mathrm{q}_{\mathrm{j}}=\mathrm{q}_{\mathrm{j}}^{\mathrm{req}} \frac{\left(\mathrm{H}_{\mathrm{j}}-\mathrm{H}_{\mathrm{j}}^{\text {min }}\right)^{2}\left(3 \mathrm{H}_{\mathrm{j}}^{\text {des }}-2 \mathrm{H}_{\mathrm{j}}-\mathrm{H}_{\mathrm{j}}^{\text {min }}\right)}{\left(\mathrm{H}_{\mathrm{j}}^{\text {des }}-\mathrm{H}_{\mathrm{j}}^{\text {min }}\right)^{3}}=\mathrm{q}_{\mathrm{j}}^{\text {req }} \mathrm{FS}_{\mathrm{j}} \\
& \mathrm{FS}=\frac{\mathrm{FS}^{\mathrm{k}}+\mathrm{FS}^{\mathrm{k}-1}}{2}
\end{aligned}
$$

Tabela 6.8 - Pressões e vazamentos obtidos Tabela 6.9 - Pressões e vazamentos obtidos utilizando o modelo de Tucciarelli et al. utilizando o modelo de Wagner et al. (1988) (1999) sem fator de relaxação

\begin{tabular}{cccc}
\hline \hline & \multicolumn{3}{c}{ TUCCIARELLI et al. (1999) } \\
Nó & Pressão & Vazamentos & Demanda Variável \\
& $\mathrm{m}$ & L/s & L/s \\
\hline 1 & 10,57 & 13,42 & 15,19 \\
2 & 13,66 & 10,39 & 15,27 \\
3 & 14,95 & 9,56 & 30,28 \\
4 & 12,34 & 5,27 & 0,00 \\
5 & 9,45 & 13,79 & 0,00 \\
6 & 10,23 & 13,70 & 20,66 \\
7 & 15,54 & 13,71 & 0,00 \\
8 & 14,36 & 14,93 & 0,00 \\
9 & 10,36 & 10,36 & 0,00 \\
10 & 15,73 & 9,15 & 0,00 \\
11 & 13,28 & 6,74 & 23,47 \\
12 & 11,47 & 11,73 & 0,00 \\
13 & 15,00 & 0,00 & 0,00 \\
14 & 15,00 & 0,00 & 0,00 \\
15 & 10,00 & 0,00 & 0,00 \\
SOMA & & 132,75 & 104,88 \\
\hline \hline
\end{tabular}
com fator de relaxação

\begin{tabular}{cccc}
\hline \hline & & \multicolumn{2}{c}{ WAGNER et al, (1988) } \\
Nó & Pressão & Vazamentos & Demanda Variável \\
& $\mathrm{m}$ & $\mathrm{L} / \mathrm{s}$ & $\mathrm{L} / \mathrm{s}$ \\
\hline 1 & 8,91 & 13,65 & 19,00 \\
2 & 10,06 & 10,69 & 21,60 \\
3 & 14,73 & 9,58 & 29,99 \\
4 & 12,20 & 5,28 & 0,00 \\
5 & 9,28 & 13,81 & 0,00 \\
6 & 9,77 & 13,78 & 21,00 \\
7 & 15,05 & 13,75 & 0,00 \\
8 & 14,27 & 14,94 & 0,00 \\
9 & 8,66 & 10,56 & 0,00 \\
10 & 14,17 & 9,24 & 0,00 \\
11 & 11,67 & 6,83 & 24,82 \\
12 & 10,95 & 11,78 & 0,00 \\
13 & 15,00 & 0,00 & 0,00 \\
14 & 15,00 & 0,00 & 0,00 \\
15 & 10,00 & 0,00 & 0,00 \\
SOMA & & 133,88 & 116,41 \\
\hline \hline
\end{tabular}

Como o modelo de FUJIWARA e LI (1998) apresentou os piores resultados para o caso em que o fator de relaxação não foi considerado, decidiu-se então demonstrar o comportamento das demandas e vazamentos ao longo das iterações em comparação com a situação em que o fator de relaxação é considerado (Tabela 6.10) ao longo das iterações. A Figura 6.27 apresenta a demanda e os vazamentos totais calculados para cada iteração do processo considerando o modelo pressão-vazamento de 
TUCCIARELLI, CRIMINISI e TERMINI (1999) e o modelo pressão-demanda de FUJIWARA e LI (1998). Através dessa figura é possível notar que os vazamentos se mantêm estabilizados durante o processo iterativo, entretanto a parcela referente à demanda oscila consideravelmente. Uma melhoria é demonstrada quando se aplica um fator de relaxação (eq. 6.12) entre consecutivas iterações.

Tabela 6.10 - Pressões e vazamentos Tabela 6.11 - Pressões e vazamentos obtidos utilizando o modelo de Fujiwara e obtidos utilizando o modelo de Tucciarelli Li (1998) com fator de relaxação

\begin{tabular}{cccc}
\hline \hline & \multicolumn{3}{c}{ FUJIWARA e LI (1998) } \\
Nó & Pressão & Vazamentos & Demanda Variável \\
& $\mathrm{m}$ & $\mathrm{L} / \mathrm{s}$ & $\mathrm{L} / \mathrm{s}$ \\
\hline 1 & 9,52 & 13,74 & 13,16 \\
2 & 10,87 & 10,78 & 19,10 \\
3 & 14,79 & 9,58 & 30,27 \\
4 & 12,24 & 5,28 & 0,00 \\
5 & 9,35 & 13,82 & 0,00 \\
6 & 10,17 & 13,83 & 16,11 \\
7 & 15,38 & 13,78 & 0,00 \\
8 & 14,31 & 14,95 & 0,00 \\
9 & 9,17 & 10,62 & 0,00 \\
10 & 14,57 & 9,26 & 0,00 \\
11 & 12,17 & 6,86 & 24,42 \\
12 & 11,14 & 11,80 & 0,00 \\
13 & 15,00 & 0,00 & 0,00 \\
14 & 15,00 & 0,00 & 0,00 \\
15 & 10,00 & 0,00 & 0,00 \\
SOMA & & 134,29 & 103,07 \\
\hline \hline
\end{tabular}
et al. (1988) com fator de relaxação

\begin{tabular}{cccc}
\hline \hline & \multicolumn{3}{c}{ TUCCIARELLI et al, (1999) } \\
Nó & Pressão & Vazamentos & Demanda Variável \\
& $\mathrm{m}$ & $\mathrm{L} / \mathrm{s}$ & $\mathrm{L} / \mathrm{s}$ \\
\hline 1 & 8,77 & 13,63 & 19,21 \\
2 & 9,83 & 10,67 & 22,35 \\
3 & 14,67 & 9,57 & 30,36 \\
4 & 12,19 & 5,27 & 0,00 \\
5 & 9,26 & 13,81 & 0,00 \\
6 & 9,69 & 13,77 & 21,93 \\
7 & 14,99 & 13,75 & 0,00 \\
8 & 14,25 & 14,94 & 0,00 \\
9 & 8,50 & 10,54 & 0,00 \\
10 & 14,04 & 9,23 & 0,00 \\
11 & 11,50 & 6,82 & 26,50 \\
12 & 10,90 & 11,78 & 0,00 \\
13 & 15,00 & 0,00 & 0,00 \\
14 & 15,00 & 0,00 & 0,00 \\
15 & 10,00 & 0,00 & 0,00 \\
SOMA & & 133,77 & 120,35 \\
\hline \hline
\end{tabular}

A Tabela 6.12 apresenta os desvios de pressão obtidos em relação à simulação convencional. Por exemplo, a segunda coluna da Tabela 6.12, corresponde aos desvios das pressões simuladas (Tabela 6.5) considerando vazamentos (sem demanda variável com a pressão) em relação às pressões obtidas pela simulação convencional (Tabela 6.5). Esses desvios foram calculados conforme a eq.(6.13), onde o índice i representa o nó da rede, k representa as energias obtidas pelas diferentes simulações (vazamentos e vazamentos com demanda variável). Através do cálculo desses desvios verifica-se o erro cometido por desconsiderar vazamentos e demandas variáveis com a pressão nas análises hidráulicas. Deve-se tomar cuidado na análise desses desvios, pois um desvio pequeno não significa que é o melhor método, mas que o método está próximo da simulação convencional em que não são considerados os modelos dirigidos pela pressão 
(vazamentos e demanda variável). Em relação aos modelos pressão-demanda, considerando a situação com o fator de relaxação por ser uma situação mais confiável (estável), nota-se que as formulações de WAGNER, SHAMIR e MARKS (1988) e TUCCIARELLI, CRIMINISI e TERMINI (1999) apresentam resultados muito semelhantes (valores na mesma ordem de magnitude). Já a proposição de FUJIWARA e LI (1998) apresenta uma situação mais restritiva de atendimento das demandas logo as pressões nos nós são mais elevadas.

$$
\text { Desvio }_{\mathrm{i}}=\left|\mathrm{H}_{\mathrm{k}}-\mathrm{H}_{\mathrm{j}}\right|
$$

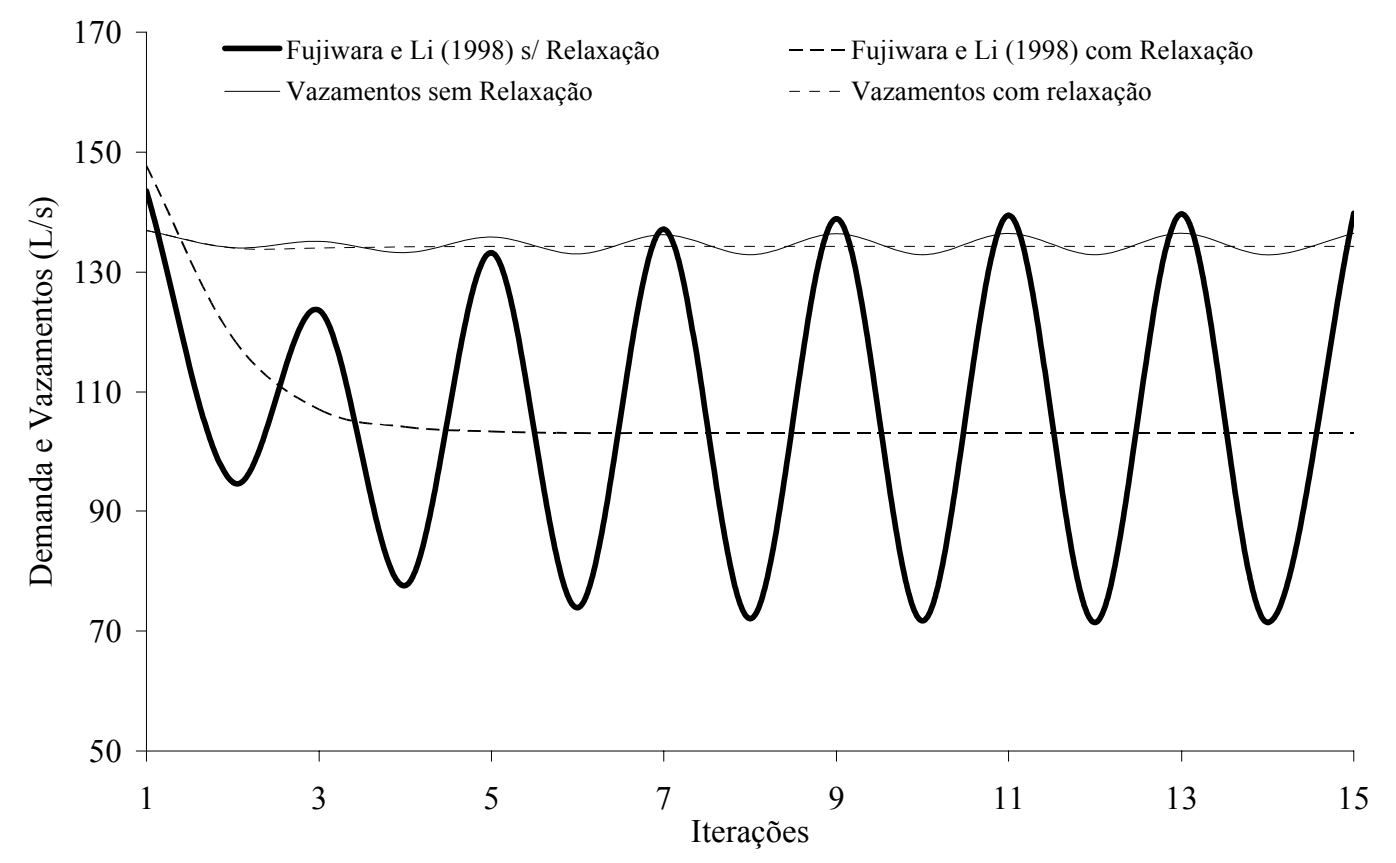

Figura 6.27 - Demanda total (FUJIWARA e LI, 1998) e vazamentos (TUCCIARELLI, CRIMINISI e TERMINI, 1999) durante o processo iterativo

O desenvolvimento de simuladores hidráulicos dirigidos pela pressão apresenta inúmeras vantagens para as análises de redes de distribuição de água. Os resultados das variáveis de estado (pressão e vazão), obtidas por meio desses simuladores, apresentamse mais próximos da realidade dos sistemas existentes, possibilitando dessa forma um melhor controle operacional. Uma outra vantagem desses simuladores refere-se ao cálculo da confiabilidade hidráulica do sistema, definida como sendo o não atendimento das demandas devido a alguma falha existente no sistema. Os modelos para análise de redes dirigidas pela pressão são bem adaptados para tal finalidade, pois explicitam quantitativamente as parcelas de vazamentos e as parcelas de demandas não atendidas. Realizando um cálculo simples entre a demanda realmente atendida pelos diferentes 
métodos de pressão-demanda (Tabela 6.13) e a demanda total requerida na rede (Tabela 6.5), $152 \mathrm{~L} / \mathrm{s}$, obtém-se a confiabilidade hidráulica (Tabela 6.13). O modelo B apresentou a menor confiabilidade devido à presença de oscilações (Figura 6.27), discutidas anteriormente, que convergiu para uma situação em que a demanda real consumida foi igual a 71,4 L/s. Entretanto, recomenda-se que com o uso do fator de relaxação, qualquer um dos modelos de demanda (D, E e F) pode ser utilizado nas simulações hidráulicas.

Tabela 6.12 - Desvio absoluto referentes às pressões nodais

\begin{tabular}{cccccccc}
\hline \hline & \multicolumn{3}{c}{ Desvio Absoluto } & \multicolumn{3}{c}{ Com Fator de Relaxação } \\
NÓ & \multicolumn{3}{c}{ Sem Fator de Relaxação } & \multicolumn{3}{c}{. } \\
& Vazamentos & WAGNER & FUJIWARA & TUCCIARELLI & WAGNER & FUJIWARA & TUCCIARELLI \\
\hline 1 & 0,99 & 4,35 & 0,01 & 2,70 & 4,36 & 3,74 & 4,49 \\
2 & 1,58 & 7,15 & 0,36 & 3,56 & 7,16 & 6,35 & 7,39 \\
3 & 0,41 & 2,52 & 1,95 & 2,30 & 2,52 & 2,47 & 2,58 \\
4 & 0,13 & 0,60 & 0,26 & 0,47 & 0,60 & 0,56 & 0,62 \\
5 & 0,15 & 0,53 & 0,10 & 0,37 & 0,53 & 0,46 & 0,55 \\
6 & 0,62 & 2,37 & 0,92 & 1,91 & 2,38 & 1,97 & 2,45 \\
7 & 0,68 & 2,23 & 0,87 & 1,75 & 2,23 & 1,91 & 2,30 \\
8 & 0,17 & 0,58 & 0,34 & 0,49 & 0,58 & 0,53 & 0,59 \\
9 & 1,05 & 4,57 & 0,22 & 2,88 & 4,57 & 4,06 & 4,74 \\
10 & 1,25 & 4,41 & 0,80 & 2,86 & 4,42 & 4,03 & 4,55 \\
11 & 1,01 & 4,57 & 0,44 & 2,97 & 4,58 & 4,08 & 4,75 \\
12 & 0,47 & 1,54 & 0,26 & 1,01 & 1,54 & 1,34 & 1,58 \\
13 & 0,00 & 0,00 & 0,00 & 0,00 & 0,00 & 0,00 & 0,00 \\
14 & 0,00 & 0,00 & 0,00 & 0,00 & 0,00 & 0,00 & 0,00 \\
15 & 0,00 & 0,00 & 0,00 & 0,00 & 0,00 & 0,00 & 0,00 \\
SOMA & 8,51 & 35,43 & 6,52 & 23,27 & 35,47 & 31,49 & 36,60 \\
\hline \hline
\end{tabular}

Tabela 6.13 - Confiabilidade hidráulica

\begin{tabular}{|c|c|c|c|c|}
\hline & Modelo & $\begin{array}{c}\text { Vazamentos } \\
(\mathrm{L} / \mathrm{s})\end{array}$ & $\begin{array}{c}\text { Demanda Total } \\
(\mathrm{L} / \mathrm{s})\end{array}$ & $\begin{array}{l}\text { Confiabilidade } \\
\text { (Adimensional) }\end{array}$ \\
\hline \multirow{3}{*}{ 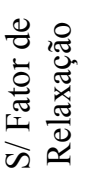 } & Wagner (A) & 133,9 & 116,3 & 0,8 \\
\hline & Fujiwara (B) & 132,9 & 71,4 & 0,5 \\
\hline & Tucciarelli (C) & 132,7 & 104,9 & 0,7 \\
\hline \multirow{3}{*}{ 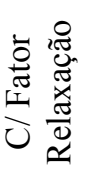 } & Wagner (D) & 133,9 & 116,4 & 0,8 \\
\hline & Fujiwara (E) & 134,3 & 103,1 & 0,7 \\
\hline & Tucciarelli (F) & 133,8 & 120,4 & 0,8 \\
\hline
\end{tabular}

As Figuras 6.28 e 6.29 apresentam ilustrações do vazamento total e da demanda total e da confiabilidade hidráulica, respectivamente, para os diferentes métodos considerados (Tabela 6.13). As Figuras 6.30 e 6.31 apresentam os níveis piezométricos da simulação hidráulica convencional e comparação com a simulação hidráulica considerando somente vazamentos e da simulação hidráulica considerando vazamentos e o modelo 
pressão-demanda, respectivamente. Nota-se, portanto que, quando somente vazamentos são considerados, os níveis piezométricos são mais elevados do que em relação as simulações hidráulicas que consideram tanto vazamentos quanto a demanda variável com a pressão.

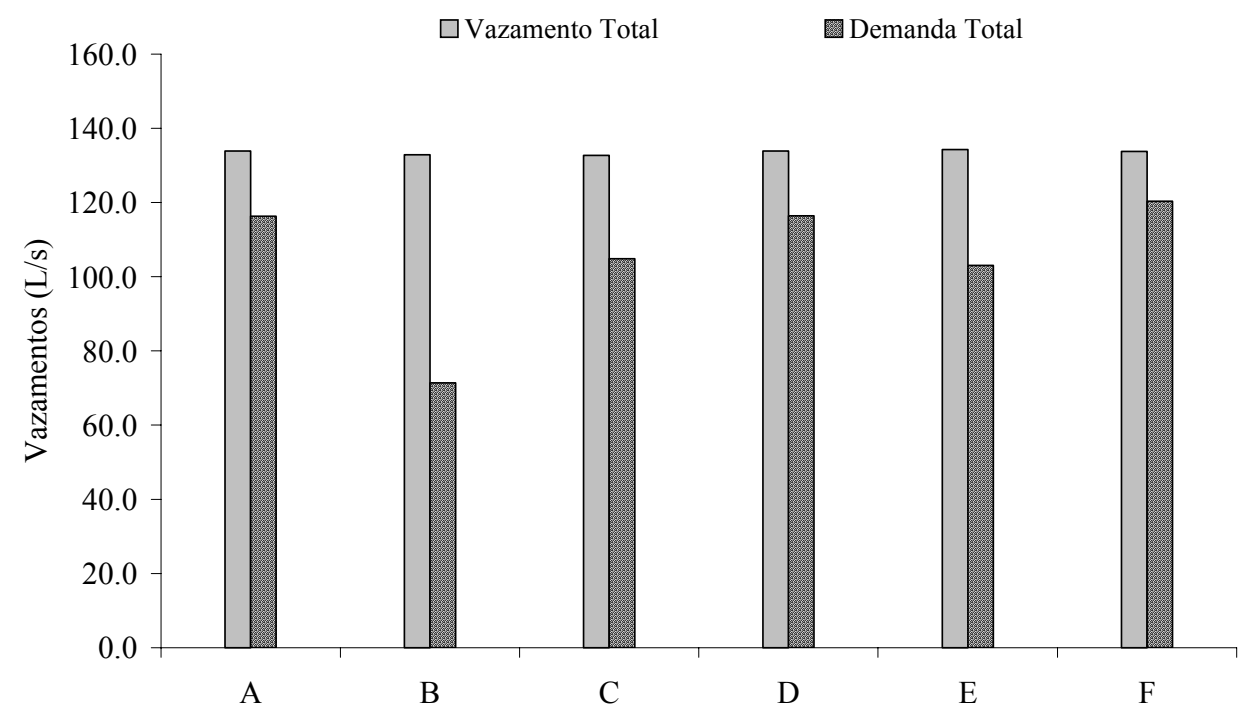

Figura 6.28 - Porcentagem de vazamentos e demandas para diferentes modelos de pressãodemanda

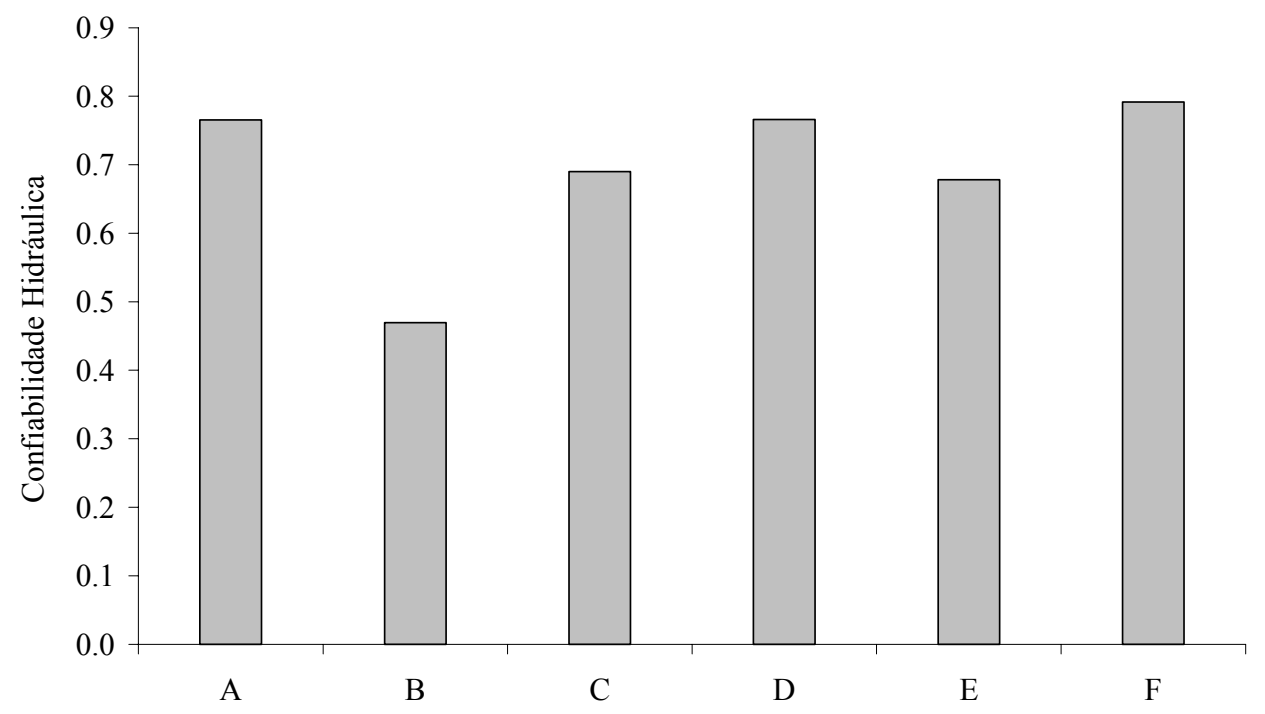

Figura 6.29 - Confiabilidade hidráulica para diferentes modelos de pressão-demanda

Esse item (6.3) foi desenvolvido com objetivo de apresentar a incorporação dos modelos de vazamentos e demanda-pressão no código do Epanet 2 e de discutir resultados obtidos para a escolha adequada do modelo de pressão-demanda mais eficiente a ser adotado para o estudo de caso real (rede exemplo 3). Dessa forma, o 
modelo de WAGNER, SHAMIR e MARKS (1988), com fator de relaxação, é o modelo-pressão demanda implementado no simulador hidráulico proposto, em conjunto com o modelo de vazamentos proposto por TUCCIARELLI, CRIMINISI e TERMINI (1999). Esse modelo foi adotado por apresentar erros absolutos na mesma magnitude para ambas as situações (com e sem relaxação). $O$ modelo de vazamentos (TUCCIARELLI, CRIMINISI e TERMINI, 1999) foi escolhido por apresentar formulação matemática que quantifica as perdas por área de superfície de vazamentos, conforme discutido no capítulo 2 deste trabalho.

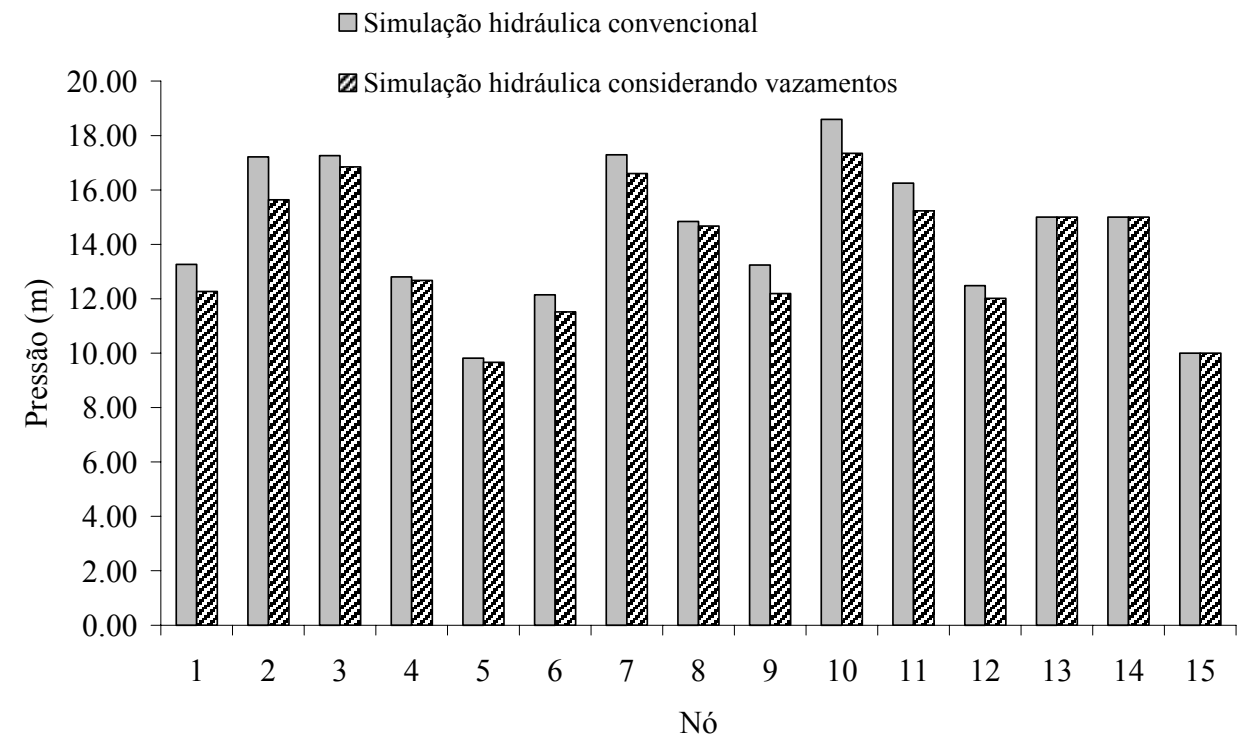

Figura 6.30 - Comparação das pressões nos nós da rede exemplo 2 considerando simulações hidráulicas convencional e com vazamentos

\subsection{Estimativa dos parâmetros do modelo de vazamentos - estudo de caso real}

Não existe um sistema totalmente estanque, todo sistema de abastecimento de água existente apresenta alguma parcela de perdas por vazamento na distribuição. Uma das formas de quantificar os vazamentos é incluir modelos pressão-vazamento (eq. 2.23) nas análises hidráulicas. Entretanto, para que esses modelos possam representar estimativas adequadas, é necessário, primeiramente, que seus parâmetros (a e ${ }^{\theta}$ ) sejam conhecidos. Nesse item, as estimativas obtidas dos parâmetros pressão-vazamento para o estudo de caso real (rede exemplo 3 - Figura 5.20) são apresentados. A calibração de tais parâmetros foi realizada através do programa computacional desenvolvido por SOARES (2003).

A calibração de um modelo de redes é um procedimento preliminar a ser adotado antes de qualquer análise de reabilitação e/ou operação de redes (sistema existente) com 
objetivo de identificar os parâmetros do sistema e assim poder representar, por meio de simulações hidráulicas, o comportamento realístico das variáveis de estado. $\mathrm{O}$ procedimento de calibração visa ajustar os parâmetros do sistema de tal forma que o desvio entre os dados simulados e os dados observados seja mínimo. No presente trabalho, os parâmetros do modelo pressão-vazamento foram identificados através da minimização do desvio dos dados observados em relação aos dados simulados.

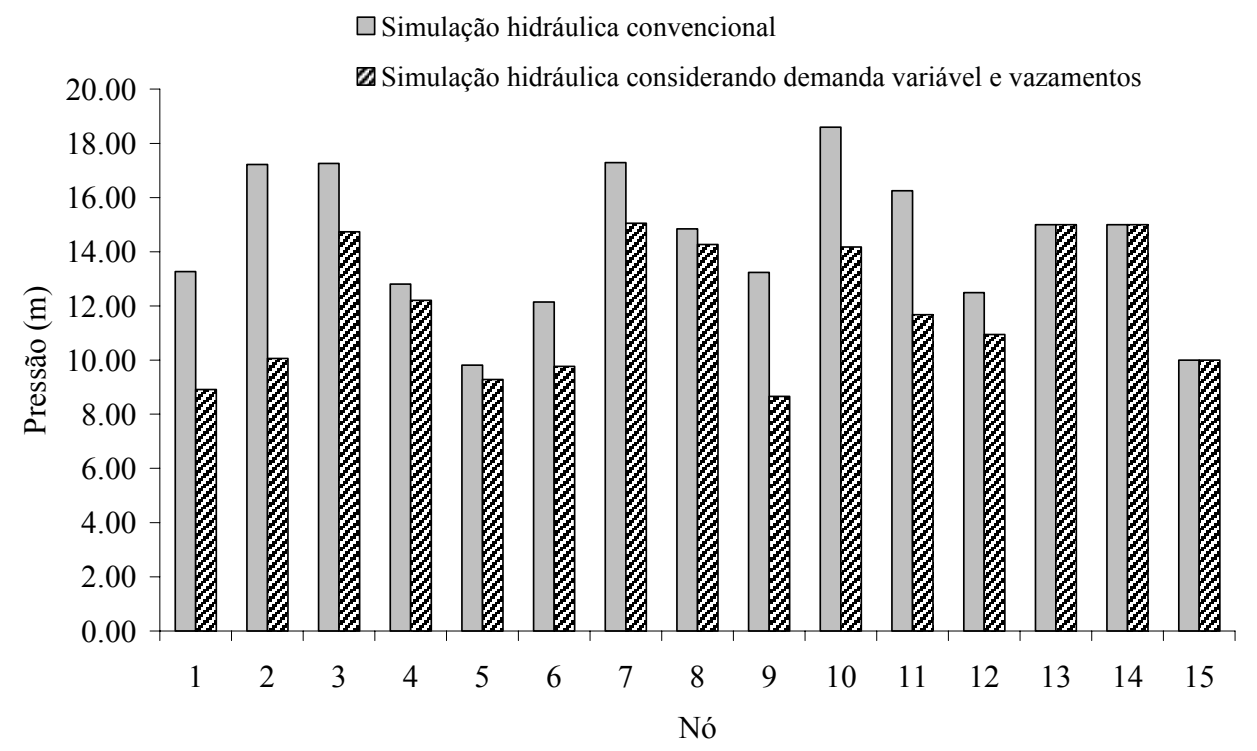

Figura 6.31 - Comparação das pressões nos nós da rede exemplo 2 considerando as simulações hidráulicas convencional e com modelo pressão-demanda de WAGNER, SHAMIR e MARKS (1988)

Para obtenção dos dados reais, referentes ao estudo de caso, foi necessária a realização de uma pesquisa de campo (ANEXO A). Apresentam-se aqui as etapas procedidas para determinação dos parâmetros do modelo pressão-vazamento. Esses parâmetros servem de dados de entrada para que as análises de reabilitação, referente ao modelo proposto neste trabalho, fossem desenvolvidas.

O suprimento de água do setor de distribuição RF-1 (rede exemplo 3) ocorre por meio de dois reservatórios semi-enterrados, localizados no nó 131 (Figura 6.32), cada qual com um volume de armazenamento de $6000 \mathrm{~m}^{3}$. Esse setor é responsável em atender a demanda em média 100.000 habitantes (SANDIM et al., 2002) sendo composto por tubulações de PVC, cimento amianto e ferro fundido.

Considerando o setor RF-1 como sendo um sistema de grande escala, neste trabalho as tubulações com diâmetros inferiores a $100 \mathrm{~mm}$ (salvo exceções ora citadas) não foram consideradas. O modelo simplificado é ilustrado pela Figura 5.19 e os dados referentes 
às características geométricas das tubulações e aos componentes hidráulicos encontramse no ANEXO A.

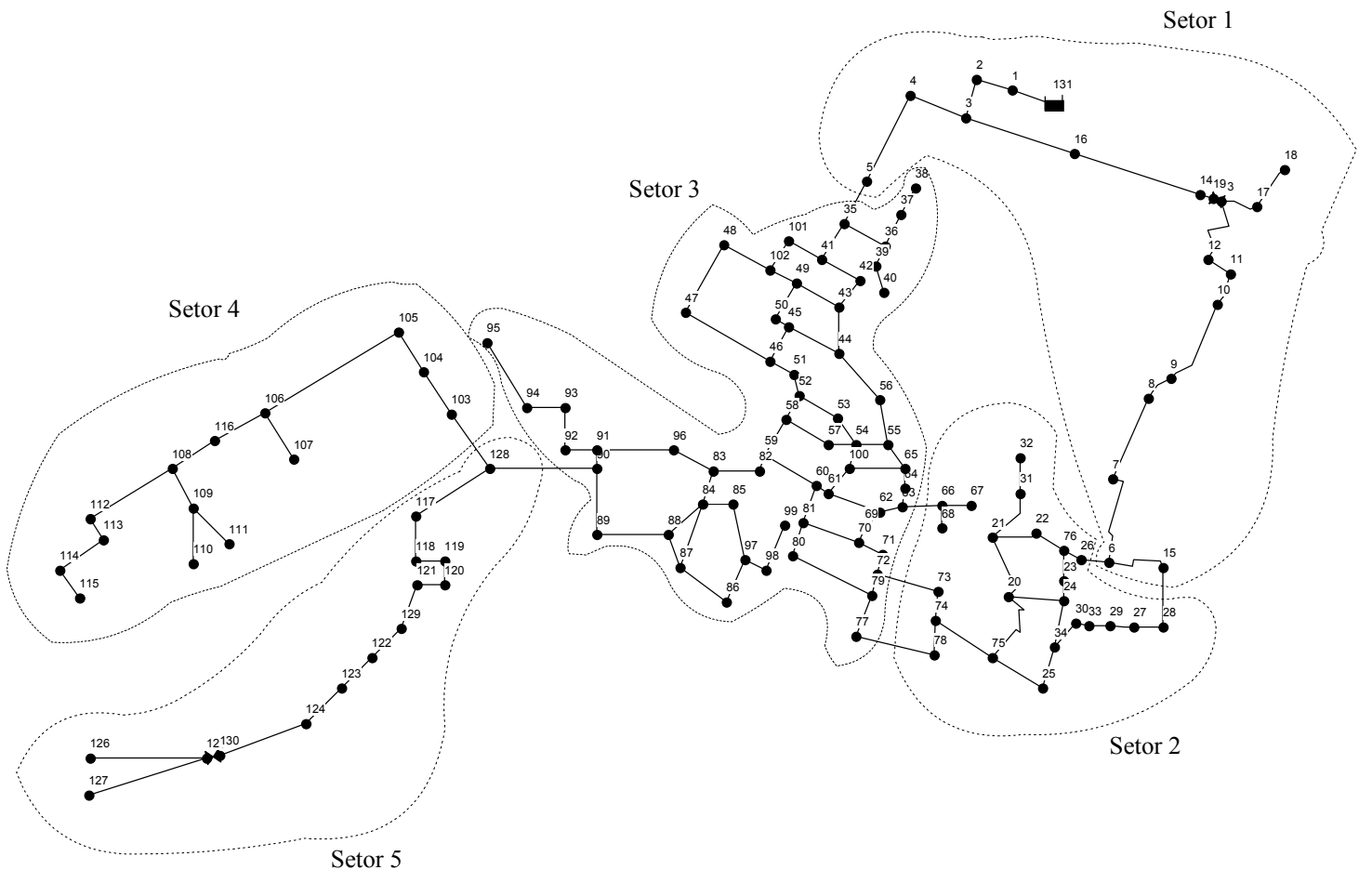

Figura 6.32 - Setores do modelo simplificado real

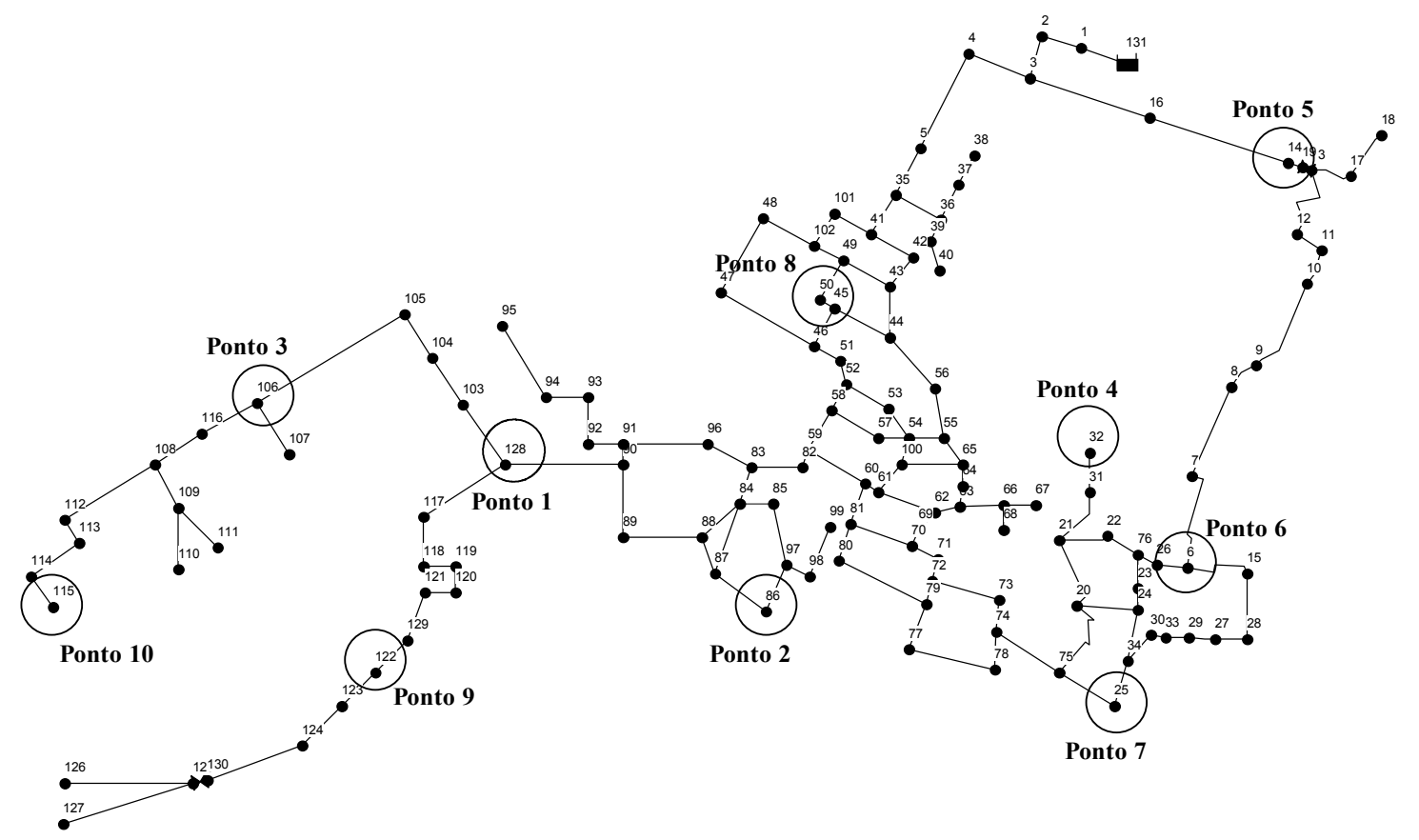

Figura 6.33 - Pontos de amostragem do modelo simplificado (rede exemplo 3) 
Tabela 6.14 - Demandas nodais da rede exemplo 3

\begin{tabular}{|c|c|c|c|c|c|c|c|c|c|}
\hline$\overline{\mathrm{ID}}$ & Elevação & Bairro & 1996 & 2003 & 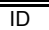 & Elevação & Bairro & 1996 & 2003 \\
\hline 1 & 627 & Coophasul & 68,1 & 75,7 & 78 & 562 & Petrópolis & 3,8 & 4,5 \\
\hline 2 & 623 & Coophasul & 0,0 & 0,0 & 79 & 560 & Petrópolis & 0,0 & 0,0 \\
\hline 3 & 620 & Coophasul & 0,0 & 0,0 & 80 & 555 & Petrópolis & 3,3 & 3,9 \\
\hline 4 & 600 & Coophasul & 0,0 & 0,0 & 81 & 550 & Petrópolis & 0,5 & 0,5 \\
\hline 5 & 602.5 & StaCarmelia & 0,0 & 0,0 & 82 & 555 & Petrópolis & 6,6 & 7,8 \\
\hline 6 & 596.5 & StaCarmelia & 0,0 & 0,0 & 83 & 556 & Recanto & 0,2 & 0,4 \\
\hline 7 & 597 & StaCarmelia & 2,4 & 2,7 & 84 & 555.5 & Recanto & 0,9 & 1,6 \\
\hline 8 & 602.5 & StaCarmelia & 4,7 & 5,3 & 85 & 550 & Recanto & 5,0 & 9,2 \\
\hline 9 & 603 & StaCarmelia & 2,0 & 2,2 & 86 & 547.5 & Recanto & 1,6 & 3,0 \\
\hline 10 & 598 & StaCarmelia & 4,7 & 5,3 & 87 & 545 & Recanto & 1,2 & 2,2 \\
\hline 11 & 599 & StaCarmelia & 1,3 & 1,4 & 88 & 560 & Petrópolis & 7,2 & 8,5 \\
\hline 12 & 590 & StaCarmelia & 0,0 & 0,0 & 89 & 562 & Petrópolis & 2,8 & 3,3 \\
\hline 13 & 595 & StaCarmelia & 0,0 & 0,0 & 90 & 562.5 & Petrópolis & 1,4 & 1,7 \\
\hline 14 & 587 & Coophatrab. & 0,5 & 0,6 & 91 & 564 & Petrópolis & 1,6 & 1,8 \\
\hline 15 & 582.5 & Coophatrab. & 6,3 & 7,1 & 92 & 536 & Popular & 5,1 & 6,3 \\
\hline 16 & 576 & Coophatrab. & 0,0 & 0,0 & 93 & 549 & Popular & 0,7 & 0,8 \\
\hline 17 & 572 & Coophatrab. & 12,0 & 13,6 & 94 & 550 & Popular & 0,2 & 0,2 \\
\hline 18 & 562.5 & Coophatrab. & 3,2 & 3,6 & 95 & 543 & Popular & 0,8 & 1,0 \\
\hline 19 & 564 & Coophatrab. & 1,1 & 1,2 & 96 & 534.5 & Popular & 4,5 & 5,6 \\
\hline 20 & 577.5 & Coophatrab. & 0,0 & 0,0 & 97 & 535 & Popular & 0,0 & 0,0 \\
\hline 21 & 574 & Coophatrab. & 5,3 & 6,0 & 98 & 534 & Popular & 2,9 & 3,5 \\
\hline 22 & 574 & Coophatrab. & 2,8 & 3,1 & 99 & 529 & Popular & 6,2 & 7,7 \\
\hline 23 & 573 & Panamá & 0,0 & 0,0 & 100 & 525 & Popular & 7,0 & 8,7 \\
\hline 24 & 575 & Panamá & 0,0 & 0,0 & 101 & 538 & Sta Monica & 0,6 & 0,8 \\
\hline 25 & 575 & Panamá & 4,1 & 7,6 & 102 & 536 & Sta Monica & 0,7 & 0,8 \\
\hline 26 & 580.5 & Panamá & 7,1 & 13,1 & 103 & 535 & Sta Monica & 0,4 & 0,5 \\
\hline 27 & 585 & Coophatrab. & 0,0 & 0,0 & 104 & 534.5 & Sta Monica & 0,8 & 1,0 \\
\hline 28 & 573 & Panamá & 4,1 & 7,5 & 105 & 530 & Petrópolis & 8,7 & 10,2 \\
\hline 29 & 571 & Panamá & 1,5 & 2,7 & 106 & 539 & Petrópolis & 0,0 & 0,0 \\
\hline 30 & 567 & Petrópolis & 0,9 & 1,0 & 107 & 544 & Petrópolis & 4,5 & 5,3 \\
\hline 31 & 569 & Petrópolis & 3,5 & 4,1 & 108 & 545 & Nova Cgde & 5,0 & 7,8 \\
\hline 32 & 571 & Alba & 0,9 & 1,7 & 109 & 539.5 & Nova Cgde & 0,0 & 0,0 \\
\hline 33 & 571.5 & Alba & 2,4 & 4,5 & 110 & 542.5 & Nova Cgde & 5,3 & 8,2 \\
\hline 34 & 576 & Panamá & 0,0 & 0,0 & 111 & 542 & Nova Cgde & 0,0 & 0,0 \\
\hline 35 & 578 & Panamá & 4,2 & 7,8 & 112 & 541 & Nova Cgde & 0,0 & 0,0 \\
\hline 36 & 583 & Panamá & 0,0 & 0,0 & 113 & 532.5 & Nova Cgde & 1,2 & 1,9 \\
\hline 37 & 580.2 & Panamá & 6,2 & 11,5 & 114 & 525 & Nova Cgde & 2,0 & 3,0 \\
\hline 38 & 581.5 & Panamá & 2,1 & 3,9 & 115 & 522.5 & Nova Cgde & 2,3 & 3,6 \\
\hline 39 & 578 & Panamá & 5,0 & 9,2 & 116 & 575 & Panamá & 0,0 & 0,0 \\
\hline 40 & 571 & Panamá & 0,0 & 0,0 & 117 & 574 & Planalto & 0,0 & 0,0 \\
\hline 41 & 570 & Alba & 2,8 & 3,2 & 118 & 566 & São Franc. & 2,3 & 2,5 \\
\hline 42 & 570 & Alba & 0,0 & 0,0 & 119 & 569 & São Franc. & 0,9 & 1,0 \\
\hline 43 & 568 & Alba & 6,6 & 7,4 & 120 & 584 & Planalto & 5,7 & 10,4 \\
\hline 44 & 572 & Alba & 4,9 & 5,5 & 121 & 585 & Planalto & 1,7 & 3,1 \\
\hline 45 & 569 & Alba & 1,1 & 1,3 & 122 & 541.5 & Petrópolis & 0,1 & 0,1 \\
\hline 46 & 571.5 & Alba & 0,0 & 0,0 & 123 & 572.5 & Planalto & 1,5 & 2,7 \\
\hline 47 & 577 & Planalto & 0,0 & 0,0 & 124 & 542.5 & Nova Cgde & 0,0 & 0,0 \\
\hline 48 & 581 & Planalto & 1,2 & 1,3 & 125 & 582 & StaCarmelia & 0,0 & 0,0 \\
\hline 49 & 581.3 & Planalto & 6,4 & 7,0 & 126 & 577.5 & Coophatrab. & 0,4 & 0,5 \\
\hline 50 & 581 & Planalto & 0,0 & 0,0 & 127 & 538 & Popular & 0,0 & 0,0 \\
\hline 51 & 577.5 & Planalto & 0,0 & 0,0 & 128 & 573.9 & Alba & 0,0 & 0,0 \\
\hline 52 & 576.5 & Planalto & 0,0 & 0,0 & 129 & 532 & & 0,0 & 0,0 \\
\hline 53 & 567.5 & Alba & 0,0 & 0,0 & 130 & 583.3 & & 0,0 & 0,0 \\
\hline 54 & 581 & Planalto & 11,1 & 20,5 & & & & & \\
\hline 55 & 579 & Planalto & 10,8 & 19,8 & & & & & \\
\hline 56 & 564.5 & Planalto & 0,0 & 0,0 & & & & & \\
\hline 57 & 570 & Planalto & 0,0 & 0,0 & & & & & \\
\hline 58 & 560 & Planalto & 0,0 & 0,0 & & & & & \\
\hline 59 & 557.5 & São Franc. & 0,9 & 1,0 & & & & & \\
\hline 60 & 560 & São Franc. & 1,7 & 1,9 & & & & & \\
\hline 61 & 570 & São Franc. & 6,0 & 6,7 & & & & & \\
\hline 62 & 583 & São Franc. & 0,0 & 0,0 & & & & & \\
\hline 63 & 594 & Coophasul & 0,2 & 0,2 & & & & & \\
\hline 64 & 562.5 & Planalto & 1,2 & 2,2 & & & & & \\
\hline 65 & 566 & Planalto & 5,1 & 9,4 & & & & & \\
\hline 66 & 564 & Planalto & 3,3 & 6,1 & & & & & \\
\hline 67 & 567 & Planalto & 9,1 & 16,7 & & & & & \\
\hline 68 & 619 & Coophasul & 0,0 & 0,0 & & & & & \\
\hline 69 & 565 & Alba & 2,3 & 2,6 & & & & & \\
\hline 70 & 565 & Alba & 0,8 & 0,9 & & & & & \\
\hline 71 & 567 & Alba & 0,0 & 0,0 & & & & & \\
\hline 72 & 564 & Alba & 0,0 & 0,0 & & & & & \\
\hline 73 & 568.5 & Alba & 7,9 & 8,9 & & & & & \\
\hline 74 & 565.5 & Petrópolis & 4,9 & 5,8 & & & & & \\
\hline 75 & 560 & Petrópolis & 0,6 & 0,7 & & & & & \\
\hline 76 & 561 & Petrópolis & 3,5 & 4,1 & & & & & \\
\hline 77 & 561.5 & Petrópolis & 4,5 & 5,3 & & & & & \\
\hline
\end{tabular}

Com propósito de identificar parâmetros de vazamentos para grupo de nós e tubulações, o modelo da rede exemplo 3 foi dividido em cinco setores. Esses setores foram divididos considerando as áreas de incidência de vazamentos, conforme o mapa 
fornecido pela Companhia de Saneamento Águas Guariroba S.A. (CD Anexo). A Figura 6.32 mostra os diversos setores, para o modelo simplificado do sistema real RF-1 (rede exemplo 3).

Os dados cadastrais da rede foram obtidos na própria companhia de saneamento (ANEXO A). As demandas nos nós (Tabela 6.14) foram obtidas através de uma base cadastral referente ao ano de 1996 e projetada para ano de 2003, utilizando índices de crescimento populacional apresentados no plano diretor do sistema de abastecimento de água (SANDIM et al., 2002).

Os dados de campo foram obtidos mediante campanhas de medição realizadas pelo autor do presente trabalho, no período entre 15 a 24 de Abril de 2003, com suporte de dez medidores de pressão (Metrolog NA Data Logger). Os pontos de instalação (pontos de amostragem) dos medidores de pressão foram escolhidos a sentimento, numa tentativa de delimitar áreas de diferentes incidências de vazamentos, em conformidade com mapa fornecido pela companhia (CD Anexo). A Figura 6.33 apresenta os pontos de monitoramento considerados. Maiores detalhes sobre a pesquisa de campo encontram-se no ANEXO A.

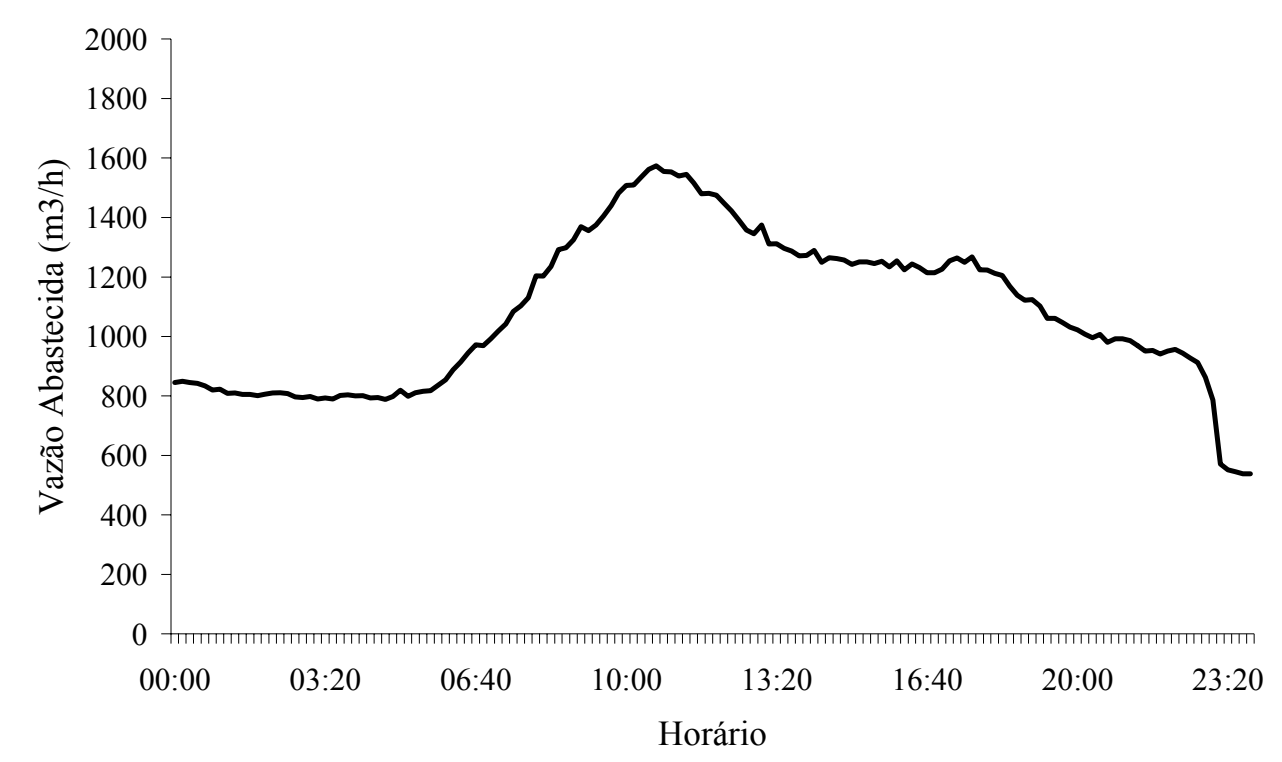

Figura 6.34 - Vazão abastecida da rede exemplo 3

A incorporação de vazamentos nas análises hidráulicas tem como objetivo principal representar uma melhor aproximação do comportamento real do sistema. É óbvio que, para cada instante de tempo os parâmetros de vazamentos variam, pois as pressões atuantes no sistema também mudam. Neste trabalho, foram adotados dois cenários de 
consumo (mínimo e máximo) tendo em vista que os modelos para análise de redes consideram regime permanente.

Um estudo foi realizado para determinação dos cenários de consumo através das vazões abastecidas (entrada do setor) na rede de distribuição. Diversos gráficos são mostrados no ANEXO A referente às vazões abastecidas no setor. A Figura 6.34 apresenta as vazões de entrada na rede de distribuição para o dia 20 de Abril de 2003. Esses dados foram obtidos junto à companhia de saneamento. $\mathrm{O}$ horário escolhido para representar $\mathrm{o}$ padrão de consumo mínimo foi 3:00 horas e para o consumo máximo foi de 11:00 horas. Esses horários foram estabelecidos observando as vazões abastecidas para diferentes dias de monitoramento.

Tabela 6.15 - Pressões nos nós monitorados (simulada e observada)

\begin{tabular}{cccccccc}
\hline \hline \multirow{2}{*}{ Ponto } & Nó & \multicolumn{2}{c}{ Simulada (m.c.a) } & \multicolumn{2}{c}{ Observada (m.c.a) } & \multicolumn{2}{c}{ Erro absoluto (m.c.a) } \\
& & Noturno & Diurno & Noturno & Diurno & Noturno & Diurno \\
\hline 1 & 128 & 83,6 & 82,2 & 73,9 & 50,6 & 9,7 & 31,6 \\
2 & 86 & 63,9 & 62,9 & 53,0 & 33,1 & 10,9 & 29,8 \\
3 & 106 & 80,1 & 78,0 & 65,1 & 37,6 & 15,0 & 40,4 \\
4 & 32 & 34,5 & 30,9 & 33,1 & 20,9 & 1,4 & 10,0 \\
5 & 14 & 34,3 & 34,2 & 28,8 & 28,6 & 5,5 & 5,6 \\
6 & 6 & 34,9 & 29,1 & 21,1 & 14,5 & 13,8 & 14,6 \\
7 & 25 & 55,5 & 53,4 & 23,2 & 15,3 & 32,3 & 38,1 \\
8 & 50 & 53,2 & 52,7 & 41,3 & 22,0 & 11,9 & 30,7 \\
9 & 122 & 82,3 & 80,9 & 72,0 & 46,0 & 10,3 & 34,9 \\
10 & 115 & 87,7 & 85,2 & 75,0 & 45,0 & 12,7 & 40,2 \\
& \multicolumn{7}{c}{ Soma Parcial } \\
\end{tabular}

A Tabela 6.15 apresenta as resultados das simulações hidráulicas efetuadas utilizando o modelo convencional (descrito no item 5.5.1), o qual não admite vazamentos. Uma comparação entre as pressões simuladas e as observadas (os valores de pressão observados durante todo período de investigação de campo são encontrados no ANEXO A) foi realizada para os dois cenários de consumo adotados. As simulações foram desenvolvidas considerando um período de 24 horas. Os fatores multiplicadores das demandas nodais considerados são apresentados na Tabela 3.2 e ilustrados pela Figura 3.4. Os termos mínimo e máximo representam os cenários de consumo noturno e diário, respectivamente. Foi calculado o desvio absoluto das pressões simuladas em relação às observadas para os dois cenários considerados. Observa-se que (Tabela 6.15) para o consumo máximo (diurno), as pressões apresentam níveis piezométricos menores quando comparados com as pressões noturnas. Através dessa comparação justifica-se a 
necessidade de incorporar vazamentos nas análises hidráulicas de tal forma que os resultados provenientes das simulações possam representar o comportamento aproximado do sistema real.

Para obter resultados representativos, o modelador deve garantir, antes de qualquer investigação, que as posições das singularidades (válvulas) estejam corretamente representadas no modelo (EGGENER e POLKOWSKI 1976; RAO, MARKEL e BREE 1977). A primeira tentativa, para determinação dos parâmetros do modelo pressãovazamento através da calibração do modelo simplificado real (rede exemplo 3), considerou duas válvulas redutoras de pressão atuando na rede, segundo informações da companhia. Essas válvulas estão localizadas próximas aos nós 130 e 14, respectivamente.

A primeira tentativa de calibração dos parâmetros de vazamento, considerado como um estudo preliminar, recebeu a denominação "sem manobras". O significado desse termo parte da hipótese que não há interferência (manobras) nos registros do sistema ao longo do dia. Essa primeira tentativa de calibração visou principalmente utilizar os dados referentes às válvulas redutoras de pressão da própria companhia. A válvula localizada próxima ao nó 14 (Figura 6.33), segundo informações do departamento de operações companhia de saneamento, reduz pressão à jusante para 10 m.c.a e a válvula localizada próximo ao nó 130 reduz a pressão à jusante para 25 m.c.a.

Através do conhecimento prévio da localização e ajuste dessas válvulas foi possível considerá-las no simulador hidráulico (item 5.5.2) e proceder à calibração do modelo simplificado real. Os parâmetros de entrada do modelo de calibração (SOARES, 2003), referente ao módulo de otimização, foram: dimensão da população igual a 100, número de gerações igual a 500, probabilidade de recombinação igual 0,70 e probabilidade de mutação igual a 0,01 .

A Tabela 6.16 apresenta os parâmetros calibrados do modelo pressão-vazamento referente ao primeiro estudo realizado (sem manobras). Inserindo os parâmetros calibrados no simulador hidráulico proposto foi possível obter as pressões nos nós da rede considerando vazamentos. Os resultados dessas simulações, referentes às pressões nos pontos monitorados, são agrupados na Tabela 6.17. Os desvios absolutos entre os dados observados e os simulados considerando vazamentos são apresentados na Tabela 6.18. Observe que a soma total desses desvios foi de 394,0 o que resulta em uma 
melhoria insignificante $(1,4 \%)$ quando comparado com o desvio das simulações sem considerar vazamentos $(399,3)$.

Tabela 6.16 - Parâmetros do modelo pressão-vazamento referente ao modelo simplificado real (rede exemplo 3)

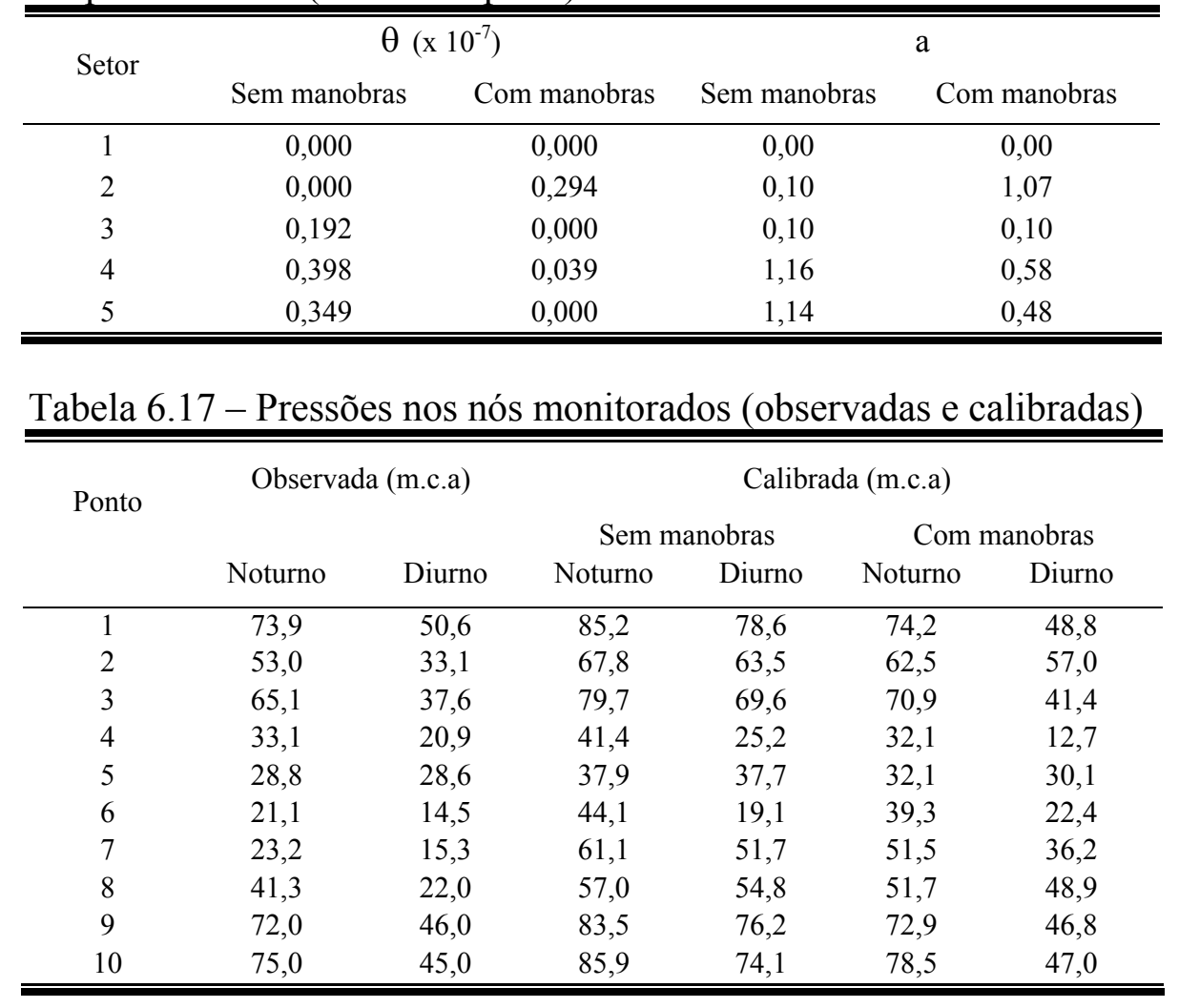

Tabela 6.18 - Erro absoluto referente às pressões calibradas

\begin{tabular}{|c|c|c|c|c|}
\hline \multirow{3}{*}{ Ponto } & \multicolumn{4}{|c|}{ Erro absoluto (m.c.a) } \\
\hline & \multicolumn{2}{|c|}{ Sem manobras } & \multicolumn{2}{|c|}{ Com manobras } \\
\hline & Noturno & Diurno & Noturno & Diurno \\
\hline 1 & 11,3 & 28,0 & 0,3 & 1,8 \\
\hline 2 & 14,8 & 30,4 & 9,5 & 23,9 \\
\hline 3 & 14,6 & 32,0 & 5,8 & 3,8 \\
\hline 4 & 8,3 & 4,3 & 1,0 & 8,2 \\
\hline 5 & 9,1 & 9,1 & 3,3 & 1,5 \\
\hline 6 & 23,0 & 4,6 & 18,2 & 7,9 \\
\hline 7 & 37,9 & 36,4 & 28,3 & 20,9 \\
\hline 8 & 15,7 & 32,8 & 10,4 & 26,9 \\
\hline 9 & 11,5 & 30,2 & 0,9 & 0,8 \\
\hline 10 & 10,9 & 29,1 & 3,5 & 2,0 \\
\hline Soma parcial & 157,1 & 236,9 & 81,2 & 97,7 \\
\hline Soma total & & 394,0 & & 178,9 \\
\hline
\end{tabular}

Um segundo estudo de calibração foi desenvolvido levando em consideração a existência de manobras nos registros da rede. As localizações das manobras foram obtidas junto à companhia de saneamento e são ilustradas pela Figura 6.35. Uma das principais dificuldades em representar operações (manobras de registros) nas 
simulações hidráulicas é identificar as aberturas das válvulas (coeficiente de perda de carga localizada - número de voltas no caso de registros manuais) resultantes das manobras. Assim, o ajuste das manobras foi considerado como variáveis de decisão do problema de calibração, em conjunto com os parâmetros do modelo pressão-vazamento.

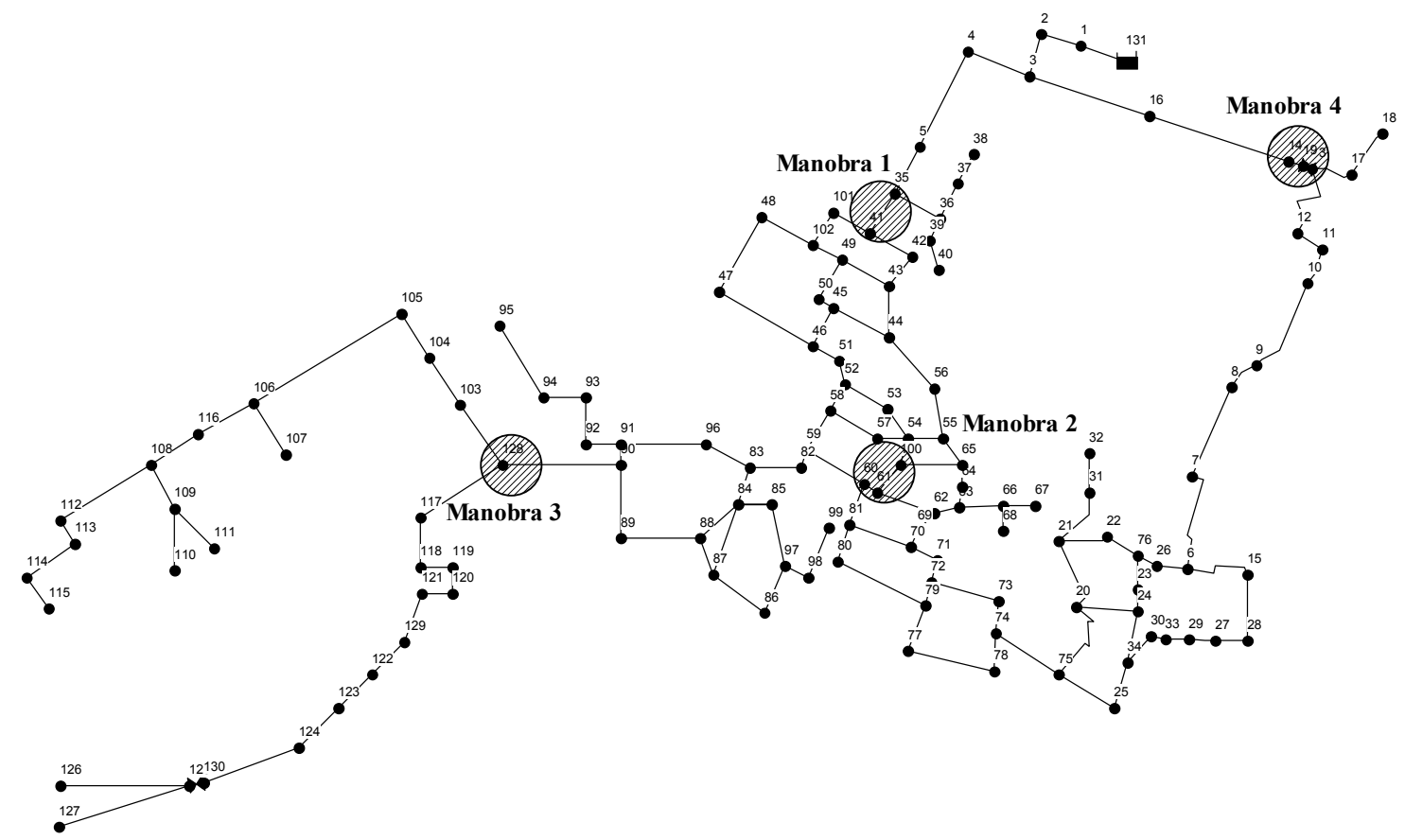

Figura 6.35 - Localização de manobras noturnas referentes o modelo simplificado real (rede exemplo 3)

A Tabela 6.16 apresenta os parâmetros calibrados (coeficiente e expoente de vazamentos) do modelo pressão-vazamento para o estudo denominado "com manobras". Nesse estudo, os parâmetros de vazamentos e aos ajustes das manobras são valores médios representativos aos cenários de consumo considerados. A Tabela 6.17 apresenta as pressões calibradas para esse estudo. Na Tabela 6.18 são calculados os desvios absolutos para esse segundo estudo de calibração. Observa-se que a soma do desvio total considerando os dois cenários de consumo é igual a 178,9. Comparando esse valor $(178,9)$ com o desvio $(399,3)$ referente à simulação em que não considera vazamentos (Tabela 6.15) observa-se uma melhoria global de 55,2\%. Entretanto, quando as pressões são analisadas em pares, para cada padrão de consumo, os resultados não são convincentes. Uma possível discrepância dessas pressões pode estar relacionada às manobras diferenciadas para cada padrão de consumo. No Brasil, manobras noturnas são realizadas com frequência em grande parte dos sistemas de distribuição de água. As 
mesmas são operações rotineiras realizadas com objetivo de reduzir a pressão noturna e, assim, minimizar as perdas por vazamento.

Tabela 6.19 - Parâmetros do modelo pressão-vazamento da rede exemplo 3 para diferentes cenários de consumo (valores médios de cinco populações iniciais)

\begin{tabular}{ccccc}
\hline \hline \multirow{2}{*}{ Setor } & \multicolumn{2}{c}{$\theta\left(\mathrm{x} \mathrm{10^{-7 } )}\right.$} & \multicolumn{2}{c}{$\mathrm{a}$} \\
& Noturno & Diurno & Noturno & Diurno \\
\hline 1 & 0,00 & 0,00 & 0,00 & 0,00 \\
2 & 0,88 & 0,00 & 1,16 & 0,32 \\
3 & 0,72 & 0,66 & 0,10 & 1,14 \\
4 & 0,37 & 0,42 & 0,47 & 1,17 \\
5 & 0,00 & 0,44 & 0,10 & 0,90 \\
\hline \hline
\end{tabular}

Tabela 6.20 -Ajuste das manobras para os diferentes cenários de consumo

\begin{tabular}{ccc}
\hline \hline Manobra & $\begin{array}{c}\text { Coeficiente de perda de carga localizada (K) do Epanet 2 } \\
\text { Noturno }\end{array}$ & Diurno \\
\hline 1 & 1187 & 994 \\
2 & 688 & 10 \\
3 & 367 & 32 \\
4 & 1178 & 132 \\
\hline \hline
\end{tabular}

Tabela 6.21 - Pressões nos nós monitorados (observadas e calibradas considerando manobras e parâmetros de vazamento diferenciados para cada padrão de consumo)

\begin{tabular}{ccccccc}
\hline \multirow{2}{*}{ Ponto } & \multicolumn{2}{c}{ Observada (m.c.a) } & \multicolumn{2}{c}{ Calibrada (m.c.a) } \\
Manobras diferenciadas & \multicolumn{2}{c}{ Erro absoluto } \\
& Noturno & Diurno & Noturno & Diurno & Noturno & Diurno \\
\hline 1 & 73,9 & 50,6 & 72,0 & 47,4 & 1,9 & 3,2 \\
2 & 53,0 & 33,1 & 54,4 & 30,6 & 1,4 & 2,5 \\
3 & 65,1 & 37,6 & 69,0 & 41,0 & 3,9 & 3,4 \\
4 & 33,1 & 20,9 & 26,9 & 4,4 & 6,2 & 16,5 \\
5 & 28,8 & 28,6 & 32,0 & 29,8 & 3,2 & 1,2 \\
6 & 21,1 & 14,5 & 34,3 & 15,4 & 13,2 & 0,9 \\
7 & 23,2 & 15,3 & 46,4 & 25,2 & 23,2 & 9,9 \\
8 & 41,3 & 22,0 & 43,3 & 21,9 & 2,0 & 0,1 \\
9 & 72,0 & 46,0 & 70,8 & 45,7 & 1,2 & 0,3 \\
10 & 75,0 & 45,0 & 76,7 & 47,1 & 1,7 & 2,1 \\
& \multicolumn{5}{c}{ Soma parcial } \\
\end{tabular}

Com decorrer das investigações e analisando as pressões obtidas através da calibração para duas situações (sem e com manobras) percebeu-se que, no sistema RF-1 (rede exemplo 3) ocorre operações (manobras em registros) distintas nos diferentes períodos (noturno e diurno) do dia. Essas operações são muito comuns na maioria dos sistemas existentes e representam soluções alternativas práticas, adotadas pelas companhias de saneamento, para minimizar os vazamentos. Dessa forma, realizou-se um outro estudo 
(terceira tentativa) de calibração com objetivo de identificar manobras e parâmetros de vazamentos distintos para cada padrão de consumo considerado.

As Tabelas 6.19 e 6.20 apresentam os parâmetros calibrados do modelo pressãovazamento referente ao terceiro estudo de calibração (manobras e parâmetros distintos para os diferentes cenários considerados) e os coeficientes de perda de carga localizada ajustados, respectivamente, para cada padrão de consumo considerado. Os valores de pressão, referentes às pressões nos pontos monitorados e os desvios absolutos para cada nó da rede são agrupados na Tabela 6.21. Observe que a soma total desses desvios foi de 98,0 o que resulta em uma melhoria de $75,5 \%$ quando comparado com o desvio das simulações sem considerar vazamentos $(399,3)$. Nota-se também que, no período noturno apenas dois pontos de monitoramento (6 e 7) não apresentaram bons ajustes.

Tabela 6.22 - Manobras calibradas considerando cenários de consumo distintos

\begin{tabular}{|c|c|c|c|c|c|}
\hline & \multirow[b]{2}{*}{ Simulação } & \multicolumn{4}{|c|}{ Coeficiente de perda de carga localizada (K) do Epanet 2} \\
\hline & & 1 & 2 & 3 & 4 \\
\hline \multirow{6}{*}{ 总 } & 1 & 994 & 10 & 32 & 132 \\
\hline & 2 & 1004 & 10 & 10 & 196 \\
\hline & 3 & 1037 & 127 & 160 & 36 \\
\hline & 4 & 1032 & 103 & 10 & 83 \\
\hline & 5 & 1009 & 157 & 57 & 10 \\
\hline & Média & 1015 & 81 & 54 & 91 \\
\hline \multirow{6}{*}{$\begin{array}{l}\stackrel{O}{E} \\
\stackrel{\Xi}{0} \\
\text { Z }\end{array}$} & 1 & 1187 & 688 & 367 & 1178 \\
\hline & 2 & 1167 & 705 & 406 & 1137 \\
\hline & 3 & 1170 & 767 & 406 & 1167 \\
\hline & 4 & 1199 & 570 & 310 & 1191 \\
\hline & 5 & 1195 & 783 & 500 & 1160 \\
\hline & Média & 1184 & 703 & 398 & 1167 \\
\hline
\end{tabular}

Para o período diurno os pontos 4 e 7 não apresentaram bons ajustes. Observe que todos os pontos que não apresentaram bons ajustes pertencem ao setor 2 (Figura 6.32). Um resultado interessante que vale ser destacado é que o procedimento de calibração permitiu identificar a regra operacional adotada pela companhia no setor RF-1 (rede exemplo 3) para diferentes períodos do dia. Isso pode ser verificado observando os ajustes das manobras na Tabela 6.20. Observa-se que no período noturno os registros 1 e 4 (Figura 6.35) são quase que fechados, já os registros 1 e 2 são parcialmente fechados. Através desses resultados (ajuste desses coeficientes) é possível afirmar a existência de manobras diferenciadas nos dois cenários de consumo considerados. 
Todos os estudos de calibração realizados até o momento foram desenvolvidos como etapas preliminares de investigação. Como o modelo de calibração adotado (SOARES, 2003) é baseado em uma técnica de busca estocástica (AGs), várias simulações, utilizando sementes aleatórias distintas, são necessárias para obter resultados confiáveis. Populações iniciais foram consideradas no modelo de calibração para um quarto estudo, que teve como objetivo determinar coeficientes de ajustes médios para cada manobra (cinco sementes aleatórias), em um primeiro passo, e parâmetros de vazamentos globais em um segundo passo (dez sementes aleatórias). Os valores médios das manobras são referentes a cada padrão de consumo. Depois de conhecidas as manobras, as mesmas foram inseridas no modelo de calibração para obter então os parâmetros do modelo pressão-vazamento global (considerando um valor para os dois cenários). Os valores ajustados das manobras são apresentados na Tabela 6.22 e os parâmetros globais calibrados são apresentados na Tabela 6.23 que também apresenta o cálculo do coeficiente de variação para as dez simulações realizadas. O setor 5 apresentou maior variação, em cada simulação, tanto para o coeficiente de vazamento $(\theta)$ quanto para o expoente de vazamento.

Tabela 6.23 - Parâmetros do modelo de vazamentos global

\begin{tabular}{|c|c|c|c|c|c|c|c|c|c|c|}
\hline \multirow[b]{2}{*}{ Simulação } & \multicolumn{5}{|c|}{$\begin{array}{c}\theta\left(\mathrm{x} 10^{-7}\right) \\
\text { Setor }\end{array}$} & \multicolumn{5}{|c|}{$\begin{array}{c}\mathrm{a} \\
\text { Setor }\end{array}$} \\
\hline & 1 & 2 & 3 & 4 & 5 & 1 & 2 & 3 & 4 & 5 \\
\hline 1 & 0,00 & 0,83 & 0,83 & 0,76 & 0,86 & 0,00 & 1,18 & 0,91 & 0,97 & 0,10 \\
\hline 2 & 0,00 & 0,89 & 0,88 & 0,59 & 0,28 & 0,00 & 1,20 & 0,46 & 0,95 & 0,10 \\
\hline 3 & 0,00 & 0,73 & 0,85 & 0,89 & 0,00 & 0,00 & 1,15 & 0,40 & 0,79 & 0,30 \\
\hline 4 & 0,00 & 0,89 & 0,48 & 0,47 & 0,00 & 0,00 & 1,19 & 1,15 & 1,13 & 0,10 \\
\hline 5 & 0,00 & 0,76 & 0,67 & 0,45 & 0,86 & 0,00 & 1,18 & 0,36 & 0,89 & 0,34 \\
\hline 6 & 0,00 & 0,89 & 0,67 & 0,82 & 0,00 & 0,00 & 1,18 & 0,93 & 0,96 & 0,10 \\
\hline 7 & 0,00 & 0,89 & 0,49 & 0,75 & 0,00 & 0,00 & 1,16 & 1,12 & 1,02 & 0,10 \\
\hline 8 & 0,00 & 0,89 & 0,73 & 0,55 & 0,14 & 0,00 & 1,12 & 0,93 & 1,00 & 0,10 \\
\hline 9 & 0,00 & 0,74 & 0,70 & 0,72 & 0,00 & 0,00 & 1,17 & 0,62 & 0,93 & 0,10 \\
\hline 10 & 0,00 & 0,82 & 0,56 & 0,56 & 0,00 & 0,00 & 1,19 & 1,11 & 1,11 & 0,10 \\
\hline Média & 0,00 & 0,83 & 0,69 & 0,66 & 0,21 & 0,00 & 1,17 & 0,80 & 0,98 & 0,14 \\
\hline $\mathrm{CV}$ & - & 0,08 & 0,21 & 0,23 & 1,65 & - & 0,02 & 0,39 & 0,10 & 0,66 \\
\hline
\end{tabular}

Os valores de pressão, referentes às pressões nos pontos monitorados, e os desvios absolutos para cada nó da rede considerando os parâmetros de vazamento global são agrupados nas Tabelas 6.24 e 6.25, respectivamente. Observe que o menor desvio total encontrado foi na simulação 2 , o que resultou em uma melhoria de $76,3 \%$ quando comparado com o desvio das simulações sem considerar vazamentos $(399,3)$. É possível 
afirmar, através dos desvios totais da simulação 2, que a utilização de parâmetros de vazamentos globais apresentam uma ligeira melhoria quando comparado como o estudo que identificou parâmetros de vazamentos distintos $(75,5 \%)$ para os diferentes cenários.

Tabela 6.24 - Pressões calibradas considerando parâmetros de vazamentos globais

\begin{tabular}{|c|c|c|c|c|c|c|c|c|c|c|c|c|c|}
\hline & \multirow{3}{*}{ Ponto } & \multirow{3}{*}{ Nó } & \multicolumn{10}{|c|}{ Calibrada (m.c.a.) } & \multirow[t]{3}{*}{ Observada (m.c.a.) } \\
\hline & & & \multicolumn{10}{|c|}{ Simulação } & \\
\hline & & & 1 & 2 & 3 & 4 & 5 & 6 & 7 & 8 & 9 & 10 & \\
\hline \multirow{10}{*}{$\begin{array}{l}\text { O } \\
\text { Z् } \\
\text { Z }\end{array}$} & 1 & 128 & 69,7 & 70,6 & 70,8 & 70,2 & 71,0 & 69,7 & 69,0 & 70,0 & 71,9 & 72,0 & 73,9 \\
\hline & 2 & 86 & 54,1 & 54,3 & 54,2 & 54,2 & 54,3 & 54,2 & 54,1 & 54,2 & 54,4 & 54,5 & 53,0 \\
\hline & 3 & 106 & 64,6 & 66,3 & 66,8 & 65,5 & 67,3 & 64,6 & 63,3 & 65,4 & 69,0 & 69,0 & 65,1 \\
\hline & 4 & 32 & 27,3 & 26,9 & 27,6 & 27,0 & 27,1 & 27,1 & 27,3 & 27,4 & 27,0 & 26,6 & 33,1 \\
\hline & 5 & 14 & 32,1 & 32,0 & 32,1 & 32,0 & 32,0 & 32,1 & 32,1 & 32,1 & 32,0 & 32,0 & 28,8 \\
\hline & 6 & 6 & 34,8 & 34,4 & 35,1 & 34,5 & 34,5 & 34,6 & 34,8 & 34,9 & 34,4 & 34,1 & 21,1 \\
\hline & 7 & 25 & 46,3 & 45,9 & 46,6 & 46,1 & 46,3 & 46,2 & 46,4 & 46,5 & 46,3 & 46,1 & 23,2 \\
\hline & 8 & 50 & 43,1 & 43,2 & 43,1 & 43,2 & 43,2 & 43,1 & 43,1 & 43,1 & 43,3 & 43,4 & 41,3 \\
\hline & 9 & 122 & 68,4 & 69,4 & 69,6 & 69,0 & 69,8 & 68,5 & 67,8 & 68,8 & 70,7 & 70,7 & 72,0 \\
\hline & 10 & 115 & 71,2 & 73,3 & 74,0 & 72,3 & 74,6 & 71,2 & 69,4 & 72,2 & 76,7 & 76,8 & 75,0 \\
\hline \multirow{10}{*}{ 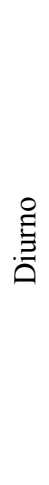 } & 1 & 128 & 48,3 & 48,8 & 48,9 & 48,7 & 49,0 & 48,4 & 48,1 & 48,6 & 49,5 & 49,6 & 50,6 \\
\hline & 2 & 86 & 33,5 & 33,6 & 33,5 & 33,6 & 33,6 & 33,5 & 33,5 & 33,5 & 33,8 & 33,8 & 33,1 \\
\hline & 3 & 106 & 39,1 & 40,2 & 40,6 & 39,9 & 41,0 & 39,1 & 38,4 & 39,8 & 42,4 & 42,4 & 37,6 \\
\hline & 4 & 32 & 4,1 & 3,9 & 4,2 & 3,9 & 3,9 & 4,0 & 4,0 & 4,0 & 3,9 & 3,7 & 20,9 \\
\hline & 5 & 14 & 29,7 & 29,7 & 29,7 & 29,7 & 29,7 & 29,7 & 29,7 & 29,7 & 29,7 & 29,7 & 28,6 \\
\hline & 6 & 6 & 14,7 & 14,5 & 14,8 & 14,5 & 14,5 & 14,6 & 14,6 & 14,7 & 14,4 & 14,2 & 14,5 \\
\hline & 7 & 25 & 26,1 & 25,9 & 26,2 & 26,0 & 26,1 & 26,0 & 26,1 & 26,1 & 26,1 & 26,1 & 15,3 \\
\hline & 8 & 50 & 24,6 & 24,7 & 24,6 & 24,7 & 24,7 & 24,6 & 24,6 & 24,7 & 24,8 & 24,9 & 22,0 \\
\hline & 9 & 122 & 46,4 & 46,9 & 47,0 & 46,8 & 47,1 & 46,5 & 46,2 & 46,7 & 47,6 & 47,6 & 46,0 \\
\hline & 10 & 115 & 43,8 & 45,2 & 45,8 & 44,8 & 46,3 & 43,7 & 42,8 & 44,7 & 48,2 & 48,1 & 45,0 \\
\hline
\end{tabular}

A Tabela 6.26 apresenta as vazões abastecidas calibradas, para as diferentes simulações, e a vazão abastecida real para os diferentes cenários de consumo considerados. Observe que o ajuste do balanço de massa é muito eficiente. Isso pode ser verificado no cálculo dos desvios relativos apresentado pela Tabela 6.27.

Como forma de realizar uma análise mais detalhada da solução que apresentou o menor desvio total (simulação 2 - Tabela 6.25) foi construída a Tabela 6.28. Observe que para o período noturno os pontos 4, 6 e 7 continuam apresentar os piores ajustes conforme discutido anteriormente. No período diurno, os piores resultados são encontrados nos pontos 4 e 7 . Esses pontos (4, 6 e 7) pertencem ao setor 2 conforme Figura 6.32. Algumas fontes de incerteza estão associadas a esses pontos merecendo ser mencionadas. 
Existe uma indefinição na estimativa da demanda referente ao ponto 4. Os dados estimados de demanda utilizados no presente trabalho foram obtidos de um estudo de demanda realizado em 1996 pela companhia. Naquela época, toda área próxima ao ponto 4 era abastecida pelo sistema RF-1. Entretanto, durante o levantamento de campo realizado para este trabalho, observou-se que um sistema isolado, contendo um bomba de sucção de água subterrânea, estava abastecendo parte da área de influência do ponto 4. Nota-se portanto que as demandas reais, referente ao ano de 2003, deveriam ser menores que as de 1996. Observa-se então na Tabela 6.28 o porquê das pressões observadas serem maiores do que as pressões calibradas, pois há menos consumo do que o estimado para aquele ponto.

Tabela 6.25 - Pressões calibradas considerando parâmetros de vazamentos globais

\begin{tabular}{|c|c|c|c|c|c|c|c|c|c|c|c|c|}
\hline \multirow{3}{*}{ Padrão } & \multirow{3}{*}{ Ponto } & \multirow{3}{*}{ Nó } & \multicolumn{10}{|c|}{ Erro absoluto } \\
\hline & & & \multicolumn{10}{|c|}{ Simulação } \\
\hline & & & 1 & 2 & 3 & 4 & 5 & 6 & 7 & 8 & 9 & 10 \\
\hline \multirow{10}{*}{$\begin{array}{l}\stackrel{0}{E} \\
\text { E् } \\
\text { Z }\end{array}$} & 1 & 128 & 4,25 & 3,27 & 3,13 & 3,72 & 2,86 & 4,15 & 4,88 & 3,86 & 1,97 & 1,92 \\
\hline & 2 & 86 & 1,15 & 1,27 & 1,18 & 1,24 & 1,31 & 1,18 & 1,13 & 1,19 & 1,43 & 1,50 \\
\hline & 3 & 106 & 0,51 & 1,22 & 1,69 & 0,38 & 2,16 & 0,48 & 1,84 & 0,26 & 3,85 & 3,89 \\
\hline & 4 & 32 & 5,83 & 6,24 & 5,48 & 6,15 & 6,01 & 5,98 & 5,81 & 5,69 & 6,07 & 6,48 \\
\hline & 5 & 14 & 3,26 & 3,24 & 3,27 & 3,24 & 3,24 & 3,25 & 3,26 & 3,26 & 3,23 & 3,21 \\
\hline & 6 & 6 & 13,68 & 13,30 & 13,96 & 13,36 & 13,44 & 13,53 & 13,65 & 13,75 & 13,35 & 12,95 \\
\hline & 7 & 25 & 23,06 & 22,74 & 23,42 & 22,88 & 23,08 & 22,96 & 23,22 & 23,30 & 23,13 & 22,90 \\
\hline & 8 & 50 & 1,79 & 1,86 & 1,81 & 1,86 & 1,92 & 1,81 & 1,82 & 1,84 & 2,00 & 2,07 \\
\hline & 9 & 122 & 3,56 & 2,57 & 2,45 & 3,03 & 2,19 & 3,45 & 4,20 & 3,18 & 1,32 & 1,27 \\
\hline & 10 & 115 & 3,83 & 1,66 & 0,98 & 2,74 & 0,41 & 3,85 & 5,57 & 2,83 & 1,73 & 1,76 \\
\hline Soma Parcial & & & 60,91 & 57,38 & 57,38 & 58,60 & 56,62 & 60,65 & 65,36 & 59,15 & 58,09 & 57,96 \\
\hline \multirow{10}{*}{$\stackrel{\stackrel{\Xi}{\Xi}}{\stackrel{\Xi}{\Xi}}$} & 1 & 128 & 2,27 & 1,82 & 1,74 & 1,93 & 1,56 & 2,22 & 2,46 & 2,00 & 1,06 & 1,05 \\
\hline & 2 & 86 & 0,37 & 0,48 & 0,42 & 0,48 & 0,55 & 0,39 & 0,38 & 0,44 & 0,67 & 0,72 \\
\hline & 3 & 106 & 1,53 & 2,62 & 3,02 & 2,30 & 3,41 & 1,50 & 0,80 & 2,19 & 4,84 & 4,80 \\
\hline & 4 & 32 & 16,82 & 16,98 & 16,72 & 16,97 & 16,97 & 16,89 & 16,86 & 16,86 & 17,05 & 17,16 \\
\hline & 5 & 14 & 1,11 & 1,10 & 1,11 & 1,09 & 1,09 & 1,10 & 1,10 & 1,10 & 1,07 & 1,06 \\
\hline & 6 & 6 & 0,22 & 0,03 & 0,34 & 0,01 & 0,01 & 0,14 & 0,14 & 0,16 & 0,12 & 0,31 \\
\hline & 7 & 25 & 10,77 & 10,64 & 10,92 & 10,71 & 10,79 & 10,73 & 10,85 & 10,85 & 10,81 & 10,75 \\
\hline & 8 & 50 & 2,60 & 2,66 & 2,63 & 2,68 & 2,73 & 2,62 & 2,64 & 2,66 & 2,81 & 2,86 \\
\hline & 9 & 122 & 0,42 & 0,89 & 0,96 & 0,77 & 1,12 & 0,49 & 0,24 & 0,70 & 1,60 & 1,61 \\
\hline & 10 & 115 & 1,22 & 0,21 & 0,78 & 0,23 & 1,29 & 1,30 & 2,24 & 0,35 & 3,20 & 3,14 \\
\hline Soma Parcial & & & 37,33 & 37,42 & 38,64 & 37,16 & 39,51 & 37,38 & 37,70 & 37,30 & 43,23 & 43,45 \\
\hline Soma Total & & & 98,24 & 94,80 & 96,01 & 95,76 & 96,13 & 98,02 & 103,06 & 96,45 & 101,32 & 101,41 \\
\hline
\end{tabular}

Já o ponto 6 apresentou um resultado muito interessante. No período diurno, houve um ótimo ajuste em relação à pressão observada por outro lado no período noturno à 
pressão observada apresentou menor nível piezométrico do que as calibradas. Concluise que alguma operação é realizada no período noturno para aliviar a pressão do ponto 6 ou que existe alguma singularidade desconhecida pela companhia naquele setor. Foi levantada a hipótese que, outras manobras estariam sendo realizadas no período noturno no setor 2 afetando dessa forma a pressão no ponto. No entanto, segundo a companhia de saneamento as manobras só ocorrem nos locais determinados pela Figura 6.35.

Tabela 6.26 - Vazões abastecidas calibradas e observadas considerando parâmetros de vazamentos globais

\begin{tabular}{|c|c|c|c|c|c|c|c|c|c|c|c|c|}
\hline \multirow{4}{*}{ Padrão } & \multirow{4}{*}{ Trecho } & \multicolumn{11}{|c|}{ Vazão abastecida (L/s) } \\
\hline & & \multicolumn{10}{|c|}{ Calibrada } & Observada \\
\hline & & \multicolumn{10}{|c|}{ Simulação } & \\
\hline & & 1 & 2 & 3 & 4 & 5 & 6 & 7 & 8 & 9 & 10 & \\
\hline Noturno & 118 & 247,0 & 247,0 & 247,0 & 247,0 & 247,0 & 247,0 & 247,0 & 247,0 & 246,9 & 246,9 & 246,94 \\
\hline Diurno & 118 & 457,4 & 457,4 & 457,4 & 457,4 & 457,4 & 457,4 & 457,4 & 457,4 & 457,4 & 457,4 & 457,50 \\
\hline
\end{tabular}

Tabela 6.27 - Erro relativo da vazão calibrada

\begin{tabular}{|c|c|c|c|c|c|c|c|c|c|c|}
\hline \multirow{3}{*}{ Padrão } & \multicolumn{10}{|c|}{ Erro relativo (\%) } \\
\hline & \multicolumn{10}{|c|}{ Simulação } \\
\hline & 1 & 2 & 3 & 4 & 5 & 6 & 7 & 8 & 9 & 10 \\
\hline Noturno & 0,03 & 0,03 & 0,04 & 0,04 & 0,03 & 0,03 & 0,03 & 0,03 & $-0,03$ & $-0,03$ \\
\hline Diurno & $-0,02$ & $-0,02$ & $-0,02$ & $-0,02$ & $-0,02$ & $-0,02$ & $-0,02$ & $-0,02$ & $-0,02$ & $-0,02$ \\
\hline
\end{tabular}

Em relação ao ponto 7, os desvios apresentados representam alívios de pressão tanto no período diurno quanto no período noturno. Segundo informações da companhia isso acontece porque recentemente foi construída uma derivação, próxima a esse ponto, para atender um bairro próximo.

Outras possíveis fontes de incerteza pode ser mencionadas, por exemplo, os erros de leitura dos equipamentos (medidores de pressão e vazão), a localização errada de monitoramento de pressão devido a cadastros desatualizados (estar monitorando um sistema isolado ao invés do sistema RF-1), erros nas estimativas de demandas nodais, coeficientes de rugosidade das tubulações e singularidades (válvulas) desconhecidas.

Reconhecendo a complexidade do problema de calibração, as incertezas adversas existentes e a dimensão do sistema real (atendimento de 100.000 habitantes), conclui-se que o modelo de calibração apresentou bons resultados para estimativa dos parâmetros 
de vazamento. Esses parâmetros são essenciais para as análises que consideram sistema existente, por exemplo, as análises de reabilitação. Entretanto, um estudo mais detalhado (demandas, cadastros dentre outros) pode ser realizado futuramente no setor 2 de forma obter ajustes mais acurados aos pontos 4,6 e 7 .

Tabela 6.28 - Análise detalhada da solução de menor desvio absoluto total (simulação 2) considerando parâmetros de vazamento globais

\begin{tabular}{|c|c|c|c|c|}
\hline & & \multicolumn{2}{|c|}{ Pressão (m.c.a.) } & \multirow[t]{2}{*}{ Erro absoluto } \\
\hline & & Calibrada & Observada & \\
\hline \multirow{10}{*}{ 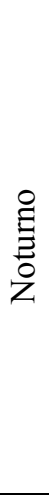 } & 1 & 69,7 & 73,9 & 4,2 \\
\hline & 2 & 54,1 & 53,0 & 1,1 \\
\hline & 3 & 64,6 & 65,1 & 0,5 \\
\hline & 4 & 27,3 & 33,1 & 5,8 \\
\hline & 5 & 32,1 & 28,8 & 3,3 \\
\hline & 6 & 34,8 & 21,1 & 13,7 \\
\hline & 7 & 46,3 & 23,2 & 23,1 \\
\hline & 8 & 43,1 & 41,3 & 1,8 \\
\hline & 9 & 68,4 & 72,0 & 3,6 \\
\hline & 10 & 71,2 & 75,0 & 3,8 \\
\hline \multirow{10}{*}{ 兽 } & 1 & 48,3 & 50,6 & 2,3 \\
\hline & 2 & 33,5 & 33,1 & 0,4 \\
\hline & 3 & 39,1 & 37,6 & 1,5 \\
\hline & 4 & 4,1 & 20,9 & 16,8 \\
\hline & 5 & 29,7 & 28,6 & 1,1 \\
\hline & 6 & 14,7 & 14,5 & 0,2 \\
\hline & 7 & 26,1 & 15,3 & 10,8 \\
\hline & 8 & 24,6 & 22,0 & 2,6 \\
\hline & 9 & 46,4 & 46,0 & 0,4 \\
\hline & 10 & 43,8 & 45,0 & 1,2 \\
\hline
\end{tabular}

REIS et al. (2003) avaliou parâmetros do modelo de vazamentos para setores da cidade de São Carlos - SP através de teste noturnos de vazamentos. Foram empregados dois métodos para determinação dos valores $\theta$ e a do modelo de vazamentos. O primeiro método, baseado em análises de regressão, identificou valores para a entre 1,15 e 1,18. O segundo método, baseado em um procedimento inverso, identificou valores de a entre 0,49 e 1,1 .

No presente trabalho, os valores obtidos para o expoente de vazamentos (Tabela 6.17), se apresentaram no intervalo entre 0,10 e 1,16, condizentes com os resultados apresentados na literatura por GERMANOPOULOS e JOWITT (1989), TUCCIARELLI, CRIMINISI e TERMINI (1999) e REIS et al. (2003). Através dessas 
investigações pode-se afirmar que cada sistema tem seus parâmetros característicos, reafirmando a necessidade de um procedimento de calibração.

Os parâmetros de vazamento adotados para o estudo de caso real, que serão realizados posteriormente no presente trabalho, são apresentados na Tabela 6.29 (simulação 2). Esses parâmetros foram escolhidos por apresentarem o menor desvio total absoluto $(94,80)$ considerando os dois cenários de consumo.

Tabela 6.29 - Parâmetros de vazamento utilizados nas análises de reabilitação

\begin{tabular}{|c|c|c|c|c|c|c|c|c|c|c|}
\hline \multirow[b]{2}{*}{ Simulação } & \multicolumn{5}{|c|}{$\begin{array}{c}\theta\left(\times 10^{-7}\right) \\
\text { Setor }\end{array}$} & \multicolumn{5}{|c|}{$\begin{array}{c}\mathrm{a} \\
\text { Setor }\end{array}$} \\
\hline & 1 & 2 & 3 & 4 & 5 & 1 & 2 & 3 & 4 & 5 \\
\hline 2 & 0,00 & 0,89 & 0,88 & 0,59 & 0,28 & 0,00 & 1,20 & 0,46 & 0,95 & 0,10 \\
\hline
\end{tabular}

Tabela 6.30 - Estimativa das perdas físicas do setor RF-1 no período diurno

\begin{tabular}{|c|c|c|c|c|c|c|c|c|c|}
\hline \multicolumn{10}{|c|}{ Vazamentos (L/s) } \\
\hline \multicolumn{5}{|c|}{$\begin{array}{l}\text { Sem Manobras } \\
\text { Setor }\end{array}$} & \multicolumn{5}{|c|}{$\begin{array}{c}\text { Com Manobras } \\
\text { Setor }\end{array}$} \\
\hline 1 & 2 & 3 & 4 & 5 & 1 & 2 & 3 & 4 & 5 \\
\hline 0,00 & 39,73 & 13,01 & 11,39 & 0,33 & 0,00 & 19,50 & 10,00 & 7,74 & 0,32 \\
\hline Total & & & & 64,46 & & Total & & & 37,56 \\
\hline
\end{tabular}

Tabela 6.31 - Estimativa das perdas físicas do setor RF-1 no período noturno

\begin{tabular}{|c|c|c|c|c|c|c|c|c|c|}
\hline \multicolumn{10}{|c|}{ Vazamentos (L/s) } \\
\hline \multicolumn{5}{|c|}{$\begin{array}{c}\text { Sem Manobras } \\
\text { Setor }\end{array}$} & \multicolumn{5}{|c|}{$\begin{array}{c}\text { Com Manobras } \\
\text { Setor }\end{array}$} \\
\hline 1 & 2 & 3 & 4 & 5 & 1 & 2 & 3 & 4 & 5 \\
\hline 0,00 & 50,08 & 13,44 & 13,02 & 0,34 & 0,00 & 40,94 & 12,50 & 11,41 & 0,33 \\
\hline Total & & & & 76,88 & Total & & & & 65,18 \\
\hline
\end{tabular}

Utilizando os parâmetros calibrados do modelo pressão-vazamento (Tabela 6.29), foram realizados quatros simulações para os dois cenários de consumo adotados (diurno e noturno). Foram também estimadas as perdas físicas (vazamentos - Tabelas 6.30 e 6.31 ) do setor RF-1 para os dois períodos considerados (diurno e noturno) através do simulador hidráulico proposto e a demanda realmente atendida (Tabela 6.32).

Observa-se na Tabela 6.30 que se não houver manobras na rede, durante o período diurno, a perda física estimada para o sistema será de 64,46 L/s. Considerando a vazão 
abastecida para esse período de 457,5, obtém-se o índice de vazamentos de 14,1\%. Considerando manobras, para o mesmo período, o índice de vazamentos apresenta-se em torno de $8,2 \%$.

Para o período noturno, se não forem realizadas manobras, as perdas por vazamento giram em torno de $31,1 \%$, considerando um vazão abastecida de 246,94 L/s (dados observados). Caso sejam realizadas manobras, as perdas por vazamento são de $26,40 \%$. As Tabelas 6.30 e 6,31 apresentam também as estimativas de vazamentos para cada setor de rede considerado (Figura 6.32).

Tabela 6.32 - Demanda efetivamente atendida e confiabilidade hidráulica do setor RF-1 (modelo simplificado real - rede exemplo 3)

\begin{tabular}{lcccc}
\hline \hline & \multicolumn{2}{c}{ Diurno } & \multicolumn{2}{c}{ Noturno } \\
& S/ manobras & C/ manobras & S/ manobras & C/ manobras \\
\hline D. Atendida* (L/s) & 393,1 & 419,8 & 170,1 & 181,8 \\
Confiabilidade & 0,81 & 0,86 & 0,35 & 0,37 \\
Demanda de referência $=486,7 \mathrm{~L} / \mathrm{s} ;$ Confiabilidade $=*$ Demanda Atendida / Demanda de Referência \\
\hline \hline
\end{tabular}

A Tabela 6.32 apresenta os somatórios das demandas efetivamente atendidas nos nós da rede exemplo 3 (modelo simplificado real) para ambos os períodos considerados e a demanda de referência. A razão entre a demanda atendida e a demanda de referência possibilita calcular a confiabilidade hidráulica do sistema, segundo a proposição de TANYIMBOH, TABESH e BURROWS (2001). Observe que para o período diurno sem manobras, o sistema é menos confiável do que para o período diurno com manobras. A situação denominada "com manobras" reduz a pressão atuante no sistema e consequentemente reduz os vazamentos, favorecendo ao atendimento de demanda nos nós. No período noturno a confiabilidade é baixa, pois as demandas requeridas nos nós são bem inferiores que no período diurno. Através desse cálculo simples de confiabilidade hidráulica é possível demonstrar a vantagem de se utilizar o simulador hidráulico dirigido pela pressão. Essa confiabilidade hidráulica é um índice global de avaliação, pois considera as falhas no sistema que comprometem o atendimento das demandas nodais. Vale lembrar que essas são as falhas mais comuns nos sistemas existentes. 


\subsection{Análise de reabilitação através da otimização multiobjetivo estática - estudo de caso real}

O planejamento da reabilitação de redes de distribuição de água através da otimização multiobjetivo estática considera algumas hipóteses simplificadoras. A primeira delas assegura que as ações de reabilitação sejam implementadas no início do período de planejamento. No caso em estudo (rede exemplo 3), foi adotado um horizonte de 15 anos, embora as avaliações das funções objetivo tenham sido realizadas em períodos menores (cinco anos) a partir de 2003. O custo de reabilitação é calculado uma única vez, pois supõe-se que as ações de reabilitação sejam implementadas no primeiro ano do horizonte de planejamento. Os benefícios, os vazamentos e a confiabilidade são valores médios representativos das condições do sistema em 2008, 2013 e 2018, como resposta às demandas projetadas. Uma segunda hipótese diz respeito ao estado da rede (rugosidades, etc), que permanece inalterado durante os quinze anos de planejamento. A terceira hipótese está relacionada à evolução temporal dos parâmetros de vazamentos que foram considerados (Tabela 6.29) constantes para o período de planejamento, por falta de dados de evolução dos mesmos ao longo do tempo. Na verdade, tais parâmetros mudam em função de diversos fatores: tempo, níveis piezométricos, deterioração das componentes da rede, tráfego, tipo de solo, dentre outros. Finalmente, pode-se dizer que, além dos custos de investimentos existem outros custos que afetam as decisões do problema e que não foram considerados no presente trabalho. Por exemplo, os vazamentos impõem um custo adicional relativo ao tratamento e bombeamento da parcela adicional de água abastecida que é perdida. Essas simplificações podem representar soluções não realísticas na tomada de decisão. Entretanto, a metodologia proposta no presente trabalho é um esforço em tentar abranger e considerar os diversos fatores que interferem no problema complexo de reabilitação de redes de distribuição de água. Além disso, o procedimento descrito nesse item (otimização multiobjetivo estática) pode ser empregado como ferramenta de análise preliminar no processo de tomada de decisão.

Nessa seção são apresentados os resultados das análises de reabilitação para o estudo de caso real (rede exemplo 3), utilizando a metodologia proposta no capítulo 5. Como esse problema é de natureza multiobjetivo, quatro funções objetivo foram consideradas: minimização de custos (e.q. 5.1), maximização de benefícios (eq. 5.6), minimização de vazamentos (eq. 5.7) e maximização da confiabilidade (eq. 5.8). As avaliações 
hidráulicas foram conduzidas com uso do simulador hidráulico iterativo (5.5.4) desenvolvido pelo autor deste trabalho. Os parâmetros utilizados para o modelo de vazamentos são apresentados na Tabela 6.29. O método de otimização multiobjetivo utilizado foi o SPEA, o qual apresentou melhor desempenho, segundo estudos teóricos apresentados no item 6.2. O vetor de decisão contou com 148 variáveis de decisão, que correspondem ao número de trechos do sistema. A Tabela 5.14 apresenta as ações de reabilitação consideradas para esse estudo. Os custos dessas ações de reabilitação são apresentados na Tabela 5.15, os quais foram adaptados do trabalho de WALTERS et al. (1999).

Os parâmetros adotados para o método de otimização via algoritmos genéticos multiobjetivo foram: dimensão da população inicial de soluções igual a 150, número máximo de gerações igual a 400, probabilidade de recombinação igual 0,9 e probabilidade de mutação igual a 0,1 . Os operadores de recombinação e mutação utilizados foram o BLX- $\alpha$ e a mutação não uniforme, respectivamente, os quais apresentaram melhor desempenho para o problema de reabilitação, conforme discutido no item 6.2 deste capítulo.

As simulações foram desenvolvidas através do procedimento geral apresentado pela Figura 5.1. Como o objetivo principal do planejamento é fornecer tecnicamente e economicamente ações de reabilitação que atendam demandas futuras, no presente estudo as demandas nodais foram projetadas para o ano de 2018, conforme o plano diretor (SANDIM et al., 2002) referente a esse sistema (rede exemplo 3). A Frente Pareto obtida através dessas simulações, é apresentada no espaço de objetivos aos pares através da Figura 6.36. Observe que tais valores correspondem às soluções ótimas Pareto, não inferiores ou não dominadas (conforme definição do capítulo 4). Essas soluções representam planos alternativos de reabilitação a serem implementados na rede. É evidente que a otimização multiobjetivo apresenta uma relação de compromisso entre os objetivos considerados, ao contrário do que acontece na otimização de objetivo único, que atende apenas um critério. 


\section{Custos}
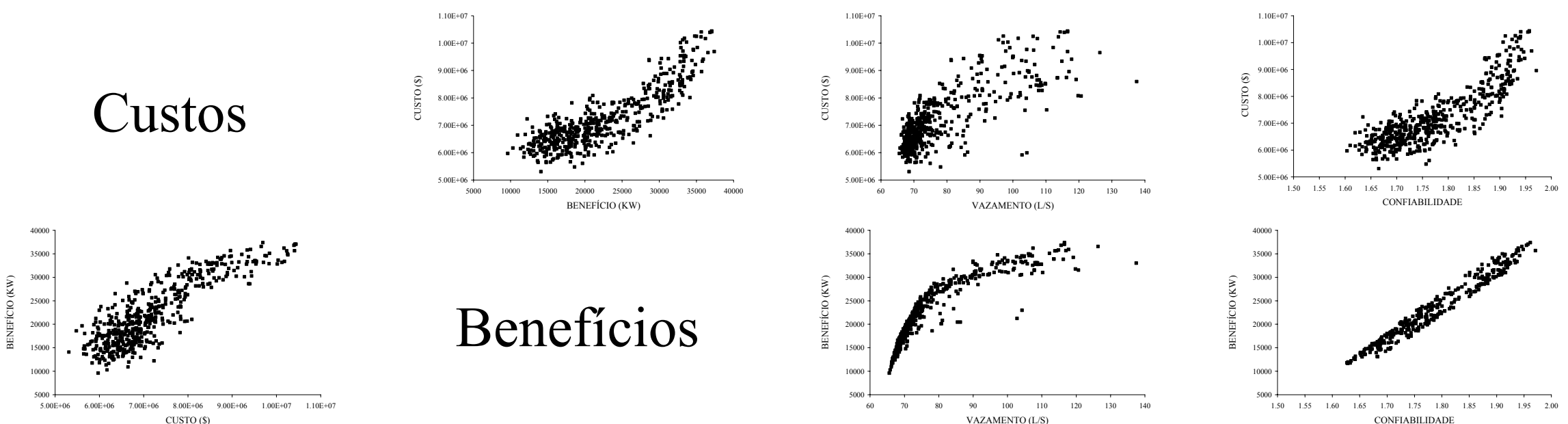

\section{Benefícios}
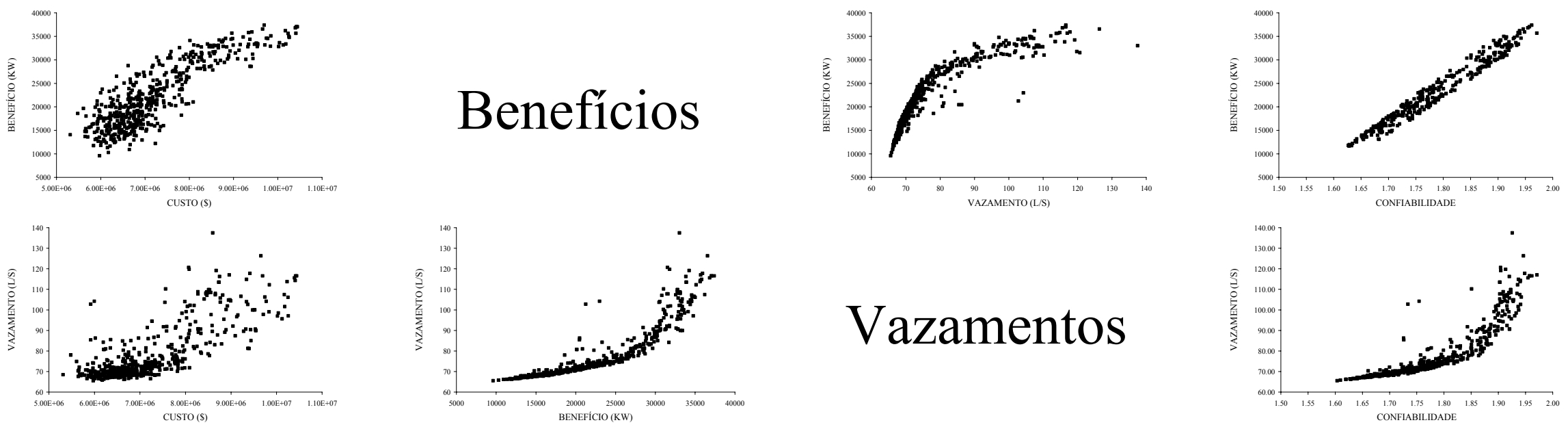

\section{Vazamentos}
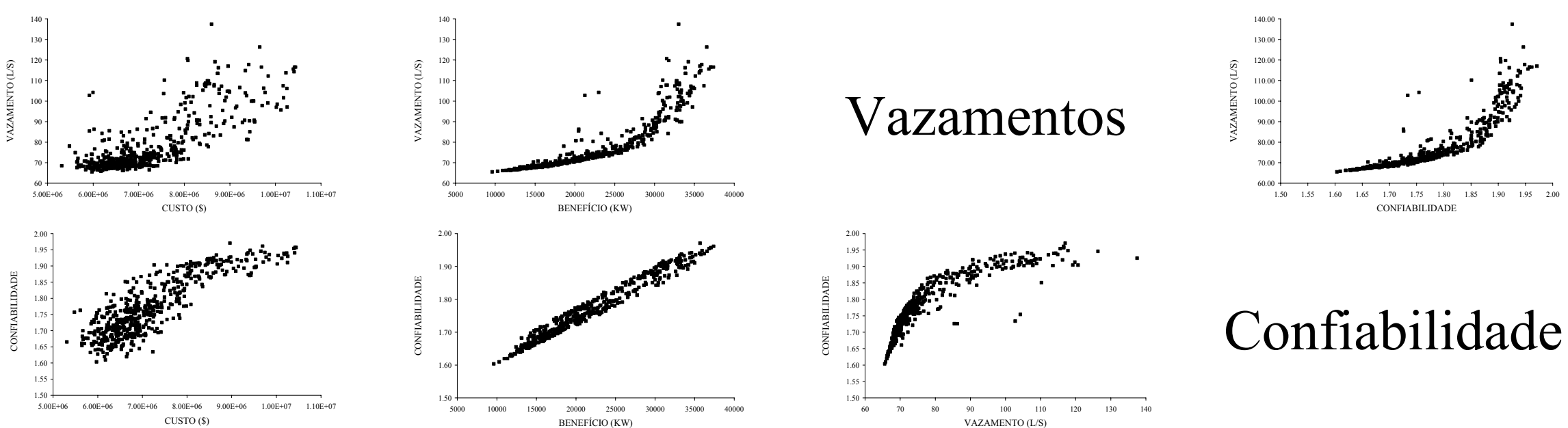

Confiabilidade

Figura 6.36 - Frente Pareto obtida através da otimização multiobjetivo estática para estudo de caso real 
As soluções obtidas da análise de reabilitação estática (Figura 6.36) mostradas aqui, apresentam custos variando no intervalo entre $\$ 5.000 .000$ (limite inferior) a $\$ 11.000 .000$ (limite superior), benefícios no intervalo de 5000 a $40000 \mathrm{KW}$, vazamentos entre 60 a $140 \mathrm{~L} / \mathrm{s}$ e confiabilidade (resiliência) entre 1,60 a 2,00. Observase (Figura 6.36) que a curva de custos contra benefícios, exibe um aglomerado de pontos que representam as soluções no intervalo de benefícios entre 10000 a $20000 \mathrm{KW}$ (soluções com custos baixos), indicando que a função objetivo custo pode apresentar valores muito semelhantes, e até mesmo iguais, para diferentes combinações de variáveis de decisão. Observe que todos os gráficos que consideram custo, em um de seus eixos, apresentam esse "aglomerado" de soluções

A Frente Pareto da Figura 6.36 mostra que na curva benefícios contra vazamentos há um tendência de crescimento exponencial dos benefícios a partir de determinado valor (no caso, $25.000 \mathrm{KW}$ ), ou seja, soluções com vazamentos elevados nem sempre correspondem a maiores benefícios. Por exemplo, soluções que apresentam diferentes valores de vazamentos podem apresentar o mesmo valor em termos de benefícios. A mesma análise pode ser feita entre custo e confiabilidade. Para exemplificar, considere o gráfico que apresenta a confiabilidade no eixo das abscissas e custo no eixo das ordenadas. Considere duas soluções, a primeira com custo próximo a $\$ 9.000 .000,0$ e a outra com custo próximo a $\$ 15.000 .000,00$. A diferença de custo entre essas soluções é de $\$ 6.000 .000,0$ (valor significativo). Observe que a confiabilidade apresentada por ambas soluções é praticamente a mesma, em torno de 1.92. Pode-se concluir, então, que nem sempre um investimento financeiro elevado (estratégia geralmente adotada pelas companhias de saneamento) para um sistema, garante maior confiabilidade, e que, os benefícios (medida da eficiência do sistema em termos de capacidade hidráulica) gerados por alguma ação de reabilitação têm um limite, a partir do qual a decisão de reabilitação estará elevando os investimentos de capital e contribuindo para os vazamentos.

Observando a curva de benefícios contra confiabilidade, nota-se que há uma forte relação (relação linear) entre os mesmos, porque ambos são função do excesso de pressão nodal. Tal comportamento sugere que apenas um desses objetivos possam ser considerados em análises futuras.

O problema de planejamento de reabilitação de redes de distribuição de água tratado no presente estudo foi formulado como um problema multiobjetivo (quatro objetivos). As 
soluções não dominadas produzidas pela otimização (Figura 6.36) representam o compromisso entre os diversos critérios considerados (custos, benefícios, vazamentos e confiabilidade). Depois de geradas as soluções ótimas, a dificuldade reside na escolha da solução que melhor satisfaça o decisor, a política de utilidade do sistema e os recursos financeiros disponíveis. Geralmente, essa escolha é realizada de modo subjetivo, baseada principalmente no julgamento e experiência do decisor, que sem dúvida não devem ser descartados no processo de planejamento. Entretanto, quando um problema envolve mais que três objetivos a visualização e a interpretação das soluções tornam-se complexas, dificultando ao decisor escolher uma solução. No presente trabalho, adotou-se a metodologia proposta por NEIMANE (2001), descrita no item 5.9, que utilizou a Análise de Componentes Principais (ACP) para identificar soluções da frente Pareto que apresentam similaridades. Segundo EVSUKOFF e EBECKEN (2003), a ACP está inserida nas técnicas de mineração de dados (Data Mining), que são técnicas de pesquisa multidisciplinar que envolve conceitos de estatística, aprendizado de máquinas, banco de dados, sistemas especialistas, técnicas de visualização de dados e computação de alto desempenho.

Tabela 6.33 - Autovalores da matriz de dados referentes aos resultados da otimização estática

\begin{tabular}{ccccc}
\hline \hline & \multicolumn{4}{c}{ Número de fatores } \\
& 1 & 2 & 3 & 4 \\
Autovalor & 3,6213 & 0,2232 & 0,1391 & 0,0169 \\
Proporção & 0,905 & 0,056 & 0,035 & 0,004 \\
Cumulativo & 0,905 & 0,961 & 0,996 & 1,000 \\
\hline \hline
\end{tabular}

Considerando as soluções não dominadas da Figura 6.36 na composição da matriz de dados X (item 5.9) e utilizando o pacote computacional de análise estatística MINITAB (versão demonstrativa), foi possível aplicar a técnica de ACP. As linhas da matriz correspondem às soluções encontradas durante o processo de otimização (frente Pareto) e as colunas representam as funções objetivo (custo, benefícios, vazamentos e confiabilidade) dessas soluções. O número total de soluções encontradas foi 520, e por razões de espaço não são apresentadas aqui. A Tabela 6.33 apresenta os autovalores 
calculados a partir da matriz de dados e a proporção de variância individual e cumulativa em relação ao número de componentes principais.

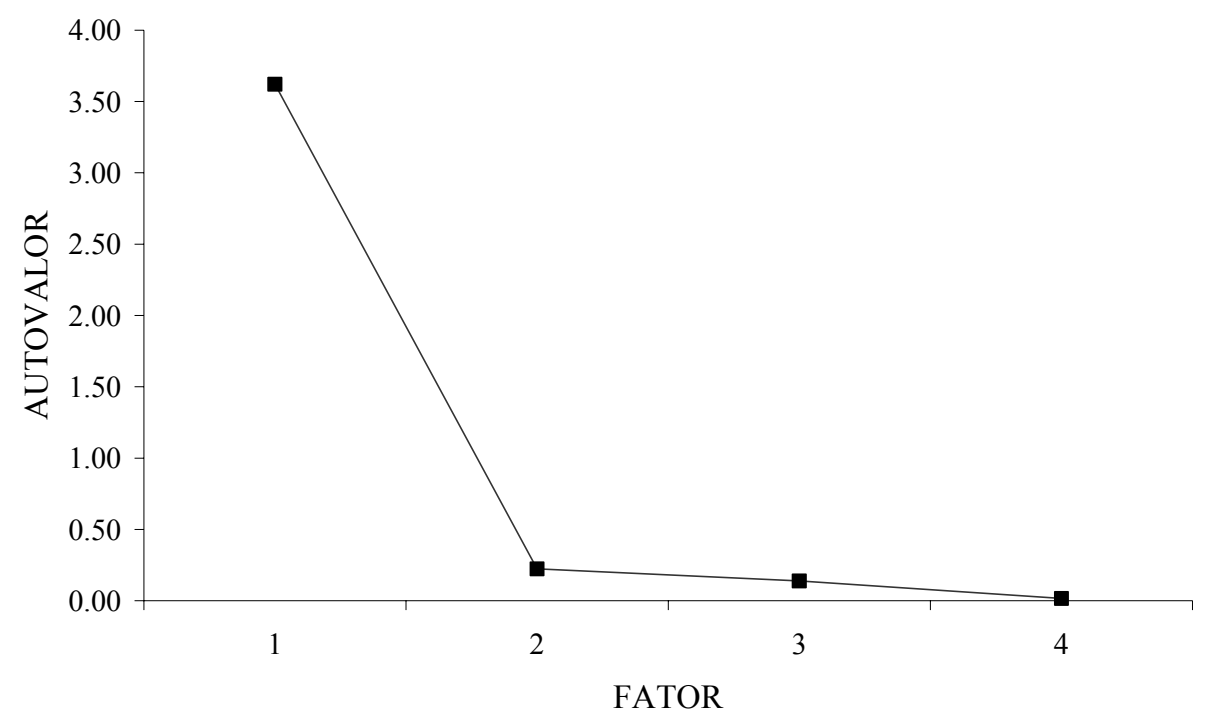

Figura 6.37 - Autovalores contra número de fatores - otimização estática

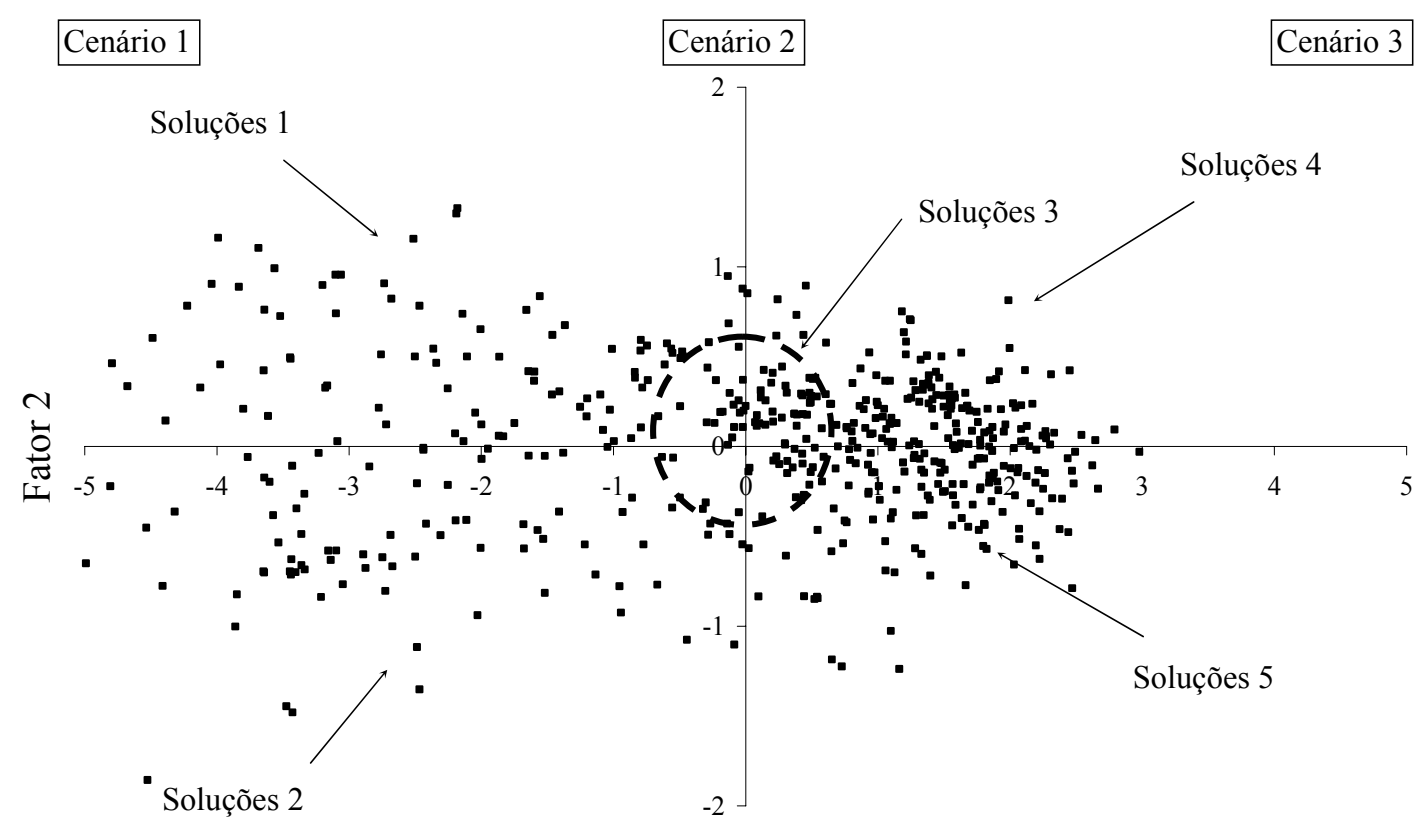

Fator 1

Figura 6.38 - Gráfico de auxílio à tomada de decisão utilizando à Análise de Componentes Principais

Geralmente, dois (ou três) componentes principais fornecem uma descrição adequada dos dados. Observe na Tabela 6.33, que se for adotado um componente principal (fator) para descrever o conjunto de dados (soluções não dominadas), a variância 
correspondente é igual a 3,6213 (autovalor) e considera 90,5\% da variabilidade total. Adotando-se dois componentes principais, o segundo fator, analisado individualmente, apresenta uma variância de 0,2232 e considera $11,3 \%$ da variabilidade total. Juntos o primeiro e o segundo fator representam $90,5 \%$ e $96,1 \%$ da variabilidade total das soluções, respectivamente. Dessa forma, justifica-se a utilização de apenas dois componentes principais (menor dimensionalidade) como sendo suficientes para representar um conjunto de dados de quatro dimensões (funções objetivo). A Figura 6.37 apresenta um gráfico dos autovalores contra número de fatores da Tabela 6.33.

A Figura 6.38 apresenta os valores das funções objetivo do problema de reabilitação no espaço bidimensional. Através desse gráfico é possível verificar as similaridades entre as soluções. Na Figura 6.38, foi construído um círculo de raio 0,5 com intuito de apresentar a diferença entre o grupo de soluções (1, 2, 3 e 4)pertencentes a cada quadrante do gráfico bidimensional.

Tabela 6.34 - Funções objetivo de soluções da otimização estática

\begin{tabular}{ccccccc}
\hline $\begin{array}{c}\text { Grupo } \\
\text { Solução }\end{array}$ & Fator 2 & Fator 1 & $\begin{array}{c}\text { Custos } \\
\$\end{array}$ & $\begin{array}{c}\text { Benefícios } \\
\text { KW }\end{array}$ & $\begin{array}{c}\text { Vazamentos } \\
\text { L/s }\end{array}$ & $\begin{array}{c}\text { Confiabilidade } \\
\text { Adimensional }\end{array}$ \\
\hline 1 & $-2,76$ & 0,51 & $9,04 \mathrm{E}+06$ & 31441,3 & 92,1 & 1,89 \\
2 & $-2,48$ & $-1,12$ & $7,55 \mathrm{E}+06$ & 30462,4 & 103,7 & 1,90 \\
3 & $-0,10$ & 0,05 & $7,14 \mathrm{E}+06$ & 24135,9 & 74,6 & 1,79 \\
4 & 1,63 & 0,52 & $7,02 \mathrm{E}+06$ & 14851,0 & 67,8 & 1,67 \\
5 & 1,76 & $-0,46$ & $5,93 \mathrm{E}+06$ & 16920,9 & 70,3 & 1,69 \\
\hline \hline
\end{tabular}

Uma solução pertencente a cada quadrante do gráfico bidimensional (Figura 6.38) e uma solução pertencente a círculo de raio 0,5 foram escolhidas aleatoriamente, cujos respectivos valores das funções objetivo e os valores das coordenadas correspondentes são apresentados na Tabela 6.34. Observe que os valores das funções objetivo das soluções 1 e 2, e das soluções 4 e 5 são muito semelhantes em termos de benefícios, vazamentos e confiabilidade e representam valores representativos distintos da frente Pareto da Figura 6.36. As soluções pertencentes ao interior do círculo, denominado neste trabalho como círculo ideal, representam o "verdadeiro" compromisso entre os critérios considerados. Observe que os valores das funções objetivo da solução 3 (pertence ao círculo) apresentam valores intermediários entre as soluções 1 e 2, e 4 e 5 , confirmando então, que existe uma similaridade entre as soluções do quadrante esquerdo superior e inferior (por exemplo, soluções 1 e 2) e das soluções pertencentes 
ao quadrante direito superior e inferior (soluções 4 e 5). Dessa forma, no presente trabalho adotou-se uma denominação para as soluções pertencentes a essa três regiões do espaço de objetivos (bidimensional). As soluções pertencentes aos quadrantes superior e inferior esquerdo representam o cenário 1. As soluções pertencentes ao círculo ideal fazem parte do grupo representativo do cenário 2 e as soluções dos quadrantes superior e inferior direito fazem parte do grupo representativo do cenário 3.

Tabela 6.35 - Decisões de reabilitação representativas dos três cenários obtidas na otimização estática

\begin{tabular}{|c|c|c|c|c|c|c|c|c|c|c|c|}
\hline \multirow{2}{*}{ Trecho } & \multicolumn{3}{|c|}{ Solução (Cenário) } & \multirow{2}{*}{ Trecho } & \multicolumn{3}{|c|}{ Solução (Cenário) } & \multirow{2}{*}{ Trecho } & \multicolumn{3}{|c|}{ Solução (Cenário) } \\
\hline & 1 & 2 & 3 & & 1 & 2 & 3 & & 1 & 2 & 3 \\
\hline 1 & 10 & 9 & 10 & 52 & 9 & 4 & 3 & 103 & 2 & 0 & 0 \\
\hline 2 & 16 & 13 & 8 & 53 & 3 & 3 & 16 & 104 & 16 & 3 & 3 \\
\hline 3 & 12 & 12 & 8 & 54 & 11 & 4 & 3 & 105 & 2 & 2 & 2 \\
\hline 4 & 12 & 5 & 8 & 55 & 6 & 9 & 4 & 106 & 2 & 2 & 2 \\
\hline 5 & 15 & 6 & 2 & 56 & 1 & 8 & 1 & 107 & 9 & 8 & 8 \\
\hline 6 & 12 & 11 & 8 & 57 & 8 & 2 & 2 & 108 & 7 & 8 & 8 \\
\hline 7 & 9 & 7 & 9 & 58 & 10 & 11 & 6 & 109 & 0 & 0 & 0 \\
\hline 8 & 13 & 16 & 5 & 59 & 2 & 9 & 2 & 110 & 15 & 4 & 3 \\
\hline 9 & 7 & 3 & 5 & 60 & 8 & 8 & 8 & 111 & 3 & 0 & 0 \\
\hline 10 & 2 & 2 & 2 & 61 & 4 & 2 & 2 & 112 & 2 & 0 & 0 \\
\hline 11 & 2 & 2 & 2 & 62 & 2 & 4 & 2 & 113 & 6 & 0 & 0 \\
\hline 12 & 6 & 4 & 3 & 63 & 2 & 2 & 2 & 114 & 3 & 3 & 3 \\
\hline 13 & 10 & 8 & 4 & 64 & 11 & 8 & 2 & 115 & 0 & 0 & 0 \\
\hline 14 & 3 & 5 & 2 & 65 & 5 & 2 & 2 & 116 & 1 & 0 & 0 \\
\hline 15 & 11 & 2 & 2 & 66 & 4 & 2 & 2 & 117 & 1 & 1 & 1 \\
\hline 16 & 12 & 4 & 2 & 67 & 8 & 4 & 4 & 118 & 7 & 7 & 7 \\
\hline 17 & 13 & 2 & 2 & 68 & 8 & 1 & 1 & 119 & 3 & 3 & 5 \\
\hline 18 & 5 & 3 & 3 & 69 & 2 & 5 & 4 & 120 & 9 & 2 & 2 \\
\hline 19 & 0 & 0 & 0 & 70 & 8 & 0 & 6 & 121 & 2 & 2 & 2 \\
\hline 20 & 2 & 2 & 2 & 71 & 0 & 0 & 0 & 122 & 4 & 1 & 1 \\
\hline 21 & 8 & 0 & 0 & 72 & 4 & 3 & 2 & 123 & 5 & 0 & 0 \\
\hline 22 & 0 & 0 & 0 & 73 & 4 & 6 & 10 & 124 & 0 & 0 & 0 \\
\hline 23 & 2 & 1 & 1 & 74 & 0 & 3 & 0 & 125 & 0 & 0 & 0 \\
\hline 24 & 16 & 0 & 0 & 75 & 14 & 5 & 8 & 126 & 11 & 1 & 0 \\
\hline 25 & 2 & 1 & 1 & 76 & 6 & 6 & 6 & 127 & 10 & 0 & 0 \\
\hline 26 & 1 & 0 & 0 & 77 & 7 & 5 & 5 & 128 & 1 & 0 & 0 \\
\hline 27 & 4 & 0 & 0 & 78 & 1 & 1 & 1 & 129 & 1 & 1 & 1 \\
\hline 28 & 0 & 0 & 0 & 79 & 8 & 1 & 0 & 130 & 16 & 0 & 0 \\
\hline 29 & 2 & 2 & 2 & 80 & 3 & 3 & 11 & 131 & 2 & 4 & 2 \\
\hline 30 & 8 & 1 & 1 & 81 & 13 & 2 & 2 & 132 & 16 & 8 & 9 \\
\hline 31 & 0 & 0 & 0 & 82 & 4 & 5 & 3 & 133 & 8 & 3 & 3 \\
\hline 32 & 0 & 0 & 0 & 83 & 4 & 4 & 4 & 134 & 11 & 3 & 9 \\
\hline 33 & 2 & 8 & 8 & 84 & 4 & 4 & 4 & 135 & 4 & 3 & 3 \\
\hline 34 & 2 & 2 & 2 & 85 & 1 & 0 & 0 & 136 & 7 & 2 & 3 \\
\hline 35 & 0 & 0 & 0 & 86 & 2 & 7 & 2 & 137 & 1 & 3 & 2 \\
\hline 36 & 2 & 2 & 2 & 87 & 2 & 2 & 2 & 138 & 1 & 2 & 1 \\
\hline 37 & 9 & 0 & 0 & 88 & 3 & 2 & 2 & 139 & 13 & 0 & 2 \\
\hline 38 & 11 & 6 & 6 & 89 & 7 & 4 & 4 & 140 & 15 & 1 & 0 \\
\hline 39 & 9 & 0 & 1 & 90 & 4 & 4 & 4 & 141 & 4 & 3 & 3 \\
\hline 40 & 12 & 7 & 6 & 91 & 5 & 5 & 5 & 142 & 12 & 9 & 10 \\
\hline 41 & 3 & 3 & 3 & 92 & 8 & 4 & 4 & 143 & 3 & 3 & 3 \\
\hline 42 & 5 & 3 & 3 & 93 & 8 & 3 & 3 & 144 & 12 & 2 & 2 \\
\hline 43 & 0 & 0 & 0 & 94 & 3 & 0 & 0 & 145 & 3 & 1 & 1 \\
\hline 44 & 11 & 6 & 5 & 95 & 3 & 3 & 3 & 146 & 3 & 1 & 1 \\
\hline 45 & 6 & 5 & 9 & 96 & 7 & 3 & 3 & 147 & 3 & 3 & 3 \\
\hline 46 & 8 & 0 & 0 & 97 & 2 & 0 & 0 & 148 & 0 & 0 & 0 \\
\hline 47 & 9 & 8 & 6 & 98 & 9 & 3 & 3 & & & & \\
\hline 48 & 4 & 4 & 4 & 99 & 4 & 4 & 8 & & & & \\
\hline 49 & 3 & 3 & 3 & 100 & 4 & 0 & 0 & & & & \\
\hline 50 & 4 & 3 & 3 & 101 & 1 & 1 & 1 & & & & \\
\hline 51 & 3 & 3 & 3 & 102 & 3 & 3 & 3 & & & & \\
\hline
\end{tabular}

A Tabela 6.35 apresenta as decisões a serem implementadas na rede (rede exemplo 3 ). Cada código inteiro corresponde a uma ação de reabilitação conforme indicação da 
Tabela 5.14. As soluções 1, 2 e 3 da Tabela 6.35 (espaço de decisão) correspondem as soluções 2, 3 e 5 da Tabela 6.34 (espaço das funções objetivo), respectivamente. Observe que para muitos trechos, a decisão (Tabela 6.35) é a mesma para as três diferentes soluções escolhidas (1, 2 e 3), como no caso dos trechos 10, 11, 22, 28, 29 e outros. A principal diferença, que reflete incisivamente no cálculo das funções objetivo, encontram-se nos trechos de adução $(1,2,3,6,7,8,9$, 12, etc.) da rede. Para verificar a localização desses trechos, veja a Tabela A2.1 (ANEXO A) e depois localize-os pelas identificações nodais nas Figuras (6.32 ou 6.33).

\subsection{Análise de reabilitação através da otimização multiobjetivo dinâmica - estudo de caso real}

Um plano de reabilitação deve estabelecer a seqüência de ações a serem implementadas na rede ao longo do horizonte de planejamento, em conformidade com o Plano Diretor de Abastecimento da cidade, subdividido em intervalos de tempo menores. No caso, foi adotado o horizonte de planejamento de 15 anos, subdividido em qüinqüênios, sendo que as ações de reabilitação (planos) obtidas devem ser implementadas no início dos respectivos períodos (qüinqüênios) para abastecimento das demandas no final dos mesmos, permitindo que cada trecho de rede sofra reabilitação em espaço de tempo não inferior a 10 anos (DANDY E ENGELHARDT, 2001).

O problema de decisão assim definido corresponde à determinação dos valores de 444 variáveis de decisão [148(variáveis por qüinqüênio) x 3 (qüinqüênios)]. Vislumbrou-se, então, a possibilidade de subdividir o problema em três estágios (programação dinâmica). Como sistemática de resolução, propôs-se uma extensão do conceito da otimalidade de Bellman (BELLMAN e KALABA, 1965) para o caso multiobjetivo conforme eq.(5.51)

A análise de reabilitação multiobjetivo dinâmica apresenta não apenas as melhores ações a serem implementadas na rede, mas também a seqüência ótima de tais intervenções ao longo dos períodos considerados. Os valores dos critérios (custo, benefícios, vazamentos e confiabilidade) são calculados para cada período de planejamento, considerando que para cada trecho de rede existem 17 ações (possibilidades) de reabilitação (Tabela 5.14).

A otimização dinâmica permite identificar trechos críticos na rede que devem ser reabilitados nos primeiros períodos do planejamento e trechos menos críticos que 
podem ser postergados para os próximos qüinqüênios. As soluções apresentadas pela otimização multiobjetivo através da programação dinâmica tornam as soluções mais flexíveis do que as apresentadas pela otimização estática. No caso dinâmico, os investimentos financeiros podem ser distribuídos durante o período e a configuração da rede (estado) pode ser diferenciada para cada estágio de planejamento.

Nessa seção são apresentados os resultados das análises de reabilitação através da otimização multiobjetivo dinâmica. Os dados do problema, os parâmetros de entrada do método de otimização (AGs) dentre outros, são os mesmos adotados na otimização estática. Entretanto, as simulações seguem o procedimento ilustrado na Figura 5.17. Observe que a etapa denominada otimização multiobjetivo segue o procedimento geral apresentado pela Figura 5.1.

O primeiro estágio da análise de reabilitação multiobjetivo dinâmica tem a função de inicializar o processo. As decisões desse estágio representam as ações a serem implementadas na rede para atendimento das demandas no final do primeiro período de planejamento (cinco anos). Conceitualmente, o primeiro estágio da otimização dinâmica não deve ser otimizado (BELLMAN e KALABA, 1965). Entretanto, adotar várias soluções iniciais oneraria o processo do ponto de vista computacional.

Assim, no presente trabalho, optou-se por estabelecer uma frente Pareto inicial (Figura 6.39) relativa ao primeiro estágio e tomar três pontos representativos da mesma. Esses pontos representativos correspondem as decisões a serem implementadas na rede no período e representam o estado da rede (rede modificada) no início do próximo período. É possível observar algumas diferenças entre o caso estático e dinâmico. No caso dinâmico, os custos de investimentos são calculados por período de planejamento (qüinqüênio) considerando uma taxa de juros. Essa taxa foi considerada aqui igual a 5\% ao ano. Os benefícios, vazamentos e confiabilidade continuam sendo calculados como valores médios dos períodos de planejamento (como no caso estático). No entanto, considera-se para o cálculo da função objetivo de um período posterior, a rede reabilitada (mudança de estados) com decisões anteriores (cenários 1, 2 e 3). As demandas nodais estimadas necessárias às avaliações hidráulicas referem-se ao final do qüinqüênio. 


\section{Custos}
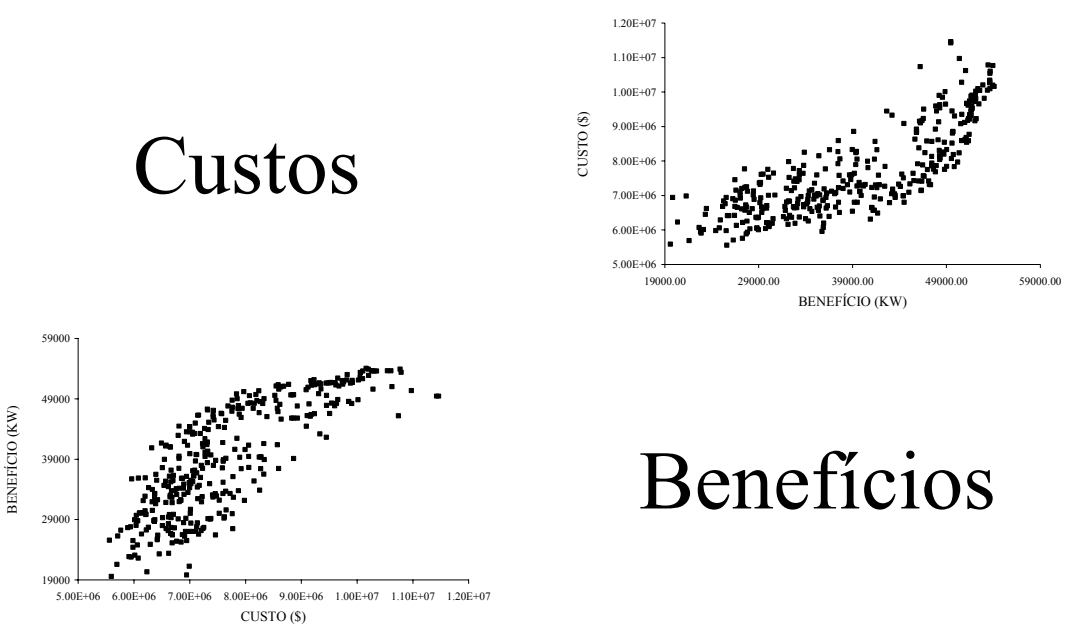

\section{Benefícios}
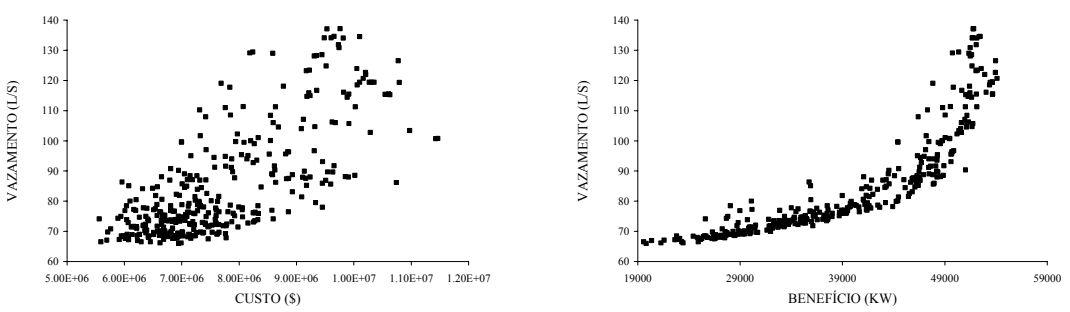

\section{Vazamentos}
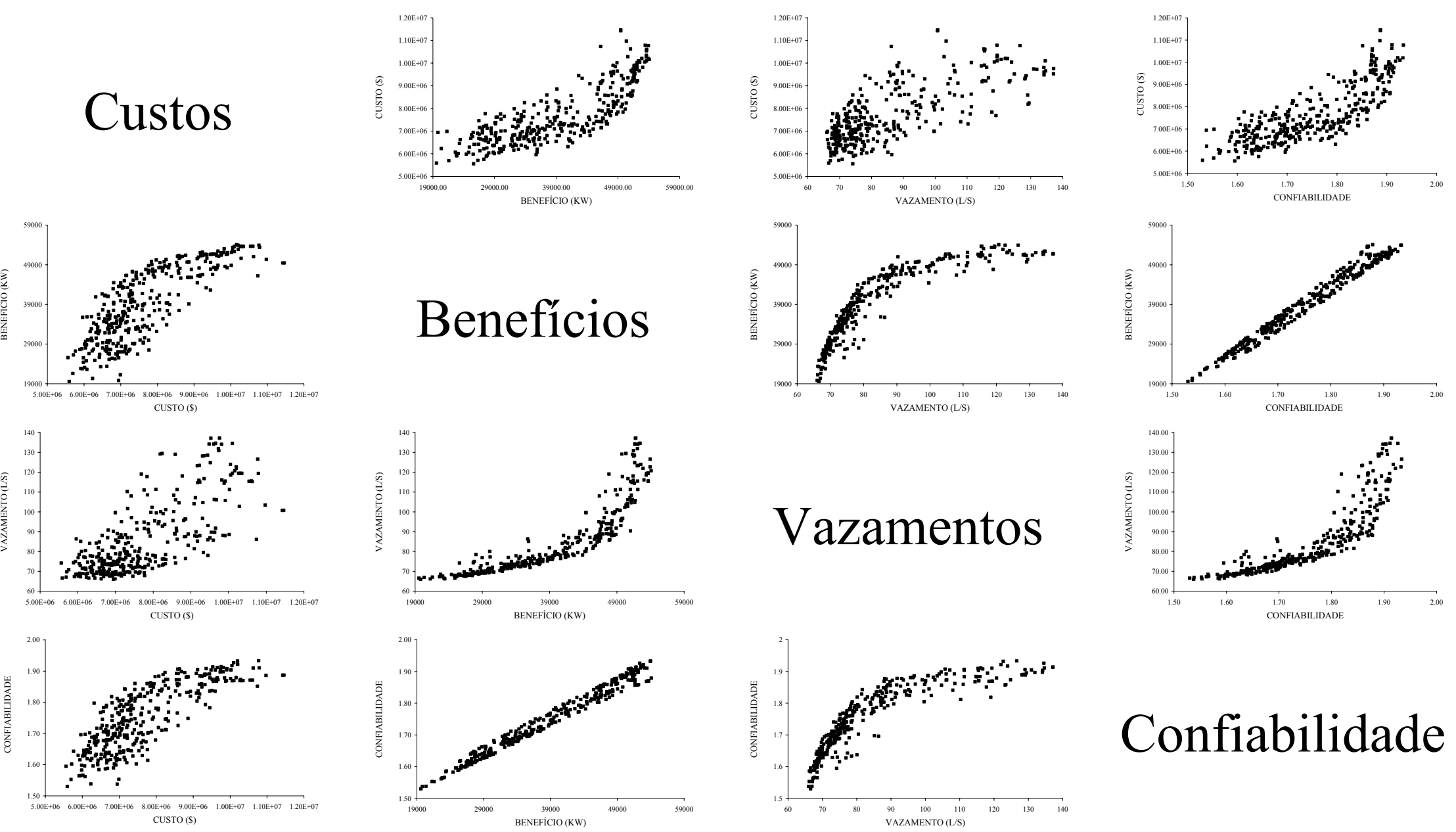

Confiabilidade

Figura 6.39 - Frente Pareto inicial da otimização multiobjetivo dinâmica 
A escolha de soluções representativas (Cenários 1, 2 e 3) da frente Pareto é uma tarefa complexa. No presente estudo (otimização dinâmica) foi adotada a técnica estatística multivariada (ACP), seguindo o mesmo procedimento (5.9) da análise de reabilitação estática apresentada no item anterior, e uma escolha subjetiva. Uma comparação entre as duas técnicas de escolha foi realizada considerando o custo como critério de elegibilidade.

Assim, três soluções (1, 2 e 3) foram escolhidas da frente Pareto inicial (Figura 6.39) com auxílio da técnica de ACP e três soluções (4, 5 e 6) foram escolhidas aleatoriamente a partir de três cenários de custos (mínimo, médio e alto). A Figura 6.40 apresenta a curva de custo contra benefícios com indicações das soluções escolhidas. As soluções 1, 2 e 3 foram escolhidas através da ACP e as soluções 4, 5 e 6 foram escolhidas considerando diferentes valores de custos. Observe que para essa curva, as soluções 4, 5 e 6 estão mais distribuídas ao longo da curva que as soluções 1, 2 e 3. Considerando a função objetivo benefícios (Figura 6.41), as soluções 1, 2 e 3 apresentaram melhor representatividade da frente do que as soluções 4, 5 e 6, pois as soluções 5 e 6 apresentaram valores muito próximos. O mesmo comportamento foi verificado para as funções objetivo vazamentos e confiabilidade. Esses resultados permitiram mostrar a eficiência da técnica ACP como ferramenta de auxílio para classificação e escolha de soluções. Além disso, é possível afirmar que nem sempre escolher soluções representativas em termos de custos (ou um outro objetivo) estará garantindo a representatividade da frente em relação aos demais critérios considerados.

Os autovalores da matriz de dados referente à frente Pareto inicial $\left(1^{\circ}\right.$ período de planejamento) são apresentados na Tabela 6.36. Observe nessa Tabela (6.36), que se for adotado um componente principal (fator) para descrever o conjunto de dados (soluções não dominadas), a variância correspondente é igual a 3,5337 (autovalor) com variabilidade total igual a $88,3 \%$. Adotando-se dois componentes principais, o segundo fator, analisado individualmente, apresenta uma variância de 0,2762 e considera o incremento de $6,9 \%$ da variabilidade total. Juntos o primeiro e o segundo fator representam $88,3 \%$ e $95,2 \%$ da variabilidade total das soluções, respectivamente. Dessa forma, justifica-se a necessidade de utilização de apenas dois componentes principais (menor dimensionalidade) como sendo essenciais para representar um conjunto de dados de quatro dimensões (funções objetivo). A Figura 6.44 apresenta um gráfico dos autovalores contra número de fatores da Tabela 6.36 . 


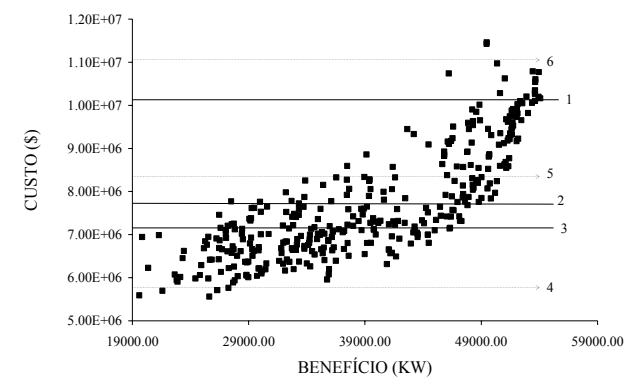

Figura 6.40 - Curva custo contra benefício

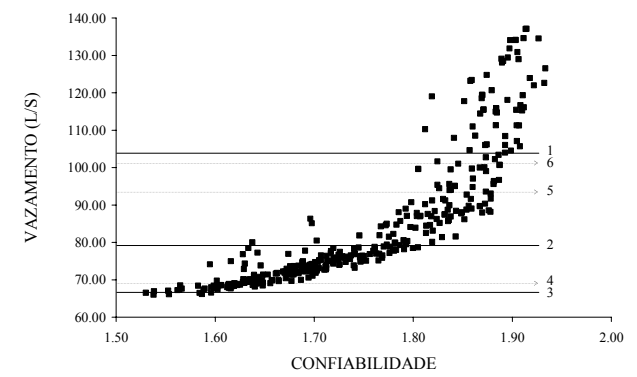

Figura 6.42 - Curva vazamento contra confiabilidade

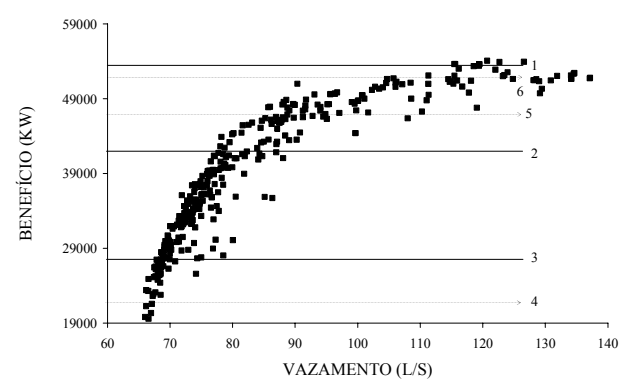

Figura 6.41 - Curva benefício contra vazamento

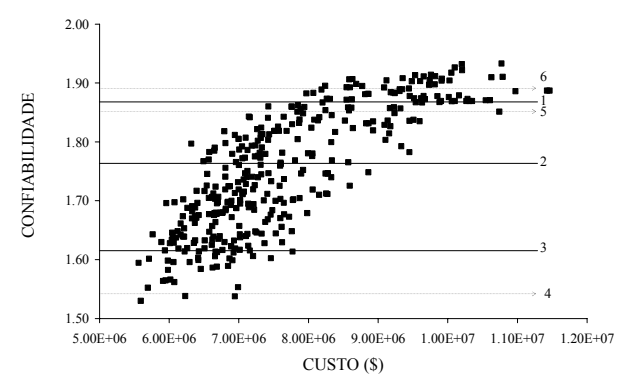

Figura 6.43 - Curva confiabilidade contra custo

O gráfico que apresenta as soluções da frente Pareto inicial (Figura 6.39) é apresentado na Figura 6.45. Uma solução pertencente a cada quadrante do gráfico bidimensional (Figura 6.45) e uma solução pertencente a círculo ideal foram escolhidas aleatoriamente, cujos respectivos valores das funções objetivo e os valores das coordenadas correspondentes são apresentados na Tabela 6.37. Essas soluções são representativas do primeiro período de planejamento (qüinqüênio) e correspondem aos estágios iniciais do próximo período (10 anos).

Tabela 6.36 - Autovalores da matriz de dados referentes a frente inicial da otimização dinâmica

Número de fatores

$\begin{array}{lcccc} & 1 & 2 & 3 & 4 \\ \text { Autovalores } & 3,5337 & 0,2762 & 0,1782 & 0,0119 \\ \text { Proporção } & 0,883 & 0,069 & 0,045 & 0,003 \\ \text { Cumulativo } & 0,883 & 0,952 & 0,997 & 1,0\end{array}$




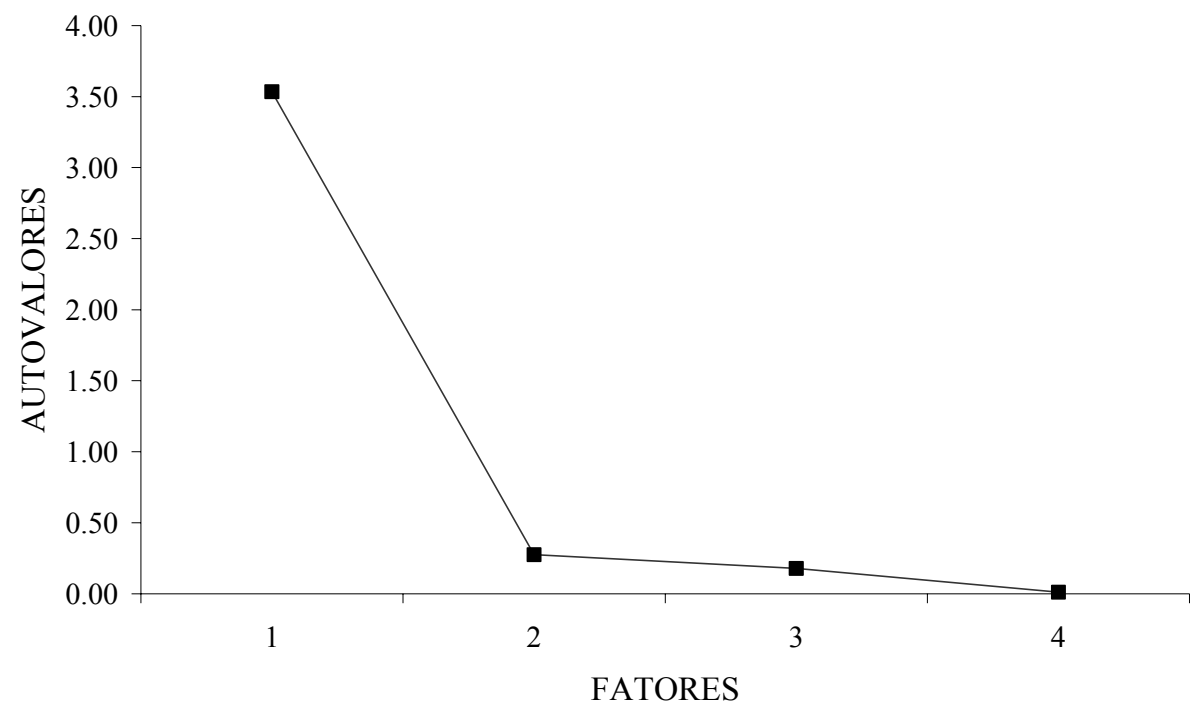

Figura 6.44 - Autovalores contra número de fatores - otimização dinâmica

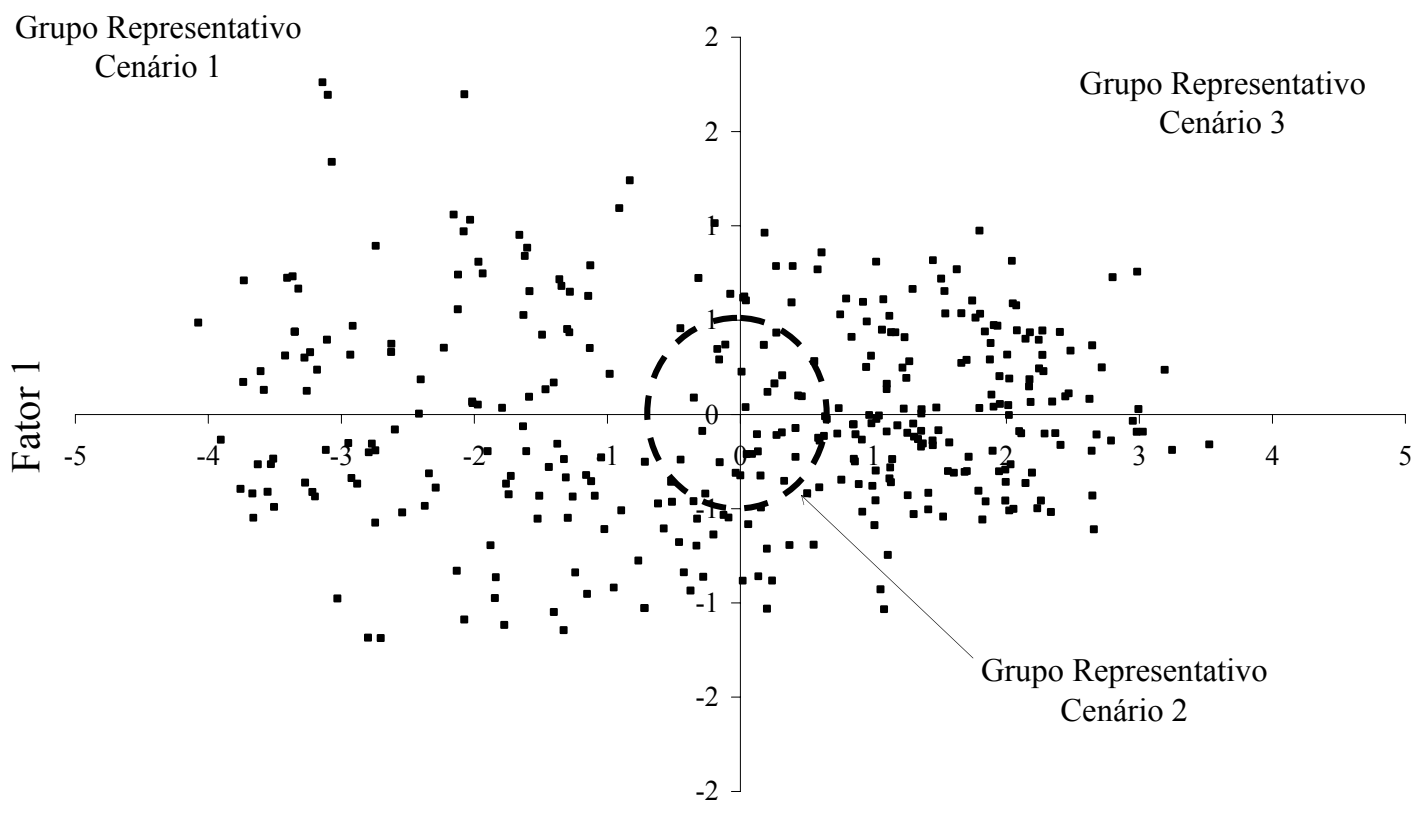

Fator 2

Figura 6.45 - Gráfico de auxílio à tomada de decisão utilizando à Análise de Componentes Principais

Tabela 6.37 - Soluções escolhidas da frente Pareto inicial - otimização dinâmica

\begin{tabular}{ccccccc}
\hline \hline $\begin{array}{c}\text { Solução } \\
\text { Cenário }\end{array}$ & Fator 1 & Fator 2 & $\begin{array}{c}\text { Custos } \\
\$\end{array}$ & $\begin{array}{c}\text { Benefícios } \\
\text { KW }\end{array}$ & $\begin{array}{c}\text { Vazamentos } \\
\text { L/s }\end{array}$ & $\begin{array}{c}\text { Confiabilidade } \\
\text { Adimensional }\end{array}$ \\
1 & $-2,7$ & 0,9 & $1,03 \mathrm{E}+07$ & 50605,2 & 102,8 & 1,87 \\
2 & 0,1 & 0,1 & $7,59 \mathrm{E}+06$ & 41760,9 & 77,7 & 1,76 \\
3 & 2,0 & 0,6 & $7,20 \mathrm{E}+06$ & 27189,2 & 68,5 & 1,61 \\
\hline \hline
\end{tabular}


As decisões referentes a cada solução escolhida (cenário 1, 2 e 3) da frente Pareto inicial são apresentadas na Tabela 6.38. A partir dessa etapa, acontece a denominada transição de estados da programação dinâmica. Por exemplo, considere o trecho 2 do cenário 1 (Tabela 6.38). Observe que a ação de reabilitação (Tabela 5.14) a ser implementada nesse trecho é a duplicação com um diâmetro de $800 \mathrm{~mm}$. Conseqüentemente, no próximo qüinqüênio, esse trecho não será reabilitado.

Tabela 6.38 - Decisões de reabilitação para o primeiro período de planejamento em relação aos cenários da otimização dinâmica

\begin{tabular}{|c|c|c|c|c|c|c|c|c|c|c|c|}
\hline \multirow{2}{*}{ Trecho } & \multicolumn{3}{|c|}{ Solução (Cenário) } & \multirow{2}{*}{ Trecho } & \multicolumn{3}{|c|}{ Solução (Cenário) } & \multirow{2}{*}{ Trecho } & \multicolumn{3}{|c|}{ Solução (Cenário) } \\
\hline & 1 & 2 & 3 & & 1 & 2 & 3 & & 1 & 2 & 3 \\
\hline 1 & 12 & 7 & 8 & 52 & 3 & 3 & 3 & 103 & 4 & 0 & 0 \\
\hline 2 & 14 & 12 & 12 & 53 & 5 & 3 & 14 & 104 & 5 & 5 & 3 \\
\hline 3 & 13 & 13 & 14 & 54 & 3 & 7 & 3 & 105 & 9 & 8 & 8 \\
\hline 4 & 5 & 4 & 2 & 55 & 4 & 3 & 3 & 106 & 9 & 8 & 8 \\
\hline 5 & 11 & 10 & 7 & 56 & 3 & 1 & 1 & 107 & 2 & 2 & 2 \\
\hline 6 & 13 & 13 & 13 & 57 & 2 & 8 & 2 & 108 & 4 & 0 & 1 \\
\hline 7 & 11 & 7 & 7 & 58 & 3 & 2 & 2 & 109 & 0 & 0 & 0 \\
\hline 8 & 4 & 5 & 4 & 59 & 11 & 3 & 8 & 110 & 3 & 3 & 3 \\
\hline 9 & 7 & 5 & 3 & 60 & 3 & 8 & 8 & 111 & 6 & 2 & 0 \\
\hline 10 & 2 & 11 & 2 & 61 & 7 & 8 & 5 & 112 & 0 & 0 & 0 \\
\hline 11 & 2 & 2 & 2 & 62 & 5 & 2 & 2 & 113 & 1 & 0 & 0 \\
\hline 12 & 5 & 3 & 3 & 63 & 3 & 2 & 2 & 114 & 5 & 3 & 3 \\
\hline 13 & 2 & 4 & 2 & 64 & 4 & 2 & 2 & 115 & 4 & 2 & 0 \\
\hline 14 & 3 & 4 & 2 & 65 & 2 & 2 & 2 & 116 & 3 & 0 & 0 \\
\hline 15 & 3 & 3 & 2 & 66 & 2 & 2 & 2 & 117 & 3 & 1 & 1 \\
\hline 16 & 3 & 3 & 2 & 67 & 5 & 4 & 4 & 118 & 7 & 7 & 7 \\
\hline 17 & 6 & 4 & 3 & 68 & 1 & 1 & 1 & 119 & 3 & 3 & 3 \\
\hline 18 & 7 & 9 & 9 & 69 & 2 & 0 & 3 & 120 & 3 & 2 & 2 \\
\hline 19 & 0 & 0 & 0 & 70 & 2 & 0 & 0 & 121 & 3 & 2 & 2 \\
\hline 20 & 2 & 3 & 2 & 71 & 0 & 1 & 0 & 122 & 4 & 2 & 1 \\
\hline 21 & 0 & 0 & 0 & 72 & 3 & 0 & 4 & 123 & 0 & 0 & 0 \\
\hline 22 & 4 & 0 & 0 & 73 & 4 & 3 & 3 & 124 & 2 & 8 & 2 \\
\hline 23 & 1 & 1 & 1 & 74 & 4 & 10 & 1 & 125 & 0 & 2 & 0 \\
\hline 24 & 1 & 2 & 0 & 75 & 15 & 9 & 5 & 126 & 11 & 0 & 0 \\
\hline 25 & 5 & 1 & 1 & 76 & 6 & 6 & 6 & 127 & 0 & 1 & 0 \\
\hline 26 & 0 & 0 & 0 & 77 & 9 & 5 & 5 & 128 & 0 & 0 & 0 \\
\hline 27 & 0 & 0 & 0 & 78 & 1 & 1 & 1 & 129 & 11 & 1 & 1 \\
\hline 28 & 0 & 1 & 0 & 79 & 11 & 6 & 10 & 130 & 0 & 0 & 0 \\
\hline 29 & 9 & 2 & 2 & 80 & 0 & 2 & 1 & 131 & 6 & 2 & 2 \\
\hline 30 & 1 & 1 & 1 & 81 & 3 & 3 & 0 & 132 & 2 & 2 & 2 \\
\hline 31 & 0 & 0 & 0 & 82 & 12 & 5 & 6 & 133 & 8 & 4 & 12 \\
\hline 32 & 1 & 0 & 0 & 83 & 6 & 4 & 4 & 134 & 4 & 3 & 5 \\
\hline 33 & 2 & 2 & 2 & 84 & 4 & 4 & 4 & 135 & 7 & 6 & 3 \\
\hline 34 & 2 & 2 & 2 & 85 & 5 & 3 & 1 & 136 & 4 & 2 & 2 \\
\hline 35 & 5 & 0 & 0 & 86 & 7 & 8 & 8 & 137 & 5 & 4 & 1 \\
\hline 36 & 2 & 2 & 2 & 87 & 7 & 8 & 16 & 138 & 7 & 2 & 1 \\
\hline 37 & 0 & 0 & 0 & 88 & 2 & 5 & 3 & 139 & 4 & 7 & 13 \\
\hline 38 & 6 & 7 & 6 & 89 & 14 & 4 & 4 & 140 & 11 & 0 & 4 \\
\hline 39 & 0 & 0 & 4 & 90 & 9 & 4 & 4 & 141 & 3 & 4 & 3 \\
\hline 40 & 7 & 6 & 6 & 91 & 12 & 5 & 5 & 142 & 3 & 3 & 3 \\
\hline 41 & 4 & 3 & 3 & 92 & 12 & 6 & 11 & 143 & 10 & 3 & 3 \\
\hline 42 & 13 & 7 & 9 & 93 & 7 & 6 & 3 & 144 & 4 & 3 & 2 \\
\hline 43 & 4 & 0 & 0 & 94 & 0 & 0 & 0 & 145 & 3 & 1 & 1 \\
\hline 44 & 15 & 5 & 5 & 95 & 5 & 3 & 3 & 146 & 1 & 2 & 1 \\
\hline 45 & 9 & 8 & 7 & 96 & 3 & 3 & 3 & 147 & 4 & 3 & 3 \\
\hline 46 & 2 & 0 & 0 & 97 & 2 & 0 & 0 & 148 & 1 & 0 & 0 \\
\hline 47 & 6 & 5 & 5 & 98 & 5 & 3 & 3 & & & & \\
\hline 48 & 4 & 5 & 4 & 99 & 7 & 5 & 4 & & & & \\
\hline 49 & 9 & 3 & 3 & 100 & 0 & 0 & 0 & & & & \\
\hline 50 & 10 & 8 & 5 & 101 & 2 & 1 & 1 & & & & \\
\hline 51 & 8 & 4 & 4 & 102 & 3 & 3 & 3 & & & & \\
\hline
\end{tabular}

Considerando os três estados iniciais (cenários 1, 2 e 3) da rede exemplo 3 (já reabilitada) como dados de entrada para o segundo ano de planejamento, aplica-se 
novamente a otimização multiobjetivo (Figura 5.1) e geram-se três novas frentes Pareto. Essas frentes são agrupadas e filtradas através de algoritmo de busca de soluções não dominadas (Algoritmo 2 - APÊNDICE A) de forma a identificar a frente Pareto resultante. Vale lembrar que para o cálculo das funções objetivo no segundo período de planejamento, considera-se os valores das funções objetivo do período (primeiro período de planejamento) que o antecede e no caso da função objetivo custo, uma taxa de juros igual a $5 \%$ ao ano. A partir da nova frente aplica-se a técnica de ACP para escolha das três soluções representativas cujos os valores das funções objetivo são apresentadas na Tabela 6.39 e as decisões apresentadas na Tabela 6.40.

As decisões de reabilitação (Tabela 6.40) referentes ao segundo ano de planejamento definem a transição do estado para o próximo período (último período do planejamento) da programação dinâmica. Depois de definido os estados iniciais para o último período de planejamento, aplica-se novamente o procedimento geral de otimização multiobjetivo para os três cenários, levando-se em conta as funções objetivo do estágio anterior (Tabela 6.39). Obtém-se as três novas frentes Pareto nas quais agrupadas e filtradas produzem a frente Pareto final para o caso dinâmico (planejamento de longo prazo).

Tabela 6.39 - Soluções da análise de reabilitação dinâmica

\begin{tabular}{ccccc}
\hline \hline Solução & Custos & Benefícios & Vazamentos & Confiabilidade \\
Cenário & $\$$ & $\mathrm{KW}$ & $\mathrm{L} / \mathrm{s}$ & Adimensional \\
1 & $7,25 \mathrm{E}+06$ & 28075,5 & 84,6 & 1,72 \\
2 & $7,82 \mathrm{E}+06$ & 29638,4 & 66,9 & 1,56 \\
3 & $7,80 \mathrm{E}+06$ & 43163,6 & 76,9 & 1,72 \\
\hline \hline
\end{tabular}

Tabela 6.40 - Trechos a serem reabilitados no segundo período de planejamento

\begin{tabular}{cc}
\hline \hline $\begin{array}{c}\text { Solução } \\
\text { Cenário }\end{array}$ & Trechos \\
\hline 1 & $51(4), 133(8)$ \\
2 & $45(8), 50(5), 57(5), 60(9), 61(2), 86(6), 87(8), 105(2), 106(3), 124(2)$ \\
3 & $1(8), 59(5), 60(8), 86(8), 105(7), 106(4)$ \\
\hline \hline
\end{tabular}




\section{Custo}
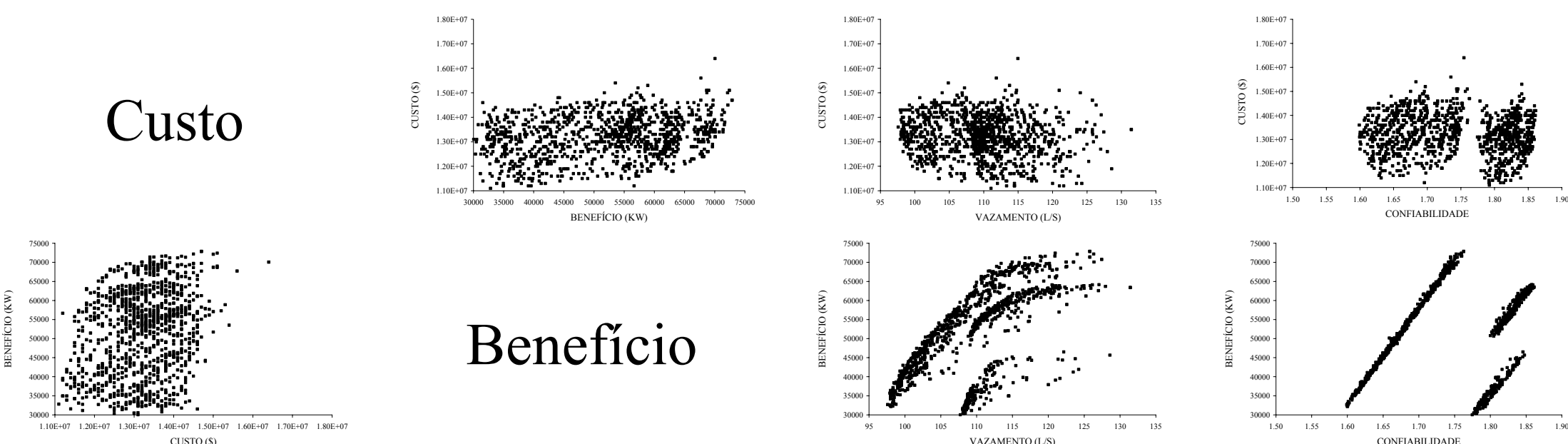

\section{Benefício}
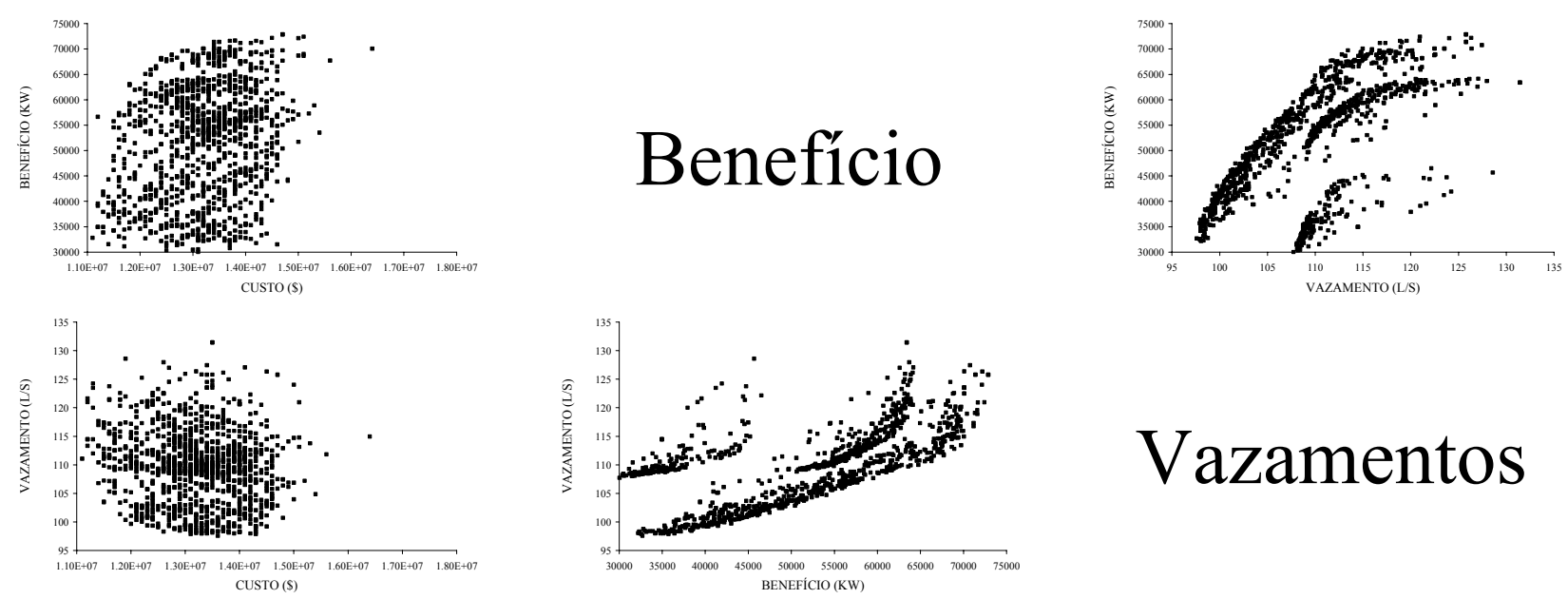

\section{Vazamentos}
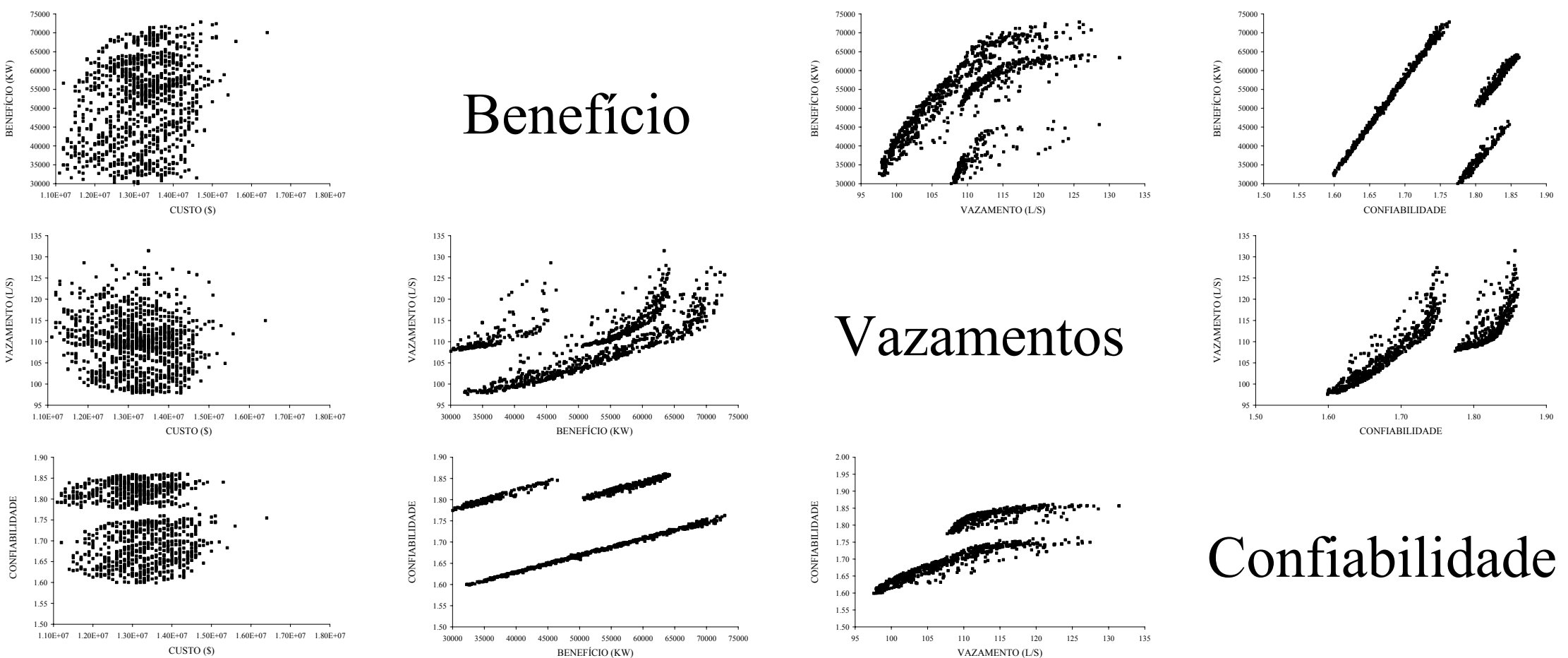

Confiabilidade

Figura 6.46 - Frente Pareto - programação dinâmica 


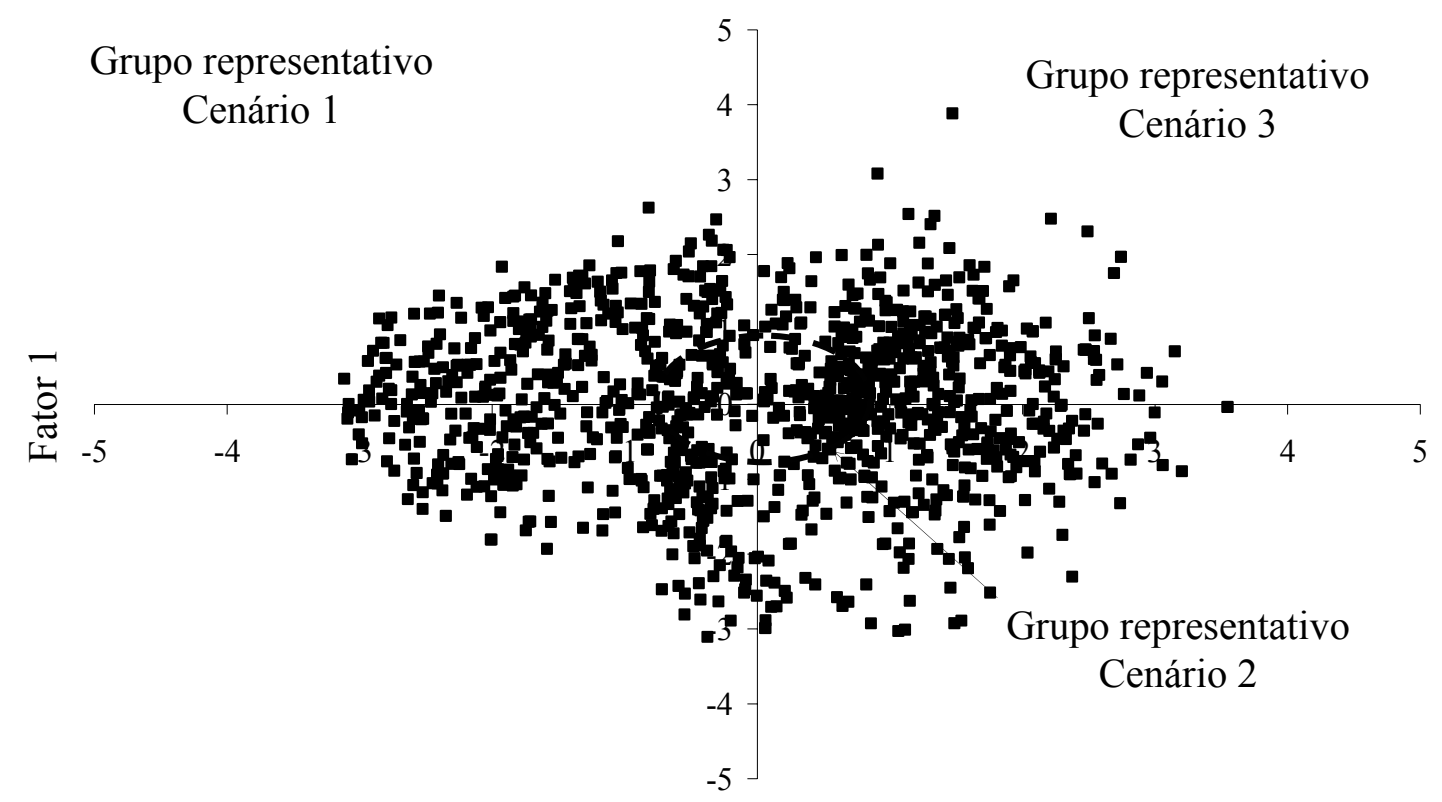

Fator 2

Figura 6.47 - Gráfico de decisão para cenário otimista - otimização dinâmica

A Figura 6.46 apresenta a frente Pareto final no espaço objetivo. Observe que existe uma transposição de curvas na frente Pareto final. Isso se deve ao fato de que a otimização multibjetivo dinâmica considera os estágios anteriores, e os valores de funções objetivo correspondentes estão associados aos valores das soluções que correspondem a esses estágios. Na realidade, percebe-se que cada curva sobreposta corresponde a uma região do espaço de busca. Por exemplo, analisando a curva de benefícios contra vazamentos é possível verificar que existem soluções com mesmo vazamento no entanto com benefícios mais elevados. O mesmo acontece para a curva de vazamentos contra confiabilidade, para um mesmo índice de vazamentos, o decisor pode optar por uma solução que apresente maior confiabilidade.

Tabela 6.41 - Soluções da análise de reabilitação dinâmica

\begin{tabular}{ccccccc}
\hline \hline $\begin{array}{c}\text { Solução } \\
\text { Cenário }\end{array}$ & Fator 1 & Fator 2 & $\begin{array}{c}\text { Custos } \\
\$\end{array}$ & $\begin{array}{c}\text { Benefícios } \\
\text { KW }\end{array}$ & $\begin{array}{c}\text { Vazamentos } \\
\text { L/s }\end{array}$ & $\begin{array}{c}\text { Confiabilidade } \\
\text { Adimensional }\end{array}$ \\
\hline 1 & $-2,00$ & $-1,80$ & $1,15 \mathrm{E}+07$ & 39393,2 & 103,5 & 1,62 \\
2 & 0,05 & 0,06 & $1,29 \mathrm{E}+07$ & 58996,5 & 109,9 & 1,70 \\
3 & 2,23 & 0,10 & $1,34 \mathrm{E}+07$ & 62726,7 & 119,2 & 1,85 \\
\hline \hline
\end{tabular}

Transformando o problema de quatro dimensões para o espaço bidimensional através da técnica da ACP foi possível construir o gráfico da Figura 6.47. Escolhendo-se 
aleatoriamente três soluções representativas (1, 2 e 3 ) referentes ao último estágio foi possível construir a Tabela 6.41. As decisões desse último período de planejamento são apresentadas na Tabela 6.42 .

Tabela 6.42 - Decisões de reabilitação para o último período de planejamento em relação aos cenários da otimização dinâmica

\begin{tabular}{|c|c|c|c|c|c|c|c|c|c|c|c|}
\hline \multirow{2}{*}{ Trecho } & \multicolumn{3}{|c|}{ "Solução (Cenário) } & \multirow{2}{*}{ Trecho } & \multicolumn{3}{|c|}{ Solução (Cenário) } & \multirow{2}{*}{ Trecho } & \multicolumn{3}{|c|}{ "Solução (Cenário) } \\
\hline & 1 & 2 & 3 & & 1 & 2 & 3 & & 1 & 2 & 3 \\
\hline 1 & 3 & 14 & 8 & 52 & 16 & 5 & 9 & 103 & 8 & 12 & 8 \\
\hline 2 & 8 & 11 & 12 & 53 & 7 & 4 & 7 & 104 & 6 & 12 & 12 \\
\hline 3 & 8 & 8 & 9 & 54 & 7 & 3 & 3 & 105 & 2 & - & - \\
\hline 4 & 10 & 5 & 13 & 55 & 4 & 13 & 4 & 106 & 2 & - & - \\
\hline 5 & 13 & 4 & 7 & 56 & 1 & 7 & 1 & 107 & 6 & 12 & 5 \\
\hline 6 & 8 & 16 & 13 & 57 & 2 & - & 2 & 108 & 2 & 6 & 2 \\
\hline 7 & 8 & 8 & 14 & 58 & 4 & 6 & 11 & 109 & 0 & 9 & 2 \\
\hline 8 & 10 & 13 & 8 & 59 & 4 & 10 & - & 110 & 3 & 13 & 10 \\
\hline 9 & 5 & 16 & 16 & 60 & 3 & - & 10 & 111 & 10 & 8 & 7 \\
\hline 10 & 8 & 9 & 6 & 61 & 8 & - & 6 & 112 & 10 & 2 & 1 \\
\hline 11 & 6 & 2 & 8 & 62 & 5 & 9 & 9 & 113 & 2 & 1 & 2 \\
\hline 12 & 3 & 5 & 7 & 63 & 4 & 10 & 4 & 114 & 8 & 14 & 8 \\
\hline 13 & 8 & 7 & 8 & 64 & 2 & 6 & 2 & 115 & 7 & 10 & 6 \\
\hline 14 & 4 & 14 & 12 & 65 & 9 & 6 & 5 & 116 & 4 & 0 & 8 \\
\hline 15 & 10 & 11 & 7 & 66 & 7 & 6 & 7 & 117 & 10 & 2 & 3 \\
\hline 16 & 8 & 6 & 3 & 67 & 12 & 9 & 4 & 118 & 9 & 8 & 12 \\
\hline 17 & 2 & 4 & 8 & 68 & 2 & 2 & 2 & 119 & 3 & 3 & 7 \\
\hline 18 & 4 & 7 & 6 & 69 & 3 & 3 & 3 & 120 & 3 & 4 & 8 \\
\hline 19 & 6 & 2 & 1 & 70 & 0 & 0 & 3 & 121 & 6 & 10 & 8 \\
\hline 20 & 1 & 10 & 10 & 71 & 1 & 1 & 2 & 122 & 2 & 4 & 2 \\
\hline 21 & 10 & 2 & 3 & 72 & 7 & 8 & 5 & 123 & 2 & 9 & 0 \\
\hline 22 & 3 & 2 & 0 & 73 & 9 & 3 & 5 & 124 & 2 & - & 6 \\
\hline 23 & 0 & 8 & 7 & 74 & 4 & 2 & 2 & 125 & 8 & 4 & 10 \\
\hline 24 & 8 & 2 & 6 & 75 & 6 & 14 & 6 & 126 & 0 & 9 & 0 \\
\hline 25 & 6 & 2 & 4 & 76 & 8 & 14 & 7 & 127 & 0 & 6 & 0 \\
\hline 26 & 4 & 0 & 0 & 77 & 5 & 9 & 8 & 128 & 8 & 8 & 8 \\
\hline 27 & 0 & 2 & 4 & 78 & 2 & 1 & 2 & 129 & 4 & 7 & 6 \\
\hline 28 & 8 & 4 & 9 & 79 & 8 & 8 & 8 & 130 & 8 & 2 & 6 \\
\hline 29 & 14 & 2 & 8 & 80 & 15 & 7 & 13 & 131 & 4 & 8 & 4 \\
\hline 30 & 8 & 8 & 2 & 81 & 5 & 11 & 5 & 132 & 2 & 10 & 2 \\
\hline 31 & 2 & 9 & 2 & 82 & 8 & 10 & 10 & 133 & 12 & 3 & 7 \\
\hline 32 & 2 & 2 & 5 & 83 & 5 & 6 & 4 & 134 & 7 & 7 & 6 \\
\hline 33 & 5 & 6 & 3 & 84 & 10 & 4 & 13 & 135 & 9 & 8 & 5 \\
\hline 34 & 8 & 6 & 4 & 85 & 1 & 8 & 2 & 136 & 3 & 2 & 4 \\
\hline 35 & 4 & 7 & 1 & 86 & 2 & - & 11 & 137 & 5 & 6 & 5 \\
\hline 36 & 0 & 8 & 3 & 87 & 7 & 9 & 7 & 138 & 2 & 7 & 5 \\
\hline 37 & 3 & 1 & 10 & 88 & 7 & 14 & 11 & 139 & 8 & 10 & 6 \\
\hline 38 & 6 & 7 & 7 & 89 & 4 & 8 & 16 & 140 & 4 & 8 & 6 \\
\hline 39 & 7 & 0 & 7 & 90 & 8 & 11 & 7 & 141 & 4 & 11 & 4 \\
\hline 40 & 8 & 13 & 7 & 91 & 10 & 13 & 8 & 142 & 7 & 7 & 9 \\
\hline 41 & 8 & 7 & 3 & 92 & 11 & 15 & 6 & 143 & 8 & 4 & 6 \\
\hline 42 & 3 & 7 & 6 & 93 & 5 & 6 & 10 & 144 & 8 & 5 & 7 \\
\hline 43 & 6 & 6 & 2 & 94 & 0 & 0 & 0 & 145 & 8 & 9 & 5 \\
\hline 44 & 2 & 13 & 6 & 95 & 5 & 4 & 9 & 146 & 11 & 2 & 1 \\
\hline 45 & 8 & 13 & 8 & 96 & 8 & 5 & 4 & 147 & 11 & 5 & 3 \\
\hline 46 & 13 & 6 & 2 & 97 & 2 & 1 & 1 & 148 & 3 & 5 & 6 \\
\hline 47 & 2 & 9 & 8 & 98 & 6 & 6 & 6 & & & & \\
\hline 48 & 8 & 5 & 6 & 99 & 5 & 8 & 5 & & & & \\
\hline 49 & 5 & 10 & 6 & 100 & 0 & 12 & 1 & & & & \\
\hline 50 & 6 & - & 5 & 101 & 5 & 3 & 5 & & & & \\
\hline 51 & - & 8 & 7 & 102 & 4 & 8 & 6 & & & & \\
\hline
\end{tabular}

Através das decisões representativas do último estágio da otimização foi possível identificar os planos ótimos de reabilitação referentes ao estudo de caso real (rede exemplo 3). A Figura 6.48 apresenta as três alternativas de reabilitação (seqüência ótima). Por exemplo, a seqüência 2-2-1 refere-se à solução 2 do primeiro período (Tabela 6.37 - espaço objetivo e Tabela 6.38 - espaço de decisão), à solução 2 do 
segundo período (Tabela 6.39 - espaço objetivo e Tabela 6.40 - espaço de decisão) e à solução 1 do último período (Tabela 6.41 - espaço objetivo e Tabela 6.42 - espaço de decisão). A seqüência 2-2-1 é o plano que apresenta menor custo, consequentemente, menores benefícios, vazamentos e confiabilidade. A seqüência 2-2-2 apresenta valores intermediários entre as seqüências 2-2-1 e 2-3-3. Observe que a escolha da melhor alternativa depende do senso de valor do decisor.

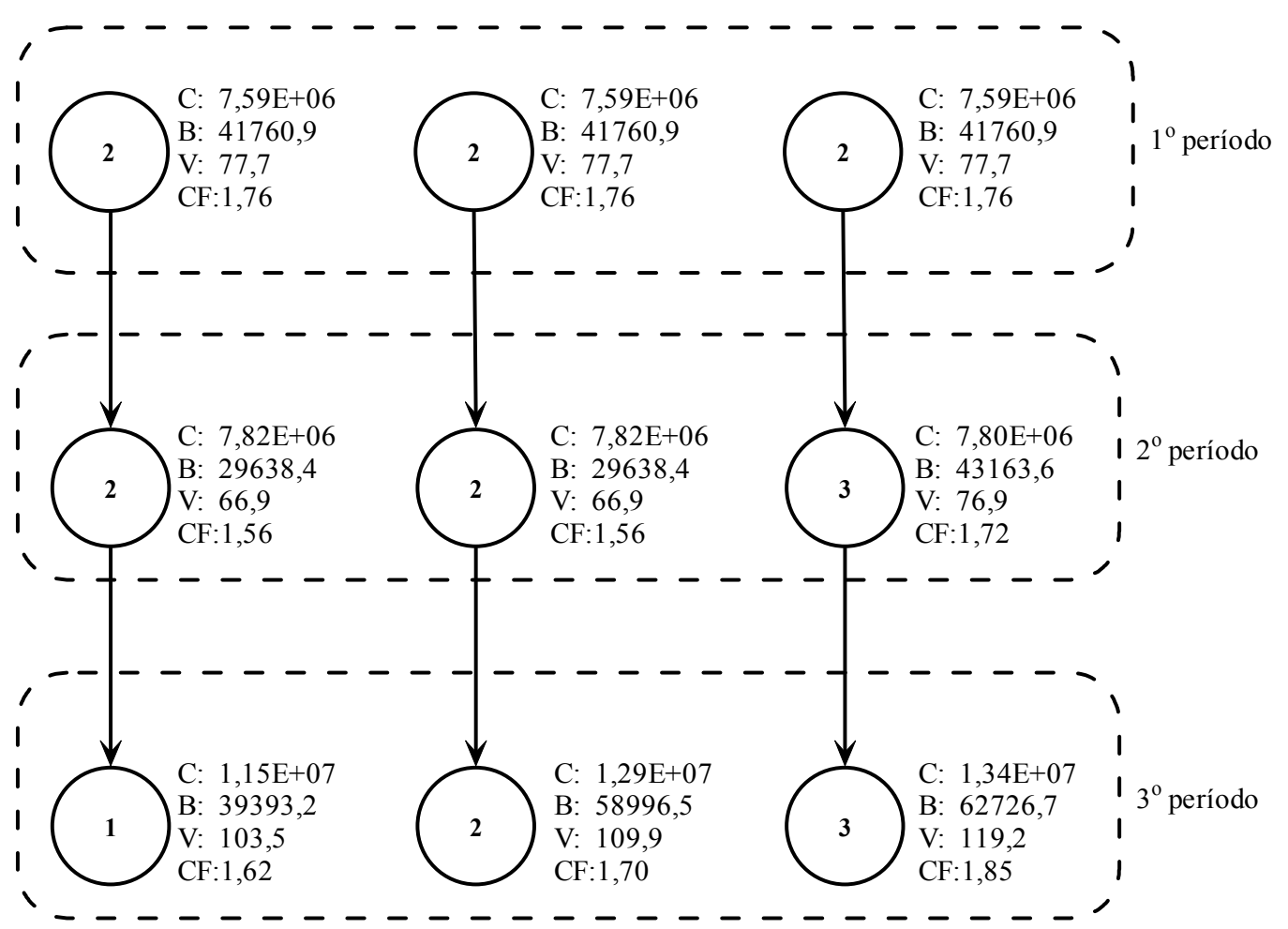

Figura 6.48 - Planos alternativos de reabilitação para rede real (rede exemplo 3)

\subsection{Comparação da análise de reabilitação estática e dinâmica}

Da mesma forma que a escolha da melhor alternativa de reabilitação, a comparação dos resultados das análises estática e dinâmica também só é possível com base no senso de valor daquele(s) a quem compete decidir. Nessa seção são discutidas algumas comparações entre a análise de reabilitação estática e dinâmica, enfocando aspectos qualitativos.

A análise de reabilitação multiobjetivo estática apresenta algumas vantagens frente à otimização dinâmica. Por exemplo, a simplicidade do procedimento computacional. No caso estático, não são considerados os procedimentos complexos de transições de estado da rede. No caso dinâmico, por exemplo, no primeiro período de planejamento o sistema existente corresponde ao estado inicial para os três cenários considerados (Figura 5.17). No segundo ano de planejamento (Figura 5.17) surge a incerteza de três 
"supostos" estados iniciais (Cenário 1, 2 e 3) a serem considerados para os próximos períodos. Recomenda-se que essas transições de estados devem ser cuidadosamente analisadas e melhor estudadas em investigações futuras. Uma outra vantagem da otimização multiobjetivo estática está relacionada ao baixo tempo computacional quando comparada com o caso dinâmico. Por exemplo, nesse estudo foi realizada uma otimização multiobjetivo (sementes aleatórias distintas) para se obter os resultados da análise estática, no caso dinâmico, foram realizados sete otimizações multiobjetivo para uma análise de 15 anos de planejamento avaliados a cada cinco anos.

No entanto, as vantagens da otimização multiobjetivo dinâmica são: resposta mais realística do problema permitindo que ações de reabilitação sejam identificadas por período de planejamento, distribuição de investimentos financeiros ao longo do horizonte de planejamento, senso de valor referentes as ações de reabilitação (planos ótimos) em relação aos critérios adotados (custos, benefícios, vazamentos e confiabilidade) para cada período de planejamento. 


\section{CONCLUSÕES}

Um modelo computacional para análise de reabilitação de redes de distribuição de água para abastecimento considerando objetivos múltiplos foi desenvolvido neste trabalho. Esse modelo foi concebido em três fases distintas.

A primeira fase, denominada etapa preliminar, compreendeu todos os estudos envolvendo o levantamento de dados (cadastro da rede, demandas nodais, registros de manutenção e operação, observações de campo e dados de telemetria das fontes de abastecimento). Um procedimento de calibração (SOARES, 2003), cuja função é ajustar os parâmetros do modelo pressão-vazamento (TUCCIARELLI, CRIMINISI e TERMINI, 1999), foi utilizado nessa fase. Esse procedimento mostrou-se necessário devido à análise de reabilitação de redes considerar, como objeto de estudo, um sistema existente. Parâmetros de entrada (parâmetros de vazamentos) foram ajustados de forma que as simulações hidráulicas realizadas posteriormente pudessem representar melhor o comportamento real do mesmo.

A segunda fase do modelo proposto, denominada etapa de avaliação, contemplou os algoritmos de otimização multiobjetivo e os simuladores hidráulicos. Quatro algoritmos evolucionários multiobjetivo (MOGA, NSGA, SPEA, NSGA II) foram investigados e testados. Três simuladores hidráulicos (Epanet 2 convencional, Epanet 2 explícito e iterativo baseado nas análises dirigida pela pressão) foram testados e acoplados aos métodos de otimização com intuito de dar suporte às avaliações das funções objetivo.

A terceira fase do modelo (etapa de decisão) foi responsável por apresentar as soluções ótimas obtidas, que representam os ações de reabilitação a serem implementadas na rede. É nessa fase que ocorre a tomada de decisão. A investigação de cada fase do modelo computacional proposto possibilitou que diversas conclusões fossem obtidas, as quais são apresentadas aqui de forma sucinta.

Os primeiros estudos realizados neste trabalho objetivaram o acoplamento do simulador hidráulico convencional (Epanet 2) ao compilador Borland Builder C++ 5.0. Esse 
acoplamento foi realizado através da Toolkit, biblioteca de funções, que possibilita que as rotinas do Epanet 2 possam ser chamadas através do compilador $\mathrm{C}++$. Não houve problemas nesse acoplamento, podendo-se afirmar que o Epanet 2, utilizado através da Toolkit, trabalha eficientemente. Um outro estudo realizado teve como objetivo desenvolver o acoplamento entre o módulo de otimização (GAlib), biblioteca de algoritmos genéticos e o simulador hidráulico (Epanet 2). A integração entre o módulo de otimização e o simulador hidráulico só foi possível porque ambos os pacotes (GAlib e Epanet 2) foram escritos em linguagens compatíveis, $\mathrm{C}++$ e $\mathrm{C}$, respectivamente.

A integração entre a GAlib e o Epanet 2 permitiu que vários testes fossem realizados sobre o problema proposto por GESSLER (1985). Através desse programa desenvolvido (GAlib/Epanet) foi possível também avaliar a adequação e o desempenho dos algoritmos genéticos à resolução do problema de reabilitação (estudo teórico). As soluções de mínimo custo, encontradas através desse programa, apresentaram resultados melhores do que os obtidos por GESSLER (1985) e SIMPSON, DANDY e MURPHY (1994). As restrições desse problema (garantia de atendimento de pressões mínimas) foram incorporadas através de um termo penalidade na função objetivo associado a um peso. Várias simulações foram realizadas considerando diferentes combinações (análise de sensibilidade) de pesos. Funções penalidades apresentam uma série de inconvenientes já conhecidos, por exemplo, a necessidade de identificação adequada de pesos. Análises de sensibilidades foram desenvolvidas com intuito de identificar o valor ideal para o peso da função penalidade. Mostrou-se a dificuldade em ajustá-lo de forma a garantir uma resposta acurada da solução de mínimo custo. Cabe lembrar que esse estudo de caso foi teórico, cuja solução ótima do problema era conhecida. Em problemas reais, nem sempre se tem um conhecimento prévio da solução.

Os estudos de otimização desenvolvidos no problema de GESSLER (1985) produziram resultados interessantes e propiciaram um entendimento da ferramenta de busca utilizada (GAlib). Em relação aos resultados, pode-se mencionar que as simulações desenvolvidas, considerando os diferentes pesos para a função penalidade, produziram respostas também distintas. Para cada peso adotado como coeficiente da função penalidade foi obtida uma única resposta representativa de uma solução sobre a curva trade-off ou frente Pareto. No entanto, a crítica que se faz a esse procedimento (método dos pesos) é o elevado tempo computacional consumido para obter uma frente Pareto descontínua. Observou-se uma forte fragilidade do método dos pesos em perder 
soluções da frente. A frente Pareto obtida pelo método dos pesos serviu de motivação para o desenvolvimento do módulo de otimização multiobjetivo, baseado na proposição de FONSECA e FLEMING (1993), denominado MOGA. O entendimento pormenorizado da GAlib, obtido através dos estudos mencionados, possibilitou o domínio da técnica e permitiu que o MOGA fosse implementado, utilizando operadores convencionais (recombinação e mutação) da GAlib.

Um dos principais questionamentos, por parte dos pesquisadores que tratam do assunto, referentes à aplicação de algoritmos genéticos é a identificação adequada dos parâmetros de entrada desses algoritmos (dimensão da população, número máximo de gerações, probabilidade de recombinação e probabilidade de mutação). Nesse sentido, o presente trabalho apresenta um esforço em identificar qual desses parâmetros interfere mais na resposta desses algoritmos. Análises estatísticas, baseadas no planejamento fatorial com ponto central ortogonal, foram desenvolvidas para o problema de reabilitação de redes e os resultados demonstraram que os parâmetros que interferem de maneira mais decisiva na resposta ótima dos algoritmos genéticos são a dimensão da população e o número máximo de gerações.

Várias simulações teste foram realizadas com o MOGA aplicado ao problema de reabilitação de redes. Uma análise simples foi desenvolvida comparando a frente obtida através do MOGA com a frente obtida através do método dos pesos. A frente produzida pelo MOGA foi melhor definida que a frente obtida pelo método dos pesos (otimização de objetivo único). Duas vantagens foram observadas pela utilização do MOGA: não há necessidade de se atribuir pesos à função objetivo, pois todos os objetivos (no caso, déficit de pressão) são tratados simultaneamente, e, com apenas uma simulação, obtémse a frente Pareto.

O MOGA, em sua concepção original, considera que as frentes não dominadas evoluam a cada iteração. No presente trabalho foi realizado um aperfeiçoamento (uma espécie de elitismo) desse método, que resultou em uma melhoria da frente Pareto resultante, quando comparada à sua proposição original. A cada iteração do algoritmo, as soluções não dominadas são armazenadas em um conjunto externo e substituídas somente quando as mesmas forem dominadas por soluções obtidas posteriormente. Comparandose a frente Pareto obtida através do procedimento original com a frente Pareto obtida considerando o conjunto externo, observou-se que o MOGA aperfeiçoado explora regiões da superfície de resposta não alcançadas pelo MOGA original. Assim, tal 
procedimento foi incorporado ao algoritmo MOGA implementado pelo autor deste trabalho e representa uma das contribuições desta pesquisa.

Como a aplicação de algoritmos evolucionários multiobjetivo na análise de reabilitação de redes de distribuição de água é um assunto relativamente novo, poucos estudos comparativos desses métodos têm sido desenvolvidos. Nessa direção e visando identificar o método mais eficiente para o problema em estudo, análises comparativas foram realizadas. É importante lembrar que para avaliar o desempenho de algoritmos evolucionários multiobjetivo, no mínimo duas métricas de desempenho devem ser aplicadas. A primeira métrica avalia a convergência da frente, a segunda avalia quão uniforme as soluções estão distribuídas ao longo da superfície Pareto. Quatro métodos evolucionários de otimização multiobjetivo (MOGA, NSGA, SPEA e NSGA II) foram comparados, sendo que os resultados do MOGA produzidos através do programa desenvolvido pelo autor deste trabalho contou com suporte da biblioteca GAlib e os resultados do NSGA, SPEA e NSGA II obtidos utilizando a biblioteca MOMHLib++. As análises comparativas demonstraram que o SPEA apresentou melhor desempenho, seguido pelo NSGA, MOGA e NSGA II.

Após a identificação do método mais eficiente (SPEA) para o problema de reabilitação de redes de distribuição de água, análises comparativas foram desenvolvidas com o objetivo de encontrar os operadores de recombinação e mutação mais eficientes. Três operadores de recombinação (Linear, BLX- $\alpha$ e Uniforme) e três operadores de mutação (Limite, Aleatória e Dinâmica) foram implementados e investigados. As análises mostraram que para o operador de recombinação, tanto o BLX- $\alpha$ quanto o uniforme, apresentaram bom desempenho. Em se tratando do operador de mutação, o melhor desempenho foi verificado através da mutação dinâmica.

Considerando o SPEA como melhor método de otimização multiobjetivo para o problema em questão, com parâmetros e operadores genéticos adequados, um terceiro objetivo foi incorporado na análise de reabilitação. O SPEA demonstrou eficiência quando um problema envolve três objetivos (minimização de custos, minimização de déficit de pressão e maximização de benefícios). A função objetivo benefícios responde o anseio de vários pesquisadores em quantificar os benefícios gerados pelas ações de melhoria realizadas no sistema. A formulação desse objetivo foi uma outra contribuição deste trabalho e representa um aperfeiçoamento da proposta de HALHAL et al. (1997). 
Evoluindo nos estudos de reabilitação de redes e verificando que as simulações hidráulicas, baseadas nas análises dirigidas pela demanda, aplicadas aos problemas reais tendem a produzir resultados poucos satisfatórios, optou-se por utilizar um simulador hidráulico baseado nas análises dirigidas pela pressão, como plataforma de avaliação, para as análises de reabilitação de redes de distribuição de água. Existia, portanto, duas possibilidades a serem adotadas: procedimento iterativo (sem intervenção no código de Epanet 2) ou procedimento direto (intervenção no código). Visando economizar tempo computacional para as investigações posteriores (sistema real considerando quatro objetivos) optou-se pelo procedimento que fornecesse intervenção direta sob o código do Epanet 2. Para isso, foi necessário utilizar um módulo de avaliação que possibilitasse mudar o método gradiente que é implementado no Epanet 2. Isso só foi possível através da utilização da biblioteca para Epanet 2 orientada a objetos (escrita em $\mathrm{C}++$ ) denominada OOTEN.

A mudança do código do Epanet 2 foi uma contribuição original deste trabalho e permitiu a inclusão explícita do modelo de vazamentos e do modelo de demanda dirigida pela pressão. O modelo de vazamentos adotado foi aquele proposto por TUCCIARELLI, CRIMINISI e TERMINI (1999). A consideração do modelo de vazamentos não causa instabilidade no método numérico. Já a demanda variável com a pressão apresentou problemas de convergência (oscilações). Vários modelos pressãodemanda foram testados (WAGNER, SHAMIR e MARKS, 1988; FUJIWARA e LI, 1998 e TUCCIARELLI, CRIMINISI e TERMINI, 1999) na rede exemplo (estudo teórico) proposta por TUCCIARELLI, CRIMINISI e TERMINI (1999). O modelo de FUJIWARA e LI (1998) apresentou os piores resultados, devido às oscilações causadas pelos gradientes da função, causando instabilidade na avaliação da matriz Jacobiana. Essas oscilações para todos os modelos pressão-demanda foram suavizadas através de um procedimento simples de relaxação. Depois de aplicado o fator de relaxação, todos os modelos de demanda não apresentaram problemas de convergência no estudo teórico. No entanto, aperfeiçoamentos no sentido de minimizar as oscilações causadas pelos modelos de demanda dirigidos pela pressão merecem ser melhor investigados para que esse simulador possa ser aplicado em estudos de caso reais.

Depois de identificado o método de otimização mais apropriado, os parâmetros genéticos, os operadores e o simulador hidráulico mais realístico, foi possível aplicar a metodologia proposta a um problema real. O sistema real estudado foi um modelo 
simplificado ("esqueleto") do sistema RF-1 da cidade de Campo Grande - MS. Como o simulador hidráulico proposto (Epanet 2 modificado) está ainda em fase de desenvolvimento pelo autor do presente trabalho, necessitando de alguns ajustes, desenvolveu-se um simulador hidráulico iterativo baseado nas análise dirigidas pela pressão que conta com os mesmos modelos (vazamento e demanda) do simulador proposto. Esse simulador hidráulico iterativo também foi desenvolvido através da biblioteca para Epanet 2 orientado a objetos (ZYL et al., 2003). Através do procedimento iterativo não há necessidade de se calcular a matriz jacobiana dos modelos de demanda, propiciando assim uma certa estabilidade no procedimento.

Uma pesquisa de campo foi realizada no sistema real com objetivo de identificar os parâmetros de característicos do modelo de vazamentos, de forma a considerá-los explicitamente no simulador hidráulico iterativo. Esses parâmetros foram encontrados através de um procedimento inverso (calibração) que estima os valores desses parâmetros através da minimização entre os dados observados em campo e os dados simulados na rede.

Uma vez que os parâmetros característicos do modelo de vazamentos para o sistema real foram obtidos e puderam ser considerados nas avaliações hidráulicas, procederamse às análises de reabilitação para identificação dos planos ótimos de reabilitação (seqüência de ações a serem implementadas na rede). Com o decorrer da pesquisa, observou-se que o problema de reabilitação de redes além de ser multicriterial pode ser tratado como um problema dinâmico. Dois tipos de investigações foram propostas nesse sentido: análise de reabilitação multiobjetivo estática e análise de reabilitação multiobjetivo dinâmica, sendo que essa última apresenta-se como outra contribuição deste trabalho.

A análise de reabilitação de redes de distribuição de água estática considera algumas hipóteses, para efeito de simplificação, no processo de planejamento. Tais hipóteses referem-se ao estado da rede (estado dos trechos, reabilitados ou não reabilitados) que permanece inalterável durante o período de análise, aos investimentos financeiros disponíveis, que devem ser empregados no primeiro ano do projeto e as avaliações dos critérios (custo, benefício, vazamentos e confiabilidade) considerando demandas nodais projetadas para os períodos de análise. Nesse caso, a função objetivo custo não considera taxa de juros, sendo calculada uma única vez. Essas simplificações podem apresentar soluções não realísticas à tomada de decisão. 
A análise dinâmica, pelo contrário, sugere que o tempo ótimo de investimentos durante o horizonte de planejamento seja levado em consideração, e dessa forma, apresenta uma alternativa mais realística do problema. Cada solução obtida no caso dinâmico fornece informações da solução correspondentes às ações de reabilitação, por período de planejamento. A determinação dos planos de reabilitação e a distribuição dos investimentos necessários ao longo do período de planejamento (15 anos) é a principal vantagem da programação multiobjetivo dinâmica. A desvantagem desse tipo de análise (dinâmica) é o tempo computacional consumido durante o processo iterativo.

As vantagens que podem ser apontadas da análise estática estão relacionadas à simplicidade do procedimento de cálculo para obtenção de ações de reabilitação de curto prazo (implementadas no primeiro período). Poucas simulações são necessárias para se ter um conhecimento preliminar do problema. No entanto, a análise estática não fornece ao decisor informações das ações a serem implementadas na rede a cada ano de planejamento. Conclui-se, portanto, que a análise de reabilitação dinâmica é o procedimento mais adequado e realístico a ser considerado em um planejamento de longo prazo, a análise de estática é um procedimento simplificado que pode ser utilizado como ferramenta de auxílio para uma investigação preliminar do problema.

O problema de planejamento de reabilitação de redes de distribuição de água tratado no presente estudo foi formulado como um problema multicriterial (quatro objetivos) de múltiplo estágios (programação dinâmica). Essa nova abordagem promove um avanço na aplicação de técnicas de análise de sistemas nos problemas de redes de distribuição de água. A Tabela 7.1 apresenta um descrição das proposições da literatura e situa o presente trabalho em termos das contribuições que o mesmo apresenta.

As soluções apresentadas pela otimização demonstraram e comprovaram os conflitos existentes e a competição entre os critérios considerados (custos, benefícios, vazamentos e confiabilidade). Depois de identificadas as soluções não dominadas (frente Pareto), a complexidade do problema torna-se escolher a melhor solução dentre um conjunto de boas soluções. Neste trabalho, considerou-se a Análise de Componentes Principais (ACP) como método de escolha. A ACP mostrou-se muito adequada ao problema e permitiu mostrar as similaridades entre as soluções da frente Pareto no espaço de decisão. Através da ACP foi possível transformar o problema de quatro dimensões em um problema bidimensional, favorecendo uma escolha favorável de soluções que pudessem garantir a representatividade da frente. 
Tabela 7.1 - Modelos para análise de reabilitação de redes de distribuição de água e a contribuição original do presente trabalho

\begin{tabular}{|c|c|c|c|c|c|c|c|c|c|}
\hline \multirow{2}{*}{ Autor } & \multirow{2}{*}{ Ano } & \multirow{2}{*}{ Modelo } & \multirow{2}{*}{$\begin{array}{l}\text { Simulador } \\
\text { Hidráulico }\end{array}$} & \multirow{2}{*}{ Ações } & \multicolumn{5}{|c|}{ Objetivos } \\
\hline & & & & & $\mathrm{C}$ & $\mathrm{V}$ & B & $\mathrm{CF}$ & Q \\
\hline SHAMIR e HOWARD & 1979 & ES & - & S & $\mathrm{E}$ & - & - & - & - \\
\hline WALSKI e PELLICIA & 1982 & ES & - & S & $\mathrm{E}$ & - & - & - & - \\
\hline WALSKI & 1982 & ES & - & $\mathrm{L} / \mathrm{R}$ & $\mathrm{E}$ & - & - & - & - \\
\hline GESSLER & 1985 & AS $(\mathrm{O})$ & ADD & $\mathrm{S} / \mathrm{L} / \mathrm{D} / \mathrm{P}$ & $\mathrm{E}$ & - & - & $\mathrm{I}(\mathrm{H})$ & - \\
\hline QUIMPO e SHAMSI & 1991 & ES & ADD & A & $\mathrm{X}$ & - & - & $\mathrm{E}(\mathrm{M})$ & - \\
\hline LANSEY et al. & 1992 & AS $(O)$ & ADD & $\mathrm{S} / \mathrm{L} / \mathrm{R}$ & $\mathrm{E}$ & - & - & - & - \\
\hline LI e HAIMES & $1992 b$ & $\mathrm{AS}(\mathrm{O})$ & ADD & $\mathrm{S}$ & $\mathrm{E}$ & - & - & $\mathrm{I}(\mathrm{H})$ & - \\
\hline KIM e MAYS & 1994 & AS $(O)$ & ADD & $\mathrm{S}$ & $\mathrm{E}$ & - & - & $\mathrm{I}(\mathrm{H})$ & - \\
\hline SIMPSON et al. & 1994 & AS $(O)$ & ADD & $\mathrm{S} / \mathrm{L} / \mathrm{D} / \mathrm{P}$ & $\mathrm{E}$ & - & - & $\mathrm{I}(\mathrm{H})$ & - \\
\hline SCHNEITER et al. & 1996 & AS (O) & ADD & $\mathrm{L}$ & $\mathrm{E}$ & - & - & $\mathrm{E}(\mathrm{H})$ & - \\
\hline HALHAL et al. & 1997 & AS (MO) & $\mathrm{ADD}$ & $\mathrm{S} / \mathrm{L} / \mathrm{R}$ & $\mathrm{E}$ & I & $\mathrm{E}$ & $\mathrm{I}(\mathrm{H})$ & I \\
\hline DE SCHAETZEN et al. & 1998 & AS $(O)$ & ADD & $\mathrm{S} / \mathrm{L} / \mathrm{R}$ & $\mathrm{E}$ & - & - & - & - \\
\hline KLEINER et al. & 1998 & AS $(O)$ & $\mathrm{ADD}$ & $\mathrm{S}$ & $\mathrm{E}$ & - & - & $\mathrm{I}(\mathrm{H})$ & - \\
\hline ENGELHARDT & 1999 & AS (MO) & ADD & S & $\mathrm{E}$ & - & - & $\mathrm{E}(\mathrm{H})$ & - \\
\hline $\begin{array}{l}\text { DANDY e } \\
\text { ENGELHARDT }\end{array}$ & 1999 & AS $(O)$ & $\mathrm{ADD}$ & S & $\mathrm{E}$ & - & - & - & - \\
\hline WALTERS et al. & 1999 & AS (MO) & $\mathrm{ADD}$ & $\mathrm{S} / \mathrm{L} / \mathrm{D} / \mathrm{P}$ & $\mathrm{E}$ & - & $\mathrm{E}$ & $\mathrm{I}(\mathrm{H})$ & - \\
\hline WU e SIMPSON & 2001 & AS $(O)$ & $\mathrm{ADD}$ & $\mathrm{S} / \mathrm{L} / \mathrm{D} / \mathrm{P}$ & $\mathrm{E}$ & - & - & $\mathrm{I}(\mathrm{H})$ & - \\
\hline CHEUNG et al. & 2003 & AS (MO) & $\mathrm{ADD}$ & $\mathrm{S} / \mathrm{L} / \mathrm{D} / \mathrm{P}$ & $\mathrm{E}$ & - & - & $\mathrm{E}(\mathrm{H})$ & - \\
\hline $\begin{array}{l}\text { CHEUNG, REIS e } \\
\text { CARRIJO }\end{array}$ & 2003 & AS (MO) & ADD & $\mathrm{S} / \mathrm{L} / \mathrm{D} / \mathrm{P}$ & $\mathrm{E}$ & - & $\mathrm{E}$ & $\mathrm{E}(\mathrm{H})$ & - \\
\hline CHEUNG e REIS & 2003 & AS (MO) & ADP & $\mathrm{S} / \mathrm{L} / \mathrm{D} / \mathrm{P}$ & $\mathrm{E}$ & $\mathrm{E}$ & $\mathrm{E}$ & - & - \\
\hline CHEUNG & 2003 & AS (MO) & ADP & $\mathbf{S} / \mathbf{L} / \mathbf{D} / \mathbf{P} /$ & $\mathbf{E}$ & $\mathbf{E}$ & $\mathbf{E}$ & E (H) & - \\
\hline
\end{tabular}

ES: Modelo estatístico; AS: Modelo baseado em análise de sistemas; O: Otimização considerando apenas um objetivo; MO: Otimização multiobjetivo; ADD: Análise de redes dirigida pela demanda; ADP: Análise de redes dirigida pela pressão; S: Substituição de tubos; L: Limpeza de tubos; R: Revestimento de tubos; D: Tubos em paralelo; P: Novos tubos (projeto); A: Setores de rede que precisam ser reabilitadas; E: Explícito; I: Implícito; H: Confiabilidade hidráulica; M: Confiabilidade Mecânica; C: Custo; V: Vazamento; CF: Confiabilidade; Q: Qualidade da água

Ressalta-se ainda a necessidade de investigar melhor os métodos de classificação de soluções, de aperfeiçoar a programação multiobjetivo dinâmica no sentido de desenvolver técnicas automáticas e "inteligentes" de transição de estados, de reavaliar o simulador hidráulico proposto (Epanet 2 modificado) para aplicações reais de maneira que as oscilações causadas pelos modelos de demanda dependentes da pressão (embora o mesmo tenha apresentado bons resultados em problemas teóricos - redes da literatura) sejam controlados e gerenciados eficientemente, de incorporar técnicas convencionais de confiabilidade (simulações monte-carlo, cut-set) para avaliação das soluções finais (frente Pareto), de reavaliar as funções objetivo propostas, de propor e incorporar outros critérios (por exemplo, qualidade da água) e de desenvolver técnicas de computação de 
alto desempenho (clusters de computadores ou sistemas distribuídos) visando economia de tempo computacional. 


\section{REFERÊNCIAS BIBLIOGRÁFICAS}

AGGARWAL, K. K. (1993). Reliability Engineering. Boston: Kluwer Academic Publishers.

ASCHER, H. e FEINGOLD, H. (1984). Repairable systems reliability: modeling, inference, misconceptions and their causes. New York: Lecture notes in statistics.

ALPEROVITS, E.; SHAMIR, U. (1977). Design of Optimal Water Distribution Systems. Water Resources Research, v. 13, n. 6, p. 885-900.

ANDREOU S.A.; MARKS D.H.; CLARK R.M. (1987). A New Methodology for Modeling Break Failure Patterns in Deteriorating Water Distribution-Systems Theory. Advances in Water Resources, v. 10, n. 1, p. 2-10.

BELlMAN, R.; KALABA, R. (1965). Dynamic Programming and Modern Control Theory, New York: Academic Press.

BHAVE, P. R. (1979). Selecting Pipe Sizes in Network Optimization by LP. Journal of the Hydraulics Division - Asce, v. 105, n. 8, p. 1019-1025.

BHAVE, P. R. (1988). Calibrating Water Distribution Network Models. Journal of Environmental Engineering, v. 114, n. 1, p. 120-136, Feb.

BOULOS, P. F.; WOOD, D. J. (1990). Explicit Calculation of Pipe-Network Parameters. Journal of Hydraulic Engineering, v. 116, n. 11, p. 1329-1344, Nov.

BOX, G. E. P. (1978). Statistics for Experiments: Introduction to Design, Data Analysis and Model Building. New York, John Wiley.

BRÉMOND, B. (1997). Statistical Modelling as Help in Network Renewal Decision. European commission co-operation on science and technology (COST), Committee C3 - diagnostics of urban infrastructure, Paris, France.

BROTHERS, K. J. (2001). Water leakage and sustainable supply - Truth or consequences? Journal American Water Works Association, v. 93, n. 4, p. 150-152.

CALIMAN, R. O. (2002). Determinação dos Parâmetros do Modelo Pressão x Vazamento para Sub-setores da Rede de Distribuição de Água de São Carlos - SP. São Carlos. 110 p. Dissertação (Mestrado). Escola de Engenharia de São Carlos, Universidade de São Paulo, Brasil.

CHANDRASHEKAR M.; STEWART K.H. (1975). Sparsity Oriented Analysis of Large Pipe Networks. Journal of The Hydraulics Division, v. 101, n. NHY4, p. 341-355.

CHANDAPILLAI, J. (1991). Realistic Simulation of Water Distribution System. Journal of Transportation Engineering, v. 117, n. 2, p. 258-263.

CHEUNG, P. B. (2001). Investigação dos Métodos Clássicos de Calibração de Redes Hidráulicas. Campo Grande. 132 p. Dissertação (Mestrado). Universidade Federal de Mato Grosso do Sul, Brasil.

CHEUNG, P. B.; REIS, L. F. R.; CARRIJO, I. B. (2003) - Multiobjective Optimization to the Rehabilitation of a Water Distribution Network. Advances in Water Supply Management (CCWI - Computing and Control for the Water Industry \& Watersave Network). Imperial College, London, England. 
CHEUNG, P. B.; REIS, L. F. R.; FORMIGA, K. T. M.; CHAUDHRY, F. H.; TICONA, W. G. C. (2003). Multiobjective Evolutionary Algorithms Applied to the Rehabilitation of a Water Distribution System: A Comparative Study. Evolutionary Multi-Criterion Optimization, v.2632, p. 662-676. Springer-Verlag, Heidelberg.

CLARK, R.M.; GOODRICH, J.A. (1989). Developing a data base on infrastructure needs. Journal of the American Water Works Association, v 81, n 7, p. 81-87.

CLARK, R.M.; STAFFORD, C.L.; GOODRICH, J.A. (1982). Water Distribution Systems: A Spatial Cost Evaluation. Journal of Water Resources Planning and Management, v. 108 (WR 3), p. 243-255.

COELlO, C. A. C. (1996). An Empirical Study of Evolutionary Techniques for Multiobjective Optimization in Engineering Design. Ph. D. Thesis. Tulane University.

COHON, J. L. (1978). Multiobjective Programming and Planning. San Diego, Academic, USA.

COLEBROOK, C. F.; WHITE, C. M. (1937). The reduction of Capacity of Pipes with Age. Journal Institution Civil Engineers. London, n. 5137, p. 99-118.

COLOMBO, A. F.; KARNEY, B. W. (2002). Energy and costs of leaky pipes toward comprehensive picture. Journal of Water Resources Planning and Management, v. 128, n 6, p. 441-450.

CONSTANTINE, A. G.; DARROCH, J. N. (1993). Pipeline Reliability: Stochastic Models in Engineering Technology and Management. Singapure: World Scientific.

CULLINANE M. J.; LANSEY K.E.; MAYS L.W. (1992). Optimization-AvailabilityBased Design Of Water-Distribution Networks. Journal of Hydraulic Engineering, v. 118 , n. 3, p. 420-441.

DANDY, G.C.; ENGELHARDT, M.O. (2001a). Optimal Scheduling of Water Pipe Replacement using Genetic Algorithms. Journal of Water Resources Planning and Management, v. 127, n. 4, p. 214-223.

DANDY, G.C.; ENGELHARDT, M.O. (2001b). Optimum Rehabilitation of Water Distribution System considering Cost and Reliability. Proceedings of the World Water and Environmental Resources Congress, Orlando, Florida.

DANDY, G. C.; SIMPSON, A. R.; MURPHY, L. J. (1996). An improved Genetic Algorithm for Pipe Network Optimization. Water Resources Research, v. 32, n. 2, p. 449-458.

DATTA, R. S. N.; SRIDHARAN, K. (1994). Parameter Estimation in Water- Distribution Systems by Least Squares. Journal of Water Resources Planning and Management, v. 120 , n. 4, p. 405-422.

DE SCHAETZEN, W.; RANDALl-SMITH, M.; SAVIC, D. A.; WALTERS, G. A. (1999). Optimal Logger Density in Water Distribution Network Calibration. In: SAVIC, D. A. (ed.); WALTERS, G. A. (ed.): Water Industry Systems: Modeling and Optimization Applications, vol. 1, p. 301-307.

DEB, K. (1999). Evolutionary Algorithms for Multi-Criterion Optimization in Engineering Design. In: Miettinen K.; Neittaanmäki, P.; Mäkelä, M. M. and Périaux, J. (Eds), Evolutionary Algorithms in Engineering and Computer Science, pp. 135-161. Chicester, UK: Wiley.

DEB, K. (2001). Multi-Objective Using Evolutionary Algorithms. John Wiley \& Sons, Ltd.

DEB, A. K.; SARKAR, A. K. (1971). Optimization in Design of Hydraulic Network, Journal of the Sanitary Engineering Division. v. 97, n. SA2, p. 141-159.

DEB, K.; PRATAP, A.; AGARWAL, S.; MEYARIVAN, T. (2002). A Fast and Elitist Multiobjective Genetic Algorithm: NSGA-II. IEEE Transactions on Evolutionary Computation. v. 6, n. 2, p. 182-197. 
DONACHIE, R. P. (1974). Digital Program for Water Network Analysis. Journal of the Hydraulics Division, v. 100, n. NHY3, p. 393-403.

EGGENER C. L.; POLKOWSKI, L.B. (1976). Network Models and Impact of Modeling Assumptions. Journal American Water Works Association, v. 68, n. 4, p. 189-196.

EPP, R., FOWLER, A. G. (1970). Efficient Code for Steady State Flows in Networks. Journal of the Hydraulic Division, v. 96, n. HY1, p. 43-56.

ESHELMAN, L. J.; SCHAFFER, J. D. (1993). Real-coded Genetic Algorithms and Interval-Schemata. Foundations of Genetic Algorithms 2 (FOGA - 2), p. 187-202.

ENGELHARDT, M.O; SKIPWORTH, P.J.; SAVIC, D.A.; SAUL, A.J.; WALTERS, G.A. (2000). Rehabilitation Strategies for Water Distribution Networks: a Literature Review with a UK Perspective. Urban Water, n. 2, p. 153-170.

ENGELHARDT, M.O.; DANDY, G.C. (1999). The Development of an Optimal Strategy to Schedule Main Replacements. Water Industry Systems: Modelling and Optimisation Applications, Research Studies Press, England, v. 2, p. 419-426.

EVSUKOFF, A.G.; EBECKEN, N.F.F. (2003). Métodos Numéricos em Recursos Hidricos. ABRH, Silva, R.C.V. (Editor), Porto Alegre.

FRANCATO, A. L. (2002). Operação Multiobjetivo para a Operação de Sistemas Urbanos de Abastecimento de Água. Tese de Doutorado. Universidade Estadual de Campinas (UNICAMP), Brasil.

FONSECA, C.M.; FLEMING, P. J. (1993). Genetic Algorithms for Multiobjective Optimization: Formulation, Discussion and Generalization. Proceedings of the Fifth International Conference, San Mateo.

FONSECA, C. M.; FLEMING, P. J. (1995). An Overview of Evolutionary in Multiobjective Optimization. Evolutionary Computation, v. 3, n. 1, p. 1-16.

FORMIGA, K. T. M. (1999). Metodologia de otimização de redes malhadas através da programação não linear. Campina Grande. 159 p. Dissertação (Mestrado). Universidade Federal da Paraíba, Brasil.

FORMIGA, K. T. M.; CHAUDHRY, F. H.; CHEUNG, P. B.; REIS, L. F. R. (2003). Optimal Design of Water Distribution System by Multiobjective Evolutionary Methods. Evolutionary Multi-Criterion Optimization, v. 2632, p. 677-691 SpringerVerlag, Heidelberg.

FUJIWARA, O.; GANESHARAJAH, T. (1993). Reliability Assessment of Water Supply Systems Withstorage and Distributions Networks. Water Resources Research. v. 29, $\mathrm{n}$. 8, p. 2917-2924.

FUJIWARA, O.; KWANG, D. B. (1990). A Two-Phase Decomposition Method for Optimal Design of Looped Water Distribution Networks. Water Resources Research, v. 26 , n. 4 , p. $539-549$.

FUJIWARA, O.; LI, J. (1998). Reliability Analysis of Water Distribution Networks in Consideration of Equity, Redistribution, and Pressure-Dependent Demand. Water Resources Research, v. 34, n. 7, p. 1843-1850.

GAMBALE, S. R. (2000). Aplicação de Algoritmo Genético na Calibração de Redes de Água. São Paulo. 266 p. Dissertação (Mestrado). Escola Politécnica, Universidade de São Paulo, Brasil.

GARCIA, C. (1997). Modelagem e Simulação de Processos Industriais e de Sistemas Eletromecânicos. Editora da Universidade de São Paulo, São Paulo, Brasil.

GAT, Y. L.; EISENBEIS, P. (2000). Using Maintenance Records to Forecast Failures in Water Networks. Urban Water, v. 2, p. 173-181.

GEN, M.; CHENG, R. (1996). Genetic Algorithms and Engineering Design. John Wiley \& Sons, INC. 
GERMANOPOULOS, G.; JOWITT, P. W. (1989). Leakage Reduction by Excess Pressure Minimization in a Water Supply Network. Proc. Instn. Civ. Engrs., Part 2 (June), p. 195-214.

GESSLER, J. (1985). Pipe network optimization by enumeration. Proceedings Computer Applications for Water Resources, ASCE, New York, N.Y., 572-581

GOICOECHEA, A.; HANSEN, D. R.; DUCKSTEIN, L. (1982). Multiobjective Decision Analysis with Engineering and Business Applications. John Wiley \& Sons.

GOLDBERG, D.E. (1989) - Genetic Algorithms in Search, Optimization, and Machine Learning, Addison-Wesley, Reading, Massachusetts.

GOLDBERG, D.E.; RICHARDSON, J. (1987). Genetic Algorithms with Sharing for Multimodal Function Optimization. In. Proceedings of the First International Conference on Genetic Algorithms and Their Applications, p. 41-49.

GOULTER, I.C. (1992). Systems Analysis in Water-Distribution Network Design from Theory to Practice. Journal of Water Resources Planning and Management, v. 118, n. 3, p. 238-248.

GOULTER, I.; DAVIDSON, J.; JACOBS, P. (1993). Predicting Water-main Breakage Rate. Journal of Water Resources Planning and Management, v. 119, n. 4, p. 419-436.

GUPTA, R.; BHAVE, P. R. (1996). Comparison of Methods for Predicting DeficientNetwork Performance. Journal of Water Resources Planning and Management, v. 122, n. 3, p. 214-217, May/June.

HAIR, J. F.; ANDERSON, R. E.; TATHAM, R. L.; BLACK, W. C. (1998). Multivariate Data Analysis. Prentice-Hall.

HALHAL, D.; WALTERS, G.A.; OUAZAR, D.; SAVIC, D.A. (1997). Water Network Rehabilitation with Structured Messy Genetic Algorithm. Journal of Water Resources Planning and Management, v. 123, n. 3, p. 137-146.

HAJELA, P.; LIN, C. Y. (1992). Genetic Search Strategies in Multi-Criterion Optimal Design. Structural Optimization, v. 4, n. 2, p. 99-107.

HARRIS, R. U. (1984). Computer Modelling in Water System Planning and Design. Journal of the American Water Works Association, p. 78-81, 1984.

HERZ, R. K. (1996). Ageing Process and Rehabilitation Needs of Drinking Water Distribution Networks. Journal of Water SRT-Aqua, v. 45, n. 5, p. 221-231.

HORN, J.; NAFPLIOTIS, N. (1993). Multiobjective Optimization using the Niched Pareto Genetic Algorithm. IlliGAL Report n. 93005.

HORN, J.; NAFPLIOTIS, N.; GOLDBERG, D. (1994). A Niched Pareto Genetic Algorithm for Multi-objective Optimization. In: Proceedings of the First IEEE Conference on Evolutionary Computation, p. 82-87.

JASKIEWICZ, A. (1999). MOMHLIB++: Multiple Objective Metaheuristics Library in $C++$. http://www-idss.cs.put.poznan.pl/ jaszkiewicz/MOMHLIB.

JACOBY, S. L. S. (1968). Design of Optimal Hydraulic Network. Journal Hydraulic Division American Society Civil Engineering, v. 94, n. HY3, p. 641-661.

JOWITT, P. W.; XU, C. (1990). Optimal Valve Control in Water Distribution Networks. Journal of Water Resources Planning and Management, v. 116, n.4, p. 455-472.

KALLY, E. (1969). Pipeline Planning by Dynamic Computer Programming. Journal American Water Works Association, v. 61, n. 3.

KAPELAN, Z. S.; SAVIC, D. A.; WALTERS, G. A. (2002). Inverse Transient Analysis in Pipe Networks for Leakage Detection and Roughness Calibration. In: SAVIC, D. A. (ed.); WALTERS, G. A. (ed.): Water Network Modelling for Optimal Design and Management, p. 143-159, Sept. 
KHURI, A. (1996). Response Surfaces. New York: Marcel Dekker.

KIM, J.H.; MAYS, L.W. (1990). Rehabilitation and Replacement of Water Distribution System Components considering Uncertainties. Stochastic Hydrology and Hydraulics, Springer Verlag, p. 277-294.

KIM, J.H.; MAYS, L.W. (1994). Optimal Rehabilitation Model for Water Distribution Systems. Journal of Water Resources Planning and Management, v. 120, n. 5, p. 674692.

KLEINER, Y.; RAJANI, B. (2001). Comprehensive Review of Structural Deterioration of Water Mains: Statistical Models. Urban Water, n. 3, p. 131-150.

KLEINER, Y.; ADAMS, B. J.; ROGERS, J. S. (1998). Long-term Planning Methodology for Water Distribution System Rehabilitation. Water Resources Research, n. 3, p. 131150 .

KNOWLES, J. D.; CORNE, D. W. (2000). Approximating the Non-Dominated Front using the Pareto Archived Evolution Strategy. Evolutionary Computation Journal, v. 8, n. 2, p. 149-172.

KUNG, H. T.; LUCCIO, F.; PREPARATA, F. P. (1975). On Finding the Maxima of a Set of Vectors. Journal of the Association for Computing Machinery v. 22, n. 4, p. 469476.

KURSAWE, F. (1991). A Variant of Evolution Strategies for Vector Optimization. Lecture Notes in Computer Science v. 496, p. 193-197.

LAMONT, P. A. (1981). Common Pipe Formulas Compared With the Theory of Roughness. Journal of the American Water Works Association, v.72, n. 5, p. 274-280.

LANSEY, K. E. (2000). Optimal Maintenance Scheduling for Water Distribution Systems. Civil Engineering Systems, v. 9, p. 211-226.

LANSEY,K., BASNET, C. (1991). Parameter Estimation for Water Distribution Networks. Journal of Water Resources Planning and Management, v. 117, n. 1, p. 126.

LANSEY, K.; MAYS, L.W. (2000). Hydraulics of Water Distribution Systems. In: Mays LW, editor. Water Distribution Systems Handbook, New York: McGraw Hill.

LANSEY, K. E.; BASNET, C.; MAYS, L. W.; WOODBURN, J. (1992). Optimal Maintenance Scheduling for Water Distribution Systems. Civil Engineering Systems, v. 9, p. 211-226.

LEI, J. (1997). Statistical Approach for Describing Lifetimes of water Mains - Case Trondheim Municipality. SINTEF Civil and Environmental Engineering, Report $\mathrm{n}$. 22F007.28, Trondheim, Norway.

LI, D.; HAIMES, Y. (1992). Optimal Maintenance-Related Decision Making for Deteriorating Water Distribution Systems. Water Resources Research, v. 28, n. 4, p. 1053-1061.

LIANG, T. (1971). Design Conduit System by Dynamic Programming. Journal of the Hydraulics Division, v. 97, n. HY3, p. 383-393.

LIN, B. W.; RARDIN, R. L. (1980). Controlled Experimental Design for Statistical Comparison of Integer Programming Algorithms. Management Science, v. 25, n. 12, p. 1258-1271.

LOGANATHAN, G.V.; PARK, S.; SHERALI, H. D. (2002). Threshold Break Rate for Pipeline Replacement in Water Distribution Systems. Journal of Water Resources Planning and Management, v. 128, n. 4, p. 271-279.

LOUCKS, D. P.; STEDINGER, J. R.; HAITH, D. A. (1981). Water Resource Systems Planning and Analysis. Prentice-Hall, Inc. Englewood Cliffs, New Jersey. 
LUVIZOTTO Jr., E. (1998). Monitoramento e Detecção de Vazamentos em Sistemas de Adução e Distribuição de Água. Relatório Final de Pós-doutoramento, 204 pp.

MAASS, A. (1962). Design of Water Resource Systems. Harvard University Press, Cambridge, Massachusetts, $620 \mathrm{pp}$.

MAILHOT, A.; PELLETIER, G. NOËL, J-F. (2000). Modeling the Evolution of the Structural State of Water Pipe Networks with Brief Recorded Pipe Break Histories: Methodology and Application. Water Resources Research, v. 36, n. 10, p. 3053-3062.

MALE J.W.; WALSKI T.M.; SLUTSKY A.H. (1990). Analyzing Water Main Replacement Policies. Journal of Water Resources Planning and Management, v. 116, n. 3, p. 362-374.

MARKS, H. D. et al. (1985). Predicting Urban Water Distribution Maintenance Strategies: A case study of New Haven Connecticut. US Environmental Protection Agency (Co-operative Agreement R8 1 0558-01-0).

MARTÍNEZ, F.; CONEJOS, P.; VERCHER, J. (1999). Developing an Integrated Model for Water Distribution Systems Considering both Distributed Leakage and PressureDependent Demands. Proceedings of the 26th ASCE WaterResources Planning and Management Division Conference, Tempe, Arizona.

MARTÍNEZ, F.; SIGNES, M.; SAVALL, R.; ANDRÉS, M.; PONZ, R.; CONEJOS, P. (1999). Construction and Use of Dynamic Simulation Model for the Valencia Metropolitan Water Supply and Distribution Network. In: SAVIC, D. A. (ed.); WALTERS, G. A. (ed.): Water Industry Systems: Modeling and Optimization Applications, vol. 1, p. 155-174.

MARTÍNEZ, M. E. (2001). Desenvolvimento de um Modelo Estatístico para Aplicação no Estudo de Fadiga em Emendas Dentadas de Madeira. São Carlos. 104 p. Tese de Doutorado. Escola de Engenharia de São Carlos, Universidade de São Paulo, Brasil.

MAYS, L. W. (1989). Reliability Analysis of Water Distribution Systems. American Society of Civil Engineers, New York.

McILROY, M. S. (1950). Direct - Reading Electric Analyzer for Pipeline Networks. Journal of the American Water Works Association, p. 347-365.

MENDENHALL, W. (1992). Statistical for Engineering and the Sciences. New York: Maxwell.

MICHALEWICZ, Z. (1992). Genetic Algorithms + Data Structure = Evolution Programs. Springer-Verlag, New York, N.Y.

MONTGOMERY, D. C. (1991). Introduction to statistical quality control. New York: Wiley.

MORGAN, D. R.; GOULTER, I. (1985). Optimal Urban Water Distribution Design. Water Resources Research, v. 21, n. 5, p. 642-652.

MURPHY, L.J.; SIMPSON, A.R. (1992). Pipe Optimization using Genetic Algorithms. Res. Rep. N. R93, Department of Civil Engineering, University of Adelaide, Australia.

NEIMANE, V. (2001). On Development Planning of Electricity Distribution Networks. Royal Institute of Technology. Doctoral Dissertation, Stockholm.

NIELSEN, H. B. (1989). Methods for Analyzing Pipe Networks. Journal of Hydraulic Engineering, v. 115, n. 2, p. 139-157, 1989.

ORMSBEE, L. E. (1989). Implicit Network Calibration. Journal of Water Resources Planning and Management, v. 115, n. 2, p. 243-257.

PELlETIER, G.; MAILHOT, A.; VILLENEUVE, J. P. (2003). Modeling Water Pipe Breaks - Three Case Studies. Journal of Water Resources Planning and Management, v. 129, n. 2 , p. $115-123$. 
PETROVSKI, A.; WILSON, A.; McCALL, J. (1998). Statistical Analysis of Genetic Algorithms and Inference about Optimal Factors. SCMS Technical Report, n. 2 (The Robert Gordon University).

PORTO, R. M. (1998). Hidráulica Básica. EESC/USP, Projeto REENGE, São Carlos.

PUDAR, R. S.; LIGGETT, J. A. (1992). Leaks in Pipe Networks. Journal of Hydraulic Engineering, v. 118, n. 7, p. 1031-1046.

QUINDRY, G. E.; BRILL, E. D.; LIEBMAN, J. C. (1981). Optimization of Looped Water Distribution Systems. Journal of the Environmental Engineering Division, v. 107, n. EE4, p. 665-679.

RAO, H. S.; MARKEL, L. C.; BREE, D. W., Jr. (1977). Extended Period Simulation of Water Systems - part B. Journal of the Hydraulic Division, v. 103, n. HY3, p. 281294.

RAJANI, B.; KLEINER, Y. (2001). Comprehensive Review of Structural Deterioration of Water Mains: Statistical Models. Urban Water, p. 151-164.

REIS, L. F. R.; PORTO, R. M.; CHAUDHRY, F. H. (1997). Optimal Location of Control Valves in Pipe Networks by Genetic Algorithm. Journal of Water Resources Planning and Management, v. 123, n. 6, p. 317-326.

REIS, L. F. R.; SANTOS, A.; CALIMAN, R. O.; SILVA, F. G. B. (2003). Avaliação dos Parâmetros de Vazamentos para Setores de Rede da Cidade de São Carlos - SP, Revista Brasileira de Recursos Hídricos (RBRH) (no prelo).

RESEARCH COMMITTEE (1974). Water Distribution Research and Applied Development Needs. Journal of the American Water Works Association, v. 66, n. 6, p. 385-390.

RICHARDSON, J. T; PALMER, M. R.; LIEPINS, G.; HILLIARD, M. (1989). Some Guidelines for Genetic Algorithms with Penalty Functions. Proceedings of the $3^{\text {rd }}$ International Conference on Genetic Algorithms, George Mason University, Fairfax, Virginia, USA.

RIGHETTO, A. M. (1977). Desenvolvimento de Modelos de Simulação para o Dimensionamento de Redes de Distribuição de Água. São Carlos. Tese de Doutorado. Escola de Engenharia de São Carlos, Universidade de São Paulo, Brasil.

RIGHETTO, A. M. (2001). Calibração de Modelo Hidráulico de Rede de Distribuição de Água. Revista Brasileira de Recursos Hídricos (RBRH), v. 6, n. 3, p. 33-44.

ROSSMAN, L. A. (1994). EPANET users manual. U.S. Environmental Protection Agency, Cincinnati, Ohio.

ROSSMAN, L. A. (2000). EPANET 2 users manual. U.S. Environmental Protection Agency, Cincinnati, Ohio.

SANDIM, M. P. et al. (2002). Plano Diretor do Sistema de Abastecimento de Água de Campo Grande (2000 - 2030).

SALGADO, R.; ROJO, J.; ZEPEDA, S. (1993). Extended Gradient Method for Fully Non-linear Head and Flow Analysis in Pipe Networks. In: COULBECK, B. (ed.): Integrated Computer Applications in Water Supply. Methods and Procedures for Systems Simulation and Control, vol. 1, p. 49-60.

SALGADO, R.; TODINI, E.; O' CONNELL, P. E. (1988). Extending the Gradient Method to Include Pressure Regulating Valves in Pipe Networks. In: COULBECK, B. (ed.): Computer Applications in Water Supply - Systems Analysis and Simulation, v. 1. 
SAVIC, D. A. (2002). Single-objective vs. Multiobjective Optimisation for Integrated Decision Support. In: Rizzoli, A. E. and Jakeman, A. J. (Eds.). Integrated Assessment and Decision Support, Proceedings of the First Biennal Meeting of the International Environmental Modelling and Software Society, 24-27 June, Lugano, Switzerland, vol. 1. pp. 7-12.

SAVIC, D. A.; WALTERS, G. A. (1997). Genetic Algorithms for Least-Cost Design of Water Distribution Networks. Journal of Water Resources Planning and Management, v. 123 , n. 2 , p. $67-77$.

SEBORG, D. E.; EDGAR, T. F.; MELLICHAMP, D. A. (1989). Process Dynamics and Control. New York: Wiley.

SCHAFFER, J. D. (1984). Some Experiments in Machine Learning using Vector Evaluated Genetic Algorithms (TCGA file number 00314). PhD dissertation, Vanderbilt University, Nashville, TN.

SHAMIR, U.; HOWARD, C. D. D. (1968). Water Distribution System Analysis. Journal of the Hydraulic Division, v. 94, n. HY1, p. 219-234.

SHAMIR, U.; HOWARD, C. D. D. (1979). An Analytic Approach to Scheduling Pipe Replacement. Journal of the American Water Works Association, p. 248-258.

SHARP, W. W.; WALSKI, T. M. (1988). Predicting Internal Roughness in Water Mains. Journal of the American Water Works Association, v. 80, n. 11, p. 248-258.

SILVA, F. G. B. (2003). Estudos de Calibração de Redes de Distribuição de Água através de Algoritmos Genéticos. São Carlos. Tese de Doutorado. 234 p. Escola de Engenharia de São Carlos, Universidade de São Paulo, Brasil.

SILVA, R. T.; CONEJO J. G. L. (1998). Definições de Perdas nos Sistemas Públicos de Abastecimento de Água. Plano Nacional de Combate ao Desperdício de Água (PNCDA), SEDU.

SIMPSON, A. R.; DANDY, G.C.; MURPHY, L. J. (1994). Genetic Algorithms Compared to Other Techniques for Pipe Optimization. Journal of Water Resources Planning and Management, v. 120, n. 4, p. 423-443.

SRINIVAS, N.; DEB, K. (1995). Multiobjective Optimization using Nondominated Sorting in Genetic Algorithms. Evolutionary Computation, Massachusetts Institute of Technology, v. 2. n. 3, p. 221-248.

SKEAT, W. O. (1961). Manual of British Water Engineering Practice. Cambridge: Institution of Water Engineers by W. Heffer.

SOARES, A. K. (2003). Calibração de Modelos de Redes de Distribuição de Água para Abastecimento Considerando Vazamentos e Demanda Dirigida pela Pressão. São Carlos. 153p. Dissertação (Mestrado). Escola de Engenharia de São Carlos, Universidade de São Paulo, Brasil.

SOUZA, R. S. (1994). Aspectos Computacionais da Análise de Redes de Distribuição de Água com Componentes Hidráulicos em Regime Permanente. São Carlos. 236 p. Dissertação (Mestrado). Escola de Engenharia de São Carlos, Universidade de São Paulo, Brasil.

SURYAPRAKASAM, M. V.; REID, G. W.; GEYER, J. C. (1950). Use of Alternating Current Network Calculator in Distribution Systems Design. Journal of the American Water Works Association, p. 1154-1164.

TABESH, M.; KARIMZADEH, A. (2000). Optimum Design of Reliable Distribution Systems Considering Pressure Dependency of Outflows. In: SAVIC, D. A. (ed.); WALTERS, G. A. (ed.): Water Network Modeling for Optimal Design and Management, p. 211-220. 
TAN, K. C.; LEE, T. H.; KHOR, E. F. (2001). Evolutionary Algorithms with Dynamic Population Size and Local Exploration for Multiobjective Optimization. IEEE Transactions on Evolutionary Computation, v. 5, n. 6, p. 565-588.

TANYIMBOH, T. T.; TABESH, M.; BURROWS, R. (2001). Appraisal of Source Head Methods for Calculating Reliability of Water Distribution Networks. Journal of Water Resources Planning and Management, v. 127, n. 4, p. 206-213.

TODINI, E. (1979). Un Metodo del Gradiente per La Verifica Delle Reti Idrauliche. Bolletino Degli Ingegneri Della Toscana, n. 11, p. 11-14.

TODINI, E. (2000). Looped Water Distribution Networks Design using a Resilience Index based Heuristic Approach. Urban Water. p. 115-122.

TODINI, E. (2003). A More Realistic Approach to the Extended Period Simulation of Water Distribution Networks. CCWI Conference, Imperial College, London (recebido do autor).

TODINI, E.; PILATI, S. (1988). A Gradient Algorithm for the Analysis of Pipe Networks. In: COULBECK, B. and CHUN-HOU O. (eds.): Computer Applications in Water Supply - Systems Analysis and Simulation, v. 1.

TUCCIARELLI, T.; CRIMINISI, A.; TERMINI, D. (1999). Leak Analysis in Pipeline Systems by Means of Optimal Valve Regulation. Journal of Hydraulic Engineering, v. 125 , n. 3, p. 277-285.

WAGNER, J. M.; SHAMIR, U.; MARKS, D. H. (1988). Water Distribution Reliability: Simulation Methods. Journal of Water Resources Planning and Management, v. 114, n. 3, p. 276-294.

WALL, M. (1996). GAlib: A C++ Library of Genetic Algorithm Components. Mechanical Engineering Department, Massachusetts Institute of Technology.

WALSKI, T. M. (1982). Economic Analysis of Rehabilitation of Water Mains. Journal of Water Resources Planning and Management, v. 108, n. WR3, p. 296-308.

WALSKI, T. M. (1983). Technique for Calibrating Network Models. Journal of Water Resources Planning and Management, v. 109, n. 4, p. 360-372.

WALSKI, T. M. (1986). Case Study: Pipe Network Model Calibration Issues. Journal of Water Resources Planning and Management, v. 112, n. 2, p. 238-249.

WALSKI, T.M. (2001). The Wrong Paradigm, Why Water Distribution Optimization Doesn't Work. Journal of Water Resources Planning and Management (Editorial), v. 123, n. 3, p. 203-205.

WALSKI, T. M.; PELLICCIA, A. (1982). Economic Analysis of Water Main Breaks. Journal of the American Water Works Association, p. 140-147.

WALSKI, T. M. et al. (1987). Battle of the Network Models: Epilogue. Journal of Water Resources Planning and Management, v. 113, n. 2, p. 191-203.

WALSKI, T. M. et al. (2003). Advanced Water Distribution Modeling and Management. Hasted Press, Waterbury, CT, USA.

WALTERS, G.A.; HALHAL, D.; SAVIC, D.A.; OUAZAR, D. (1999). Improved Design of Anytown Distribution Network using Structured Messy Genetic Algorithms. Urban Water, v. 1, p. 23-38.

WATANATADA, T. (1973). Least-Cost Design of Water Distribution Systems. Journal of Hydraulics Division, v. 99, n. HY9, p. 1497-1513.

WOOD, D. J.; CHARLES, C. O. A. (1972). Hydraulic Network Analysis using Linear Theory. Journal of the Hydraulic Division, v. 98, n. HY7, p.1157-1170.

WRIGHT, A. (1991). Genetic Algorithms for Real Parameter Optimization. In Foundations of Genetic Algorithms 2 (FOGA-1): 205-218. 
WU, Z. Y.; SIMPSON, A. R. (1996). Messy Genetic Algorithms for Optimisation of Water Distribution Systems. Research Report N. R 140. The University of Adelaide.

WU, Z.Y.; SIMPSON, A. R. (2001). Competent Genetic-Evolutionary Optimization of Water Distribution Systems. Journal of Computing in Civil Engineering, v. 15, n. 2, p. 89-101.

VAIRAVAMOORTHY, K.; LUMBERS, J. (1998). Leakage Reduction in Water Distribution Systems: Optimal Valve Control. Journal of Hydraulic Engineering, v. 124, n. 11, p. 1146-1153, Nov.

VELDHUIZEN, D. V. (1999). Multiobjective Evolutionary Algorithms: Classifications, Analyses, and New Innovations. Ph. D. Thesis. Air Force Institute of Technology, Wright-Patterson AFB, OH 45433, USA.

ZYL, J.E. van; BORTHWICK, J.; HARDY, A. (2003). OOTEN: An Object-oriented Programmers Toolkit for Epanet. Advances in Water Supply Management (CCWI Computing and Control for the Water Industry \& Watersave Network). Imperial College, London, England.

ZITZLER, E. (1999). Evolutionary Algorithms for Multiobjective Optimization: Methods and Applications. Ph. D. Thesis. Swiss Federal Institute of Technology Zurich.

ZITZLER, E.; THIELE, L. (1998). An Evolutionary Algorithm for Multiobjective Optimization: The Strength Pareto Approach. Technical Report, 43, Zürich. Switzerland: Computer Engineering and Networks Laboratory (TIK), Swiss Federal Institute of Technology.

YANG, K. P.; LIANG, T.; WU, I. P. (1975). Design of Conduit System with Diverging Branches. Journal of Hydraulics Division, v. 101, n. HY1, p. 167-188. 
APÊNDICE A - Algoritmos de busca de soluções não dominadas 
Algoritmo 1 - Esse algoritmo (Figura a.1) foi desenvolvido com objetivo de identificar o número de soluções que dominam uma determinada solução i. Como o módulo de avaliação do MOGA necessita calcular o rank de cada vetor solução, esse algoritmo faz parte da implementação do MOGA.

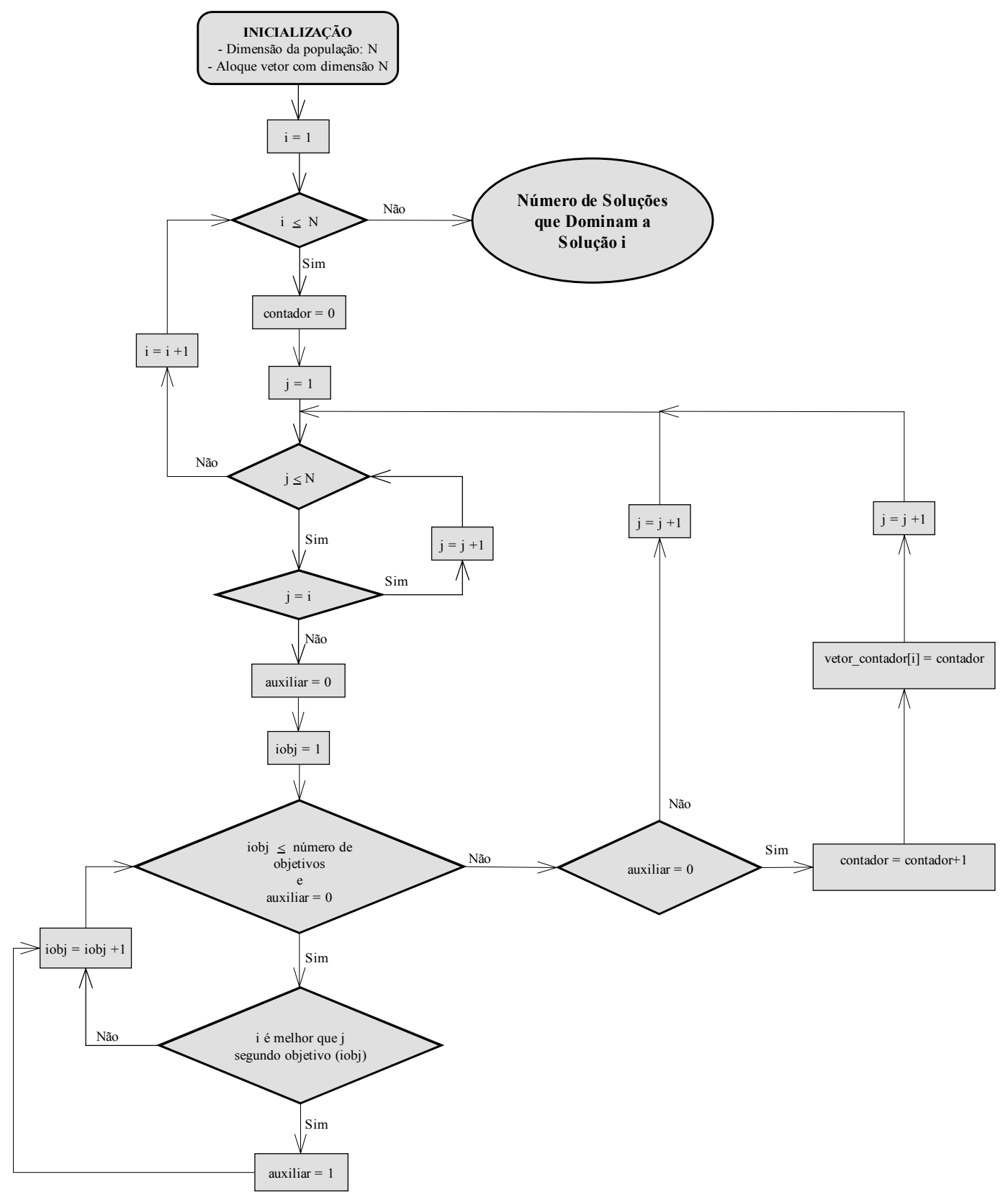

Figura a.1 -Algoritmo de busca de soluções que dominam determinada solução i 
Algoritmo 2 - Nesse algoritmo (Figura a.2), cada solução i é comparada com todas outras soluções na população para verificar se essa solução é dominada por alguma solução na população. Se for encontrada uma solução que domina i, isso menciona que existe no mínimo uma solução na população que é melhor que i em todos os objetivos. Conseqüentemente a solução i não pertence ao conjunto não dominado.

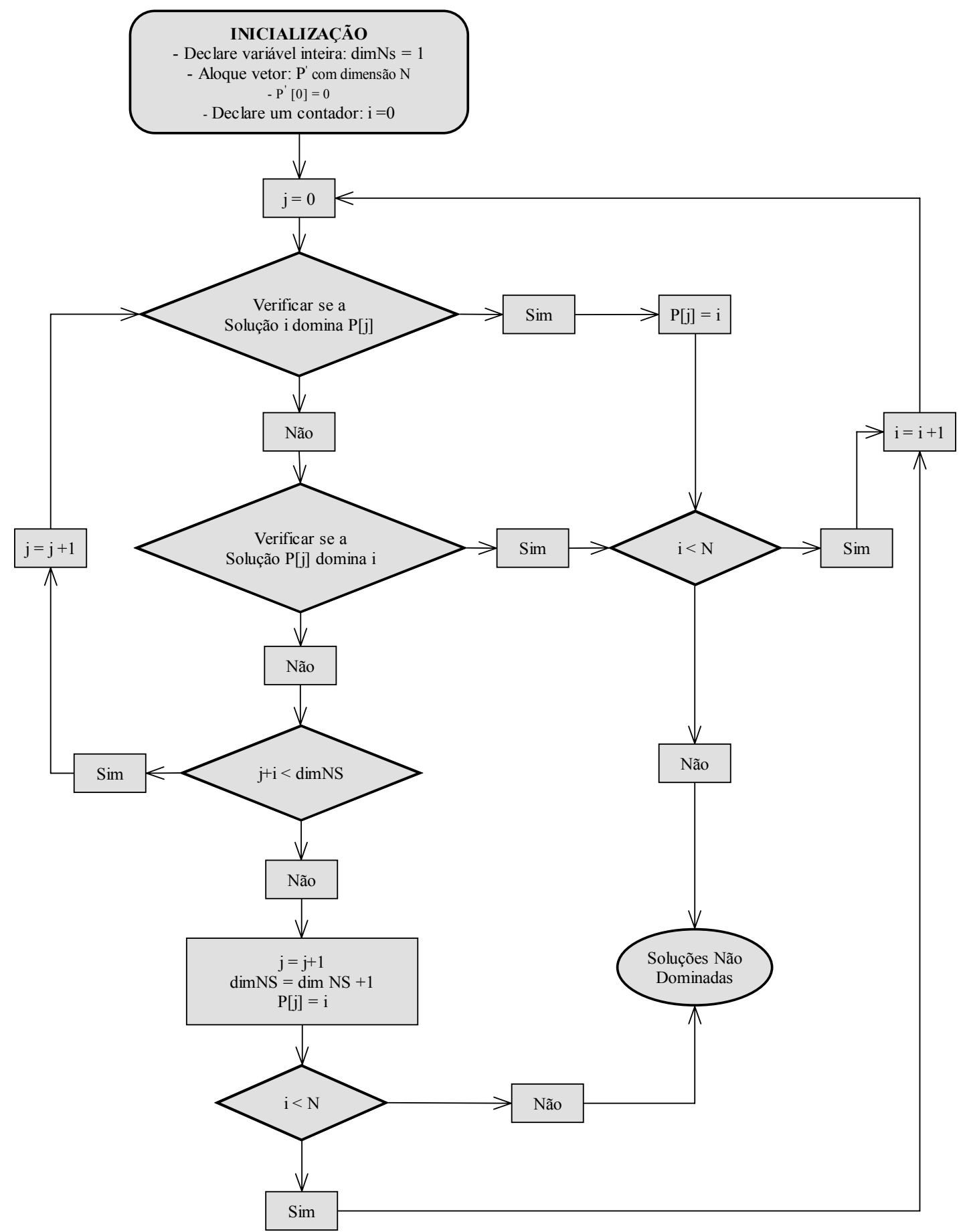

Figura a.2 - Algoritmo de busca de soluções não dominadas 2 
Algoritmo 3 - Esse algoritmo (Figura a.3) é um dos mais eficientes em termos de custo computacional. Todas as soluções da população são verificadas com uma população de soluções não dominadas.

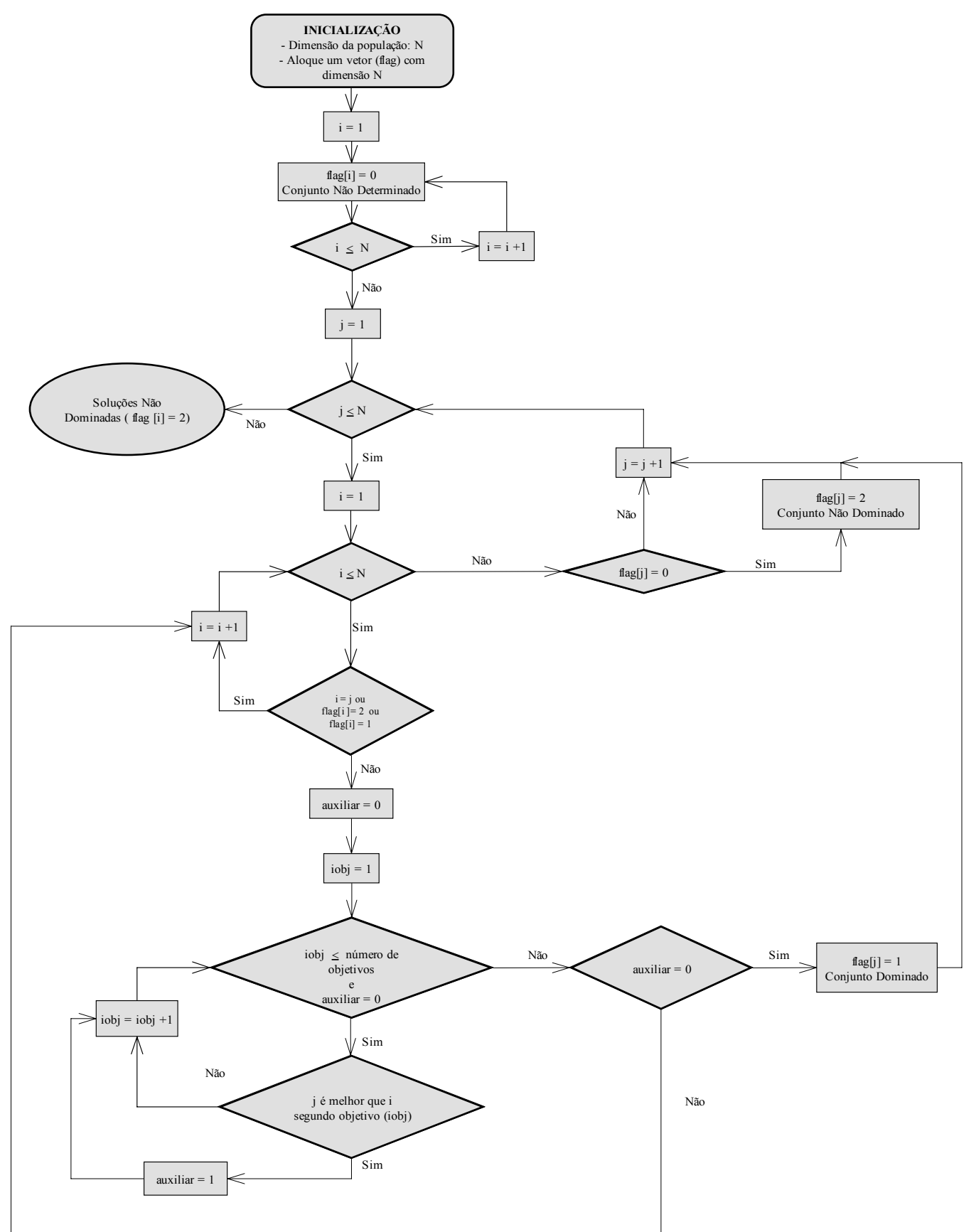

Figura a.3 - Algoritmo de busca soluções não dominadas 3

Algoritmo 4 - Esse algoritmo (Figura a.4) foi desenvolvido com objetivo de identificar o número de soluções não dominadas e classificá-las em relação às frentes não dominadas. Esse algoritmo é utilizado no módulo de avaliação do NSGA. 


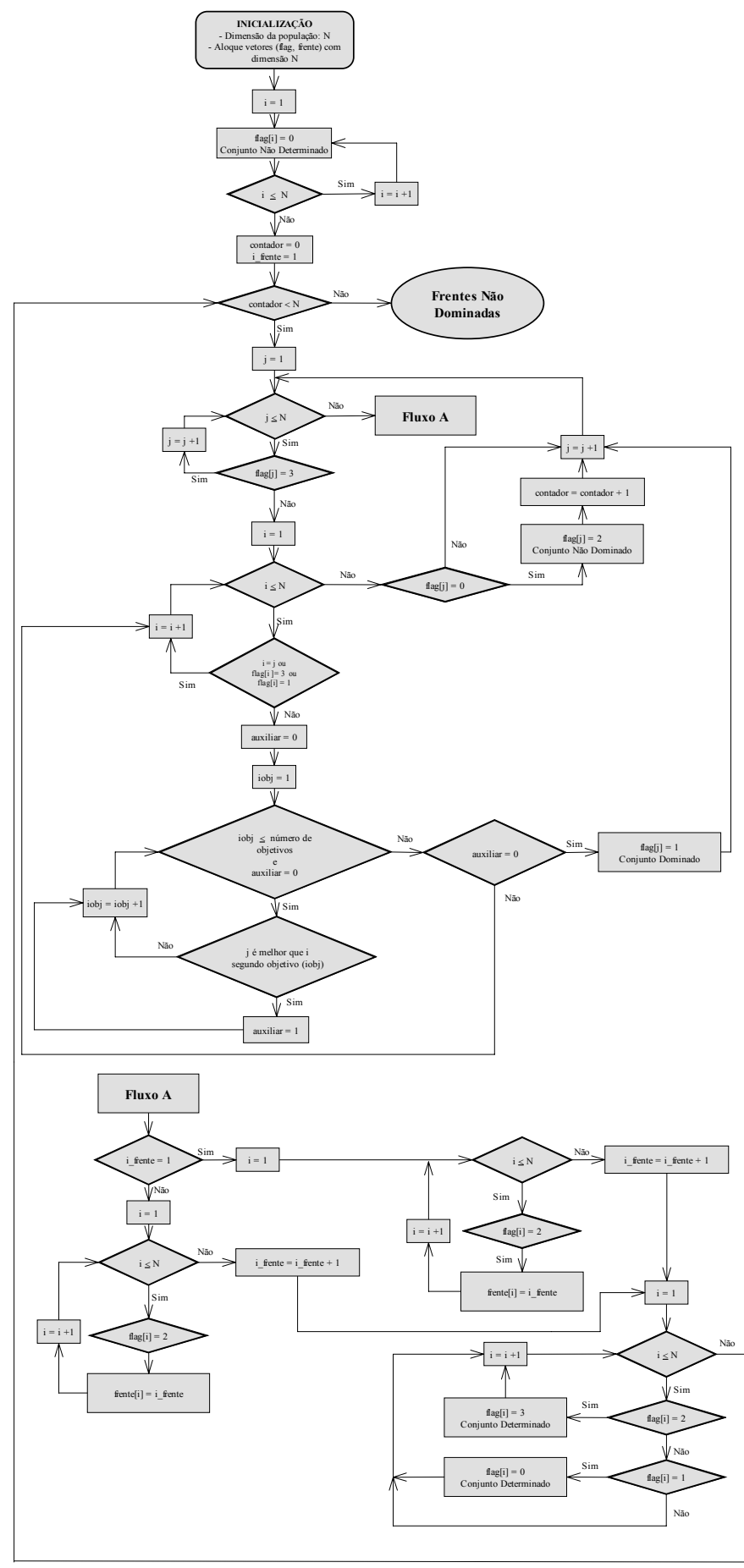

Figura a.4 -Algoritmo de classificação de frentes não dominadas 
ANEXO A - Descrição da pesquisa de campo e preparação dos dados para determinação dos parâmetros do modelo de vazamentos para o sistema real (Setor RF 1) da cidade de Campo Grande, MS 


\section{A1 MODELO SIMPLIFICADO REAL}

É objetivo do presente anexo ressaltar os testes realizados em campo durante o período de 15 a 24 de Abril de 2003 e apresentar os dados resultantes dessa investigação de campo. Prioritariamente, buscou-se obter dados referentes às pressões atuantes no sistema e à vazão abastecida do setor para que tais dados fossem introduzidos em um modelo de calibração a fim de obter estimativas dos parâmetros do modelo de vazamentos.

\section{A1.1 Preparação dos dados}

Uma rede de distribuição de água é definida como sendo uma combinação de tubos, componentes hidráulicos (bombas e válvulas) e obras de arte (reservatórios e estações de bombeamento) interconectados com propósito de transportar água potável para população, em quantidade e qualidade satisfatória. As redes são representadas por nós (características de localizações específicas dentro do sistema) e ligações (relações entre os nós). A preparação do modelo considerando todas estas tubulações faz com que o problema se torne complexo sob o ponto de vista computacional.

$\mathrm{Na}$ prática, portanto, as tubulações menores que $100 \mathrm{~mm}$ ou muitas vezes iguais a 150mm são eliminadas (FAIR, GEYER e OKUN 1971) ou agrupadas e substituídas por tubulações equivalentes (JEPPSON 1982; WALSKI 1983a) de tal forma que a topologia resultante possa ser representativa do sistema real. Se muitas tubulações são removidas durante este processo, o modelo resultante pode não representar adequadamente a rede de distribuição.

Para obter resultados significativos, o modelador deve garantir que as posições das válvulas (completamente abertas ou fechadas) e as colocações de válvulas redutoras de pressão sejam corretamente representadas no modelo (EGGENER e POLKOWSKI 1976; RAO, MARKEL e BREE 1977). 


\section{Energia das Fontes de Abastecimento}

As energias nos nós fonte devem ser determinadas com certo grau de acurácia. A elevação de água nos reservatórios e a energia proveniente das bombas podem ser medidas com manômetros apropriados ou por um sistema de telemetria (reservatórios).

\section{Consumo nos Nós de Demanda}

A estimação correta da taxa de consumo nos nós de demanda é de difícil compreensão. A taxa de consumo de água depende dos hábitos e propósito (industrial, residencial, comercial, etc.) de consumo da população que está contida na área de influência daquele nó e depende do período do dia. Deste modo, a estimação de demandas nos nós está suscetível a erros grosseiros e pode precisar de ajuste durante o processo de calibração.

\section{Coeficientes de Perda de Carga}

Segundo EGGENER e POLKOWSKI (1976), o coeficiente de perda de carga de uma tubulação em uma rede é um parâmetro que representa não apenas o atrito das tubulações, mais também outras causas da perda de carga tais como singularidades (válvulas e acessórios). Esse coeficiente depende também da velocidade do escoamento. A interseção dos condutos se assemelha, em se tratando de condições operacionais, às válvulas desligadas e, portanto as perdas de ramificações e interseções que são apresentadas durante a operação normal são eliminadas durante os testes.

O RESEARCH COMMITTEE (1974) declarou que a maior fonte de erros, na simulação hidráulica, estaria nas cargas assumidas nos nós e nas suas próprias variações, enfatizando assim o ajuste de consumo.

Procedimento geral de calibração

O procedimento geral para calibração de um modelo de redes, descrito por CHEUNG (2001), é dividido em cinco etapas:

1. Simplificar a rede desconsiderando diâmetros menores que $150 \mathrm{~mm}$ salvo algumas exceções (ponta de rede, proximidades de reservatórios, mudança de diâmetro, dentre outros);

2. Dividir a rede em setores de rugosidade e/ou vazamentos, de forma que as estimativas para cada setor de rede correspondam a um fator de ajuste global; 
3. Obter dados cadastrais (consulta de informações) referentes as: características geométricas das tubulações (diâmetros, rugosidades, comprimento e material) e características dos componentes (válvulas e bombas), elevações topográficas, consumos nos nós, dentre outros;

4. Instalar medidores de pressão e vazão (medidas preliminares de campo) na rede de forma armazenar dados contínuos e obter dados (medidas preliminares de campo) dos reservatórios (níveis) durante 24 horas através de telemetria ou através de medições em campo;

5. Simular a rede (análises através de computador) utilizando os dados de projeto para obter valores das variáveis de estado (pressão e vazão) e compará-las (modelo de calibração) com os dados reais obtidos no campo. Se o ajuste é aceitável, a calibração é finalizada, caso contrário, volta-se a etapa de simulação ajustando novos valores (por algum processo) e assim por diante, até que a convergência seja satisfeita.

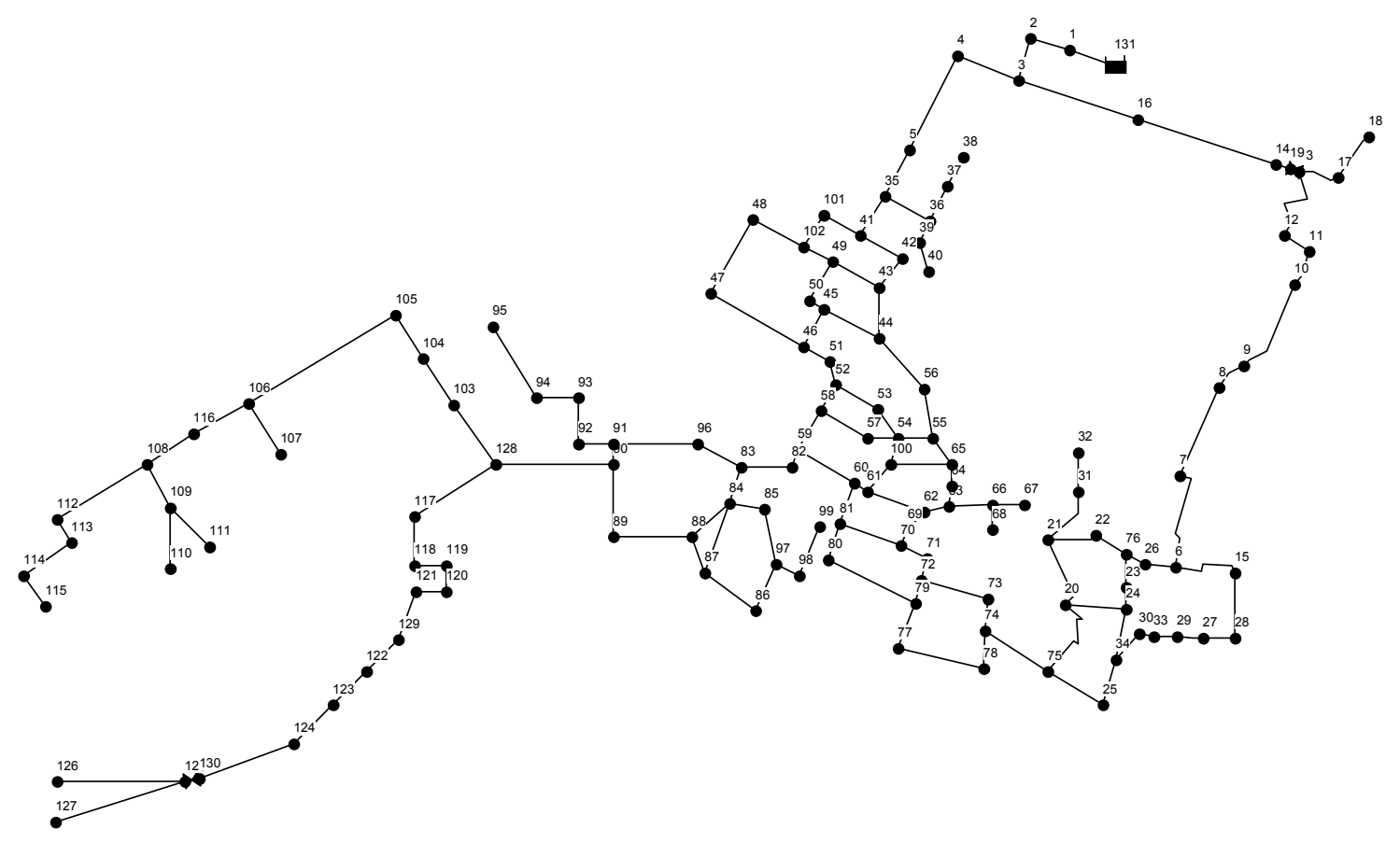

Figura A1.1 - Modelo simplificado real

\section{A1.2 Estudo de caso real: rede simplificada correspondente ao setor operacional}

\section{RF-1 da cidade de Campo Grande, MS}

O sistema de abastecimento de água da cidade de Campo Grande - MS é dividido em 20 setores operacionais e responsáveis pelo atendimento de 706.442 mil habitantes de 
(SANDIM et al., 2002). Especificamente, o sistema de distribuição RF-1/TH é o setor operacional que apresenta mais perda de água, em média 48\% (contemplando físicas e não físicas), e por isso, está sendo objeto de estudo deste trabalho. Esse setor localiza-se na região norte do município de Campo Grande, sendo abastecido totalmente pelo sistema integrado (compreende as regiões da cidade cujo abastecimento tem como fontes suprimento principais às captações superficiais). Esse setor é divido em: parte alta $(\mathrm{TH})$ e parte baixa (RF-1), e neste trabalho, apenas a parte baixa (setor RF-1) está sendo investigada.

O suprimento de água do setor de distribuição RF1 ocorre por meio de dois reservatórios semi-enterrados, cada qual com um volume de armazenamento de 6000 $\mathrm{m}^{3}$. Esse setor é responsável pelo atendimento de aproximadamente 100.000 habitantes (SANDIM et al., 2002) sendo a sua rede composta por PVC, cimento amianto e ferro fundido.

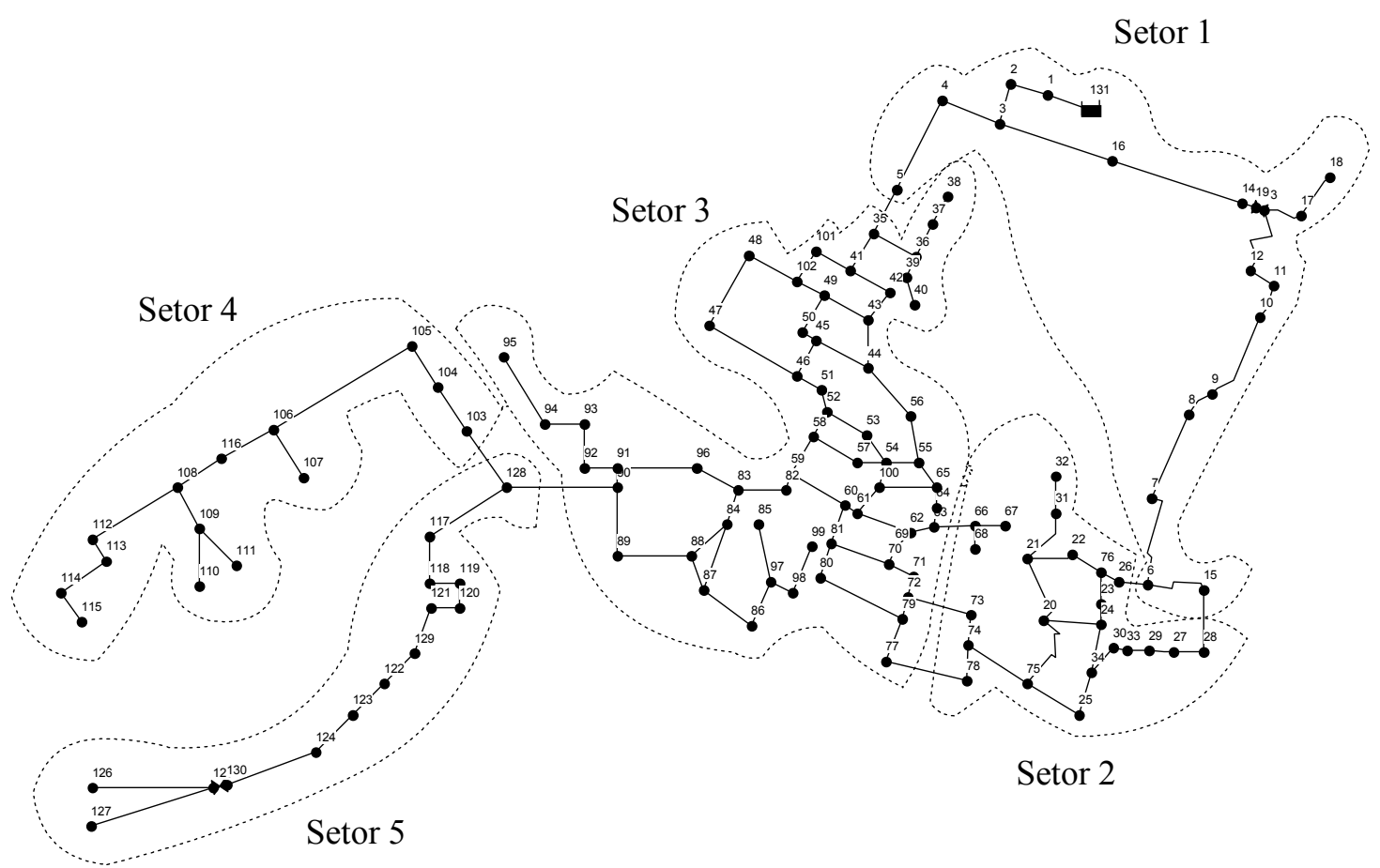

Figura A1.2 - Modelo simplificado real divido em setores de vazamento

\section{A1.2.1 Simplificação da rede}

Considerando que a rede de distribuição do setor RF-1 é de grande escala, neste trabalho foram desprezados tubulações com diâmetros inferiores a $100 \mathrm{~mm}$ (salvo exceções ora citadas) conforme procedimento geral descrito no item A1.1. O modelo simplificado é ilustrado pela Figura A1.1. Os dados referentes às características 
geométricas das tubulações e aos componentes hidráulicos encontram-se no final desse anexo.

\section{A1.2.2 Divisão da rede em setores}

Conforme procedimento geral de calibração do modelo descrito no item A.1.1, a segunda etapa refere-se à divisão da rede em setores. Esses setores podem ser divididos em termos de tubulações de mesma rugosidade, em termos das características de tráfego e solo, em termos das características de consumo, em termos de áreas de incidência de vazamentos. Neste trabalho, a rede foi divida em termos das áreas de incidências de vazamentos conforme o mapa fornecido pela Companhia de Saneamento Águas Guariroba S.A., que se encontra no CD anexo. A Figura A1.2 apresenta o modelo simplificado real divido em setores.

Os dados cadastrais da rede foram obtidos na própria companhia de saneamento. As demandas nos nós (Tabela A1.1) foram obtidas através de um base cadastral do ano de 1996 e transposta para ano de 2003 utilizando índices de crescimento populacional apresentados no plano diretor do sistema de abastecimento de água (SANDIM et al., 2002).

\section{A1.2.3 Equipamentos para aquisição de dados}

Dez medidores de pressão (Metrolog NA Data Logger da Technolog) foram utilizados para armazenar dados referentes às pressões atuantes na rede durante o período de observação (10 a 25 de Abril de 2003). A Figura A1.3 mostra o medidor de pressão acoplado a um equipamento (Psion) que serve de auxílio para extração dos dados armazenados nesses medidores. A Figura A1.4 mostra o computador portátil utilizado para extrair os dados armazenados em campo.

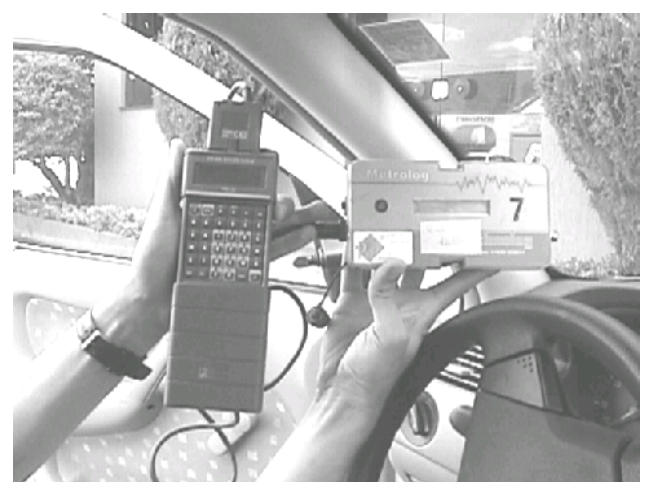

Figura A1.3 - Medidor de pressão

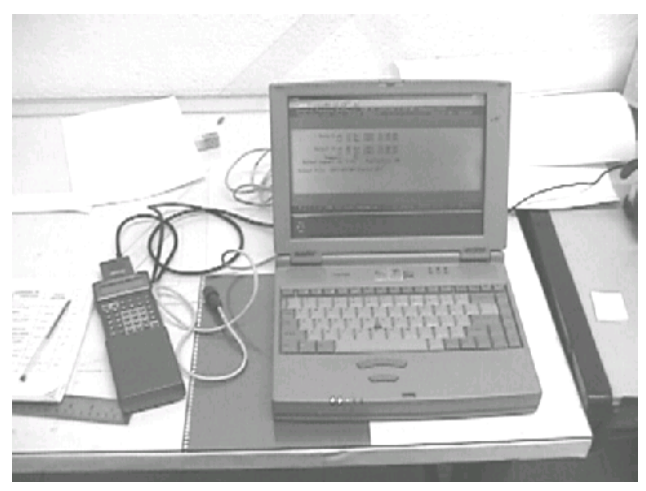

Figura A1.4 - Computador portátil 
Tabela A1.1 - Demandas nos nós para modelo real simplificado

\begin{tabular}{|c|c|c|c|c|c|c|c|c|c|}
\hline$\overline{\mathrm{IID}}$ & Elevação & Bairro & 1996 & 2003 & $\overline{I D}$ & Elevação & Bairro & 1996 & 2003 \\
\hline$\overline{1}$ & 627 & Coophasul & 68,1 & 75,7 & 78 & 562 & Petrópolis & 3,8 & 4,5 \\
\hline 2 & 623 & Coophasul & 0,0 & 0,0 & 79 & 560 & Petrópolis & 0,0 & 0,0 \\
\hline 3 & 620 & Coophasul & 0,0 & 0,0 & 80 & 555 & Petrópolis & 3,3 & 3,9 \\
\hline 4 & 600 & Coophasul & 0,0 & 0,0 & 81 & 550 & Petrópolis & 0,5 & 0,5 \\
\hline 5 & 602.5 & StaCarmelia & 0,0 & 0,0 & 82 & 555 & Petrópolis & 6,6 & 7,8 \\
\hline 6 & 596.5 & StaCarmelia & 0,0 & 0,0 & 83 & 556 & Recanto & 0,2 & 0,4 \\
\hline 7 & 597 & StaCarmelia & 2,4 & 2,7 & 84 & 555.5 & Recanto & 0,9 & 1,6 \\
\hline 8 & 602.5 & StaCarmelia & 4,7 & 5,3 & 85 & 550 & Recanto & 5,0 & 9,2 \\
\hline 9 & 603 & StaCarmelia & 2,0 & 2,2 & 86 & 547.5 & Recanto & 1,6 & 3,0 \\
\hline 10 & 598 & StaCarmelia & 4,7 & 5,3 & 87 & 545 & Recanto & 1,2 & 2,2 \\
\hline 11 & 599 & StaCarmelia & 1,3 & 1,4 & 88 & 560 & Petrópolis & 7,2 & 8,5 \\
\hline 12 & 590 & StaCarmelia & 0,0 & 0,0 & 89 & 562 & Petrópolis & 2,8 & 3,3 \\
\hline 13 & 595 & StaCarmelia & 0,0 & 0,0 & 90 & 562.5 & Petrópolis & 1,4 & 1,7 \\
\hline 14 & 587 & Coophatrab. & 0,5 & 0,6 & 91 & 564 & Petrópolis & 1,6 & 1,8 \\
\hline 15 & 582.5 & Coophatrab. & 6,3 & 7,1 & 92 & 536 & Popular & 5,1 & 6,3 \\
\hline 16 & 576 & Coophatrab. & 0,0 & 0,0 & 93 & 549 & Popular & 0,7 & 0,8 \\
\hline 17 & 572 & Coophatrab. & 12,0 & 13,6 & 94 & 550 & Popular & 0,2 & 0,2 \\
\hline 18 & 562.5 & Coophatrab. & 3,2 & 3,6 & 95 & 543 & Popular & 0,8 & 1,0 \\
\hline 19 & 564 & Coophatrab. & 1,1 & 1,2 & 96 & 534.5 & Popular & 4,5 & 5,6 \\
\hline 20 & 577.5 & Coophatrab. & 0,0 & 0,0 & 97 & 535 & Popular & 0,0 & 0,0 \\
\hline 21 & 574 & Coophatrab. & 5,3 & 6,0 & 98 & 534 & Popular & 2,9 & 3,5 \\
\hline 22 & 574 & Coophatrab. & 2,8 & 3,1 & 99 & 529 & Popular & 6,2 & 7,7 \\
\hline 23 & 573 & Panamá & 0,0 & 0,0 & 100 & 525 & Popular & 7,0 & 8,7 \\
\hline 24 & 575 & Panamá & 0,0 & 0,0 & 101 & 538 & Sta Monica & 0,6 & 0,8 \\
\hline 25 & 575 & Panamá & 4,1 & 7,6 & 102 & 536 & Sta Monica & 0,7 & 0,8 \\
\hline 26 & 580.5 & Panamá & 7,1 & 13,1 & 103 & 535 & Sta Monica & 0,4 & 0,5 \\
\hline 27 & 585 & Coophatrab. & 0,0 & 0,0 & 104 & 534.5 & Sta Monica & 0,8 & 1,0 \\
\hline 28 & 573 & Panamá & 4,1 & 7,5 & 105 & 530 & Petrópolis & 8,7 & 10,2 \\
\hline 29 & 571 & Panamá & 1,5 & 2,7 & 106 & 539 & Petrópolis & 0,0 & 0,0 \\
\hline 30 & 567 & Petrópolis & 0,9 & 1,0 & 107 & 544 & Petrópolis & 4,5 & 5,3 \\
\hline 31 & 569 & Petrópolis & 3,5 & 4,1 & 108 & 545 & Nova Cgde & 5,0 & 7,8 \\
\hline 32 & 571 & Alba & 0,9 & 1,7 & 109 & 539.5 & Nova Cgde & 0,0 & 0,0 \\
\hline 33 & 571.5 & Alba & 2,4 & 4,5 & 110 & 542.5 & Nova Cgde & 5,3 & 8,2 \\
\hline 34 & 576 & Panamá & 0,0 & 0,0 & 111 & 542 & Nova Cgde & 0,0 & 0,0 \\
\hline 35 & 578 & Panamá & 4,2 & 7,8 & 112 & 541 & Nova Cgde & 0,0 & 0,0 \\
\hline 36 & 583 & Panamá & 0,0 & 0,0 & 113 & 532.5 & Nova Cgde & 1,2 & 1,9 \\
\hline 37 & 580.2 & Panamá & 6,2 & 11,5 & 114 & 525 & Nova Cgde & 2,0 & 3,0 \\
\hline 38 & 581.5 & Panamá & 2,1 & 3,9 & 115 & 522.5 & Nova Cgde & 2,3 & 3,6 \\
\hline 39 & 578 & Panamá & 5,0 & 9,2 & 116 & 575 & Panamá & 0,0 & 0,0 \\
\hline 40 & 571 & Panamá & 0,0 & 0,0 & 117 & 574 & Planalto & 0,0 & 0,0 \\
\hline 41 & 570 & Alba & 2,8 & 3,2 & 118 & 566 & São Franc. & 2,3 & 2,5 \\
\hline 42 & 570 & Alba & 0,0 & 0,0 & 119 & 569 & São Franc. & 0,9 & 1,0 \\
\hline 43 & 568 & Alba & 6,6 & 7,4 & 120 & 584 & Planalto & 5,7 & 10,4 \\
\hline 44 & 572 & Alba & 4,9 & 5,5 & 121 & 585 & Planalto & 1,7 & 3,1 \\
\hline 45 & 569 & Alba & 1,1 & 1,3 & 122 & 541.5 & Petrópolis & 0,1 & 0,1 \\
\hline 46 & 571.5 & Alba & 0,0 & 0,0 & 123 & 572.5 & Planalto & 1,5 & 2,7 \\
\hline 47 & 577 & Planalto & 0,0 & 0,0 & 124 & 542.5 & Nova Cgde & 0,0 & 0,0 \\
\hline 48 & 581 & Planalto & 1,2 & 1,3 & 125 & 582 & StaCarmelia & 0,0 & 0,0 \\
\hline 49 & 581.3 & Planalto & 6,4 & 7,0 & 126 & 577.5 & Coophatrab. & 0,4 & 0,5 \\
\hline 50 & 581 & Planalto & 0,0 & 0,0 & 127 & 538 & Popular & 0,0 & 0,0 \\
\hline 51 & 577.5 & Planalto & 0,0 & 0,0 & 128 & 573.9 & Alba & 0,0 & 0,0 \\
\hline 52 & 576.5 & Planalto & 0,0 & 0,0 & 129 & 532 & & 0,0 & 0,0 \\
\hline 53 & 567.5 & Alba & 0,0 & 0,0 & 130 & 583.3 & & 0,0 & 0,0 \\
\hline 54 & 581 & Planalto & 11,1 & 20,5 & & & & & \\
\hline 55 & 579 & Planalto & 10,8 & 19,8 & & & & & \\
\hline 56 & 564.5 & Planalto & 0,0 & 0,0 & & & & & \\
\hline 57 & 570 & Planalto & 0,0 & 0,0 & & & & & \\
\hline 58 & 560 & Planalto & 0,0 & 0,0 & & & & & \\
\hline 59 & 557.5 & São Franc. & 0,9 & 1,0 & & & & & \\
\hline 60 & 560 & São Franc. & 1,7 & 1,9 & & & & & \\
\hline 61 & 570 & São Franc. & 6,0 & 6,7 & & & & & \\
\hline 62 & 583 & São Franc. & 0,0 & 0,0 & & & & & \\
\hline 63 & 594 & Coophasul & 0,2 & 0,2 & & & & & \\
\hline 64 & 562.5 & Planalto & 1,2 & 2,2 & & & & & \\
\hline 65 & 566 & Planalto & 5,1 & 9,4 & & & & & \\
\hline 66 & 564 & Planalto & 3,3 & 6,1 & & & & & \\
\hline 67 & 567 & Planalto & 9,1 & 16,7 & & & & & \\
\hline 68 & 619 & Coophasul & 0,0 & 0,0 & & & & & \\
\hline 69 & 565 & Alba & 2,3 & 2,6 & & & & & \\
\hline 70 & 565 & Alba & 0,8 & 0,9 & & & & & \\
\hline 71 & 567 & Alba & 0,0 & 0,0 & & & & & \\
\hline 72 & 564 & Alba & 0,0 & 0,0 & & & & & \\
\hline 73 & 568.5 & Alba & 7,9 & 8,9 & & & & & \\
\hline 74 & 565.5 & Petrópolis & 4,9 & 5,8 & & & & & \\
\hline 75 & 560 & Petrópolis & 0,6 & 0,7 & & & & & \\
\hline 76 & 561 & Petrópolis & 3,5 & 4,1 & & & & & \\
\hline 77 & 561.5 & Petrópolis & 4,5 & 5,3 & & & & & \\
\hline
\end{tabular}


A etapa de aferição de equipamentos é de fundamental importância para obtenção de dados confiáveis. Os medidores de pressão foram aferidos no laboratório de Hidráulica do Departamento de Hidráulica e Saneamento (EESC/USP) através de piezômetros.

Em relação às medidas de vazão, foram utilizados dados da Central de Controle de Processos (CCP), que recebe informações dos reservatórios e da vazão abastecida do setor RF-1 através de um sistema de telemetria. Para alimentar o sistema de telemetria, há um macromedidor eletromagnético instalado na saída do reservatório (dois reservatórios semi-enterrados funcionando como vasos comunicantes) e entrada na rede de distribuição do sistema RF-1. Há um aparelho de telemetria enviando informações a cada minuto, da vazão abastecida, para a CCP.

Para que as medidas fossem instantâneas, ajustou-se o mesmo horário de leitura de ambos os aparelhos: medidores de pressão e macromedidor eletromagnético. Os medidores de pressão foram ajustados para registrar pressões em intervalos consecutivos de 10 minutos. Esse ajuste, bem como a formatação dos dados, é feito por um software (GP2) fornecido pelo fabricante dos medidores de pressão.

\section{A1.2.4 Medidas de campo}

Antes de realizar as medidas de campo foi realizada uma reunião com a equipe responsável pela companhia de saneamento (Águas Guariroba S.A.) da cidade de Campo Grande, de forma solicitar intervenções a serem realizadas no sistema.

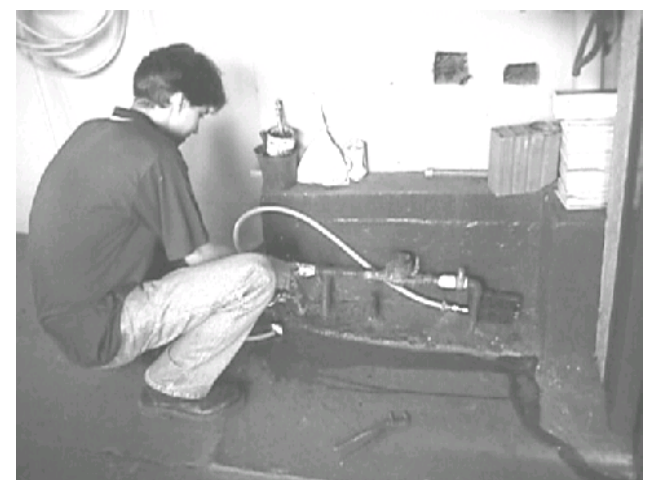

Figura A1.5 - Instalação de Medidor

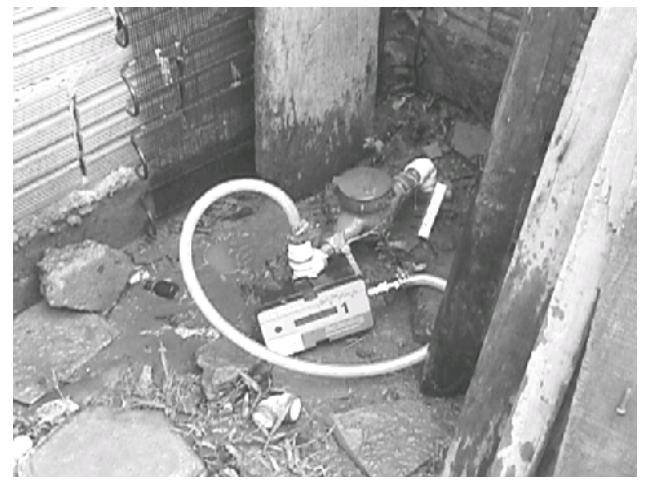

Figura A1.6 - Medidor de pressão

Para avaliar as vazões mínimas noturnas (avaliação de vazamentos), conforme algumas metodologias propõem, foi solicitada à companhia a possibilidade de se manobrar o registro de entrada da rede (setor RF-1). Entretanto, a companhia alegou que a manobra desse registro não seria possível devido a diversos fatores prejudiciais: 
comprometimento do abastecimento, entrada de ar na rede, estabilização do transiente hidráulico, dentre outros fatores. Além disso, foi solicitado que pelo menos um dia nesse período de investigação não fossem realizadas manobras na rede para não interferir nos dados de pressão.

As tomadas de pressão foram realizadas em cavaletes residenciais, conforme mostrado nas Figuras A1.5 e A1.6. As diferenças existentes entre as cotas da rede e as cotas dos cavaletes residenciais foram desprezadas.

Os pontos de instalação (pontos de amostragem) dos medidores de pressão foram escolhidos conforme mapa de incidência de vazamentos fornecido pela companhia de saneamento e apresentado no CD anexo. A Tabela A1.2 apresenta os pontos de monitoramento conforme Figura A1.1.

Tabela A1.2 - Pontos de monitoramento de pressão

\begin{tabular}{|c|c|c|c|c|c|c|c|}
\hline \multirow{3}{*}{$\begin{array}{l}\text { Ponto } \\
\text { Coleta }\end{array}$} & \multicolumn{7}{|c|}{ MONITORAMENTO DA SITUAÇÃO DE PRESSÃO NO SETOR RF-01 - COOPHASUL ZB } \\
\hline & \multirow{2}{*}{$\begin{array}{l}\text { Nó } \\
\text { Epanet }\end{array}$} & \multirow{2}{*}{ Endereço } & \multicolumn{2}{|c|}{ Instalado em } & \multicolumn{2}{|c|}{ Retirado em } & \multirow{2}{*}{ Observações } \\
\hline & & & DATA & HORA & DATA & HORA & \\
\hline PONTO 1 & 128 & $\begin{array}{c}\text { Rua Paracatú, } 1423 \\
\text { B.Silvia Regina }\end{array}$ & $11 / 7 / 2003$ & $09: 25$ & $24 / 4 / 2003$ & $15: 30$ & $\begin{array}{l}\text { Antes da VRP } \\
\text { Rua Timóteo }\end{array}$ \\
\hline PONTO 2 & 86 & $\begin{array}{c}\text { Rua Porto Carreiro, } 39 \\
\text { Jd.Petrópolis }\end{array}$ & $11 / 7 / 2003$ & 08:40 & $24 / 4 / 2003$ & $14: 50$ & $\begin{array}{c}\text { Entre R.dos Caiuás } \\
\text { e R.Itatiaia }\end{array}$ \\
\hline PONTO 3 & 106 & $\begin{array}{c}\text { Av.Cezar Augusto Telles, } 2376 \\
\text { Vila Popular }\end{array}$ & $11 / 7 / 2003$ & $10: 40$ & $24 / 4 / 2003$ & $15: 50$ & $\begin{array}{l}\text { Entre R.Diva L.Albertini } \\
\text { e R.Geraldo L. Moraes }\end{array}$ \\
\hline PONTO 4 & 32 & $\begin{array}{c}\text { Rua Barão de Ladário, } 122 \\
\text { Vila Sobrinho }\end{array}$ & $10 / 4 / 2003$ & $16: 15$ & $24 / 4 / 2003$ & $14: 55$ & $\begin{array}{l}\text { Entre R.Ipanema e R. } \\
\text { Guarujá }\end{array}$ \\
\hline PONTO 5 & 14 & $\begin{array}{c}\text { Rua Bartíra x Rua Juiz de Fora } \\
\text { Jardim Seminário }\end{array}$ & $10 / 4 / 2003$ & $16: 50$ & $24 / 4 / 2003$ & $16: 20$ & $\begin{array}{l}\text { Instalado antes da VRP, } \\
\text { à R.Juiz de Fora C/ Bartira }\end{array}$ \\
\hline PONTO 6 & 6 & $\begin{array}{c}\text { Rua Dr.Silvio de Andrade, } 497 \\
\text { Vila Planalto }\end{array}$ & $16 / 4 / 2003$ & 09:20 & $24 / 4 / 2003$ & $14: 25$ & $\begin{array}{l}\text { Entre a R.Augusto Severo } \\
\text { e R.Benjamim Constant }\end{array}$ \\
\hline PONTO 7 & 25 & $\begin{array}{c}\text { Avenida Tamandaré, } 249 \\
\text { Próx. Vila Petengil }\end{array}$ & $15 / 4 / 2003$ & $17: 00$ & $24 / 4 / 2003$ & $14: 45$ & $\begin{array}{l}\text { Entre R. Paraibuna e } \\
\text { R. Piracicaba }\end{array}$ \\
\hline PONTO 8 & 50 & $\begin{array}{l}\text { Rua Flamengo em frente ao } \mathrm{N}^{\mathrm{o}} \\
1276\end{array}$ & $11 / 4 / 2003$ & $08: 15$ & $25 / 4 / 2003$ & $08: 15$ & $\begin{array}{l}\text { Entre R.Pres.Arthur Bernar } \\
\text { des e Pres.Delfim Moreira }\end{array}$ \\
\hline & & Vila Almeida & & & & & \\
\hline PONTO 9 & 122 & $\begin{array}{c}\text { Av.59, } 402 \\
\text { Nova Campo Grande }\end{array}$ & $16 / 4 / 2000$ & $15: 00$ & $24 / 4 / 2003$ & $16: 00$ & Entre R.49 e R.53 \\
\hline PONTO 10 & 115 & $\begin{array}{c}\text { Rua Merced, } 85 \\
\text { B.Bosque Santa Mônica }\end{array}$ & $11 / 4 / 2003$ & $10: 15$ & $24 / 4 / 2003$ & $15: 55$ & $\begin{array}{c}\text { Entre R.Caravelas e } \\
\text { R.Monterrey }\end{array}$ \\
\hline
\end{tabular}

Como já mencionado, o período da investigação de campo foi entre 10 e 24 de Abril de 2003. Entretanto, entre os dias 10 e 16 as investigações foram destinadas à observação e 
a verificação dos medidores de pressão (trabalhando corretamente). Nota-se na Tabela A1.2 que os medidores referentes os pontos 6, 7 e 9 foram reinstalados dia 15 e 16 . Na realidade, esses medidores foram instalados dia 10 e 11, mas como todos os pontos eram percorridos diariamente, percebeu-se que os mesmos estavam registrando pressões desnecessárias. Por exemplo, o ponto 9 foi mudado de local pois estava registrando pressão a jusante da VRP (Figura A1.2 - Setor 5, próximo ao nó 130). Foi verificado através de inspeção diária que o ponto 6 não estava registrando pressão da rede, mas, pressão de um sistema isolado (poço), por isso o medidor foi mudado de local. O ponto 7 foi mudado de local devido à caixa d' água da residência anterior não possuir bóia ${ }^{20}$.

\section{A1.2.5 Simulações hidráulicas}

Procedimentos de calibração de modelo de redes de distribuição de água sempre devem ser aplicados antes de qualquer análise de reabilitação de redes (sistema existente), para que o comportamento aproximado do sistema existente possa ser conhecido. Através do conhecimento dos sistemas existentes é possível simular a hidráulica das redes de maneira mais confiável.

Uma das formas de realizar análises hidráulicas das redes existentes é identificar os parâmetros para o modelo de vazamentos e incorporá-los nos modelos de análises hidráulicas. Para isso, é necessário que os dados obtidos sejam formatados e organizados de tal maneira que os resultados esperados possam representar o comportamento do sistema real. Optou-se por trabalhar com modelos para análises de redes em regime permanente, sendo necessário que cenários de consumo (por exemplo, mínimo, médio e máximo) sejam identificados e os parâmetros representem os valores médios de vazamentos para o sistema. Com a introdução de vazamentos nas simulações hidráulicas as pressões obtidas devem ser menores que aquelas obtidas nas simulações sem vazamentos.

As Figuras A1.7-A1.16 mostram as pressões observadas nos nós monitorados. Esses dados refletem o comportamento do sistema durante o período de monitoramento. Através dessas ilustrações é possível identificar as manobras (pressão próxima de zero) realizadas na rede nos períodos noturnos. Esse tipo de ação é comum em quase todos os sistemas de abastecimento de água no Brasil. Durante o período noturno a demanda é mínima, com isso, a pressão torna-se elevada, e, como os vazamentos são proporcionais

\footnotetext{
${ }^{20}$ Foi solicitado aos moradores das residências nas quais os medidores de pressão estavam instalados, que não fechassem o registro durante o período de investigação de campo.
} 
às pressões, manobras na rede são necessárias como forma de minimizar as pressões e, consequentemente, os vazamentos. Os dados referentes às pressões observadas podem ser encontrados em uma pasta denominada DadosLoggers que está contida no CD de dados incorporado no final desse trabalho.

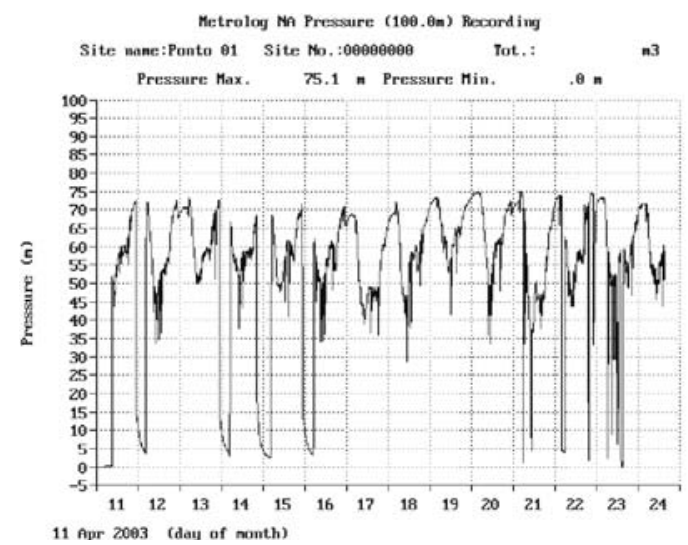

Figura A1.7 - Pressões observadas (p. 1)

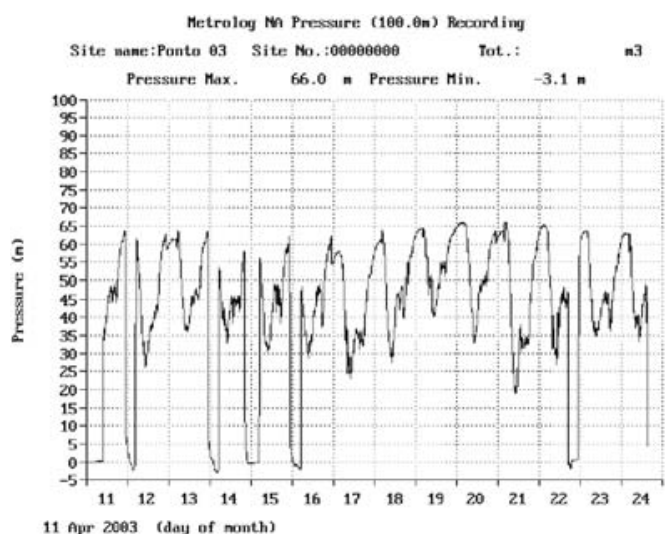

Figura A1.9 - Pressões observadas (p. 3)

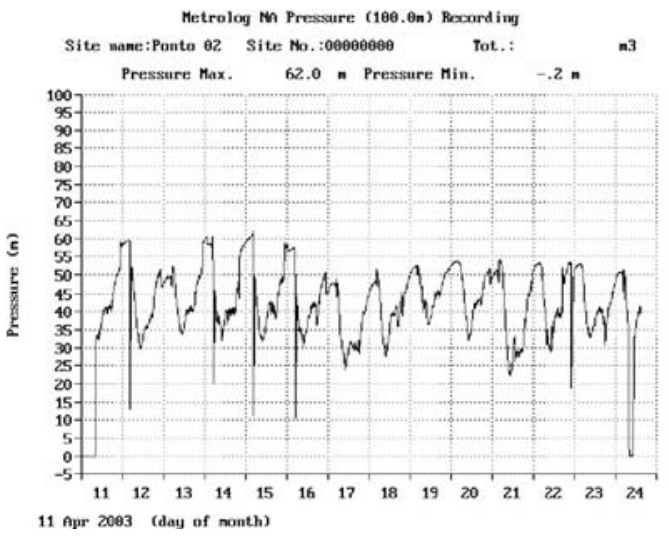

Figura A1.8 - Pressões observadas (p. 2)

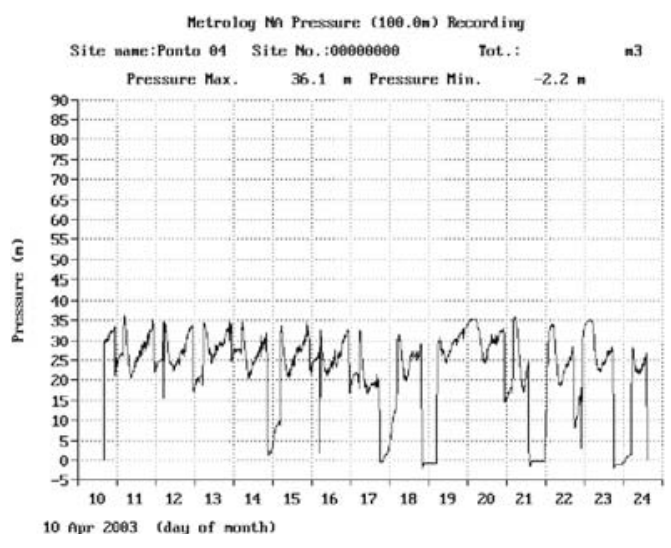

Figura A1.10 - Pressões observadas (p. 4) 


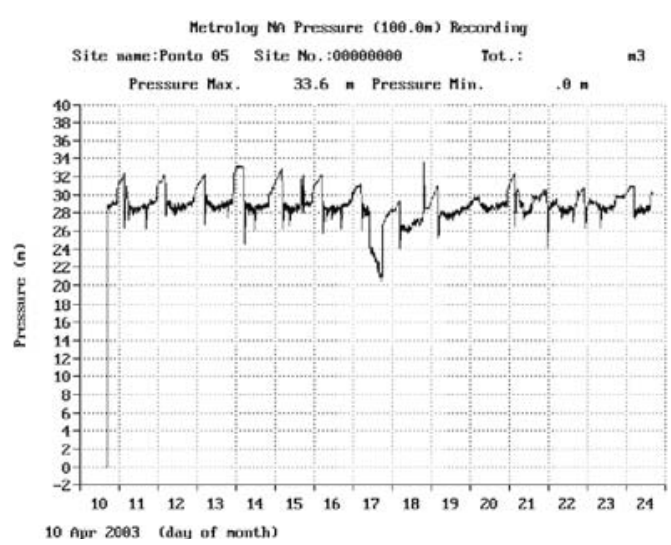

Figura A1.11 - Pressões observadas (p. 5)

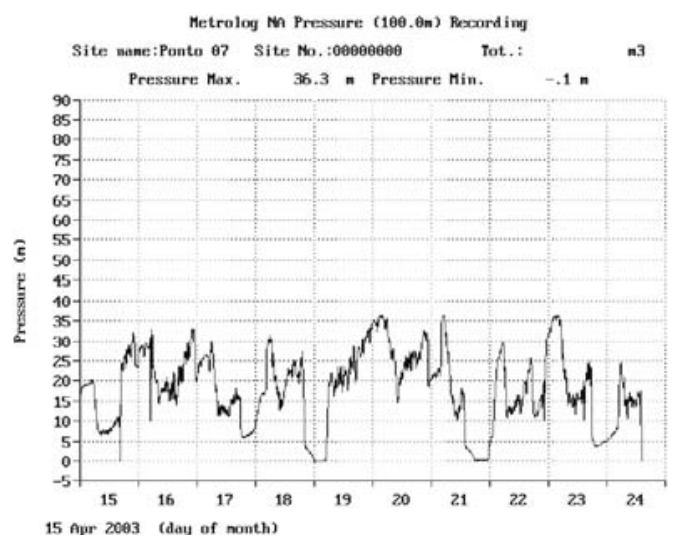

Figura A1.13 - Pressões observadas (p. 7)

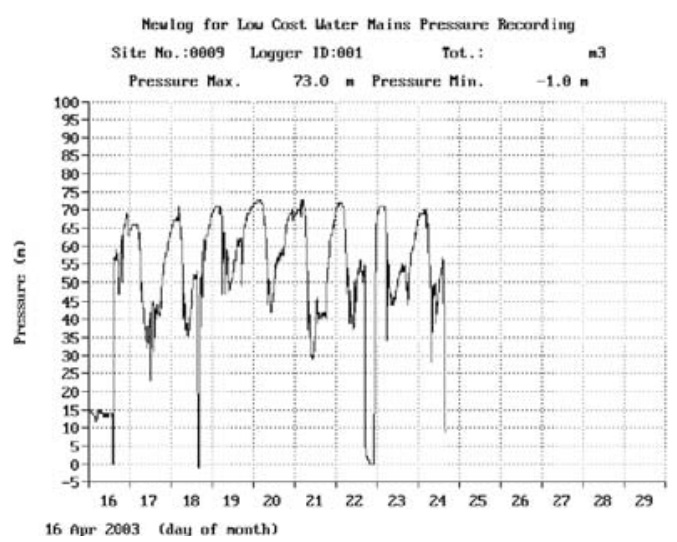

Figura A1.15 - Pressões observadas (p. 9)

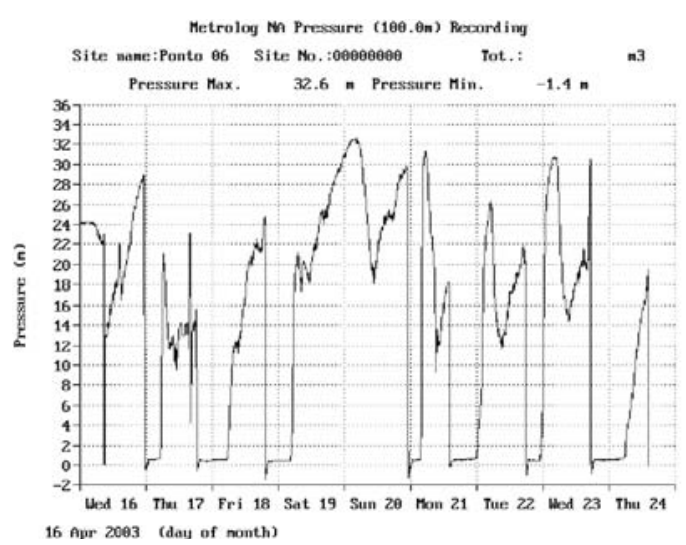

Figura A1.12 - Pressões observadas (p. 6)

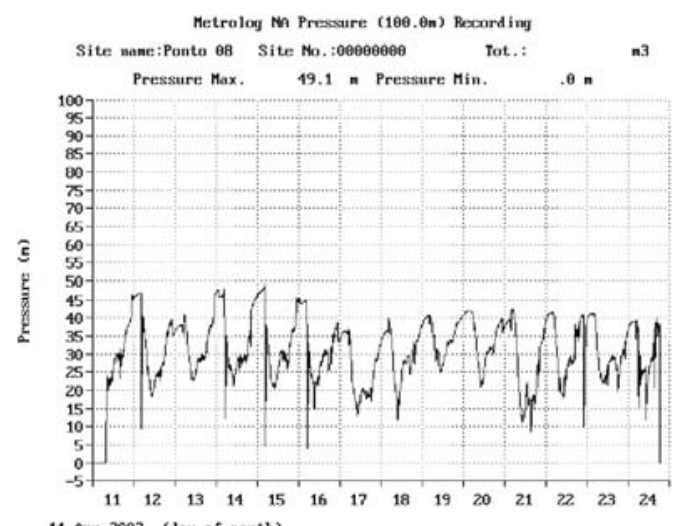

Figura A1.14 - Pressões observadas (p. 8)

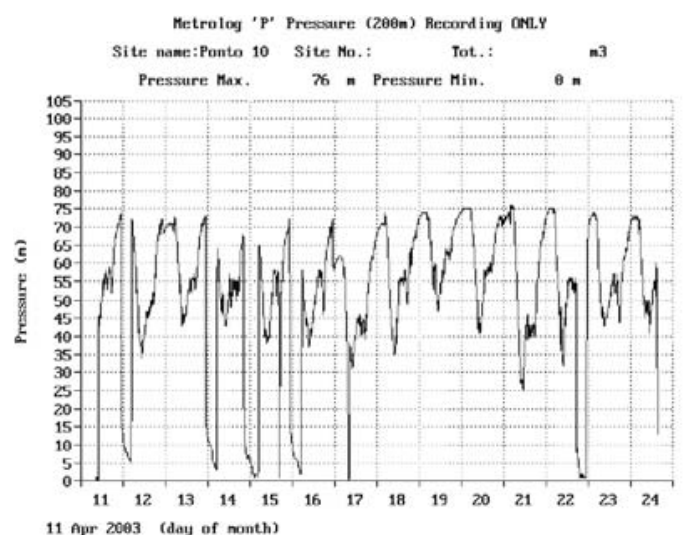

Figura A1.16 - Pressões observadas (p. 10)

Durante o período de experimentação em campo foi observada uma mudança climática na cidade de Campo Grande - MS que registrou temperaturas diárias abaixo da média 
típica para o período. Como os cenários de consumo variam em função do clima, optouse por desprezar os dias (15 a 18 de Abril de 2003), em que as temperaturas ficaram mais baixas que a média por não representar consumos típicos do sistema. Assim, determinou-se o período para análises entre os dias 19 e 23 de Abril de 2003.

A primeira etapa para determinação dos cenários de consumo a serem considerados na calibração foi avaliar as vazões abastecidas (entrada do setor) na rede de distribuição. As Figuras A1.17-A1.21 mostram as vazões de entrada na rede de distribuição. Esses dados foram fornecidos pela própria companhia, que conta com um equipamento de telemetria enviando informações a cada minuto (via rádio).
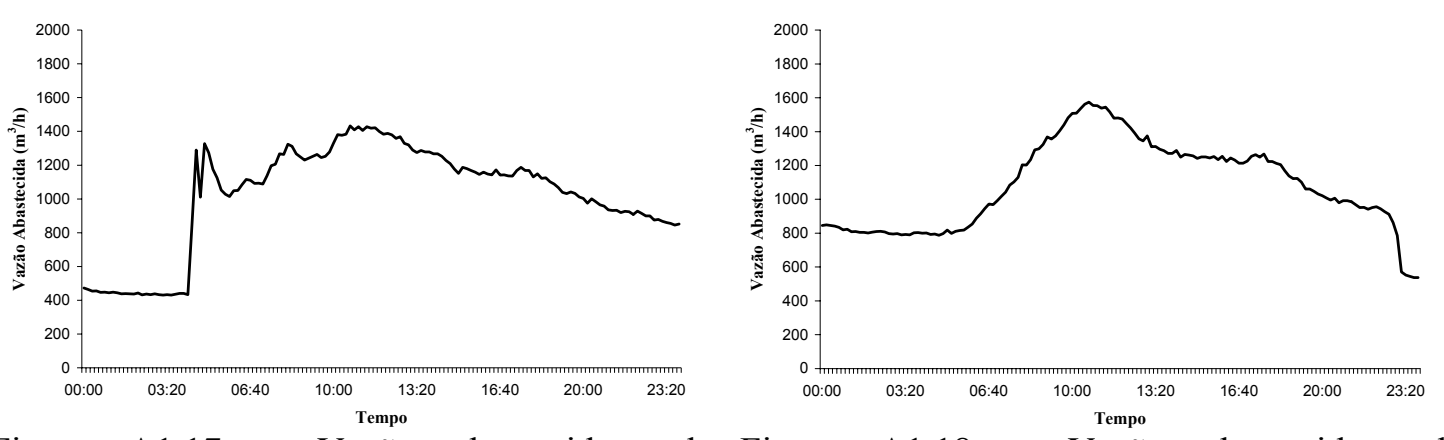

Figura A1.17 - Vazão abastecida pelo Figura A1.18 - Vazão abastecida pelo reservatório (19 04 2003)

reservatório (20 04 2003)
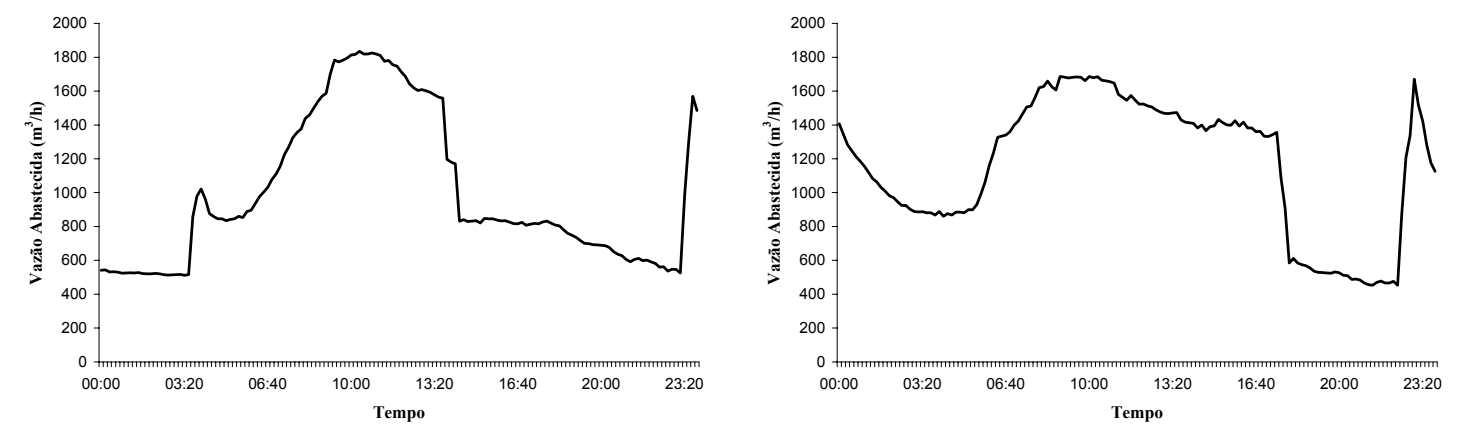

Figura A1.19 - Vazão abastecida pelo Figura A1.20 - Vazão abastecida pelo reservatório (21 04 2003)

reservatório (22 04 2003)

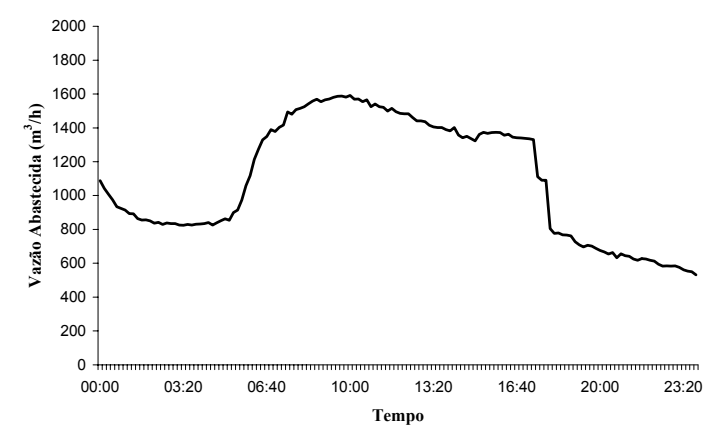

Figura A1.21 - Vazão abastecida pelo reservatório (2304 2003) 
Observando as Figuras A1.17 e A1.19 pode-se constatar a presença de manobras no registro de entrada do setor no período noturno. Segundo informações da própria companhia, essas manobras são realizadas de forma a minimizar as perdas (minimizar pressão) no sistema, durante o período em que as pressões são elevadas (consumo baixo). Dessa forma, optou-se por analisar os dados do dia 20, 21 e 23, que apresentam uma curva típica da vazão de consumo e não apresenta manobras nos períodos de demanda máxima. $\mathrm{O}$ horário escolhido para representar o padrão de consumo mínimo foi 3:00 horas e o horário escolhido como representativo ao consumo máximo foi 11:00 horas, podendo ser verificado através das Figuras (A1.17-A1.19).

A operação de manobras de registros na rede como forma de diminuir e até cessar o abastecimento em algumas regiões que registram pressões elevadas em períodos noturnos (pressão alta) é constatada através das Figuras A1.25, A1.27 e A1.28. Esses pontos (4, 6 e 7), por pertencerem ao mesmo setor de rede (2 - Figura A1.2), apresentaram o mesmo comportamento em termos de pressões. A identificação das manobras nesse setor (em períodos noturnos) é verificada através das pressões nulas registradas pelos medidores de pressão no dia 19 (Figuras A1.25, A1.27 e A1.28).

Valores para as variáveis de estado do sistema podem ser obtidos verificando os dados armazenados pelos medidores de pressão durante a experimentação em campo. Esses dados demonstram o comportamento do sistema e a operação diária realizada na rede. Por exemplo, o ponto 5 (Figuras A1.26, A1.36, A1.46, A1.56 e A1.66), localizado próximo (a montante) a uma válvula redutora de pressão (VRP), registrou pressões constantes de 30 m.c.a. Outro fato interessante observado foi a distinção entre manobras noturnas para minimização de vazamentos (Figuras A1.25, A1.27 e A1.28) e manobras de manutenção de redes (Figuras A1.42 e A1.52). Por exemplo, no dia 22 foram constatadas várias manobras realizadas na rede através dos dados armazenados pelos medidores de pressão. Essas manobras comprometeram o abastecimento dos setores $4 \mathrm{e}$ 5 (Figuras A1.54, A1.60 e A1.61) e do setor 2 (Figuras A1.55, A1.57, A1.58) no período entre 17:00 as 23:00 horas. Segundo informações fornecidas pela CCP, nesse dia houve um problema na captação e adução do sistema. Os reservatórios apresentaram níveis baixos para suprir a demanda diária, então, tais manobras serviram como limitadores de consumo em vários locais do setor RF-1. 

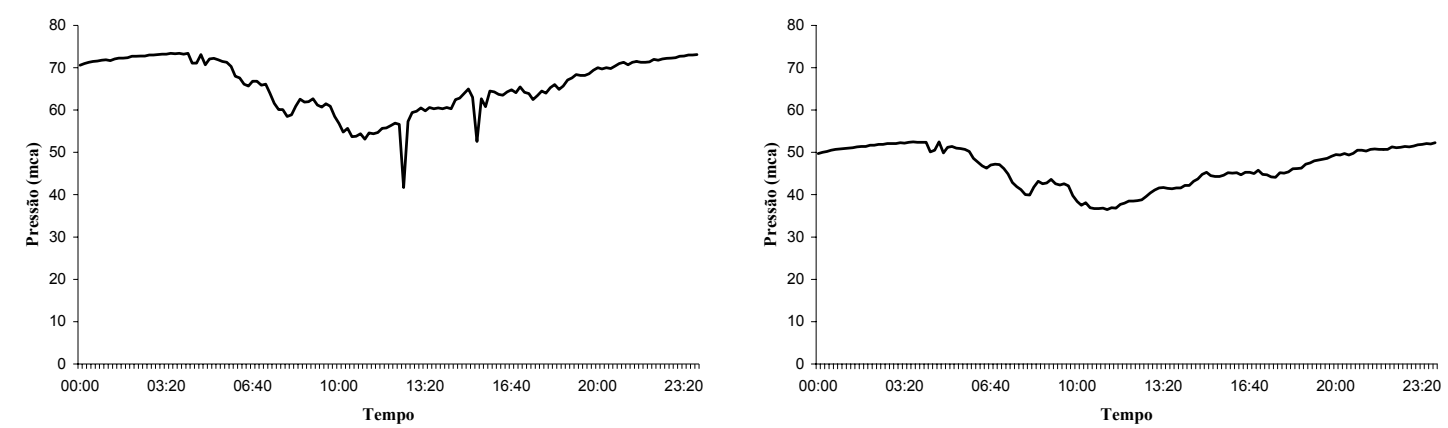

Figura A1.22 - Pressão Monitorada no ponto 1 Figura A1.23 - Pressão Monitorada no ponto 2 (1904 2003)

(1904 2003)
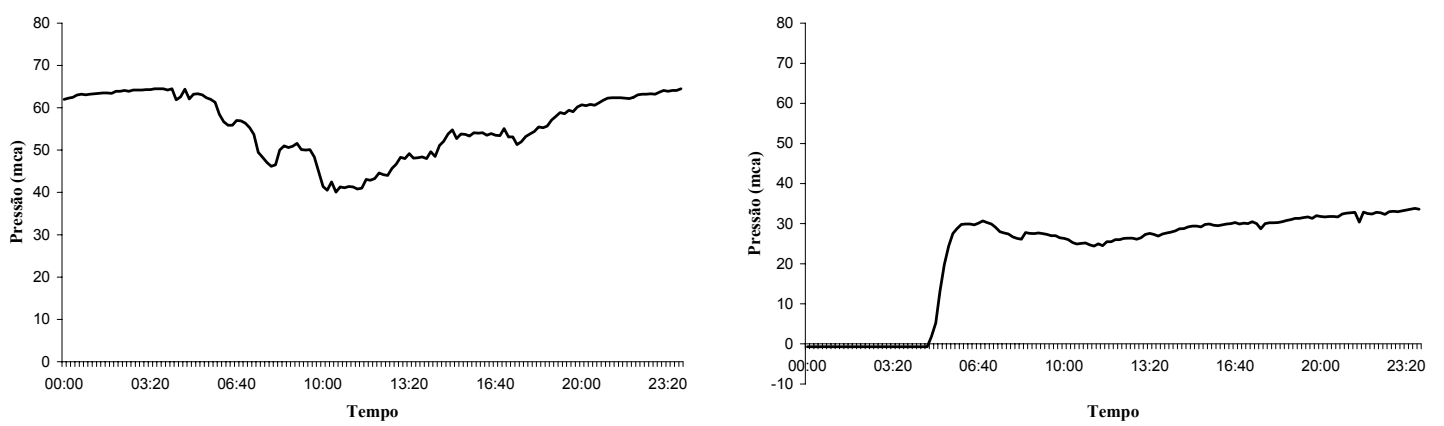

Figura A1.24 - Pressão Monitorada no ponto 3 Figura A1.25 - Pressão Monitorada no ponto 4 (1904 2003)

(1904 2003)
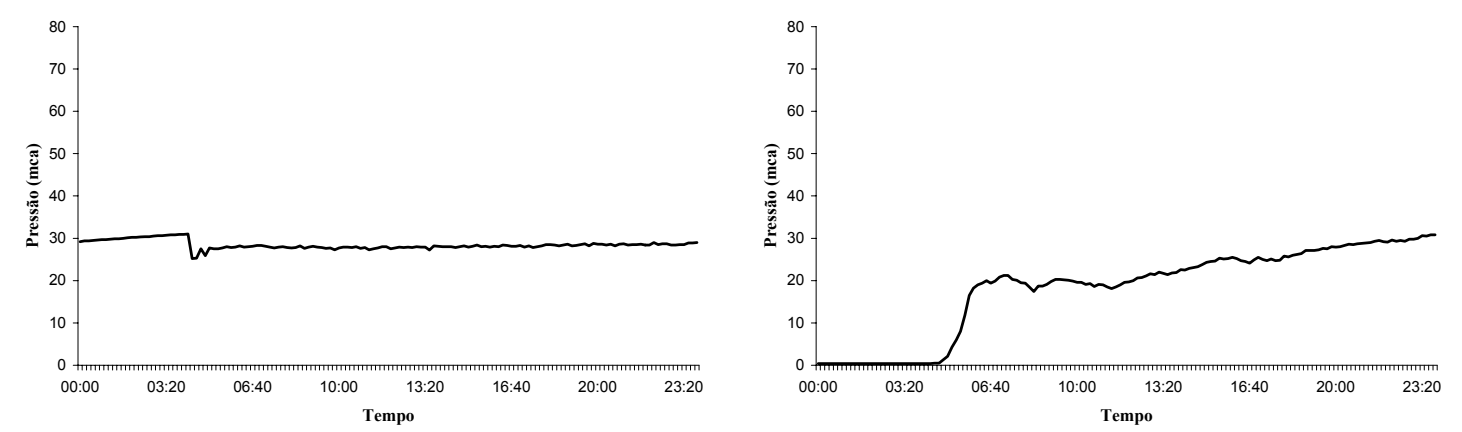

Figura A1.26 - Pressão Monitorada no ponto 5 Figura A1.27 - Pressão Monitorada no ponto 6 (1904 2003)

(1904 2003)
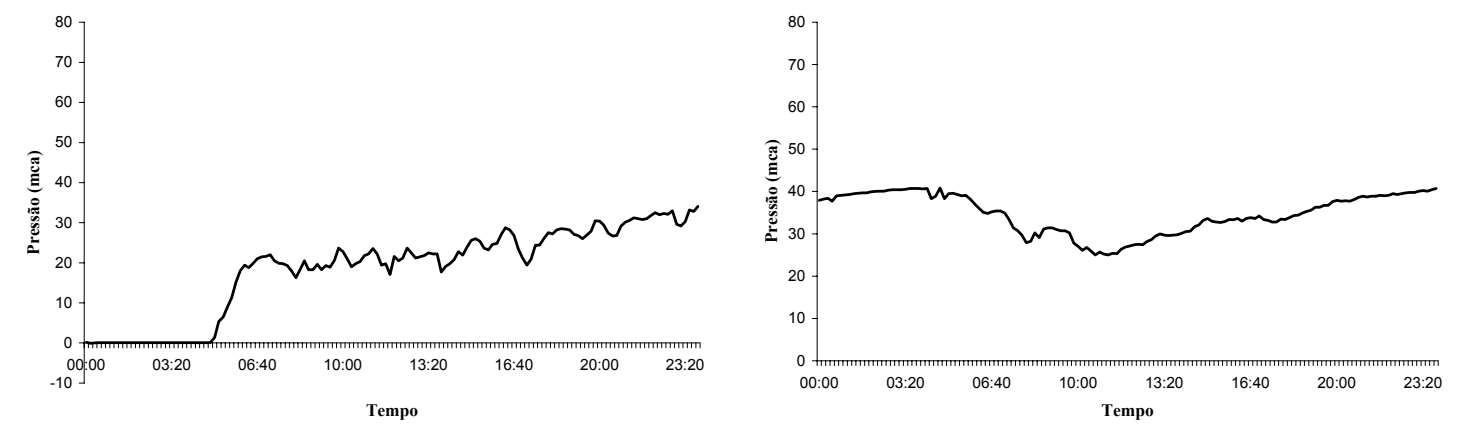

Figura A1.28 - Pressão Monitorada no ponto 7 Figura A1.29 - Pressão Monitorada no ponto 8 (19 04 2003)

(1904 2003) 

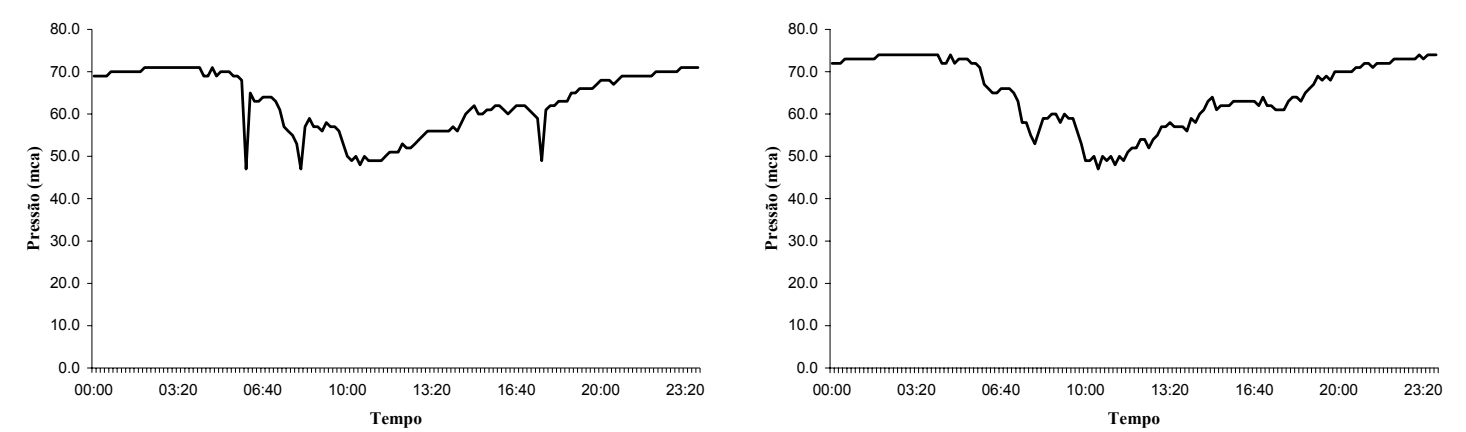

Figura A1.30 - Pressão Monitorada no ponto 9 Figura A1.31 - Pressão Monitorada no ponto (19 04 2003)

$10(19042003)$
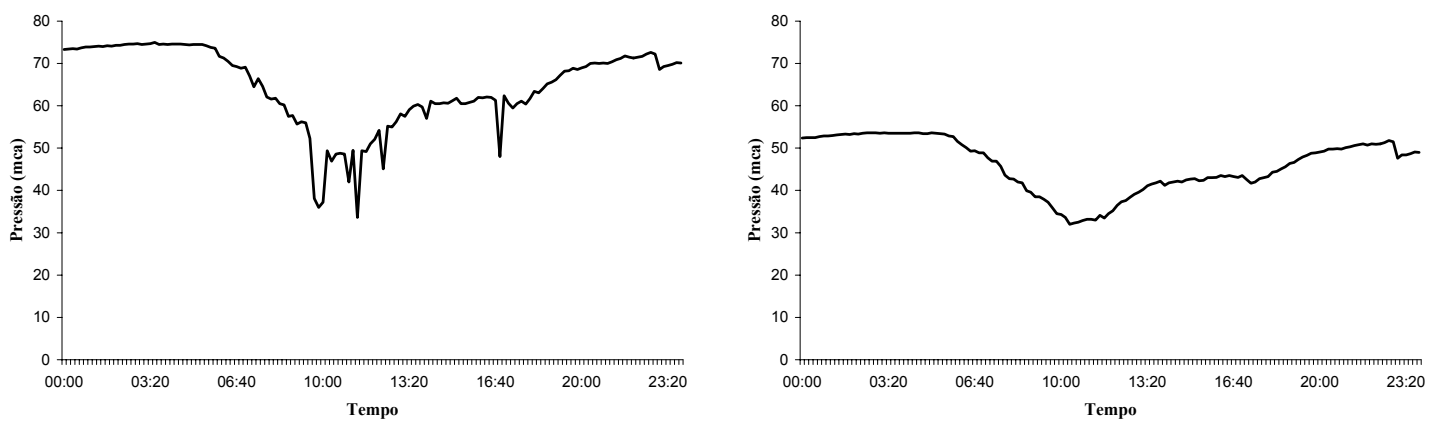

Figura A1.32 - Pressão Monitorada no ponto 1 Figura A1.33 - Pressão Monitorada no ponto 2 (2004 2003)

(2004 2003)
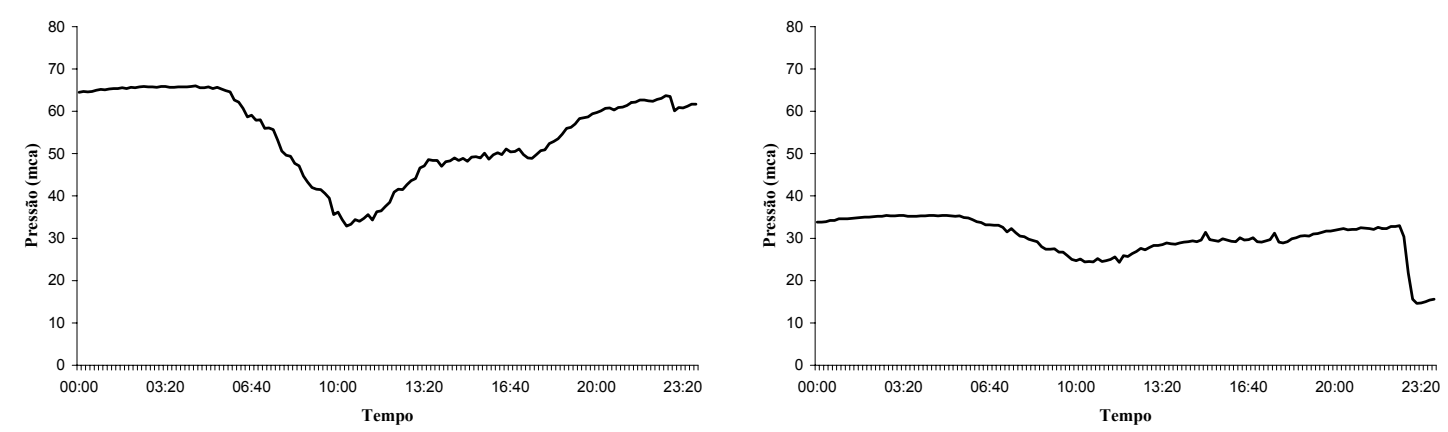

Figura A1.34 - Pressão Monitorada no ponto 3 Figura A1.35 - Pressão Monitorada no ponto 4 (2004 2003)

(2004 2003)
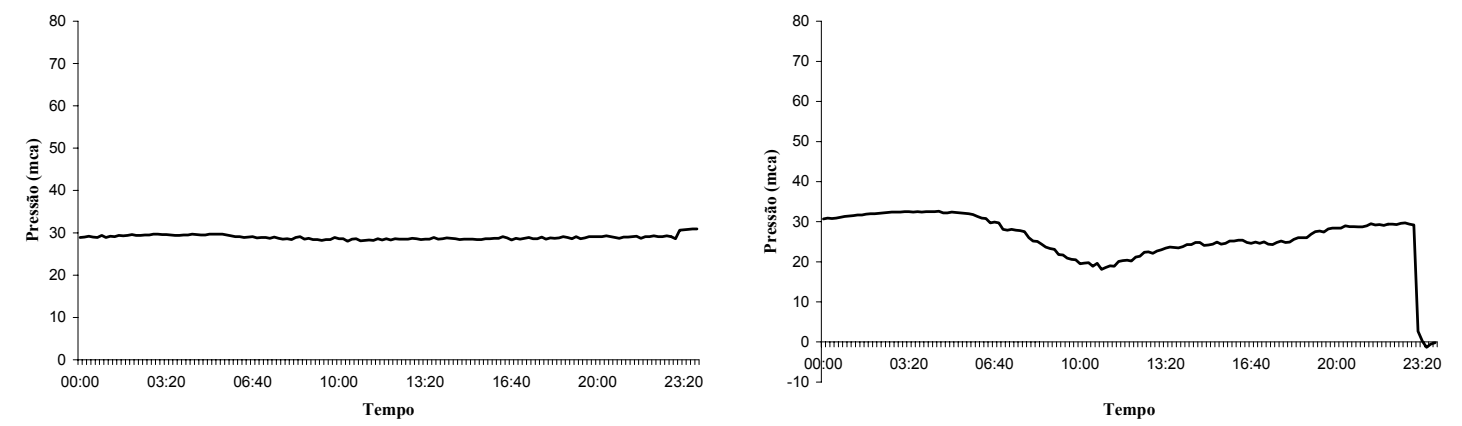

Figura A1.36 - Pressão Monitorada no ponto 5 Figura A1.37 - Pressão Monitorada no ponto 6 (20 04 2003)

(20 04 2003) 


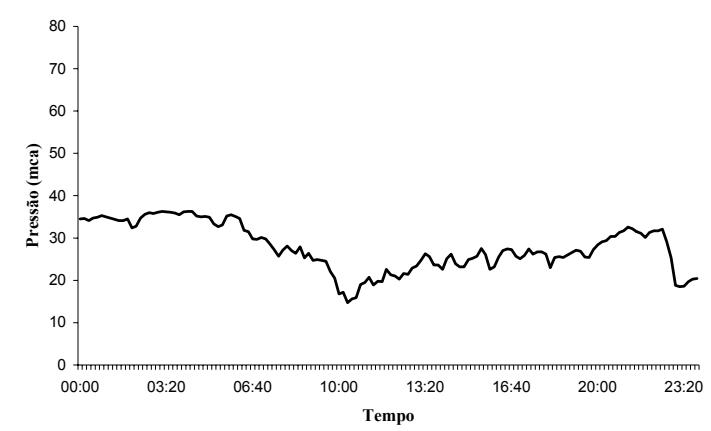

Figura A1.38 - Pressão Monitorada no ponto 7 (20 04 2003)

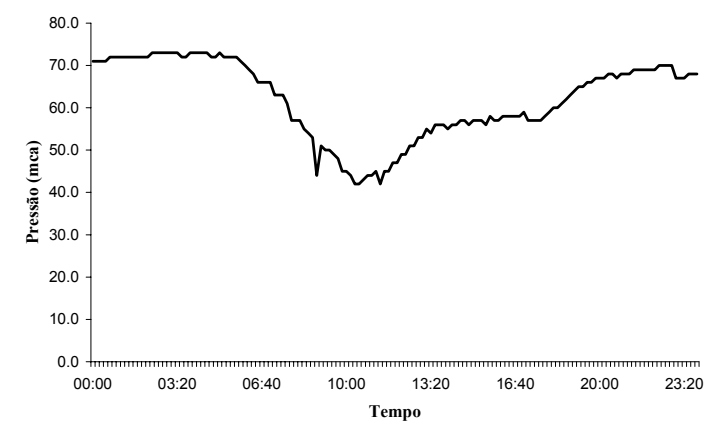

Figura A1.40 - Pressão Monitorada no ponto 9 (2004 2003)

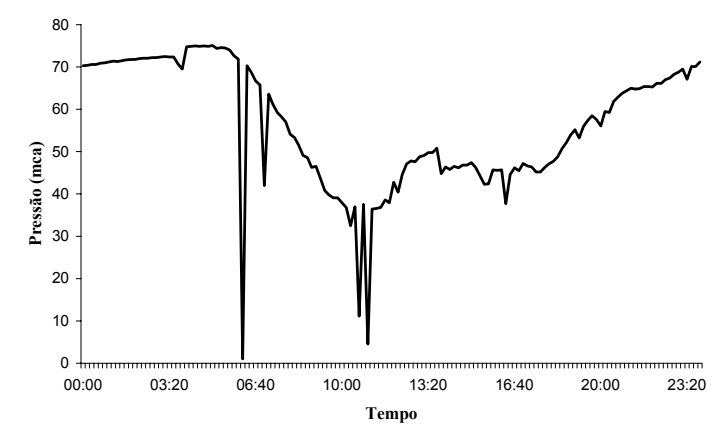

Figura A1.42 - Pressão Monitorada no ponto 1 (21 04 2003)

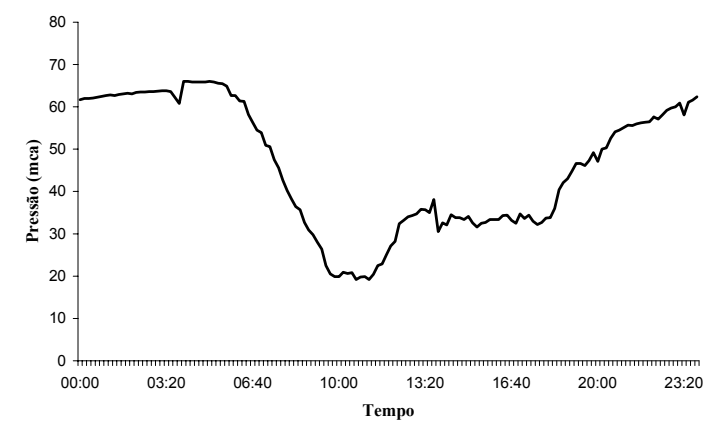

Figura A1.44 - Pressão Monitorada no ponto 3 (21 04 2003)

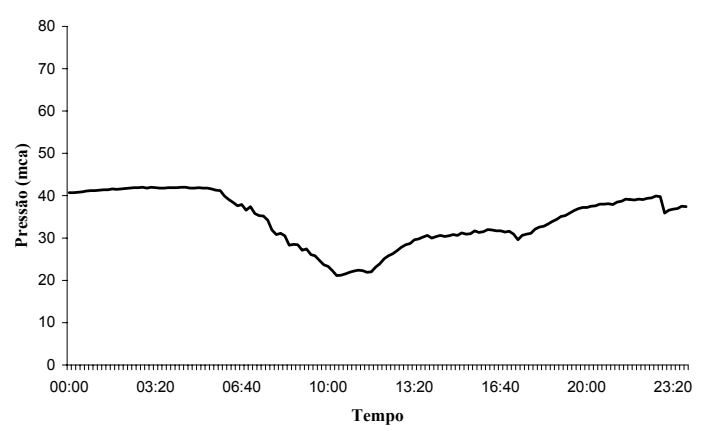

Figura A1.39 - Pressão Monitorada no ponto 8 (2004 2003)

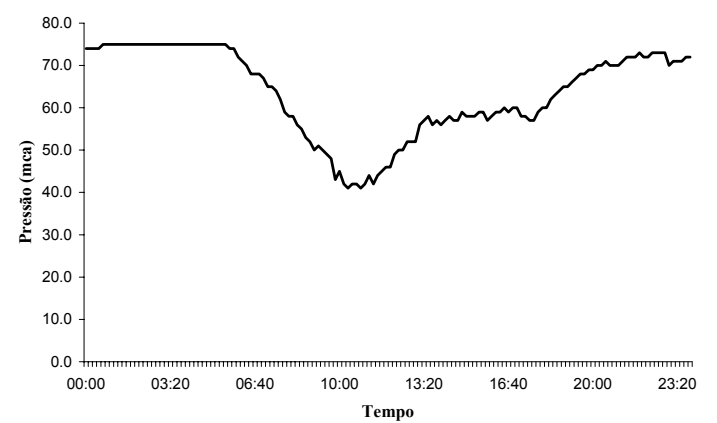

Figura A1.41 - Pressão Monitorada no ponto 10 (2004 2003)

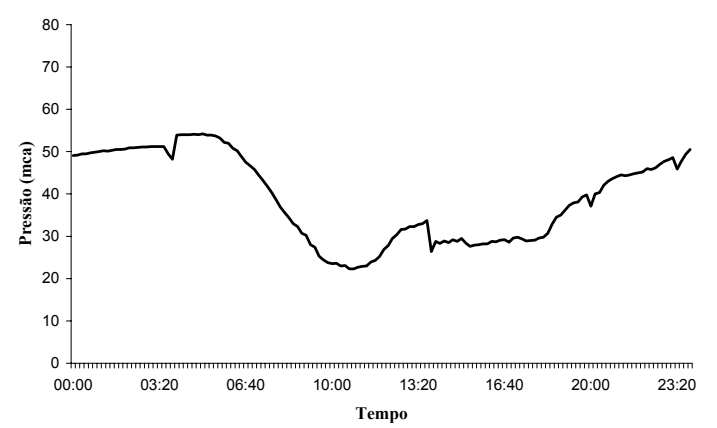

Figura A1.43 - Pressão Monitorada no ponto 2 (21 04 2003)

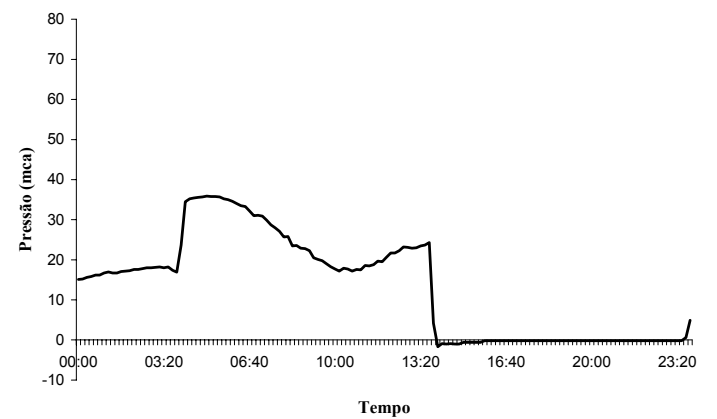

3 Figura A1.45 - Pressão Monitorada no ponto 4 (21 04 2003) 

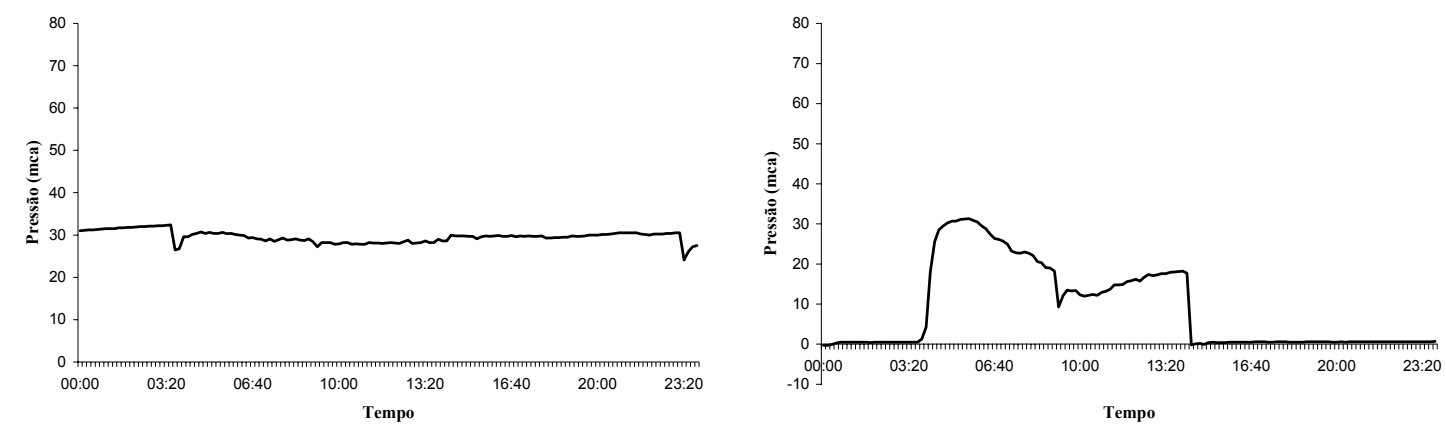

Figura A1.46 - Pressão Monitorada no ponto 5 Figura A1.47 - Pressão Monitorada no ponto 6 (21 04 2003)

(21 04 2003)
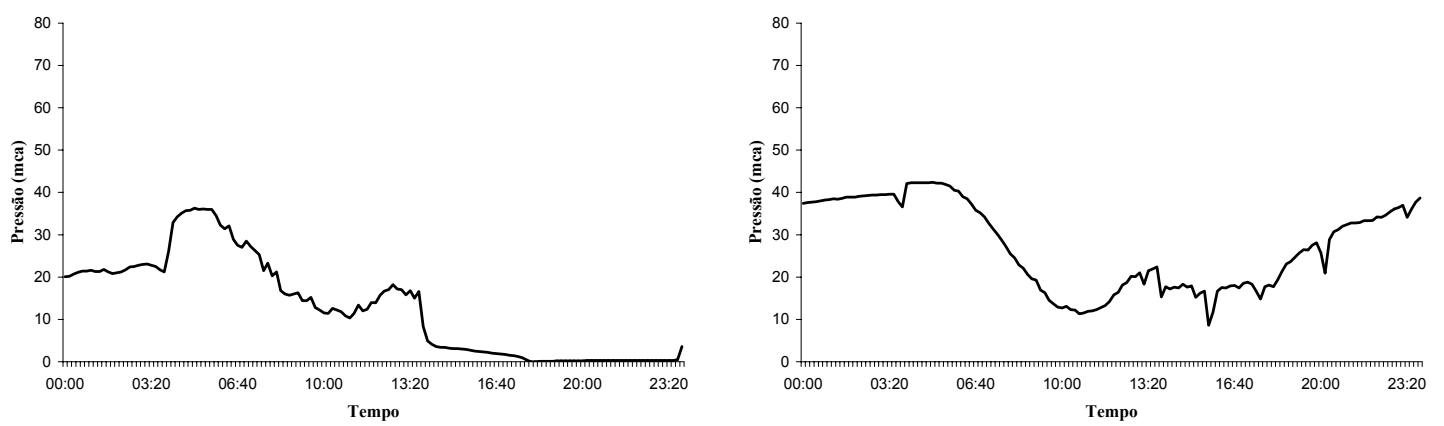

Figura A1.48 - Pressão Monitorada no ponto 7 Figura A1.49 - Pressão Monitorada no ponto 8 (21 04 2003)

(2104 2003)
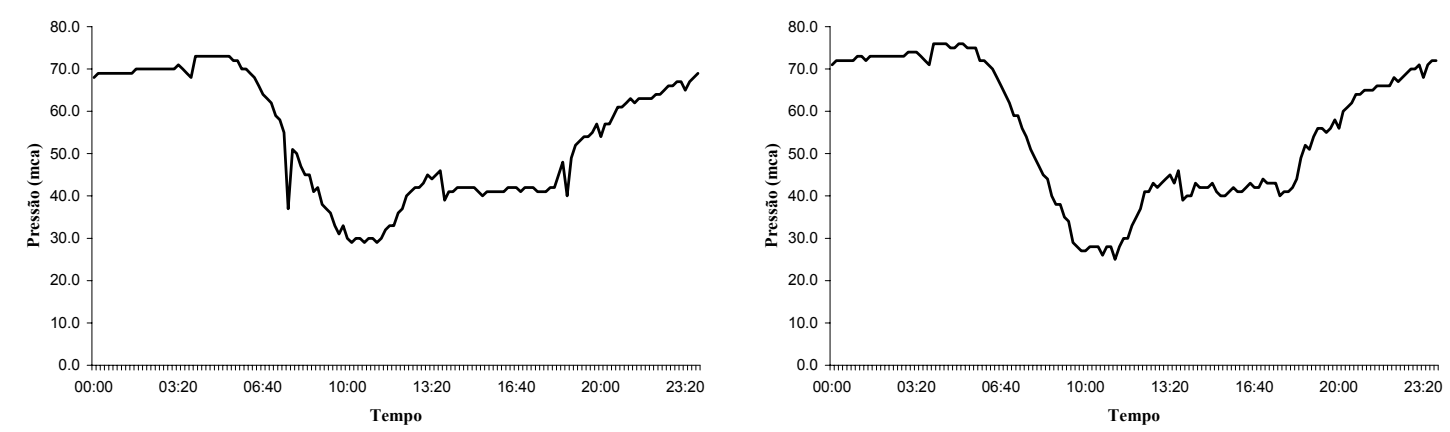

Figura A1.50 - Pressão Monitorada no ponto 9 Figura A1.51 - Pressão Monitorada no ponto (21 04 2003)

10 (2104 2003)
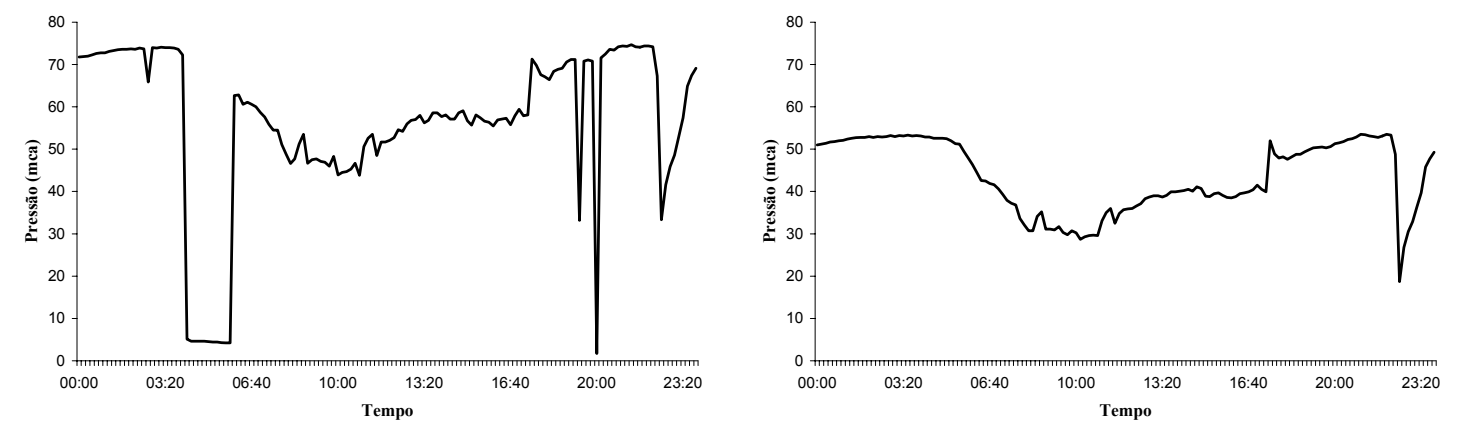

Figura A1.52 - Pressão Monitorada no ponto 1 Figura A1.53 - Pressão Monitorada no ponto 2 (22 04 2003)

(22 04 2003) 

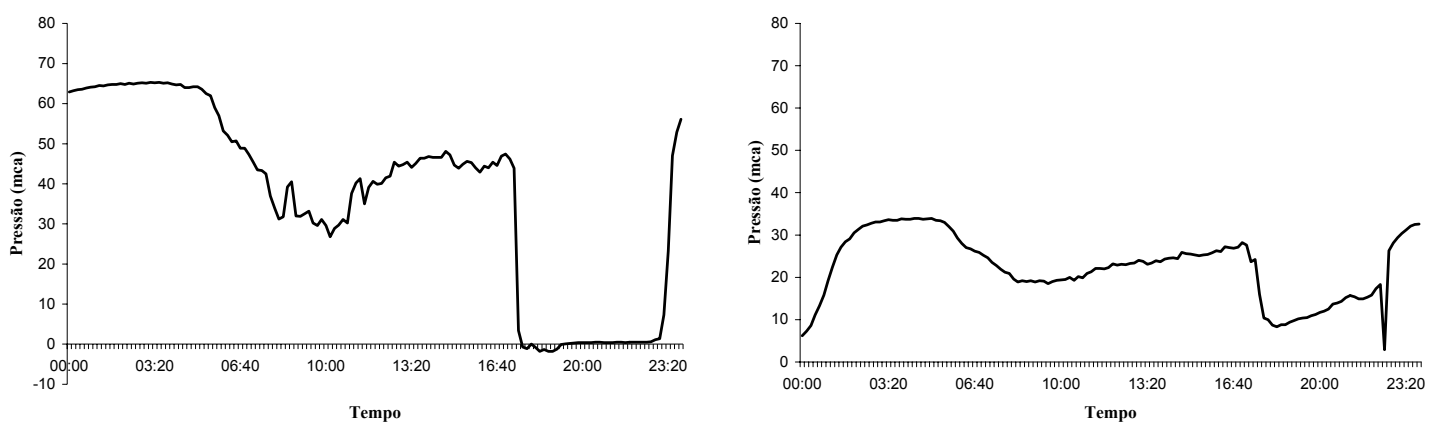

Figura A1.54 - Pressão Monitorada no ponto 3 Figura A1.55 - Pressão Monitorada no ponto 4 (22 04 2003)

(2204 2003)
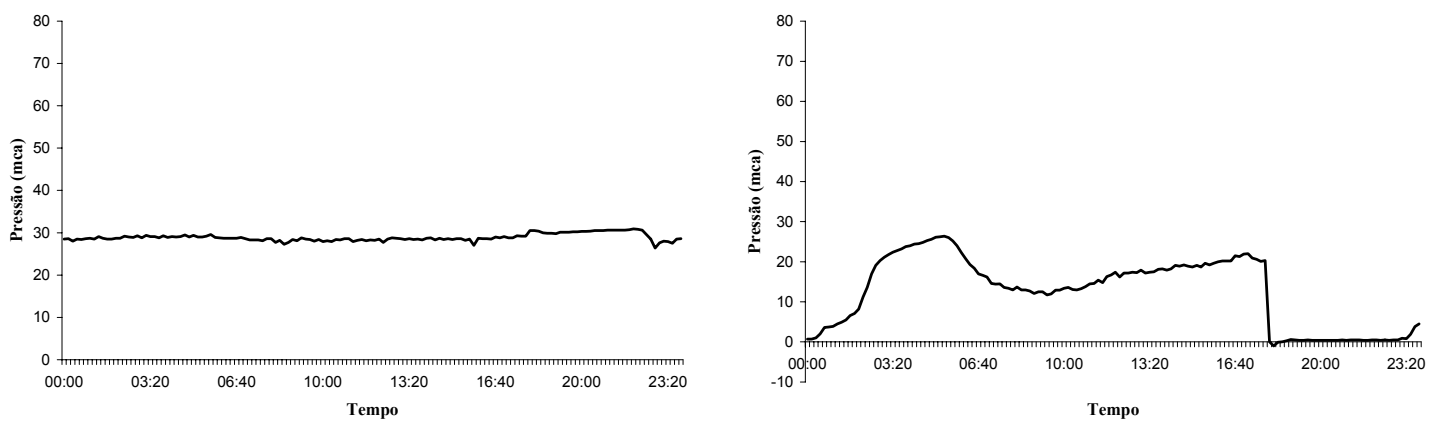

Figura A1.56 - Pressão Monitorada no ponto 5 Figura A1.57 - Pressão Monitorada no ponto 6 (2204 2003)

(2204 2003)
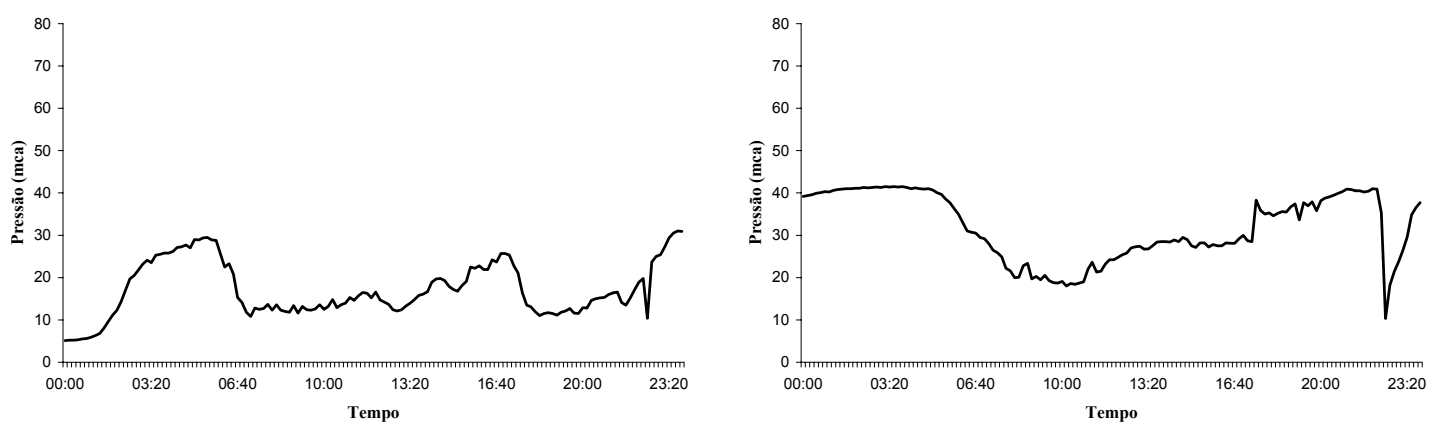

Figura A1.58 - Pressão Monitorada no ponto 7 Figura A1.59 - Pressão Monitorada no ponto 8 (22 04 2003)

(2204 2003)
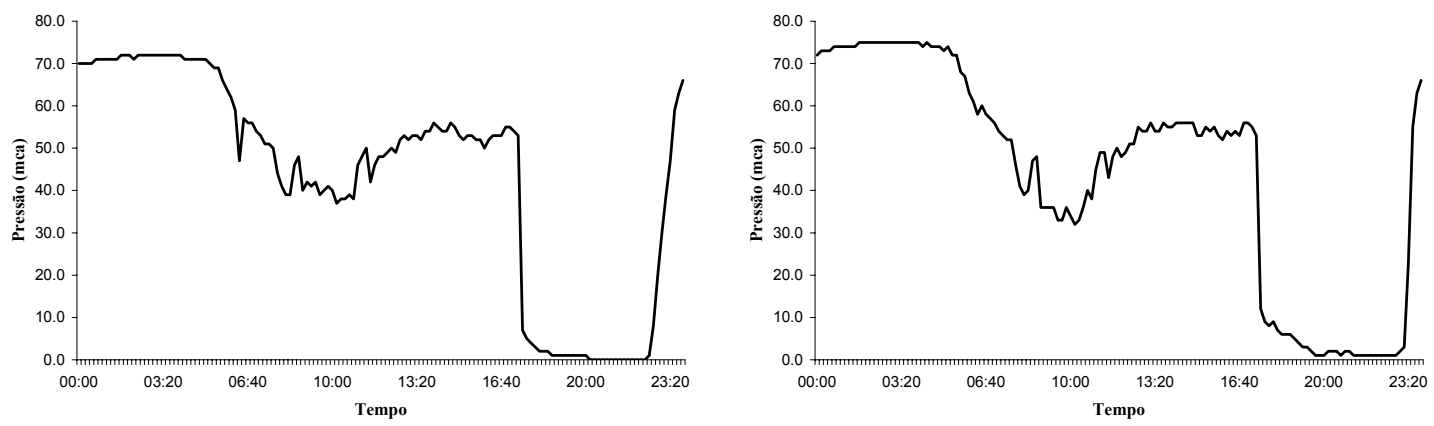

Figura A1.60 - Pressão Monitorada no ponto 9 Figura A1.61 - Pressão Monitorada no ponto (22 04 2003)

10 (22 04 2003) 

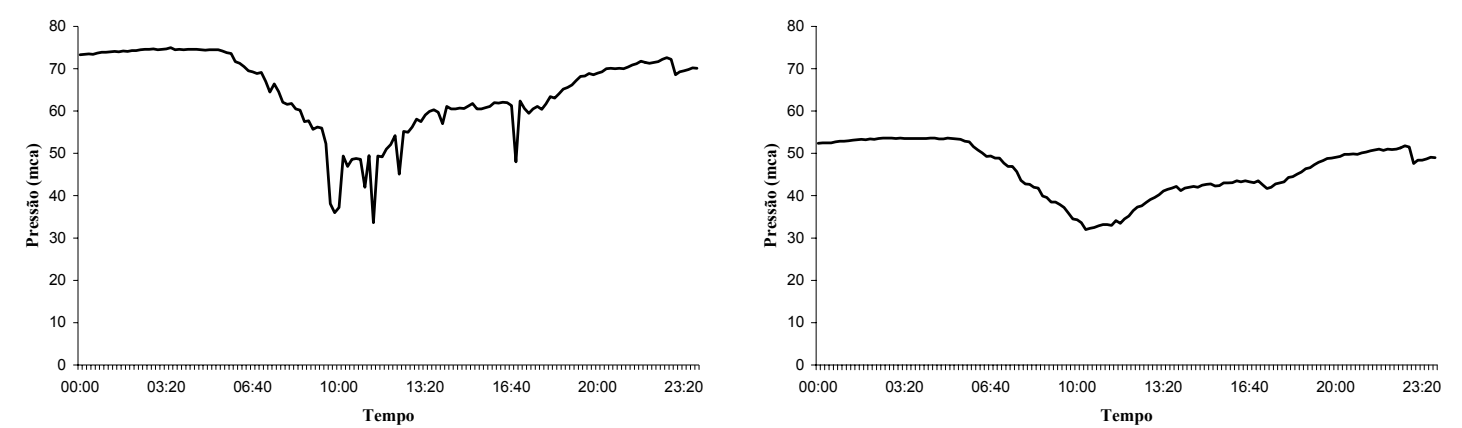

Figura A1.62 - Pressão Monitorada no ponto 1 Figura A1.63 - Pressão Monitorada no ponto 2 (2304 2003)

(2304 2003)
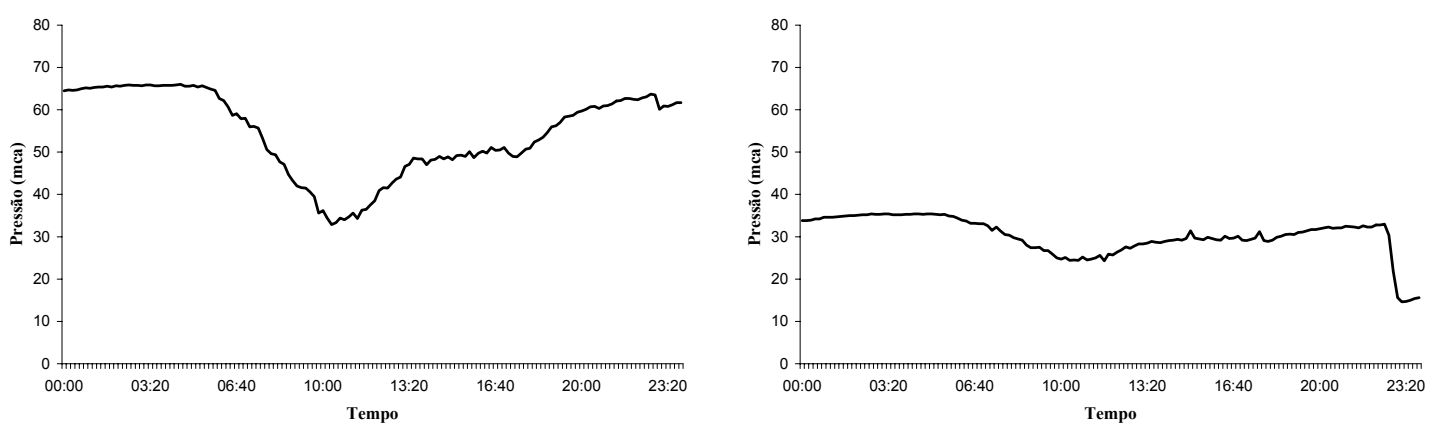

Figura A1.64 - Pressão Monitorada no ponto 3 Figura A1.65 - Pressão Monitorada no ponto 4 (2304 2003)

(2304 2003)
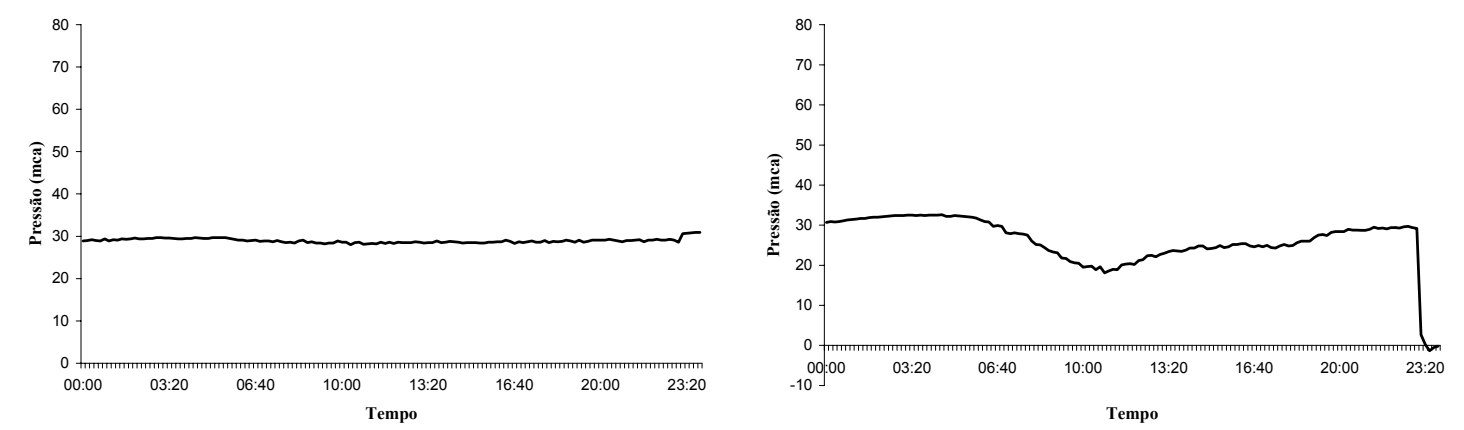

Figura A1.66 - Pressão Monitorada no ponto 5 Figura A1.67 - Pressão Monitorada no ponto 6 (2304 2003)

(2304 2003)
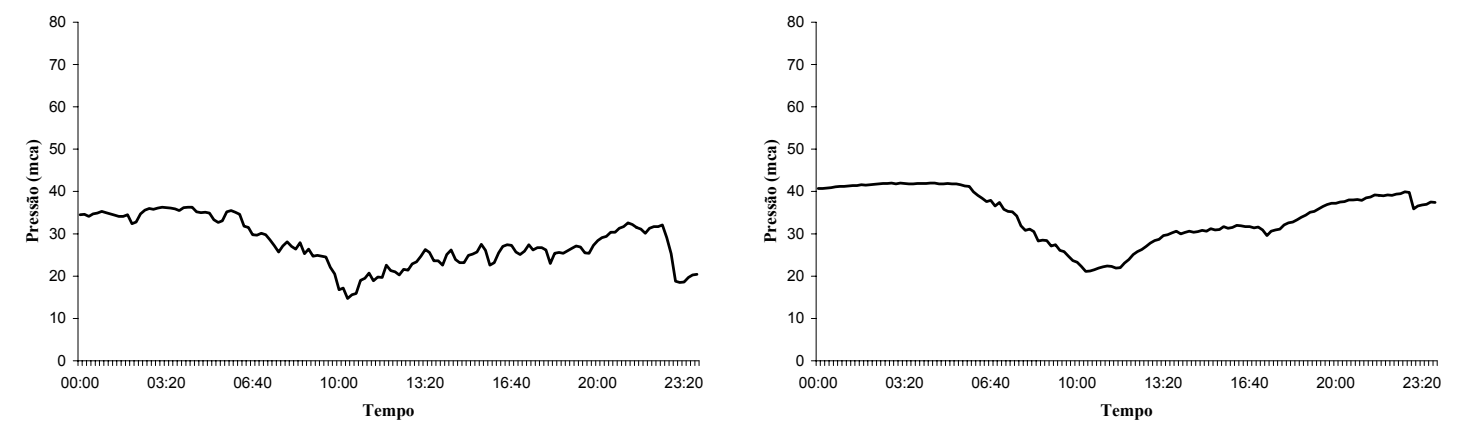

Figura A1.68 - Pressão Monitorada no ponto 7 Figura A1.69 - Pressão Monitorada no ponto 8 (23 04 2003)

(2304 2003) 

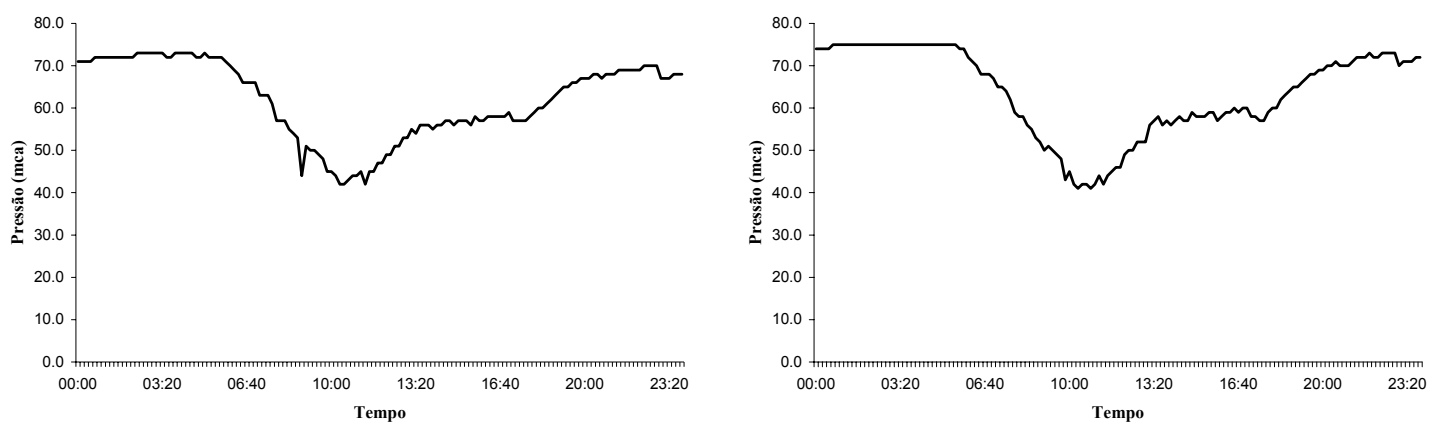

Figura A1.70 - Pressão Monitorada no ponto 9 Figura A1.71 - Pressão Monitorada no ponto (23 04 2003)

10 (23 04 2003) 


\section{A2 DADOS DA REDE EXEMPLO 3 (SETOR RF-1)}

Tabela A2.1 - Dados da rede exemplo 3 (setor RF-1)

\begin{tabular}{|c|c|c|c|c|c|c|c|c|c|c|c|}
\hline ID & Nó 1 & Nó 2 & $\begin{array}{c}\text { Comp. } \\
\text { m }\end{array}$ & $\begin{array}{l}\text { Diam. } \\
\text { mm }\end{array}$ & $\begin{array}{l}\text { Coef. de } \\
\text { Hazen }\end{array}$ & ID & Nó 1 & Nó 2 & $\begin{array}{l}\text { Comp. } \\
\text { m }\end{array}$ & $\begin{array}{l}\text { Diam. } \\
\text { mm }\end{array}$ & $\begin{array}{c}\text { Coef. de } \\
\text { Hazen }\end{array}$ \\
\hline 1 & 2 & 3 & 320 & 900 & 100 & 43 & 44 & 45 & 470 & 100 & 130 \\
\hline 2 & 3 & 4 & 440 & 800 & 100 & 44 & 45 & 46 & 310 & 700 & 100 \\
\hline 3 & 5 & 35 & 490 & 800 & 100 & 45 & 45 & 50 & 120 & 700 & 100 \\
\hline 4 & 7 & 8 & 770 & 300 & 100 & 46 & 47 & 48 & 620 & 100 & 130 \\
\hline 5 & 11 & 12 & 200 & 300 & 100 & 47 & 49 & 50 & 310 & 700 & 100 \\
\hline 6 & 4 & 5 & 840 & 800 & 100 & 48 & 52 & 58 & 120 & 600 & 100 \\
\hline 7 & 1 & 2 & 255 & 900 & 100 & 49 & 52 & 53 & 370 & 400 & 100 \\
\hline 8 & 3 & 16 & 1860 & 500 & 100 & 50 & 60 & 61 & 120 & 400 & 100 \\
\hline 9 & 16 & 14 & 1337 & 500 & 100 & 51 & 63 & 64 & 264 & 400 & 100 \\
\hline 10 & 17 & 18 & 370 & 250 & 100 & 52 & 64 & 65 & 375 & 400 & 100 \\
\hline 11 & 17 & 13 & 343 & 300 & 100 & 53 & 60 & 81 & 120 & 400 & 100 \\
\hline 12 & 13 & 12 & 615 & 400 & 100 & 54 & 65 & 100 & 386 & 400 & 100 \\
\hline 13 & 11 & 10 & 275 & 300 & 100 & 55 & 100 & 54 & 5 & 400 & 100 \\
\hline 14 & 10 & 9 & 750 & 300 & 100 & 56 & 66 & 68 & 200 & 200 & 100 \\
\hline 15 & 9 & 8 & 250 & 300 & 100 & 57 & 69 & 70 & 74 & 300 & 100 \\
\hline 16 & 7 & 6 & 775 & 250 & 100 & 58 & 70 & 71 & 230 & 300 & 100 \\
\hline 17 & 6 & 15 & 529 & 200 & 100 & 59 & 71 & 72 & 140 & 250 & 130 \\
\hline 18 & 14 & 19 & 190 & 500 & 100 & 60 & 74 & 75 & 643 & 400 & 100 \\
\hline 19 & 22 & 76 & 425 & 150 & 100 & 61 & 77 & 79 & 510 & 250 & 130 \\
\hline 20 & 23 & 24 & 55 & 250 & 100 & 62 & 79 & 72 & 80 & 250 & 130 \\
\hline 21 & 20 & 24 & 430 & 150 & 100 & 63 & 78 & 74 & 290 & 300 & 100 \\
\hline 22 & 27 & 28 & 36 & 150 & 80 & 64 & 79 & 80 & 710 & 300 & 100 \\
\hline 23 & 28 & 15 & 690 & 200 & 100 & 65 & 80 & 81 & 460 & 300 & 100 \\
\hline 24 & 33 & 30 & 100 & 150 & 80 & 66 & 85 & 97 & 50 & 250 & 100 \\
\hline 25 & 26 & 6 & 235 & 200 & 100 & 67 & 84 & 87 & 480 & 600 & 100 \\
\hline 26 & 31 & 32 & 165 & 150 & 100 & 68 & 86 & 87 & 356 & 200 & 100 \\
\hline 27 & 31 & 21 & 350 & 150 & 100 & 69 & 90 & 91 & 162 & 150 & 100 \\
\hline 28 & 21 & 22 & 145 & 150 & 100 & 70 & 93 & 94 & 105 & 100 & 130 \\
\hline 29 & 21 & 20 & 530 & 250 & 100 & 71 & 94 & 95 & 105 & 75 & 130 \\
\hline 30 & 76 & 23 & 342 & 200 & 100 & 72 & 91 & 96 & 580 & 100 & 130 \\
\hline 31 & 27 & 29 & 105 & 150 & 80 & 73 & 61 & 100 & 430 & 400 & 100 \\
\hline 32 & 33 & 29 & 190 & 150 & 80 & 74 & 43 & 49 & 430 & 100 & 130 \\
\hline 33 & 20 & 75 & 500 & 250 & 100 & 75 & 41 & 101 & 340 & 700 & 100 \\
\hline 34 & 24 & 34 & 444 & 250 & 100 & 76 & 101 & 102 & 270 & 800 & 100 \\
\hline 35 & 34 & 25 & 155 & 100 & 100 & 77 & 102 & 49 & 45 & 700 & 100 \\
\hline 36 & 25 & 75 & 464 & 250 & 100 & 78 & 76 & 26 & 30 & 200 & 100 \\
\hline 37 & 30 & 34 & 270 & 150 & 80 & 79 & 93 & 92 & 510 & 150 & 100 \\
\hline 38 & 35 & 36 & 20 & 800 & 100 & 80 & 92 & 91 & 185 & 150 & 100 \\
\hline 39 & 37 & 38 & 168 & 150 & 130 & 81 & 96 & 83 & 400 & 150 & 130 \\
\hline 40 & 35 & 41 & 328 & 800 & 100 & 82 & 90 & 89 & 240 & 400 & 100 \\
\hline 41 & 41 & 42 & 140 & 400 & 100 & 83 & 88 & 87 & 455 & 600 & 100 \\
\hline 42 & 42 & 43 & 300 & 400 & 100 & 84 & 84 & 83 & 280 & 600 & 100 \\
\hline
\end{tabular}




\begin{tabular}{|c|c|c|c|c|c|c|c|c|c|c|c|}
\hline ID & Nó 1 & Nó 2 & $\begin{array}{l}\text { Comp. } \\
\text { m }\end{array}$ & $\begin{array}{l}\text { Diam. } \\
\text { mm }\end{array}$ & $\begin{array}{l}\text { Coef. de } \\
\text { Hazen }\end{array}$ & ID & Nó 1 & Nó 2 & $\begin{array}{l}\text { Comp. } \\
\text { m }\end{array}$ & $\begin{array}{l}\text { Diam. } \\
\text { mm }\end{array}$ & $\begin{array}{c}\text { Coef. de } \\
\text { Hazen }\end{array}$ \\
\hline 85 & 88 & 84 & 570 & 100 & 130 & 125 & 113 & 112 & 440 & 150 & 100 \\
\hline 86 & 97 & 86 & 112 & 250 & 100 & 126 & 110 & 109 & 340 & 150 & 100 \\
\hline 87 & 98 & 99 & 400 & 250 & 100 & 127 & 109 & 111 & 345 & 150 & 100 \\
\hline 88 & 97 & 98 & 355 & 250 & 100 & 128 & 112 & 108 & 830 & 150 & 100 \\
\hline 89 & 59 & 82 & 160 & 600 & 100 & 129 & 116 & 108 & 250 & 200 & 100 \\
\hline 90 & 83 & 82 & 505 & 600 & 100 & 130 & 106 & 107 & 290 & 150 & 130 \\
\hline 91 & 46 & 51 & 207 & 700 & 100 & 131 & 105 & 104 & 296 & 250 & 100 \\
\hline 92 & 52 & 51 & 264 & 600 & 100 & 132 & 104 & 103 & 225 & 300 & 100 \\
\hline 93 & 54 & 53 & 330 & 400 & 100 & 133 & 117 & 118 & 340 & 400 & 100 \\
\hline 94 & 57 & 58 & 368 & 110 & 130 & 134 & 118 & 119 & 280 & 400 & 100 \\
\hline 95 & 44 & 56 & 630 & 400 & 100 & 135 & 120 & 121 & 280 & 400 & 100 \\
\hline 96 & 56 & 55 & 466 & 400 & 100 & 136 & 129 & 122 & 210 & 250 & 100 \\
\hline 97 & 55 & 54 & 248 & 100 & 130 & 137 & 123 & 122 & 240 & 200 & 100 \\
\hline 98 & 55 & 65 & 145 & 400 & 100 & 138 & 123 & 124 & 560 & 200 & 100 \\
\hline 99 & 59 & 58 & 446 & 600 & 100 & 139 & 127 & 125 & 640 & 150 & 100 \\
\hline 100 & 60 & 59 & 496 & 100 & 130 & 140 & 126 & 125 & 567 & 150 & 100 \\
\hline 101 & 66 & 63 & 352 & 200 & 100 & 141 & 121 & 129 & 525 & 400 & 100 \\
\hline 102 & 63 & 62 & 464 & 400 & 100 & 142 & 119 & 120 & 210 & 400 & 100 \\
\hline 103 & 62 & 61 & 590 & 100 & 130 & 143 & 128 & 117 & 740 & 400 & 100 \\
\hline 104 & 62 & 69 & 81 & 400 & 100 & 144 & 128 & 103 & 800 & 300 & 100 \\
\hline 105 & 73 & 72 & 330 & 300 & 100 & 145 & 124 & 130 & 1140 & 200 & 100 \\
\hline 106 & 74 & 73 & 348 & 300 & 100 & 146 & 130 & 125 & 5 & 200 & 100 \\
\hline 107 & 78 & 77 & 664 & 250 & 130 & 147 & 19 & 13 & 5 & 500 & 100 \\
\hline 108 & 47 & 46 & 635 & 100 & 130 & 148 & 84 & 85 & 180 & 100 & 130 \\
\hline 109 & 102 & 48 & 475 & 100 & 130 & & & & & & \\
\hline 110 & 43 & 44 & 448 & 400 & 100 & & & & & & \\
\hline 111 & 36 & 39 & 205 & 150 & 130 & & & & & & \\
\hline 112 & 39 & 40 & 315 & 150 & 130 & & & & & & \\
\hline 113 & 36 & 37 & 332 & 150 & 130 & & & & & & \\
\hline 114 & 90 & 128 & 1030 & 400 & 100 & & & & & & \\
\hline 115 & 70 & 81 & 570 & 100 & 130 & & & & & & \\
\hline 116 & 54 & 57 & 244 & 100 & 130 & & & & & & \\
\hline 117 & 66 & 67 & 154 & 200 & 100 & & & & & & \\
\hline 118 & 131 & 1 & 5 & 900 & 130 & & & & & & \\
\hline 119 & 89 & 88 & 515 & 400 & 100 & & & & & & \\
\hline 120 & 105 & 106 & 960 & 250 & 100 & & & & & & \\
\hline 121 & 106 & 116 & 360 & 250 & 100 & & & & & & \\
\hline 122 & 108 & 109 & 60 & 200 & 100 & & & & & & \\
\hline 123 & 113 & 114 & 230 & 150 & 100 & & & & & & \\
\hline 124 & 114 & 115 & 150 & 150 & 100 & & & & & & \\
\hline
\end{tabular}

